\title{
DESARROLLO Y APLICACIÓN DE UNA NUEVA METODOLOGÍA PARA LA EVALUACIÓN DE PASOS PARA PECES DE ESTANQUES SUCESIVOS
}

\author{
Presentada por Jorge Valbuena Castro \\ para optar al grado de \\ Doctor por la Universidad de Valladolid
}

Dirigida por:

Dr. Ing. Francisco Javier Sanz Ronda Dr. Ing. Andrés Martínez de Azagra Paredes

\author{
Palencia (España) \\ 2021
}




\section{ÍNDICE DEL DOCUMENTO}

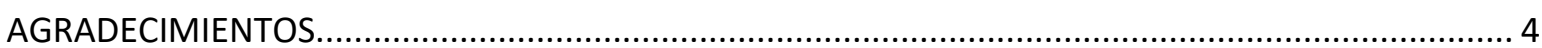

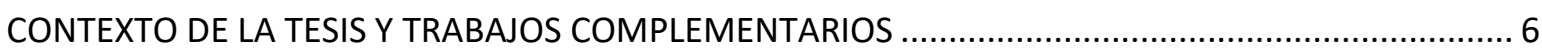

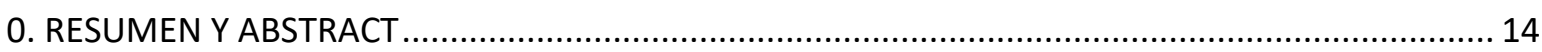

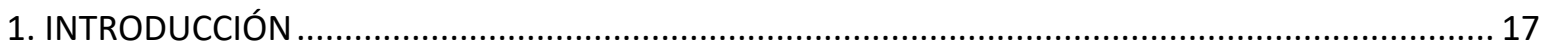

1.1. EL SER HUMANO, LOS RÍOS Y LA PÉRDIDA DE CONECTIVIDAD LONGITUDINAL .................... 18

1.2. RECUPERACIÓN DE LA CONECTIVIDAD LONGITUDINAL: LOS PASOS PARA PECES ................ 21

1.3. EVALUACIÓN DE PASOS PARA PECES: UNA TAREA PENDIENTE.......................................... 24

2. OBJETIVOS

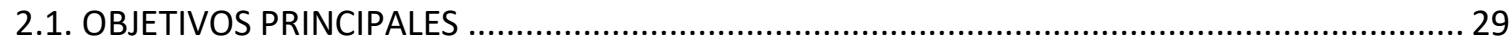

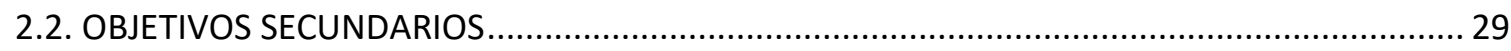

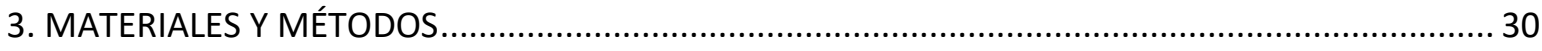

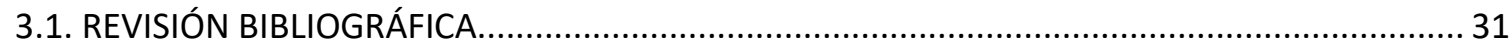

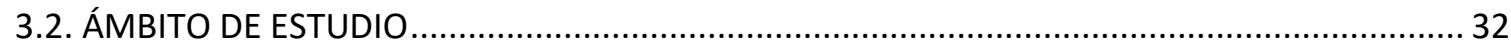

3.3. ETAPAS A SUPERAR POR LOS PECES PARA ATRAVESAR UN PASO ....................................... 35

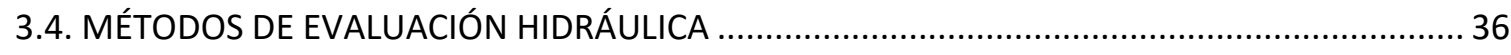

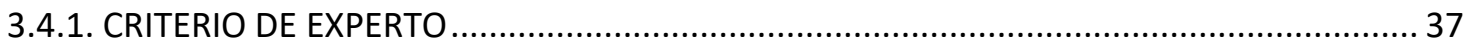

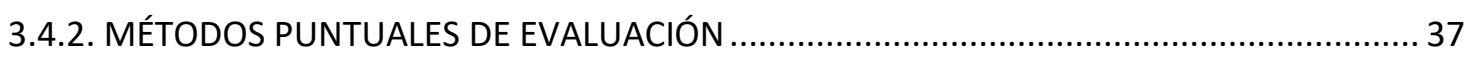

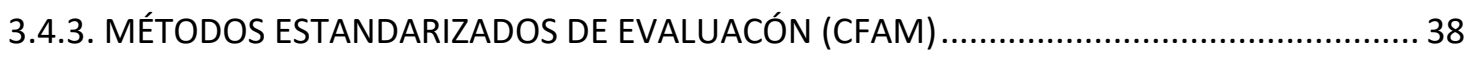

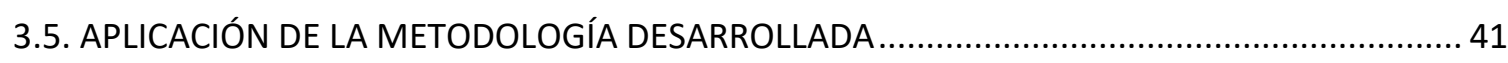

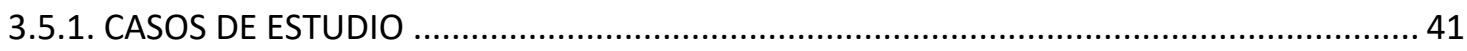

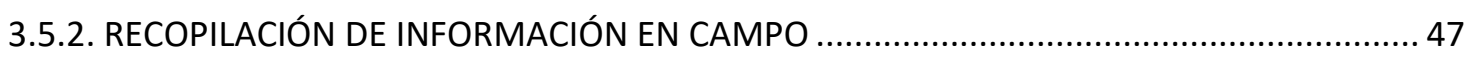

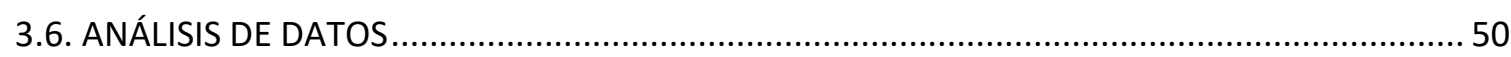

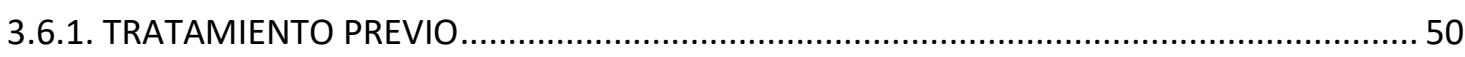

3.6.2. INFLUENCIA DE LAS ETAPAS Y LOS TIPOS DE ESCALAS EN LAS PUNTUACIONES DE

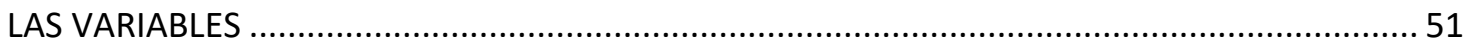

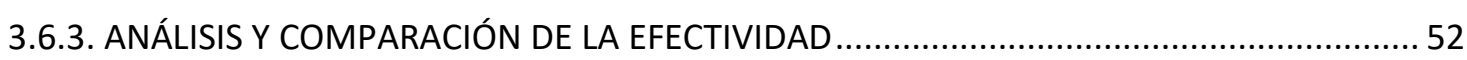

3.6.4. EVOLUCIÓN DE LA EFECTIVIDAD EN EL TIEMPO .......................................................... 52

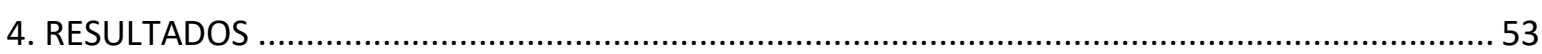

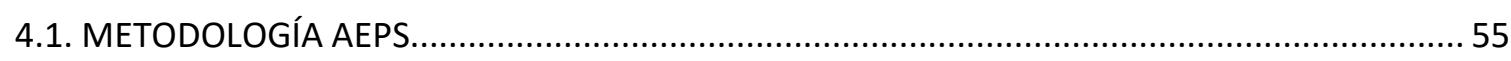

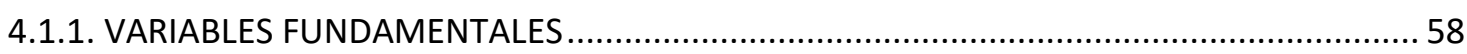

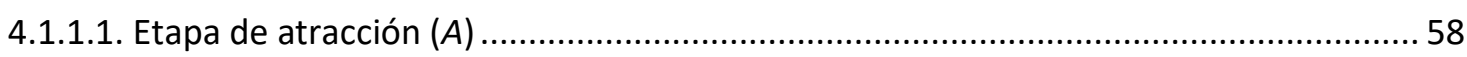

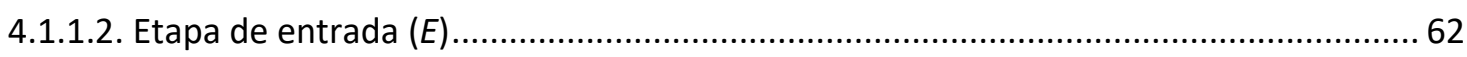

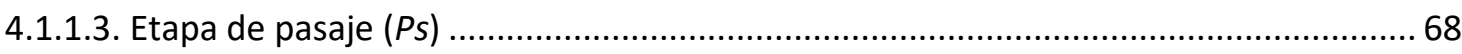




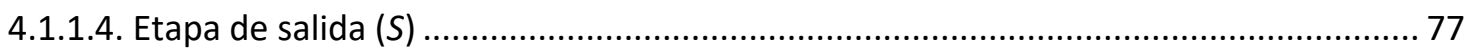

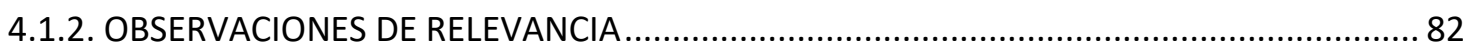

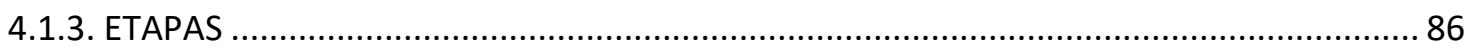

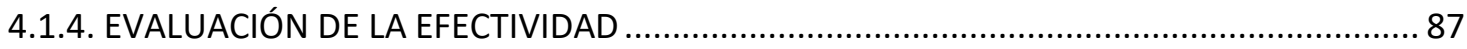

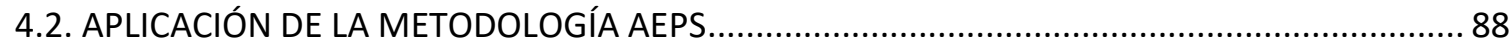

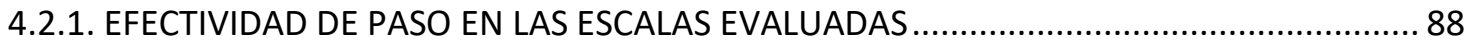

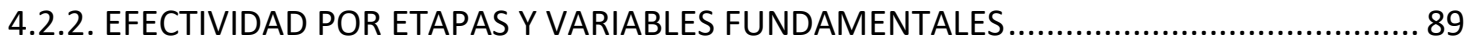

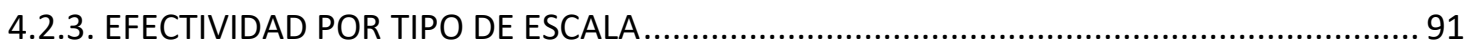

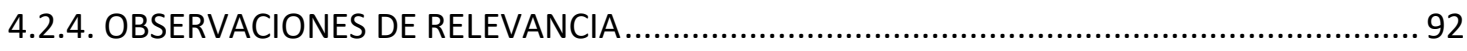

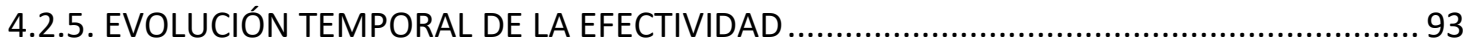

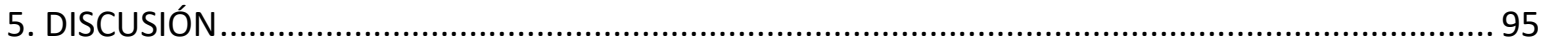

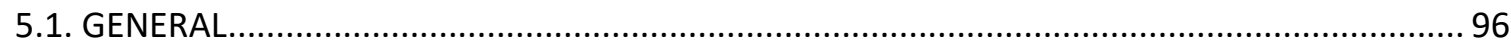

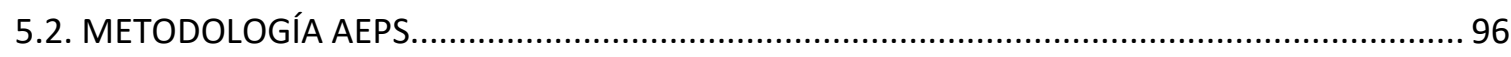

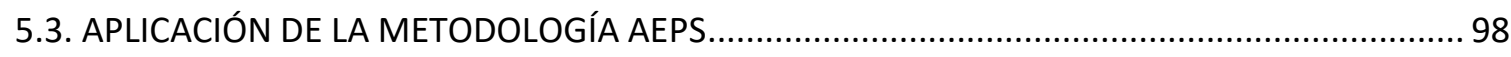

5.3.1. EVALUACIÓN DE LAS ESCALAS Y DE LOS TIPOS ...................................................... 98

5.3.2. EVALUACIÓN DE LAS ETAPAS Y DE LAS VARIABLES FUNDAMENTALES ...........................99

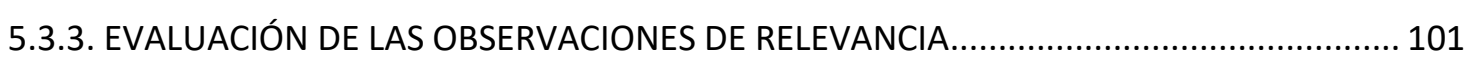

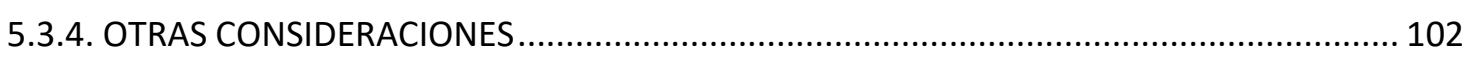

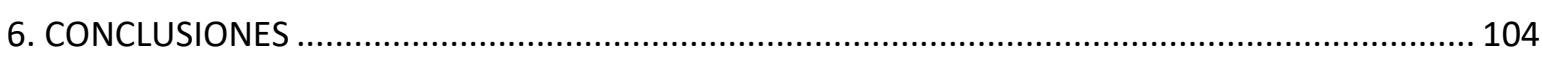

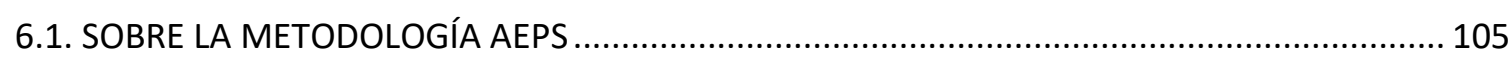

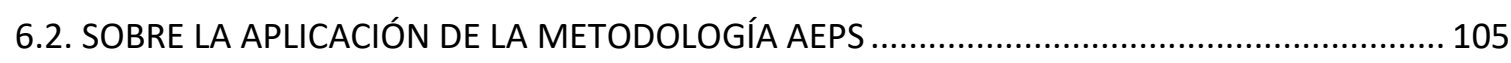

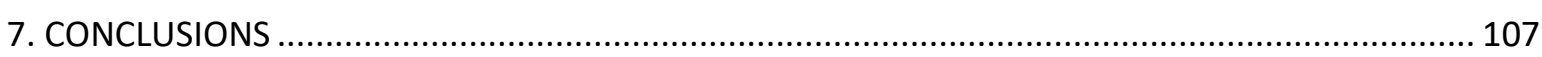

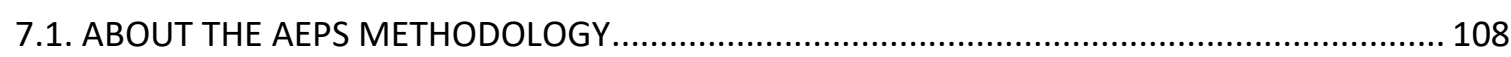

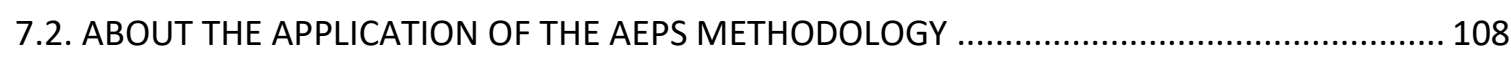

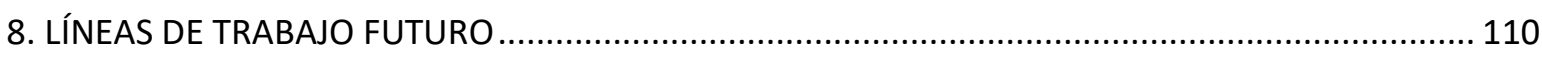

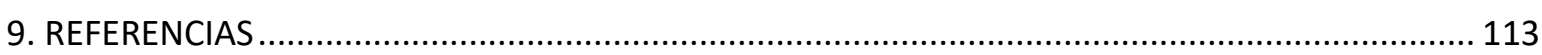

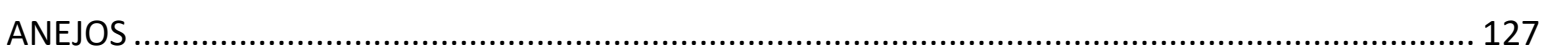

A.1. FAUNA PISCÍCOLA DE LOS ECOSISTEMAS FLUVIALES DE LA PENÍNSULA IBÉRICA ................. 128

A.2. HOJA DE CÁLCULO PARA LA APLICACIÓN DE LA METODOLOGÍA AEPS............................... 134

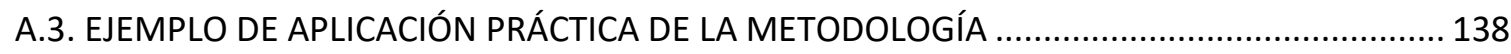

A.4. DESCRIPCIÓN Y EVALUACIÓN INDIVIDUAL DE LAS ESCALAS PARA PECES VISITADAS .......... 161

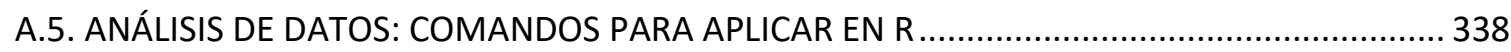

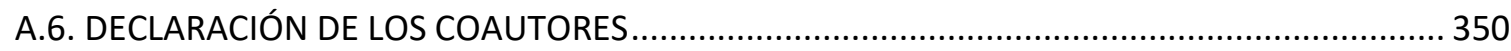

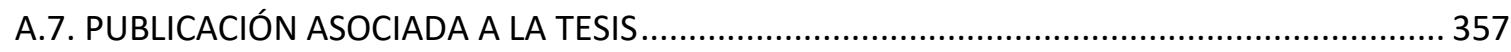


El origen de esta tesis se remonta a varios años atrás, cuando mi padre me llevó a pescar siendo yo un niño.

Ese día descubrí mi amor por los ríos.

En ese momento empezó todo ... 
AGRADECIMIENTOS 


\section{AGRADECIMIENTOS}

A mis directores de tesis, Javier Sanz Ronda y Andrés Martínez de Azagra Paredes. Gracias por enseñarme tanto a lo largo de todos estos años y por vuestra enorme e incansable dedicación para sacar lo mejor de mí. Habéis conseguido que esta profesión me haga plenamente feliz y que mi pasión por los ríos haya crecido como nunca hubiera imaginado.

A Joaquín Navarro Hevia. Gracias por ponerme en contacto con Javier para hacer mi trabajo final de carrera. Sin duda alguna, el mundo necesita más ingenieros, docentes e investigadores como tú.

A todos los miembros del Grupo de Ecohidráulica Aplicada (GEA) y en especial a Fran, Jorge, Niti, Txafu y Navas. Gracias por haber conseguido que ir a trabajar siempre haya sido un auténtico placer. Empezamos siendo compañeros y os habéis convertido en verdaderos amigos.

A mi familia. Gracias a todos por haber sido siempre un ejemplo en todos los aspectos de la vida. Sin vuestro esfuerzo y apoyo no hubiera sido posible llegar hasta este punto. No hay suficientes palabras para mostraros toda mi gratitud.

A mis amigos (Trillo, Pablo, Alfonso, Borja, Galache, Dani, Cris, Paula, María, Bea, ...). Gracias por estar siempre a mi lado, en lo bueno y en lo malo. De uno u otro modo me habéis ayudado a sacar esta tesis adelante.

A los tutores y cotutoras de mis estancias, Sergio Makrakis, António Pinheiro, Maristela Cavicchioli Makrakis e Isabel Boavida. Gracias por darme la oportunidad de colaborar con vuestros grupos de trabajo. Siempre recordaré todo lo que he aprendido durante estas experiencias y toda vuestra hospitalidad.

A las personas del mundo de los ríos que he conocido durante estos años (Leandro, Camila, Max, Miguel, Maria João, Juan Francisco, Arturo, Filipe, Susana, ...). Gracias por las vivencias que hemos compartido. Todos esos momentos me han enseñado a mejorar en lo profesional y en lo personal.

A todas las instituciones que han apoyado este trabajo (Confederación Hidrográfica del Duero, Junta de Castilla y León, Unión Europea, Itagra.ct, Universidad de Valladolid, Confederación Hidrográfica del Segura, Fundación Naturaleza y Hombre, titulares de los pasos para peces, ...). Gracias por ayudar al desarrollo de la investigación y/o al sustento del investigador. 


\section{CONTEXTO DE LA TESIS Y TRABAJOS COMPLEMENTARIOS}




\section{CONTEXTO DE LA TESIS Y TRABAJOS COMPLEMENTARIOS}

La presente tesis doctoral se divide en dos partes. La primera consiste en un documento monográfico estructurado en varios apartados habituales en este tipo de trabajos y recogidos en la normativa vigente: resumen (en español y en inglés), introducción, objetivos, materiales y métodos, resultados, discusión, conclusiones (en español y en inglés), líneas de trabajo futuro y referencias. La segunda reúne seis documentos anejos que desarrollan aspectos recogidos en la primera parte.

La tesis se ha enmarcado en el Programa de Doctorado en Conservación y Uso Sostenible de Sistemas Forestales, ubicado en la Escuela Técnica Superior de Ingenierías Agrarias de Palencia de la Universidad de Valladolid. Este trabajo se ha desarrollado dentro de la Unidad Docente de Hidráulica e Hidrología y del grupo de investigación GEA (Grupo de Ecohidráulica Aplicada).

El trabajo del autor ha sido financiado inicialmente por la Confederación Hidrográfica del Duero y, más tarde, cofinanciado por la Consejería de Educación de la Junta de Castilla y León y el Fondo Social Europeo de la Unión Europea mediante un contrato público para personal investigador predoctoral (Orden EDU/1100/2017).

Los resultados de este trabajo se han recogido en tres publicaciones de carácter científico, una de ellas publicada en una revista indexada, y varias comunicaciones a congresos:

- Valbuena-Castro, J., Fuentes-Pérez, J.F., García-Vega, A., Bravo-Córdoba, F.J., Ruiz-Legazpi, J., Martínez de Azagra-Paredes, A. y Sanz-Ronda, F.J. (2020) Coarse fishway assessment to prioritize retrofitting efforts: a case study in the Duero River basin. Ecological Engineering 155, 105946.

- Valbuena-Castro, J., Sanz-Ronda, F.J., García-Vega, A., et al. (2019) Metodología "AEPS" aplicada a la evaluación de escalas para peces en la cuenca hidrográfica del río Duero. Cuadernos de la Sociedad Española de Ciencias Forestales 45, 279-288.

- Valbuena-Castro, J., Sanz-Ronda, F.J., García-Vega, A., Fuentes-Pérez, J.F., Bravo-Córdoba, F.J., Navas-Pariente, A., Ruiz-Legazpi, J. y Martínez de Azagra, A. (2017) AEPS: a methodology to quickly assess pool and weir fishways. En: Fish Passage 2017: International Conference on Engineering and Ecohydrology for Fish Passage. Corvallis (Estados Unidos de América).

- Valbuena-Castro, J., Sanz-Ronda, F.J., Bravo-Córdoba, F.J., Ruiz-Legazpi, J. y Martínez de Azagra-Paredes, A. (2016) Application of a new methodology to assess fishways in the Segura River basin. En: SIBIC 2016, VI Iberian Congress of Ichthyology. Murcia (España). 
- Confederación Hidrográfica del Duero (2016) Manual para la evaluación de la funcionalidad de pasos para peces de estanques sucesivos. Metodología AEPS (1.0). Coordinación: Sanz-Ronda, F.J., et al.; Autores: Valbuena-Castro, J., et al. Confederación Hidrográfica del Duero, Valladolid (España).

- Sanz-Ronda, F.J., Valbuena-Castro, J., Martínez de Azagra-Paredes, A., BravoCórdoba, F.J., Bernabé-de la Iglesia, J.C., Prieto-Blanco, A., Rubio-Polo, J.M. y Rodríguez-Muñoz, I. (2015) Fish passes evaluation in the Spanish Duero River basin (Northwestern Spain). En: Fish Passage 2015: International conference on river connectivity best practices and innovations. Groningen (Países Bajos).

- Sanz-Ronda, F.J., Valbuena-Castro, J., Martínez de Azagra-Paredes, A., BravoCórdoba, F.J., Bernabé-de la Iglesia, J.C., Prieto-Blanco, A., Rubio-Polo, J.M. y Rodríguez-Muñoz, I. (2015) Evaluación de pasos para peces en la cuenca Duero. En: II Congreso Ibérico sobre Restauración Fluvial: "Restaura Ríos”. Pamplona (España).

De manera complementaria, el autor ha participado y colaborado en otros trabajos nacionales e internacionales como publicaciones científicas, comunicaciones a congresos, estancias, proyectos y premios. A continuación se resumen brevemente:

\section{ARTÍCULOS Y PUBLICACIONES CIENTÍFICAS}

- Bravo-Córdoba, F.J., Fuentes-Pérez, J.F., Valbuena-Castro, J., Martínez de Azagra Paredes, A. y Sanz-Ronda, F.J. (2021) Turning pools in stepped fishways: Biological assessment via fish response and CFD models. Water 13, 1186.

DOI: https://doi.org/10.3390/w13091186

- García-Vega, A., Fuentes-Pérez, J.F., Bravo-Córdoba, F.J., Ruiz-Legazpi, J., Valbuena-Castro, J. y Sanz-Ronda, F.J. (2021) Pre-reproductive movements of potamodromous cyprinids in the Iberian Peninsula: when environmental variability meets semipermeable barriers. Hydrobiologia.

DOI: https://doi.org/10.1007/s10750-021-04537-6

- Bravo-Córdoba, F.J., Valbuena-Castro, J., García-Vega, A., Fuentes-Pérez, J.F., Ruiz-Legazpi, J. y Sanz-Ronda, F.J. (2021) Fish passage assessment in stepped fishways: Passage success and transit time as standardized metrics. Ecological Engineering 162.

DOI: https://doi.org/10.1016/j.ecoleng.2021.106172 
- Moreira, M., Costa, M.J., Valbuena-Castro, J., Pinheiro, A.N. y Boavida, I. (2020) Cover or velocity: What triggers Iberian barbel (Luciobarbus bocagei) refuge selection under experimental hydropeaking conditions?. Water 12, 317.

DOI: https://doi.org/10.3390/w12020317

- Sanz-Ronda, F.J., Bravo-Córdoba, F.J., Sánchez-Pérez, A., García-Vega, A., Valbuena-Castro, J., Fernandes-Celestino, L., Torralva, M. y Oliva-Paterna, F.J. (2019) Passage performance of technical pool-type fishways for potamodromous cyprinids: Novel experiences in semiarid environments. Water 11, 2362.

DOI: https://doi.org/10.3390/w11112362

- Sanz-Ronda, F.J., Bravo-Córdoba, F.J., Fuentes-Pérez, J.F., Ruiz-Legazpi, J., García-Vega, A., Valbuena-Castro, J., Ramos-González, N., González-Alemán, N.J., Smarth, R., Navas-Pariente, A. y Martínez de Azagra Paredes, A. (2018) Pasos para peces: escalas y otros dispositivos. En: Hacia un agua justa (eds. A. Martínez de Azagra Paredes y A. Gomez-Ramos). Universidad de Valladolid, Valladolid (España), pp 249-270.

ISBN: 978- 84-8448-942-9.

- Bravo-Córdoba, F.J., Sanz-Ronda, F.J., Ruiz-Legazpi, J., Valbuena-Castro, J. y Makrakis, S. (2018) Vertical slot versus submerged notch with bottom orifice: Looking for the best technical fishway type for Mediterranean barbels. Ecological Engineering 122, 120-125.

DOI: https://doi.org/10.1016/j.ecoleng.2018.07.019

- Bravo-Córdoba, F.J., Sanz-Ronda, F.J., Navas-Pariente, A. y Valbuena-Castro, J. (2018) Comportamiento del barbo ibérico (Luciobarbus bocagei) en una escala de peces de vertedero sumergido con orificio de fondo. Cuadernos de la Sociedad Española de Ciencias Forestales 45, 231-240.

DOI: https://doi.org/10.31167/csecfv0i45.19501

\section{COMUNICACIONES A CONGRESOS}

- Sanz-Ronda, F.J., Valbuena-Castro, J., Navas-Pariente, A., Martínez-Pérez, S., Sastre-Merlín, A. y Morcillo, F. (2019) La escala para peces del Limnoembalse de Pareja (río Ompólveda, Guadalajara): problemas y soluciones. En: VI Jornadas de Ingeniería del Agua. Toledo (España).

- Moreira, M., Valbuena-Castro, J., Costa, M.J., Pinheiro, A. y Boavida, I. (2019) LUNKERS-type structures as potential hydropeaking flow-refuges for Iberian barbel (Luciobarbus bocagei) in experimental conditions. En: 6th Biennial Symposium of the International Society for River Science. Viena (Austria). 
- Sanz-Ronda, F.J., Bravo-Córdoba, F.J., Sánchez-Pérez, A., García-Vega, A., Valbuena-Castro, J., Fernandes-Celestino, L., Torralva, M. y Oliva-Paterna, F.J. (2019) Pool type fishways assessment: experiences in the Segura River. En: III Congreso Ibérico sobre Restauración Fluvial: "Restaura Ríos”. Murcia (España).

- Sanz-Ronda, F.J., Bravo-Córdoba, F.J., Ruiz-Legazpi, J., Fuentes-Pérez, J.F., Valbuena-Castro, J., González-Alemán, N., Smarth-Apinas, R., Navas-Pariente, A. y García-Vega, A. (2017) Fishway location, entrance and passage for potamodromous Mediterranean cyprinids. En: Fish Passage 2017: International Conference on Engineering and Ecohydrology for Fish Passage. Corvallis (Estados Unidos de América).

- Sanz-Ronda, F.J., Bravo-Córdoba, F.J., Ruiz-Legazpi, J., Fuentes-Pérez, J.F., García-Vega, A., Valbuena-Castro, J. y González-Alemán, N. (2016) Evaluate for understanding. The case of the most assessed fishway in Spain. En: SIBIC 2016, VI Iberian Congress of Ichthyology. Murcia (España).

- Valbuena-Castro, J., Sanz-Ronda, F.J., Bravo-Córdoba, F.J. y Ruiz-Legazpi, J. (2016) Assessment of longitudinal connectivity of fish passes in rivers of the Duero River Basin. En: IX Young Researchers Meeting on Conservation and Sustainable Use of Forest Systems. Valsaín (España).

- Sanz-Ronda, F.J., Bravo-Córdoba, F.J., Fuentes-Pérez, J.F., Ruiz-Legazpi, J., García-Vega, A., Valbuena-Castro, J. y Martínez de Azagra Paredes, A. (2015) Escalas para peces, una herramienta para mejorar la conectividad longitudinal de los ríos. En: V Congreso de la naturaleza de la Región de Murcia y II del Sureste Ibérico. Murcia (España).

- Bravo-Córdoba, F.J., Sanz-Ronda, F.J., Fuentes-Pérez, J.F., Ruiz-Legazpi, J., Salgado, V., García-Vega, A., Valbuena-Castro, J. y Peña-Garrido, A. (2015) Fishway with two entrance locations. En: Fish Passage 2015: International conference on river connectivity best practices and innovations. Groningen (Países Bajos).

- Valbuena-Castro, J. y Sanz-Ronda, F.J. (2015) Hydraulic and biological evaluation of a vertical slot fishway in Vegas del Condado, León (Spain). En: VIII Young Researchers Meeting on Conservation and Sustainable Use of Forest Systems. Valsaín (España).

\section{ESTANCIAS}

- Universidade Estadual do Oeste do Paraná. Toledo (Brasil), 11 de septiembre de 2017 (duración 13 semanas). 


\section{PROYECTOS}

- LIFE DIVAQUA: MEJORANDO LA DIVERSIDAD ACUÁTICA EN PICOS DE EUROPA.

- Importe: $352.261,00 €$.

- Entidad financiadora: Proyecto cofinanciado por la Unión Europea.

- Entidades participantes: Instituto de Hidráulica Ambiental de la Universidad de Cantabria, Consejo Superior de Investigaciones Científicas, Fundación IH Cantabria, Gobierno del Principado de Asturias, Itagra.ct, Junta de Castilla y León, Red Cambera, Repsol, Gobierno de Cantabria y Navarro Generación.

- Duración: 15 de julio de 2019 - 29 de febrero de 2024.

- Investigador principal: José Barquín Ortiz (Universidad de Cantabria).

\section{- FITHYDRO: FISHFRIENDLY INNOVATIVE TECHNOLOGIES FOR HYDROPOWER.}

- Importe: 7.171.550,16€.

- Entidad financiadora: Proyecto cofinanciado por la Unión Europea (H2020).

- Entidades participantes: Technische Universität München, Associação do Instituto Superior Técnico de Investigação e Desenvolvimento, Centre National de la Recherche Scientifique, Itagra.ct, Eidgenössische Technische Hochschule Zürich, Leibniz-Institut Für Gewässerökologie Und Binnenfischerei, Norges Teknisk-Naturvitenskapelige Universitet, Sintef Energi AS, Tallinna Tehnikaulikool, University of Hull, Ecologic Institut $\mathrm{gGmbH}$, Ecohydraulic Engineering, Bayerische Elektrizitätswerke $\mathrm{GmbH}$, BKW Energie AG, Hidroerg, Projectos Energéticos, Lda., Peter FishConsulting, C.H. Salto de Vadocondes S.A., Statkraft AS y Verbund Hydro Power GmbH.

- Duración: 1 de noviembre de 2016 - 1 de noviembre de 2020.

- Investigador principal: Peter Rutschmann (Technische Universität München).

\section{- ESTUDIO DE LA MIGRACIÓN DE LOS PECES EN ENTORNOS MEDITERRÁNEOS.}

- Importe: $10.200,00 €$.

- Entidad financiadora: Itagra.ct.

- Entidades participantes: Fundación General Universidad de Valladolid e Itagra.ct.

- Duración: 12 de octubre de 2016 - 30 de octubre de 2020.

- Investigador principal: Francisco Javier Sanz Ronda (Universidad de Valladolid). 
- LIFE MIERA: CONSERVACIÓN DE LA BIODIVERSIDAD EN EL RÍO MIERA.

- Importe: $1.650 .105,00 €$.

- Entidad financiadora: Proyecto cofinanciado por la Unión Europea.

- Entidades participantes: Fundación Naturaleza y Hombre, Gobierno de Cantabria y MARE.

- Duración: 1 de julio de 2014 - 31 de diciembre de 2018.

- Investigador principal: Carlos Sánchez Martínez (Fundación Naturaleza y Hombre).

- ESTUDIO PARA EL DESARROLLO Y APLICACIÓN DE UNA METODOLOGÍA PARA LA EVALUACIÓN DE PASOS PARA PECES EN LA CUENCA DUERO.

- Importe: $60.500,00 €$.

- Entidad financiadora: Confederación Hidrográfica del Duero.

- Entidades participantes: Confederación Hidrográfica del Duero e Itagra.ct.

- Duración: 19 de mayo de 2014 - 31 de agosto de 2019.

- Investigador principal: Francisco Javier Sanz Ronda (Universidad de Valladolid).

- LIFE SEGURA RIVERLINK.

- Importe: 3.424.250,00€.

- Entidad financiadora: Proyecto cofinanciado por la Unión Europea.

- Entidades participantes: Confederación Hidrográfica del Segura, Asociación de Naturalistas del Sureste, Dirección General de Medio Ambiente de la Comunidad Autónoma de la Región de Murcia, Itagra.ct y Universidad de Murcia.

- Duración: 1 de agosto de 2013 - 30 de julio de 2017.

- Investigador principal: Eduardo Lafuente Sacristán (Confederación Hidrográfica del Segura).

- MONITORAMENTO DOS SISTEMAS DE TRANSPOSICÃO DE PEIXES NA USINA ENGENHEIRO SÉRGIO MOTTA-CESP-PRIMAVERA/SP.

- Importe: $660.000,00 €$.

- Entidad financiadora: Companhia Energética de São Paulo. 
- Entidades participantes: Companhia Energética de São Paulo, Universidade Estadual do Oeste do Paraná, Grupo de Pesquisa em Tecnologia em Ecohidráulica e Conservação de Recursos Pesqueiros e Hídricos.

- Duración: 1 de enero de 2004 - 1 de enero de 2019.

- Investigador principal: Sergio Makrakis (Universidade Estadual do Oeste do Paraná).

- ESTUDOS DO COMPORTAMENTO E CAPACIDADE NATATÓRIA DE PEIXES EM CANAL HIDRÁULICO EXPERIMENTAL (FLUME) NO LABORATÓRIO DE ECOHIDRÁULICA E HIDROBIOLOGIA.

- Importe: 400.000,00€.

- Entidad financiadora: Financiadora de Estudos e Projetos - Ministerio de Ciencia y Tecnología (Brasil).

- Entidades participantes: Universidade Estadual do Oeste do Paraná, Grupo de Pesquisa em Tecnologia em Ecohidráulica e Conservação de Recursos Pesqueiros e Hídricos, Universidad de Valladolid, United States Geographical Survey (USGS).

- Duración: 1 de febrero de 2012 - actualidad.

- Investigador principal: Sergio Makrakis (Universidade Estadual do Oeste do Paraná).

\section{PREMIOS}

- Distinguished project in fisheries engineering and ecohydrology award 2015, concedido a GEA por la American Fisheries Society (AFS) y el Environmental Water Research Institute (EWRI-ASCE).

- Premios Innovadores de Castilla y León 2014 al mejor Proyecto de I+D+I de Castilla y León, concedido a GEA por el periódico El Mundo, Diario de Castilla y León. 


\section{RESUMEN Y ABSTRACT}




\section{RESUMEN Y ABSTRACT}

\subsection{RESUMEN}

Los cursos de agua de todo el mundo se encuentran fragmentados por la presencia de obstáculos transversales realizados por el ser humano. Para recuperar su conectividad longitudinal, se construyen masivamente una serie de estructuras conocidas como pasos para peces. A pesar de su elevado número, su funcionamiento sólo se estudia en algunos casos, obteniéndose resultados muy diversos. Dentro de las alternativas existentes para evaluar su funcionamiento están los llamados métodos hidráulicos, que se caracterizan por su aplicación sencilla, rápida y económica.

Los principales objetivos de esta tesis son desarrollar, testar y aplicar un nuevo método hidráulico capaz de evaluar de manera fiable la tipología más común de pasos para peces, las escalas de estanques sucesivos o de artesas, para conocer el funcionamiento de algunas de estas estructuras ubicadas en la Península Ibérica.

Para lograr esos objetivos se han llevado a cabo varias acciones. Se ha desarrollado una metodología de evaluación basada en información bibliográfica y experiencias de campo. Se trata de una metodología que analiza los aspectos de las escalas que influyen en el ascenso de tres especies piscícolas ibéricas. Asimismo, se ha aplicado en distintas cuencas hidrográficas para estudiar la efectividad de varios pasos para peces. Los resultados obtenidos de su aplicación han sido analizados atendiendo a la tipología de las escalas, a las diferentes etapas a superar por los peces en un paso (atracción, entrada, pasaje y salida) y al momento en que han sido construidos.

La metodología es capaz de evaluar un gran número de pasos para peces de manera objetiva y detallada en base a información hidráulica y biológica, lo que la convierte en una alternativa que conserva las ventajas y reduce los inconvenientes de los métodos hidráulicos de evaluación. Los resultados de su aplicación muestran que el 55 \% de las escalas evaluadas son adecuadas para el paso de los peces, siendo la mayoría de ellas de reciente construcción. Las deficiencias observadas en los pasos se han debido a su diseño, construcción y funcionamiento, demostrando la necesidad de evaluar estas estructuras a lo largo de las tres fases con el objetivo de mejorar su funcionalidad final.

Esta tesis ofrece una herramienta práctica para conocer el funcionamiento de las escalas de estanques sucesivos, identificando sus problemas y ayudando a solucionarlos para mejorar los pasos para peces actuales y futuros. 


\subsection{ABSTRACT}

Watercourses around the world are fragmented by the presence of human-made transversal obstacles. To restore their longitudinal connectivity, structures named fish passes are massively constructed. Despite their large number, their performance is studied just in some cases, with very different results. Among the existing alternatives to evaluate their performance are the hydraulic assessment methods, characterized by their easy, fast and economical application.

The main objectives of this thesis are to develop, test and apply a new hydraulic method to evaluate reliably the most common typology of fish passes, the stepped or pool-type fishways, in order to know the performance of some of these structures located in the Iberian Peninsula.

To achieve these objectives, different actions were performed. An assessment methodology was developed based on bibliographic information and field experiences. It analyses the aspects of the fishways that influence the ascent of three Iberian fish species. The methodology was applied in different river basins to study the effectiveness of various fish passes. The results of its application were analyzed attending to the typology of the fishways, the different stages to overcome by fishes into a fish pass (attraction, entry, passage and exit) and the time when they were constructed.

The methodology assesses many fish passes in detail and objectively based on hydraulic and biological information, allowing it to retains the advantages and reduce the disadvantages of the hydraulic assessment methods. The results of its application reveal that $55 \%$ of the evaluated fishways are adequate for fish movements, being most of them recently constructed. The observed deficiencies in the fish passes are due to their design, construction and operation, demonstrating the need to evaluate these structures during the three phases to enhance their final performance.

This thesis provides a practical tool for understanding the performance of stepped fishways, identifying their problems and helping to solve them to improve the current and future fish passes. 


\section{INTRODUCCIÓN}




\section{INTRODUCCIÓN}

\subsection{EL SER HUMANO, LOS RÍOS Y LA PÉRDIDA DE CONECTIVIDAD LONGITUDINAL}

El ser humano siempre ha estado, está y estará ligado al agua. Muestra de ello es, que desde la antigüedad y hasta nuestros días, la mayoría de sus asentamientos se encuentran cerca de masas de agua para satisfacer necesidades y obtener servicios (abastecimiento, agricultura, producción energética, industria, recreo, etc.) (Cooke et al. 2012). Esos usos del agua han alterado los ecosistemas dulceacuícolas hasta convertirlos en unos de los más amenazados en todo el planeta (Dudgeon et al. 2006). Una de las alteraciones más frecuentes y perjudiciales es la construcción de obras transversales, tales como presas, azudes, estaciones de aforo, etc. (Figura 1).
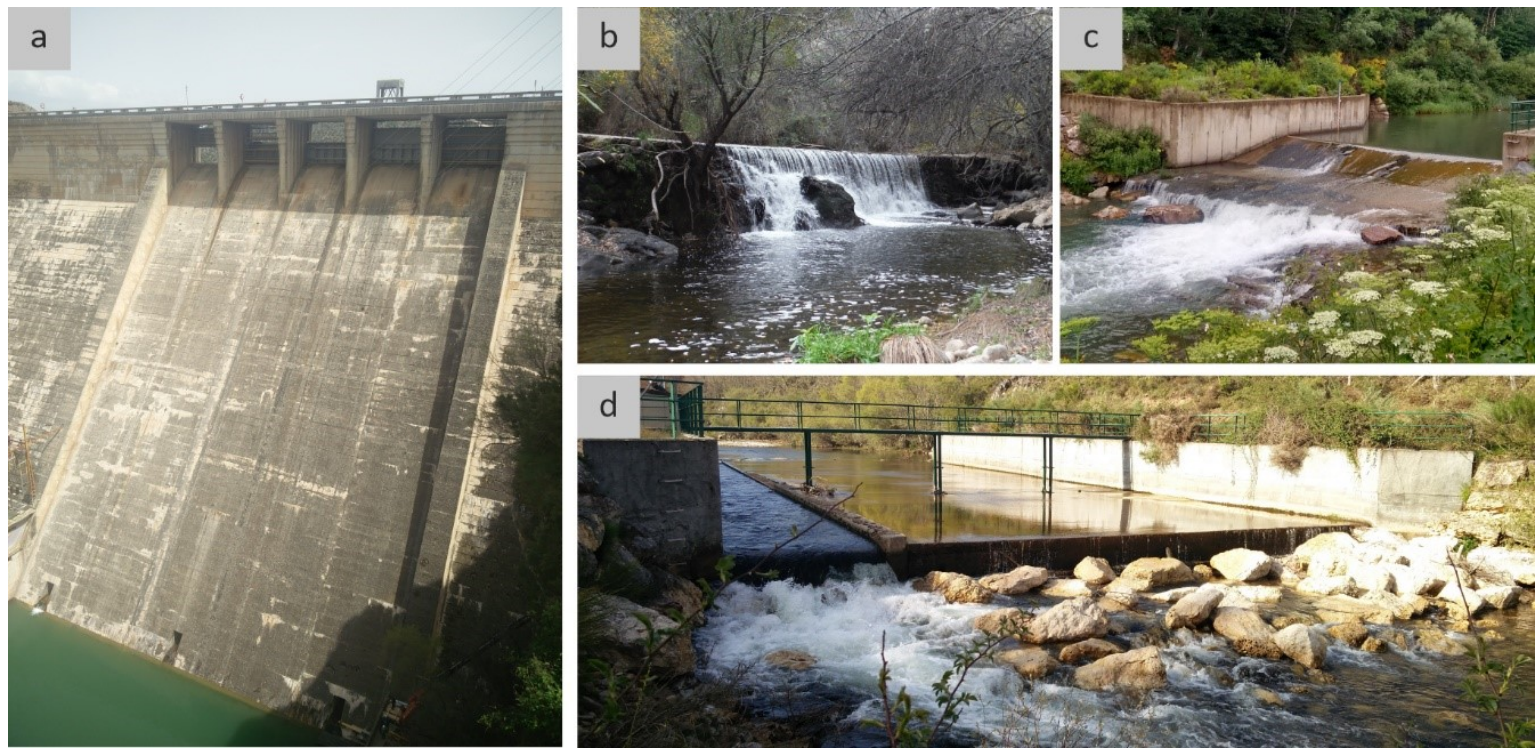

Figura 1. Algunos de los obstáculos más habituales en los ríos: presas (a), azudes (b), y obras descalzadas como las estaciones de aforo tipo V-flat (c) o de canal (d).

Entre otros, este tipo de obras pueden alterar el ciclo hidrológico natural, las características del agua (temperatura, concentración de oxígeno, velocidad, ...), el transporte de materiales, la composición de especies, o provocan la pérdida de la continuidad longitudinal que dificulta o impide los desplazamientos de la fauna piscícola (Nilsson et al. 2005). A esto último se lo conoce como "efecto barrera" (Roscoe y Hinch 2010; Sanz-Ronda et al. 2013), el cual implica múltiples cambios en los ecosistemas. 
Prácticamente todos los peces realizan desplazamientos de mayor o menor entidad. Algunos de esos movimientos reciben el nombre de migraciones y son necesarios para que la ictiofauna satisfaga sus necesidades biológicas y complete sus ciclos vitales (Lucas et al. 2001; FAO/ DVWK 2002; Porcher y Travade 2002). Se trata de desplazamientos regulares que hacen la mayoría de los individuos de una población entre dos o más hábitats (Northcote 1984) para buscar alimento, refugio, ambientes, o reproducirse (Lucas et al. 2001).

En función de sus patrones migratorios, estas especies pueden clasificarse en (Lucas et al. 2001):

- Diádromas: especies que migran entre aguas dulces y saladas. Se dividen en:

+ Anádromas: la mayor parte de su alimentación y crecimiento se desarrolla en ambientes salobres, migrando hacia zonas de agua dulce para reproducirse. Entre los migradores anádromos ibéricos encontramos al salmón, las lampreas, el sábalo, o la saboga (Figura 2.a y b).

+ Catádromas: su alimentación y crecimiento tiene lugar principalmente en aguas dulces, migrando hacia aguas saladas para reproducirse. La única especie migradora de este tipo presente en la Península es la anguila (Figura 2.c).

+ Anfídromas: tras la eclosión de los huevos en aguas dulces, las larvas migran hacia aguas saladas donde pasan una fase inicial de alimentación y crecimiento. Después, viajan hacia aguas dulces donde llevan a cabo la mayor parte de su alimentación y crecimiento, y acaban por reproducirse. Ejemplos de estos migradores en nuestros ríos son las lisas, el pejerrey o la platija.

- Potamódromas: especies que migran únicamente por aguas dulces. La mayoría de las especies piscícolas ibéricas son potamódromas, aportando la mayor parte de la biomasa que existe en nuestros ríos. Algunos ejemplos son la bermejuela, el cacho o el gobio (Figura 2.d, e y f). 

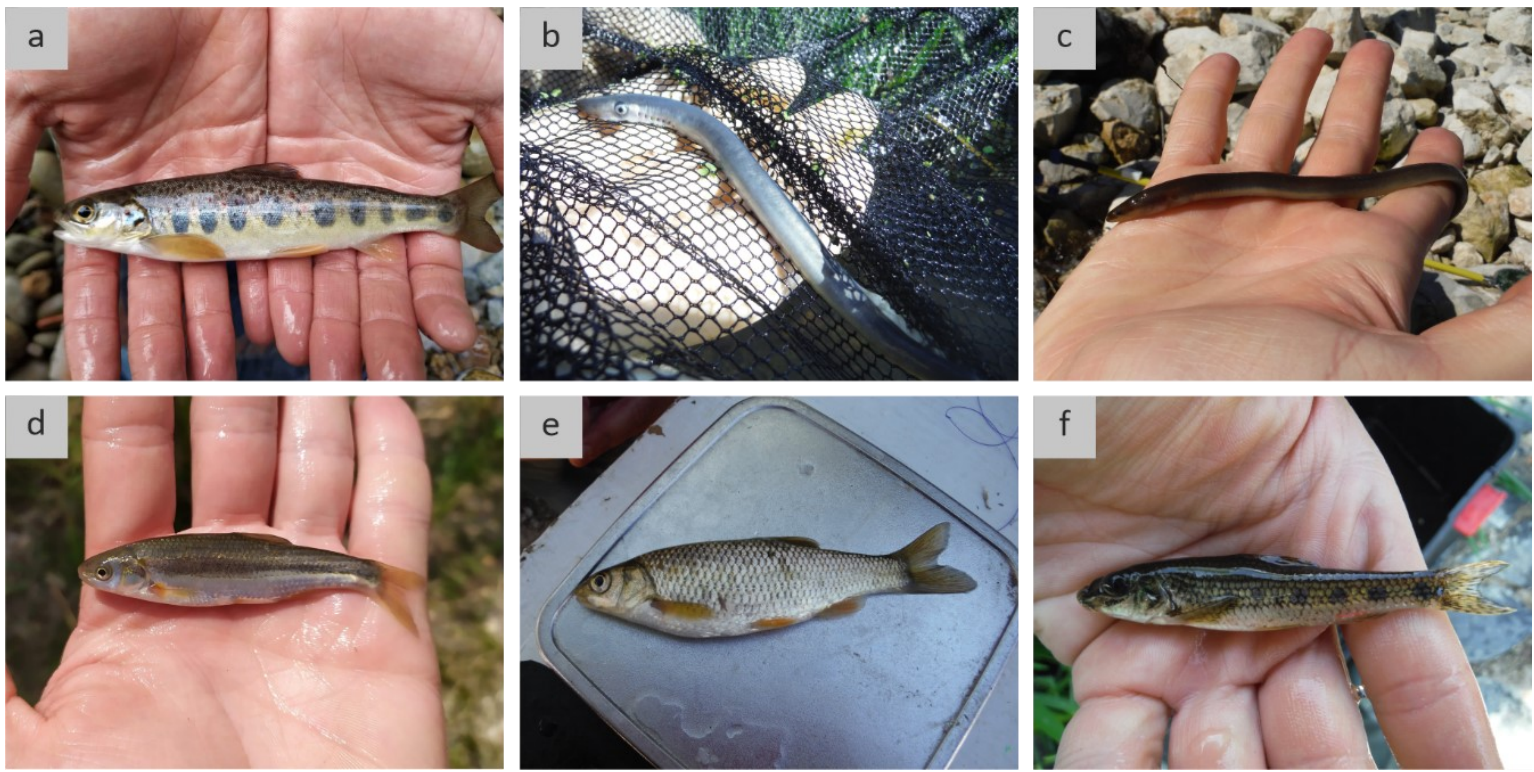

Figura 2. Algunos peces migradores de la Península Ibérica: juvenil “pinto” de salmón (a), lamprea (b), anguila (c), bermejuela (d), cacho (e) o gobio (f).

En los ríos de la Península Ibérica habitan ciento dos especies de peces autóctonos, entre las que se encuentran varios endemismos y taxones que presentan un área de distribución muy reducida que abarca la Península y el sur de Francia (Doadrio 2002; Leunda et al. 2009; Doadrio et al. 2011; SIBIC 2017; Alves et al. 2018). Actualmente, 35 de ellas se encuentran dentro de alguna de las categorías de amenaza establecidas por la IUCN (International Union for Conservation of Nature and Natural Resources 2021). No obstante, aplicando los mismos criterios podrían llegar a incluirse hasta cincuenta y seis en las categorías de mayor amenaza (diez en peligro crítico, once en peligro, treinta como vulnerables y cinco como casi amenazadas) (Doadrio et al. 2011) (véase el anejo A.1. Fauna piscícola de los ecosistemas fluviales de la Península Ibérica).

El $65 \%$ de estas especies autóctonas ibéricas realizan migraciones, aumentando ese porcentaje hasta el 80 \% si únicamente consideramos a los endemismos (Sanz-Ronda et al. 2013). Uno de los factores más perjudiciales para la ictiofauna continental es la pérdida de continuidad longitudinal generada por los obstáculos transversales, ya que provocan el aislamiento de los individuos, la pérdida de variabilidad genética, cambios en los patrones migratorios, alteraciones del crecimiento, etc. (Figura 3). Todo ello conduce a la disminución y desaparición de las poblaciones piscícolas (Larinier 1998; FAO/ DVWK 2002; Sanz-Ronda et al. 2013). Por lo tanto, recuperar o mantener la continuidad longitudinal de nuestros ríos es fundamental para conservar las poblaciones de peces. 


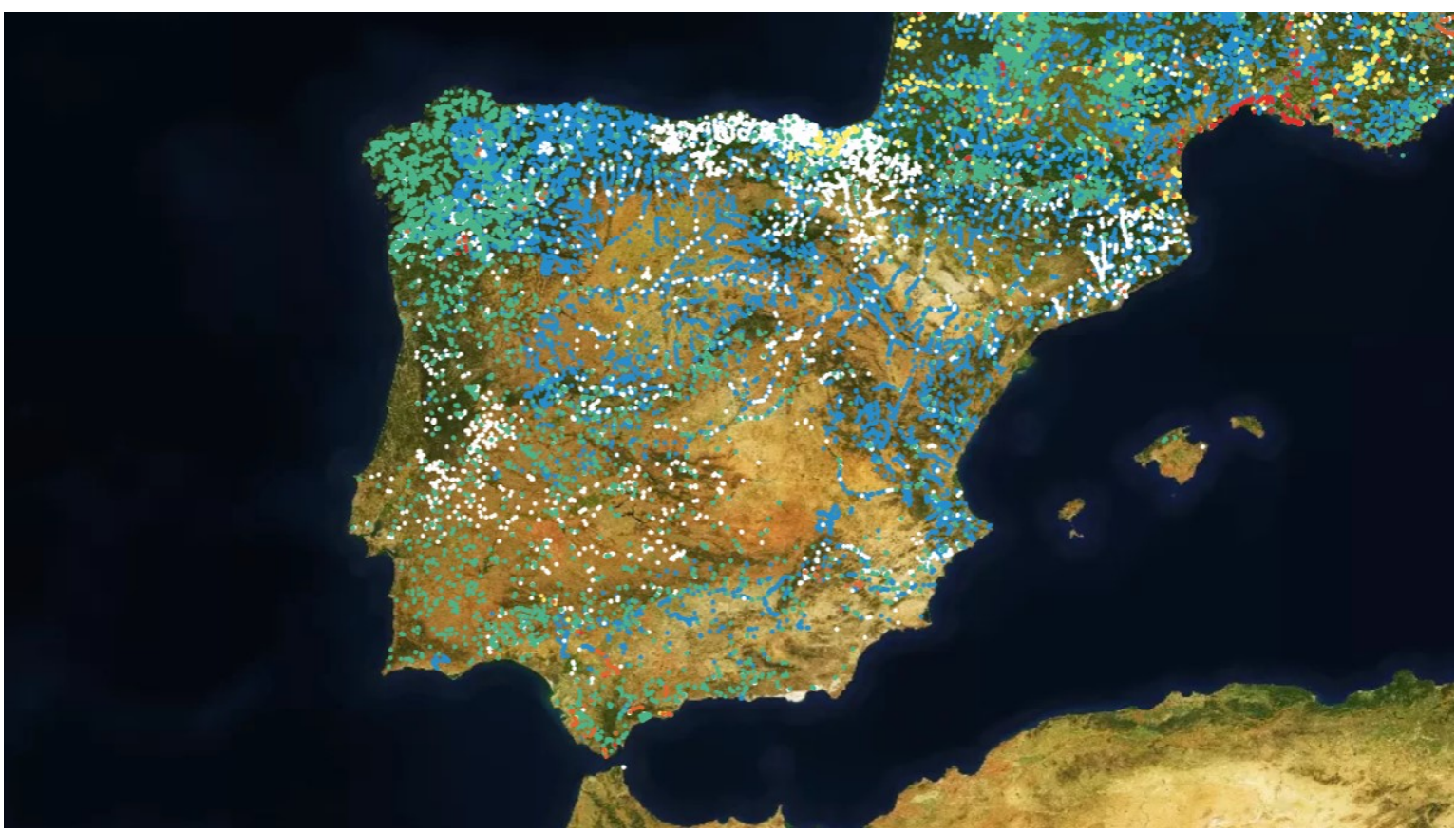

Figura 3. Obstáculos identificados en los ríos de la Península Ibérica: presas (en verde), azudes (azul), culverts (amarillo), rampas (morado), vados (naranja), canalizaciones (rojo) y otros (blanco) (fuente: AMBER Consortium 2020).

\subsection{RECUPERACIÓN DE LA CONECTIVIDAD LONGITUDINAL: LOS PASOS PARA PECES}

Desde hace cientos de años, los seres humanos son conscientes de los perjuicios que los obstáculos presentes en los ríos causan a la fauna piscícola (Clay 1995; Katopodis y Williams 2012). Por ello, se han planteado diferentes medidas con el fin de mitigar o solventar sus efectos.

Algunas de ellas consisten en el desarrollo de herramientas legales que garanticen los desplazamientos de los peces a lo largo de los ríos. Con el paso del tiempo, esas normativas se han hecho más comunes y han evolucionado en los objetivos que persiguen. Así, por ejemplo, en la Península Ibérica, una de las primeras legislaciones en esta materia buscaba impedir que los obstáculos cerrasen por completo las secciones de los ríos (Liber ludiciorum, 654 d.C. en Sanz-Ronda y Martínez de Azagra 2013). Posteriormente, la legislación española fue cambiando hasta fomentar la permeabilización o eliminación de los obstáculos [p. ej. Reales Ordenes de 1795, 1830 y 1832 (en Sanz-Ronda y Martínez de Azagra 2013); Ley de Aguas de 1879 (Gobierno de España 1879), Ley de Pesca Fluvial de 1907 y variaciones de 1929 (Gobierno de España 1929), o Ley de Fomento y Conservación de la Pesca Fluvial de 1942 (Gobierno de España 1942)], lo que se ha mantenido hasta nuestros días a nivel nacional [p. ej. Ley de Aguas de 1985 (Gobierno de España 1985), Ley de modificación de la Ley de Aguas de 1985 (Gobierno de España 1999), o Real Decreto Legislativo 1/2001 por el que se aprueba el texto refundido de la Ley de Aguas (Gobierno de España 2001)] y 
autonómico [p. ej. Ley 4/2015 del Patrimonio Natural de Castilla y León (Junta de Castilla y León 2015)]. No obstante, no ha sido hasta el año 2000 cuando se produjo un punto de inflexión con la aparición de la Directiva Marco del Agua (2000/60/CE) (Parlamento Europeo y Consejo 2000).

Esta Directiva ha cambiado el modo de evaluar el estado de las masas de agua de los estados miembros de la Unión Europea. Al igual que se hacía anteriormente, la Directiva propuso estudiar la calidad de las aguas atendiendo a parámetros fisicoquímicos, pero también, propuso su estudio desde un punto de vista ecológico, mediante indicadores hidromorfológicos. Esos indicadores buscan evaluar los desplazamientos de la fauna hacia aguas abajo y aguas arriba de los ríos, el transporte de sedimentos y la recuperación de los ríos. A nivel español, la Directiva se encuentra reflejada en el Real Decreto Legislativo 1/2001, y los indicadores hidromorfológicos a aplicar en los cauces vienen definidos por el "Protocolo de Caracterización Hidromorfológica de Masas de Agua de la Categoría Ríos" (MITECO 2019). En España, esos indicadores contemplan características hidrológicas (caudales, alteraciones del régimen hidrológico y conexión con masas de agua subterráneas), morfológicas (profundidad y anchura del cauce, estructura y sustrato del lecho, y estructura de las riberas), y la continuidad de los ríos.

Además de los elementos legales, el ser humano ha desarrollado diferentes alternativas con el fin de recuperar la continuidad longitudinal. Las más comunes son la eliminación de los obstáculos, la captura y transporte de los peces, y la construcción de pasos para peces. La eliminación de un obstáculo implica múltiples beneficios ecológicos y económicos, por lo que resulta la alternativa más recomendable (Martínez de Azagra-Paredes 1999; FAO/ DVWK 2002; Sanz-Ronda et al. 2013) (Figura 4.a). Sin embargo, hay casos en los que la concesión legal asociada está en uso y se hace imposible su eliminación, teniendo que aplicarse una de las otras alternativas. La captura y transporte de los animales hasta otros lugares resulta una opción laboriosa y costosa. Suele utilizarse puntualmente y por periodos de tiempo cortos como durante la construcción de un paso para peces (Cada y Sale 1993; Clay 1995; Schmetterling 2003), o en obstáculos de gran altura en los que conlleva menos retrasos, aglomeraciones o esfuerzos para los peces que un paso convencional (Clay 1995). La construcción de pasos para peces es la alternativa más habitual en todo el mundo (Clay 1995; FAO/ DVWK 2002; Larinier 2002a,c; Bunt et al. 2012) (Figura 4.b). De manera ideal, se trata de estructuras que permiten el libre desplazamiento de los peces hacia aguas arriba o hacia aguas abajo de un obstáculo sin capturarlos, causarlos perjuicios, o ser selectivos en cuanto a los individuos que son capaces de utilizarlos con éxito (Armstrong et al. 2004; Castro-Santos et al. 2009; Roscoe y Hinch 2010; Towler et al. 2013). 

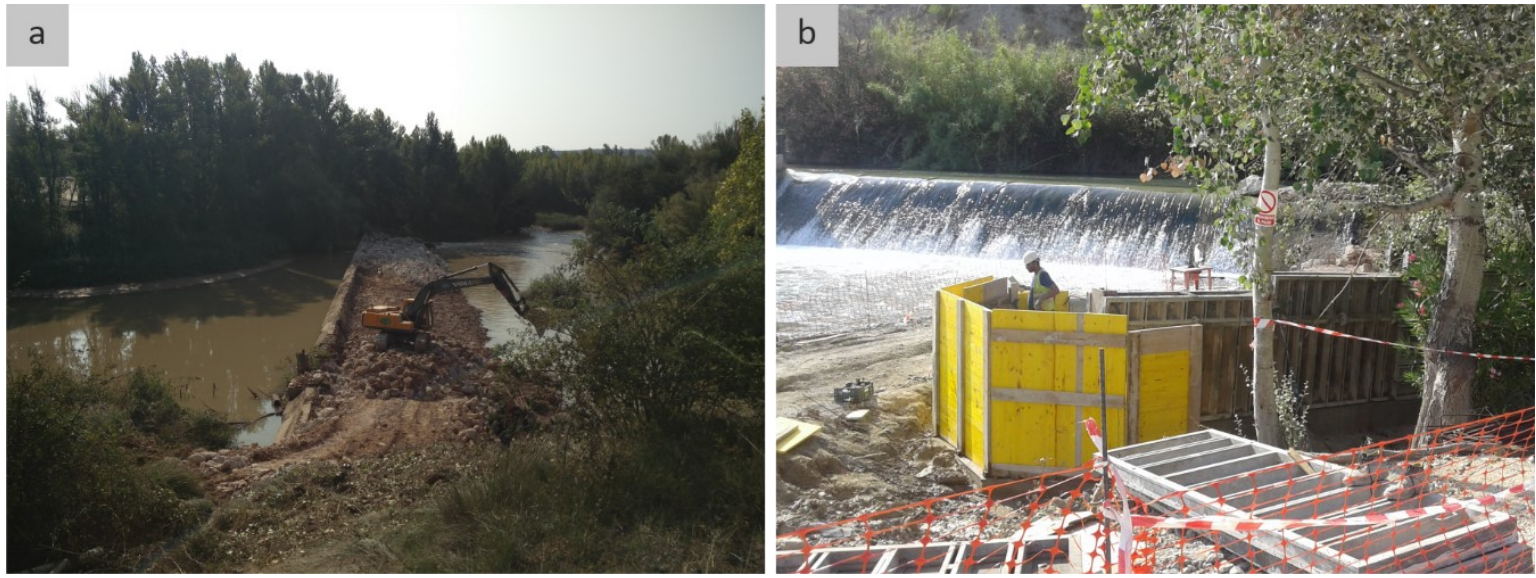

Figura 4. Ejemplos de actuaciones para recuperar la conectividad longitudinal en los ríos: eliminación de un azud en desuso (a) y construcción de un paso para peces (b).

Los pasos para peces modernos comenzaron a construirse en el siglo XVII (Clay 1995), con el nombre de escalas salmoneras, puesto que en sus orígenes únicamente buscaban permitir el ascenso de los salmónidos (Armstrong et al. 2004; Katopodis y Williams 2012) (Figura 5). Su diseño y ejecución se basaba en la observación, la lógica y el "ensayo y error", hasta que a inicios del siglo XX surgió una nueva línea de investigación con el fin de aumentar el conocimiento sobre estas estructuras, establecer pautas para su diseño y mejorar su funcionamiento (García Nájera 1953; Clay 1995; Katopodis and Williams 2012).
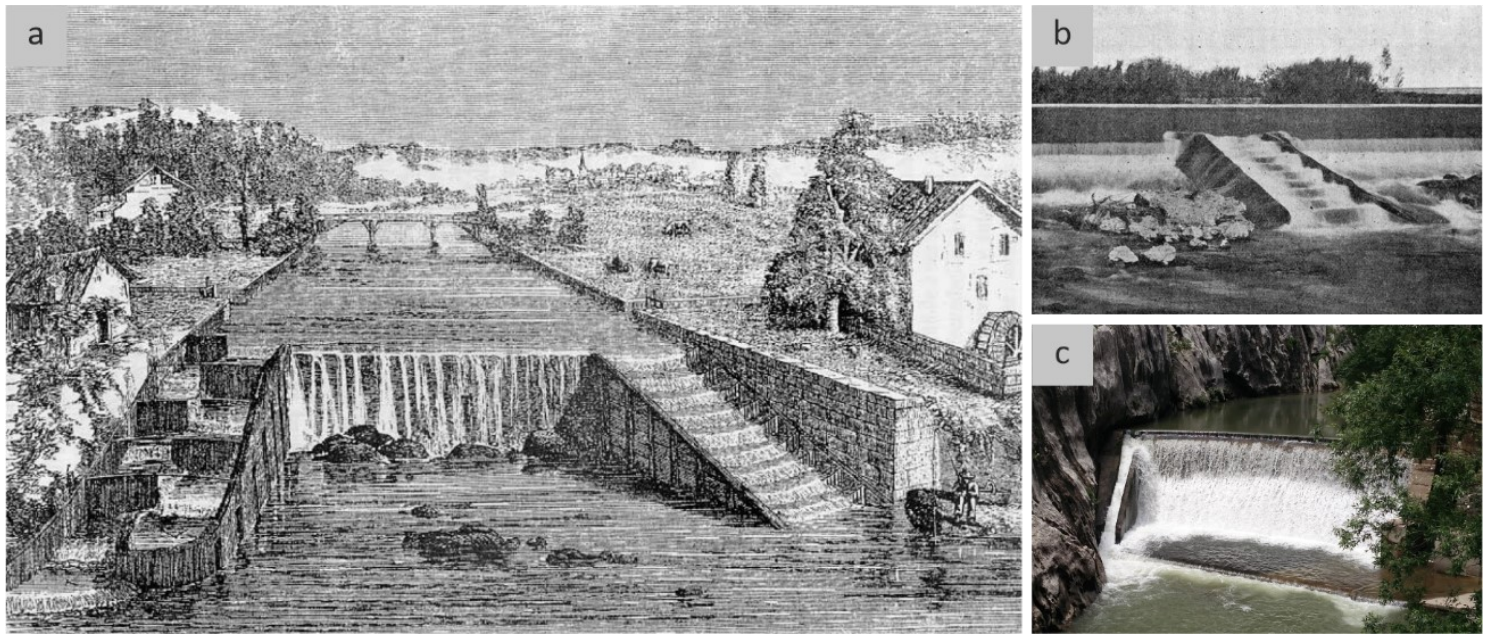

Figura 5. Dos antiguas escalas salmoneras en Escocia (fuente: Graells, 1864 en Sanz-Ronda y Martínez de Azagra 2013) (a), y dos de los primeros pasos para peces construidos en España en torno a 1913 (b y c) (fuente: Revista Montes en Sanz-Ronda y Martínez de Azagra 2013, y Grupo de Ecohidráulica Aplicada). 
Actualmente, estas estructuras presentan una gran diversidad constructiva y geométrica, incluso pueden habilitarse para ciertas especies concretas. No obstante, se suelen clasificar en dos grandes grupos: pasos naturalizados y pasos técnicos (FAO/ DVWK 2002; Towler et al. 2013). Los pasos naturalizados presentan materiales procedentes de los cauces y su entorno ( $p$. ej. bloques de piedra), lo que les proporciona una mejor integración en el paisaje. Entre ellos encontramos a las prepresas, ríos artificiales o bypasses, y rampas de piedras (Figura 6.a, b y c). Los pasos técnicos utilizan mayoritariamente materiales típicos de la obra civil (metal y hormigón), por lo que su integración paisajística es menor. Este grupo incluye los conocidos como pasos o escalas de estanques sucesivos, de ralentizadores, esclusas, ascensores, y las escalas anguleras o anguileras (Figura 6.d, e, f y g).
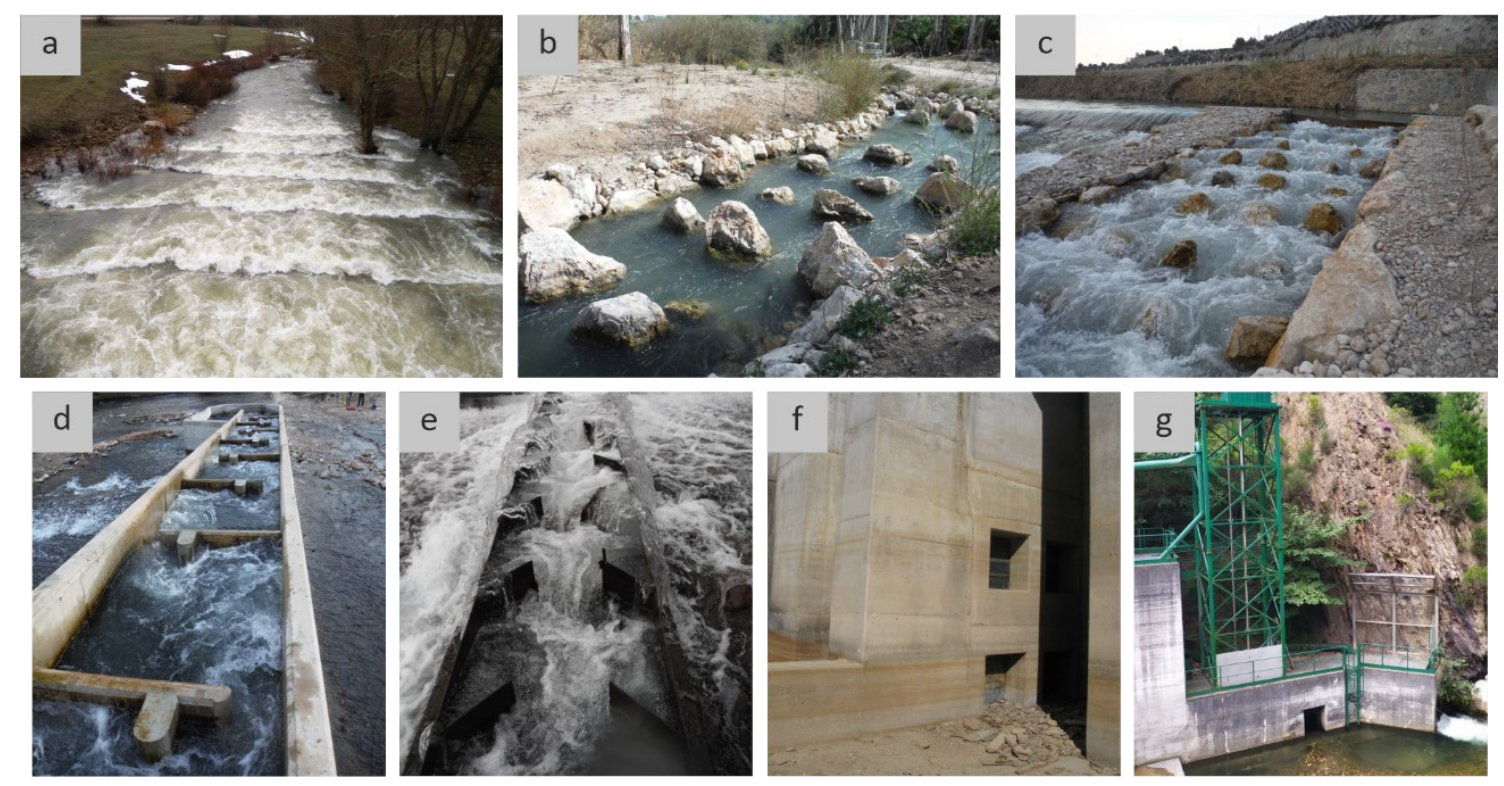

Figura 6. Pasos para peces que encontramos habitualmente en los ríos: prepresas (a), ríos artificiales (b), rampas de piedras (c), escalas de estanques sucesivos (d), escalas de ralentizadores tipo Denil (e), esclusas (f) y ascensores para peces $(\mathrm{g})$.

\subsection{EVALUACIÓN DE PASOS PARA PECES: UNA TAREA PENDIENTE}

Los pasos para peces se han construido y construyen masivamente en todo el planeta (Silva et al. 2017). Sin embargo, solo se ha estudiado el funcionamiento de una pequeña parte de ellos, obteniendo resultados muy diversos (Roscoe y Hinch 2010; Bunt et al. 2012; Noonan et al. 2012; Bravo-Córdoba et al. 2021). Algunos permiten el paso de los peces sin dificultades, mientras que otros resultan desfavorables (aglomeraciones, retrasos, etc.). Por tanto, la mera construcción de un paso para peces no garantiza que la ictiofauna pueda superarlo con éxito, siendo muy aconsejable evaluar todas y cada una de estas estructuras (Larinier 1998; CastroSantos et al. 2009; Roscoe y Hinch 2010) durante las diferentes fases que van a 
condicionar su resultado final: diseño, construcción y funcionamiento (Clay 1995; Noonan et al. 2012; Sanz-Ronda et al. 2013).

El desconocimiento sobre el funcionamiento de los pasos para peces también existe en el ámbito ibérico. Consciente de esta problemática, la Confederación Hidrográfica del Duero (CHD) promovió dos acuerdos de colaboración, uno en el año 2014 y otro en el 2019, con el Instituto Tecnológico Agrario y Agroalimentario (ITAGRA.CT) y el Grupo de Ecohidráulica Aplicada (GEA) de la Universidad de Valladolid (UVa), para conocer la funcionalidad de los pasos para peces. Ambos convenios de colaboración han permitido el desarrollo del trabajo de investigación recogido en esta tesis. En estos acuerdos se han desarrollado herramientas de evaluación, y se ha estudiado el funcionamiento y los efectos de varias de estas obras sobre los desplazamientos piscícolas, la conectividad longitudinal y el estado ecológico de los ríos de acuerdo con la Directiva Marco del Agua (2000/60/CE) (Parlamento Europeo y Consejo 2000).

A la hora de establecer el nivel de funcionamiento de un paso para peces podemos estudiar su efectividad o su eficiencia. La efectividad es un parámetro cualitativo que estima de forma general si los peces son capaces de moverse o no a través de un paso; mientras que la eficiencia es un aspecto cuantitativo que calcula la proporción de peces que realmente son capaces de localizar, entrar y desplazarse por el mismo (Larinier 2001; Castro-Santos y Haro 2010; Bunt et al. 2012). El funcionamiento de un paso depende de las características biológicas de las especies objetivo, y de las condiciones hidráulicas presentes en el propio paso (Roscoe y Hinch 2010; Noonan et al. 2012). De manera que para comprender adecuadamente ese funcionamiento debemos atender a ambos tipos de características. Los métodos empleados para estudiar la efectividad y eficiencia de los pasos se clasifican en dos grandes grupos: biológicos e hidráulicos (Sanz-Ronda et al. 2013) (Tabla 1).

Tabla 1. Principales tipos de métodos de evaluación de pasos para peces, sus variables atendidas y de salida, tipo de información de salida que ofrecen, y algunas técnicas o herramientas utilizadas en cada uno.

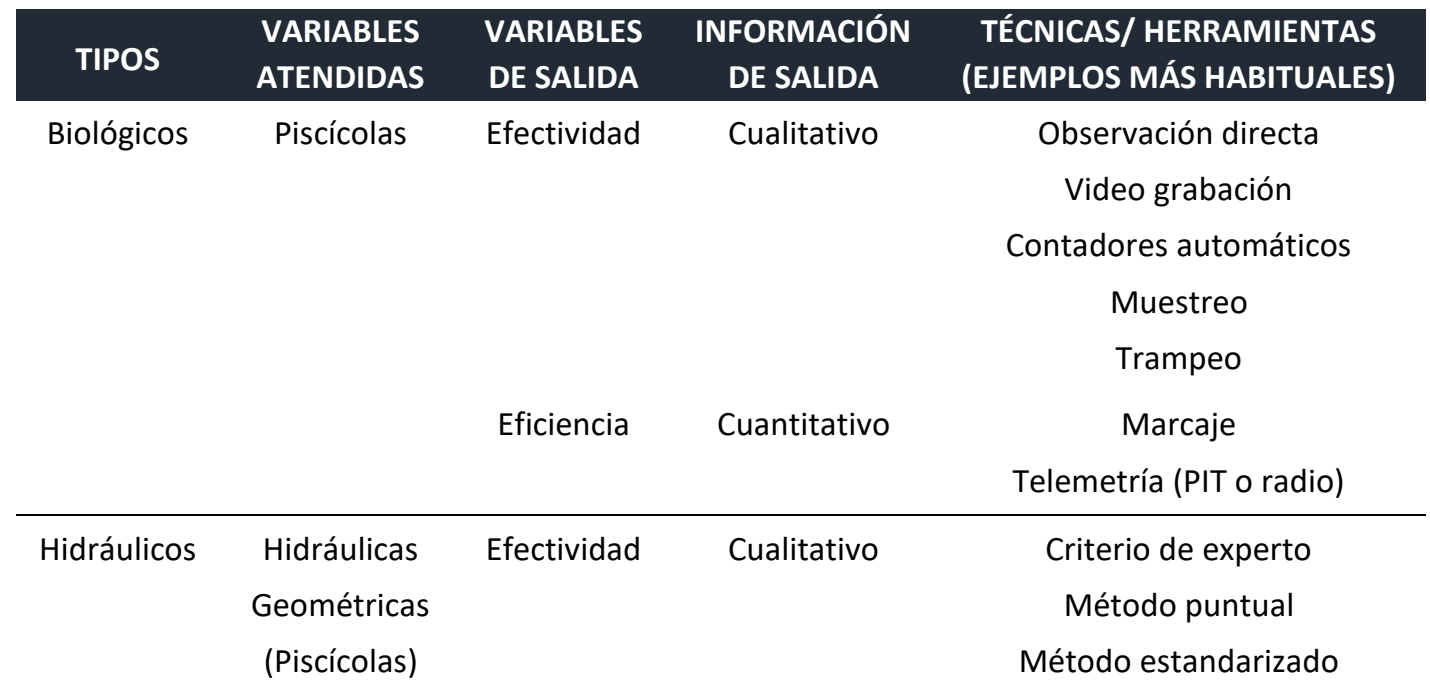


Los métodos de evaluación biológica analizan la efectividad y/o la eficiencia de un paso atendiendo directamente a los peces. La efectividad se estudia habitualmente mediante la observación directa de los peces a través de sistemas de video grabación, contadores, muestreos, trampas, etc. La eficiencia se determina, en general, mediante equipos de telemetría (radio, acústica o PIT -passive integrated transponders-) (Roscoe y Hinch 2010; King et al. 2017), marcando peces y estudiando sus desplazamientos por el paso (Figura 7). Estos métodos tienen un gran interés, puesto que ofrecen información precisa de qué especies y qué tamaños utilizan un paso, cómo lo hacen, el número de individuos que tiene éxito, etc. No obstante, su aplicación resulta compleja y costosa debido al tiempo, material y personal necesario para su aplicación (Barry et al. 2018).
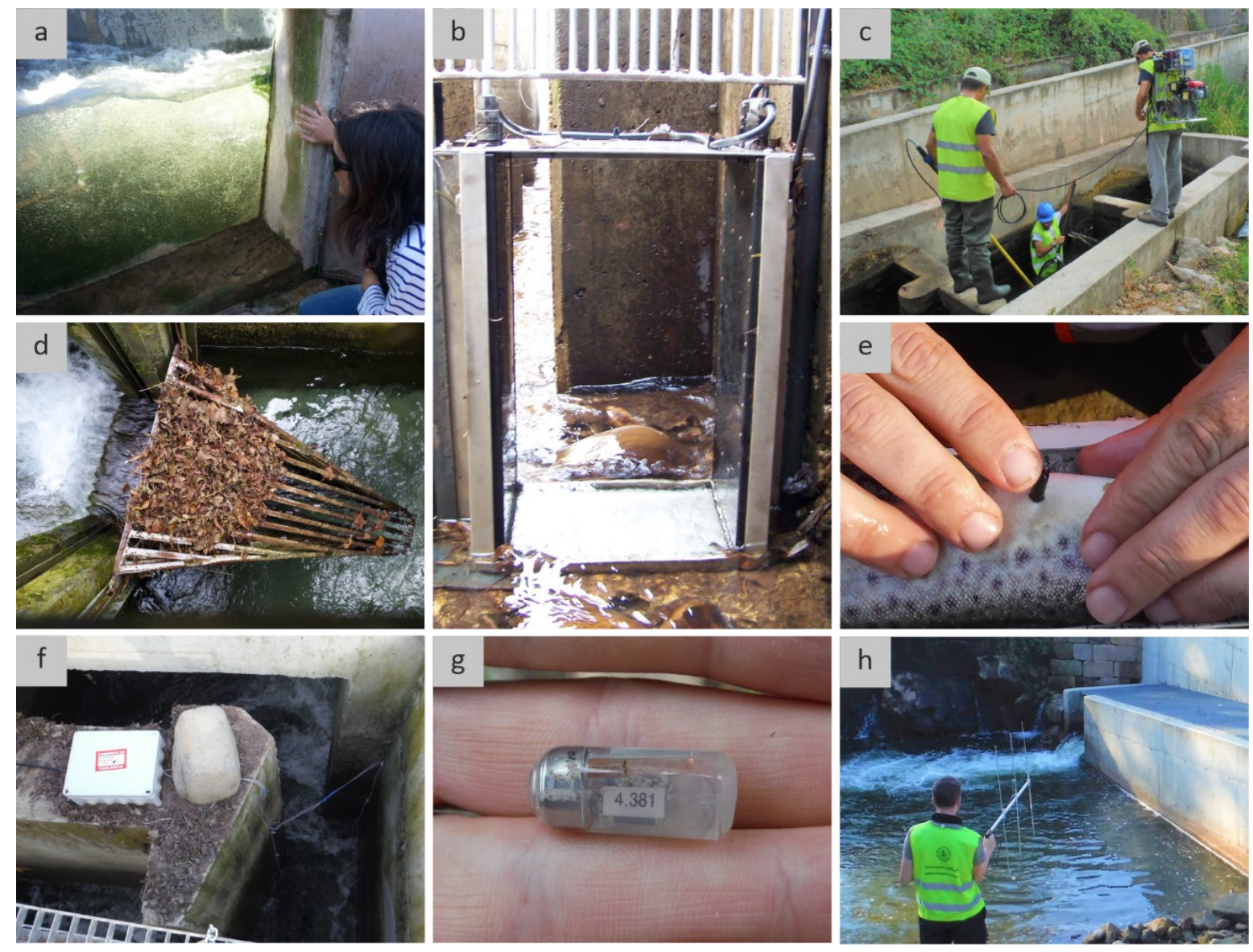

Figura 7. Ejemplos de técnicas y herramientas utilizadas en evaluaciones biológicas de pasos para peces: observación directa (a), contador de peces (b), muestreo mediante pesca eléctrica (c), butrón antirretorno para trampear ejemplares vivos (d), implantación de una marca PIT-tag de telemetría (e), equipo para la detección de PIT-tags (f), marca de radio para telemetría (g) y radio seguimiento (h).

Los métodos hidráulicos estudian la efectividad de los pasos para peces comparando sus características geométricas e hidráulicas con la biología de las especies (capacidad de salto y natación, comportamiento, etc.) (Baudoin et al. 2015; Barry et al. 2018). Se 
trata de métodos rápidos, sencillos y poco costosos de aplicar que resultan ideales para evaluar un gran número de pasos para peces (Barry et al. 2018), ayudando a tomar y priorizar decisiones de gestión. Sin embargo, no ofrecen información tan detallada como los métodos biológicos, presentan diferentes grados de subjetividad, y en algunos casos son difícilmente replicables (Figura 8).
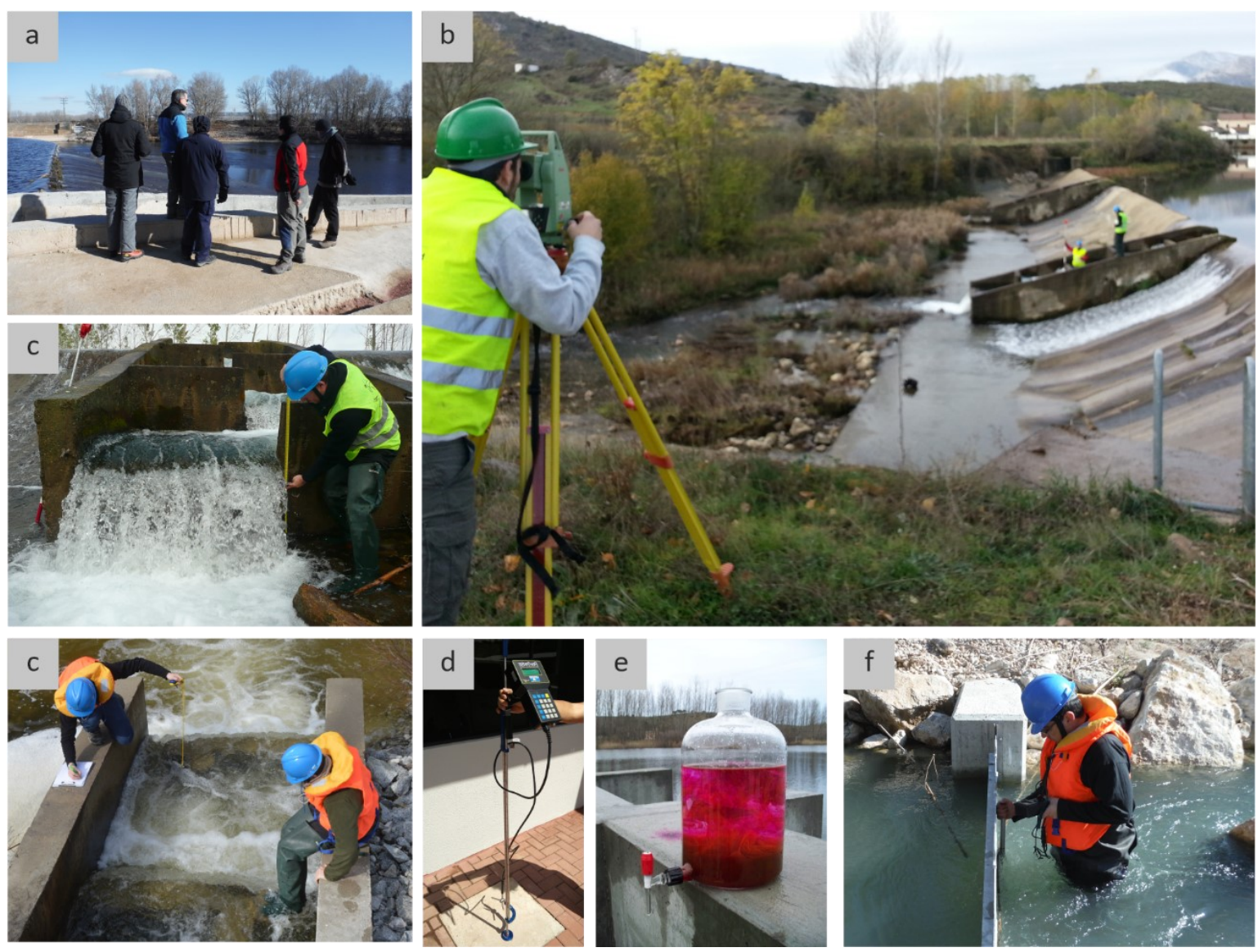

Figura 8. Ejemplos de técnicas y herramientas empleadas en evaluación hidráulica: “criterio de experto" (a), caracterización geométrica de la estructura con levantamiento topográfico (b) y cintas métricas (c), y caracterización hidráulica mediante aforador Doppler (d), trazador químico (e) o molinete hidráulico

(f).

La presente tesis plantea y aplica un método de evaluación hidráulica de pasos para peces estandarizado y objetivo, que se enfoca a tres especies piscícolas de la Península Ibérica. Este trabajo ofrece una herramienta para conocer el funcionamiento, problemas y posibles mejoras de este tipo de estructuras. Los resultados de esta tesis demuestran la aplicabilidad de estos métodos de evaluación para identificar aspectos a mejorar durante las fases de diseño, construcción y funcionamiento de un paso para peces. Asimismo, la tesis muestra que estos métodos sirven para comparar distintos pasos, ayudando en la gestión de los recursos con el objetivo de mejorar las obras existentes y futuras. 


\section{OBJETIVOS}




\section{OBJETIVOS}

\subsection{OBJETIVOS PRINCIPALES}

A continuación, se presentan los principales objetivos perseguidos en esta tesis:

1. Desarrollar una metodología operativa con una sólida base hidráulica y biológica, para evaluar pasos para peces de estanques sucesivos durante el ascenso de algunas de las principales especies piscícolas de la Península Ibérica.

2. Aplicar esta nueva metodología para testarla, y obtener información sobre el funcionamiento de varios pasos para peces de estanques sucesivos ubicados en diferentes cuencas hidrográficas de la Península Ibérica, con objeto de conocer su funcionalidad y problemática.

\subsection{OBJETIVOS SECUNDARIOS}

En este trabajo se plantean una serie de objetivos secundarios que son:

1. Crear un método de evaluación estandarizado, detallado, objetivo, sólido, práctico, y sencillo de interpretar por diferentes sectores de la sociedad con mayor o menor conocimiento de la temática.

2. Generar una metodología que evalúe, de forma cuantitativa e individualizada, los parámetros que influyen en las cuatro etapas que deben superar los peces en un paso: atracción, entrada, pasaje y salida.

3. Plantear una herramienta capaz de estudiar el funcionamiento, problemas y mejoras de un paso en todas sus fases: diseño, ejecución y funcionamiento.

4. Crear un sistema que permita comparar fácilmente los resultados de las evaluaciones de distintos pasos para peces, ayudando en la gestión de los ecosistemas fluviales.

5. Comprobar la aplicabilidad de la metodología de evaluación desarrollada.

6. Conocer el funcionamiento, parámetros favorables, problemas y posibles mejoras de pasos existentes en la Península Ibérica.

7. Colaborar en la recuperación de la conectividad longitudinal de los ríos, mejorando y conservando su estado ecológico y el de las poblaciones piscícolas que en ellos habitan.

8. Determinar si el funcionamiento de los pasos para peces ha mejorado con el paso del tiempo gracias a los esfuerzos realizados (investigación, formación, etc.).

9. Ayudar a crear pasos para peces más funcionales.

10. Crear una herramienta informática que automatice y simplifique la utilización del método de evaluación desarrollado. 
3. MATERIALES Y MÉTODOS 


\section{MATERIALES Y MÉTODOS}

En este apartado se recoge el marco metodológico seguido, que comprende cinco grandes bloques: revisión bibliográfica, ámbito de estudio, etapas a superar por los peces para atravesar un paso, métodos de evaluación hidráulica, aplicación de la metodología desarrollada, y análisis de datos.

Dentro de la revisión bibliográfica se explica la metodología seguida para describir y evaluar la búsqueda realizada. En cuanto al ámbito de estudio y etapas a superar por los peces para atravesar un paso, se presentan los aspectos hacia los que se ha enfocado el trabajo y que han servido como punto de partida. En el apartado de métodos de evaluación hidráulica se estudian las alternativas existentes, incluyendo una primera aproximación al método propuesto en esta tesis. A continuación, se explican una serie de casos de estudio sobre los que se ha utilizado la metodología de evaluación desarrollada, y cómo se ha recogido la información necesaria para su aplicación. Por último, se detalla el análisis de los resultados obtenidos al utilizar la metodología en los casos de estudio.

\subsection{REVISIÓN BIBLIOGRÁFICA}

Como punto de partida de este trabajo, desde mayo de 2014 hasta noviembre de 2016 se ha realizado una revisión bibliográfica sistemática siguiendo la metodología PRISMA (Preferred Reporting Items for Systematic Reviews and Meta-Analyses) (Moher et al. 2009).

En la búsqueda se han consultado documentos publicados entre 1960 y 2016 que incluyen literatura científica revisada por pares, literatura gris (p. ej. actas de congresos, cursos formativos o informes técnicos), y experiencias de campo del grupo de investigación en que se ha desarrollado la presente tesis. Los motores de búsqueda empleados han sido: ISI Web of Knowledge, Scopus, Research Gate, Google y su versión Google Académico. Se han utilizado varios términos de búsqueda que se han combinado o modificado para ampliar y acotar las búsquedas. Esos términos han sido: paso para peces, escala para peces, evaluación hidráulica, evaluación biológica, peces ibéricos, ciprínidos, salmónidos, Península Ibérica. La búsqueda ha podido contar con algún sesgo lingüístico debido a que se ha realizado en inglés y en español, aunque también se han considerado algunos documentos en portugués y francés. Con el objetivo de reducir errores, sólo se han tenido en cuenta aquellos documentos respaldados por metodologías, datos y/o fuentes apropiadas, detalladas y fiables.

La revisión ha permitido recabar un volumen importante de información procedente de varias fuentes empleadas por los diferentes sectores de la sociedad (investigadores, administraciones públicas, empresas privadas, etc.). 


\section{2. ÁMBITO DE ESTUDIO}

El presente trabajo se ha enfocado a los desplazamientos ascendentes de algunos peces ibéricos dentro de pasos o escalas de estanques sucesivos. Esta tipología de paso consiste en estanques escalonados que conectan entre sí por tabiques transversales con hendiduras, vertederos y/u orificios. Las artesas dividen el desnivel total entre las láminas de agua a ambos lados de un obstáculo $\left(H_{\text {total }}\right)$ en saltos menores $(\Delta H)$, asegurando que las condiciones hidráulicas permitan el paso de la fauna piscícola (Larinier 2002c; Fuentes-Pérez et al. 2017; Sanz-Ronda et al. 2019). Son los pasos para peces más estudiados y comunes en todo el mundo (Clay 1995; FAO/ DVWK 2002; Noonan et al. 2012), así como en el ámbito Mediterráneo (Guiny 2001; Verep et al. 2016; Pervin 2017), y en la Península Ibérica (Elvira et al. 1998a; SanzRonda et al. 2016; Bravo-Córdoba et al. 2018b) (Figura 9).
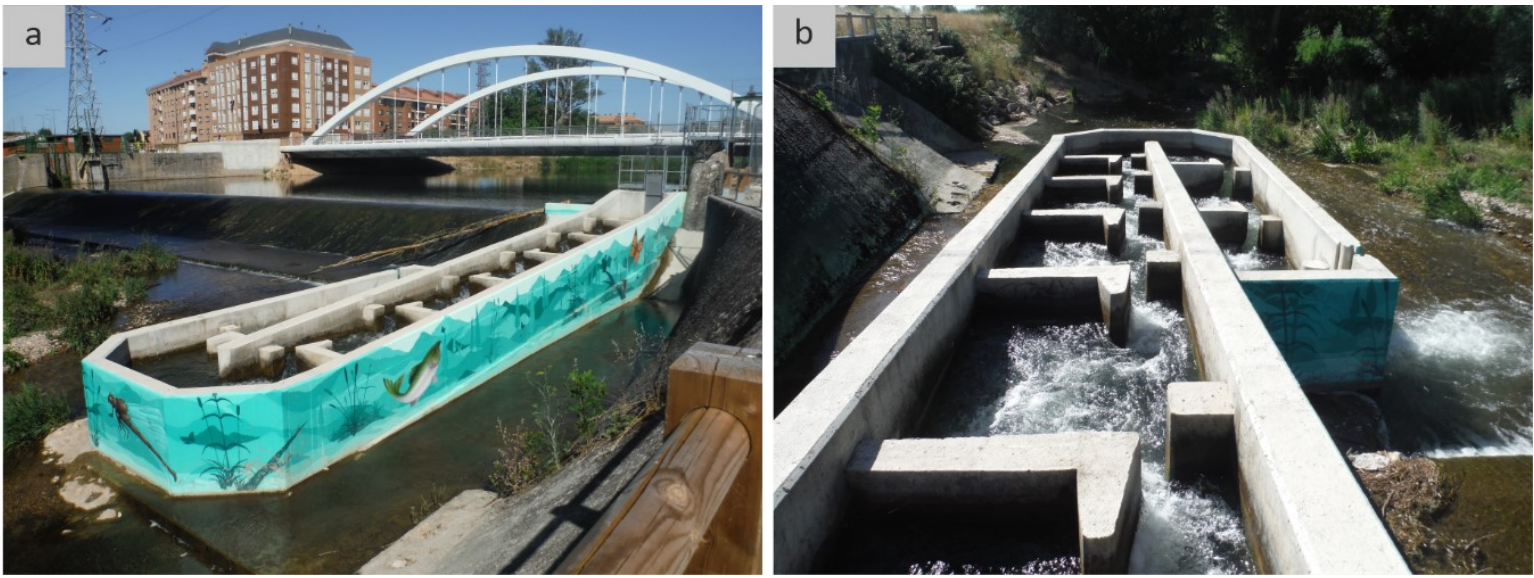

Figura 9. Escala de artesas o estanques sucesivos vista desde fuera junto al azud sobre el que se encuentra (a), y su interior con los tabiques que dividen el salto total de agua y dan lugar a los estanques (b).

El estudio se ha centrado en tres especies piscícolas muy representativas en la Península Ibérica: la trucha común -Salmo trutta (Linnaeus 1758)-, el barbo común Luciobarbus bocagei (Steindachner 1864)- y la boga del Duero -Pseudochondrostoma duriense (Coelho 1985)- (Figura 10). 

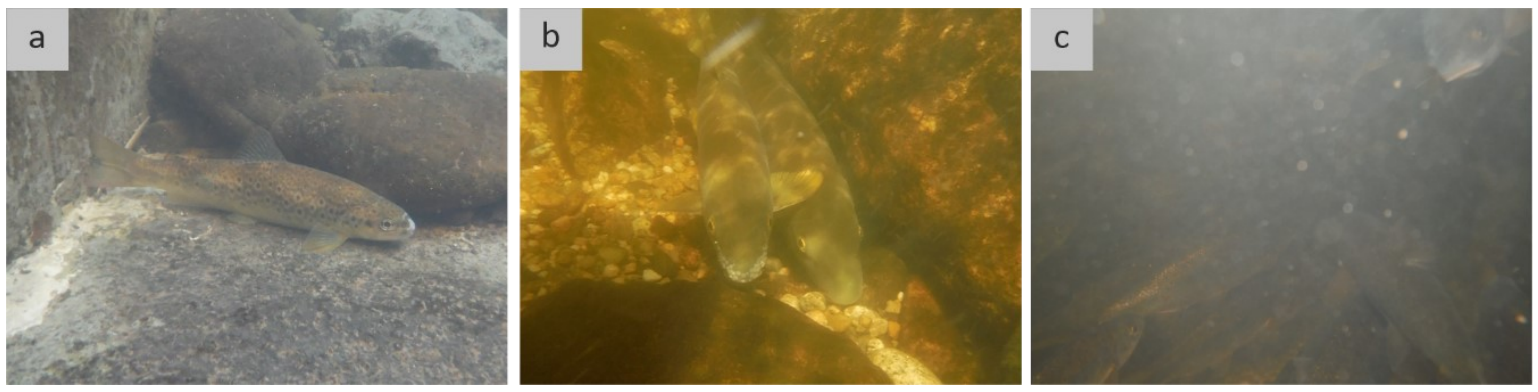

Figura 10. Ejemplares de trucha común (a), barbo común (b) y boga del Duero (c).

En la Península Ibérica, la trucha común cuenta con poblaciones de individuos autóctonos y alóctonos. Se distribuye por las cuencas cantábricas, catalanas, gallegas, Duero, Tajo, Guadalquivir, Segura, Júcar y Ebro (SIBIC 2017). Presenta una forma anádroma y otra potamódroma, que es la que encontramos en la cuenca del Duero. Esta especie migra hacia los tramos altos de los ríos para reproducirse, donde encuentra lechos de gravas y arenas, aguas de velocidad alta o moderada, frías y bien oxigenadas. Su periodo reproductivo abarca desde noviembre hasta enero (Doadrio et al. 2011; García-Vega et al. 2017, 2018; SIBIC 2017).

Por otro lado, el barbo común es una de las nueve especies de barbos que habitan en la Península Ibérica. Se trata de un pez potamódromo endémico que se localiza en el noroeste peninsular y, más concretamente, en las cuencas de los ríos Limia, Duero, Vouga, Mondego, Tajo y Sado (Kottelat y Freyhof 2007; SIBIC 2017). Suele encontrase en los tramos medios y bajos de los ríos, aunque migra para reproducirse hacia los tramos altos en busca de aguas rápidas, y sustratos de arenas y gravas. Su periodo reproductivo se extiende desde febrero o marzo hasta julio (Kottelat y Freyhof 2007; Doadrio et al. 2011; SIBIC 2017; García-Vega et al. 2021).

Finalmente, la boga del Duero es una de las tres especies del género Pseudochondrostoma que habitan en la Península. Es un endemismo potamódromo del noroeste peninsular, presente desde el sur de la cuenca del Duero hasta la del río Navia (en el norte de la península) (Doadrio et al. 2011; SIBIC 2017). Habita en los tramos medios de los ríos, y realiza migraciones hacia los tramos altos en busca de zonas con lechos de grava y arena en los que frezar. Su época de reproducción abarca desde abril hasta julio (Kottelat y Freyhof 2007; Doadrio et al. 2011; SIBIC 2017; García-Vega et al. 2021).

Las razones que han justificado la elección de estas especies han sido las siguientes:

- Las tres especies presentan una amplia distribución en la Península Ibérica y, en el caso de la trucha, a nivel mundial (Doadrio 2002; Kottelat y Freyhof 2007; Doadrio et al. 2011).

- Son relevantes y abundantes en los ecosistemas fluviales de la Península Ibérica de los que forman parte (Doadrio 2002; Kottelat y Freyhof 2007; Doadrio et al. 2011). 
- Dentro de la escasez de información científica sobre la ictiofauna ibérica, estas especies son algunas de las más conocidas de nuestro ámbito (p. ej. García-Vega et al. 2017, 2018, 2021; Romão et al. 2017; Silva et al. 2020).

- Son especies potamódromas con comportamientos semejantes durante sus migraciones reproductivas hacia aguas arriba (Doadrio 2002; Kottelat y Freyhof 2007; Doadrio et al. 2011).

- Presentan capacidades de nado parecidas (Castro-Santos et al. 2013; SanzRonda et al. 2015c; Ruiz-Legazpi et al. 2018).

- Tienen un comportamiento similar dentro de los pasos para peces en que se centra este trabajo (Sanz-Ronda et al. 2016; Bravo-Córdoba et al. 2018a,b, 2021).

- Las tres especies cuentan con un importante valor socioeconómico debido a su interés para la pesca deportiva.

- Son muy relevantes en la elaboración de planes de gestión de la pesca a nivel nacional [p. ej. ORDEN FYM/1383/2018 (Junta de Castilla y León 2018)].

- Cuentan con una gran importancia ecológica y se requieren actuaciones que ayuden a su conservación (Collares-Pereira et al. 1996; Kottelat and Freyhof 2007; Maceda-Veiga 2013) (Tabla 2).

Tabla 2. Estado de conservación en el ámbito ibérico de la trucha común, el barbo común ibérico y la boga del Duero.

\begin{tabular}{|c|c|c|c|c|c|}
\hline ESPECIE & $\begin{array}{c}\text { CATÁLOGO } \\
\text { ESPAÑOL DE } \\
\text { ESPECIES } \\
\text { AMENAZADAS } \\
\text { (RD 139/2011, } \\
4 \text { DE FEBRERO) }\end{array}$ & $\begin{array}{c}\text { LIVRO VERMELHO } \\
\text { DOS } \\
\text { VERTEBRADOS DE } \\
\text { PORTUGAL } \\
\text { (DL 193/93, } 24 \text { DE } \\
\text { MAIO) }\end{array}$ & $\begin{array}{l}\text { LISTA ROJA DE } \\
\text { ESPECIES } \\
\text { AMENAZADAS } \\
\text { (IUCN, 2019) }\end{array}$ & \multicolumn{2}{|c|}{$\begin{array}{l}\text { ICTIOFAUNA } \\
\text { CONTINENTAL } \\
\text { ESPAÑOLA }\end{array}$} \\
\hline $\begin{array}{l}\text { Trucha } \\
\text { común }\end{array}$ & No amenazada & $\begin{array}{l}\text { Preocupación } \\
\text { menor (LC) }\end{array}$ & $\begin{array}{c}\text { Preocupación } \\
\text { menor (LC) (2010) }\end{array}$ & $\begin{array}{l}\text { Vulnerable } \\
(\mathrm{VU})\left({ }^{1}\right)\end{array}$ & $\begin{array}{l}\text { Vulnerable } \\
\qquad(\mathrm{V})\left({ }^{2}\right)\end{array}$ \\
\hline $\begin{array}{l}\text { Barbo } \\
\text { común }\end{array}$ & No amenazada & $\begin{array}{l}\text { Preocupación } \\
\text { menor (LC) }\end{array}$ & $\begin{array}{c}\text { Preocupación } \\
\text { menor (LC) (2008) }\end{array}$ & $\begin{array}{l}\text { Vulnerable } \\
\qquad(\mathrm{VU})\left({ }^{1}\right)\end{array}$ & $\begin{array}{l}\text { Vulnerable } \\
\text { (V) }\left(^{2}\right)\end{array}$ \\
\hline $\begin{array}{l}\text { Boga del } \\
\text { Duero }\end{array}$ & No amenazada & $\begin{array}{l}\text { Preocupación } \\
\text { menor (LC) }\end{array}$ & $\begin{array}{l}\text { Vulnerable (VU) } \\
\qquad(2006)\end{array}$ & $\begin{array}{l}\text { Vulnerable } \\
\qquad(\mathrm{VU})\left({ }^{1}\right)\end{array}$ & $\begin{array}{l}\text { Vulnerable } \\
\qquad(\mathrm{V})\left({ }^{2}\right)\end{array}$ \\
\hline
\end{tabular}

$\left({ }^{1}\right)$ Clasificación propuesta por Doadrio et al. (2011) de acuerdo con los criterios de la IUCN.

$\left({ }^{2}\right)$ Clasificación propuesta por Doadrio et al. (2011) de acuerdo con los criterios del Catálogo Español de Especies Amenazadas (RD 139/2011 de 4 de Febrero). 
Los peces utilizan los pasos piscícolas tanto durante sus desplazamientos hacia aguas arriba como hacia aguas abajo (Lucas et al. 2001; Celestino et al. 2019; Sanz-Ronda et al. 2021), siendo necesario realizar trabajos en el futuro que estudien con más profundidad los movimientos descendentes de la ictiofauna a través de estas estructuras.

\subsection{ETAPAS A SUPERAR POR LOS PECES PARA ATRAVESAR UN PASO}

Las cuatro etapas que los peces deben superar cuando ascienden a través de una escala son: atracción $(A)$, entrada $(E)$, pasaje $(P S)$ y salida $(S)$ (Odeh 1999; CastroSantos et al. 2009; Castro-Santos 2012). La atracción hace referencia al acercamiento de los peces que están en el río hacia las proximidades del paso. La entrada es la etapa en la que los peces pasan del río al interior de la escala. El pasaje considera el tránsito de los peces desde la parte inferior hasta la superior del paso. La salida es la fase en la que los peces abandonan la escala y llegan al río, aguas arriba del obstáculo (Figura 11).

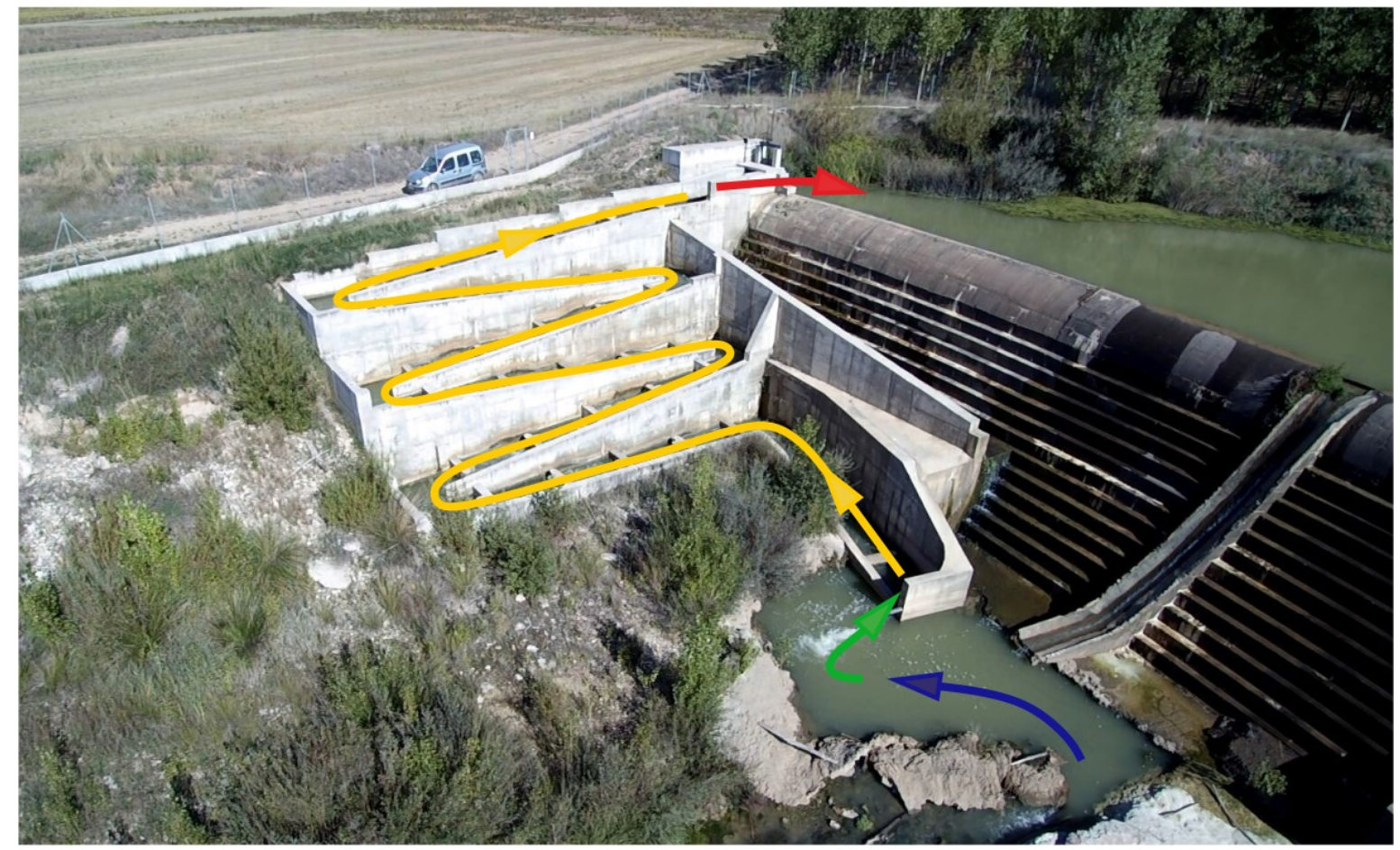

Figura 11. Los peces deben superar cuatro etapas en un paso: atracción ( $A$, en azul), entrada ( $E$, en verde), pasaje ( $P S$, en amarillo) y salida ( $S$, en rojo). 


\subsection{MÉTODOS DE EVALUACIÓN HIDRÁULICA}

Existe un amplio abanico de métodos de evaluación hidráulica que han sido desarrollados y aplicados en diferentes lugares del mundo: Estados Unidos (Towler et al. 2013; Barrett y Zweifel 2019; Platt 2019), Australia (Jones y O'Connor 2017), o Corea del Sur (Choi et al. 2016; Baek 2019), entre otros. Sin embargo, a pesar de la diversidad existente, suelen clasificarse en tres grandes grupos: criterio de experto, métodos puntuales y métodos estandarizados. A continuación, se presentan los que pudieran tener más interés para Europa y la Península Ibérica. La tabla 3 ofrece una panorámica de estos métodos, lo que permite compararlos entre sí y con la metodología que se desarrolla en esta tesis.

Tabla 3. Parámetros estudiados para estimar la efectividad en el ascenso de peces por pasos de estanques sucesivos mediante los métodos hidráulicos aplicados en Europa, y el presentado en este trabajo (AEPS).

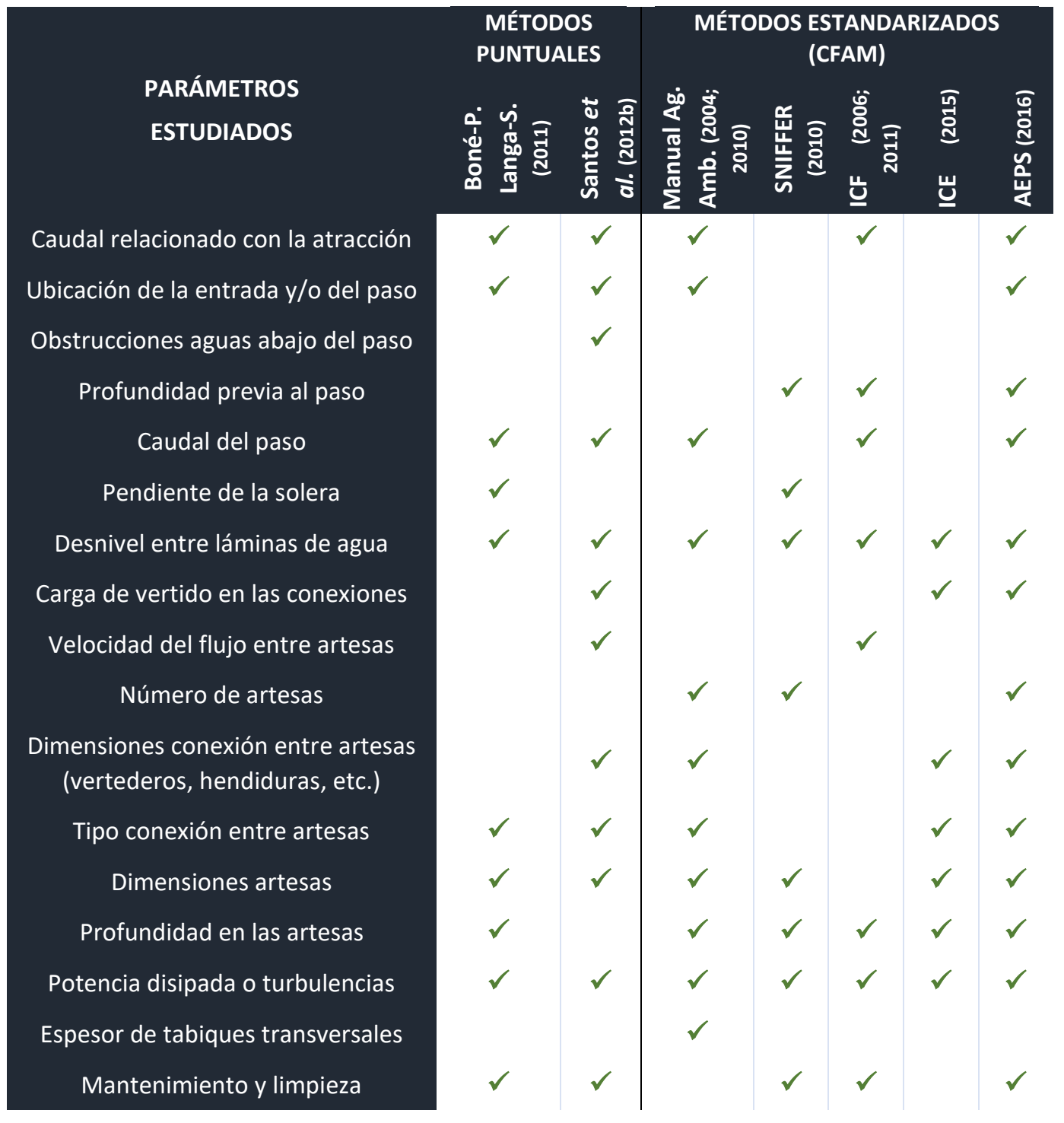




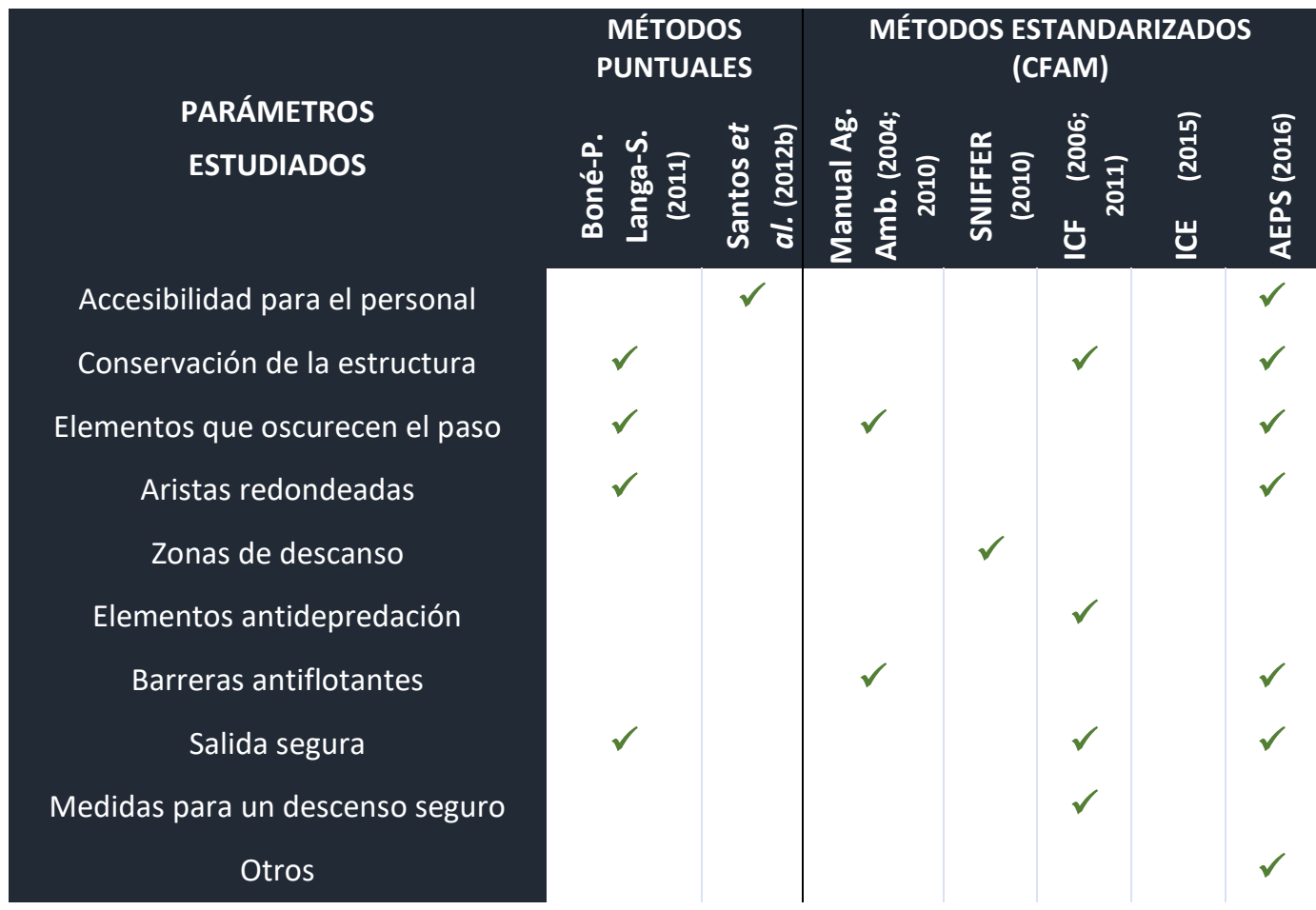

\subsubsection{CRITERIO DE EXPERTO}

El llamado criterio de experto es una alternativa utilizada tradicionalmente. Consiste en una simplificación de los métodos hidráulicos que puede aplicarse a cualquier paso para peces y especie objetivo. El evaluador atiende a distintos aspectos de un paso para determinar si los peces lo superan o no en base a su experiencia. Suponen una alternativa rápida, sencilla y poco costosa de aplicar, que presenta una alta subjetividad y bajo nivel de detalle que hace que sus resultados carezcan de un respaldo sólido. En el ámbito ibérico existen varios trabajos que emplean esta alternativa para evaluar distintas estructuras de paso para peces (p. ej. Elvira et al. 1998b; Santo 2005; Seisdedos-Fidalgo et al. 2010; MITECO 2019).

\subsubsection{MÉTODOS PUNTUALES DE EVALUACIÓN}

Se consideran como tales a los métodos que se han desarrollado para estimar la efectividad de pasos para peces en trabajos concretos. En general, se caracterizan por presentar una descripción simplificada de los criterios de evaluación que emplean y por ser aplicados por las mismas personas. Dos ejemplos desarrollados y aplicados en los ríos de la Península Ibérica son los utilizados por Boné-Puyo y Langa-Sánchez (2011), y por Santos et al. (2012b).

Boné-Puyo y Langa-Sánchez (2011) han desarrollado una metodología propia para evaluar un gran número de pasos en la cuenca del Ebro (en el este peninsular). Según 
la proporción de especies capaces de ascender por un paso y por cuánto tiempo al año, el funcionamiento de las estructuras se clasifica en cuatro categorías: alto, medio, bajo y nulo. Se trata de un método que estima el ascenso de los peces a través de varias tipologías de paso. Evalúa cualitativamente un gran número de parámetros en las cuatro etapas a superar por los peces (Tabla 3), aunque de manera simplificada y sin detallar los criterios empleados, lo que dificulta su replicación y lo convierte en una alternativa cercana al criterio de experto.

Otro de estos métodos es el implementado por Santos et al. (2012b) para estudiar el funcionamiento de varios pasos para peces situados en Portugal. A partir de la suma de las puntuaciones asignadas a los distintos parámetros que estudia (Tabla 3), se clasifica la efectividad de los pasos en cuatro categorías: altamente adecuados, adecuados, bajos e impasables. Es un método que evalúa el ascenso de varios ciprínidos ibéricos a través de las escalas de artesas. Para ello, analiza algunos parámetros de manera objetiva y otros subjetivamente en las etapas de atracción y pasaje.

\subsubsection{MÉTODOS ESTANDARIZADOS DE EVALUACÓN (CFAM)}

Los métodos estandarizados (Coarse Fishway Assessment Methods, CFAM, en inglés) son alternativas más detalladas y completas que los métodos anteriores. Se trata de herramientas que permiten a diferentes personas evaluar el funcionamiento de los pasos para peces de manera homogénea. En Europa existen varias opciones que pueden utilizarse con este tipo de estructuras: el manual de la Agencia Ambiental de Reino Unido (Armstrong et al. 2004, 2010), el protocolo SNIFFER (Kemp et al. 2008; SNIFFER 2010), el método ICF (Munné et al. 2006 y Solà et al. 2011) y el protocolo ICE (Baudoin et al. 2015).

\subsubsection{Manual de pasos para peces de la Agencia Ambiental Británica}

La Agencia Ambiental de Reino Unido ha publicado dos ediciones de un manual sobre el tema (Armstrong et al. 2004, 2010). Este manual busca desarrollar y evaluar propuestas de pasos para la ictiofauna británica en general, pudiendo utilizarse también en estructuras ya ejecutadas. Supone una herramienta versátil, aplicable al ascenso y descenso de muchas especies, que permite cualificar la atracción y el pasaje de cualquier tipo de paso. Sin embargo, sus resultados cuentan con una alta subjetividad, ya que el evaluador debe determinar la adecuación de los parámetros estudiados y del paso según su criterio (Tabla 3), comparándolos con una serie de recomendaciones recogidas en el manual. 


\subsubsection{Protocolo SNIFFER}

El protocolo SNIFFER (SNIFFER 2010), ha sido desarrollado por el Fórum para la Investigación Ambiental de Escocia e Irlanda del Norte en base a un trabajo previo (Kemp et al. 2008). Este protocolo evalúa la capacidad de la ictiofauna del Reino Unido para superar obstáculos en los cursos de agua. Asimismo, también sirve para evaluar escalas de estanques sucesivos. En función de las características del obstáculo o del paso para peces, se asigna una puntuación que se corresponde con cuatro categorías, que reflejan la dificultad y el tiempo de migración durante el cual los peces pueden superarlo: obstáculo impasable, parcial con alto impacto, parcial con bajo impacto, y sin obstáculo. Este protocolo estudia la permeabilidad de cualquier obstáculo y de tipologías muy concretas de pasos, tanto para ascenso como descenso de muchas especies, considerando diferentes estadios de vida de algunas de ellas. Se trata de un método que, en general, es subjetivo, aunque sea capaz de evaluar objetivamente, pero con poco detalle, un grupo reducido de parámetros relacionados con la etapa del pasaje de las escalas (Tabla 3).

\subsubsection{Método ICF}

El Índice de Conectividad Fluvial (ICF) (Munné et al. 2006), y su modificación (Solà et al. 2011), forman parte del procedimiento para evaluar la calidad hidromorfológica de los ríos desarrollado por la Agencia Catalana del Agua. El ICF estudia la permeabilidad de los obstáculos fluviales, con o sin pasos, para los peces autóctonos de las cuencas hidrográficas de Cataluña (en el este de la Península Ibérica). En base a varios parámetros, se proporciona una puntuación que interpreta y clasifica en cinco categorías su franqueabilidad: muy bueno, bueno, moderado, pobre y malo. EI ICF destaca por evaluar los efectos de cualquier obstáculo y su paso para peces en los movimientos de ascenso de varias especies. A pesar de atender a distintos parámetros en las cuatro etapas a superar por los peces, las evaluaciones que hace de las escalas tienen cierta subjetividad y son poco detalladas (Tabla 3).

\subsubsection{Protocolo ICE}

Onema, Ecogea y la Universidad de Lieja han desarrollado el protocolo ICE (Baudoin et al. 2015). Su objetivo es evaluar el impacto de los obstáculos presentes en los ríos para los desplazamientos de varias especies piscícolas. Además, analiza la efectividad de los pasos para peces, distinguiendo los que claramente no son funcionales de los que sí que pueden serlo y necesitan una evaluación más detallada. Este método 
determina si un paso funciona o no, comparando sus características con unos valores máximos o mínimos de referencia. Evalúa la efectividad de cualquier obstáculo y tipología de paso para el ascenso de los individuos jóvenes y adultos de un gran número de especies. Sus conclusiones son altamente objetivas, aunque poco detalladas debido a que únicamente atiende a unos pocos parámetros en la etapa del pasaje de las escalas (Tabla 3).

\subsubsection{La necesidad de nuevos métodos de evaluación hidráulica}

Más allá de sus características individuales, los métodos de evaluación hidráulica presentan tres ventajas comunes que los hacen muy interesantes: son sencillos, rápidos y poco costosos de aplicar. Sin embargo, en general, son procedimientos no estandarizados de manera objetiva, con una base biológica limitada y con escasa comprobación sobre la precisión de sus estimaciones.

El funcionamiento de los pasos para peces es un fenómeno complejo cuya evaluación depende de muchos parámetros (Baudoin et al. 2015; Bravo-Córdoba et al. 2021). Por ello, resulta necesario atender a todos ellos para evaluar de manera completa y detallada el funcionamiento de estas estructuras. Así, su evaluación debe ser objetiva e independiente de la opinión de expertos o evaluadores, para lo que debe basarse en informaciones biológicas sobre los peces. El uso de este tipo de información también hace que los criterios de evaluación empleados sean más fiables, ya que reflejan con precisión las características, comportamientos y requerimientos de las especies estudiadas dentro de los pasos. No obstante, la información existente acerca de las especies piscícolas en general es escasa, lo que debería limitar las especies objetivo a las que los métodos atienden. Para fomentar el uso de estos métodos, resulta necesario el desarrollo de nuevas alternativas que mantengan las ventajas que los caracterizan a la vez que superen sus inconvenientes.

En este trabajo se propone y aplica como parte de la presente tesis un CFAM, denominado metodología AEPS que ha sido desarrollado para la CHD (Confederación Hidrográfica del Duero 2016). Este método evalúa la efectividad de las escalas de estanques sucesivos para tres especies de peces ibéricos. Para ello, divide el ascenso en las cuatro etapas que los peces deben superar: atracción, entrada, pasaje y salida; estudiando un total de cuarenta y tres parámetros que lo condicionan. Estos parámetros se puntúan de 0 a 10 en función de su idoneidad. A partir de las puntuaciones, la metodología clasifica las evaluaciones en cuatro categorías: muy favorable, favorable, desfavorable y muy desfavorable. En definitiva, AEPS ofrece una radiografía detallada, cuantitativa y objetiva del funcionamiento de estas estructuras para el ascenso de los peces. En la Tabla 3 se ofrece un primer listado resumido con los parámetros que considera, cuyo desarrollo se muestra con detalle en el apartado "4. Resultados". 


\subsection{APLICACIÓN DE LA METODOLOGÍA DESARROLLADA}

\subsubsection{CASOS DE ESTUDIO}

Para la aplicación de la metodología AEPS se han visitado ochenta y seis escalas de estanques sucesivos. Estas escalas están asociadas a presas y azudes con uno o varios usos como: producción hidroeléctrica (91\%), agricultura (16\%), ambiental, recreativo o sin uso (6\%), navegación (5\%), trasvases (2\%), industria y acuicultura (2\%), aforos (1\%), y vías de comunicación (1\%). Esas escalas se encuentran ubicadas en las cuencas hidrográficas de los ríos Duero, Segura y Miera de la Península Ibérica, en el suroeste de Europa (Figura 12). En el anejo "A.4. Descripción y evaluación individual de las escalas para peces visitadas" se muestra una descripción completa de cada paso para peces.

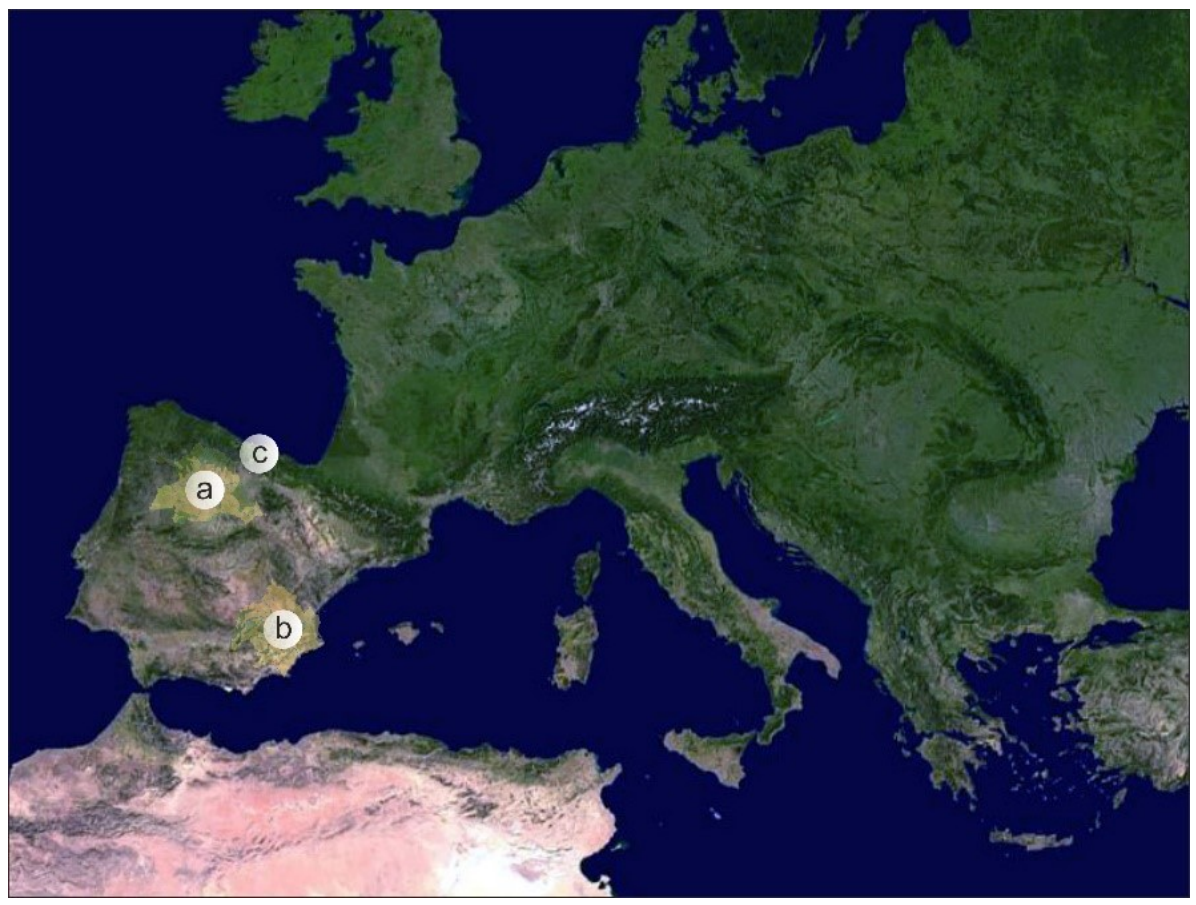

Figura 12. Cuencas hidrográficas de los ríos Duero (a), Segura (b) y Miera (c) en la Península Ibérica, en el suroeste de Europa (fuente: www.mapas-del-mundo.net).

La cuenca hidrográfica del río Duero presenta más de 5228 obstáculos en sus cursos de agua (Confederación Hidrográfica del Duero 2020b), lo que supone de media un obstáculo cada aproximadamente $2,7 \mathrm{~km}$ de río. De esos obstáculos, solamente 223 (en torno al $6 \%$ ) cuentan con algún tipo de paso para peces (datos propios y Confederación Hidrográfica del Duero 2020b). A día de hoy, sólo se ha estudiado el funcionamiento de una pequeña parte de ellos. Con el objetivo de conocer mejor estas estructuras, la Confederación Hidrográfica del Duero promovió dos acuerdos de 
colaboración que permitieron evaluar 80 de las escalas incluidas en esta tesis (Figura 13).

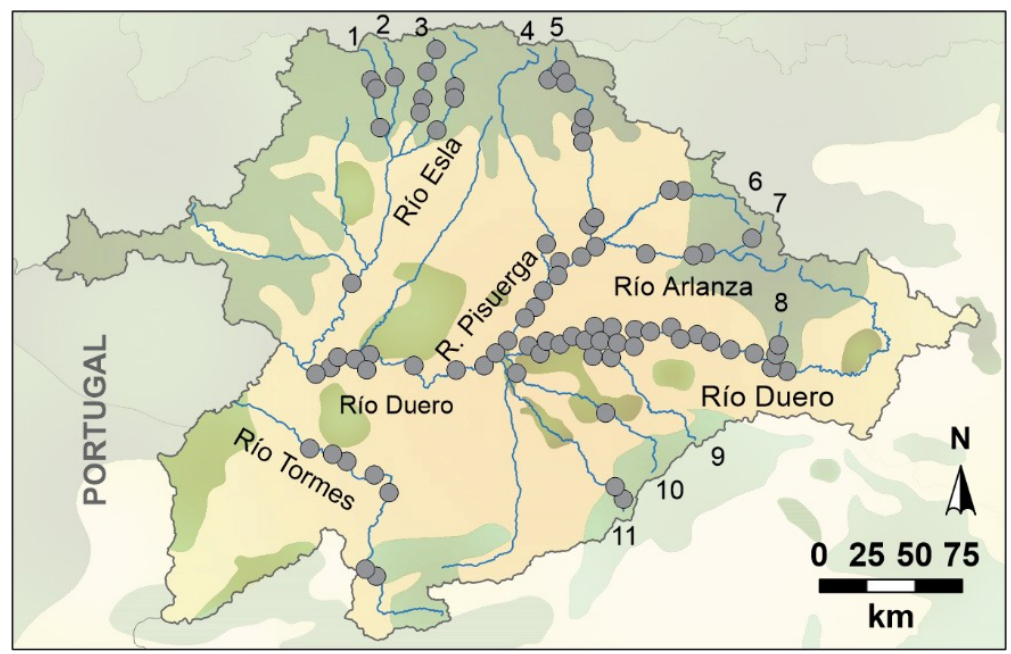

Figura 13. Pasos para peces visitados en la cuenca hidrográfica del río Duero (1 - Río Bernesga, 2 - Río Torío, 3 - Río Porma, 4 - Río Carrión, 5 - Río Pisuerga, 6 - Río Arlanzón, 7 - Río Pedroso, 8 - Río Ucero, 9 - Río Duratón, 10 - Río Cega, 11 - Río Eresma).

En la cuenca hidrográfica del río Segura existen más de 169 obstáculos (Confederación Hidrográfica del Segura 2020a), que hasta el año 2013 contaban con un único paso para peces ubicado en el río Mundo. En ese año, el proyecto Life "Segura Riverlink" promovió el diseño y construcción de 8 nuevos pasos de distintas tipologías para recuperar parte de la conectividad longitudinal del río Segura. Una vez finalizadas las obras, se llevó a cabo la evaluación de todos los pasos con el fin de estudiar su funcionamiento. En esta tesis se ha incluido la información recogida en los cuatro pasos de estanques sucesivos evaluados para esta cuenca (Figura 14 y figura 15).

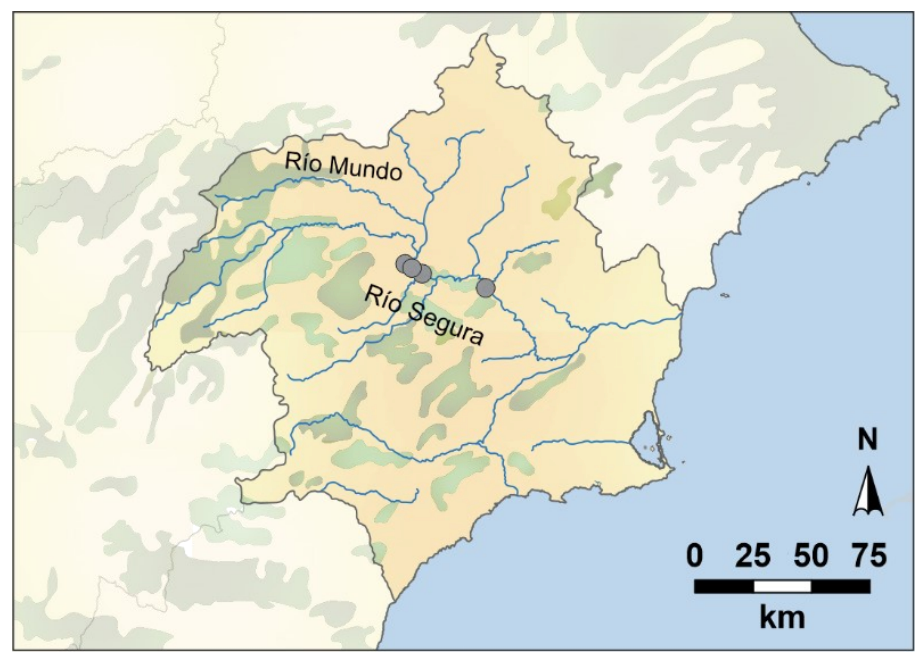

Figura 14. Escalas estudiadas en la cuenca hidrográfica del río Segura. 

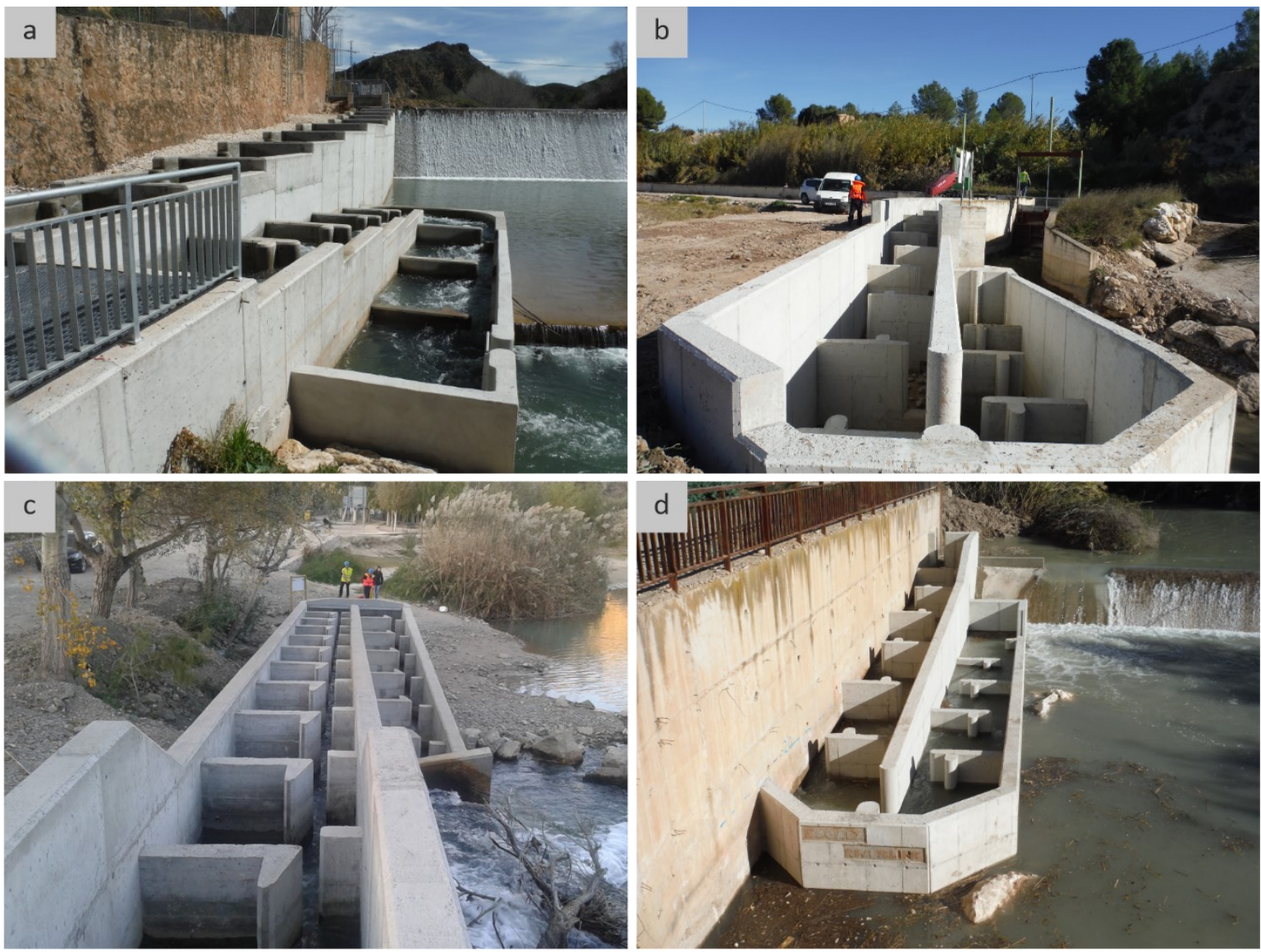

Figura 15. Escalas de estanques sucesivos visitadas en la cuenca del Segura: Cañaverosa (a), El Esparragal (b), El Jarral (c) y Elevación Postrasvase (d).

En el río Miera existen cerca de 15 obstáculos a la migración de los peces (IH Cantabria et al. 2000), lo que supone de media un obstáculo cada 3,0 km de río. Los obstáculos más limitantes para los desplazamientos hacia aguas arriba de los peces se encuentran en el tramo medio, a su paso por el municipio de Liérganes. En el año 2014 se inició el proyecto Life "Conservación de la biodiversidad en el río Miera" que, entre otras acciones, propuso la construcción y posterior evaluación de 3 pasos para peces que recuperasen la conectividad longitudinal del río. En el presente documento se analizan 2 pasos de estanques sucesivos, mientras que el tercero se ha descartado por combinar características de escalas de artesas y de pasos naturalizados (Figura 16 y figura 17). 


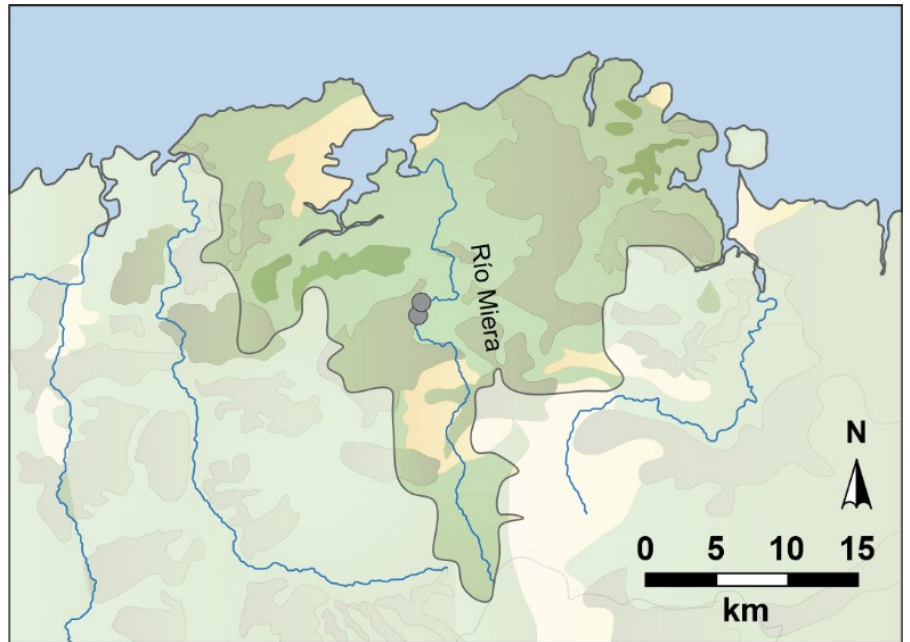

Figura 16. Escalas consideradas en la cuenca del río Miera.
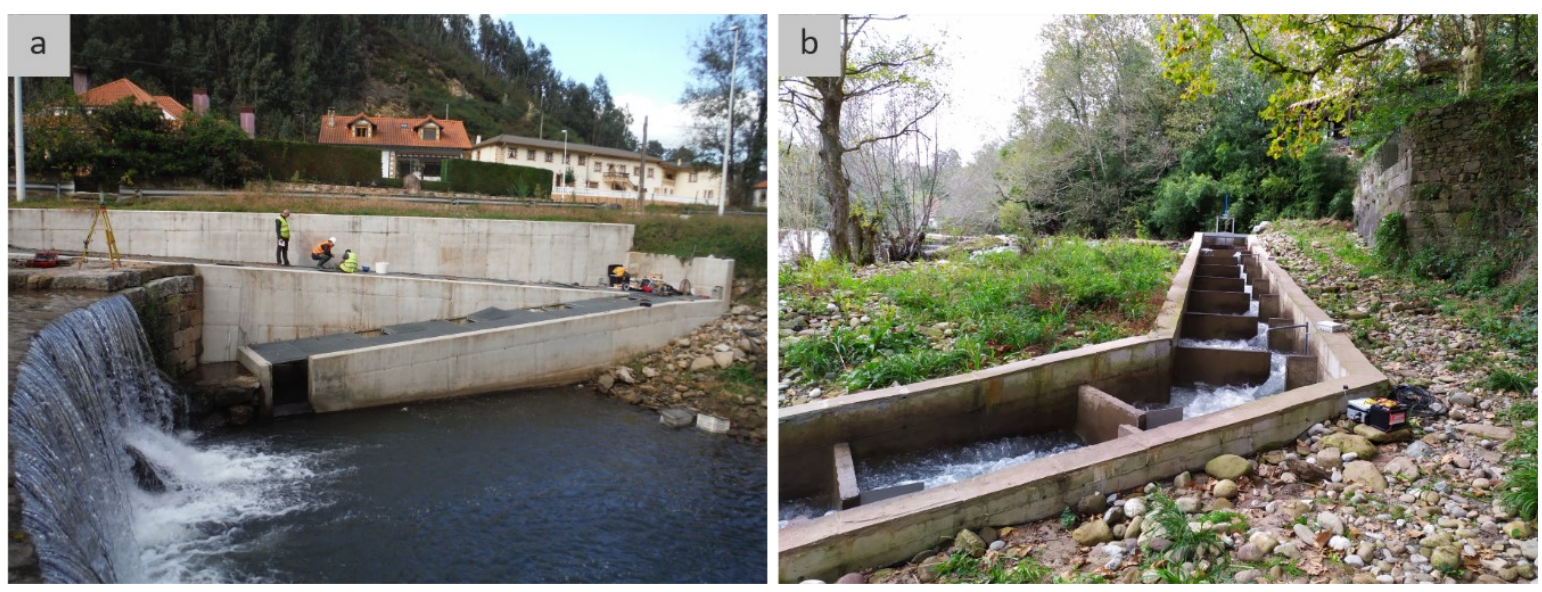

Figura 17. Escalas de estanques sucesivos estudiadas en el río Miera: Revolvo (a) y El Arral (b).

En las cuencas hidrográficas visitadas existen múltiples especies piscícolas. Entre ellas destaca un grupo de especial interés formado por truchas, barbos y bogas, cuya conservación es muy relevante para el mantenimiento de los ecosistemas acuáticos y por razones socioeconómicas (Collares-Pereira et al. 1996; Kottelat y Freyhof 2007; Maceda-Veiga 2013). Este grupo de especies presenta características contrastadas o potenciales muy similares en cuanto a su capacidad natatoria (Romão et al. 2012; Branco et al. 2013; Castro-Santos et al. 2013; Sanz-Ronda et al. 2015c, 2016, 2019; Bravo-Córdoba et al. 2018a,b; Ruiz-Legazpi et al. 2018) (Tabla 4). 
Tabla 4. Especies objetivo consideradas en las cuencas hidrográficas visitadas.

\section{CUENCA HIDROGRÁFICA DEL CUENCA HIDROGRÁFICA DEL CUENCA HIDROGRÁFICA DEL RÍO DUERO RÍO SEGURA RÍO MIERA

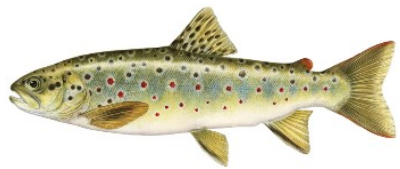 \\ Trucha común \\ (Salmo trutta)

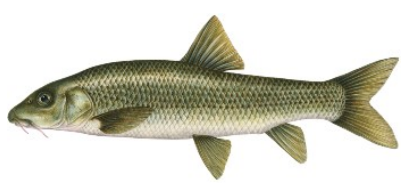 \\ Barbo común ibérico \\ (Luciobarbus bocagei)

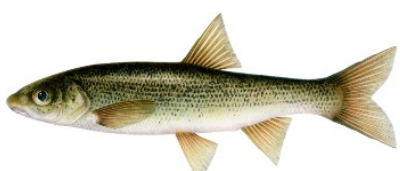 \\ Boga del Duero \\ (Pseudochondrostoma duriense)

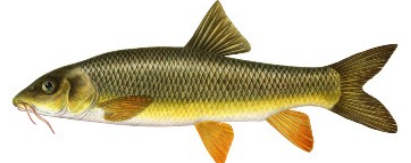 \\ Barbo del sur \\ (Luciobarbus sclateri)

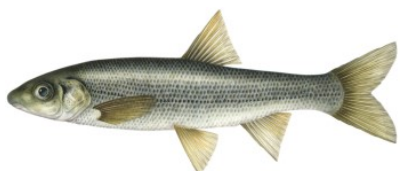 \\ Boga de río o del Tajo (Pseudochondrostoma polylepis)

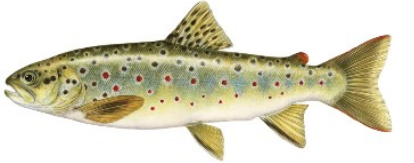 \\ Trucha común \\ (Salmo trutta)}

Autora: Claudia Baeta (fuente: SIBIC 2017)

Las escalas estudiadas se encuentran en tramos de río con presencia actual o potencial de alguna de las especies de interés de cada cuenca. Se trata de escalas que han sido construidas por iniciativa privada o pública desde principios de los años 1990 hasta 2019, siendo más del 75 \% de ellas posteriores a la implantación de la Directiva Marco del Agua en el año 2000 (Parlamento Europeo y Consejo 2000). A continuación, se muestra una tabla resumen con las características de diseño (Tabla 5 y figura 18) (véase el anejo “A.4. Descripción y evaluación individual de las escalas para peces visitadas"): 
Tabla 5. Resumen de las características de las escalas visitadas.

$\begin{array}{ccc}\text { VARIABLE } & \text { VALOR MíNIMO } & \text { VALOR MÁXIMO } \\ \text { Caudal de diseño } & 150 \mathrm{~L} / \mathrm{s} & 500 \mathrm{~L} / \mathrm{s} \\ \text { Salto total de agua }\left(H_{\text {total }}\right) & 1,2 \mathrm{~m} & 8 \mathrm{~m} \\ \text { Pendiente de la solera }(\text { Pte. }) & 5 \% & 28 \% \\ \text { Número de estanques } & 3 & 34 \\ \text { Longitud de los estanques }(L) & 0,80 \mathrm{~m} & 3,20 \mathrm{~m} \\ \text { Anchura de los estanques }(B) & 0,80 \mathrm{~m} & 2,40 \mathrm{~m} \\ \text { Anchura de los vertederos y hendiduras }(b) & 0,15 \mathrm{~m} & 0,40 \mathrm{~m} \\ \text { Área de los orificios }(\text { Área }) & 0,01 \mathrm{~m} & 0,03 \mathrm{~m} \\ \text { Carga de vertido }(h) & 0,20 \mathrm{~m} & 0,40 \mathrm{~m} \\ \text { Tirante medio de agua }\left(t_{\text {med }}\right) & 0,00 \mathrm{~m} & 0,60 \mathrm{~m} \\ \text { Potencia disipada por unidad de volumen }(N) & 0,40 \mathrm{~m} & 1,20 \mathrm{~m}\end{array}$

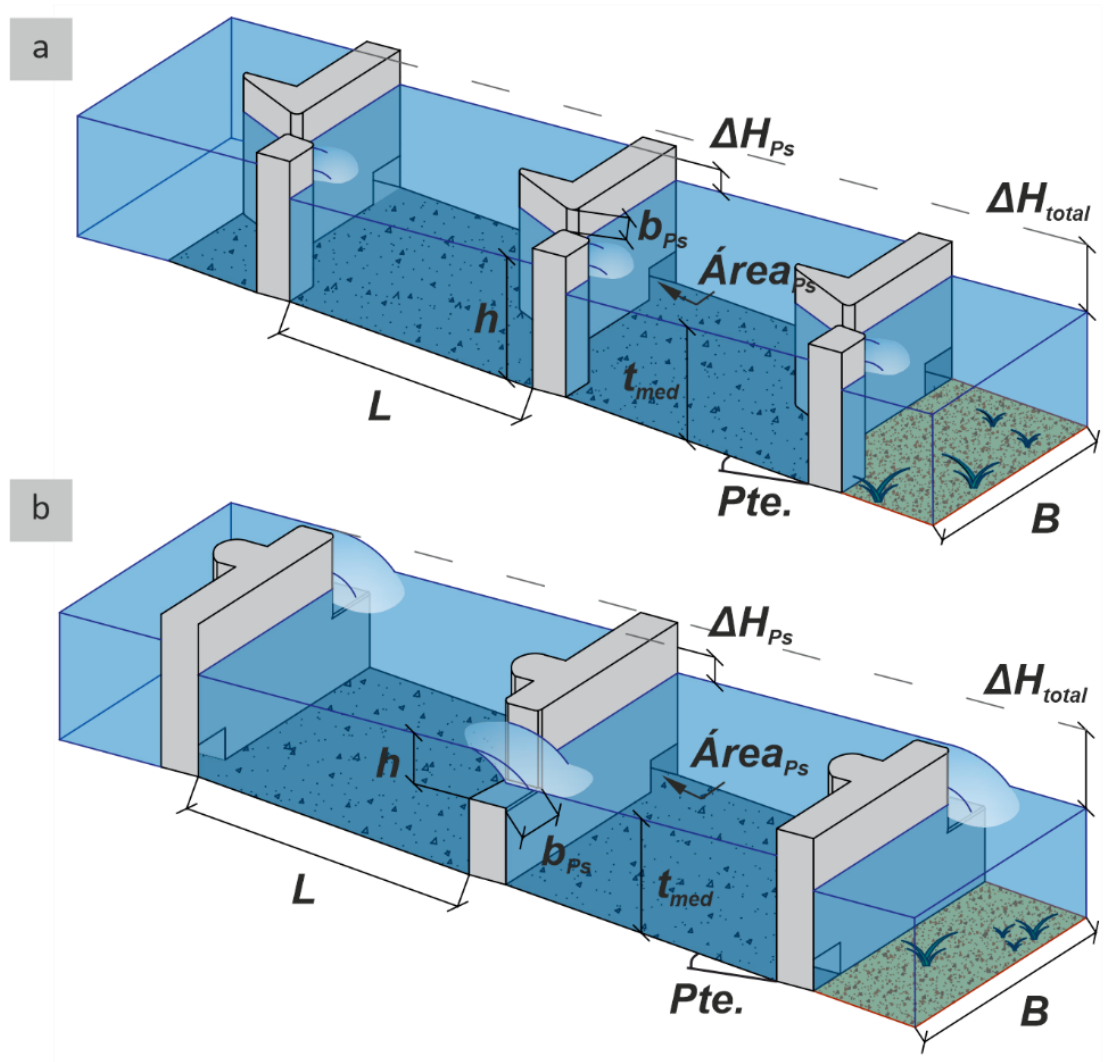

Figura 18. Representación de las variables más relevantes medidas sobre una escala de hendiduras verticales (a) y de vertederos sumergidos con orificios de fondo (b) ( $\Delta H$-diferencia de nivel entre láminas de agua, $h$ - carga de vertido, $h_{E}, h_{P_{S}}$ y $h_{S}$ - profundidad de paso en la entrada, pasaje y salida respectivamente, $b$ - anchura de vertederos o hendiduras, Área - área de los orificios, $L$ - longitud de los estanques, $B$ - anchura de los estanques, $h_{\text {prev } E}$ - profundidad previa a la entrada, $t_{m e d}$ - profundidad media en los estanques, $h_{\text {posterior } s}$ - profundidad posterior a la salida, subíndices: $E$ - entrada, $p_{s}-$ pasaje, $s-$ salida). 


\subsubsection{RECOPILACIÓN DE INFORMACIÓN EN CAMPO}

Los pasos para peces deben funcionar correctamente en cualquier momento del año (Martínez de Azagra-Paredes 1999; FAO/ DVWK 2002). Sin embargo, es especialmente importante asegurar que los peces puedan superarlos cuando realizan movimientos esenciales para la supervivencia de sus poblaciones (Larinier 2002c; Armstrong et al. 2004). Por ello, las escalas a evaluar se han visitado entre mayo de 2014 y febrero de 2020 durante las migraciones reproductivas hacia aguas arriba de las especies de interés en cada curso de agua. Así, en aquellos tramos de río con ciprínidos, las visitas se han realizado entre abril y junio; mientras que en las zonas de salmónidos, las visitas se han hecho entre septiembre y febrero, conforme a las recomendaciones de diferentes autores (Kottelat y Freyhof 2007; Doadrio et al. 2011; García-Vega et al. 2017, 2021). Para conocer las especies de interés presentes en los ríos de la cuenca del Duero se ha recurrido al sistema de información cartográfica MíRAME-IDEDuero (Confederación Hidrográfica del Duero 2020b); mientras que para la cuenca del Segura se ha consultado bibliografía (Oliva-Paterna et al. 2014), y para la del Miera se ha contado con la información facilitada por la Confederación Hidrográfica correspondiente (Confederación Hidrográfica del Cantábrico 2021).

En cada una de las escalas visitadas se ha recogido información hidráulica y geométrica, siguiendo un protocolo estandarizado. Se ha empleado un prisma con jalón y una estación total Leica TC310 con precisión centimétrica para la medición de niveles de agua y cotas de las escalas. Para medir su geometría se han utilizado cintas métricas con la misma precisión (Figura 19).
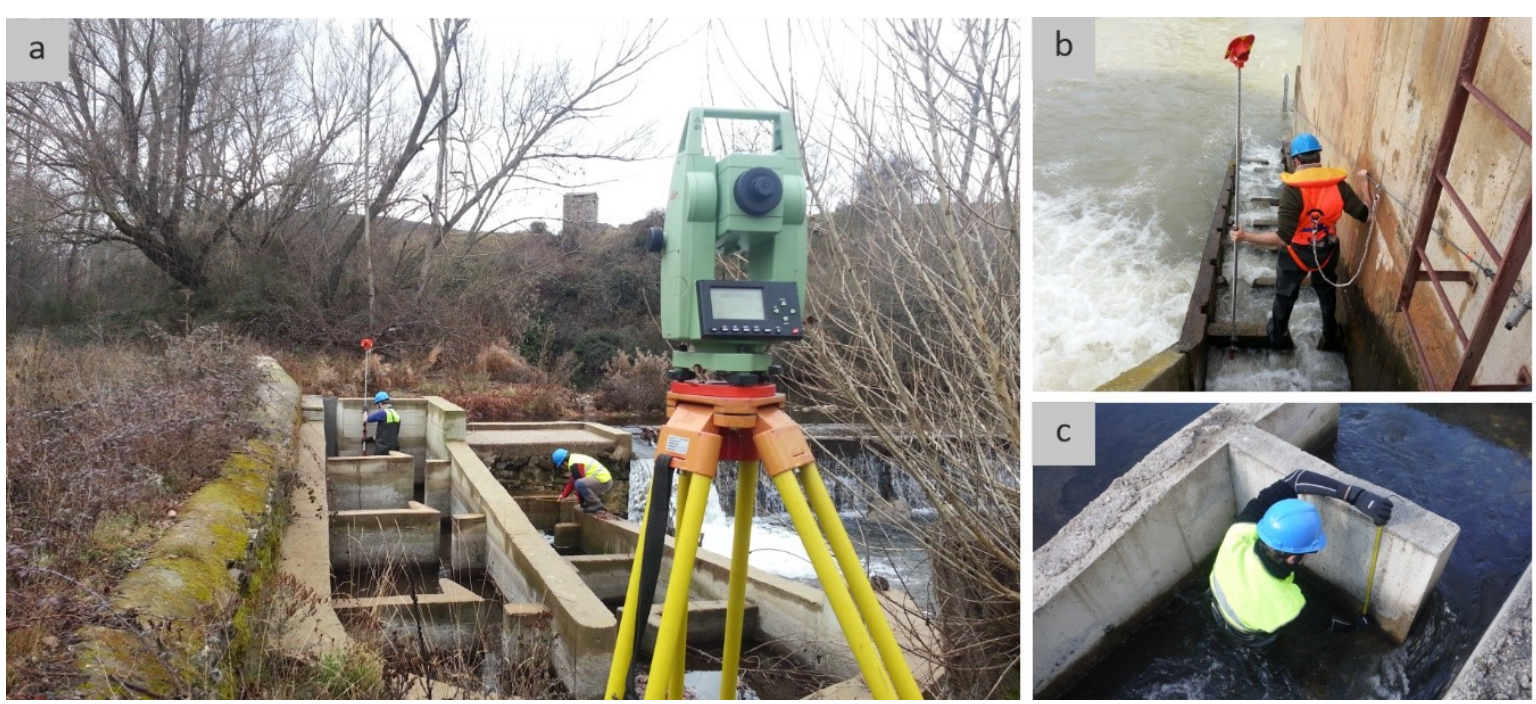

Figura 19. La información de las escalas se ha recogido mediante estación total (a), prisma con jalón (b) y cintas métricas (c). 
Las escalas para peces de estanques sucesivos suelen clasificarse de acuerdo con el tipo de conexión que presentan entre sus estanques (Fuentes-Pérez et al. 2016, 2017). En este trabajo se han agrupado en cinco categorías: hendiduras verticales, vertederos sumergidos con orificios, vertederos no sumergidos con orificios, vertederos sumergidos únicamente, o solamente vertederos no sumergidos (Figura 20).
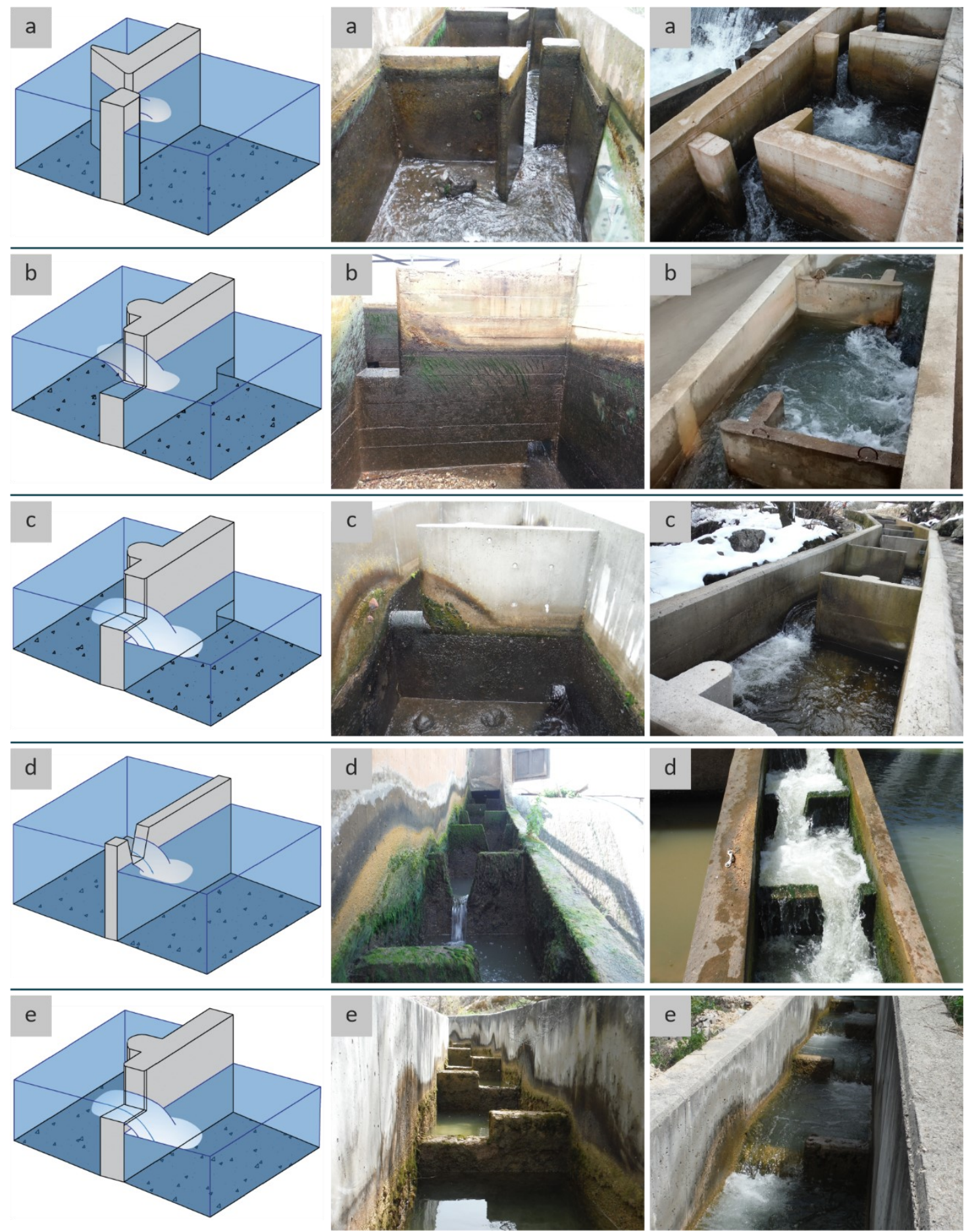

Figura 20. Conexiones entre estanques en las escalas evaluadas: hendiduras verticales (a), vertederos sumergidos con orificios (b), vertederos libres o no sumergidos con orificios (c), vertederos sumergidos (d) y vertederos libres o no sumergidos (e). 
A partir de mediciones realizadas en campo, se ha estimado en gabinete el caudal que circulaba por las escalas en base a las ecuaciones ajustadas para este tipo de pasos planteadas por Fuentes-Pérez et al. $(2014,2016)$ (Ec. 1 (Ec. 7):

Para orificios:

$$
Q_{O}=C_{O} \cdot b \cdot d \cdot \sqrt{2 \cdot g \cdot \Delta H}
$$

Para vertederos no sumergidos:

$$
\begin{aligned}
Q_{V L} & =\frac{2}{3} \cdot C_{p} \cdot b \cdot h^{1,5} \cdot \sqrt{2 \cdot g} \\
C_{p} & =0,689 \cdot\left(1-\mathrm{e}^{-8,889 \cdot h}\right)
\end{aligned}
$$

Para vertederos sumergidos:

$$
\begin{gathered}
Q_{V S}=\frac{2}{3} \cdot C_{p} \cdot C_{V S} \cdot b \cdot h^{1,5} \cdot \sqrt{2 \cdot g} \\
C_{V S}=\left[1-\left(\frac{h-\Delta H}{h}\right)^{1,5}\right]^{0,331}
\end{gathered}
$$

Para hendiduras verticales:

$$
\begin{gathered}
Q_{H V}=\frac{2}{3} \cdot C_{H V} \cdot b \cdot h^{1,5} \cdot \sqrt{2 \cdot g} \\
C_{H V}=0,72 \cdot\left[1-\left(\frac{h-\Delta H}{h}\right)^{1,5}\right]^{0,385}
\end{gathered}
$$

donde $Q_{0}$ es el caudal a través de un orificio $\left(\mathrm{m}^{3} / \mathrm{s}\right), C_{O}$ es el coeficiente adimensional de descarga para orificios $\left(C_{O}=0,876\right), b$ es la anchura de la conexión entre estanques (orificios, vertederos o hendiduras) $(\mathrm{m}), d$ es la altura de un orificio $(\mathrm{m}), g$ es la aceleración de gravedad $\left(\mathrm{m} / \mathrm{s}^{2}\right), \Delta H$ es el desnivel entre dos láminas de agua sucesivas $(\mathrm{m}), Q_{V L}$ es el caudal a través de un vertedero no sumergido $\left(\mathrm{m}^{3} / \mathrm{s}\right), C_{p}$ es el coeficiente adimensional de descarga a través de vertederos no sumergidos, $h$ es la carga de vertido $(\mathrm{m}), Q_{v s}$ es el caudal a través de un vertedero sumergido $\left(\mathrm{m}^{3} / \mathrm{s}\right), C_{V s}$ es el coeficiente adimensional de descarga a través de un vertedero sumergido, $Q_{H V}$ es el caudal a través de una hendidura vertical $\left(\mathrm{m}^{3} / \mathrm{s}\right)$, y $C_{H V}$ es el coeficiente adimensional de descarga para hendiduras verticales.

En todas las escalas se ha recopilado información de al menos un estanque tipo, es decir, aquél que sirve de base para el diseño y que es el más representativo de la escala. En ocasiones, también se han recogido datos de los estanques singulares, en caso de existir, o lo que es lo mismo, de los que son distintos a cualquier otro. Con el fin de evitar accidentes, las mediciones se han realizado habitualmente desde el interior de los estanques después de ser vaciados, o desde sus tabiques perimetrales siempre que no estuviesen sumergidos bajo el nivel de agua del río.

Para conocer los caudales que discurrían por los ríos durante las visitas se ha acudido a los sistemas automáticos de información hidrológica de las distintas 
Confederaciones, conocidos como SAIH o SAl (Confederación Hidrográfica del Cantábrico 2020; Confederación Hidrográfica del Duero 2020a; Confederación Hidrográfica del Segura 2020b). Asimismo, se han estudiado los caudales medios que circulan por los tramos de río en los que se encuentran los pasos durante el momento de mayor actividad migratoria de las especies objetivo. Para los ciprínidos, entre los que se incluyen el barbo y la boga, se han considerado los caudales de mayo y junio como los de los meses con más movimientos migratorios; mientras que, para los salmónidos, como la trucha, se han considerado los caudales de noviembre y diciembre.

Cuando los obstáculos asociados a los pasos para peces no derivan agua del río, el caudal del tramo es el promedio de los caudales medios de los meses de migración. En los casos en que los obstáculos con pasos derivan agua, el caudal del tramo considerado ha sido el caudal ecológico fijado para los meses de migración. Los caudales medios mensuales se han obtenido de los anuarios de las diferentes estaciones de aforo (CEDEX 2021), mientras que los caudales ecológicos han sido facilitados por las Confederaciones Hidrográficas o extraídos del plan hidrológico de la parte española de la cuenca del Duero (Confederación Hidrográfica del Duero 2015) .

\subsection{ANÁLISIS DE DATOS}

La metodología AEPS se ha aplicado a las escalas visitadas. Así, se ha obtenido para cada escala una valoración que refleja la efectividad de sus principales parámetros y etapas a superar. Esas puntuaciones se han estudiado desde diferentes puntos de vista, realizando una serie de análisis estadísticos con la versión 3.5.2 del programa informático R (R Core Team 2020), y varios de sus paquetes de funciones: Ime4 (Bates et al. 2015), nlme (Pinheiro et al. 2020), dplyr (Wickham et al. 2020), nortest (Gross y Ligges 2015), FSA (Ogle et al. 2020), PMCMR (Pohlert 2018) y multcompView (Graves et al. 2019) (véase el anejo “A.5. Análisis de los datos: comandos para aplicar en R").

\subsubsection{TRATAMIENTO PREVIO}

El buen funcionamiento de una escala es consecuencia del éxito de las diferentes etapas que los peces deben superar en ella. Por lo tanto, la efectividad general de estas estructuras viene definida por la efectividad de sus cuatro etapas, y está limitada por la etapa más desfavorable que actúa como cuello de botella. En base a ello, se ha considerado que la puntuación general de una escala se corresponde con la menor puntuación de sus etapas, calculadas a partir de los parámetros evaluados en cada una de dichas etapas. 
En función de la puntuación obtenida, los parámetros evaluados como "favorables" o "muy favorables" se han agrupado como "adecuados", mientras que los que han sido "desfavorables" o "muy desfavorables" se han calificado como inadecuados.

\subsubsection{INFLUENCIA DE LAS ETAPAS Y LOS TIPOS DE ESCALAS EN LAS PUNTUACIONES DE LAS VARIABLES}

Se han realizado varios modelos lineales mixtos, para conocer si la puntuación que la metodología asigna a un parámetro estudiado depende o no de la etapa y del tipo de escala en que se evalúa. Este tipo de modelos son una extensión de los lineales generalizados, pero que pueden aplicarse sobre datos agrupados que no siguen una distribución normal. La normalidad de los datos se ha estudiado mediante el test de Shapiro-Wilk (recomendado para muestras menores a 30 observaciones) y el de Lilliefors (para tamaños muestrales mayores). Los modelos mixtos describen la relación entre una variable respuesta o dependiente ante una o varias variables explicativas, llamadas efectos fijos, contemplando la posible existencia de observaciones correlacionadas o con variabilidad heterogénea vinculadas a la presencia de efectos aleatorios. La fórmula general de los modelos lineales mixtos es la siguiente:

$$
y=X \cdot \mu+Z \cdot u+\epsilon
$$

donde $y$ es el vector de medidas repetidas de un individuo $i, X$ es la matriz de diseño para los efectos fijos, $\mu$ es un vector de efectos fijos, $Z$ es la matriz de diseño para los efectos aleatorios, $u$ es un vector de efectos aleatorios, y $\epsilon$ es el vector de errores aleatorios. Donde $u$ y $\epsilon$ se distribuyen normalmente con una media de 0 y una desviación típica concreta.

Los modelos planteados se han caracterizado por presentar constante la variable respuesta, "Puntuación de la variable", y el factor aleatorio, "Variable", mientras que eliminaban o cambiaban entre factores fijos y aleatorios los otros dos parámetros considerados, "Etapa" y "Tipo de escala". Se han comparado los modelos entre sí mediante análisis de la varianza (ANOVA), determinando cuáles presentan un mejor ajuste con un menor número de variables de acuerdo con el criterio de Akaike, el de información Bayesiana y el de máxima verosimilitud. De esta manera, se ha determinado qué parámetros predicen mejor y de manera significativa la "Puntuación de la variable". 


\subsubsection{ANÁLISIS Y COMPARACIÓN DE LA EFECTIVIDAD}

Con el objetivo de conocer los parámetros que resultan problemáticos para el ascenso de los peces se ha comparado la valoración de la efectividad (muy favorable, favorable, desfavorable o muy desfavorable) estimada mediante la metodología AEPS a nivel de (1) escala en general, (2) etapa, (3) tipo de escala y (4) parámetros evaluados.

Asimismo, se ha estudiado si existen diferencias entre la valoración obtenida por las distintas etapas y tipos de escalas evaluados. Para saber qué prueba estadística se puede aplicar a los datos ha sido necesario estudiar su homocedasticidad, es decir, si existe homogeneidad de varianzas, para lo que se ha empleado el test de FlignerKilleen.

A partir de los resultados obtenidos del test anterior, se ha decidido analizar con la prueba de Kruskal-Wallis la existencia de diferencias entre las medianas de las puntuaciones de las distintas etapas y tipos de escala. Posteriormente, se ha aplicado el test de Dunn para hacer comparaciones múltiples dos a dos y saber exactamente entre qué puntuaciones existen diferencias significativas.

\subsubsection{EVOLUCIÓN DE LA EFECTIVIDAD EN EL TIEMPO}

Finalmente, se ha estudiado si existe relación entre la época en que las escalas han sido construidas y su efectividad. Para ello, y debido a que en algunos casos no se conoce la fecha exacta de construcción, las escalas se han clasificado en dos grupos: construidas o modificadas para mejorar su funcionamiento anteriormente al año 2000, y desde 2000 hasta 2019. El límite que separa los dos periodos de tiempo considerados, el año 2000, se ha establecido para reflejar los posibles efectos de la entrada en vigor de la Directiva Marco del Agua. Se han analizado las etapas y tipos de escalas adecuados e inadecuados en cada periodo de tiempo.

Posteriormente, se han realizado varias pruebas Chi-cuadrado para saber si existen diferencias en la efectividad de las etapas en función de la época de ejecución. Los test Chi-cuadrado son pruebas estadísticas descriptivas que confrontan dos variables nominales o cualitativas, para comparar sus frecuencias teóricas o esperadas con sus frecuencias observadas en una muestra de datos; de manera que, si coinciden se asume que existe dependencia entre esas variables. La falta de datos para ciertos tipos de escalas ha impedido aplicar esta prueba para estudiar la existencia de diferencias en su efectividad según la época de construcción. 


\section{RESULTADOS}




\section{RESULTADOS}

La mayor parte de los resultados que se recogen en esta tesis se han plasmado en tres publicaciones científicas y varias comunicaciones a congresos:

- Valbuena-Castro, J., Fuentes-Pérez, J.F., García-Vega, A., Bravo-Córdoba, F.J., Ruiz-Legazpi, J., Martínez de Azagra-Paredes, A. y Sanz-Ronda, F.J. (2020) Coarse fishway assessment to prioritize retrofitting efforts: a case study in the Duero River basin. Ecological Engineering 155, 105946.

- Valbuena-Castro, J., Sanz-Ronda, F.J., García-Vega, A., et al. (2019) Metodología "AEPS" aplicada a la evaluación de escalas para peces en la cuenca hidrográfica del río Duero. Cuadernos de la Sociedad Española de Ciencias Forestales 45, 279-288.

- Valbuena-Castro, J., Sanz-Ronda, F.J., García-Vega, A., Fuentes-Pérez, J.F., Bravo-Córdoba, F.J., Navas-Pariente, A., Ruiz-Legazpi, J. y Martínez de Azagra, A. (2017) AEPS: a methodology to quickly assess pool and weir fishways. En: Fish Passage 2017: International Conference on Engineering and Ecohydrology for Fish Passage. Corvallis (Estados Unidos de América).

- Valbuena-Castro, J., Sanz-Ronda, F.J., Bravo-Córdoba, F.J., Ruiz-Legazpi, J. y Martínez de Azagra-Paredes, A. (2016) Application of a new methodology to assess fishways in the Segura River basin. En: SIBIC 2016, VI Iberian Congress of Ichthyology. Murcia (España).

- Confederación Hidrográfica del Duero (2016) Manual para la evaluación de la funcionalidad de pasos para peces de estanques sucesivos. Metodología AEPS (1.0). Coordinación: Sanz-Ronda, F.J., et al.; Autores: Valbuena-Castro, J., et al. Confederación Hidrográfica del Duero, Valladolid (España).

- Sanz-Ronda, F.J., Valbuena-Castro, J., Martínez de Azagra-Paredes, A., BravoCórdoba, F.J., Bernabé-de la Iglesia, J.C., Prieto-Blanco, A., Rubio-Polo, J.M. y Rodríguez-Muñoz, I. (2015) Fish passes evaluation in the Spanish Duero River basin (Northwestern Spain). En: Fish Passage 2015: International conference on river connectivity best practices and innovations. Groningen (Países Bajos).

- Sanz-Ronda, F.J., Valbuena-Castro, J., Martínez de Azagra-Paredes, A., BravoCórdoba, F.J., Bernabé-de la Iglesia, J.C., Prieto-Blanco, A., Rubio-Polo, J.M. y Rodríguez-Muñoz, I. (2015) Evaluación de pasos para peces en la cuenca Duero. En: Il Congreso Ibérico sobre Restauración Fluvial: "Restaura Ríos". Pamplona (España). 


\subsection{METOdOLOGÍA AEPS}

La búsqueda bibliográfica realizada, la reflexión y las experiencias en campo durante el periodo de 1999 hasta 2016 del grupo de investigación al que pertenezco, GEA, han permitido desarrollar un método hidráulico de evaluación de pasos para peces de artesas que es la base de la presente tesis (Confederación Hidrográfica del Duero 2016, disponible en: www.geaecohidraulica.org/AEPSv1.pdf; Valbuena-Castro et al. 2020). Este método evalúa el funcionamiento de las escalas para peces durante el ascenso de la trucha común, el barbo común ibérico, y la boga del Duero. Se denomina "metodología AEPS", por las siglas de las cuatro etapas que estudia y que los peces deben superar en su remonte por un paso: Atracción, Entrada, Pasaje y Salida (Odeh 1999; Castro-Santos et al. 2009; Castro-Santos 2012; Valbuena-Castro et al. 2019). En esas cuatro etapas, la metodología valora la adecuación de cuarenta y tres parámetros que influyen en el éxito del ascenso de las especies objetivo. Los veinte parámetros más determinantes en el movimiento de los peces reciben el nombre de "variables fundamentales"; mientras que los veintitrés restantes que influyen, aunque no de una manera tan determinante, se llaman "observaciones de relevancia" (Tabla 6 y figura 21 ). 
Tabla 6. Variables fundamentales y observaciones de relevancia que la metodología AEPS evalúa para el ascenso de los peces por una escala de estanques sucesivos.

\begin{tabular}{|c|c|c|}
\hline ETAPA & VARIABLES FUNDAMENTALES & OBSERVACIONES DE RELEVANCIA \\
\hline Atracción & Caudal relativo de atracción ( $Q_{\text {atracción }}$ ) & Mantenimiento y limpieza \\
\hline (A) & Ubicación de la entrada de peces $\left(U_{E}\right)$ & Accesibilidad \\
\hline \multirow{6}{*}{$\begin{array}{l}\text { Entrada } \\
\qquad(E)\end{array}$} & $\begin{array}{c}\text { Desnivel entre la lámina de agua del río y del } \\
\text { estanque inferior }\left(\Delta H_{E}\right)\end{array}$ & Mantenimiento y limpieza \\
\hline & Profundidad en la entrada $\left(h_{E}\right)$ & $\begin{array}{l}\text { Elementos para la regulación del } \\
\text { salto entre láminas de agua }\end{array}$ \\
\hline & Anchura y/o área de la entrada ( $b_{E}$ y/o Área $\left.a_{E}\right)$ & Descargas de flujo en la entrada \\
\hline & Profundidad previa a la entrada $\left(h_{\text {previa } E}\right)$ & $\begin{array}{l}\text { Ausencia de otras descargas de } \\
\text { flujo que alejen el pez de la escala }\end{array}$ \\
\hline & Orientación de la entrada respecto del río $\left(O r t_{E}\right)$ & Aristas redondeadas \\
\hline & Tipología de la entrada $\left(T_{E}\right)$ & Accesibilidad \\
\hline \multirow{9}{*}{$\begin{array}{l}\text { Pasaje } \\
\text { (Ps) }\end{array}$} & $\begin{array}{l}\text { Desnivel entre láminas de agua de estanques } \\
\text { sucesivos }\left(\Delta H_{P_{S}}\right)\end{array}$ & Mantenimiento y limpieza \\
\hline & Potencia disipada por unidad de volumen $(N)$ & Forma de los estanques \\
\hline & Tirante medio en los estanques $\left(t_{\text {med }}\right)$ & Deflectores en los estanques \\
\hline & Profundidad de paso entre estanques $\left(h_{P_{S}}\right)$ & Conservación de la estructura \\
\hline & $\begin{array}{l}\text { Anchura y/o área de paso entre estanques }\left(b_{P_{S}} \text { y/o }\right. \\
\left.\text { Área } a_{P_{S}}\right)\end{array}$ & Solera naturalizada con piedras \\
\hline & Tipología del paso (conexión) entre estanques ( $\left.T P_{s}\right)$ & Aristas redondeadas \\
\hline & & $\begin{array}{l}\text { Oscuridad por elementos que } \\
\text { cubren la escala }\end{array}$ \\
\hline & & Resguardo en los estanques \\
\hline & & Accesibilidad \\
\hline
\end{tabular}

Desnivel entre la lámina de agua en el río y en el estanque superior $\left(\Delta H_{s}\right)$

$$
\text { Profundidad en la salida }\left(h_{s}\right)
$$

Salida

(S)
Anchura y/o área de la salida (bs y/o Áreas)

Profundidad posterior a la salida ( $h_{\text {posterior }}$ )

Orientación de la salida respecto del río (Orts)

Tipología de la salida $\left(T_{S}\right)$
Mantenimiento y limpieza

Compuerta de regulación de caudales

Dispositivo contra la entrada de arrastres

Salida segura

Aristas redondeadas

Accesibilidad 


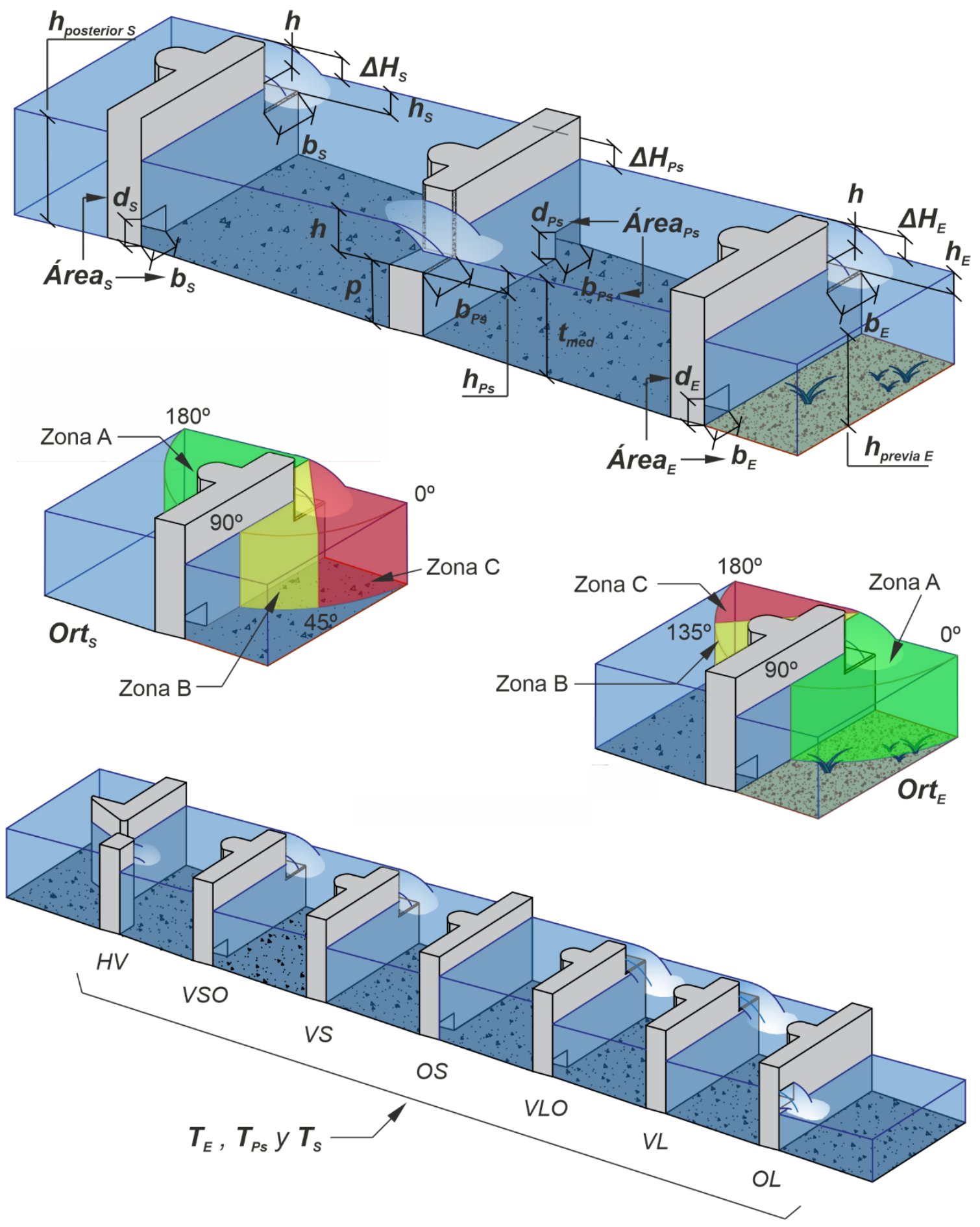

Figura 21. Variables fundamentales estudiadas en un paso $(\Delta H-$ desnivel entre láminas de agua, $h-$ carga de vertido, $h_{E}, h_{P_{S}}$ o $h_{S}$ - profundidad de paso en la entrada, pasaje y salida respectivamente, $b-$

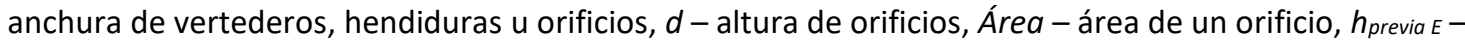
profundidad previa a la entrada, $t_{m e d}$ - tirante medio de los estanques, $h_{\text {posterior } s}$ - profundidad posterior a la salida, Ort - orientación respecto del río, $T$ - tipo de conexión, $H V$ - hendidura vertical con o sin orificio y $p<0,25 \mathrm{~m}, p$-altura umbral de la conexión entre estanques, VSO - vertedero con vertido sumergido y orificio, VS - vertedero con vertido sumergido, OS - orificio sumergido, VLO - vertedero con vertido libre y orificio, $V L$ - vertedero con vertido libre y $O L$ - orificio con vertido libre, subíndices: $E$ - entrada, $p_{s}$ - pasaje, $s$ - salida). 


\subsubsection{VARIABLES FUNDAMENTALES}

\subsubsection{Etapa de atracción $(A)$}

La atracción es la etapa en la que la ictiofauna que se desplaza por el río se dirige hacia las proximidades de un paso para peces, desde donde es capaz de localizar su entrada.

\subsubsection{1.a. Caudal relativo de atracción (Qatracción)}

Se trata de un caudal que genera unas condiciones hidráulicas (agitación, ruido, oxigenación, velocidad, etc.) que atraen a los peces que se desplazan por un río hacia las proximidades de un paso. Durante sus desplazamientos, los peces tienden a seguir la corriente más importante de un río (FAO/ DVWK 2002; Lundqvist et al. 2008; Calles y Greenberg 2009), por lo que el caudal de atracción debe ser suficientemente grande como para atraerles, siendo más atractivo cuanto mayor sea (Larinier 2002b; Calles y Greenberg 2009; NMFS 2011). Si resulta demasiado pequeño en comparación con el resto del caudal que circula por el río, los peces pueden dirigirse hacia otros lugares distintos al paso.

Si un caudal auxiliar "llama" a los peces hacia una zona desde la que no son atraídos por el propio paso, se retrasará y dificultará que sean capaces de localizar la entrada. Por ello, debe liberarse a una distancia igual o menor a 3 metros de la entrada (Bunt et al. 1999, 2012; Aarestrup et al. 2003). El caudal relativo de atracción es la suma de todos los caudales que "Ilamen" a los peces en relación con el caudal total del río:

$$
\begin{aligned}
& Q_{\text {llamada }}=Q_{\text {escala }}+Q_{\text {auxiliar }} \\
& Q_{\text {atracción }}=\frac{Q_{\text {llamada }}}{Q_{\text {curso }}} \cdot 100
\end{aligned}
$$

donde Qllamada es el caudal total que atrae a los peces hacia las proximidades de la entrada del paso $\left(\mathrm{m}^{3} / \mathrm{s}\right)$, Q Q escala es el que circula por el paso $\left(\mathrm{m}^{3} / \mathrm{s}\right)$, Quxiliar es el que ayuda a la atracción de los peces (puede ser el que circula sobre el azud, rebajes, toboganes, tuberías, salida de turbinas cercanas, etc.) ( $\left.\mathrm{m}^{3} / \mathrm{s}\right), Q_{\text {atracción }}$ es la proporción que supone el caudal de llamada respecto del total que circula por esa sección del cauce (\%), y $Q_{\text {curso }}$ es el caudal que circula por el curso de agua en la sección en que se encuentra el paso para peces durante la evaluación. 
Algunos autores recomiendan caudales relativos de atracción que varíen entre el 5,0 y el $10,0 \%$ del caudal total durante la época de migración de las especies objetivo (Larinier 2002c; NMFS 2011; Williams et al. 2012). Otros indican que los peces pueden ser atraídos con caudales que varíen entre el 1,0 y el 5,0 \% del que circula por el curso de agua, especialmente en grandes ríos (Larinier 1998, 2002b; Wolter y Schomaker 2019). Zitek et al. (2012) han comprobado que caudales de atracción del 1,0 al 5,0 \% resultan suficientes para una boga (Chondrostoma nasus).

En base a todo ello, proponemos un sistema de puntuación en el que valores de la variable menores al $1,0 \%$ son inapropiados por no atraer a los peces. Cuando son iguales o mayores del 1,0 \% resultan suficientes, siendo más favorables a medida que aumentan, hasta alcanzar un óptimo cuando son iguales o mayores al 10,0 \% del caudal circulante por el curso de agua (Figura 22).

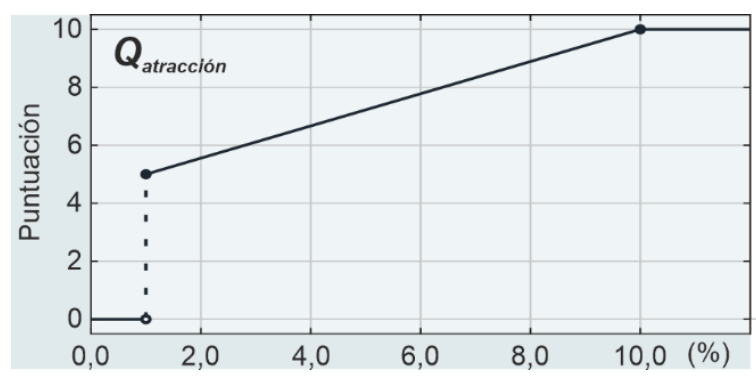

\begin{tabular}{cc} 
Nivel de idoneidad para la $\boldsymbol{U}_{\boldsymbol{E}}$ & Punt. \\
\hline Muy adecuado & 10 \\
Adecuado & 6,7 \\
Inadecuado & 3,3 \\
Muy inadecuado & 0,0
\end{tabular}

Figura 22. Sistemas de puntuación para las variables fundamentales estudiadas en la etapa de atracción ( $Q_{\text {atracción }}$ - caudal relativo de atracción (\%) y $U_{E}$ - ubicación de la entrada para peces).

\subsubsection{1.b. Ubicación de la entrada para peces $\left(U_{E}\right)$}

Esta variable compara el emplazamiento de la entrada de un paso para peces con su ubicación teórica-ideal. Los peces se desplazan por los ríos siguiendo unos patrones comunes que conviene tener presentes al ubicar la entrada de un paso para facilitar su localización y entrada.

Como ya se ha comentado, la ictiofauna tiende a seguir la corriente más importante (FAO/ DVWK 2002; Lundqvist et al. 2008; Calles y Greenberg 2009), por lo que es recomendable ubicar la entrada donde se concentre un mayor caudal (p. ej. salida de turbinas a pie de presa, vertederos de llamada, compuertas, etc.) (FAO/ DVWK 2002; Larinier 2002c; Aigoui et al. 2008). Además, los peces se desplazan entre la orilla y la zona más profunda del río, denominada "talweg", siendo interesante que la entrada esté cerca de la orilla para ayudar a que los peces la encuentren cuando se mueven hacia aguas arriba (Clay 1995; FAO/ DVWK 2002; Larinier 2002c).

Las especies en que se centra la metodología presentan un fuerte carácter reófilo durante sus migraciones reproductivas, el cual las hace desplazarse lo más aguas arriba que les sea posible y no volver hacia aguas abajo (Alexandre et al. 2013). Por 
ello, la entrada deberá ubicarse lo más aguas arriba que permita la planta del obstáculo y cercana a su base para que, si los peces no la localizan al primer intento, sean capaces de encontrarla cuando queden bloqueados en la base del obstáculo sin necesidad de nadar hacia aguas abajo (Clay 1995; Bunt 2001; FAO/ DVWK 2002; Armstrong et al. 2004).

Para esta variable se consideran los siguientes aspectos (Figura 23 y figura 24):

- Localización donde se concentre un mayor caudal en la sección.

- Proximidad a la orilla (o que no exista vertido entre el paso y la orilla).

- Ubicación lo más aguas arriba posible.

- Colocación junto al obstáculo (pudiendo estar un poco alejada si por ella circula todo el caudal).
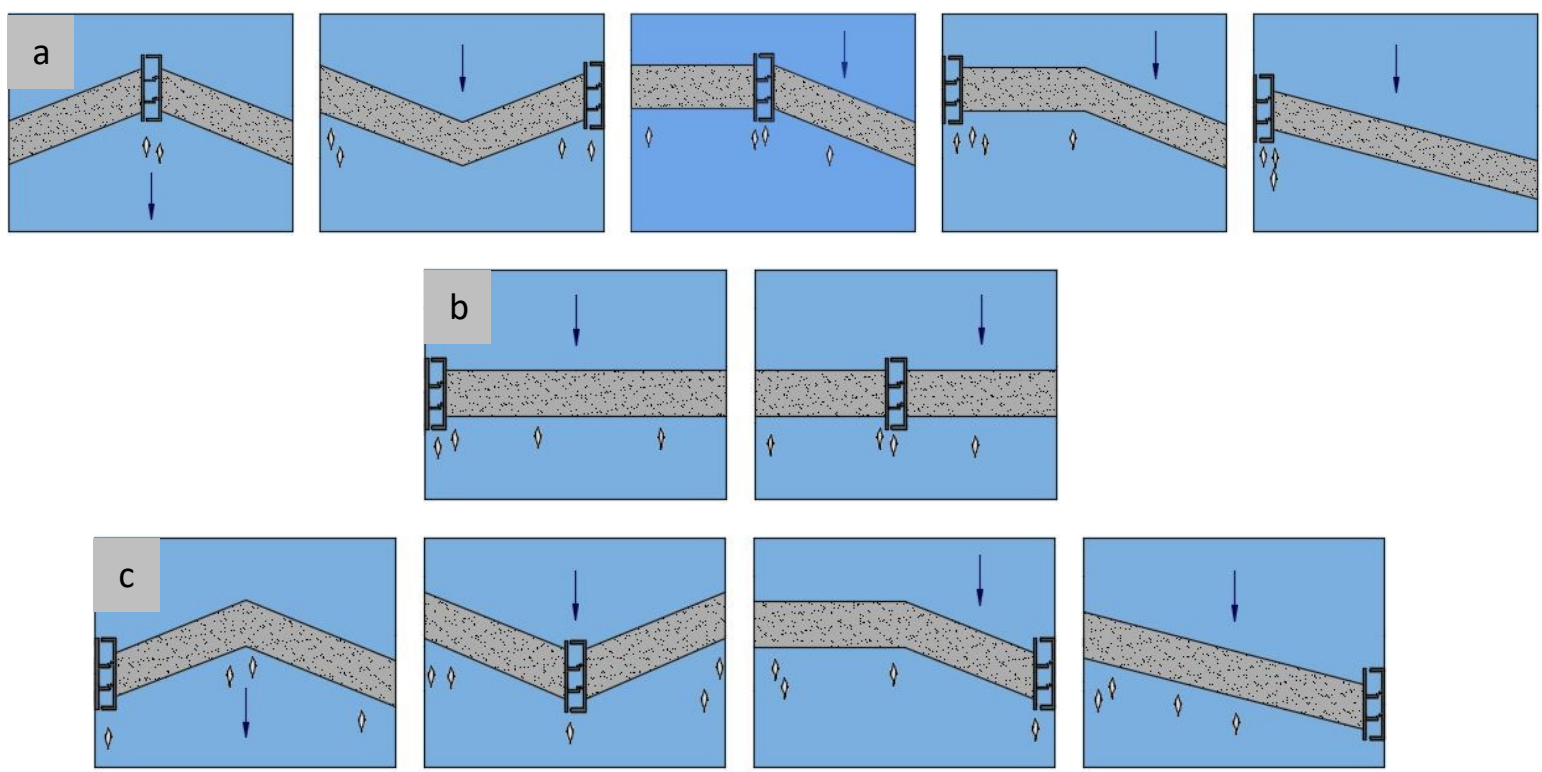

Figura 23. Localización de la entrada de pasos para peces respecto a la planta del obstáculo sobre el que se ubica: idóneas (a), neutras (b) y desaconsejables (c). 

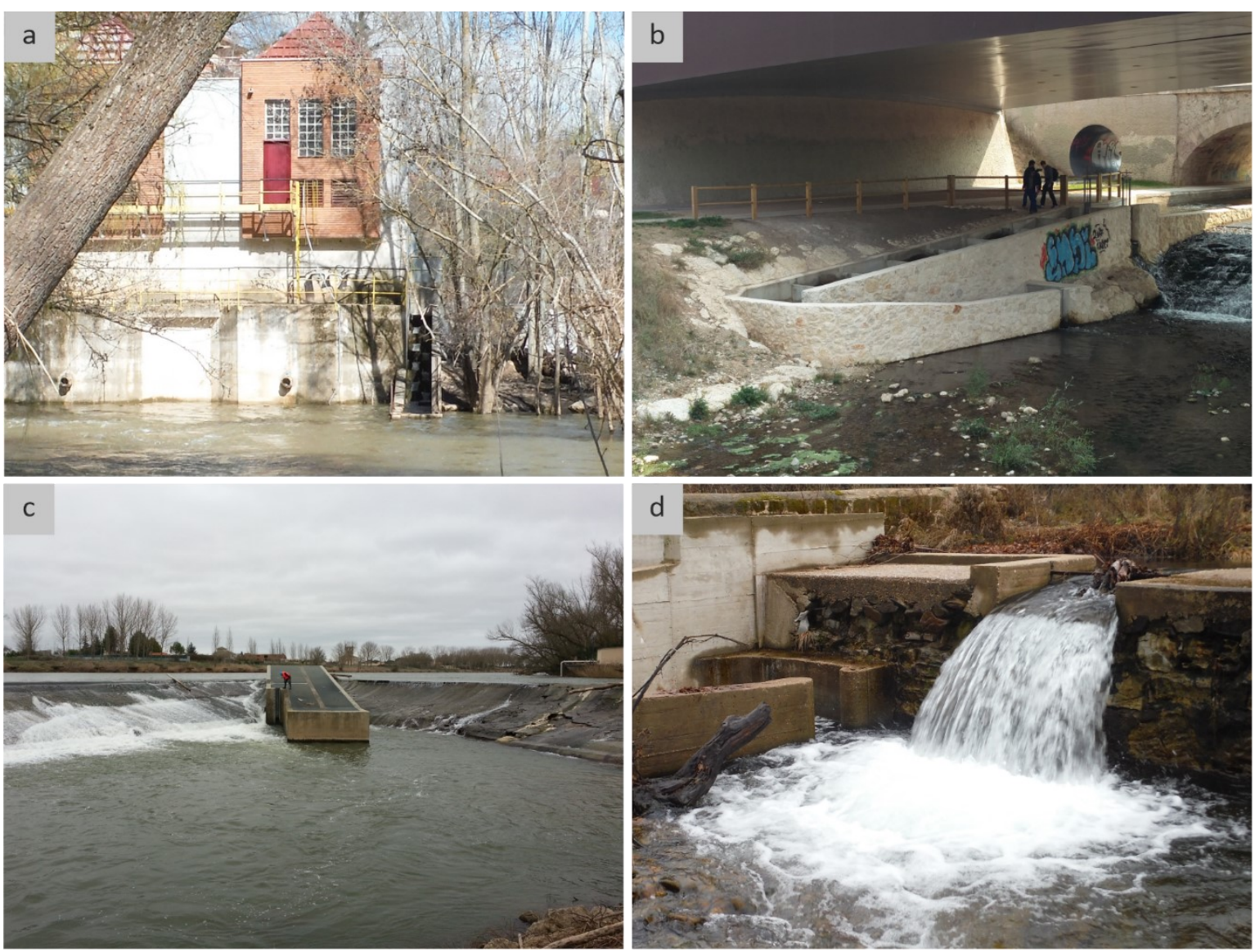

Figura 24. Aspectos a evaluar en relación con la ubicación de la entrada: localización donde se concentre el mayor caudal (p. ej. salida de turbinas de una central hidroeléctrica) (a), proximidad a la orilla (b), lo más aguas arriba que permita el azud (p. ej. vértice de la planta de un azud en forma de embudo, Figura 23.a) (c), y cercanía al obstáculo (d).

Si la escala concentra todo el caudal del tramo de río en que se encuentra (p. ej. el caudal ecológico), su ubicación siempre va a resultar muy adecuada.

Si la escala no está junto a la orilla, pero no se vierte ningún caudal entre medias que pueda atraer a los peces, a efectos de la evaluación se considera que la escala está junto a la orilla.

Los aspectos a valorar para esta variable se evalúan individualmente, realizando posteriormente una media aritmética con las puntuaciones asignadas a cada uno de ellos (Figura 22). 


\subsubsection{Etapa de entrada $(E)$}

En la etapa de entrada, la fauna que se encuentra en el río junto al paso para peces se adentra en su interior.

\subsubsection{2.a. Desnivel entre la lámina de agua en el río y en el estanque inferior $\left(\Delta H_{E}\right)$}

Diferencia de nivel entre la lámina de agua del estanque inferior de la escala y la del río aguas abajo del paso. El desnivel entre dos láminas está directamente relacionado con la velocidad con la que fluye el agua y, por tanto, con la turbulencia que genera (Fuentes-Pérez et al. 2016). Desniveles demasiado pequeños implican velocidades reducidas que pueden disminuir la atracción (Bravo-Córdoba et al. 2021). Por el contrario, desniveles grandes conllevan velocidades y turbulencias elevadas que dificultan la entrada de los peces.

Se mide como la diferencia de cota entre la lámina de agua del estanque inferior del paso y del río aguas abajo (Figura 21).

Esta variable cambia en función de los caudales del río (Fuentes-Pérez et al. 2014, 2016), aunque la velocidad del flujo debe ser suficiente como para que los peces localicen fácilmente la entrada (Armstrong et al. 2004). Velocidades mayores a 1,00 $\mathrm{m} / \mathrm{s}$ pueden resultar suficientemente atractivas (que se corresponden con desniveles mayores a $0,05 \mathrm{~m}$ ) (Larinier 2002b), aunque se aconseja que la velocidad varíe entre 2,00 y $2,40 \mathrm{~m} / \mathrm{s}$ (que se corresponden con desniveles de 0,20 a 0,30 m) (Aigoui et al. 2008; Ordeix et al. 2011; Baudoin et al. 2015).

El sistema de puntuación propuesto para esta variable considera inadecuados los desniveles menores a 0,05 $\mathrm{m}$, siendo este valor el mínimo para que el flujo atraiga a los peces hacia el interior de la escala. La variable mejora su puntuación progresivamente desde 0,05 $\mathrm{m}$ hasta los $0,20 \mathrm{~m}$, desde donde presenta su puntuación máxima hasta los $0,30 \mathrm{~m}$. Valores por encima de $0,30 \mathrm{~m}$ reducen su puntuación hasta llegar a 0,50 m, que implica una velocidad del flujo demasiado elevada como para permitir la entrada de los peces (Figura 25). 

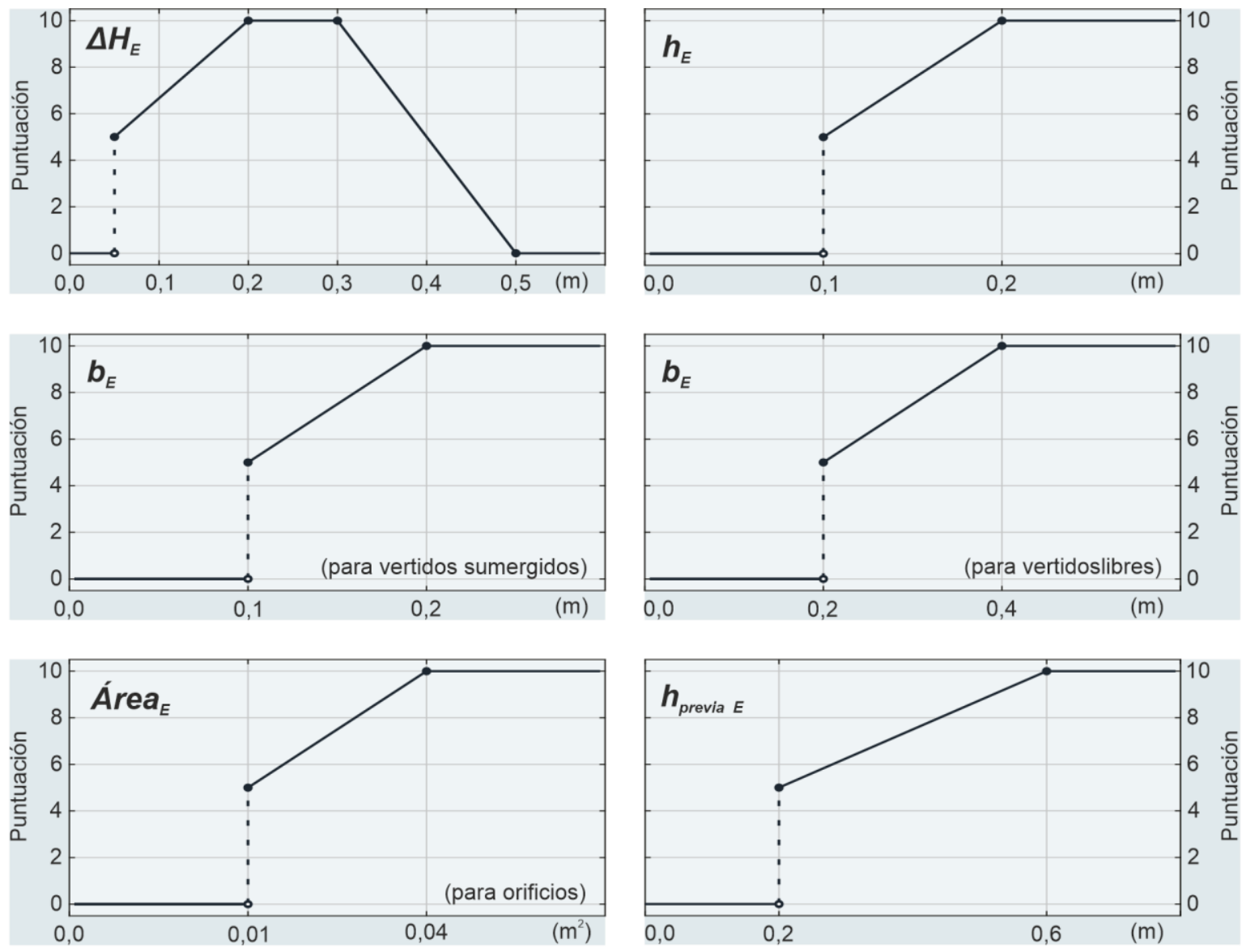

\section{Ort $_{E}$}

Descripción

Punt.

Entrada orientada paralela respecto de la corriente y en el sentido de la aproximación de los peces $\left(0^{\circ} \leq \alpha \leq 90^{\circ}\right)$

Entrada orientada perpendicular a la corriente $\left(90^{\circ}<\alpha \leq 135^{\circ}\right)$

Entrada orientada paralela a la corriente y en dirección contraria a la aproximación de los peces $\left(135^{\circ}<\alpha \leq 180^{\circ}\right)$

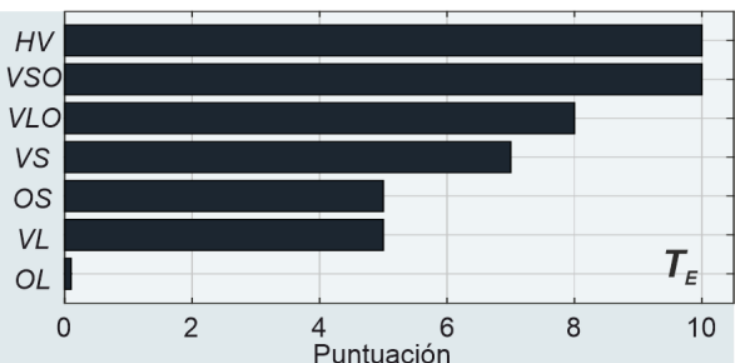

Figura 25. Gráficos de puntuación para las variables fundamentales evaluadas en la entrada $\left(\Delta H_{E}-\right.$ desnivel entre la lámina de agua en el río y en el estanque inferior $(\mathrm{m}), h_{E}$ - profundidad de paso en la entrada $(\mathrm{m}), b_{E}$ - anchura de la entrada $(\mathrm{m})$, Área $a_{E}$ - área de la entrada $\left(\mathrm{m}^{2}\right), h_{\text {previa } E}$ - profundidad previa a la entrada $(\mathrm{m})$, Ort $\mathrm{O}_{E}$ - orientación de la entrada respecto del río $\left({ }^{\circ}\right), \alpha$-ángulo que forma la entrada respecto del eje hidráulico del río, $T_{E}$ - tipo de entrada, $H V$ - hendidura vertical con o sin orificio y $p<0,25 \mathrm{~m}$, VSO - vertedero con vertido sumergido y orificio, VLO - vertedero con vertido libre y orificio, VS - vertedero con vertido sumergido, $O S$ - orificio sumergido, $V L$ - vertedero con vertido libre y $O L$ - orificio con vertido libre). 


\subsubsection{2.b. Profundidad de paso en la entrada $\left(h_{E}\right)$}

Profundidad de agua disponible para la entrada de los peces en una escala. Cuando es demasiado pequeña obliga a los peces a saltar para entrar en el paso, pudiendo golpearse o rozarse con la estructura, mientras que cuando es grande se facilita el acceso (Bravo-Córdoba et al. 2021).

En vertidos sumergidos, se mide como la diferencia de cota entre la lámina de agua del río y el umbral del elemento que sirve como entrada. Cuando el valor de esta variable es inferior a $10 \mathrm{~cm}$, se considera desde un punto de vista práctico que los peces entran en la escala a través de un vertedero en régimen libre o no sumergido. En vertidos libres, esta variable se mide como la carga de vertido en la entrada, es decir, la diferencia de cota entre la lámina de agua del estanque inferior y el umbral del elemento de entrada. Si la entrada se realiza a través de un orificio, esta variable se corresponde con la altura del orificio $\left(d_{E}\right)$ (Figura 21). Cuando la entrada se haga a través de un vertedero y un orificio, solo se tiene en cuenta el vertedero.

La profundidad mínima debe ser $>1,5 \times h_{p e z}$ y la óptima $>2,5 \times h_{p e z}$ (donde $h_{p e z}$ es la altura dorsoventral de las especies objetivo) (Baudoin et al. 2015). Los ejemplares más grandes de las especies objetivo que se encuentran en la cuenca del Duero tienen una altura dorsoventral media $\left(h_{\text {pez }}\right)<8 \mathrm{~cm}$ (González-Alemán 2016). En consecuencia, la profundidad mínima debe ser de 0,10 m, siendo óptima si llega a los 0,20 m. Katopodis (1992) y Armstrong et al. (2004) apuntan que el valor mínimo de esta variable debe ser al menos de 0,20 $\mathrm{m}$.

El sistema de puntuación propuesto considera que $0,10 \mathrm{~m}$ es la profundidad mínima que permite la entrada de la mayoría de los peces. La variable incrementa su puntuación desde ese mínimo hasta alcanzar el máximo a los 0,20 m (Figura 25).

\subsubsection{2.c. Anchura y/o área de la entrada ( $b_{E}$ y/o Área $a_{E}$}

Anchura del vertedero o hendidura y/o área del orificio para la entrada de los peces al interior del paso. Cuanto mayor sea la entrada, más fácil es el paso de los peces más grandes, reduciéndose el riesgo de que se golpeen o rocen, y es más difícil que se obstruya por restos arrastrados por la corriente.

En vertederos y hendiduras se mide como la anchura que conecta el río con el estanque inferior. En orificios se mide como su área (Figura 21). Cuando haya vertederos trapezoidales, la anchura a considerar es la media de la base menor del trapecio y la base mayor marcada por el nivel de agua del estanque inferior del paso. Cuando existan varias alternativas para la entrada (p. ej. vertedero sumergido y orificio), la puntuación de esta variable será el resultado de la media aritmética calculada a partir de las puntuaciones de cada una de las posibles entradas. 
Videler y Wardle (1991) indican que la aleta caudal en las especies objetivo oscila con una amplitud que suele ser menor a 0,2 x $L_{p e z}$. En la cuenca del Duero, los individuos más grandes de trucha y barbo común presentan una longitud media $\left(L_{p e z}\right)$ de $50 \mathrm{~cm}$, mientras que los de boga difícilmente alcanzan los $35 \mathrm{~cm}$ (González-Alemán 2016). Por tanto, la aleta caudal de los peces más grandes de la cuenca oscilará con una amplitud de unos 0,10 m, siendo ese el valor mínimo que permite la entrada de la mayoría de los ejemplares.

La anchura mínima recomendada para evitar obstrucciones es de 0,15 m (Martínez de Azagra-Paredes 1999; Larinier 2002c; Baudoin et al. 2015). Con vertidos sumergidos se consideran adecuados valores mayores a $0,20 \mathrm{~m}$ para las especies objetivo (FAO/ DVWK 2002; Larinier 2002c; Aigoui et al. 2008). Con vertidos libres se aconsejan anchuras mayores para facilitar que los peces no choquen con la estructura cuando saltan (Larinier 2002c; Baudoin et al. 2015). Experiencias de campo han mostrado la misma eficiencia de paso en vertidos sumergidos de $0,20 \mathrm{~m}$ anchura que en vertidos no sumergidos de $0,40 \mathrm{~m}$ de ancho (siendo el resto de las variables hidráulicas iguales) (Sanz-Ronda et al. 2015a). En cuanto a los orificios, es suficiente con que presenten un área igual o mayor a 0,03 $\mathrm{m}^{2}$ (Baudoin et al. 2015), aunque se aconseja que sean iguales o mayores a 0,04 m² (Elvira et al. 1998a; Martínez de Azagra-Paredes 1999; FAO/ DVWK 2002).

Se proponen varios sistemas de puntuación para las diferentes opciones por las que los peces pueden entrar en una escala. En todos los casos, las dimensiones menores a 0,10 m se consideran inadecuadas por impedir el acceso de los peces más grandes y tener un alto riesgo de obstrucción. En el caso de vertidos sumergidos, la variable va aumentando su puntuación desde 0,10 $\mathrm{m}$ hasta ser muy adecuada a los 0,20 m. De acuerdo con lo que indica la bibliografía, la anchura con vertidos libres debe ser mayor que la recomendada para vertidos sumergidos. Por tanto, se asume que 0,20 m es el ancho mínimo que permite el acceso de los peces con vertidos libres, siendo mejor cuanto más grande sea hasta alcanzar su máxima puntuación en 0,40 m. Para los orificios, se considera que el valor mínimo que permite el acceso de los peces es 0,01 $\mathrm{m}^{2}$, alcanzándose la puntuación máxima a partir de los 0,04 $\mathrm{m}^{2}$ (Figura 25).

\subsubsection{2.d. Profundidad previa a la entrada ( $\left.h_{\text {previa E }}\right)$}

Profundidad de agua en la zona del río antes de la entrada de peces. Cuando es demasiado pequeña, los peces pueden rozarse con el lecho, no pueden descansar sin temor a ser depredados, ni pueden impulsarse para entrar en la escala (FAO/ DVWK 2002). Por ello, se recomienda que sea suficientemente grande, independientemente de los caudales que circulen por el río.

Se calcula como el desnivel entre la lámina de agua del río y el lecho aguas abajo de la entrada de los peces al paso (Figura 21). 
Muchos trabajos aconsejan que haya una poza, conocida como poza de remonte, aguas abajo de la entrada de una escala (Clay 1995; Martínez de Azagra-Paredes 1999; NMFS 2011). Los peces son capaces de nadar con seguridad con profundidades mayores a 0,20 m (Katopodis 1992; FAO/ DVWK 2002; Armstrong et al. 2004). Sin embargo, se recomienda que la profundidad en la poza sea mayor a 0,50 m (FAO/ DVWK 2002), siendo preferible que supere los 0,60 m para evitar situaciones de estrés y predación (Martínez de Azagra-Paredes 1999; Larinier 2002b; Baudoin et al. 2015). Estudios previos han señalado que los juveniles de truchas, barbos y bogas prefieren zonas con profundidades mayores a $0,40 \mathrm{~m}$, mientras que los adultos prefieren que superen los 0,60 m (Martínez-Capel et al. 2004; Ayllón et al. 2010).

Se plantea un sistema de puntuación en el que profundidades menores a 0,20 $\mathrm{m}$ se penalizan por dificultar la natación de los peces. La puntuación de la variable aumenta progresivamente hasta alcanzar los 0,60 $\mathrm{m}$, que se considera óptima para todos los individuos de las especies objetivo (Figura 25).

\subsubsection{2.e. Orientación de la entrada respecto del río (Ort $t_{E}$}

Dirección hacia la que se enfoca la entrada de un paso en relación con el eje hidráulico del río y el sentido de la corriente. La orientación influye en la facilidad con la que los peces que se desplazan hacia río arriba encuentran la entrada. Además, facilita o dificulta que se introduzcan restos arrastrados por la corriente dentro del paso.

Se mide como el ángulo que existe entre la dirección hacia la que se orienta la entrada de los peces y el eje hidráulico del río en el sentido de la corriente (Figura 21).

La bibliografía recomienda que la entrada sea perpendicular al eje longitudinal del río (NMFS 2011; Sanz-Ronda et al. 2014), o se oriente en la dirección de la corriente (FAO/ DVWK 2002; NMFS 2011). Así, se facilita que los peces que ascienden por el río se adentren en la escala y se dificulta que entren arrastres. Las entradas que van desde la perpendicular hasta enfrentarse a la corriente obligan a los peces a realizar giros menos naturales, y acumulan restos con mayor facilidad.

En base a ello, se propone un sistema de puntuación en el que se consideran idóneas las orientaciones $(\alpha)$ que van desde la dirección de la corriente hasta su perpendicular $\left(0^{\circ} \leq \alpha \leq 90^{\circ}\right)$. El resto de las orientaciones $(\alpha)$ se consideran progresivamente más desfavorables desde la perpendicular a la corriente hasta enfrentarse totalmente al flujo $\left(90^{\circ}<\alpha \leq 180^{\circ}\right)$ (Figura 25). 


\subsubsection{2.f. Tipo de entrada $\left(T_{E}\right)$}

Se refiere a cómo es la entrada de una escala. Existen distintas alternativas que ofrecen diferentes vertidos y profundidades que atraen a la ictiofauna de diferente manera (Figura 21).

Las hendiduras verticales se adaptan bien a las variaciones de los niveles de agua de los ríos (Clay 1995; Martínez de Azagra-Paredes 1999; Baudoin et al. 2015), su funcionamiento se ve poco alterado por obstrucciones parciales (FAO/ DVWK 2002; Larinier 2002c; Armstrong et al. 2004), y permiten que los peces entren en la escala nadando a la profundidad que prefieran (Katopodis 1992; Elvira et al. 1998a), independientemente de la especie, tamaño y capacidades (Jungwirth et al. 1998; FAO/ DVWK 2002). Los vertederos ofrecen un rango de profundidades de paso menor. Cuando funcionan en régimen sumergido se adaptan bien a los cambios de niveles y obstrucciones (Elvira et al. 1998a; Martínez de Azagra-Paredes 1999; Larinier 2002c), y permiten la entrada de los peces nadando (Elvira et al. 1998a; Aigoui et al. 2008). Cuando funcionan en régimen libre presentan menor adaptación a los cambios en los niveles de agua y a las obstrucciones (Elvira et al. 1998a; Larinier 2002c; Armstrong et al. 2004), y obligan a los peces a saltar, limitando el acceso de las especies e individuos con menores capacidades (Larinier 2002c; Armstrong et al. 2004; Aigoui et al. 2008). Se recomienda combinar vertederos con orificios para amortiguar mejor los cambios de nivel (Clay 1995; Larinier 2002c). Los orificios tienen cierta tolerancia a las variaciones en los niveles de agua, pero se obstruyen con facilidad (Elvira et al. 1998a; Larinier 2002c; Armstrong et al. 2004). Además, aunque los peces pueden atravesarlos nadando, pueden causar recelo en algunas especies por estar próximos al fondo o por presentar áreas y profundidades de paso reducidas.

En base a lo anterior, se propone un sistema de puntuación para los diferentes tipos de entrada que evalúa la exigencia que implican para los peces, el rango de profundidades que ofrecen, y su adaptación ante los cambios de los niveles de agua y obstrucciones parciales (Figura 25). 


\subsubsection{Etapa de pasaje (Ps)}

El pasaje es el proceso por el que la ictiofauna que ha entrado en un paso para peces se desplaza hasta su otro extremo, superando el desnivel total de agua dentro de la estructura.

\subsubsection{3.a. Desnivel entre láminas de agua de estanques sucesivos $\left(\Delta H_{P_{s}}\right)$}

Diferencia de nivel entre las láminas de agua de dos estanques consecutivos. Esta variable está relacionada con la velocidad del flujo y, por tanto, con la turbulencia que genera (Fuentes-Pérez et al. 2016). Desniveles demasiado grandes implican velocidades excesivas y turbulencias que pueden desorientar a los individuos, llegando incluso a impedirles ascender.

Esta variable se mide como la diferencia de cota entre zonas estables de las láminas de agua de dos estanques consecutivos de una escala (Figura 21).

La bibliografía aconseja desniveles que van de 0,25 a 0,30 $\mathrm{m}$ para estanques conectados por vertederos sumergidos y orificios, y de $0,20 \mathrm{~m}$ si conectan mediante hendiduras verticales (FAO/ DVWK 2002; Larinier 2002c; Baudoin et al. 2015). En estas escalas, Bravo-Córdoba et al. (2021) han observado que el barbo asciende más rápido cuanto mayor es el desnivel entre láminas dentro de los límites aconsejados. Con vertidos sumergidos, los peces se deben enfrentar a las velocidades máximas del flujo en distancias menores a 2,00 m (Tarrade et al. 2008). En términos generales, se aconseja que esas velocidades máximas no superen los 2,00 m/s (FAO/ DVWK 2002), aunque se ha observado que el $95 \%$ de los individuos de las especies objetivo pueden nadar distancias de 2,00 m con velocidades de hasta $3 \mathrm{~m} / \mathrm{s}$ (Castro-Santos et al. 2013; Sanz-Ronda et al. 2015c), lo que aproximadamente equivale a un desnivel de 0,50 m. Desniveles mayores sobrepasan las capacidades de la mayoría de la población y provocan un retraso o selección en los individuos que ascienden. En esta línea, (SanzRonda et al. 2016) han manifestado que en torno al $40 \%$ de los ejemplares de boga que han estudiado (rango de longitud furcal $12-26 \mathrm{~cm}$ ), han sido capaces de superar una sola hendidura vertical con un desnivel de $0,60 \mathrm{~m}$, aunque ha habido una selección de individuos por tamaño (éxito con longitudes furcales superiores a $18 \mathrm{~cm}$ ).

Las guías de diseño recomiendan que el desnivel entre las láminas de agua $\left(\Delta H_{P_{S}}\right)$ en vertidos libres no supere los 0,30 m (Larinier 1998). Además, se aconseja que haya una profundidad aguas abajo para tomar impulso antes de saltar de al menos dos veces el desnivel entre láminas $\left(\Delta H_{P_{s}}\right)$, y una carga de vertido $(h)$ en el vertedero superior a $0,20 \mathrm{~m}$ para evitar daños (Baudoin et al. 2015). No obstante, las especies objetivo pueden realizar saltos puntuales mayores, aunque si se repitiesen varias veces podrían conllevar gastos energéticos demasiado elevados. Kondratieff y Myrick (2006) han propuesto con salvelinos (Salvelinus fontinalis, longitud media de $13,5-26,5 \mathrm{~cm}$ ), que 
son salmónidos con capacidad de nado similar a la trucha y al barbo común (CastroSantos et al. 2013; Sanz-Ronda et al. 2015c), y Amaral et al. (2016) con barbo común (longitud media 18,7 cm), que el éxito al superar vertederos libres depende de la combinación del desnivel entre las láminas y la profundidad disponible para el impulso; reduciéndose los éxitos con desniveles mayores a los 0,35 - 0,40 m, y mejorando con profundidades que superan los 0,20 m. Asimismo, (Sanz-Ronda et al. 2015a) han observado que la mayoría de ejemplares de las especies objetivo (longitud superior a $12 \mathrm{~cm}$ ), han superado saltos naturales con desniveles mayores a 0,50 $\mathrm{m}$ y profundidades de más de 1,00 m. GEA (datos no publicados) ha observado que en torno al $85 \%$ de los barbos comunes estudiados han superado un desnivel puntual que rondaba 0,60 m con una profundidad de aproximadamente 1,00 m. También, GEA (datos no publicados) ha determinado que el $43 \%$ de bogas del Duero adultas estudiadas son capaces de superar un salto de 0,66 $\mathrm{m}$ con una profundidad hacia aguas abajo cercana a los 0,80 m. Morán-López y Uceda Tolosa (2016) describen barbos del sur (Luciobarbus comizo y L. microcephalus, longitud media menor a $35 \mathrm{~cm}$ ) realizando saltos medios de $0,80 \mathrm{~m}$ con profundidades cercanas a 1,00 m.

Desniveles reducidos $\left(\Delta H_{P_{S}}<0,05 \mathrm{~m}\right.$ ) conllevan velocidades de la corriente pequeñas $(<1,0 \mathrm{~m} / \mathrm{s})$, que pueden reducir la motivación y dificultar la orientación de los individuos durante el ascenso (Castro-Santos et al. 2013; Goettel et al. 2015; BravoCórdoba et al. 2021). Sin embargo, esos desniveles suelen deberse a obstrucciones puntuales y no al propio diseño del pasaje (Fuentes-Pérez et al. 2016).

A partir de lo anterior, se proponen dos sistemas de puntuación: uno para vertederos sumergidos o libres con o sin orificio, y otro para hendiduras verticales u orificios. Para vertederos, con o sin orificios, se consideran óptimos los desniveles que van hasta los $0,25 \mathrm{~m}$. A partir de ese valor, la puntuación se va reduciendo hasta alcanzar su mínimo con desniveles mayores a los 0,50 m. Para las hendiduras y orificios se consideran como óptimos los desniveles de hasta 0,20 m. Por encima de ese valor, la puntuación se va reduciendo hasta llegar a 0 puntos a los 0,50 m (Figura 26). 

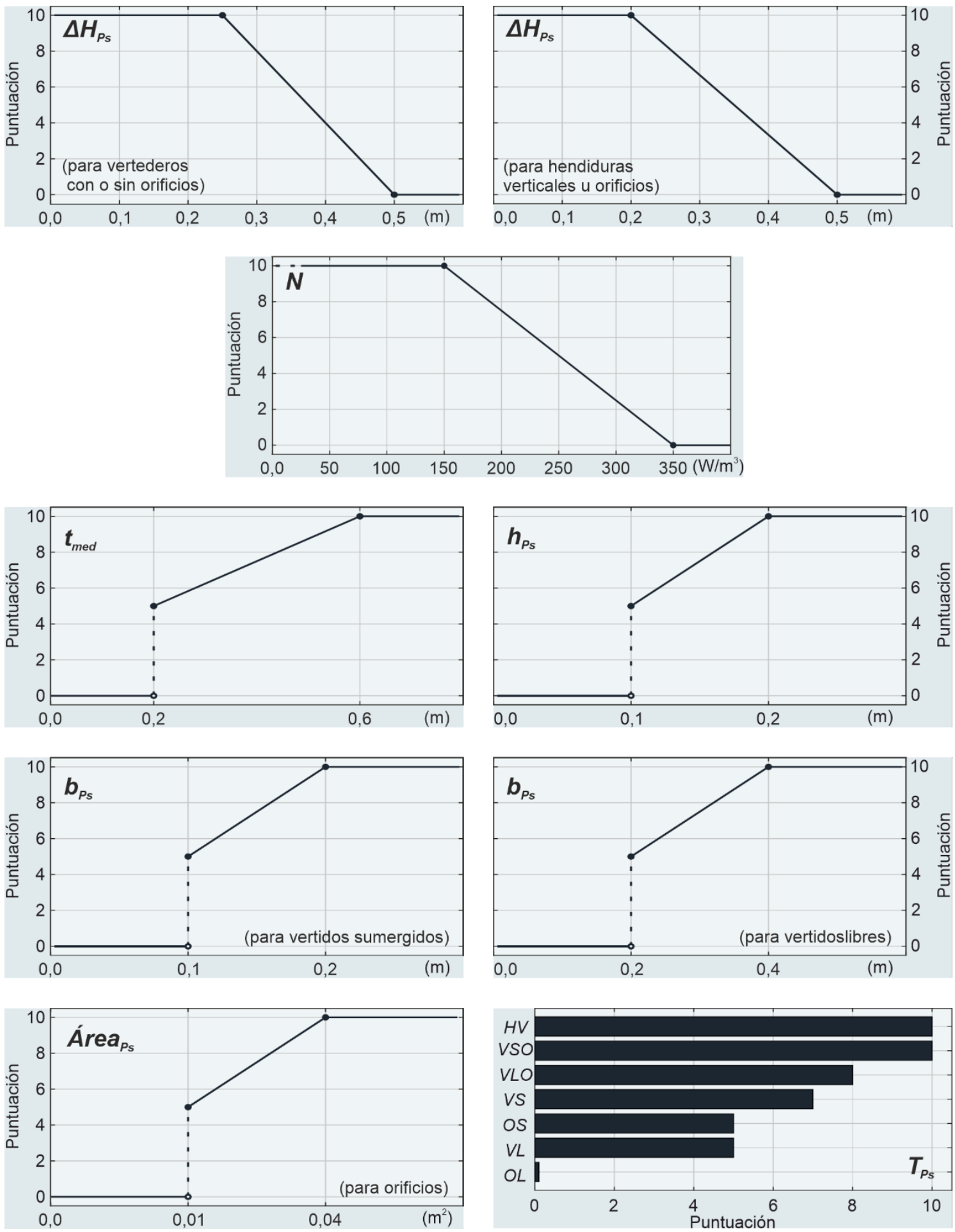

Figura 26. Puntuación de las variables fundamentales del pasaje ( $\Delta H_{P_{s}}$ - desnivel entre láminas de agua de estanques sucesivos $(\mathrm{m}), N$ - potencia disipada por unidad de volumen $\left(\mathrm{W} / \mathrm{m}^{3}\right), t_{\text {med }}$ - tirante medio de los estanques $(\mathrm{m}), h_{P_{s}}-$ profundidad de paso entre estanques $(\mathrm{m}), b_{P_{s}}-$ anchura de paso entre estanques $(\mathrm{m})$, Área $a_{P_{s}}$ - área de paso entre estanques $\left(\mathrm{m}^{2}\right), T_{P_{s}}$ - tipo de paso entre estanques, $H V-$ hendidura vertical con o sin orificio y $p<0,25 \mathrm{~m}$, VSO - vertedero con vertido sumergido y orificio, VLO - vertedero con vertido libre y orificio, VS - vertedero con vertido sumergido, OS - orificio sumergido, $V L$ - vertedero con vertido libre y $O L$ - orificio con vertido libre). 


\subsubsection{3.b. Potencia disipada por unidad de volumen (N)}

Es la potencia del flujo que se disipa por unidad de volumen de agua contenida en el estanque inferior al salto considerado (Martínez de Azagra 1999). Esta variable se utiliza habitualmente para el dimensionado de las artesas y como indicador de la turbulencia en ellas (Larinier 2002c; Bravo-Córdoba et al. 2021). Valores reducidos ayudan a que los peces tengan éxito en el ascenso (Bravo-Córdoba et al. 2021); mientras que si son demasiado elevados conllevan gran aireación del flujo, turbulencias y recirculaciones que desorientan a los peces y dificultan su natación dentro de la escala (Odeh et al. 2002; Silva et al. 2012).

Se calcula mediante la siguiente expresión:

$$
N=\frac{g \cdot \rho \cdot Q_{\text {escala }} \cdot \Delta H_{P s}^{\prime}}{L \cdot B \cdot t_{m e d}}
$$

donde $N$ es la potencia disipada por unidad de volumen $\left(\mathrm{W} / \mathrm{m}^{3}\right), g$ es la aceleración de la gravedad $\left(9,81 \mathrm{~m} / \mathrm{s}^{2}\right), \rho$ es la densidad absoluta del agua $\left(\mathrm{kg} / \mathrm{m}^{3}\right), \Delta H_{P_{s}}^{\prime}$ es el desnivel entre la lámina de agua del estanque evaluado y del superior $(m), L$ y $B$ son respectivamente la longitud y anchura del estanque evaluado $(\mathrm{m})$, y $t_{\text {med }}$ es el tirante medio del estanque estudiado (m).

Existen recomendaciones sobre esta variable que aconsejan menos de $150 \mathrm{~W} / \mathrm{m}^{3}$ para ciprínidos reófilos y desde 175 hasta $200 \mathrm{~W} / \mathrm{m}^{3}$ para la trucha, pudiendo superarse ligeramente esos valores en escalas con pocos estanques (Martínez de Azagra-Paredes 1999; Larinier 2002c; Armstrong et al. 2004). Sanz-Ronda et al. (2016a) han concluido que el tiempo de paso y el porcentaje de éxito era muy parecido en dos tipos de escalas con potencias disipadas desde los 125 hasta los $200 \mathrm{~W} / \mathrm{m}^{3}$, para juveniles y adultos de trucha, barbo y boga. Con valores superiores a $300 \mathrm{~W} / \mathrm{m}^{3}$, estos autores han observado una menor proporción de éxitos y una selección de los individuos que ascendían en función de su tamaño y/o capacidad de nado. Silva et al. (2012) han concluido que los barbos prefieren zonas con bajas turbulencias, siendo más susceptibles a esa turbulencia los ejemplares de menor tamaño $(<0,25 \mathrm{~m})$. Además, han percibido una correlación negativa entre el tiempo de ascenso y la turbulencia.

Se propone un sistema de puntuación en el que potencias disipadas menores a 150 $\mathrm{W} / \mathrm{m}^{3}$ son idóneas para el ascenso de los peces, reduciendo su puntuación paulatinamente hasta llegar a los $350 \mathrm{~W} / \mathrm{m}^{3}$. Por encima de ese valor se asume que la mayoría de los ejemplares tendrían dificultades para pasar por la escala (Figura 26). 


\subsubsection{3.c. Tirante medio de los estanques ( $\left.t_{\text {med }}\right)$}

Profundidad media del agua en un estanque (Figura 21). Valores reducidos de esta variable pueden provocar daños a los peces por rozaduras, así como la imposibilidad de descansar durante el ascenso por ser depredados o el temor a ello. Por tanto, se aconseja aumentar la profundidad para evitar estos problemas (Armstrong et al. 2004).

Se calcula de la siguiente manera:

$$
t_{m e d}=\frac{p+h_{P_{S}}+p^{\prime}+h_{P_{S}}^{\prime}-\Delta H_{P_{S}}^{\prime}}{2}
$$

donde $t_{\text {med }}$ es el tirante medio en un estanque $(\mathrm{m}), p$ es la altura al umbral del elemento que conecta el estanque evaluado con el inferior $(\mathrm{m}), h_{P_{s}}$ es la carga de vertido en la conexión con el estanque inferior $(m), p^{\prime}$ es la altura al umbral del elemento que conecta el estanque superior con el evaluado $(\mathrm{m}), h_{P_{S}}^{\prime}$ es la carga de vertido en la conexión con el estanque superior $(\mathrm{m})$, y $\Delta H_{P_{S}}^{\prime}$ es el desnivel entre las láminas de agua del estanque evaluado y del superior $(\mathrm{m})$.

La bibliografía recomienda profundidades mínimas de 0,20 m para permitir a los peces nadar con facilidad, poco estrés, un riesgo moderado de ser depredados y poder descansar (Katopodis 1992; FAO/ DVWK 2002; Armstrong et al. 2004). Las curvas de preferencia para las tres especies objetivo proponen más de $0,40 \mathrm{~m}$ de profundidad para juveniles, y más de 0,60 m para adultos (Martínez-Capel et al. 2004; Ayllón et al. 2010). En general, en los estanques se recomiendan profundidades de más de $0,60 \mathrm{~m}$ (Martínez de Azagra-Paredes 1999; FAO/ DVWK 2002; Larinier 2002c). Además, con vertidos libres, debe existir una profundidad aguas abajo mayor al doble del desnivel entre láminas de agua $\left(\Delta H_{P_{S}}\right)$ para que los peces puedan tomar suficiente impulso para saltar (Baudoin et al. 2015).

Se propone un sistema de puntuación en el que profundidades menores a 0,20 m se considera que no permiten el paso de los peces con seguridad. Con 0,20 m se considera que los peces ya son capaces de ascender sin rozarse ni golpearse, aunque tienen riesgo de ser depredados y no pueden descansar convenientemente. La puntuación de la variable va aumentando hasta alcanzar su máximo en 0,60 m, profundidad a partir de la cual los peces pueden pasar los estanques con facilidad y sin riesgos (Figura 26). 


\subsubsection{3.d. Profundidad de paso entre estanques $\left(h_{P_{s}}\right)$}

Profundidad de agua de la que disponen los peces para pasar entre estanques. Valores reducidos de la variable hacen que los peces puedan rozarse, golpearse o verse obligados a saltar para pasar de un estanque al siguiente. Por ello, se aconseja que esta variable sea lo más grande posible para facilitar el paso (Bravo-Córdoba et al. 2021).

En vertidos sumergidos, esta variable se mide como la diferencia de cota entre la lámina de agua del estanque inferior y el umbral de la conexión entre ese estanque y el evaluado. En caso de que un vertido sumergido presente una profundidad menor a $0,10 \mathrm{~m}$, se considera que se trata de un vertido libre a efectos del paso de los peces. En vertidos libres, se corresponde con la carga de vertido $(h)$, que se mide como la diferencia de cota entre la lámina de agua del estanque evaluado y el umbral de la conexión de este estanque con el inferior. En caso de que los estanques conecten por orificios, esta variable se corresponde con la altura del orificio $\left(d_{P_{s}}\right)$ (Figura 21). Si existen a la vez vertedero y orificio para el paso entre estanques, solo se tiene en cuenta el vertedero.

La bibliografía aconseja que la profundidad mínima sea $>1,5 \times h_{\text {pez }}$, siendo óptima si fuese $>2,5 \times h_{p e z}$ (donde $h_{p e z}$ es la altura dorsoventral de las especies objetivo) (Baudoin et al. 2015). En la cuenca del Duero, los mayores ejemplares de las especies objetivo presentan una altura dorsoventral $\left(h_{p e z}\right)<8 \mathrm{~cm}$ (González-Alemán 2016). Por tanto, la profundidad mínima adecuada para estas especies será de unos 0,10 $\mathrm{m}$ y la idónea será cercana a los 0,20 m. Otros trabajos recomiendan profundidades mayores a 0,20 m (Katopodis 1992; FAO/ DVWK 2002; Armstrong et al. 2004). Al realizarse de manera rápida, una profundidad de paso entre estanques grande no es tan relevante como sucede con el tirante medio de los estanques, donde los peces pasan más tiempo moviéndose o descansando.

Se propone un sistema de puntuación en el que se penalizan profundidades menores a 0,10 m por provocar daños en los peces (rozaduras y golpes), así como por dificultar su paso al quedar parte del cuerpo fuera del agua. Cuando la variable alcance $0,10 \mathrm{~m}$ se considera adecuada para permitir el paso de los peces, aunque no sea de una manera idónea. La puntuación va aumentando hasta llegar a su máximo con una profundidad igual o mayor de $0,20 \mathrm{~m}$, ya que resulta adecuada para el paso de los peces de manera cómoda y sin riesgos (Figura 26).

\subsubsection{3.e. Anchura y/o área de paso entre estanques ( $b_{P_{S}} \mathrm{y} / \mathrm{o}$ Área $\left.\mathrm{P}_{\mathrm{P}}\right)$}

Anchura de los vertederos y hendiduras, y/o área de los orificios por los que los peces pasan entre estanques. Si la conexión entre estanques es demasiado pequeña, los peces pueden rozarse e, incluso, los individuos más grandes pueden no pasar. 
Además, aumenta el riesgo de obstrucciones por restos arrastrados por la corriente. Por el contrario, cuanto más grande sea esta variable, más se facilita el paso de los peces entre estanques y más difícil es que se produzcan atascos.

En el caso de vertederos y hendiduras que conectan los estanques entre sí se mide como la anchura. En orificios se mide como su área (Figura 21). Cuando los estanques conectan por vertederos trapezoidales, la anchura que se considera para esta variable es la media de la base mayor marcada por el nivel de agua del estanque superior y de la base menor del trapecio. Si hay varias conexiones entre estanques ( $p$. ej. vertedero sumergido y orificio), la puntuación de la variable será el resultado de la media aritmética calculada a partir de las puntuaciones de cada conexión.

La anchura debe ser suficiente como para que los peces pasen entre estanques sin riesgos. Los ejemplares más grandes de trucha y barbo en la cuenca del Duero presentan una longitud media $\left(L_{p e z}\right)$ de $0,50 \mathrm{~m}$, mientras que los de boga no suelen superar los 0,35 m (González-Alemán 2016). Estos individuos presentan una distancia intercostal media $\left(b_{p e z}\right)$ igual o menor a $7 \mathrm{~cm}$ (González-Alemán 2016). Videler y Wardle (1991) indican que, para especies como en las que se centra este trabajo, la amplitud con que oscila la aleta caudal de los peces es función de su longitud y viene definida por la siguiente expresión: 0,2 $\times L_{p e z}$. Por tanto, en la cuenca del Duero, la máxima amplitud de la aleta caudal de los mayores individuos será de unos 0,10 m, siendo este el tamaño mínimo que deben presentar las conexiones entre estanques.

A pesar de lo anterior, se recomienda que la anchura mínima sea mayor a 0,15 m para evitar obstrucciones (Martínez de Azagra-Paredes 1999; Larinier 2002c; Baudoin et al. 2015). Con vertidos sumergidos se recomiendan anchuras de 0,20 a 0,25 m para permitir el paso de los peces con facilidad (Martínez de Azagra-Paredes 1999; FAO/ DVWK 2002; Larinier 2002c). Con vertidos libres se recomiendan valores de entre 0,30 y 0,40 m (Armstrong et al. 2004). Sanz-Ronda et al. (2015a) han obtenido la misma eficiencia de paso en vertederos sumergidos de 0,20 $\mathrm{m}$ de anchura que en vertederos libres de 0,40 m de anchura (a igualdad del resto de variables hidráulicas). Los orificios siempre deben ser mayores de 0,01 $\mathrm{m}^{2}$ para garantizar que los peces de mayor tamaño puedan atravesarlos. No obstante, se suele aconsejar un área mínima de 0,03 $\mathrm{m}^{2}$ (Baudoin et al. 2015), siendo idónea si es igual o mayor 0,04 $\mathrm{m}^{2}$ (Elvira et al. 1998a; Martínez de Azagra-Paredes 1999; FAO/ DVWK 2002).

Se proponen tres sistemas de valoración: para vertidos sumergidos, libres y orificios. Todos ellos consideran inadecuadas las anchuras menores a 0,10 m por dificultar mucho el paso de los peces y obstruirse con facilidad. Para vertidos sumergidos, la puntuación aumenta desde ese valor mínimo hasta alcanzar el valor recomendado de 0,20 m. Para vertidos libres, la anchura debe ser mayor que para los sumergidos (Larinier 2002c; Baudoin et al. 2015). Por ello, se establece que la anchura mínima que permite pasar a los peces con éxito es de 0,20 $\mathrm{m}$ y resulta idónea cuando supera los 0,40 m. El tamaño mínimo de los orificios que se considera que permite el paso de los peces es de $0,01 \mathrm{~m}^{2}$, asignando la máxima puntuación a aquellos iguales o mayores a $0,04 \mathrm{~m}^{2}$ (Figura 26). 


\subsubsection{3.f. Tipo de paso entre estanques $\left(T_{P_{s}}\right)$}

Tipo de conexión entre estanques para el paso de los peces. El tipo de conexión influye en cómo deben desplazarse, las profundidades que pueden utilizar, la disipación de la energía del flujo, las áreas de recirculación y las zonas de descanso dentro de los estanques (Larinier 2002c).

Como ya se ha comentado en la etapa de la entrada, los diferentes tipos de conexión presentan diferentes respuestas ante los cambios de caudal, obstrucciones parciales y ofrecen diferentes circunstancias para el paso de los peces (Figura 21 y Tabla 7). A continuación, se muestra una tabla resumen para cada una de las alternativas más habituales:

Tabla 7. Tipos de conexiones entre estanques y sus efectos en el ascenso de los peces.

\begin{tabular}{l|l}
\multicolumn{1}{c|}{ TIPO DE CONEXIÓN ENTRE } \\
ESTANQUES
\end{tabular}




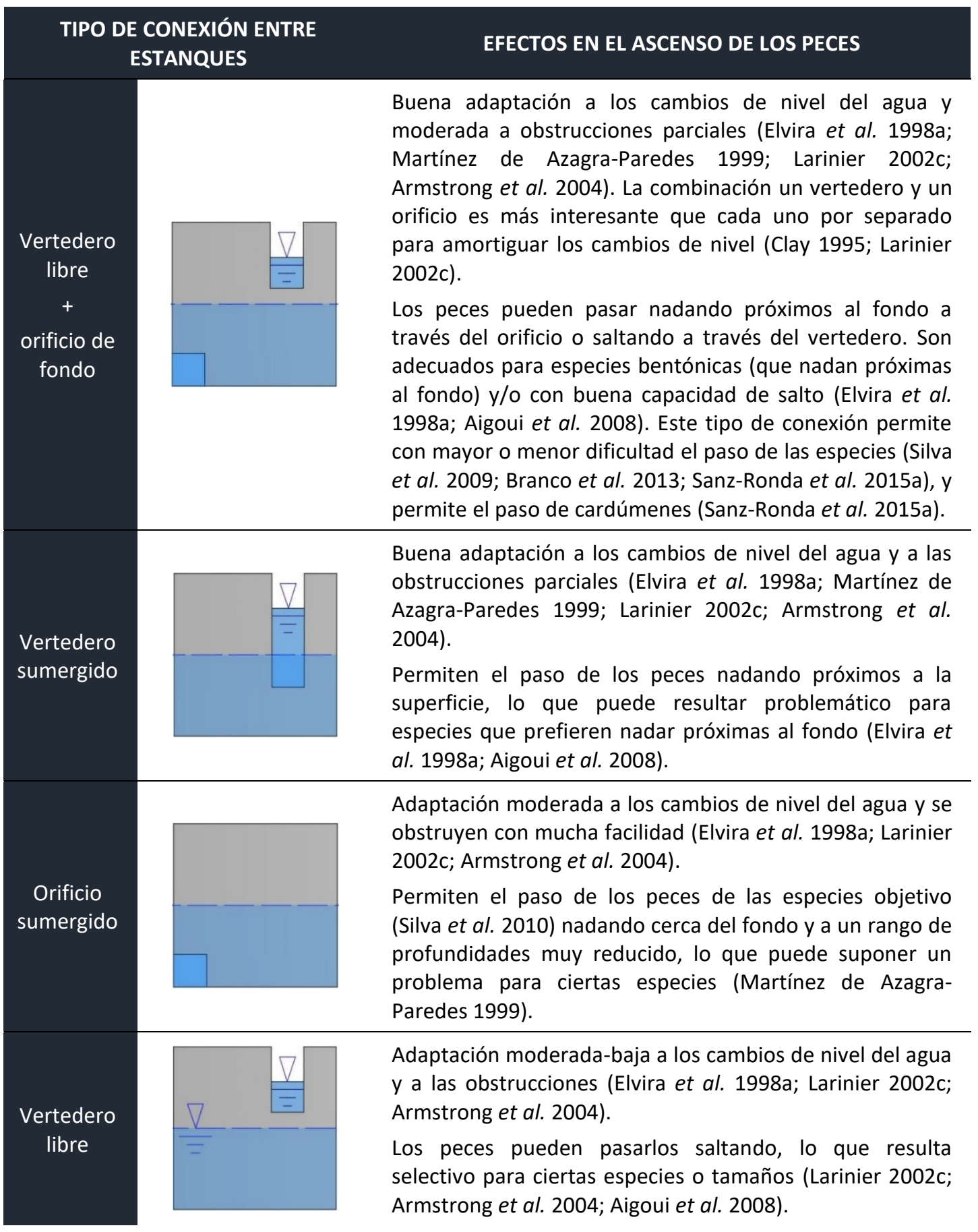

De acuerdo con todo lo anterior, se propone un sistema de puntuación que evalúa la exigencia de cada tipo de conexión para los peces y su adaptabilidad a cambios de nivel y obstrucciones (Figura 26). 


\subsubsection{Etapa de salida (S)}

La salida es la etapa en la que los peces que han recorrido todo el paso para peces abandonan la estructura y regresan al río.

\subsubsection{4.a. Desnivel entre la lámina de agua en el río y en el estanque superior $\left(\Delta H_{S}\right)$}

Diferencia de nivel entre la lámina de agua del río hacia aguas arriba del paso y del estanque superior. El desnivel está relacionado con la velocidad del flujo entre láminas y la turbulencia que genera (Fuentes-Pérez et al. 2016). Por ello, si esta variable es demasiado pequeña puede reducirse la motivación de los peces para salir del paso (Bravo-Córdoba et al. 2021), sin llegar a suponer un problema tan relevante como en la entrada. Si es demasiado grande puede sobrepasar las capacidades de los peces e impedir su salida.

Se mide como la diferencia de cota entre la lámina de agua del río aguas arriba de la salida y del estanque superior del paso (Figura 21).

La bibliografía recomienda con vertidos sumergidos desniveles máximos que varíen entre 0,15 y $0,30 \mathrm{~m}$, lo que implica velocidades menores a unos $2,4 \mathrm{~m} / \mathrm{s}$; mientras que para vertidos libres, se aconsejan saltos máximos comprendidos entre los 0,30 y 0,45 $\mathrm{m}$, que equivalen a velocidades menores a 3,00 m/s (Martínez de Azagra-Paredes 1999; FAO/ DVWK 2002; Larinier 2002c).

Se proponen puntuaciones que penalizan parcialmente los desniveles pequeños por disminuir la motivación. El óptimo de la variable se alcanza entre los 0,20 y 0,30 m, ya que implican velocidades del flujo que ayudan a la orientación de los peces y son fácilmente superables. La valoración de la variable disminuye con desniveles mayores de 0,30 $\mathrm{m}$ hasta llegar a los 0,50 $\mathrm{m}$, ya que implican velocidades que pueden ser superadas solo por una parte reducida de la población piscícola (Figura 27). 

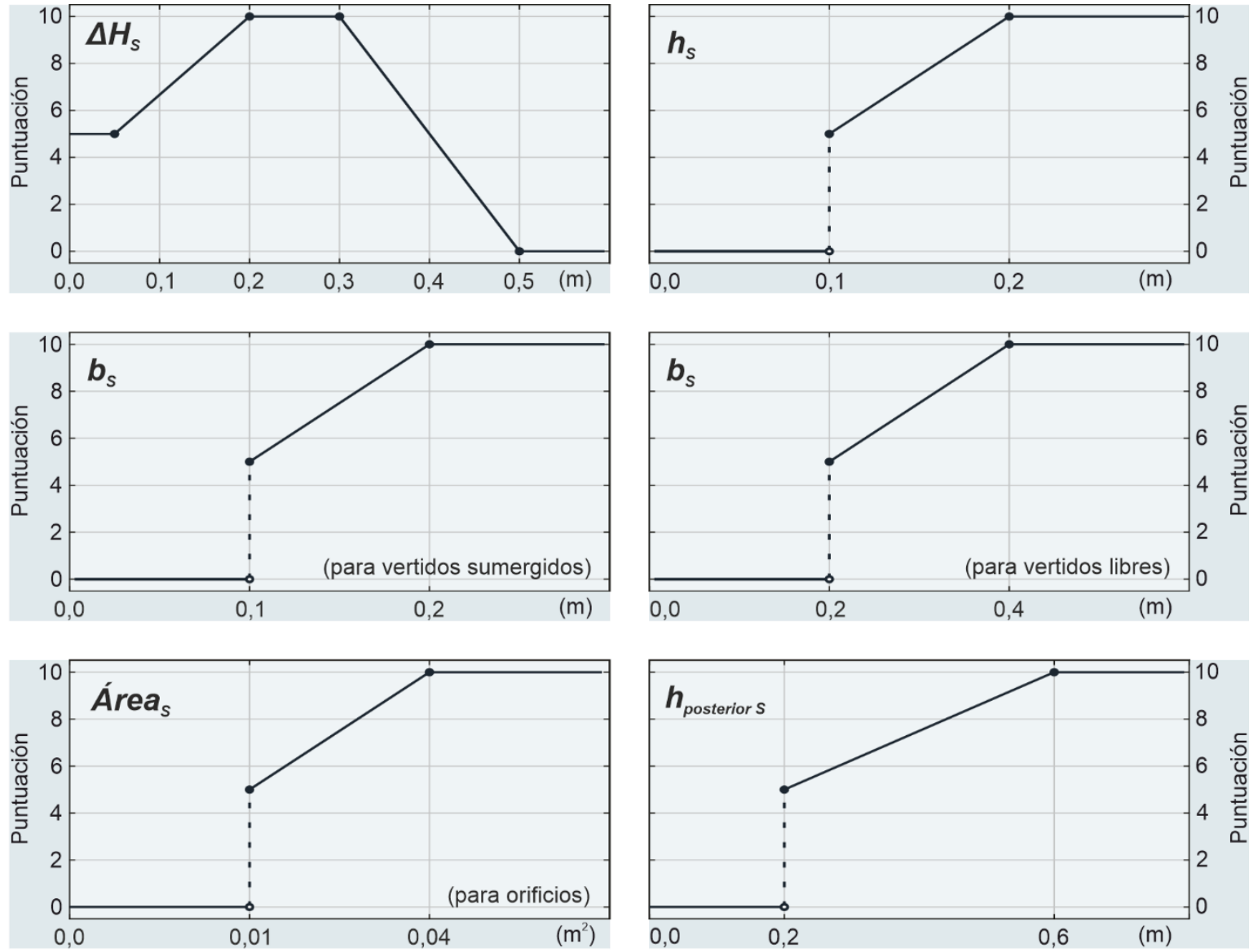

\section{Ort $_{s}$}

Descripción

Punt.

A

Salida en dirección de la corriente, aunque en sentido contrario $\left(90^{\circ} \leq \alpha \leq 180^{\circ}\right)$

B Salida perpendicular al flujo $\left(45^{\circ} \leq \alpha<90^{\circ}\right) \quad 1-5$

Salida situada a favor de la corriente y en su mismo sentido $\left(0^{\circ} \leq \alpha<45^{\circ}\right)$

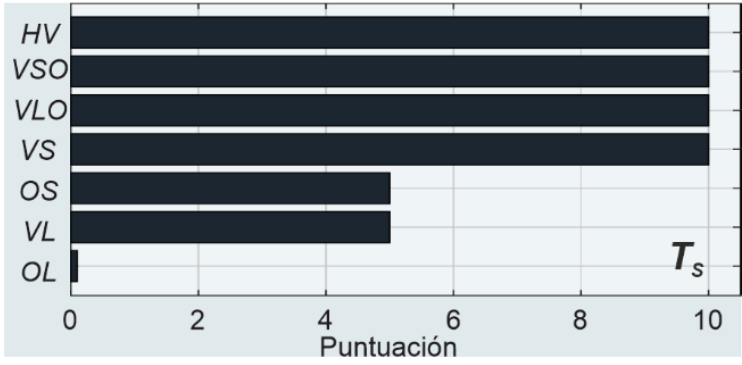

Figura 27. Sistemas de puntuación para las variables fundamentales de la salida $\left(\Delta H_{s}-\right.$ desnivel entre la lámina de agua en el río y en el estanque superior $(\mathrm{m}), h_{s}$ - profundidad de paso en la salida $(\mathrm{m}), b_{s}-$

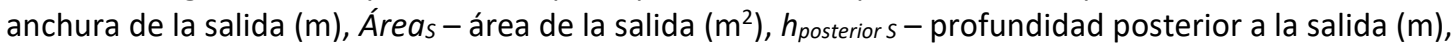

Orts - orientación de la salida respecto del río $\left({ }^{\circ}\right), \alpha$ - ángulo que forma la salida respecto del eje hidráulico del río, $T_{S}$ - tipo de salida, $H V$ - hendidura vertical con o sin orificio y $p<0,25 \mathrm{~m}, V S O-$ vertedero con vertido sumergido y orificio, $V L O$ - vertedero con vertido libre y orificio, $V S$ - vertedero con vertido sumergido, $O S$ - orificio sumergido, $V L$ - vertedero con vertido libre y $O L$ - orificio con vertido libre). 


\subsubsection{4.b. Profundidad de paso en la salida $\left(h_{s}\right)$}

Profundidad de agua disponible para la salida de los peces. Profundidades pequeñas aumentan el riesgo de que se golpeen o rocen con la estructura e, incluso, pueden obligarles a saltar para salir del paso. Por tanto, se aconseja que esta variable sea lo más grande posible. Además, se ha observado que valores elevados de esta variable reducen el tiempo de ascenso empleado por las especies objetivo en las escalas (Bravo-Córdoba et al. 2021).

En vertidos sumergidos, se mide como la diferencia de cota entre la lámina de agua del estanque superior del paso y el umbral de la salida. Aquellos vertidos sumergidos con una profundidad menor a 0,10 m se consideran vertidos libres o no sumergidos para el paso de los peces. En vertidos libres, esta variable se mide como la carga de vertido en la salida, es decir, la diferencia de nivel entre la lámina de agua del río y el umbral de la salida. Si la salida se realiza a través de un orificio, esta variable se mide como su altura $\left(d_{s}\right)$ (Figura 21 ). En caso de que la salida pueda hacerse a través de un vertedero y un orificio, solo se tiene en cuenta el vertedero.

Baudoin et al. (2015) indican que la profundidad mínima debe ser $>1,5 \times h_{p e z}$ y la óptima es $>2,5 \times h_{p e z}$ (donde $h_{p e z}$ es la altura dorsoventral de las especies objetivo). Los mayores ejemplares de las especies objetivo presentan en la cuenca del Duero una altura dorsoventral media $\left(h_{p e z}\right)<8 \mathrm{~cm}$ (González-Alemán 2016). Por tanto, la profundidad mínima para estas especies será de unos $0,10 \mathrm{~m}$, y la óptima cercana a los $0,20 \mathrm{~m}$; lo que coincide con trabajos previos que recomiendan profundidades por encima de los 0,20 m (Katopodis 1992; FAO/ DVWK 2002; Armstrong et al. 2004).

El sistema de puntuación propuesto para esta variable considera 0,10 $\mathrm{m}$ como la profundidad mínima que permite la salida de los peces del paso, aunque con cierta dificultad. La puntuación de la variable aumenta desde ese mínimo hasta alcanzar el máximo con 0,20 m de profundidad, a partir del cual los peces pueden salir sin riesgos ni dificultades (Figura 27).

\subsubsection{4.c. Anchura y/o área de la salida (bs y/o Áreas)}

Anchura del vertedero y hendidura, y/o área del orificio por el que los peces salen del paso hacia el río. Si esta variable resulta muy reducida, los peces pueden rozarse, golpearse o ser incapaces de salir. Además, cuanto más pequeña sea, más fácil es que se obstruya por restos arrastrados por la corriente. Por el contrario, cuanto mayor sea la salida, más fácil es el paso de los peces y más difícil su obstrucción.

En vertederos y hendiduras se mide como la anchura que conecta el estanque superior del paso con el río. En orificios se mide como su área (Figura 21). Cuando la salida sea a través de vertederos trapezoidales, la anchura vendrá dada por la media de la base menor del trapecio y la base mayor marcada por el nivel de agua del río. En 
caso de que la salida se realice a través de varias opciones (p. ej. vertedero sumergido y orificio), el valor de esta variable será la media aritmética de las puntuaciones de cada una de ellas.

Los mayores ejemplares de las especies objetivo en la cuenca del Duero presentan una anchura intercostal ( $b_{p e z}$ ) de unos $7 \mathrm{~cm}$ (González-Alemán 2016). Los ejemplares más grandes de trucha y barbo en la cuenca del Duero tienen una longitud $\left(L_{p e z}\right)$ de unos 50 $\mathrm{cm}$, mientras que en el caso de la boga son de unos $35 \mathrm{~cm}$ de largo. Se estima que la amplitud máxima con la que estas especies mueven su aleta caudal viene dada por la expresión 0,2 x $L_{p e z}$ (Videler y Wardle 1991). En base a ello, la anchura mínima que precisan los peces más grandes para nadar con comodidad será de unos $10 \mathrm{~cm}$.

Algunos trabajos recomiendan anchuras mayores a 0,15 $\mathrm{m}$ con el fin de evitar obstrucciones (Martínez de Azagra-Paredes 1999; Larinier 2002c; Baudoin et al. 2015). Existen especificaciones sobre la anchura para los distintos tipos de vertidos y orificios. Para vertidos sumergidos se aconsejan anchuras de como mínimo 0,20 m (FAO/ DVWK 2002; Larinier 2002c; Aigoui et al. 2008). Para vertidos no sumergidos se recomiendan anchuras mayores que ayuden a garantizar el éxito del salto que tiene que realizar el pez (Larinier 2002c; Baudoin et al. 2015). Sanz-Ronda et al. (2015a) han observado una eficiencia de paso similar en vertidos sumergidos con anchuras de 0,20 $\mathrm{m}$ que en vertidos libres con $0,40 \mathrm{~m}$ de ancho (siendo el resto de las variables hidráulicas iguales). Para orificios se recomienda que su área sea mayor a 0,03 $\mathrm{m}^{2}$ (Baudoin et al. 2015), siendo idóneo si superan los 0,04 $\mathrm{m}^{2}$ (Elvira et al. 1998a; Martínez de Azagra-Paredes 1999; FAO/ DVWK 2002).

Se proponen tres sistemas de puntuación para los diferentes tipos de salida: vertidos sumergidos, libres y orificios. Los tres sistemas penalizan aquellas anchuras menores a los $0,10 \mathrm{~m}$, ya que dificultan el paso de parte de la población y se obstruyen con facilidad. En el caso de los vertidos sumergidos, la puntuación aumenta desde esa anchura mínima hasta ser idónea con 0,20 m. En los vertidos no sumergidos, se considera que el óptimo se alcanza con anchuras iguales o mayores a los 0,40 m. Para los orificios, se establece que el tamaño mínimo para el paso de los peces es $0,01 \mathrm{~m}^{2}$, aumentando la puntuación hasta los 0,04 m² (Figura 27).

\subsubsection{4.c. Profundidad posterior a la salida ( $h_{\text {posterior } s)}$}

Profundidad en el río aguas arriba de la salida. Si es reducida puede hacer que los peces se rocen, golpeen o sean depredados. Por ello, se aconseja que esta variable sea lo más grande posible para facilitar que los peces se desplacen hacia río arriba.

Se calcula como la diferencia de nivel entre la lámina de agua del río y el lecho de aguas arriba de la salida (Figura 21).

Como se ha comentado para otras profundidades, el valor mínimo recomendando es de 0,20 m (Katopodis 1992; FAO/ DVWK 2002; Armstrong et al. 2004), mientras que se 
consideran idóneas profundidades iguales o mayores a 0,60 m (Martínez de AzagraParedes 1999; FAO/ DVWK 2002; Larinier 2002c).

Se propone un sistema de puntuación basado en lo anterior. El valor mínimo que se considera que permite el paso de los peces con cierta comodidad es $0,20 \mathrm{~m}$, asignando la máxima puntuación a profundidades iguales o mayores a 0,60 m (Figura 27).

\subsubsection{4.d. Orientación de la salida respecto del río (Orts)}

Dirección de la salida de un paso en relación con el eje hidráulico del río y la corriente. Esta variable influye en la facilidad con la que los peces que salen del paso continúan con sus desplazamientos, así como en la posibilidad de que se introduzcan restos arrastrados por la corriente dentro del paso.

Se mide como el ángulo que existe entre la dirección hacia la que se enfoca la salida y el eje hidráulico del río en el sentido de la corriente (Figura 21).

Las salidas que se orientan hacia aguas abajo y están cerca del azud presentan recirculaciones que pueden desorientar a los peces, pudiendo llegar a hacerles caer hacia la base del obstáculo (Larinier 2002c). Además, este tipo de salidas les obliga a realizar giros bruscos y poco naturales para seguir ascendiendo por el río. Se recomiendan salidas en la dirección del ascenso del pez, es decir, que vayan desde la perpendicular hasta ser contrarias a la corriente, aunque el riesgo de obstrucción aumenta cuanto más se oponen al flujo (Aigoui et al. 2008; Sanz-Ronda et al. 2014).

Se plantea un sistema de valoración en el que se consideran más adecuadas las orientaciones $(\alpha)$ que están en la trayectoria de ascenso del pez $\left(90^{\circ} \leq \alpha \leq 180^{\circ}\right)$. La puntuación disminuye a medida que la salida es más paralela al eje del río y a favor de la corriente, porque pueden darse recirculaciones no deseadas y obligar a los peces a hacer giros bruscos (Figura 27).

\subsubsection{4.e. Tipo de salida $\left(T_{S}\right)$}

Esta variable hace referencia a cómo los peces salen del paso. Los diferentes tipos de salida ofrecen a los peces distintas maneras para salir y resultan más o menos atractivos (Figura 21).

Las hendiduras verticales presentan buena adaptación ante los cambios de nivel de agua y obstrucciones (Clay 1995; Martínez de Azagra-Paredes 1999; FAO/ DVWK 2002). Además, permiten que los peces salgan nadando a la profundidad que prefieran, independientemente de su especie, tamaño o capacidades de nado (Katopodis 1992; Elvira et al. 1998a; Jungwirth et al. 1998). Las hendiduras ofrecen un 
rango de profundidades mayor que los vertederos. Los vertederos sumergidos se adaptan bien a los cambios de nivel y permiten a los peces pasar nadando. Los vertederos libres se adaptan peor a los cambios y obligan a los peces a saltar, pudiendo ser más restrictivos. Se recomienda la combinación de vertederos y orificios para mejorar su adaptación ante cambios en los niveles de agua (Clay 1995; Larinier 2002c). Los orificios toleran moderadamente las variaciones en los niveles de agua (Clay 1995; Elvira et al. 1998a; Aigoui et al. 2008), pero se obstruyen con facilidad (Elvira et al. 1998a; Larinier 2002c). Este tipo de salida puede ser atravesada por los peces nadando cerca del fondo, lo que puede no ser favorable para algunas especies.

Para esta variable se propone un sistema que valore para cada tipo de salida por cuestiones hidráulicas, tales como adaptación a cambios en los niveles y obstrucciones, y biológicas como el tipo de vertido o el rango de profundidades que ofrecen (Figura 27).

\subsubsection{OBSERVACIONES DE RELEVANCIA}

La metodología AEPS evalúa una serie de observaciones de relevancia en cada una de las etapas a superar por los peces. La siguiente tabla muestra las que se consideran en cada etapa y por qué son relevantes para el ascenso de los peces:

Tabla 8. Observaciones de relevancia consideradas por la metodología y cómo afectan a los peces.

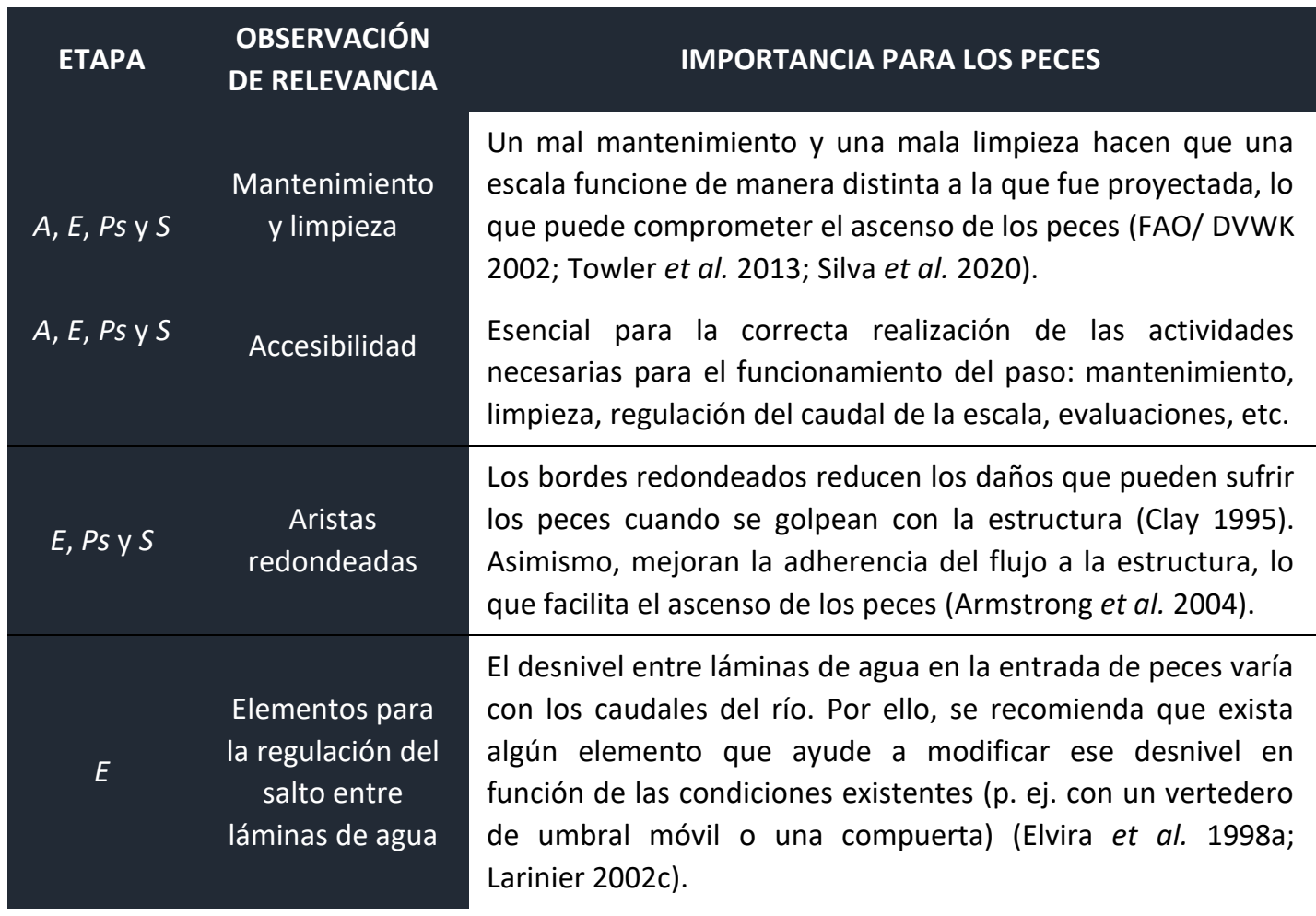




\begin{tabular}{|c|c|c|}
\hline ETAPA & $\begin{array}{l}\text { OBSERVACIÓN } \\
\text { DE RELEVANCIA }\end{array}$ & IMPORTANCIA PARA LOS PECES \\
\hline & $\begin{array}{l}\text { Descargas de } \\
\text { flujo en la } \\
\text { entrada }\end{array}$ & $\begin{array}{l}\text { Existencia de flujos que, junto al de la escala, ayudan a atraer } \\
\text { a los peces a las proximidades del paso (p. ej. rebajes en el } \\
\text { azud, compuertas parcialmente abiertas, tuberías, etc.) }\end{array}$ \\
\hline$E$ & $\begin{array}{l}\text { Ausencia de } \\
\text { otras descargas } \\
\text { de flujo que } \\
\text { alejen al pez de } \\
\text { la entrada }\end{array}$ & $\begin{array}{l}\text { Los peces pueden no ser atraídos hacia un paso y } \\
\text { desorientarse si existen otras corrientes suficientemente } \\
\text { importantes que se liberan alejadas de la entrada (Baudoin et } \\
\text { al. 2015). Esto se traduce en retrasos en los desplazamientos } \\
\text { o en que, incluso, no lleguen a entrar en el paso. }\end{array}$ \\
\hline \multirow{5}{*}{ Ps } & $\begin{array}{l}\text { Deflectores en } \\
\text { los estanques }\end{array}$ & $\begin{array}{l}\text { Los peces pueden desorientarse dentro de los estanques } \\
\text { debido a que el flujo choque a gran velocidad contra las } \\
\text { paredes (Larinier 2002c). Para evitarlo, se recomienda que la } \\
\text { longitud de los estanques (L) varíe entre } 7 \text { y } 12 \text { veces } \beta \text {, } \\
\text { donde } \beta \text { es la anchura de paso ( } b_{P_{s}} \text { ) en hendiduras verticales, } \\
\text { la carga de vertido ( } h \text { ) en vertederos libres, el menor valor de } \\
b_{P_{S}} \text { o } h \text { para vertederos sumergidos, o la menor dimensión de } \\
\text { los orificios entre estanques (Clay 1995; Larinier 2002c). } \\
\text { Además, se aconseja que la anchura de los estanques (B) } \\
\text { oscile entre } 4 \text { y } 8 \text { veces } \beta \text { (Clay 1995; Larinier 2002c). } \\
\text { Los deflectores bien ubicados y suficientemente grandes } \\
\text { ayudan a que no existan turbulencias fuertes en los } \\
\text { estanques que desorienten a los peces (Baudoin et al. 2015), } \\
\text { a la vez que generan zonas de bajas velocidades que sirven } \\
\text { para el descanso (Katopodis } 1992 \text {; Sanz-Ronda et al. 2014). }\end{array}$ \\
\hline & $\begin{array}{c}\text { Conservación de } \\
\text { la estructura }\end{array}$ & $\begin{array}{l}\text { Analiza aspectos que pueden alterar el correcto } \\
\text { funcionamiento del paso tales como fugas de caudal, } \\
\text { tabiques rotos o desplazados, etc. }\end{array}$ \\
\hline & $\begin{array}{l}\text { Solera } \\
\text { naturalizada con } \\
\text { piedras }\end{array}$ & $\begin{array}{l}\text { Piedras fijadas al fondo que aumentan la rugosidad y generan } \\
\text { una mayor variedad de velocidades del flujo, ayudando al } \\
\text { ascenso de los peces con distintas capacidades y ofreciendo } \\
\text { lugares de descanso (FAO/ DVWK 2002; Santos et al. 2012a; } \\
\text { Sanz-Ronda et al. 2014; Baudoin et al. 2015). }\end{array}$ \\
\hline & $\begin{array}{l}\text { Oscuridad por } \\
\text { elementos que } \\
\text { cubren la escala }\end{array}$ & $\begin{array}{l}\text { Puede afectar a la motivación de los peces por ascender el } \\
\text { paso, ya que algunas especies son reacias a pasar por lugares } \\
\text { oscuros o con cambios bruscos de iluminación (FAO/ DVWK } \\
\text { 2002; Armstrong et al. 2004; Baudoin et al. 2015). }\end{array}$ \\
\hline & $\begin{array}{l}\text { Resguardo en } \\
\text { los estanques }\end{array}$ & $\begin{array}{l}\text { Incluso con vertidos sumergidos, los peces pueden pasar } \\
\text { entre estanques nadando o saltando. Por ello, los cajeros } \\
\text { laterales de las escalas deben presentar una altura suficiente } \\
\text { como para que si un pez falla en su salto no caiga fuera del } \\
\text { paso. }\end{array}$ \\
\hline
\end{tabular}




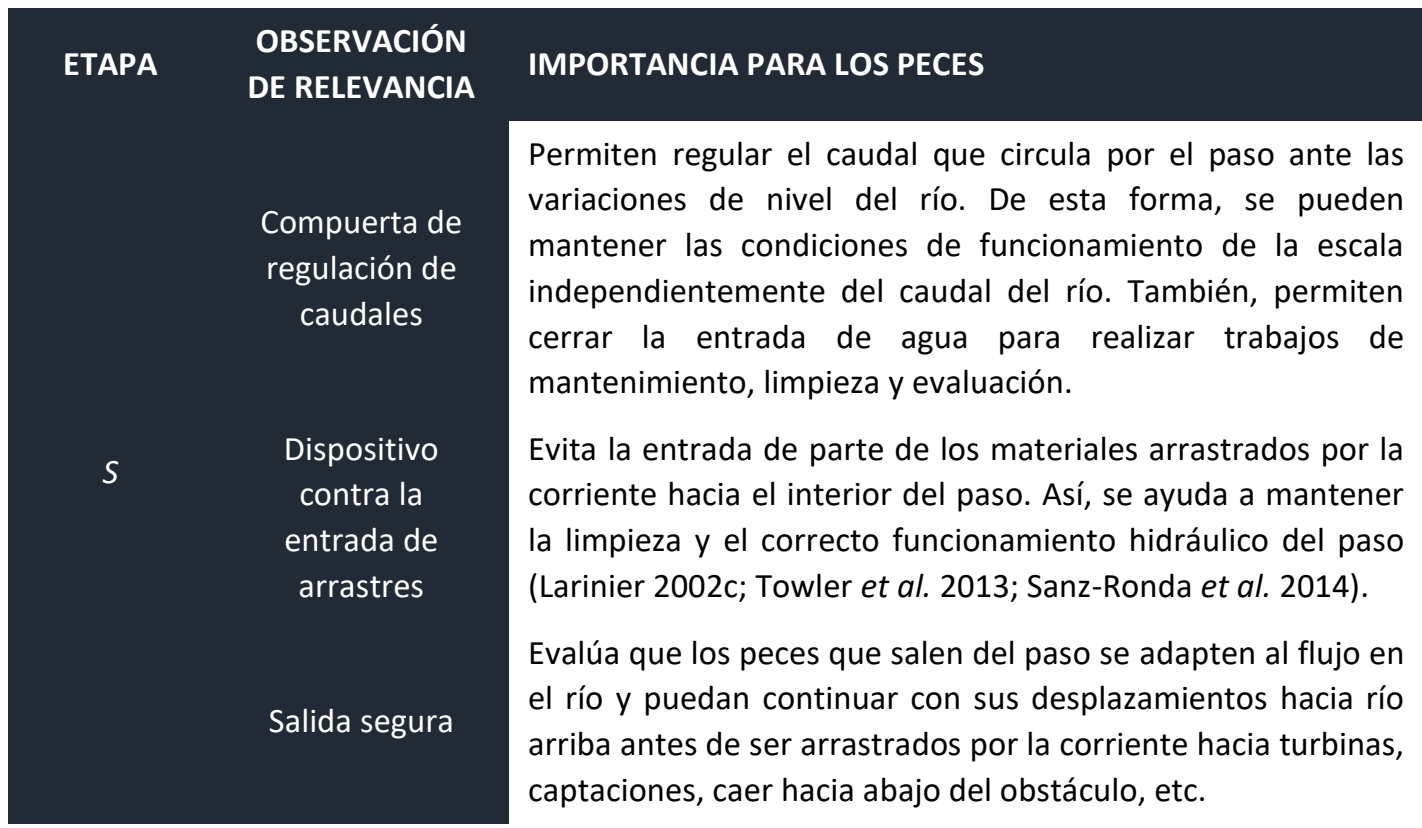

Las observaciones de relevancia se clasifican en tres categorías según su adecuación para las especies objetivo. En función de la categoría en que se incluyan se les asigna una puntuación: 
Tabla 9. Criterios para la puntuación de las observaciones de relevancia.

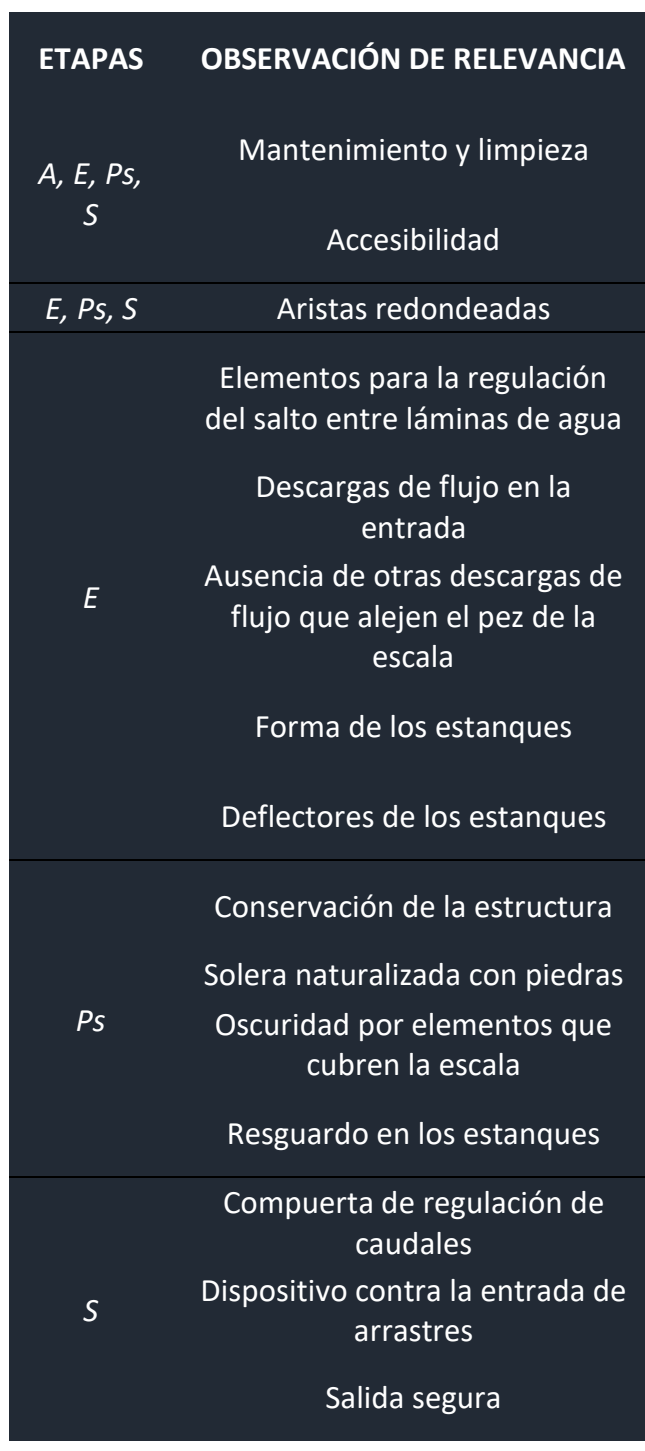

\section{NO ADECUADO/ NO FAVORABLE/ NO EXISTE (O PUNTOS)}

ADECUADO/ FAVORABLE (5 PUNTOS)

MUY ADECUADO/ MUY FAVORABLE (10 PUNTOS)

Obstrucciones impiden completamente el Obstrucciones dificultan, aunque permiten, Obstrucciones no influyen en el ascenso. ascenso.

Acceso a la escala y a su interior complicados. el ascenso.

Ausencia de restos.

Acceso a la escala y a su interior muy fácil.

Ausencia de aristas redondeadas. Solo algunas aristas son redondeadas.

Elementos generan un salto inadecuado.

Ausencia de elementos.

Elementos generan un salto favorable, aunque no idóneo.

No existe un flujo que ayude a la atracción.

Existe un flujo que ayuda ligeramente a la atracción.

Grandes descargas y/o descargas con Descargas con caudal medio-bajo alejadas caudal medio-bajo próximas a la escala.

de la escala.

$\mathrm{Ni} L$ ni $B$ cumplen las recomendaciones de $L$ O $B$ respetan las recomendaciones de diseño: $L: 7-12$ veces $\beta$ y $B: 4-8$ veces $\beta$. diseño.

Ausencia de deflectores.

Deflectores demasiado pequeños y/o con ubicación inadecuada.

Fugas de caudal de relevancia y/o daños Algunas fugas de importancia o daños leves importantes en los tabiques.

Ausencia de piedras. en los tabiques.

Pocas piedras o mala ubicación. Todas las aristas son redondeadas.

Elementos generan un salto idóneo (que puede ser superado por cualquier individuo).

Existe un flujo que ayuda a la atracción.

Ausencia de otras descargas.

Tanto $L$ como $B$ satisfacen las recomendaciones de diseño.

Deflectores con dimensiones y ubicación adecuada.

Oscuridad absoluta en algún tramo.

Oscuridad parcial en algún tramo. daños en los tabiques.

Múltiples piedras.

Ningún tramo en oscuridad.

Resguardos laterales insuficientes en toda la escala $(\leq 20 \mathrm{~cm})$.

Resguardos laterales mínimos en toda la escala (> $20 \mathrm{~cm}-<40 \mathrm{~cm}$ ).

esguardos laterales muy adecuados en toda la escala $(\geq 40 \mathrm{~cm})$.

Ausencia de compuertas.

Ausencia de dispositivo.

Distancia insuficiente a coronación $(<2 \mathrm{~m})$ y a turbinas o captaciones $(<5 \mathrm{~m})$.
No se puede regular adecuadamente el Se puede regular adecuadamente el caudal caudal y/o se dificulta que los peces salgan. y no dificultan que los peces salgan.

Presencia de dispositivo que impide la Presencia de dispositivo que impide la entrada de parte de los elementos. entrada de la mayoría de los elementos.

Distancia suficiente a coronación ( $\geq 2 \mathrm{~m}$ ) o a Distancia adecuada a coronación ( $\geq 2 \mathrm{~m}$ ) y turbinas y captaciones ( $\geq 5 \mathrm{~m}$ ). 


\subsubsection{ETAPAS}

Las puntuaciones de las diferentes variables fundamentales y observaciones de relevancia permiten otorgar una calificación o nota a cada etapa de la escala evaluada. Por un lado, se proponen medias geométricas para cada etapa, calculadas a partir de las puntuaciones de las variables fundamentales (Ec. 13 a(Ec. 16). Las medias geométricas permiten que la valoración global de una etapa sea nula para el ascenso de los peces (0 puntos) si alguno de los parámetros estudiados es completamente limitante. Por otro lado, se plantean medias aritméticas, calculadas con las puntuaciones de las observaciones de relevancia (Ec. 17). Las medias aritméticas hacen que la valoración de una etapa no sea nula ( 0 puntos), aunque alguno de los parámetros evaluados sea muy desfavorable.

$$
\begin{gathered}
A=\left(Q_{\text {atracción }} \cdot U_{E}\right)^{1 / 2} \\
E=\left(\Delta H_{E} \cdot h_{E} \cdot b_{E} \cdot h_{\text {previa } E} \cdot \text { Ort }_{E} \cdot T_{E}\right)^{1 / 6} \\
P S=\left(\Delta H_{P_{S}} \cdot N \cdot t_{\text {med }} \cdot h_{P_{S}} \cdot b_{P_{S}} \cdot T_{P_{S}}\right)^{1 / 6} \\
S=\left(\Delta H_{S} \cdot h_{S} \cdot b_{S} \cdot h_{\text {posterior } S} \cdot \text { Ort }_{S} \cdot T_{S}\right)^{1 / 6} \\
O i=\frac{O_{1 i}+\ldots+O_{n i}}{N_{O i}}
\end{gathered}
$$

donde $O i$ es la puntuación de las observaciones de relevancia de una etapa $i$ en conjunto, $O_{1 i}$ y $O_{n i}$ son la puntuación de las observaciones 1 y $n$ de la etapa, respectivamente, y $N_{o i}$ es el número total de observaciones de esa etapa $i$.

En el pasaje, se calcula la puntuación de cada variable y observación en el estanque tipo, que es aquél que se usa de base para el diseño, y en cada uno de los estanques singulares, que son aquéllos distintos al estanque tipo, si los hubiera. Después, se pondera la puntuación de cada uno de los estanques en función de su cantidad (Ec. 18).

$$
\text { Punt }_{i}=\frac{N_{\text {tipo }} \cdot \text { Punt }_{i_{\text {tipo }}}+\sum \text { Punt }_{i_{\text {singular }}}}{N_{\text {estanques }}}
$$

donde Punt $_{i}$ es la puntuación conjunta de una variable u observación del pasaje, $N_{\text {tipo }}$

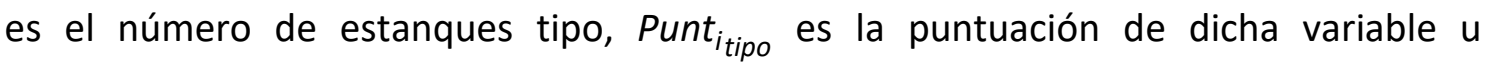




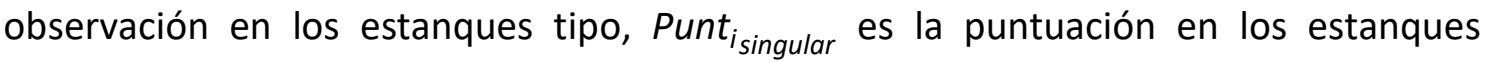
singulares, y $N_{\text {estanques }}$ es el número total de estanques de la escala.

\subsubsection{EVALUACIÓN DE LA EFECTIVIDAD}

La metodología permite interpretar las puntuaciones otorgadas a los diferentes parámetros estudiados a nivel de variable, de observación y de etapa. Presenta un resultado de la evaluación, acompañado por una recomendación para realizar mejoras.

La tabla 10 muestra el sistema para evaluar las puntuaciones de las variables fundamentales por separado o para el conjunto de una etapa:

Tabla 10. Interpretación de las puntuaciones de las variables fundamentales a nivel individual o para el conjunto de las que se consideran en una etapa.

\begin{tabular}{ccc} 
PUNTUACIÓN & RESULTADO DE LA EVALUACIÓN & MODIFICACIONES O MEJORAS \\
\hline $0 \leq$ Parámetro $\leq 4$ & Muy desfavorable & Imprescindibles o evaluación biológica \\
$4<$ Parámetro $\leq 6$ & Desfavorable & Muy necesarias o evaluación biológica \\
$6<$ Parámetro $\leq 8$ & Favorable & Recomendables \\
$8<$ Parámetro $\leq 10$ & Muy favorable & Opcionales
\end{tabular}

A continuación, se muestra el sistema de evaluación para las observaciones de relevancia de forma individual o para una etapa a la vez:

Tabla 11. Interpretación de las puntuaciones de las observaciones de relevancia a nivel individual o para el conjunto de las que se consideran en una etapa.

\begin{tabular}{ccc} 
PUNTUACIÓN & RESULTADO DE LA EVALUACIÓN & MODIFICACIONES O MEJORAS \\
\hline $0 \leq$ Parámetro $<2$ & Muy desfavorable & Muy necesarias \\
$2 \leq$ Parámetro $<5$ & Desfavorable & Necesarias \\
$5 \leq$ Parámetro $<8$ & Favorable & Recomendables \\
$8 \leq$ Parámetro $\leq 10$ & Muy favorable & Opcionales
\end{tabular}

La efectividad general de un paso para peces, es decir, de la escala en su conjunto viene definida por la efectividad de la etapa más desfavorable, que es la que más condiciona el ascenso de los peces por toda la estructura. 


\subsection{APLICACIÓN DE LA METODOLOGÍA AEPS}

La aplicación de la metodología AEPS ha permitido obtener algunos resultados generales referentes a su uso. Su aplicación se ha realizado en dos fases: recopilación de la información en campo, y su análisis y evaluación en gabinete.

Su uso en campo ha demostrado la facilidad de medición y de estudio de todos los parámetros que precisa. Muestra de ello es que la información necesaria de cada una de las escalas evaluadas se ha recogido en campo en un tiempo medio de $1 \mathrm{~h} 30 \mathrm{~min}$, siendo el máximo de $2 \mathrm{~h} 05 \mathrm{~min}$ y el mínimo de $50 \mathrm{~min}$. El tiempo de muestreo de una escala ha dependido del acceso a los distintos puntos de medición y del número de estanques objeto de estudio.

En términos generales, el procesado y evaluación de los datos en gabinete ha sido sencillo, presentando una mayor dificultad el estudio de la ubicación de la entrada $\left(U_{E}\right)$, su orientación $\left(O r t_{E}\right)$ y la de la salida $\left(O r t_{S}\right)$. El tiempo medio empleado en evaluar cada escala ha sido de $1 \mathrm{~h} 25$ min, siendo el máximo de $1 \mathrm{~h} 45$ min y el mínimo de $1 \mathrm{~h}$ 00 min. El tiempo necesario para evaluar una escala en gabinete ha sido independiente de las características hidráulicas y geométricas de la estructura.

Estos datos sirven para estimar el tiempo de aplicación de la metodología (especialmente en los casos en los que se conocen sus características), lo que permite ajustar los tiempos necesarios para recoger la información en campo para futuros trabajos.

A su vez, la aplicación de la metodología a cada una de las ochenta y seis escalas visitadas ha permitido evaluar su efectividad, detectar sus fortalezas y debilidades, e identificar cómo mejorar su funcionamiento. En este apartado se muestran estos resultados analizados desde diferentes puntos de vista (Valbuena-Castro et al. 2020).

\subsubsection{EFECTIVIDAD DE PASO EN LAS ESCALAS EVALUADAS}

La efectividad de cerca del $55 \%$ de los pasos para peces evaluados ha resultado adecuada para el ascenso de los peces (23,2 \% muy favorable y 32,6 \% favorable), mientras que en el $45 \%$ restante ha sido inadecuada por diferentes razones que se analizan posteriormente (4,7 \% desfavorables y $39,5 \%$ muy desfavorables).

Al considerar las cuencas visitadas por separado, vemos que en la cuenca del Duero ( $\mathrm{n}$ $=80$, que son el 35,9\% de los pasos de la cuenca) y del Miera ( $n=2$, que son el 66,6 \%) hubo una tendencia similar a la general, es decir, en torno la mitad de las escalas evaluadas han sido adecuadas (32,5\% favorables y $22,5 \%$ muy favorables en el Duero, y $50,0 \%$ favorables en el Miera), y la otra mitad han sido inadecuadas $(5,0 \%$ desfavorables y $40,0 \%$ son muy desfavorables en la cuenca del Duero, y 50,0 \% muy desfavorables en la del Miera). En la cuenca del Segura $(n=4$, que son el $44,4 \%$ de los 
pasos de la cuenca), la proporción de pasos con una efectividad adecuada ha sido mayor que la de inadecuados (50,0\% muy favorables, 25,0\% favorables, 25,0\% muy desfavorables) (Valbuena-Castro et al. 2020) (Figura 28).
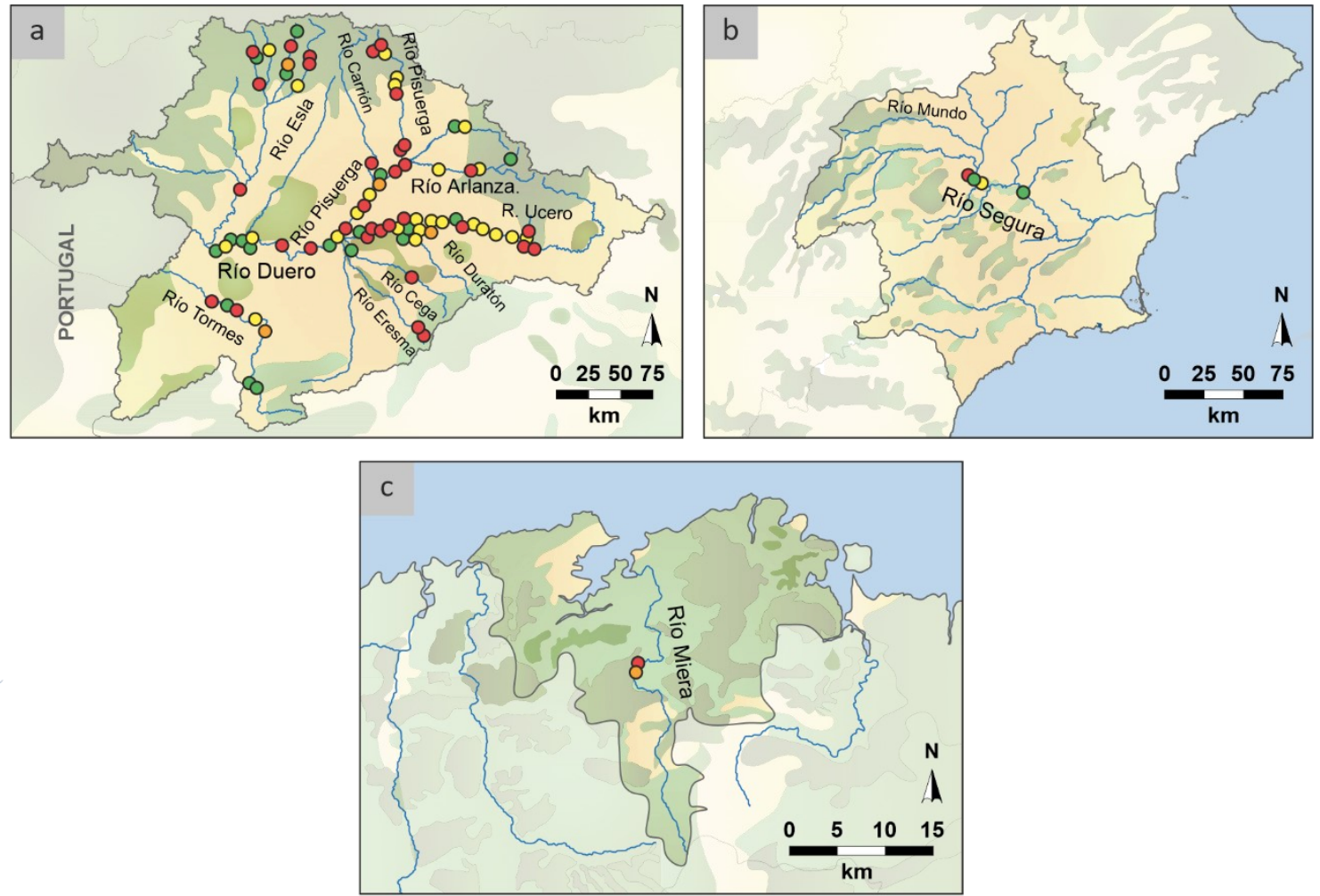

Leyenda:

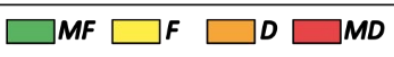

Figura 28. Efectividad general de las escalas para peces evaluadas en las diferentes cuencas hidrográficas: Duero (a), Segura (b) y Miera (c) (MF- muy favorable, $F$ - favorable, $D$ - desfavorable y $M D$ - muy desfavorable).

\subsubsection{EFECTIVIDAD POR ETAPAS Y VARIABLES FUNDAMENTALES}

De acuerdo con los modelos mixtos (véase el anejo "A.5. Análisis de los datos: comandos para aplicar en $\mathrm{R}^{\prime \prime}$ ), las puntuaciones que se asignan a las variables fundamentales no dependen de la etapa en la que son evaluadas. Además, no se han detectado diferencias significativas entre las puntuaciones medias calculadas para las efectividades de las cuatro etapas evaluadas, siendo la salida la que obtuvo una mayor puntuación, seguida por la entrada, la atracción y el pasaje ( $p$-valor $<0,05$ ) (Tabla 12). Una tendencia parecida se ha detectado en la proporción de casos problemáticos de cada etapa. La salida ha presentado pocos casos inadecuados $(17,5 \%)$, seguida de la entrada $(23,5 \%)$, el pasaje $(27,9 \%)$ y la atracción (31,39 \%) (Figura 29) (ValbuenaCastro et al. 2020). 
Tabla 12. Puntuaciones medias y desviaciones estándar de los tipos de escalas y etapas evaluadas. Las letras mayúsculas ( $A, B, C$ y $D)$ hacen referencia a diferencias entre etapas y las letras minúsculas $(a, b$ y c) reflejan diferencias entre tipologías. Letras distintas indican que hay diferencias estadísticamente significativas $(\alpha=0,05)$ ( $H V$ - hendidura vertical, VSO - vertedero con vertido sumergido y orificio, VS vertedero con vertido sumergido, $V L O$ - vertedero con vertido libre y orificio y $V L$ - vertedero con vertido libre).

\begin{tabular}{|c|c|c|c|c|c|c|}
\hline \multirow{2}{*}{ TIPO } & \multirow{2}{*}{$n$} & \multicolumn{4}{|c|}{ ETAPA } & \multirow{2}{*}{$\begin{array}{c}\text { TODAS LAS } \\
\text { ETAPAS }\end{array}$} \\
\hline & & ATRACCIÓN & ENTRADA & PASAJE & SALIDA & \\
\hline$H V$ & 19 & $\begin{array}{c}\text { B a } \\
(8,37 \pm 1,24)\end{array}$ & $\begin{array}{c}\text { B ab } \\
(7,90 \pm 3,53)\end{array}$ & $\begin{array}{c}C b \\
(9,20 \pm 2,27)\end{array}$ & $\begin{array}{c}A a \\
(7,35 \pm 3,41)\end{array}$ & $\begin{array}{c}a \\
(8,21 \pm 1,83)\end{array}$ \\
\hline VSO & 43 & $\begin{array}{c}A B \text { a } \\
(7,38 \pm 1,59)\end{array}$ & $\begin{array}{c}\text { B bc } \\
(8,10 \pm 2,78)\end{array}$ & $\begin{array}{c}\text { BC C } \\
(8,34 \pm 3,42)\end{array}$ & $\begin{array}{c}A b \\
(8,05 \pm 2,71)\end{array}$ & $\begin{array}{c}a b \\
(7,97 \pm 1,57)\end{array}$ \\
\hline VS & 4 & $\begin{array}{c}\text { AC ab } \\
(4,15 \pm 2,90)\end{array}$ & $\begin{array}{c}A B a \\
(8,85 \pm 0,34)\end{array}$ & $\begin{array}{c}\text { ABD b } \\
(2,03 \pm 4,05)\end{array}$ & $\begin{array}{c}A a b \\
(8,38 \pm 0,61)\end{array}$ & $\begin{array}{c}a b \\
(5,85 \pm 1,35)\end{array}$ \\
\hline VLO & 10 & $\begin{array}{c}A B C a \\
(6,50 \pm 2,02)\end{array}$ & $\begin{array}{c}A B \text { a } \\
(4,48 \pm 4,74)\end{array}$ & $\begin{array}{c}A D a \\
(3,55 \pm 4,59)\end{array}$ & $\begin{array}{c}A a \\
(7,05 \pm 3,74)\end{array}$ & $\begin{array}{c}a \\
(5,40 \pm 2,85)\end{array}$ \\
\hline$V L$ & 10 & $\begin{array}{c}\mathrm{Ca} \\
(4,55 \pm 1,91)\end{array}$ & $\begin{array}{c}\text { A a } \\
(3,41 \pm 4,42)\end{array}$ & $\begin{array}{c}D a \\
(2,07 \pm 3,35)\end{array}$ & $\begin{array}{c}A a \\
(5,54 \pm 3,93)\end{array}$ & $\begin{array}{c}a \\
(3,90 \pm 2,26)\end{array}$ \\
\hline $\begin{array}{l}\text { TODOS } \\
\text { LOS TIPOS }\end{array}$ & 86 & $\begin{array}{c}A B \\
(7,02 \pm 2,07)\end{array}$ & $\begin{array}{c}A B \\
(7,12 \pm 3,76)\end{array}$ & $\begin{array}{c}A B C \\
(6,95 \pm 4,28)\end{array}$ & $\begin{array}{c}A \\
(7,50 \pm 3,15)\end{array}$ & \\
\hline
\end{tabular}

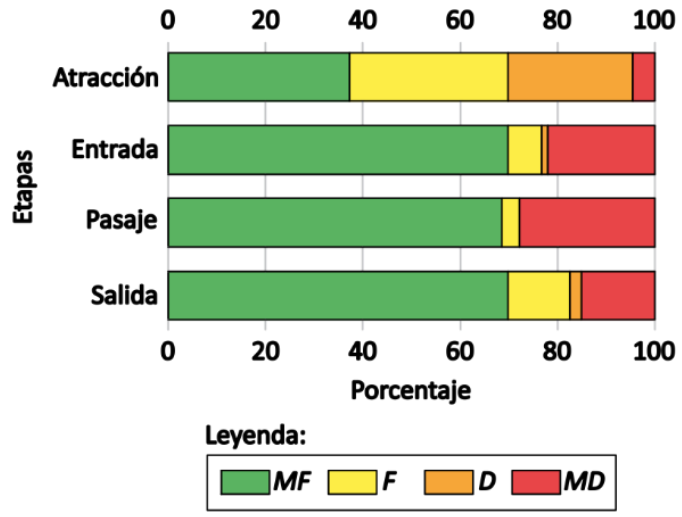

Figura 29. Evaluación de las variables fundamentales estudiadas en cada una de las etapas a superar en los pasos ( $M F$ - muy favorable, $F$ - favorable, $D$ - desfavorable y $M D$ - muy desfavorable).

Atendiendo a las variables fundamentales incluidas en la etapa de atracción, el caudal relativo de atracción (Qatracción) (61,63\% muy favorable y 34,9\% favorable) ha sido adecuado en más casos que la ubicación de la entrada de peces $\left(U_{E}\right)(26,7 \%$ muy favorable y 51,2 \% favorable). En la entrada, la variable más adecuada ha sido la anchura y/o área de la entrada ( $b_{E}$ y/o Área $)$ (93,0 \% muy favorables y 5,8\% favorable). La más adecuada en el pasaje ha sido el tirante medio en los estanques ( $\left.t_{\text {med }}\right)(96,5 \%$ muy favorable y $2,3 \%$ favorable). En la salida ha habido varias variables adecuadas en todas las escalas evaluadas. Esas variables han sido la anchura y/o área de la salida ( $b_{s}$ y/o Áreas) (98,8\% muy favorable y $1,2 \%$ favorable), la profundidad posterior a la salida ( $\left.h_{\text {posterior }} s\right)(97,7 \%$ muy favorable y $2,3 \%$ favorable), y la 
orientación de la salida respecto del río (Orts) (98,8 \% muy favorable y 1,2 \% favorable) (Figura 30).
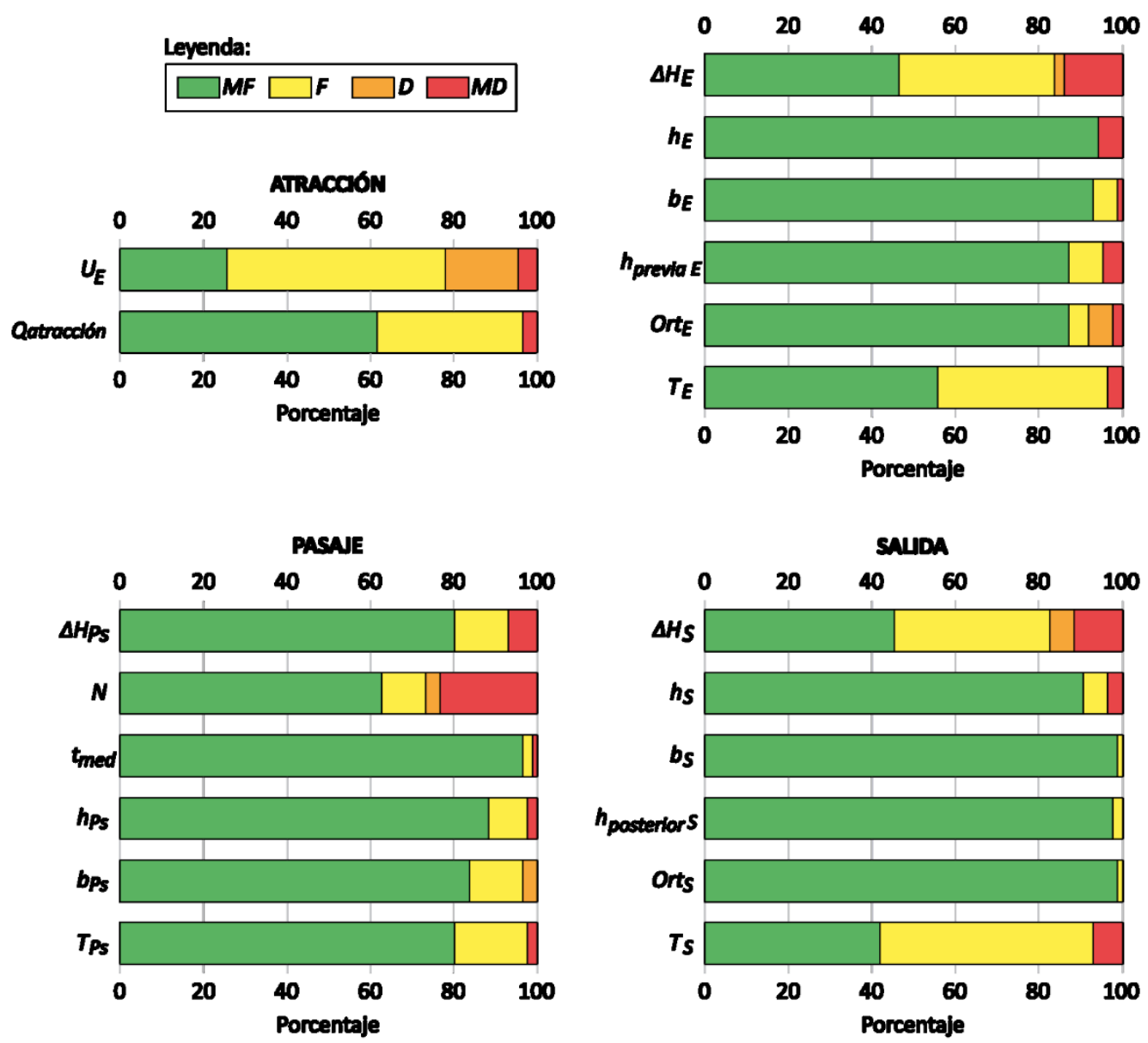

Figura 30. Variables fundamentales evaluadas en las distintas etapas a superar por los peces ( $M F-$ muy favorable, $F$-favorable, $D$ - desfavorable y $M D$ - muy desfavorable) (Ver Tabla 6 para el resto de las abreviaturas).

\subsubsection{EFECTIVIDAD POR TIPO DE ESCALA}

El tipo de escala en base a las conexiones entre estanques ha influido significativamente en la puntuación obtenida por las variables evaluadas. Sin embargo, no se han obtenido diferencias significativas en la puntuación media correspondiente a la efectividad de cada tipo. Las escalas que han obtenido una mayor valoración global han sido las de hendiduras verticales y de vertederos sumergidos con orificios, seguidas de las de vertederos sumergidos únicamente (sin orificios), de las que las que cuentan con vertederos no sumergidos con orificios, y de las que solamente tienen vertederos no sumergidos ( $p$-valor $<0,05$ ) (Tabla 12). Los tipos de escalas han presentado diferentes porcentajes de casos inadecuados, siendo mayor en las escalas que únicamente contaban con vertederos sumergidos (100\%), y vertederos no sumergidos $\sin (100 \%)$ o con orificios (70,0 \%) (Figura 31$)$. 


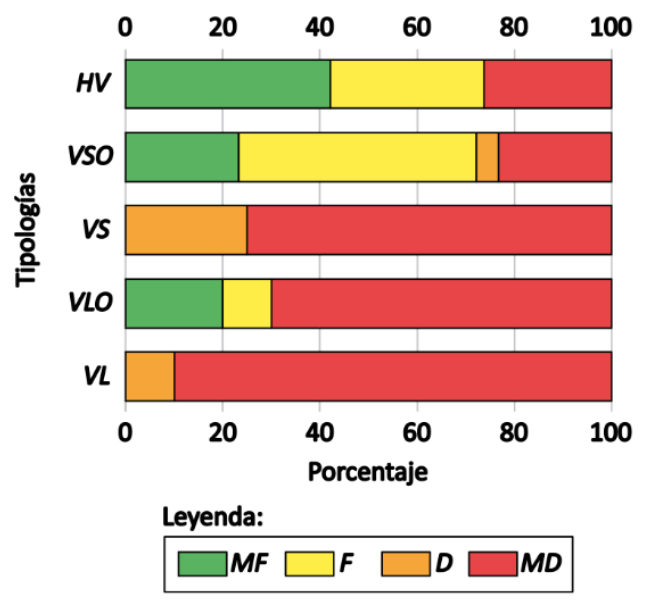

Figura 31. Evaluación de las variables fundamentales en los diferentes tipos de pasos para peces de estanques sucesivos ( $H V$ - hendidura vertical, VSO - vertedero con vertido sumergido y orificio, VS vertedero con vertido sumergido, $V L O$ - vertedero con vertido libre y orificio, $V L$ - vertedero con vertido libre, $M F$ - muy favorable, $F$ - favorable, $D$ - desfavorable y $M D$ - muy desfavorable).

\subsubsection{OBSERVACIONES DE RELEVANCIA}

En el 44,0 \% de los pasos visitados, el conjunto de observaciones de relevancia evaluadas ha sido clasificado como adecuado para facilitar el ascenso de los peces $(3,5$ $\%$ muy favorable y $40,7 \%$ favorable), siendo inadecuado en el $56,0 \%$ restante $(39,5 \%$ desfavorable y $16,3 \%$ muy desfavorable). Atendiendo al conjunto de observaciones estudiadas en cada etapa, las menos problemáticas han sido las de la atracción (5,8 \% inadecuadas), seguidas de lejos por las del pasaje $(20,9 \%)$, la salida $(33,7 \%)$ y la entrada (39,5 \%) (Figura 32).

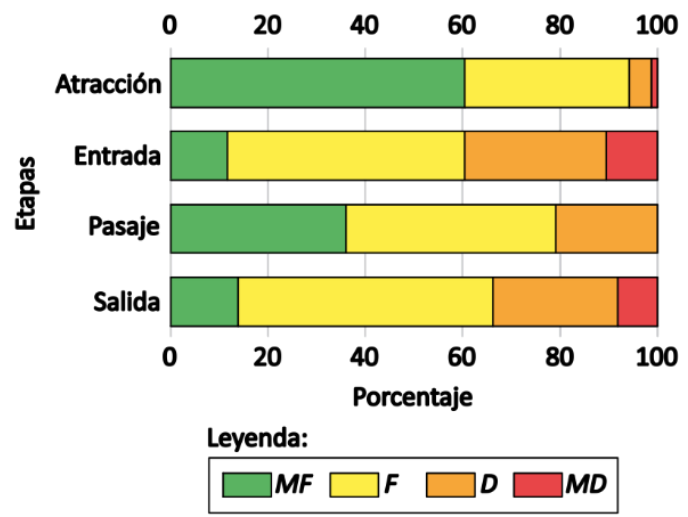

Figura 32. Evaluación de las observaciones de relevancia analizadas en cada una de las etapas a las que se enfrentan los peces en un paso ( $M F$ - muy favorable, $F$ - favorable, $D$ - desfavorable y $M D$ - muy desfavorable). 
Durante las visitas llevadas a cabo, más del 75,0 \% de las escalas para peces evaluadas han presentado una buena accesibilidad y no han contado con ningún problema de mantenimiento o limpieza. Asimismo, se ha observado que más del 65,0 \% de los pasos para peces tienen estanques con características que ayudan al movimiento de los peces a lo largo del pasaje (aristas redondeadas, forma de las artesas, deflectores, conservación, naturalización, luminosidad y resguardos). El 66,3\% de las escalas están equipadas con alguna compuerta para regular el caudal que entra del río; mientras que el 34,9\% tienen algún sistema contra la entrada de restos arrastrados por la corriente dentro del paso (Figura 33).
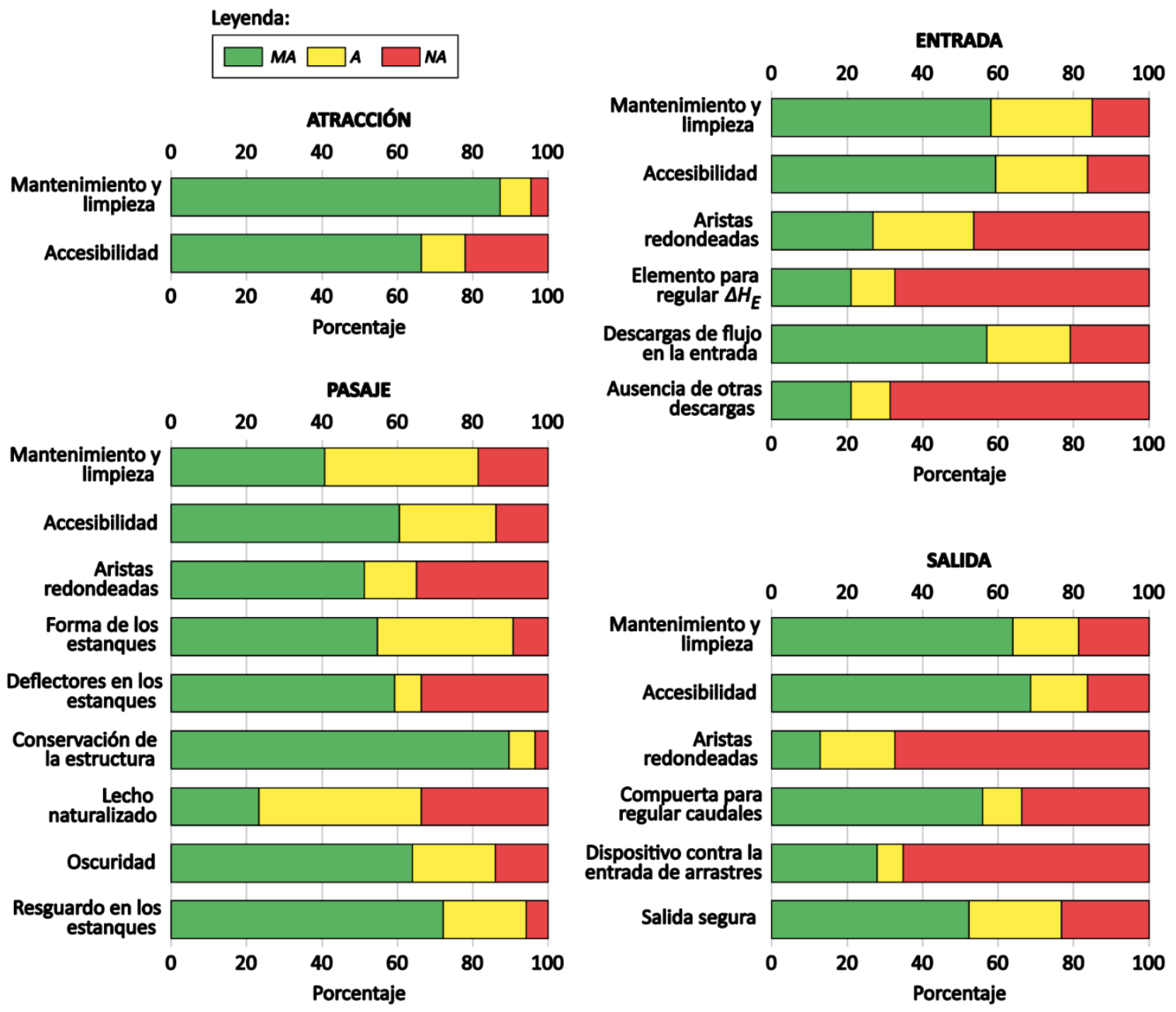

Figura 33. Efectividad de las observaciones de referencia evaluadas según la metodología AEPS en las distintas etapas a superar por los peces ( $M A$ - muy adecuado, $A$ - adecuado, $N A$ - no adecuado y $\Delta H_{E}-$ desnivel entre la lámina de agua del río y del estanque inferior).

\subsubsection{EVOLUCIÓN TEMPORAL DE LA EFECTIVIDAD}

Al analizar las escalas estudiadas en función de la época en que han sido construidas, se aprecia que la mayoría de ellas se han llevado a cabo o han sido modificadas a partir 
del año 2000 (79,1 \%). A lo largo del tiempo se ha producido un cambio en el tipo de escalas ejecutadas. La mayoría de las anteriores al año 2000 han sido de vertederos libres $(44,4 \%)$ o de vertederos libres con orificios $(27,8 \%)$, mientras que a partir de ese año se han realizado generalmente de vertederos sumergidos con orificios $(60,3 \%)$ y de hendiduras verticales (27,9\%), siendo las últimas construidas exclusivamente a partir del año 2000. Las escalas más nuevas han presentado mayor efectividad en las etapas que los peces deben superar y en su funcionamiento general ( $p$-valor $<0,05$ ) (Tabla 13 y figura 34 ).

Tabla 13. Efectividad de los tipos de escalas para peces evaluados (a) y las etapas a superar (b) en función de la época en que han sido construidas ( $H V$ - hendidura vertical, VSO - vertedero con vertido sumergido y orificio, VS - vertedero con vertido sumergido, VLO - vertedero con vertido libre y orificio y $V L$ - vertedero con vertido libre).

\begin{tabular}{|c|c|c|c|c|c|c|c|c|c|c|}
\hline \multicolumn{11}{|c|}{ A) EFECTIVIDAD POR TIPO DE ESCALA } \\
\hline & \multicolumn{2}{|c|}{ HV } & \multicolumn{2}{|c|}{ vso } & \multicolumn{2}{|c|}{ VS } & \multicolumn{2}{|l|}{ VLO } & \multicolumn{2}{|c|}{ VL } \\
\hline & $<2000$ & $\geq 2000$ & $<2000$ & $\geq 2000$ & $<2000$ & $\geq 2000$ & $<2000$ & $\geq 2000$ & $<2000$ & $\geq 2000$ \\
\hline Adecuado & - & $73,7 \%$ & - & $75,6 \%$ & - & $100 \%$ & $20,0 \%$ & $40,0 \%$ & - & - \\
\hline Inadecuado & - & $26,3 \%$ & $100 \%$ & $24,4 \%$ & $100 \%$ & - & $80,0 \%$ & $60,0 \%$ & $100 \%$ & $100 \%$ \\
\hline$n$ & - & 19 & 2 & 41 & 3 & 1 & 5 & 5 & 8 & 2 \\
\hline
\end{tabular}

\begin{tabular}{|c|c|c|c|c|c|c|c|c|c|c|}
\hline \multicolumn{11}{|c|}{ B) EFECTIVIDAD POR ETAPA } \\
\hline & \multicolumn{2}{|c|}{ ATRACCIÓN } & \multicolumn{2}{|c|}{ ENTRADA } & \multicolumn{2}{|c|}{ PASAJE } & \multicolumn{2}{|c|}{ SALIDA } & \multicolumn{2}{|c|}{ GENERAL } \\
\hline & $<2000$ & $\geq 2000$ & $<2000$ & $\geq 2000$ & $<2000$ & $\geq 2000$ & $<2000$ & $\geq 2000$ & $<2000$ & $\geq 2000$ \\
\hline Adecuado & $27,8 \%$ & $79,4 \%$ & $61,1 \%$ & $80,9 \%$ & $33,3 \%$ & $82,4 \%$ & $66,7 \%$ & $86,8 \%$ & $5,6 \%$ & $69,1 \%$ \\
\hline Inadecuado & $72,2 \%$ & $20,6 \%$ & $38,9 \%$ & $19,1 \%$ & $66,7 \%$ & $17,7 \%$ & $33,3 \%$ & $13,2 \%$ & $94,4 \%$ & $30,9 \%$ \\
\hline$n$ & 18 & 68 & 18 & 68 & 18 & 68 & 18 & 68 & 18 & 68 \\
\hline
\end{tabular}

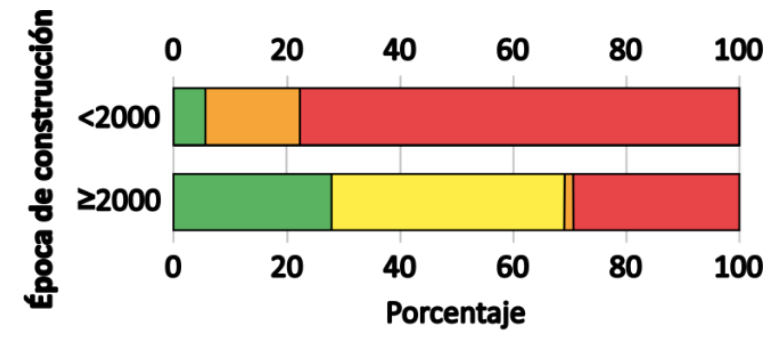

Leyenda:

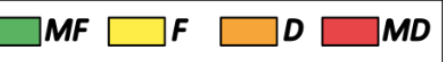

Figura 34. Efectividad de los pasos evaluados en función del momento de su construcción (MF - muy favorable, $F$ - favorable, $D$ - desfavorable y $M D$ - muy desfavorable). 


\section{DISCUSIÓN}




\section{DISCUSIÓN}

\subsection{GENERAL}

En los cursos de agua de todo el planeta existe un gran número de obstáculos transversales que provocan la pérdida de continuidad longitudinal (Nilsson et al. 2005; Katopodis y Williams 2012; Sanz-Ronda et al. 2013). Esta discontinuidad supone una de las principales causas de la disminución o desaparición de los peces (Larinier 1998; FAO/ DVWK 2002; Santos et al. 2002; Sanz-Ronda et al. 2013), ya que impide o dificulta sus desplazamientos, algunos de los cuales son necesarios en sus ciclos biológicos (Lucas et al. 2001; FAO/ DVWK 2002; Porcher y Travade 2002). Con el objetivo de recuperar la continuidad fluvial y permitir los movimientos piscícolas, el ser humano ha construido un gran número de pasos para peces. En Europa, la construcción de estas estructuras ha aumentado especialmente a partir de la entrada en vigor de la Directiva Marco del Agua en el año 2000 (Barry et al. 2018). Sin embargo, se desconoce si la mayoría de ellos cumplen con sus objetivos, puesto que solo una pequeña parte ha sido evaluada (Santos et al. 2002; Roscoe and Hinch 2010; Birnie-Gauvin et al. 2019). Esas evaluaciones han proporcionado resultados muy dispares (Roscoe y Hinch 2010; Bunt et al. 2012; Noonan et al. 2012), mostrando la necesidad de evaluar todas y cada una de estas estructuras (Larinier 1998; Roscoe y Hinch 2010). Para ello, resulta necesario contar con una herramienta práctica que permita evaluar un gran número de pasos para peces, especialmente en el ámbito ibérico, donde la mayoría de los sistemas de evaluación existentes no pueden ser aplicados con fiabilidad por haber sido desarrollados para especies de fuera de la Península.

Esta tesis desarrolla una metodología nueva de evaluación hidráulica (Coarse Fishways Assessment Method, CFAM, en inglés) que analiza muchos parámetros que influyen en el ascenso de los peces a través de las escalas de estanques sucesivos. La metodología se aplica en ochenta y seis escalas emplazadas en tres cuencas hidrográficas en las que habitan varias especies de interés: la trucha común, el barbo común ibérico, el del sur, la boga del Duero, y la del Tajo.

\subsection{METODOLOGÍA AEPS}

La metodología desarrollada en este trabajo evalúa cuarenta y tres parámetros, dentro de las cuatro etapas que los peces deben superar para ascender por una escala de artesas. Estos parámetros son puntuados de 0 a 10 en función de su adecuación. Posteriormente, a partir de la valoración de los parámetros estudiados, calcula una puntuación media para cada etapa. En base a las puntuaciones de los parámetros 
estudiados, la metodología estima sus efectividades y la necesidad de realizar mejoras, llegado el caso.

Se trata de un método general de evaluación hidráulica que se particulariza para tres especies objetivo: la trucha común (Salmo trutta), el barbo común (Luciobarbus bocagei) y la boga del Duero (Pseudochondrostoma duriense). Sin embargo, puede aplicarse a cualquier otra especie con tal de ajustar los sistemas de asignación de puntuaciones a las capacidades y comportamiento del pez objetivo; ya que cada especie presenta características, requerimientos y comportamientos diferentes en estas estructuras (Silva et al. 2017).

La metodología AEPS es un método de evaluación que combina cuestiones hidráulicas y biológicas. Ese doble enfoque, hidráulico y biológico, resulta necesario para comprender en profundidad el funcionamiento de los pasos para peces (Castro-Santos et al. 2009; Roscoe y Hinch 2010; Bravo-Córdoba et al. 2021). Los métodos hidráulicos estiman de manera sencilla, rápida y económica si los peces son potencialmente capaces de utilizar un paso con éxito atendiendo a aspectos geométricos e hidráulicos de un paso (Barry et al. 2018; Valbuena-Castro et al. 2020), lo que les convierte en una herramienta idónea frente a los métodos biológicos para evaluar gran cantidad de estas obras en poco tiempo. Los métodos biológicos se centran directamente en los peces, pudiendo aplicarse a cualquier especie y eliminando ciertas incertidumbres de los procedimientos puramente hidráulicos, como qué individuos superan el paso, cómo lo hacen, cuánto tiempo necesitan, etc.; aunque acarrean un gran esfuerzo humano y económico (Confederación Hidrográfica del Duero 2016; Barry et al. 2018). La metodología AEPS se caracteriza por ser un método hidráulico con una importante base biológica. Así, aparte de la información hidráulica y geométrica que emplean los métodos hidráulicos clásicos, esta metodología considera el funcionamiento de un paso en base a evaluaciones biológicas previas (p. ej. Sanz-Ronda et al. 2016, 2019; Bravo-Córdoba et al. 2018b, 2021). De esta manera, conserva las ventajas características de los métodos hidráulicos, a la vez que reduce sus inconvenientes.

La evaluación de un paso para peces debe atender a todas las etapas que la ictiofauna tiene que superar cuando atraviesa estas estructuras: atracción, entrada, pasaje y salida (Odeh 1999; Castro-Santos et al. 2009; Valbuena-Castro et al. 2020). La metodología AEPS evalúa en base a bibliografía y experiencias de campo cada una de estas etapas, así como los distintos aspectos que influyen en los peces cuando intentan superarlas (Confederación Hidrográfica del Duero 2016). Destaca de otros métodos de evaluación hidráulica por estudiar la totalidad del ascenso de los peces a través de una escala con detalle, fiabilidad, objetividad y rapidez.

Esta metodología es una herramienta que biólogos e ingenieros pueden aplicar de forma generalizada durante todas las fases de una escala (diseño, construcción y funcionamiento), para evaluar su funcionalidad, identificar sus problemas y saber cómo solucionarlos. De manera que puede ayudar en la toma de decisiones y a priorizar los recursos empleados en la restauración fluvial a gran escala. No obstante, es necesario seguir investigando sobre este tema. En concreto, se necesita continuar 
comparando evaluaciones biológicas con métodos hidráulicos para mejorarlos y hacerlos más fiables. Además, se precisa de un mayor conocimiento sobre los peces ibéricos para adaptar los métodos de evaluación y poderlos aplicar en más tipologías de paso, especies y regiones.

\subsection{APLICACIÓN DE LA METODOLOGÍA AEPS}

En este estudio se ha aplicado la metodología AEPS para evaluar ochenta y seis escalas para peces situadas en diferentes cuencas hidrográficas de la Península Ibérica. Cerca de la mitad de ellas presentan deficiencias que dificultan el ascenso de las especies objetivo. Esas dificultades se han concentrado especialmente en la atracción y en el pasaje, así como en las escalas que tienen sus estanques conectados únicamente por vertederos sumergidos, o por vertederos no sumergidos $\sin y$ con orificios. Los resultados también reflejan que las escalas más nuevas son las más efectivas. Con todo y a pesar de que la efectividad ha mejorado con el paso del tiempo, todavía resulta necesario evaluar el funcionamiento de un gran número de estas estructuras y mejorar algunas de ellas.

\subsubsection{EVALUACIÓN DE LAS ESCALAS Y DE LOS TIPOS}

La efectividad general de las escalas evaluadas ha revelado que cerca del $55 \%$ son adecuadas para el ascenso de las especies objetivo. Algunos trabajos realizados en la Península Ibérica han llegado a resultados similares. Elvira et al. (1998b) concluyen que el 59 \% de las escalas que han estudiado en España permitían el paso de los peces. Santo (2005) señala que el 78 \% de las escalas de estanques que ha estudiado en diferentes cuencas de Portugal funcionan de manera favorable para la fauna piscícola. Ordeix et al. (2011) y Solà et al. (2011) han observado que en torno al 55 \% de los pasos para peces que han evaluado en Cataluña resultan adecuados. Santos et al. (2012b) han encontrado que el $49 \%$ de los que han estudiado en Portugal son aptos. Por el contrario, Boné-Puyo y Langa-Sánchez (2011) han concluido que solo el $18 \%$ de los que han analizado en la cuenca del Ebro han resultado favorables. Recientemente, Navarro-Barquero y Boné-Puyo (2018) elevan ligeramente el porcentaje de pasos funcionales en esa cuenca hasta el $21 \%$. Las diferencias encontradas entre todos los pasos de las distintas cuencas pueden deberse al método de evaluación empleado, al criterio del propio evaluador, a la época de construcción de la escala, a la cuenca donde se sitúan las escalas, a los peces objetivo, entre otros aspectos.

En este trabajo se percibe un cambio en la efectividad de las escalas con el paso del tiempo. Así, las escalas más recientemente construidas son más favorables para los movimientos de los peces. Esta mejora puede deberse a que a lo largo de los años ha aumentado el conocimiento de las especies piscícolas (p. ej. Romão et al. 2012; Castro- 
Santos et al. 2013; Sanz-Ronda et al. 2015b; Ruiz-Legazpi et al. 2018), su comportamiento en los pasos para peces (Sanz-Ronda et al. 2016, 2019; BravoCórdoba et al. 2018a,b), a que se sabe más sobre el funcionamiento hidráulico de las propias escalas (p. ej. Fuentes-Pérez et al. 2017; Quaresma et al. 2018), a que se ha generalizado el uso de guías de diseño (p. ej. Clay 1995; Martínez de Azagra-Paredes 1999; FAO/ DVWK 2002; Larinier 2002c), o a que los organismos responsables de los ríos han incrementado el control del diseño y ejecución de este tipo de obras (SanzRonda et al., 2013).

La mejora de la efectividad con el paso de los años también podría deberse a un cambio de tendencia en el tipo de escalas construidas. Los resultados han mostrado que con el paso del tiempo se ha tendido a construir escalas con estanques conectados por vertidos sumergidos, más concretamente de hendiduras verticales $(H V)$ y de vertederos sumergidos con orificios (VSO). El vertido sumergido permite el paso de los peces entre estanques nadando con poco esfuerzo, lo que favorece a los individuos o especies con menores capacidades de nado y de salto (Elvira et al. 1998a; Aigoui et al. 2008). Las escalas $H V$ y VSO presentan buena auto-regulación ante los cambios de caudal y obstrucciones (Clay 1995; Martínez de Azagra-Paredes 1999; Larinier 2002c), así como ante problemas debidos a pequeñas desviaciones del proyecto original durante su construcción (Fuentes-Pérez et al. 2014, 2016). Además, se ha demostrado que permiten el paso de los ciprínidos ibéricos y la trucha común sin dificultades (Silva et al. 2009; Sanz-Ronda et al. 2016; Bravo-Córdoba et al. 2018b,a, 2021). Por todo ello, suponen la alternativa más interesante a la hora de construir o mejorar una escala en ríos ibéricos con distintas especies (Silva et al. 2009; Santos et al. 2012b; Branco et al. 2013; Sanz-Ronda et al. 2016).

\subsubsection{EVALUACIÓN DE LAS ETAPAS Y DE LAS VARIABLES FUNDAMENTALES}

Se han identificado distintas variables como la causa de muchos de los problemas del funcionamiento de las escalas: falta de caudal de atracción, problemas en la localización de la entrada, condiciones hidráulicas inadecuadas en el interior del paso, o problemas de mantenimiento (Larinier 2001; FAO/ DVWK 2002; Williams et al. 2012). En nuestro caso, los modelos mixtos han demostrado que la efectividad de cualquier variable fundamental depende de las características específicas de los pasos (tipo de escala, geometría, e hidráulica) y no de la etapa en que ha sido estudiada. Esas etapas no han mostrado diferencias significativas entre sus puntuaciones medias, aunque la atracción y el pasaje han sido las peor valoradas.

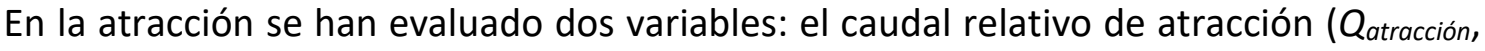
con un $3,5 \%$ de las escalas inadecuadas) y la ubicación de la entrada de peces $\left(U_{E}\right.$, con el 22,1\%). Los resultados indican que una parte importante de las entradas estudiadas no se ubicaban en los lugares más idóneos, es decir, lo más aguas arriba que permita el obstáculo, cerca de su base y de la orilla, y en la parte de la sección donde circula un 
mayor caudal (Larinier 2002b; Williams et al. 2012). En consecuencia, se dificulta que los peces sean capaces de encontrar la entrada de un paso con facilidad y sin retrasos, lo que puede comprometer el éxito de toda la estructura. Algunos trabajos previos han indicado que estas dos variables son la principal causa de fracaso del funcionamiento de los pasos para peces (p. ej. Larinier et al. 2005; Bunt et al. 2012; Williams et al. 2012). De hecho, Bunt (2001) ha mejorado significativamente la eficiencia de la atracción de dos escalas modificando únicamente la entrada de peces. Por ello, resulta de especial interés prestar atención a estas variables a la hora de diseñar y construir una escala para peces.

Los problemas detectados en el pasaje han estado relacionados mayoritariamente con la potencia disipada por unidad de volumen ( $N$, con un $26,8 \%$ de escalas inadecuadas). Esta variable se relaciona con la turbulencia en los estanques de una escala y es un factor clave en el paso de los peces (Larinier 2002c; Castro-Santos et al. 2009; BravoCórdoba et al. 2021). $N$ debe variar en un rango de valores que facilite el movimiento de los peces (Goettel et al. 2015). Valores grandes conllevan una fuerte aireación de las aguas, turbulencias y recirculaciones que pueden desorientar a los peces (Larinier 2002c; Odeh et al. 2002; Silva et al. 2012) y dificultar su natación (Enders et al. 2005). Se ha visto que esos valores provocan retrasos y selección en los individuos de trucha, barbo común y boga del Duero que consiguen ascender por una escala (Silva et al. 2012; Sanz-Ronda et al. 2016). Por el contrario, valores reducidos favorecen el ascenso de la trucha, el barbo y la boga (Bravo-Córdoba et al. 2021). $N$ se calcula a partir de varias variables, dos de las cuales $\left(\Delta H_{P_{s}}\right.$ y $\left.t_{m e d}\right)$ son estudiadas de manera independiente por la metodología AEPS, obteniendo mejores resultados en las escalas visitadas. Por tanto, los problemas detectados en los valores de $N$ se deben a las otras variables de las que depende, siendo frecuentes un exceso de caudal y/o un escaso volumen de agua de los estanques (es decir, a un tamaño demasiado pequeño de las artesas).

Además de $N$, la variable más limitante del pasaje ha sido el desnivel entre las láminas de agua de los estanques ( $\Delta H_{P_{S}}$, inadecuada en el $7,0 \%$ de los casos), que se relaciona con la velocidad del agua y la turbulencia (Fuentes-Pérez et al. 2016). Esta variable tiene un efecto directo sobre el ascenso de las especies objetivo a través de las escalas de estanques sucesivos (Bravo-Córdoba et al. 2021). Desniveles grandes pueden superar las capacidades de nado y de salto de los peces, provocando retrasos o selección de los individuos que ascienden (Larinier, 2002a; Sanz-Ronda et al., 2016), mientras que si son pequeños pueden ir asociados a turbulencias reducidas y causar una pérdida de motivación y de orientación (Castro-Santos et al. 2013; Goettel et al. 2015; Bravo-Córdoba et al. 2021). La metodología AEPS no penaliza los desniveles reducidos en el pasaje, los cuales además son poco habituales (Fuentes-Pérez et al. 2016), por lo que los problemas detectados se deben a saltos excesivos, fruto de errores de diseño y construcción, o de obstrucciones que alteran el normal funcionamiento hidráulico del paso. 
La variable más problemática en la entrada y en la salida ha sido el desnivel entre las láminas de agua de los estanques y el río ( $\Delta H_{E}$ inadecuado en el $16,3 \%$ de las escalas y $\Delta H_{s}$ en el $\left.17,4 \%\right)$. Por un lado, Williams et al. (2012) recomiendan desniveles grandes y/o vertidos libres para favorecer la atracción, aunque no deben superar las capacidades de nado y salto de los peces (Castro-Santos et al. 2013; Sanz-Ronda et al. 2015c; Ruiz-Legazpi et al. 2018). Por otro lado, desniveles demasiado pequeños pueden causar en los peces una pérdida de atracción (Larinier 2002b). Por ello, para especies reófilas se aconsejan desniveles que hagan que el flujo tenga una velocidad mayor a 1,0 m/s (Larinier 2002b), y no superen $2,4 \mathrm{~m} / \mathrm{s}$ en vertidos sumergidos y 3,0 $\mathrm{m} / \mathrm{s}$ en vertidos libres (Martínez de Azagra-Paredes 1999; FAO/ DVWK 2002; Larinier 2002c). Los problemas de estas variables podrían deberse a cambios en el caudal del río, lo que lleva asociado variaciones de los niveles de agua no consideradas en el diseño y durante el funcionamiento de la escala, así como a errores y cambios en la sección de control del río durante la construcción (Fuentes-Pérez et al. 2014; Valbuena-Castro et al. 2020).

\subsubsection{EVALUACIÓN DE LAS OBSERVACIONES DE RELEVANCIA}

El conjunto de observaciones de relevancia evaluadas en cada escala ha sido favorable para el ascenso de los peces en cerca de la mitad de los casos (44,0 \%). Estos parámetros deben considerarse durante el diseño, construcción, funcionamiento y evaluación de cualquier paso para peces, ya que influyen en el éxito o fracaso de los peces cuando intentan superar las estructuras. Sin embargo, las referencias sobre estos parámetros son escasas, mostrando la necesidad de llevar a cabo nuevos trabajos para conocer con más detalle sus efectos sobre la ictiofauna.

Más de tres cuartas partes de las escalas para peces evaluadas han contado con un acceso fácil, y no han presentado problemas de mantenimiento o limpieza que afectasen a su funcionamiento. Los resultados obtenidos para las dos observaciones indican una posible relación entre la facilidad para acceder a las escalas y un mantenimiento y limpieza adecuados, tal y como han indicado anteriormente FAO/ DVWK (2002) y Santo (2005). La diferencia entre las dos observaciones en la etapa de atracción podría deberse a que las crecidas de los ríos limpian los restos arrastrados por los caudales ordinarios, pudiendo hacer necesario un mantenimiento y limpieza menos exhaustivo que en el resto de etapas.

Es frecuente que los pasos cuenten con un caudal complementario suficiente como para ayudar a atraer a los peces hacia la entrada (57,0 \% muy adecuados y $22,1 \%$ adecuados). Estos caudales ayudan a que los individuos encuentren el paso de manera más fácil y rápida. Más de la mitad de las escalas cuentan con aristas redondeadas en la entrada (26,7 \% muy adecuados y $26,7 \%$ adecuados) y en el pasaje (51,2 \% muy adecuados y $14,0 \%$ adecuados), aunque solo cerca de un tercio de ellas las presentan en la salida (12,8\% muy adecuados y $19,8 \%$ adecuados). Este tipo de aristas ayudan al 
ascenso de los peces al adherir mejor el flujo a la estructura (Armstrong et al. 2004), y al reducir el riesgo de sufrir daños al pasar entre estanques (Clay 1995).

Los deflectores encontrados en los estanques de muchas escalas (59,3 \% muy adecuados y $7,0 \%$ adecuados) han sido adecuados para ofrecer a los peces lugares en los que descansar (Katopodis 1992; Sanz-Ronda et al. 2014), y evitar que el agua realice recirculaciones que los desorienten (Baudoin et al. 2015). Muchas escalas cuentan con naturalización en las artesas mediante la instalación de piedras embebidas en la solera (23,3\% muy adecuados y 43,0 \% adecuados). Esta medida ayuda a los movimientos de las distintas especies al hacer que el flujo presente velocidades más heterogéneas y zonas de descanso (FAO/ DVWK 2002; Larinier 2002c; Baudoin et al. 2015), y facilita el ascenso de especies bentónicas y pequeños ejemplares (Santos et al. 2014).

Parte de las escalas visitadas cuentan en su entrada con elementos para regular el desnivel entre la lámina de agua del río y la del estanque inferior (20,9 muy adecuados y $11,6 \%$ adecuados). Una mayor proporción de ellas presenta alguna compuerta en la salida para regular los caudales que circulan por el paso $(55,8 \%$ muy adecuados y 10,5 $\%$ adecuados). La instalación de este tipo de elementos permite mantener las condiciones hidráulicas de las escalas dentro de su rango de funcionamiento óptimo, independientemente de los cambios de nivel y de caudal de los ríos (Clay 1995; Elvira et al. 1998a; Larinier 2002c). Además, las compuertas sirven para cerrar el paso de agua y facilitar las labores de mantenimiento y limpieza, entre otras. Estas labores pueden simplificarse y reducirse colocando un dispositivo que funcione contra la entrada de restos arrastrados por la corriente, tal y como se ha observado en algunos casos ( $27,9 \%$ muy adecuados y $7,0 \%$ adecuados).

Todas estas observaciones afectan directa o indirectamente a los peces y a su ascenso, por lo que es muy importante prestar atención a estos detalles. Aunque puede hacerse en cualquier momento, se recomienda que sean resueltos antes de acabar las obras por razones de sencillez y economía.

\subsubsection{OTRAS CONSIDERACIONES}

De forma tradicional, se consideraba especialmente importante que las escalas funcionasen correctamente al menos durante las migraciones con fines reproductivos de la fauna piscícola (Larinier 2002c; Armstrong et al. 2004). Sin embargo, estas estructuras deben funcionar durante todo el año (Martínez de Azagra-Paredes 1999; FAO/ DVWK 2002), puesto que se ha demostrado que las especies ibéricas se desplazan y las utilizan en todas las épocas del año (García-Vega et al. 2017, 2018, 2021; Sanz-Ronda et al. 2021). No obstante, tal y como se ha observado en parte de las escalas evaluadas en esta tesis, su funcionamiento puede variar a lo largo del tiempo como consecuencia de un mantenimiento deficiente y de cambios en los caudales de 
los ríos (Fuentes-Pérez et al. 2014). Esto demuestra la necesidad de evaluar este tipo de obras en diferentes épocas del año para asegurar el paso de los peces siempre que lo deseen.

La metodología AEPS se ha utilizado en tres cuencas hidrográficas con varias especies objetivo. En la cuenca del Duero han sido la trucha común (Salmo trutta), el barbo común (Luciobarbus bocagei) y la boga del Duero (Pseudochondrostoma duriense), en la del Segura han sido el barbo del sur (Luciobarbus sclateri) y la boga del Tajo (Pseudochondrostoma polylepis), y en el Miera ha sido la trucha. En general, existe un conocimiento reducido sobre las especies piscícolas ibéricas (capacidades de nado, salto, comportamiento, etc.) y cómo se comportan en los pasos (Sanz-Ronda et al. 2016; Bravo-Córdoba et al. 2018b; Silva et al. 2020). Por ello, la metodología AEPS ha sido diseñada inicialmente para tres de las más conocidas: la trucha común, el barbo común y la boga del Duero. No obstante, existen similitudes entre esas y las demás especies objetivo al atravesar las escalas (Kottelat y Freyhof 2007; Doadrio et al. 2011; Romão et al. 2012; Branco et al. 2017a; Sanz-Ronda et al. 2019), que permiten aplicar la metodología en todos los casos considerados en esta tesis.

La aplicación de la metodología AEPS ha permitido evaluar la efectividad de varias escalas para peces en la Península Ibérica. Este trabajo sirve para conocer cómo funcionan estas estructuras y sus efectos en la continuidad longitudinal de los cauces y los desplazamientos de los peces. Además, puede ser utilizado por gestores para identificar problemas en otras escalas, saber cómo solucionarlos y prevenirlos. Las diferencias encontradas entre los casos y las cuencas estudiadas muestran la necesidad de seguir estudiando todas las escalas construidas. Asimismo, se aconseja llevar a cabo investigaciones y acciones ( $p$. ej. control detallado de nuevos proyectos y su ejecución) que eviten en las escalas que se construyan en el futuro las deficiencias del pasado. 


\section{CONCLUSIONES}




\section{CONCLUSIONES}

A continuación, se muestran las conclusiones generales derivadas de los apartados anteriores de esta tesis. A pesar de ser el final de este documento, estas conclusiones abren la puerta a trabajos e investigaciones futuras, algunas de las cuales se recogen en el apartado "8. Líneas de trabajo futuro".

\subsection{SOBRE LA METODOLOGÍA AEPS}

1. La metodología AEPS evalúa de manera objetiva el funcionamiento de las escalas de estanques sucesivos en base a información hidráulica y biológica, a la vez que identifica posibles problemas y ayuda a solucionarlos.

2. Esta metodología conserva las ventajas que presentan los métodos de evaluación hidráulicos CFAM frente a los métodos biológicos (sencillez, rapidez y economía de aplicación) sin renunciar a la objetividad de sus resultados.

3. La metodología analiza en detalle múltiples aspectos que influyen en los peces cuando se enfrentan a las distintas etapas a superar en un paso (atracción, entrada, pasaje y salida).

4. Aunque la metodología se haya desarrollado para estudiar pasos para peces ya ejecutados, también puede resultar útil en las fases previas de diseño y ejecución, al orientar al proyectista, al constructor y al supervisor de la obra sobre las pautas correctas a seguir.

5. La metodología puede ser aplicada a otras especies de peces sin más que adaptar los criterios de asignación de puntos para ellas, conforme a sus aptitudes y necesidades biológicas particulares.

\subsection{SOBRE LA APLICACIÓN DE LA METODOLOGÍA AEPS}

1. Parte de las escalas evaluadas presenta deficiencias en su funcionamiento, demostrando la necesidad de evaluar todas estas estructuras para conocer si la fauna piscícola puede superarlas con éxito.

2. La efectividad de las escalas mejora con el paso del tiempo, lo cual se debe a un mayor conocimiento sobre su diseño, de los peces y su comportamiento cuando ascienden por estas estructuras, y a un mayor control de los proyectos y de las obras. 
3. El éxito de un paso para peces depende de todos sus parámetros que influyen en los movimientos de la fauna piscícola, siendo necesario analizar todos esos aspectos en cualquier evaluación.

4. Las escalas evaluadas presentan problemas debidos a fallos cometidos durante las fases de diseño, construcción o funcionamiento, lo que demuestra la necesidad de evaluar este tipo de obras en cada una de esas fases.

5. La efectividad de los pasos puede variar a lo largo del año debido a los cambios hidrológicos de los ríos, lo que indica que este tipo de obras se deben evaluar en diferentes momentos o dentro de un rango de caudales para los cuáles deberían ser funcionales. 


\section{CONCLUSIONS}




\section{CONCLUSIONS}

The general conclusions derived from the previous sections of this thesis are presented below. Despite that they are the end of the document, these conclusions open the door to future works and investigations, some of which are included in the section " 8 . Líneas de trabajo futuro".

\subsection{ABOUT THE AEPS METHODOLOGY}

1. The AEPS methodology objectively evaluates the performance of the stepped fishways based on hydraulic and biological information, while it identifies the potential problems and helps to solve them.

2. This methodology retains the advantages of the hydraulic assessment methods CFAM over the biological methods (easy, fast and economical application) without sacrificing the objectivity of the results.

3. The methodology analyzes in detail multiple aspects that influence fish when they face the different stages to overcome in a fish pass (attraction, entry, passage and exit).

4. Although the methodology has been developed to study fish passes already executed, it can also be useful in previous design and construction phases by guiding the designer, the builder and the construction supervisor on the correct guidelines to follow.

5. The methodology can be applied to other fish species just modifying the scoring systems to them, according to their specific biological aptitudes and needs.

\subsection{ABOUT THE APPLICATION OF THE AEPS METHODOLOGY}

1. Some of the assessed fishways present deficiencies in their performance, demonstrating the need to evaluate all these structures to know if the fish fauna can successfully overcome them.

2. The effectiveness of the fishways improves over time, which is due to a knowledge increase of their design, of fishes and their behavior when they ascend through these structures and better control of projects and constructions. 
3. The success of fish passes depends on all their parameters that influence the movements of fish fauna, being necessary to analyze all these aspects in any evaluation.

4. The assessed fishways present problems due to failures committed during the stages of design, construction and operation, demonstrating the need to evaluate these structures in each one of the phases.

5. The effectiveness of the fish passes can vary throughout the year due to the hydrological changes of the rivers, indicating that these constructions must be evaluated in different moments of the year or within a range of flows for which they must be functional. 


\section{LÍNEAS DE TRABAJO FUTURO}




\section{LÍNEAS DE TRABAJO FUTURO}

Esta tesis ha intentado dar respuesta a algunas de las preguntas que existen en torno a los pasos para peces y su evaluación: ¿los métodos hidráulicos permiten evaluar pasos para peces?, ¿estas estructuras funcionan de manera adecuada?, ¿'ese funcionamiento ha mejorado con el paso del tiempo?, ... Sin embargo, como ya se intuye, este trabajo no supone un punto final, puesto que todavía quedan muchas incógnitas dentro de la temática que requieren nuevos trabajos y líneas de investigación.

Los pasos para peces son esenciales para mitigar los impactos de los obstáculos construidos en los ríos y conservar las poblaciones piscícolas a lo largo del tiempo. Aun así, hoy en día, sólo se sabe cómo funciona una pequeña parte ellos. Por ello, se deben seguir evaluando con el objetivo de comprender cómo afectan a los peces, mejorar las estructuras ya existentes y optimizar las que se realicen en el futuro. Asimismo, tradicionalmente, la mayoría de las evaluaciones se centraban en el ascenso de los individuos. Sin embargo, se sabe que la ictiofauna puede utilizar los pasos tanto para realizar movimientos hacia aguas arriba como hacia aguas abajo. Aunque es necesario seguir evaluando el ascenso, también se deben promover investigaciones que ayuden a conocer el uso que hacen los peces de los pasos durante sus movimientos descendentes.

De manera idónea, la recuperación de la continuidad longitudinal de los cauces pasa porque la ictiofauna sea capaz de superar todos los obstáculos que haya en su camino. Sin embargo, la mayoría de los trabajos de evaluación estudian los pasos para peces de manera puntual, olvidando que la fauna piscícola realiza desplazamientos a lo largo de los cursos de agua de decenas, cientos o miles de kilómetros. Por tanto, resulta necesario evaluar todos los obstáculos de un curso de agua a los que se enfrentan los peces, con el fin de saber si los esfuerzos realizados consiguen recuperar la continuidad total del curso o solo de ciertos tramos.

Los métodos de evaluación hidráulicos son una excelente alternativa para llevar a cabo esa tarea. Estos métodos estiman la efectividad de un paso para peces de manera indirecta sin atender a los propios peces, lo que les aporta ciertas ventajas (rapidez, economía, etc.), aunque también tienen ciertos inconvenientes (subjetividad, incertidumbre, etc.). Para reforzarlos, sus criterios de evaluación deben validarse y ajustarse comparándolos con información biológica. Entre las alternativas que ofrecen esta información, resultan especialmente interesantes aquéllas que estudian cómo la ictiofauna utiliza realmente los pasos, tal y como hace la telemetría con etiquetas PIT. De este modo, los métodos hidráulicos contarán con una mayor fiabilidad que fomentará su uso.

Independientemente de los métodos de evaluación utilizados, existen múltiples incógnitas sobre la fauna piscícola y cómo utiliza los pasos para peces (tamaños y especies que los utilizan, preferencias, etc.). Además de las investigaciones llevadas a 
cabo hasta el momento, se requieren nuevos estudios que ayuden a conocer con más detalle los aspectos hidráulicos, geométricos y biológicos que influyen en el movimiento de los peces por estas estructuras, prestando especial atención a las particularidades de las distintas tipologías de pasos y especies. Conociendo la relación existente entre estas estructuras y la fauna, se podrán establecer criterios sólidos para evaluar el grado de adecuación de las características de cualquier tipología de paso para las diferentes especies. Así, se obtendrán métodos de evaluación hidráulica aún más sólidos.

Los trabajos e investigaciones pendientes muestran la deuda que el ser humano mantiene con los ríos y su restauración. Para saldar esa deuda no basta con disponer de recursos económicos o técnicos, sino que también es necesario el factor humano que, entre otras cosas, aporta tesón y pasión. Dos elementos que fueron claves para que los pioneros de los pasos para peces tornasen en realidad lo que hasta entonces sólo eran ideas. Hoy en día esos elementos siguen siendo cruciales $y$, al igual que hicieron esos pioneros, esta tesis pretende transmitir conocimientos y motivación para que los que se enfrenten a los retos que plantean los pasos para peces sean capaces de resolverlos con éxito en el futuro. 


\section{REFERENCIAS}


Aarestrup, K., Lucas, M. y Hansen, J. (2003) Efficiency of a nature-like bypass channel for sea trout (Salmo trutta) ascending a small Danish stream studied by PIT telemetry. Ecology of Freshwater Fish 12, 160-168.

Aigoui, F., Dufour, M., Isidore, G., et al. (2008) Guide passes à poissons. Centre d’Étudies Techiniques Maritimes et Fluviales, CETMEF, Béthune (Francia).

Alexandre, C.M., Almeida, P.R., Neves, T., Mateus, C.S., Costa, J.L. y Quintella, B.R. (2016) Effects of flow regulation on the movement patterns and habitat use of a potamodromous cyprinid species. Ecohydrology 9, 326-340.

Alexandre, C.M., Ferreira, M.T. y Almeida, P.R. (2013) Fish assemblages in nonregulated and regulated rivers from permanent and temporary Iberian systems. River Research and Applications 29, 1042-1058.

Alves, M.J., Ribeiro, F., Aboim, M.A., et al. (2018) Identificaçao de peixes dos ecossistemas fluviais de Portugal. Curso presencial. Museu Nacional de História Natural e da Ciência, Lisboa (Portugal).

Amaral, S.D., Branco, P., Teixeira da Silva, A., et al. (2016) Upstream passage of potamodromous cyprinids over small weirs: The influence of key-hydraulic parameters. Journal of Ecohydraulics 2470-5365.

AMBER Consortium (2020) The AMBER Barrier Atlas. A Pan-European database of artificial instream barriers. Version 1.0.

Armstrong, G., Apahamian, M., Fewings, G., Gough, P., Reader, N. y Varallo, P. (2010) Guidance notes on the legislation, selection and approval of fish passes in England and Wales. $2^{\text {nd }}$ Edition. Environment Agency, Bristol (Inglaterra).

Armstrong, G., Apahamian, M., Fewings, G., Gough, P., Reader, N. y Varallo, P. (2004) Guidance notes on the legislation, selection and approval of fish passes in England and Wales. Environment Agency, Bristol (Inglaterra).

Ayllón, D., Almodóvar, A., Nicola, G.G. y Elvira, B. (2010) Ontogenetic and spatial variations in brown trout habitat selection. Ecology of Freshwater Fish 19, 420432.

Baek, K.O. (2019) Evaluation technique for efficiency of fishway based on hydraulic analysis. Journal of Korea Water Resources Association 52, 855-863.

Barrett, D. y Zweifel, J. (2019) Fish passage inventory, assessment and prioritization manual. Washington Department of Fish and Wildlife, Olympia (Estados Unidos de América).

Barry, J., Coghlan, B., Cullagh, A., Kerr, J.R. y King, J.J. (2018) Comparison of coarseresolution rapid methods for assessing fish passage at riverine barriers: ICE and SNIFFER protocols. River Research and Applications 34, 1168-1178. 
Bates, D., Mächler, M., Bolker, B. y Walker, S. (2015) Fitting linear mixed-effects models using Ime4. Journal of Statistical Software 67, 1-48.

Baudoin, J.-M., Burgun, V., Chanseau, M., et al. (2015) Assessing the passage of obstacles by fish. Concepts, design and application. Onema. The National Agency for Water and Aquatic Environments, Paris (Francia).

Birnie-Gauvin, K., Franklin, P., Wilkes, M. y Aarestrup, K. (2019) Moving beyond fitting fish into equations: Progressing the fish passage debate in the Anthropocene. Aquatic Conservation: Marine and Freshwater Ecosystems 29, 1095-1105.

Boné-Puyo, P. y Langa-Sánchez, A. (2011) Evaluación de los pasos de peces en la demarcación del Ebro. Confederación Hidrográfica del Ebro y Tecnoma, Zaragoza (España).

Branco, P., Amaral, S., Ferreira, M.T. y Santos, J.M. (2017) Do small barriers affect the movement of freshwater fish by increasing residency? Science of the Total Environment 581-582, 486-494.

Branco, P., Santos, J.M., Katopodis, C., Pinheiro, A. y Ferreira, M.T. (2013) Pool-type fishways: Two different morpho-ecological cyprinid species facing plunging and streaming flows. PLOS ONE 8, 1-9.

Bravo-Córdoba, F.J. (2016) Evaluación biológica de escalas de artesas para algunas de las principales especies de peces ibéricos. Tesis Doctoral, Universidad de Valladolid, Palencia (España).

Bravo-Córdoba, F.J., Sanz-Ronda, F.J., Ruiz-Legazpi, J., Fernandes Celestino, L. y Makrakis, S. (2018a) Fishway with two entrance branches: Understanding its performance for potamodromous Mediterranean barbels. Fisheries Management and Ecology 25, 12-21.

Bravo-Córdoba, F.J., Sanz-Ronda, F.J., Ruiz-Legazpi, J., Valbuena-Castro, J. y Makrakis, S. (2018b) Vertical slot versus submerged notch with bottom orifice: Looking for the best technical fishway type for Mediterranean barbels. Ecological Engineering $122,120-125$.

Bravo-Córdoba, F.J., Valbuena-Castro, J., García-Vega, A., Fuentes-Pérez, J.F., RuizLegazpi, J. y Sanz-Ronda, F.J. (2021) Fish passage assessment in stepped fishways: Passage success and transit time as standardized metrics. Ecological Engineering 162.

Bunt, C.M. (2001) Fishway entrance modifications enhance fish attraction. 95-106.

Bunt, C.M., Castro-Santos, T. y Haro, A. (2012) Performance of fish passage structures at upstream barriers to migration. River Research and Applications 28, 457-478. 
Bunt, C.M., Castro-Santos, T. y Haro, A. (2016) Reinforcement and validation of the analyses and conclusions related to fishway evaluation data from Bunt et al.: 'performance of fish passage structures at upstream barriers to migration.' River Research and Applications 32, 2125-2137.

Bunt, C.M., Katopodis, C. y McKinley, R.S. (1999) Attraction and passage efficiency of white suckers and smallmouth bass by two Denil fishways. North American Journal of ... 19, 793-803.

Cada, G.F. y Sale, M.J. (1993) Status of fish passage at nonfederal hydropower projects. Fisheries 18, 4-12.

Calles, O. y Greenberg, L. (2009) Connectivity is a two-way street. The need for a holistic aprroach to fish passage problems in regultated rivers. River Research and Applications 25, 1268-1286.

Castro-Santos, T. (2012) Adaptive fishway design: A framework and rationale for effective evaluations. Monitoring, Funktionskontrollen und Qualitätssicherung an Fischaufstiegsanlagen, 76-90.

Castro-Santos, T. (2004) Quantifying the combined effects of attempt rate and swimming capacity on passage through velocity barriers. Canadian Journal of Fisheries and Aquatic Sciences 61, 1602-1615.

Castro-Santos, T., Cotel, A. y Webb, P. (2009) Fishway evaluations for better bioengineering: An integrative approach a framework for fishway. En: Challenges for diadromous fishes in a dynamic global environment, Vol. 69. (eds A. Haro, K.G. Smith, R.A. Rulifson, et al.). American Fisheries Society Symposium, Bethesda (Estados Unidos de América), pp 557-575.

Castro-Santos, T. y Haro, A. (2010) Fish guidance and passage at barriers. En: Fish locomotion: an eco-ethological perspective. (eds P. Domeneci y B.G. Kapoor). Science Publishers, Enfield (Estados Unidos de América), pp 62-89.

Castro-Santos, T., Sanz-Ronda, F.J. y Ruiz-Legazpi, J. (2013) Breaking the speed limitcomparative sprinting performance of brook trout (Salvelinus fontinalis) and brown trout (Salmo trutta). Canadian Journal of Fisheries and Aquatic Sciences 70, 280-293.

Castro-Santos, T. y Vono, V. (2013) Posthandling survival and PIT tag retention by alewives- A comparison of gastric and surgical implants. North American Journal of Fisheries Management 33, 790-794.

CEDEX (2020) Anuario de aforos. Disponible en: www.ceh-flumen64.cedex.es [Visitado el 20 de marzo de 2020].

Celestino, L.F., Sanz-Ronda, F.J., Miranda, L.E., Makrakis, M.C., Dias, J.H.P. y Makrakis, S. (2019) Bidirectional connectivity via fish ladders in a large Neotropical river. River Research and Applications 35, 236-246. 
Choi, J.W., Park, C.S. y An, K.G. (2016) Development of fishway assessment model based on the fishway structure, hydrology and biological characteristics in lotic ecosystem. Journal of Ecology and Environment 39, 71-80.

Clay, C.H. (1995) Design of Fishways and Other Fish Facilities, 2nd edn. CRC Press, Boca Raton (Estados Unidos de América).

Collares-Pereira, M.J., Martins, M.J., Pires, A.M., Geraldes, A.M. y Coelho, M.M. (1996) Feeding behaviour of Barbus bocagei assessed under a spatio-temporal approach. Folia Zoologica 45, 65-76.

Confederación Hidrográfica del Cantábrico (2021) Marco biótico. Disponible en: www.chcantabrico.es/organismo/las-cuencas-cantabricas/marco-biotico [Visitado el 5 de febrero de 2021].

Confederación Hidrográfica del Cantábrico (2020) Sistema Automático de Información Hidrológica (SAI CHC). Disponible en: www.chcantabrico.es/sai-sistemaautomatico-de-informacion [Visitado el 29 de octubre de 2020].

Confederación Hidrográfica del Duero (2015) Anejo 4. Caudales ecológicos. En: Plan hidrológico de la parte española de Demarcación Hidrográfica del Duero (20152021). Valladolid (España), p 45.

Confederación Hidrográfica del Duero (2016) Manual para la evaluación de la funcionalidad de pasos para peces de estanques sucesivos. Metodología AEPS (1.0). Coordinación: Sanz-Ronda, F.J., et al.; Autores: Valbuena-Castro, J., et al. Confederación Hidrográfica del Duero, Valladolid (España).

Confederación Hidrográfica del Duero (2020a) Sistema Automático de Información Hidrológica (SAIH Duero). Disponible en: www.saihduero.es [Visitado el 20 de junio de 2020].

Confederación Hidrográfica del Duero (2020b) Sistema de información cartográfica MÍRAME-IDEDuero. Disponible en: www.mirame.chduero.es [Visitado el 20 de marzo de 2020].

Confederación Hidrográfica del Segura (2020a) Obstáculos a la continuidad longitudinal del río Segura. Disponible en: www.chsegura.es/chs/cuenca/restauracionderios/obstaculos/visorjs.html [Visitado el 23 de febrero de 2020].

Confederación Hidrográfica del Segura (2020b) Sistema Automático de Información Hidrológica (SAIH Segura). Disponible www.chsegura.es/chs/cuenca/redesdecontrol/SAIH [Visitado el 15 de septiembre de 2020].

Cooke, S.J. y Hinch, S.G. (2013) Improving the reliability of fishway attraction y passage efficiency estimates to inform fishway engineering, science, and practice. Ecological Engineering 58, 123-132. 
Cooke, S.J., Paukert, C. y Hogan, Z. (2012) Endangered river fish: Factors hindering conservation and restoration. Endangered Species Research 17, 179-191.

Doadrio, I. (2002) Atlas y Libro Rojo de los Peces Continentales de España. Dirección General de Conservación de la Naturaleza. Museo Nacional de Ciencias Naturales, Madrid (España).

Doadrio, I., Perea, S., Garzón-Heydt, P. y González, J.L. (2011) Ictiofauna continental española: bases para su seguimiento. Ministerio de Medio Ambiente y Medio Rural y Marino, Madrid (España).

Dudgeon, D., Arthington, A.H., Gessner, M.O., et al. (2006) Freshwater biodiversity: Importance, threats, status and conservation challenges. Biological reviews 81, 163-182.

Elvira, B., Nicola, G. y Almodóvar, A. (1998a) Sistemas de paso para peces en presas. Centro de Estudios y Experimentación de Obras Públicas, CEDEX, Madrid (España).

Elvira, B., Nicola, G.G. y Almodóvar, A. (1998b) Impacto de las obras hidráulicas en la ictiofauna: dispositivos de paso para peces en las presas de España. Organismo Autónomo Parques Nacionales, Madrid (España).

Enders, E.C., Boisclair, D. y Roy, A.G. (2005) A model of total swimming costs in turbulent flow for juvenile Atlantic salmon (Salmo salar). Canadian Journal of Fisheries and Aquatic Sciences 62, 1079-1089.

FAO/ DVWK (2002) Fish passes: Design, dimensions and monitoring. Food and Agriculture Organization of the United Nations (FAO), Roma (Italia).

Ficke, A.D., Myrick, C.A. y Kondratieff, M.C. (2012) The effects of PIT tagging on the swimming performance and survival of three nonsalmonid freshwater fishes. Ecological Engineering 48, 86-91.

Fuentes-Pérez, J.F., García-Vega, A., Sanz-Ronda, F.J. y Martínez de Azagra Paredes, A. (2017) Villemonte's approach: Validation of a general method for modeling uniform and non-uniform performance in stepped fishways. Knowledge and Management of Aquatic Ecosystems 418, 11.

Fuentes-Pérez, J.F., Sanz-Ronda, F.J., Martínez de Azagra, A. y García-Vega, A. (2014) Modeling water-depth distribution in vertical-slot fishways under uniform and nonuniform scenarios. Journal of Hydrualic Engineering 140, 1-5.

Fuentes-Pérez, J.F., Sanz-Ronda, F.J., Martínez de Azagra, A. y García-Vega, A. (2016) Non-uniform hydraulic behavior of pool-weir fishways: $A$ tool to optimize its design and performance. Ecological Engineering 86, 5-12. 
García-Vega, A., Fuentes-Pérez, J.F., Bravo-Córdoba, F.J., Ruiz-Legazpi, J., ValbuenaCastro, J. y Sanz-Ronda, F.J. (2021) Pre-reproductive movements of potamodromous cyprinids in the Iberian Peninsula: when environmental variability meets semipermeable barriers. Hydrobiologia.

García-Vega, A., Sanz-Ronda, F.J., Fernandes Celestino, L., Makrakis, S. y Leunda, P.M. (2018) Potamodromous brown trout movements in the North of the Iberian Peninsula: Modelling past, present and future based on continuous fishway monitoring. Science of the Total Environment 640-641, 1521-1536.

García-Vega, A., Sanz-Ronda, F.J. y Fuentes-Pérez, J.F. (2017) Seasonal and daily upstream movements of brown trout Salmo trutta in an Iberian regulated river. Knowledge \& Management of Aquatic Ecosystems 418, 9.

García Nájera, J.M. (1953) Esclusa salmonera automática. Paso de presas de cualquier altura. Instituto Forestal de Investigaciones y Experiencias (I.F.I.E.), Madrid (España).

Gobierno de España (1942) Ley, de 20 de febrero de 1942, por la que se regula el fomento y conservación de la pesca fluvial. Boletín Oficial del Estado 67, 16811694.

Gobierno de España (1985) Ley 19/1985, de 2 de agosto, de Aguas. Boletín Oficial del Estado 189, 25123-25135.

Gobierno de España (1999) Ley 46/1999, de 13 de diciembre, de modificación de la Ley 29/1985, de 2 de agosto, de Aguas. Boletín Oficial del Estado 298, 43100-43113.

Gobierno de España (1879) Ley de Aguas, de 13 de junio de 1879. Gaceta de Madrid 170, 799-805.

Gobierno de España (1929) Real Decreto-Ley, de 24 de septiembre de 1929, introduciendo las variaciones que se indican en la legislación de pesca fluvial. Gaceta de Madrid 267, 1906-1913.

Gobierno de España (2001) Real Decreto Legislativo 1/2001, de 24 de julio de 2001, por el que se aprueba el texto refundido de la Ley de Aguas. Boletín Oficial del Estado 176, 26791-26817.

Goettel, M.T., Atkinson, J.F. y Bennett, S.J. (2015) Behavior of western blacknose dace in a turbulence modified flow field. Ecological Engineering 74, 230-240.

González-Alemán, N.J. (2016) Índice gonadosomático en barbo ibérico (Luciobarbus bocagei) y en boga del Duero (Pseudochondrostoma duriense) al momento de su migración y paso por escalas para peces en el río Tormes (Salamanca). Tesis de Máster, Universidad de Valladolid, Palencia (España).

Graves, S., Piepho, H.-P., Selzer, L. y Dorai-Raj, S. (2019) MultcompView: Visualizations of paired comparisons. 
Gross, J. y Ligges, U. (2015) nortest: Tests of normality.

Guiny (2001) Hydraulic and biological aspects of fish passes for dams. Tesis Doctoral, University of Glasgow, Glasgow (Escocia).

Instituto de hidráulica ambiental IH Cantabria, Consejería de Desarrollo Rural, Ganadería, Pesca y Biodiversidad y Gobierno de Cantabria (2000) Anejo VII-E LIC Río Miera (ES1300015). Santander (España).

International Union for Conservation of Nature and Natural Resources (2021) The IUCN Red List of Threatened Species. Disponible en: www.iucnredlist.org [Visitado el 30 de abril de 2021].

Jones, M.J. y O'Connor, J.P. (2017) Monitoring the performance of fishways and fish passage works. Arthur Rylah Institute for Environmental Research. Department of Environment, Land, Water and Planning, Heidelberg (Australia).

Jungwirth, M., Schmutz, S. y Weiss, S. (1998) Fish Migration and Fish Bypasses, (Vol. 4). Oxford: Fishing News Books, Oxford (Inglaterra).

Junta de Castilla y León (2015) Ley 4/2015, de 24 de marzo de 2015, del Patrimonio Natural de Castilla y León. Boletín Oficial de Castilla y León 61, 23956-24016.

Junta de Castilla y León (2018) Orden FYM/1383/2018, de 19 de diciembre, por la que se declaran los cotos de pesca, escenarios deportivo-sociales, aguas en régimen especial y refugios de pesca de la Comunidad de Castilla y León y se aprueban los correspondientes planes de pesca. Boletín Oficial de Castilla y León 249, 5082551680.

Katopodis, C. (1992) Introduction to fishway design. Oceans, 67.

Katopodis, C. y Williams, J.G. (2012) The development of fish passage research in a historical context. Ecological Engineering 48, 8-18.

Kemp, P.S., Russon, I.J., Waterson, B. y O’Hanley, J.R. (2008) Recommendations for a "coarse-resolution rapid-assessment" methodology to assess obstacles to fish migration, and associated priorization tool. Edimburgo (Escocia).

King, S., O'Hanley, J.R., Newbold, L.R., Kemp, P.S. y Diebel, M.W. (2017) A toolkit for optimizing fish passage barrier mitigation actions. Journal of Applied Ecology 54, 599-611.

Kondratieff, M.C. y Myrick, C.A. (2006) How high can brook trout jump? A laboratory evaluation of brook trout jumping performance. Transactions of the American Fisheries Society 135, 361-370.

Kottelat, M. y Freyhof, J. (2007) Handbook of European freshwater fishes. Publications Kottelat, Cornol (Suiza). 
Larinier, M. (2002a) Biological factors to be taken into account in the design of fishways, the concept of obstructions to upstream migration. Bulletin Français de la Pêche et de la Pisciculture 364 suppl., 28-38.

Larinier, M. (2001) Environmental issues, dams and fish migration. FAO; Fisheries Technical Paper 419, 45-89.

Larinier, M. (2002b) Location of fishways. Bulletin Français de la Pêche et de la Pisciculture 364 suppl., 39-53.

Larinier, M. (2002c) Pool fishways, pre-barrages and natural bypass channels. Bulletin Français de la Pêche et de la Pisciculture 364 suppl., 54-82.

Larinier, M. (1998) Upstream and Downstream Fish Passage Experience in France. En: Fish Migration and Fish Bypasses. Fishing News, Londres (Inglaterra), pp 127-145.

Larinier, M., Chanseau, M., Bau, F. y Croze, O. (2005) The use of radio telemetry for optimizing fish pass design. En: Aquatic telemetry: Advances and applications: Proceedings of the fifth conference on fish telemetry. (eds M.T. Spedicato, G. Lembo y G. Marmulla). Roma (Italia), pp 53-60.

Leunda, P.M., Elvira, B., Ribeiro, F., Miranda, R., Oscoz, J., Alves, M.J. y Collares-Pereira, M.J. (2009) International standardization of common names for Iberian endemic freshwater fishes. Limnetica 28, 189-202.

Lobón-Cerviá, J. y Elvira, B. (1981) Edad, crecimiento y reproducción de la boga de río (Chondrostoma polylepis polylepis Stein., 1865) en el embalse de Pinilla (río Lozoya). Bol. Inst. Espa. Oceano 6, 200-213.

Lucas, M.C., Baras, E., Thom, T.J., Duncan, A. y Slavík, O. (2001) Migration of Freshwater Fishes. Blackwell Science, Oxford (Inglaterra).

Lundqvist, H., Rivinoja, P., Leonardsson, K. y McKinnell, S. (2008) Upstream passage problems for wild Atlantic salmon (Salmo salar L.) in a regulated river and its effect on the population. Hydrobiologia, 111-127.

Maceda-Veiga, A. (2013) Towards the conservation of freshwater fish: Iberian Rivers as an example of threats and management practices. Reviews in Fish Biology and Fisheries 23, 1-22.

Martínez-Capel, F., García de Jalón, D. y Rodilla-Alamá (2004) On the estimation of nose velocities and their influence on the physical habitat simulation for Barbus bocagei. Hydroécologie Appliquée 14, 139-159.

Martínez de Azagra-Paredes, A. (1999) Escalas para peces. Universidad de Valladolid, Palencia (España).

MITECO (2019) Protocolo de caracterización hidromorfológica de masas de agua de la categoría ríos. Ministerio para la Transición Ecológica, Madrid (España). 
Moher, D., Liberati, A., Tetzlaff, J., et al. (2009) Preferred reporting items for systematic reviews and meta-analyses: The PRISMA statement. PLoS Medicine 6.

Morán-López, R. y Uceda Tolosa, O. (2016) Relative leaping abilities of native versus invasive cyprinids as criteria for selective barrier design. Biological Invasions, Published on-line.

Munné, A., Solà, C. y Pagés, J. (2006) HIDRI: Protocolo para la valoración de la calidad hidromorfológica de los ríos. Barcelona (España).

Navarro-Barquero, P. y Boné-Puyo, P. (2018) Evaluación de los pasos para peces en la demarcación del Ebro. Años 2017 y 2018. Confederación Hidrográfica del Ebro y Grupo TYPSA, Zaragoza (España).

Nilsson, C., Reidy, C. a, Dynesius, M. y Revenga, C. (2005) Fragmentation and flow regulation of the world's large river systems. Science 308, 405-408.

NMFS (2011) Anadromous salmonids passage facility design. National Marine Fisheries Service Northwest Region, Northwest Region, Portl y (Estados Unidos de América).

Noonan, M.J., Grant, J.W.A. y Jackson, C.D. (2012) A quantitative assessment of fish passage efficiency. Fish and Fisheries 13, 450-464.

Northcote, T.G. (1984) Mechanisms of fish migration in rivers. En: Mechanisms of migration in fishes. (eds J.D. McCleave, J.J. Dodson y W.H. Neill). Plenum, New York (Estados Unidos de América), pp 317-355.

Odeh, M. (1999) Fish passage innovation for ecosystem and fishery restoration. En: Innovations in fish passage technology. (ed M. Odeh). American Fisheries Society, Bethesda (Estados Unidos de América), p 24.

Odeh, M., Noreika, J., Haro, A., Maynard, A., Castro-Santos, T. y Cada, G.F. (2002) Evaluation of the effects of turbulence on the behavior of migratory fish. Final Report 2002, Report to Bonneville Power Administration, Contract No. 00000022, Project No. 200005700. Portl y (Estados Unidos de América).

Ogle, D.H., Wheeler, P. y Dinno, A. (2020) FSA: Fisheries stock analysis.

Oliva-Paterna, F.J., Verdiell-Cubedo, D., Ruiz-Navarro, A. y Torralva, M. (2014) La ictiofauna continental de la Cuenca del río Segura (SE Península Ibérica): décadas después de Mas (1986). Anales de Biología 6, 37-45.

Ordeix, M., Pou-Rovira, Q., Sellarès, N., Bardina, M., Casamitjana, A., Solà, C. y Munné, A. (2011) Fish pass assessment in the rivers of Catalonia (NE Iberian Peninsula). A case study of weirs associated with hydropower plants and gauging stations. Limnetica 30, 405-426.

Ostrand, K.G., Zydlewski, G.B., Gale, W.L. y Zydlewski, J.D. (2011) Long term retention, survival, growth, and physiological indicators of juvenile salmonids with passive integrated transponder tags. American Fisheries Society Symposium 76, 1-11. 
Parlamento Europeo y Consejo (2000) Directiva Marco del Agua (2000/60/CE), de 23 de octubre de 2000, por la que se establece un marco comunitario de actuación en el ámbito de la política de aguas. Diario Oficial De Las Comunidades Europeas 327, $1-73$.

Pervin, A. (2017) Fish passages from past to future in Turkey. En: Presentation abstracts. International Conference on Engineering and Ecohydrology for Fish Passage, Oregon (Estados Unidos de América), p 49.

Pinheiro, J., Bates, D., DebRoy, S., Sarkar, D. y R Core Team (2020) Linear and nonlinear mixed effects models.

Platt, N.C. (2019) Designing and assessing the effectiveness of Denil fishways using hydraulic modeling-based approaches.

Pohlert, T. (2018) Calculate pairwise multiple comparisons of mean rank sums (PMCMR).

Porcher, J.P. y Travade, F. (2002) Fisways: Biological basis, limits and legal considerations. Bulletin Français de la Pêche et de la Pisciculture 364 suppl., 9-20.

Quaresma, A.L., Romão, F., Branco, P., Ferreira, M.T. y Pinheiro, A.N. (2018) Multi slot versus single slot pool-type fishways: A modelling approach to compare hydrodynamics. Ecological Engineering 122, 197-206.

R Core Team (2020) R: A language and environment for statistical computing.

Romão, F., Quaresma, A.L., Branco, P., et al. (2017) Passage performance of two cyprinids with different ecological traits in a fishway with distinct vertical slot configurations. Ecological Engineering 105, 180-188.

Romão, F., Quintella, B.R., Pereira, T.J. y Almeida, P.R. (2012) Swimming performance of two Iberian cyprinids: The Tagus nase Pseudochondrostoma polylepis (Steindachner, 1864) and the bordallo Squalius carolitertii (Doadrio, 1988). Journal of Applied Ichthyology 28, 26-30.

Roscoe, D.W. y Hinch, S.G. (2010) Effectiveness monitoring of fish passage facilities: Historical trends, geographic patterns and future directions. Fish and Fisheries 11, 12-33.

Ruiz-Legazpi, J., Sanz-Ronda, F.J., Bravo-Córdoba, F.J., Fuentes-Pérez, J.F. y CastroSantos, T. (2018) Influencia de factores ambientales y biométricos en la capacidad de nado del barbo ibérico (Luciobarbus bocagei Steindachner, 1864), un ciprínido potamódromo endémico de la Península Ibérica. Limnetica 37, 251-265.

Santo, M. (2005) Dispositivos de passagem para peixes em Portugal. Lisboa (Portugal). 
Santos, J.M., Branco, P., Katopodis, C., Ferreira, T., Pinheiro, A.N. y Ferreira, M.T. (2014) Retrofitting pool-and-weir fishways to improve passage performance of benthic fishes: Effect of boulder density and fishway discharge. Ecological Engineering 73, 335-344.

Santos, J.M., Branco, P.J., Silva, A.T., Katopodis, C., Pinheiro, A.N., Viseu, T. y Ferreira, M.T. (2012a) Effect of two flow regimes on the upstream movements of the Iberian barbel (Luciobarbus bocagei) in an experimental pool-type fishway. Journal of Applied Ichthyology 29, 425-430.

Santos, J.M., Ferreira, M.T., Godinho, F.N. y Bochechas, J. (2002) Performance of fish lift recently built at the Touvedo Dam on the Lima River Portugal. Journal of Applied Ichthyology 18, 118-123.

Santos, J.M., Silva, A., Katopodis, C., Pinheiro, P., Pinheiro, A., Bochechas, J. y Ferreira, M.T. (2012b) Ecohydraulics of pool-type fishways: Getting past the barriers. Ecological Engineering 48, 38-50.

Sanz-Ronda, F.J., Bravo-Córdoba, F.J., Fuentes-Pérez, J.F., et al. (2013) Pasos para peces: escalas y otros dispositivos de paso. Notas técnicas del CIREF 7, 17.

Sanz-Ronda, F.J., Bravo-Cordoba, F.J., Fuentes-Pérez, J.F. y Castro-Santos, T. (2016) Ascent ability of brown trout, Salmo trutta, and two Iberian cyprinids - Iberian barbel, Luciobarbus bocagei, and northern straight-mouth nase, Pseudochondrostoma duriense - in a vertical slot fishway. Knowledge and Management of Aquatic Ecosystems 417, 10.

Sanz-Ronda, F.J., Bravo-Córdoba, F.J., Ruiz-Legazpi, J., et al. (2014) Criterios de diseño, construcción y evaluación. En: VI curso sobre pasos para peces: criterios de diseño, construcción y evaluación. Palencia (España), pp 1-100.

Sanz-Ronda, F.J., Bravo-Córdoba, F.J., Ruiz-Legazpi, J. y Fuentes-Pérez, J.F. (2015a) The most evaluated fishway in Spain: A new lesson every year. En: Fish Passage 2015. International conference on river connectivity, best practices and innovations. Groningen (Países Bajos), pp 146-147.

Sanz-Ronda, F.J., Bravo-Córdoba, F.J., Sánchez-Pérez, A., et al. (2019) Passage performance of technical pool-type fishways for potamodromous cyprinids: Novel experiences in semiarid environments. Water 11, 2362.

Sanz-Ronda, F.J., Fuentes-Pérez, J.F., García-Vega, A. y Bravo-Córdoba, F.J. (2021) Fishways as downstream routes in small hydropower plants: Experiences with a potamodromous cyprinid. Water 13, 1041.

Sanz-Ronda, F.J. y Martínez de Azagra, A. (2013) Escalas para peces en España. Una historia forestal. En: 6o Congreso Forestal Nacional. (ed Sociedad Española de Ciencias Forestales). Vitoria (España), p 22. 
Sanz-Ronda, F.J., Ruiz-Legazpi, J., Bravo-Córdoba, F.J., Makrakis, S. y Castro-Santos, T. (2015b) Sprinting performance of two Iberian fish: Luciobarbus bocagei and Pseudochondrostoma duriense in an open channel flume. Ecological Engineering $83,61-70$.

Schmetterling, D.A. (2003) Reconnecting a fragmented river: Movements of westslope cutthroat trout and bull trout after transport upstream of Miltown dam, Montana. North American Journal of Fisheries Management 23, 721-731.

Seisdedos-Fidalgo, P., González-Fernández, G., Pérez-Cardenal, D., et al. (2010) Diagnóstico de la conectividad longitudinal de la cuenca del Duero. Ministerio de Medio Ambiente, Rural y Marino, y Confederación Hidrográfica del Duero, Valladolid (España).

SIBIC (2017) Carta piscícola española. Disponible en: www.cartapiscicola.es [Visitado el 21 de mayo de 2020].

Silva, A.T., Bermúdez, M., Santos, J.M., Rabuñal, J.R. y Puertas, J. (2020) Pool-type fishway design for a potamodromous cyprinid in the Iberian Peninsula: The Iberian barbel-synthesis and future directions. Sustainability 12, 1-25.

Silva, A.T., Katopodis, C., Santos, J.M., Ferreira, M.T. y Pinheiro, A.N. (2012) Cyprinid swimming behaviour in response to turbulent flow. Ecological Engineering 44, 314-328.

Silva, A.T., Lucas, M.C., Castro-Santos, T., et al. (2017) The future of fish passage science, engineering, and practice. Fish and Fisheries, 1-23.

Silva, A.T., Santos, J.M., Ferreira, M.T., Pinheiro, A.N. y Katopodis, C. (2010) Passage efficiency of offset and straight orifices for upstream movements of iberian barbel in a pool-type fishway. River research and applications 28, 529-542.

Silva, A.T., Santos, J.M., Franco, A.C., Ferreira, M.T. y Pinheiro, A.N. (2009) Selection of Iberian barbel Barbus bocagei (Steindachner, 1864) for orifices and notches upon different hydraulic configurations in an experimental pool-type fishway. Journal of Applied Ichthyology 25, 173-177.

SNIFFER (2010) Trialling of the methodology for quantifying the impacts of obstacles to fish passage. Edimburgo (Escocia).

Solà, C., Ordeix, M., Pou-Rovira, Q., et al. (2011) Longitudinal connectivity in hydromorphological quality assessments of rivers. The ICF index: A river connectivity index and its application to Catalan rivers. Limnetica 30, 273-292.

Tarrade, L., Texier, A., David, L. y Larinier, M. (2008) Topologies and measurements of turbulent flow in vertical slot fishways. Hydrobiologia 609, 177-188.

Towler, B., Orvis, C., Dow, D. y Haro, A. (2013) TR-2013-1 Fishway inspection guidelines (6/5/2013). UMass Amherst Fish Passage Technical Reports, Amherst (Estados Unidos de América). 
Valbuena-Castro, J., Fuentes-Pérez, J.F., García-Vega, A., Bravo-Córdoba, F.J., RuizLegazpi, J., Martínez de Azagra-Paredes, A. y Sanz-Ronda, F.J. (2020) Coarse fishway assessment to prioritize retrofitting efforts: a case study in the Duero River basin. Ecological Engineering 155, 105946.

Valbuena-Castro, J., Sanz-Ronda, F.J., García-Vega, A., et al. (2019) Metodología "AEPS" aplicada a la evaluación de escalas para peces en la cuenca hidrográfica del río Duero. Cuadernos de la Sociedad Española de Ciencias Forestales 45, 279-288.

Verep, B., Küçükali, S., Turan, D. y Alp, A. (2016) A critical analysis of existing fish pass structures at small hydropower plants in Turkey. En: Presentation abstracts. International Conference on Engineering and Ecohydrology for Fish Passage, Amherst (Estados Unidos de América), p 53.

Videler, J.J. y Wardle, C.S. (1991) Fish swimming stride by stride: Speed limits and endurance. Reviews in Fish Biology and Fisheries 1, 23-40.

Wickham, H., Henry, L., Müller, K. y R Studio (2020) dplyr: A grammar of data manipulation.

Williams, J.G., Armstrong, G., Katopodis, C., Larinier, M. y Travade, F. (2012) Thinking like a fish: A key ingredient for development of effective fish passage facilities at river obstructions. River Research and Applications 28, 407-417.

Wolter, C. y Schomaker, C. (2019) Fish passes design discharge requirements for successful operation. River Research and Applications 35, 1697-1701.

Zitek, A., Pacher, K., Honsig-Erlenburg, W. y Schmutz, S. (2012) Attraction and passage efficiency of a fish pass within a chain of impoundments at the River Drau, Villach, Austria. En: 9th International Symposium on Ecohydraulics. (eds H. Mader y J. Kraml). Viena (Austria), pp 2-6. 
ANEJOS 


\section{A.1. FAUNA PISCÍCOLA DE LOS ECOSISTEMAS FLUVIALES DE LA PENÍNSULA IBÉRICA}




\section{A.1. FAUNA PISCÍCOLA DE LOS ECOSISTEMAS FLUVIALES DE LA PENÍNSULA IBÉRICA}

Este anejo muestra las especies piscícolas que pueden encontrarse en las aguas continentales de la Península Ibérica junto con su origen, hábitos migratorios más habituales, y el nivel de amenaza bajo el que se encuentran según la Unión Internacional para la Conservación de la Naturaleza y los Recursos Naturales (IUCN).

Tabla A.1.1. Características de las especies piscícolas presentes en los ecosistemas fluviales de la Península Ibérica ( $N C$ - no catalogada, $P M$ - preocupación menor, $C A$ - casi amenazada, VU vulnerable, $E P$ - en peligro, $C R$ - en peligro crítico) (fuentes: Doadrio 2002; Leunda et al. 2009; Doadrio et al. 2011; SIBIC 2017; Alves et al. 2018; International Union for Conservation of Nature and Natural Resources 2021).

\begin{tabular}{|c|c|c|c|c|}
\hline FAMILIA & ESPECIE & ORIGEN & MIGRACIÓN & AMENAZA \\
\hline Acipenseridae & Acipenser sturio (Linnaeus, 1758) & Nativo & Anádroma & CR \\
\hline Anguillidae & Anguilla anguilla (Linnaeus, 1758) & Nativo & Catádroma & CR \\
\hline Atherinidae & Atherina boyeri (Risso, 1810) & Nativo & Sedentaria & PM \\
\hline Balitoridae & Barbatula barbatula (Linnaeus, 1758) & Alóctono & Sedentaria & PM \\
\hline Balitoridae & $\begin{array}{c}\text { Barbatula quignardi (Bâcescu-Mester, } \\
\text { 1967) }\end{array}$ & Nativo & Sedentaria & PM \\
\hline Blenniidae & Salaria fluviatilis (Asso, 1801) & Nativo & Sedentaria & PM \\
\hline Centrarchidae & Lepomis gibbosus (Linnaeus, 1758) & Alóctono & $\begin{array}{l}\text { Sedentaria y } \\
\text { potamódroma }\end{array}$ & PM \\
\hline Centrarchidae & $\begin{array}{l}\text { Micropterus salmoides (Lacépede, } \\
\text { 1802) }\end{array}$ & Alóctono & Sedentaria & PM \\
\hline Cichlidae & Australoheros facetus (Jenyns, 1842) & Alóctono & Sedentaria & NC \\
\hline Clupeidae & Alosa alosa (Linnaeus, 1758) & Nativo & Anádroma & PM \\
\hline Clupeidae & Alosa fallax (Lacépede, 1803) & Nativo & Anádroma & PM \\
\hline Cobitidae & Cobitis calderoni (Bascescu, 1962) & Nativo & Sedentaria & EP \\
\hline Cobitidae & Cobitis paludica (de Buen, 1930) & Nativo & Sedentaria & VU \\
\hline Cobitidae & $\begin{array}{c}\text { Cobitis vettonica (Doadrio y Perdices, } \\
\text { 1997) }\end{array}$ & Nativo & Sedentaria & EP \\
\hline Cobitidae & $\begin{array}{c}\text { Misgurnus anguillicaudatus (Cantor, } \\
1842 \text { ) }\end{array}$ & Alóctono & Sedentaria & PM \\
\hline
\end{tabular}

(Continuación en la página siguiente) 


\section{FAMILIA}

Cottidae

Cottus aturi (Freyhof, Kottelat y Nolte, 2005)

Nativo Sedentaria PM

Cottidae

Cottus hispaniolensis (Bâcescu y

Bâcescu-Mester, 1964)

Nativo Sedentaria

PM

Cyprinidae

Achondrostoma arcasii (Steindachner,

1866)

Nativo Potamódroma VU

Cyprinidae

Achondrostoma salmantinum (Doadrio

y Elvira, 2007)

Nativo Potamódroma EP

Achondrostoma occidentale (Robalo,

Cyprinidae

Almada, Santos, Moreira y Doadrio,

Nativo Sedentaria EP

2005)

Cyprinidae

Achondrostoma oligolepis (Robalo, Doadrio, Almada y Kottelat, 2005)

Nativo Sedentaria PM

Cyprinidae

Alburnus alburnus (Linnaeus, 1758)

Nativo Sedentaria

PM

Cyprinidae

Anaecypris hispanica (Steindachner, 1866)

Nativo Potamódroma EP

Cyprinidae

Barbonymus schwanenfeldii (Bleeker, 1853)

Alóctono Sedentaria PM

Cyprinidae

Barbus haasi (Mertens, 1925)

Nativo Sedentaria

VU

Cyprinidae

Barbus meridionalis (Risso, 1827)

Nativo Potamódroma

CA

Cyprinidae

Carassius auratus (Linnaeus, 1758)

Alóctono Sedentaria

PM

Cyprinidae

Carassius gibelio (Bloch, 1782)

Alóctono Sedentaria NC

Cyprinidae

Complexo Squalius alburnoides

(Steindachner, 1866)

Nativo Sedentaria VU

Cyprinidae

Cyprinus carpio (Linnaeus, 1758)

Alóctono Sedentaria VU

Cyprinidae

Gobio lozanoi (Doadrio y Madeira, 2004)

Nativo Potamódroma PM

Cyprinidae

Gobio occitaniae (Kottelat y Persat, 2005)

Alóctono Potamódroma PM

Iberochondrostoma almacai (Coelho, Mesquita y Collares-Pereira, 2005)

Nativo Sedentaria CR

Cyprinidae Iberochondrostoma lemmingii

Cyprinidae

(Steindachner, 1866)

Cyprinidae

Iberochondrostoma lusitanicum

(Collares-Pereira, 1980)

Nativo Sedentaria

CR 


\begin{tabular}{|c|c|c|c|c|}
\hline FAMILIA & ESPECIE & ORIGEN & MIGRACIÓN & AMENAZA \\
\hline Cyprinidae & $\begin{array}{l}\text { Iberochondrostoma olisiponensis } \\
\text { (Gante, Santos y Alves, 2007) }\end{array}$ & Nativo & Sedentaria & CR \\
\hline Cyprinidae & $\begin{array}{c}\text { Iberochondrostoma oretanum (Doadrio } \\
\text { y Carmona, 2003) }\end{array}$ & Nativo & Sedentaria & CR \\
\hline Cyprinidae & $\begin{array}{l}\text { Luciobarbus bocagei (Steindachner, } \\
\text { 1864) }\end{array}$ & Nativo & Potamódroma & PM \\
\hline Cyprinidae & $\begin{array}{l}\text { Luciobarbus comizo (Steindachner, } \\
\text { 1864) }\end{array}$ & Nativo & Potamódroma & VU \\
\hline Cyprinidae & $\begin{array}{l}\text { Luciobarbus graellsii (Steindachner, } \\
\text { 1866) }\end{array}$ & Nativo & Potamódroma & PM \\
\hline Cyprinidae & $\begin{array}{l}\text { Luciobarbus guiraonis (Steindachner, } \\
\text { 1866) }\end{array}$ & Nativo & Potamódroma & VU \\
\hline Cyprinidae & $\begin{array}{l}\text { Luciobarbus microcephalus (Almaça, } \\
\text { 1967) }\end{array}$ & Nativo & Potamódroma & VU \\
\hline Cyprinidae & Luciobarbus sclateri (Günther, 1868) & Nativo & Potamódroma & PM \\
\hline Cyprinidae & $\begin{array}{l}\text { Luciobarbus steindachneri (Almaça, } \\
\text { 1967) }\end{array}$ & Nativo & Potamódroma & VU \\
\hline Cyprinidae & $\begin{array}{l}\text { Parachondrostoma arrigonis } \\
\text { (Steindachner, 1866) }\end{array}$ & Nativo & Potamódroma & CR \\
\hline Cyprinidae & $\begin{array}{l}\text { Parachondrostoma miegii } \\
\text { (Steindachner, 1866) }\end{array}$ & Nativo & Potamódroma & PM \\
\hline Cyprinidae & $\begin{array}{l}\text { Parachondrostoma turiense (Elvira, } \\
\text { 1987) }\end{array}$ & Nativo & Potamódroma & EP \\
\hline Cyprinidae & Phoxinus phoxinus (Linnaeus, 1766) & Nativo & Sedentaria & PM \\
\hline Cyprinidae & Phoxinus bigerri (Kottelat, 2007) & Nativo & Potamódroma & PM \\
\hline Cyprinidae & $\begin{array}{c}\text { Pseudochondrostoma polylepis } \\
\text { (Steindachner, 1864) }\end{array}$ & Nativo & Potamódroma & PM \\
\hline Cyprinidae & $\begin{array}{l}\text { Pseudochondrostoma wlilkommii } \\
\text { (Steindachner, 1866) }\end{array}$ & Nativo & Potamódroma & NC \\
\hline Cyprinidae & $\begin{array}{c}\text { Pseudorasbora parva (Temminck y } \\
\text { Schlegel, 1846) }\end{array}$ & Alóctono & Sedentaria & PM \\
\hline Cyprinidae & Rutilus rutilus (Linnaeus, 1758) & Alóctono & Sedentaria & PM \\
\hline Cyprinidae & $\begin{array}{l}\text { Scardinius erythrophthalmus (Linnaeus, } \\
\qquad 1758 \text { ) }\end{array}$ & Alóctono & Sedentaria & PM \\
\hline Cyprinidae & $\begin{array}{c}\text { Squalius aradensis (Coelho, } \\
\text { Bogustskaya, Rodrigues y Collares- } \\
\text { Pereira, 1998) }\end{array}$ & Nativo & Sedentaria & VU \\
\hline
\end{tabular}

(Continuación en la página siguiente) 


\begin{tabular}{|c|c|c|c|c|}
\hline FAMILIA & ESPECIE & ORIGEN & MIGRACIÓN & AMENAZA \\
\hline Cyprinidae & Squalius carolitertii (Doadrio, 1987) & Nativo & Potamódroma & PM \\
\hline Cyprinidae & $\begin{array}{l}\text { Squalius castellanus (Doadrio, Perea y } \\
\text { Alonso, 2007) }\end{array}$ & Nativo & Sedentaria & EP \\
\hline Cyprinidae & Squalius cephalus (Linnaeus, 1758) & Nativo & Sedentaria & PM \\
\hline Cyprinidae & $\begin{array}{l}\text { Squalius laietanus (Doadrio. Kottelat y } \\
\text { Sostosa, 2007) }\end{array}$ & Nativo & Potamódroma & PM \\
\hline Cyprinidae & $\begin{array}{c}\text { Squalius malacitanus (Doadrio y } \\
\text { Carmona, 2006) }\end{array}$ & Nativo & Sedentaria & $\mathrm{EP}$ \\
\hline Cyprinidae & Squalius palaciosi (Doadrio, 1980) & Nativo & Sedentaria & CR \\
\hline Cyprinidae & Squalius pyrenaicus (Günther, 1868) & Nativo & Potamódroma & NC \\
\hline Cyprinidae & $\begin{array}{c}\text { Squalius torgalensis (Coelho, } \\
\text { Bogustskaya, Rodrigues y Collares- } \\
\text { Pereira, 1998) }\end{array}$ & Nativo & Sedentaria & EP \\
\hline Cyprinidae & $\begin{array}{l}\text { Squalius valentinus (Doadrio y } \\
\text { Carmona, 2006) }\end{array}$ & Nativo & Sedentaria & VU \\
\hline Cyprinidae & Tinca tinca (Linnaeus, 1758) & Nativo & Sedentaria & PM \\
\hline Cyprinodontidae & $\begin{array}{c}\text { Aphanius baeticus (Doadrio, Carmona y } \\
\text { Fernández-Delgado, 2002) }\end{array}$ & Nativo & Sedentaria & EP \\
\hline Cyprinodontidae & Aphanius fasciatus (Valenciennes, 1821) & Alóctono & Sedentaria & PM \\
\hline Cyprinodontidae & $\begin{array}{l}\text { Aphanius iberus (Cuvier y Valenciennes, } \\
\text { 1846) }\end{array}$ & Nativo & Sedentaria & EP \\
\hline Cyprinidontidae & Fundulus heteroclitus (Linnaeus, 1766) & Alóctono & Sedentaria & PM \\
\hline Esocidae & Esox lucius (Linnaeus, 1758) & Alóctono & Sedentaria & PM \\
\hline Gasterosteidae & $\begin{array}{l}\text { Gasterosteus aculeatus (Linnaeus, } \\
1758 \text { ) }\end{array}$ & Nativo & Sedentaria & PM \\
\hline Gobiidae & Pomatoschistus microps (Krøyer, 1838) & Nativo & Anádroma & PM \\
\hline Ictaluridae & Ameiurus melas (Rafinesque, 1820) & Alóctono & Sedentaria & PM \\
\hline Ictaluridae & Ictalurus punctatus (Rafinesque, 181) & Alóctono & Potamódroma & PM \\
\hline Moronidae & Dicentrarchus labrax (Linnaeus, 1758) & Nativo & Estuarina & PM \\
\hline Mugilidae & Chelon labrosus (Risso, 1827) & Nativo & $\begin{array}{l}\text { Oceanódroma } \\
\text { y anfídroma }\end{array}$ & PM \\
\hline Mugilidae & Liza aurata (Risso, 1810) & Nativo & Catádroma & PM \\
\hline Mugilidae & Liza ramada (Risso, 1826) & Nativo & Catádroma & PM \\
\hline
\end{tabular}

(Continuación en la página siguiente) 


\begin{tabular}{|c|c|c|c|c|}
\hline FAMILIA & ESPECIE & ORIGEN & MIGRACIÓN & AMENAZA \\
\hline Mugilidae & Mugil cephalus (Linnaeus, 1758) & Nativo & Anádroma & PM \\
\hline Percidae & Perca fluviatilis (Linnaeus, 1758) & Alóctono & Sedentaria & PM \\
\hline Percidae & Sander lucioperca (Linnaeus, 1758) & Alóctono & Potamódroma & PM \\
\hline Percidae & Herichthys facetum (Jenyns, 1842) & Alóctono & Sedentaria & NC \\
\hline Petromyzontidae & Lampetra fluviatilis (Linnaeus, 1758) & Nativo & Anádroma & PM \\
\hline Petromyzontidae & Lampetra planeri (Bloch,1784) & Nativo & Sedentaria & PM \\
\hline Petromyzontidae & $\begin{array}{l}\text { Lampetra lusitanica (Mateus, Alves, } \\
\text { Quintella y Almeida, 2013) }\end{array}$ & Nativo & Sedentaria & NC \\
\hline Petromyzontidae & $\begin{array}{l}\text { Lampetra auremensis (Mateus, Alves, } \\
\text { Quintella y Almeida, 2013) }\end{array}$ & Nativo & Sedentaria & NC \\
\hline Petromyzontidae & $\begin{array}{c}\text { Lampetra alavariensis (Mateus, Alves, } \\
\text { Quintella y Almeida, 2013) }\end{array}$ & Nativo & Sedentaria & NC \\
\hline Petromyzontidae & Petromyzon marinus (Linnaeus, 1758) & Nativo & Anádroma & PM \\
\hline Pleuronectidae & Platichthys flesus (Linnaeus, 1758) & Nativo & Catádroma & PM \\
\hline Poeciliidae & Gambusia holbrooki (Girard, 1879) & Alóctono & Sedentaria & PM \\
\hline Poeciliidae & Poecilia reticulata (Peters, 1859) & Alóctono & Sedentaria & PM \\
\hline Salmonidae & Oncorhynchus mykiss (Walbaum, 1792) & Alóctono & $\begin{array}{l}\text { Sedentaria y } \\
\text { anádroma }\end{array}$ & NC \\
\hline Salmonidae & Oncorhynchus kisutch (Walbaum, 1792) & Alóctono & $\begin{array}{l}\text { Sedentaria y } \\
\text { potamódroma }\end{array}$ & NC \\
\hline Salmonidae & Salmo salar (Linnaeus, 1758) & Nativo & Anádroma & PM \\
\hline Salmonidae & Salvelinus fontinalis (Mitchell, 1815) & Alóctono & Sedentaria & NC \\
\hline Salmonidae & Hucho hucho (Linnaeus, 1758) & Alóctono & Potamódroma & EP \\
\hline Salmonidae & Salmo trutta (Linnaeus, 1758) & Nativo & $\begin{array}{l}\text { Anádroma y } \\
\text { potamódroma }\end{array}$ & PM \\
\hline Siluridae & Silurus glanis (Linnaeus, 1758) & Alóctono & Sedentaria & PM \\
\hline Syngnathidae & Syngnathus abaster (Risso, 1827) & Nativo & Sedentaria & PM \\
\hline Valenciidae & Valencia hispanica (Valenciennes, 1846) & Nativo & Sedentaria & CR \\
\hline
\end{tabular}




\section{A.2. HOJA DE CÁLCULO PARA LA APLICACIÓN DE LA METODOLOGÍA AEPS}




\section{A.2. HOJA DE CÁLCULO PARA LA APLICACIÓN DE LA METODOLOGÍA AEPS}

A continuación, se presenta una herramienta informática que automatiza el uso de la metodología AEPS. De esta forma, se simplifica y agiliza su empleo para cualquier persona que quiera utilizarla. Se trata de una herramienta que consiste en un libro de Excel, cuyo formato resulta familiar para la mayoría de los usuarios potenciales, y puede utilizarse sin necesidad de aplicaciones específicas en diferentes soportes electrónicos: teléfonos móviles, tabletas, y ordenadores portátiles o de sobremesa. El libro incluye un total de once hojas con distinta información; cinco de ellas son visibles para cualquier usuario, mientras que las seis restantes están ocultas.

\section{A.2.1. HOJAS VISIBLES}

Pueden ser consultadas desde el momento en que se abre el libro de Excel. Presentan tres tipos de celdas: que pueden ser editadas libremente, bloqueadas para no ser sobrescritas, y listas desplegables en las que se selecciona la opción que mejor se ajusta a cada caso. Entre estas hojas encontramos:

Tabla A.2.1. Hojas visibles de la herramienta que automatiza el uso de la metodología AEPS.

\begin{tabular}{|c|c|c|c|}
\hline HOJA & INFORMACIÓN DE ENTRADA & INFORMACIÓN DE SALIDA & CELDAS \\
\hline $\begin{array}{c}\text { Instrucciones de } \\
\text { uso }\left({ }^{1}\right)\end{array}$ & - & $\begin{array}{l}\text { Anotaciones sobre cómo } \\
\text { utilizar la herramienta }\end{array}$ & Bloqueadas \\
\hline $\begin{array}{l}\text { Información } \\
\text { inicial }\left({ }^{1}\right)\end{array}$ & $\begin{array}{c}\text { Información de campo y de la } \\
\text { hoja Anejo cálculo de } \\
\text { caudales }\end{array}$ & - & $\begin{array}{l}\text { Editables, } \\
\text { bloqueadas y } \\
\text { listas }\end{array}$ \\
\hline Evaluación $\left({ }^{1}\right)$ & $\begin{array}{c}\text { Hojas Puntuación ATRACCIÓN, } \\
\text { ENTRADA y SALIDA, y } \\
\text { ponderación parámetros } \\
\text { pasaje }\end{array}$ & $\begin{array}{l}\text { Puntuación, evaluación y } \\
\text { mejoras de los parámetros } \\
\text { estudiados }\end{array}$ & $\begin{array}{l}\text { Editables y } \\
\text { bloqueadas }\end{array}$ \\
\hline $\begin{array}{l}\text { Anejo cálculo de } \\
\text { caudales }\left({ }^{1}\right)\end{array}$ & Hoja Información inicial & Caudal que circula por el paso & Bloqueadas \\
\hline $\begin{array}{c}\text { Croquis } \\
\text { explicativos }\left({ }^{1}\right)\end{array}$ & - & $\begin{array}{c}\text { Esquemas de parámetros a } \\
\text { evaluar en el paso }\end{array}$ & Bloqueadas \\
\hline
\end{tabular}


a

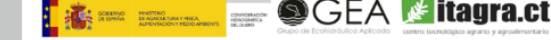

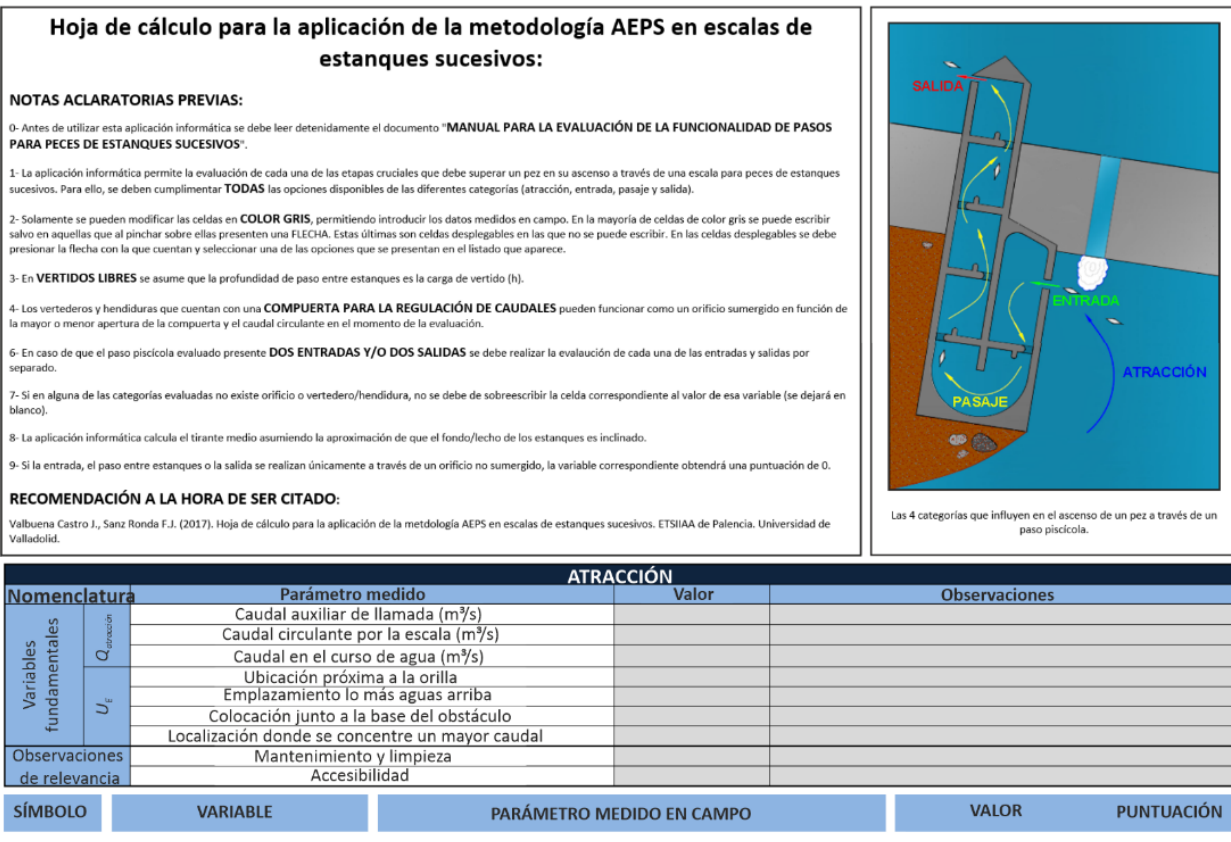

C
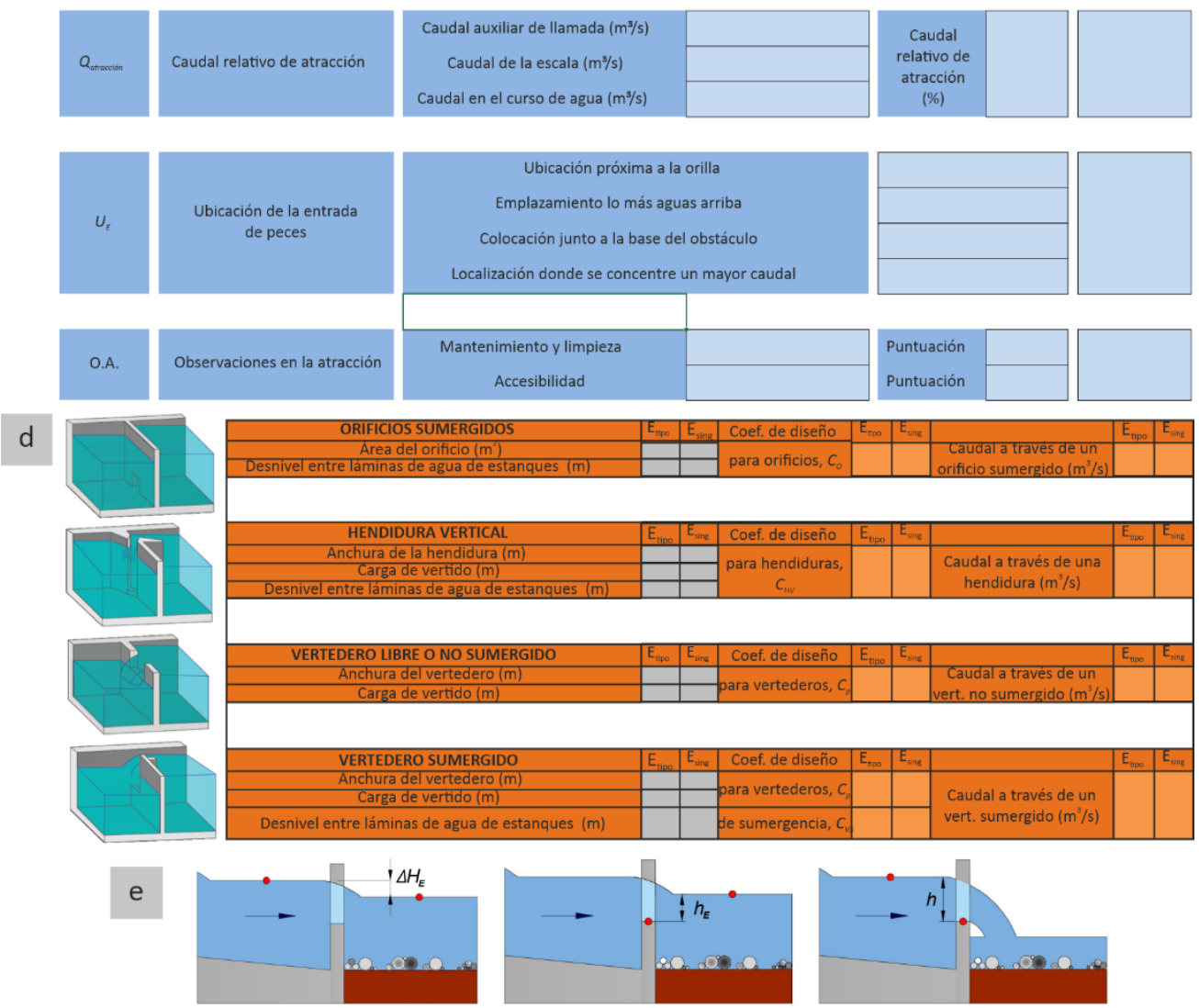

Figura A.2.1. Partes de las hojas visibles de la herramienta informática: instrucciones de uso (a), información inicial (b), evaluación (c), anejo cálculo de caudales (d), y croquis explicativos (e) (Qatracción caudal relativo de atracción, $U_{E}$ - ubicación de la entrada de peces, $E_{\text {tipo }}$ - estanque tipo, $E_{\text {sing }}$ - estanque singular, $C_{O}$ - coeficiente adimensional de descarga para orificios, $C_{H V}$ - coeficiente adimensional de descarga para hendiduras verticales, $C_{p}$ - coeficiente adimensional de descarga a través de vertederos no sumergidos, $C_{V S}$ - coeficiente adimensional de descarga a través de un vertedero sumergido, $\Delta H_{E}-$ desnivel entre la lámina de agua del río y del estanque inferior, $h_{E}$ - profundidad en la entrada, $h$ - carga de vertido). 


\section{A.2.2. HOJAS OCULTAS}

Estas hojas no son editables y aplican la información de la escala a la metodología AEPS mediante distintos comandos y macros de Excel. Puntúan y evalúan los parámetros estudiados con operaciones que van desde medias aritméticas o geométricas, hasta estimaciones de una variable respuesta a partir de funciones. Sus resultados se plasman automáticamente en la hoja visible "evaluación". Las hojas ocultas que contiene el libro son:

Tabla A.2.2. Hojas ocultas de la herramienta informática que contiene la metodología AEPS.

\section{HOJA} INFORMACIÓN DE ENTRADA

Desplegables

Puntuación

ATRACCIÓN

Hoja Información inicial (Tabla

$\begin{array}{cc}\begin{array}{c}\text { Puntuación } \\ \text { ENTRADA }\end{array} & \text { Hoja Información inicial (Tabla } \\ \text { A.2.1) } \\ \begin{array}{c}\text { Puntuación } \\ \text { PASAJE }\end{array} & \text { Hoja Información inicial (Tabla } \\ & \text { A.2.1) }\end{array}$

Ponderación parámetros pasaje

Puntuación SALIDA
Hoja Puntuación PASAJE

Hoja Información inicial (Tabla

A.2.1)

\section{INFORMACIÓN DE SALIDA}

Listas desplegables para la hoja Información inicial

Criterios de evaluación y

puntuación de parámetros Bloqueadas estudiados

Criterios de evaluación y

puntuación de parámetros Bloqueadas estudiados

Criterios de evaluación y

puntuación de parámetros Bloqueadas estudiados

Puntuación ponderada de los

parámetros del pasaje según Bloqueadas el número de estanques

Criterios de evaluación y puntuación de parámetros estudiados

\section{CELDAS}

Bloqueadas

Bloqueadas 


\section{A.3. EJEMPLO DE APLICACIÓN PRÁCTICA DE LA METODOLOGÍA}




\section{A.3. EJEMPLO DE APLICACIÓN PRÁCTICA DE LA METODOLOGÍA}

En este apartado se detalla el uso de la metodología AEPS para evaluar una escala de artesas localizada en la cuenca hidrográfica del Duero. Este anejo se divide en tres apartados: caso de estudio, información recogida en campo y análisis de las efectividades (Tabla A.3.1).

Tabla A.3.1. Esquema de utilización de la metodología AEPS.

\begin{tabular}{|c|c|}
\hline APARTADO & PROCESO REALIZADO \\
\hline Caso de estudio & Descripción del paso para peces y otros aspectos relevantes. \\
\hline Información recogida en campo & Recopilación de información de los parámetros a evaluar. \\
\hline \multirow{9}{*}{$\begin{array}{l}\text { Análisis de las efectividades } \\
\qquad \text { (para cada etapa) }\end{array}$} & Cálculo de las variables fundamentales no medidas en campo. \\
\hline & Puntuación de las variables fundamentales. \\
\hline & $\begin{array}{l}\text { Ponderación de las puntaciones de las variables fundamentales } \\
\text { del pasaje. }\end{array}$ \\
\hline & Evaluación de las variables fundamentales. \\
\hline & Puntuación de las observaciones de relevancia. \\
\hline & $\begin{array}{l}\text { Ponderación de las puntaciones de las observaciones de } \\
\text { relevancia del pasaje. }\end{array}$ \\
\hline & Evaluación de las observaciones de relevancia \\
\hline & $\begin{array}{l}\text { Puntuación de cada etapa a partir de sus variables } \\
\text { fundamentales y observaciones de relevancia }\end{array}$ \\
\hline & $\begin{array}{l}\text { Evaluación de cada etapa a partir de sus variables } \\
\text { fundamentales y observaciones de relevancia. }\end{array}$ \\
\hline
\end{tabular}

La metodología puede aplicarse sobre cualquier paso manualmente (Confederación Hidrográfica del Duero 2016), o automáticamente gracias a la herramienta presentada en el anejo anterior (véase el anejo "A.2. Hoja de cálculo para la aplicación de la metodología AEPS").

\section{A.3.1. CASO DE ESTUDIO}

El paso para peces elegido se ubica en el río Arlanzón a su paso por la ciudad de Burgos (España), en el norte de la Península Ibérica (ETRS 89 HUSO 30, X: 440.037 m, Y: 4.688.296 m). Está construido junto a la margen izquierda del río (en dirección hacia aguas abajo), sobre el azud de los Canales del Arlanzón (código 1005946; Confederación Hidrográfica del Duero 2020b) (Figura A.3.1). Este azud es de hormigón, 
y cuenta con una altura desde cimientos de $3,0 \mathrm{~m}$ y una longitud de coronación de 60 m.

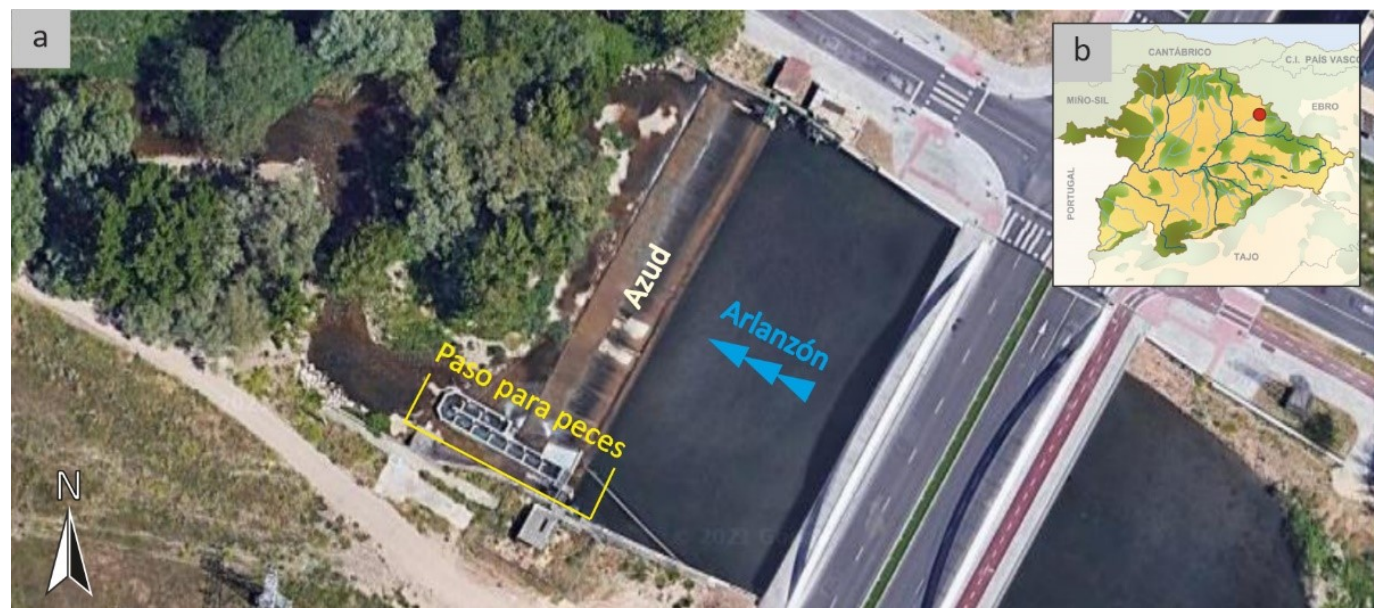

Figura A.3.1. Ubicación del paso para peces en el río Arlanzón (a) (fuente: Google Maps) y en la cuenca hidrográfica del Duero (b).

La mayor parte del caudal del río se deriva para uso agrícola e industrial, mientras que el resto circula por el azud y la escala de peces. El caudal que no se deriva permite conservar el ecosistema fluvial aguas abajo de la captación y recibe el nombre de caudal ecológico a efectos de este trabajo, que en esta parte del río debe ser al menos de $0,80 \mathrm{~m}^{3} / \mathrm{s}$.

En este tramo habitan varias especies autóctonas de peces. Esas especies son la trucha común (Salmo trutta), el barbo común ibérico (Luciobarbus bocagei), la boga del Duero (Pseudochondrostoma duriense), la bermejuela (Achondrostoma arcasii) y el gobio (Gobio lozanoi) (Confederación Hidrográfica del Duero 2020b). En concreto, las especies para las que se evalúa el funcionamiento de la escala son tres: la trucha, el barbo y la boga.

La información necesaria para la evaluación se ha recogido durante una visita al paso para peces llevada a cabo a las 17:00 h del 18 de julio de 2019. En ese momento, el desnivel entre las láminas de agua a ambos lados del azud ha sido de 2,02 $\mathrm{m}$ y el caudal que circulaba por el río ha sido de $1,72 \mathrm{~m}^{3} / \mathrm{s}$ (estación de aforos 2139 , código SAIH). La accesibilidad al paso, su mantenimiento y limpieza han sido muy adecuados. La escala cuenta con hendiduras verticales que conectan nueve estanques, dos de ellos singulares, es decir, distintos a la mayoría (Figura A.3.2). 

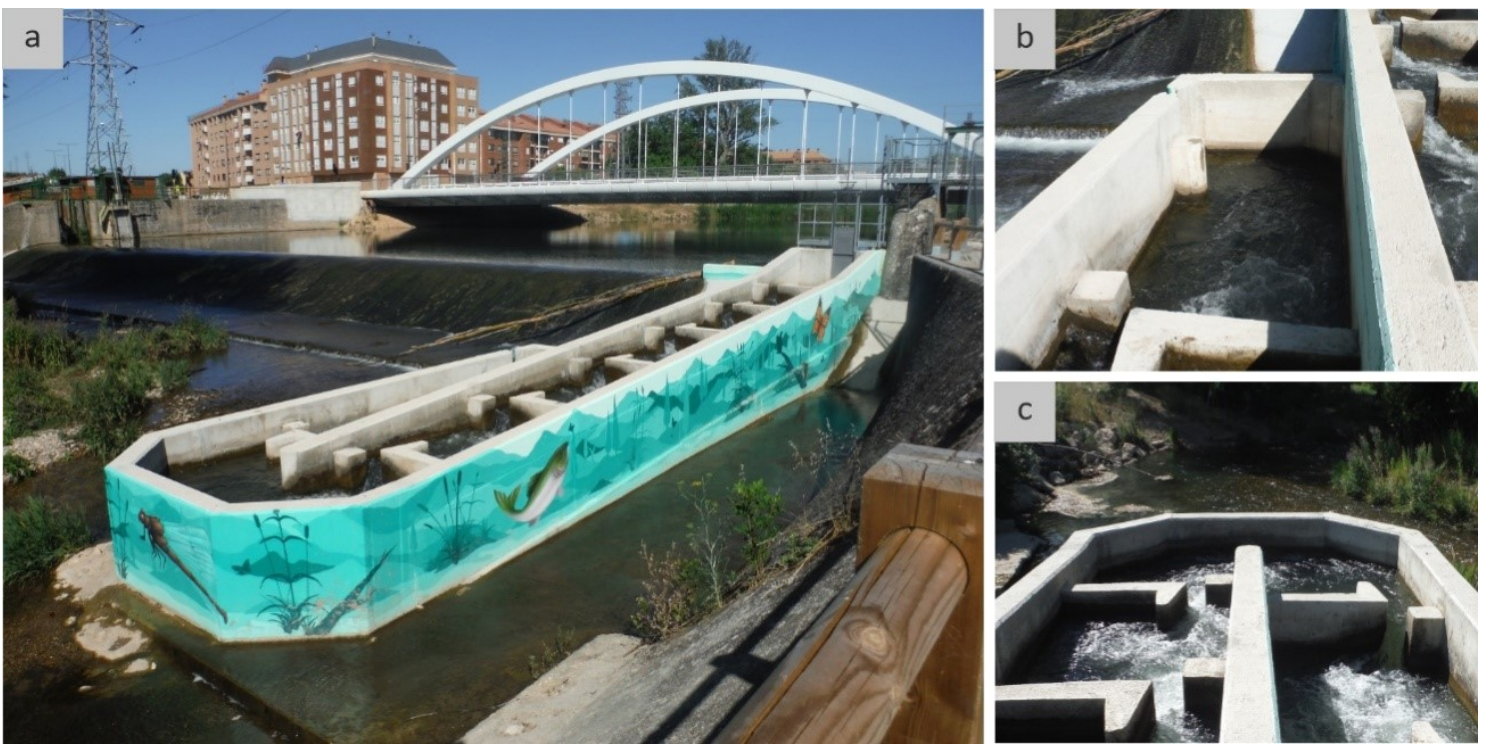

Figura A.3.2. Escala evaluada (a) y sus estanques singulares: el inferior (b) y uno en curva que es el tercero desde aguas abajo (c).

\section{A.3.2. INFORMACIÓN RECOGIDA EN CAMPO}

Siguiendo el procedimiento explicado en la memoria de este trabajo (véase el apartado "3.4.2. Recopilación de información en campo"), se ha recogido la información necesaria para aplicar la metodología AEPS a la escala.

\section{A.3.2.1. ATRACCIÓN}

La atracción de los peces hacia el paso se ve favorecida por un rebaje de 1,0 $\mathrm{m}$ de ancho en la coronación del azud. El caudal que vierte llega a la base del obstáculo, a menos de 2,0 m de la entrada de la escala. Durante la visita, se ha medido una carga de vertido en el rebaje que superaba ligeramente los 0,18 m (Tabla A.3.2 y figura A.3.3).

Una parte importante del caudal del río circula por el rebaje y la escala. El resto se reparte por toda la coronación del obstáculo, generando una atracción uniforme y reducida para los peces.

El azud es perpendicular al río (Figura A.3.1), por lo que todas las posibles ubicaciones de la escala estarían igual de aguas arriba en la sección. Entre el paso y la margen más cercana existe una compuerta para el vaciado del azud que permite realizar labores de mantenimiento, limpieza, etc. La compuerta permanece abierta únicamente en momentos puntuales, por lo que normalmente no existe ningún vertido entre la escala y la orilla que pueda atraer a los peces. Así, y de acuerdo con lo que indica la metodología, para la evaluación se considera que la escala está junto a la orilla. 
Tabla A.3.2. Información referente a la atracción de la escala.

\begin{tabular}{|c|c|c|c|}
\hline \multicolumn{2}{|c|}{ VARIABLES FUNDAMENTALES } & \multicolumn{2}{|c|}{ OBSERVACIONES DE RELEVANCIA } \\
\hline PARÁMETRO & MEDICIÓN & PARÁMETRO & MEDICIÓN \\
\hline $\begin{array}{l}\text { Anchura del rebaje para la } \\
\text { llamada }\end{array}$ & $1,0 \mathrm{~m}$ & $\begin{array}{l}\text { Mantenimiento y } \\
\text { limpieza }\end{array}$ & Muy adecuado \\
\hline $\begin{array}{c}\text { Carga de vertido en el } \\
\text { rebaje }\end{array}$ & $\approx 0,18 \mathrm{~m}$ & Accesibilidad & Muy adecuado \\
\hline $\begin{array}{l}\text { Caudal en el tramo de río } \\
\text { (caudal ecológico) }\end{array}$ & $0,80 \mathrm{~m}^{3} / \mathrm{s}$ & & \\
\hline $\begin{array}{l}\text { Colocación junto a la base } \\
\text { del obstáculo }\end{array}$ & Muy adecuado & & \\
\hline $\begin{array}{l}\text { Instalación donde se } \\
\text { concentre un mayor caudal }\end{array}$ & Muy adecuado & & \\
\hline $\begin{array}{l}\text { Emplazamiento aguas } \\
\text { arriba }\end{array}$ & Muy adecuado & & \\
\hline $\begin{array}{c}\text { Ubicación próxima a la } \\
\text { orilla }\end{array}$ & Muy adecuado & & \\
\hline
\end{tabular}
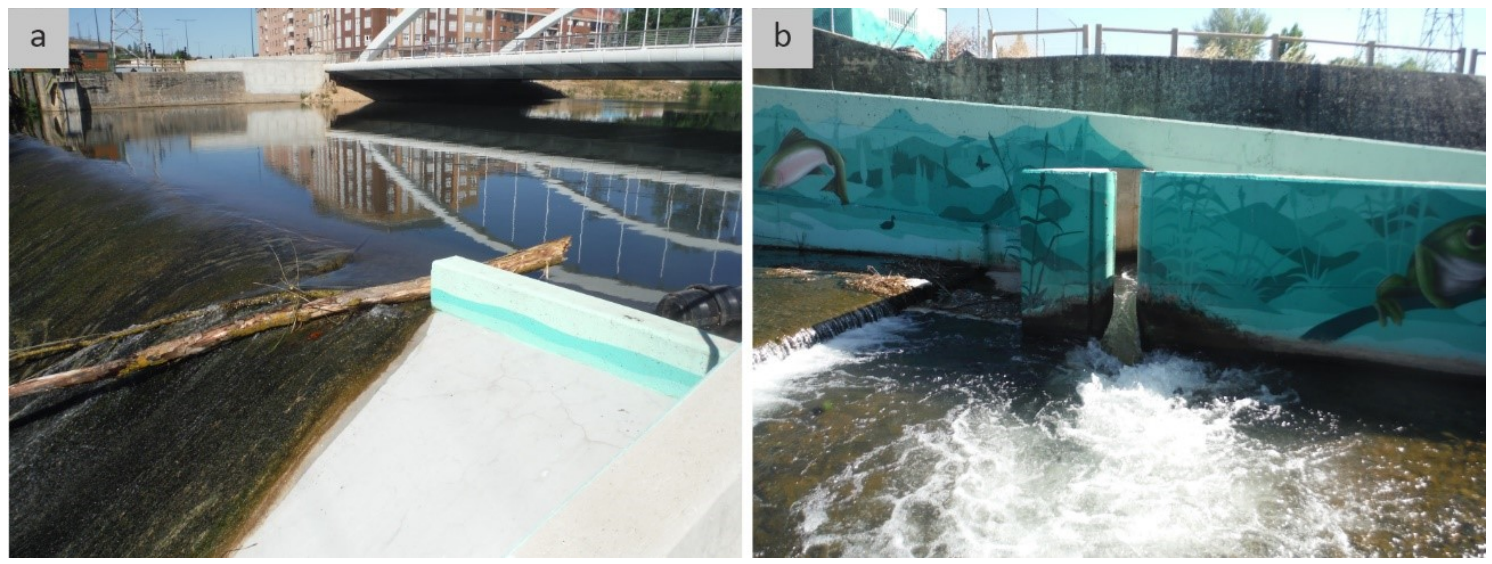

Figura A.3.3. Rebaje en el azud para la llamada (a) y la base del obstáculo junto a la entrada de peces (b).

\section{A.3.2.2. ENTRADA}

La entrada de los peces se realiza a través de un vertedero sumergido de 0,21 $\mathrm{m}$ de ancho que se orienta perpendicular al eje hidráulico del río. Cuenta con dos ranuras que permiten colocar tablones para regular la altura de su umbral y el salto entre las láminas de agua (Figura A.3.4.b). Durante la visita, el desnivel entre la lámina de agua del estanque inferior y del río ha sido de 0,31 $\mathrm{m}$, y la profundidad de agua en el vertedero de 0,21 m. La profundidad previa a la entrada ha sido de 0,70 m. Aparte del caudal que circula por la escala y por el rebaje del azud, no existe ningún otro lo suficientemente importante como para atraer a los peces (Tabla A.3.3 y figura A.3.4). 
Tabla A.3.3. Parámetros estudiados en la entrada de la escala.

\begin{tabular}{|c|c|c|c|}
\hline \multicolumn{2}{|c|}{ VARIABLES FUNDAMENTALES } & \multicolumn{2}{|c|}{ OBSERVACIONES DE RELEVANCIA } \\
\hline PARÁMETRO & MEDICIÓN & PARÁMETRO & MEDICIÓN \\
\hline $\begin{array}{l}\text { Desnivel entre la lámina de } \\
\text { agua del río y del estanque } \\
\text { inferior }\left(\Delta H_{E}\right)\end{array}$ & $0,31 \mathrm{~m}$ & $\begin{array}{l}\text { Mantenimiento y } \\
\text { limpieza }\end{array}$ & Muy adecuado \\
\hline $\begin{array}{l}\text { Profundidad en la entrada } \\
\qquad\left(h_{E}\right)\end{array}$ & $0,38 m$ & $\begin{array}{l}\text { Elementos para la } \\
\text { regulación del salto } \\
\text { entre láminas de agua }\end{array}$ & Muy adecuado \\
\hline Anchura de la entrada $\left(b_{E}\right)$ & $0,21 \mathrm{~m}$ & $\begin{array}{c}\text { Descargas de flujo en la } \\
\text { entrada }\end{array}$ & Muy adecuado \\
\hline $\begin{array}{l}\text { Profundidad previa a la } \\
\text { entrada }\left(h_{\text {previa } E}\right)\end{array}$ & $0,70 \mathrm{~m}$ & $\begin{array}{c}\text { Ausencia de otras } \\
\text { descargas de flujo que } \\
\text { alejen el pez de la escala }\end{array}$ & Muy adecuado \\
\hline $\begin{array}{l}\text { Orientación de la entrada } \\
\text { respecto del río }\left(O r t_{E}\right)\end{array}$ & $\begin{array}{c}\text { Zona A } \\
\left(0^{\circ} \leq \alpha \leq 90^{\circ}\right)\end{array}$ & Aristas redondeadas & Muy adecuado \\
\hline Tipología de la entrada $\left(T_{E}\right)$ & $\begin{array}{l}\text { Vertedero } \\
\text { sumergido }\end{array}$ & Accesibilidad & Muy adecuado \\
\hline
\end{tabular}
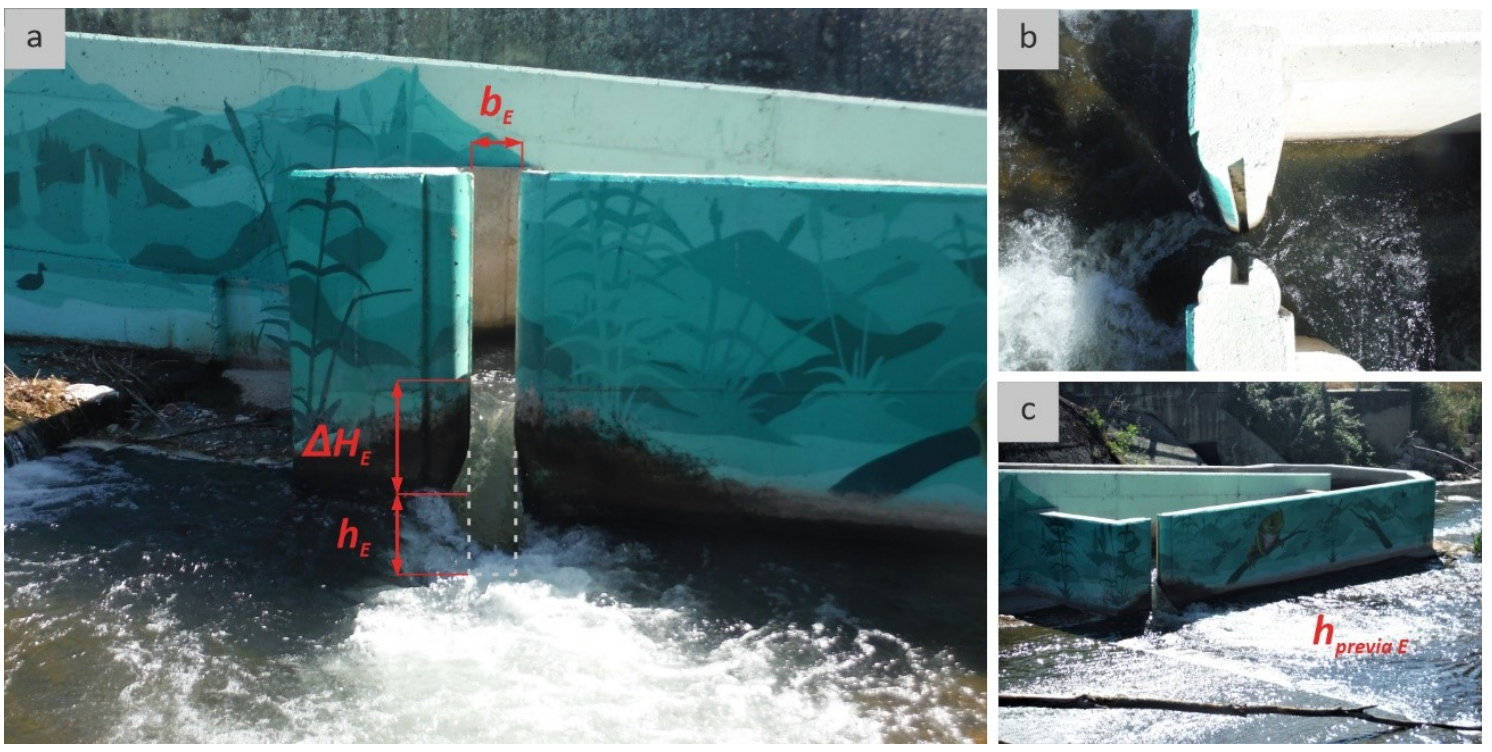

Figura A.3.4. Algunas variables de la entrada (a), ranuras para regular la altura del vertedero (b) y lugar de medición de la profundidad previa (c) $\left(\Delta H_{E}\right.$ - desnivel entre la lámina de agua del río y del estanque inferior, $h_{E}$ - profundidad en la entrada, $b_{E}$ - anchura de la entrada, $h_{\text {previa } E}$ - profundidad previa a la entrada).

\section{A.3.2.3. PASAJE}

La escala cuenta con siete estanques tipo de 1,70 m de ancho y 2,20 m de largo que conectan entre sí por hendiduras verticales de 0,20 $\mathrm{m}$ de anchura. Además, presenta 
dos estanques singulares: el inferior y uno en curva (tercero desde aguas abajo). El estanque inferior presenta una anchura de $1,70 \mathrm{~m}$ y una longitud de 3,35 $\mathrm{m}$. El estanque en curva tiene una anchura de $3,70 \mathrm{~m}$ y una longitud de $2,45 \mathrm{~m}$. Todas las artesas cuentan con deflectores, naturalización mediante piedras fijadas a la solera y resguardos laterales suficientes para evitar la salida de los peces en caso de que salten. Se trata de una escala en un buen estado de conservación. Durante las mediciones, el desnivel promedio entre las láminas de agua de los estanques tipo ha sido de 0,20 m y la profundidad de agua en las hendiduras ha sido de 0,73 m (Tabla A.3.4 y figura A.3.5).

Tabla A.3.4. Datos recogidos en campo sobre el pasaje.

\begin{tabular}{|c|c|c|c|}
\hline \multicolumn{2}{|c|}{ VARIABLES FUNDAMENTALES } & \multicolumn{2}{|c|}{ OBSERVACIONES DE RELEVANCIA } \\
\hline PARÁMETRO & MEDICIÓN & PARÁMETRO & MEDICIÓN \\
\hline $\begin{array}{c}\text { Desnivel entre láminas de } \\
\text { agua de estanques } \\
\text { sucesivos }\left(\Delta H_{P_{S}}\right)\end{array}$ & $0,20 \mathrm{~m}\left({ }^{1}\right), 0,26 \mathrm{~m}\left({ }^{2}\right), 0,14 \mathrm{~m} \mathrm{({ } ^ { 3 } )}$ & $\begin{array}{l}\text { Mantenimiento y } \\
\text { limpieza }\end{array}$ & Muy adecuado \\
\hline Longitud del estanque $(L)$ & $2,20 \mathrm{~m}\left({ }^{1}\right), 3,35 \mathrm{~m}\left({ }^{2}\right), 2,45 \mathrm{~m} \mathrm{({ } ^ { 3 } )}$ & $\begin{array}{l}\text { Deflectores en los } \\
\text { estanques }\end{array}$ & Muy adecuado \\
\hline Anchura del estanque $(B)$ & $1,70 \mathrm{~m}\left({ }^{1,2}\right), 3,70 \mathrm{~m}\left({ }^{3}\right)$ & $\begin{array}{l}\text { Forma de los } \\
\text { estanques }\end{array}$ & Adecuado \\
\hline $\begin{array}{l}\text { Carga de vertido } \\
\left(h=\Delta H_{P_{S}}+h_{P_{s}}\right)\end{array}$ & $0,93 \mathrm{~m}\left({ }^{1}\right), 0,91 \mathrm{~m}\left({ }^{2}\right), 0,96 \mathrm{~m}\left({ }^{3}\right)$ & $\begin{array}{c}\text { Conservación de la } \\
\text { estructura }\end{array}$ & Muy adecuado \\
\hline $\begin{array}{l}\text { Profundidad de paso } \\
\text { entre estanques }\left(h_{P S}\right)\end{array}$ & $0,73 \mathrm{~m}\left({ }^{1}\right), 0,65 \mathrm{~m}\left({ }^{2}\right), 0,82 \mathrm{~m}\left({ }^{3}\right)$ & $\begin{array}{c}\text { Solera naturalizada } \\
\text { con piedras }\end{array}$ & Muy adecuado \\
\hline $\begin{array}{c}\text { Anchura de paso entre } \\
\text { estanques }\left(b_{P_{S}}\right)\end{array}$ & $0,20 \mathrm{~m}(1,2,3)$ & Aristas redondeadas & Adecuado \\
\hline \multirow[t]{3}{*}{$\begin{array}{l}\text { Tipología del paso } \\
\text { (conexión) entre } \\
\text { estanques }\left(T_{P_{S}}\right)\end{array}$} & Hendidura vertical $(1,2,3)$ & $\begin{array}{l}\text { Oscuridad por } \\
\text { elementos que } \\
\text { cubren la escala }\end{array}$ & Muy adecuado \\
\hline & & $\begin{array}{l}\text { Resguardo en los } \\
\text { estanques }\end{array}$ & Muy adecuado \\
\hline & & Accesibilidad & Muy adecuado \\
\hline \multicolumn{4}{|l|}{$\left.{ }^{1}\right)$ Estanque tipo. } \\
\hline singular inferic & & & \\
\hline
\end{tabular}



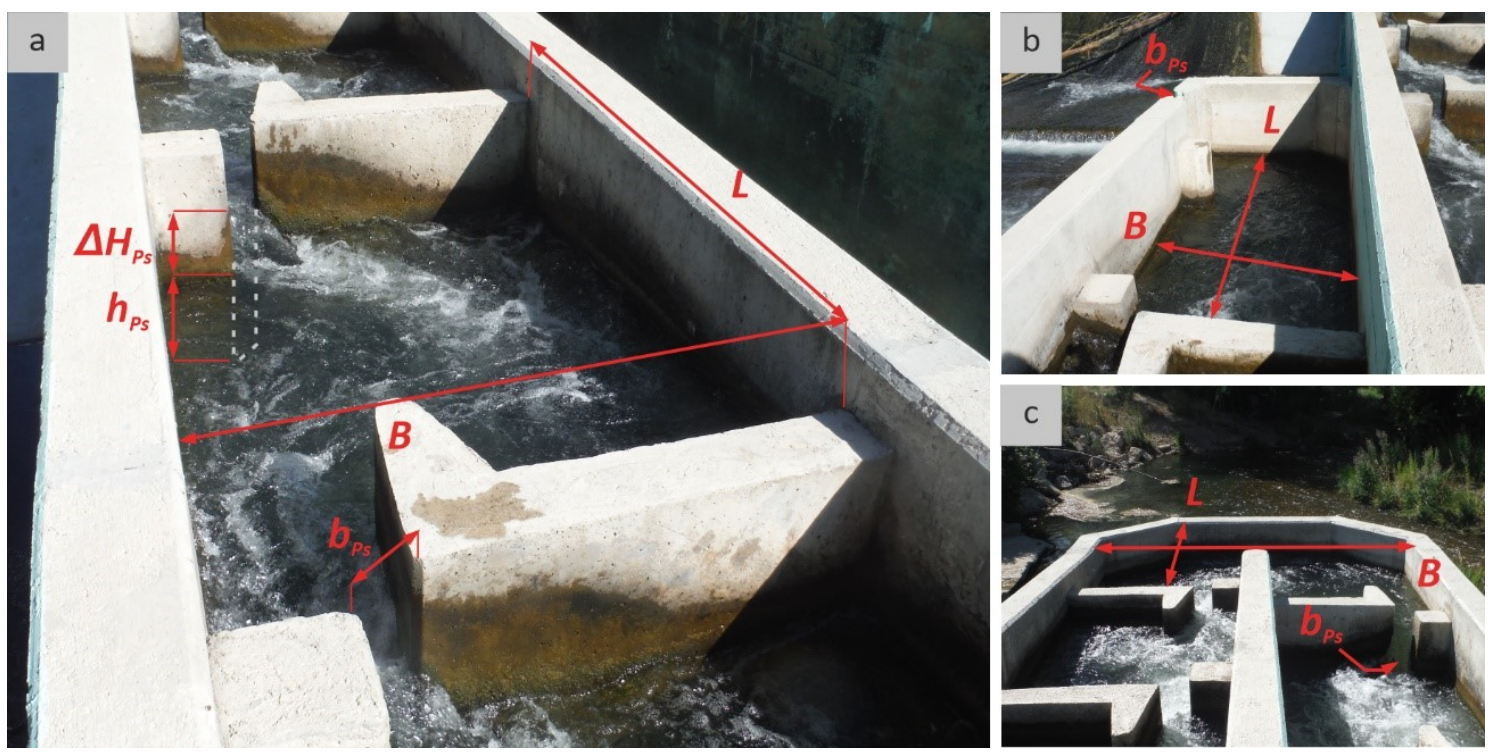

Figura A.3.5. Algunas variables estudiadas en un estanque tipo $\left(\Delta H_{p_{s}}-\right.$ desnivel entre láminas de agua de estanques sucesivos, $B$ - anchura del estanque, $L$ - longitud del estanque, $h_{P_{S}}$ - profundidad de paso, $b_{P_{S}}$ - anchura de paso).

\section{A.3.2.4. SALIDA}

La salida de los peces se hace a través de una hendidura vertical de 0,55 $\mathrm{m}$ de ancho que se orienta paralela al eje hidráulico del río, pero en sentido contrario a la corriente. Cuenta con una compuerta para regular el caudal del paso y una barrera flotante contra la entrada de restos arrastrados por la corriente (Figura A.3.6.a y b). En el momento de la visita, el desnivel entre la lámina de agua del río y del estanque superior ha sido de 0,10 $\mathrm{m}$ y la profundidad de agua de 0,38 m. Aguas arriba de la salida se ha medido una profundidad de 0,49 m. La salida de los peces es segura, ya que se realiza suficientemente alejada de la coronación del azud y de la captación de caudal (Tabla A.3.5 y figura A.3.6.c).

Tabla A.3.5. Parámetros analizados en la salida de la escala.

\begin{tabular}{|c|c|c|c|}
\hline \multicolumn{2}{|c|}{ VARIABLES FUNDAMENTALES } & \multicolumn{2}{|c|}{ OBSERVACIONES DE RELEVANCIA } \\
\hline PARÁMETRO & MEDICIÓN & PARÁMETRO & MEDICIÓN \\
\hline $\begin{array}{c}\text { Desnivel entre la lámina de } \\
\text { agua en el río y en el } \\
\text { estanque superior }\left(\Delta H_{s}\right)\end{array}$ & $0,10 \mathrm{~m}$ & $\begin{array}{l}\text { Mantenimiento y } \\
\text { limpieza }\end{array}$ & Muy adecuado \\
\hline $\begin{array}{l}\text { Profundidad en la salida } \\
\qquad\left(h_{s}\right)\end{array}$ & $0,38 \mathrm{~m}$ & $\begin{array}{l}\text { Compuerta de } \\
\text { regulación de caudales }\end{array}$ & Muy adecuado \\
\hline Anchura de la salida (bs) & $0,55 \mathrm{~m}$ & $\begin{array}{l}\text { Dispositivo contra la } \\
\text { entrada de arrastres }\end{array}$ & Muy adecuado \\
\hline
\end{tabular}




\begin{tabular}{cccc}
\multicolumn{2}{c}{ VARIABLES FUNDAMENTALES } & \multicolumn{2}{c|}{ OBSERVACIONES DE RELEVANCIA } \\
PARÁMETRO & MEDICIÓN & PARÁMETRO & MEDICIÓN \\
\hline $\begin{array}{c}\text { Profundidad posterior a la } \\
\text { salida ( } h_{\text {posterior } s)}\end{array}$ & $0,49 \mathrm{~m}$ & Salida segura & Muy adecuado \\
$\begin{array}{c}\text { Orientación de la salida } \\
\text { respecto del río }(\text { Orts })\end{array}$ & $\begin{array}{c}\text { Zona A } \\
\left(90^{\circ} \leq \alpha \leq 180^{\circ}\right)\end{array}$ & Aristas redondeadas & Muy adecuado \\
Tipología de la salida $(T s)$ & $\begin{array}{c}\text { Hendidura } \\
\text { vertical }\end{array}$ & Accesibilidad & Muy adecuado
\end{tabular}
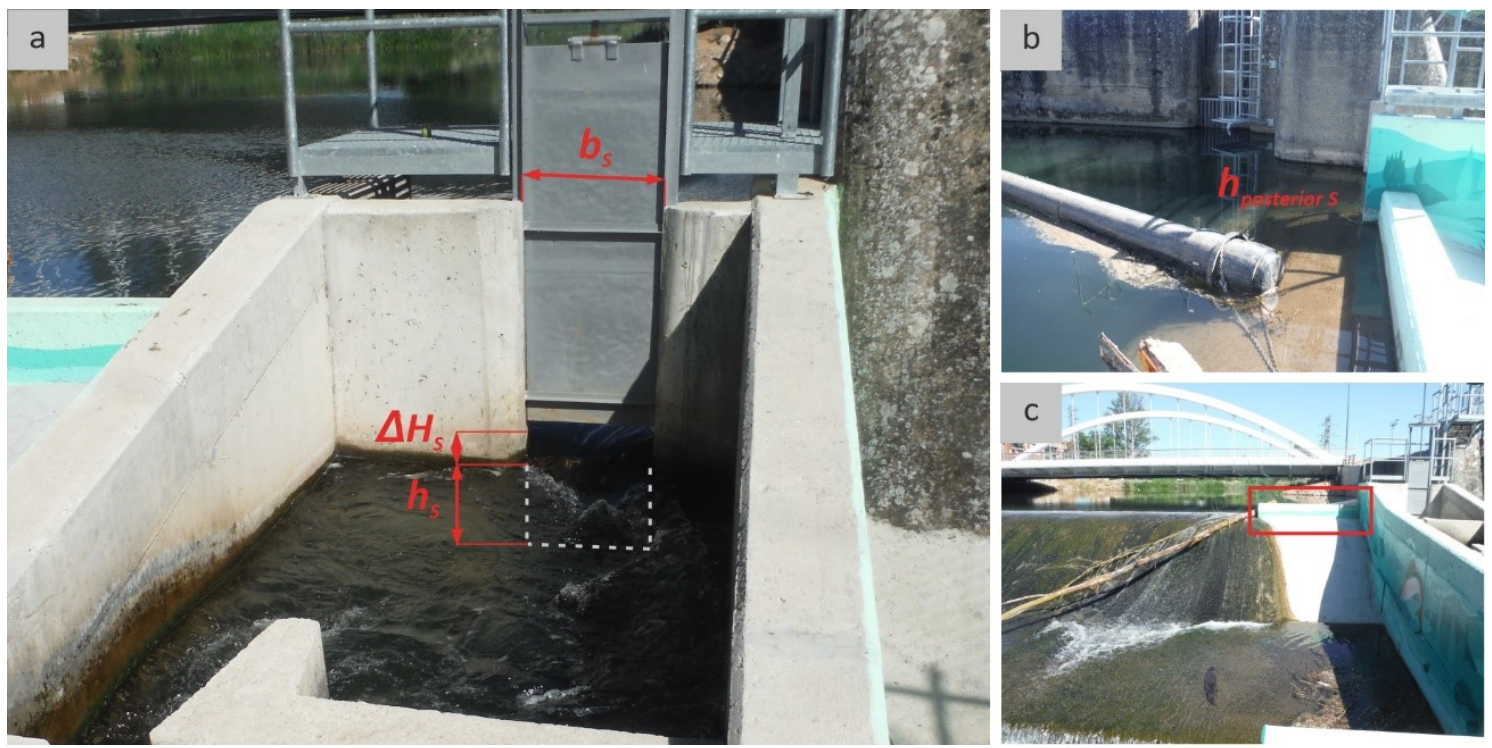

Figura A.3.6. Algunas variables de la salida y la compuerta para regular los caudales en el paso para peces (a), barrera contra los restos arrastrados por la corriente y lugar donde se mide la profundidad posterior a la salida (b) y recrecimiento (en rojo) para evitar la caída de los peces cuando salen (c) $\left(\Delta H_{S}-\right.$ desnivel entre la lámina de agua en el río y en el estanque superior, $h_{s}$ - profundidad en la salida, $b_{s}-$ anchura de la salida, $h_{\text {posterior } s}$ - profundidad posterior a la salida).

\section{A.3.3. ANÁLISIS DE LAS EFECTIVIDADES}

\section{A.3.3.1. VARIABLES FUNDAMENTALES}

A partir de la información recogida en campo, se han calculado algunas variables fundamentales que no se miden directamente en campo, pero que sí considera la metodología. Después se han valorado y evaluado todas ellas (Tabla A.3.6). 
Tabla A.3.6. Criterios para evaluar las variables fundamentales por separado y en conjunto para cada una de las etapas.

\section{PUNTUACIÓN RESULTADO DE LA EVALUACIÓN MODIFICACIONES O MEJORAS}

\begin{tabular}{|c|c|c|}
\hline $0 \leq$ Parámetro $\leq 4$ & Muy desfavorable & Imprescindibles o evaluación biológica \\
\hline $4<$ Parámetro $\leq 6$ & Desfavorable & Muy necesarias o evaluación biológica \\
\hline $6<$ Parámetro $\leq 8$ & Favorable & Recomendables \\
\hline $8<$ Parámetro $\leq 10$ & Muy favorable & Opcionales \\
\hline
\end{tabular}

\section{A.3.3.1.1. ATRACCIÓN}

En la atracción, las variables calculadas a partir de la información recogida en campo son el caudal relativo de atracción (Qatración), y la puntuación de la ubicación de la entrada $\left(U_{E}\right)$. Para el cálculo del caudal relativo de atracción debemos conocer el que circula por el rebaje del azud. Para ello, se ha utilizado la fórmula para vertederos libres o no sumergidos:

$$
\begin{aligned}
Q_{V L} & =\frac{2}{3} \cdot C_{p} \cdot b \cdot h^{1,5} \cdot \sqrt{2 \cdot g} \\
C_{p} & =0,689 \cdot\left(1-\mathrm{e}^{-8,889 \cdot h}\right)
\end{aligned}
$$

donde $Q_{V L}$ es el caudal a través de un vertedero no sumergido $\left(\mathrm{m}^{3} / \mathrm{s}\right), C_{p}$ es el coeficiente adimensional de descarga a través de vertederos no sumergidos, $b$ es la anchura de la conexión entre estanques (orificios, vertederos o hendiduras) ( $\mathrm{m}), h$ es la carga de vertido $(\mathrm{m}), \mathrm{y} g$ es la aceleración de gravedad $\left(9,81 \mathrm{~m} / \mathrm{s}^{2}\right)$. Sustituyendo en la expresión anterior:

$$
\begin{gathered}
Q_{V L}=\frac{2}{3} \cdot 0,689 \cdot\left(1-\mathrm{e}^{-8,889 \cdot 0,185}\right) \cdot 1,0 \cdot 0,185^{1,5} \cdot \sqrt{2 \cdot 9,81} \\
Q_{V L}=0,13 \mathrm{~m}^{3} / \mathrm{s}
\end{gathered}
$$

La escala que estamos evaluando presenta estanques que conectan entre sí por hendiduras verticales. Por ello, para calcular el caudal que circula a través del paso, se ha empleado la ecuación de gasto para este tipo de conexiones con los coeficientes ajustados por Fuentes-Pérez et al. $(2014,2016)$ : 


$$
\begin{gathered}
Q_{H V}=\frac{2}{3} \cdot C_{H V} \cdot b \cdot h^{1,5} \cdot \sqrt{2 \cdot g} \\
C_{H V}=0,72 \cdot\left[1-\left(\frac{h-\Delta H}{h}\right)^{1,5}\right]^{0,385}
\end{gathered}
$$

donde $Q_{H V}$ es el caudal a través de una hendidura vertical $\left(\mathrm{m}^{3} / \mathrm{s}\right), C_{H V}$ es el coeficiente adimensional de descarga para hendiduras verticales, $b$ es la anchura de las hendiduras $(\mathrm{m}), h$ es la carga de vertido $(\mathrm{m}), g$ es la aceleración de gravedad $\left(9,81 \mathrm{~m} / \mathrm{s}^{2}\right), y \Delta H$ es el desnivel entre dos láminas de agua sucesivas $(\mathrm{m})$. De acuerdo con los valores medidos en campo:

$$
\begin{gathered}
Q_{H V}=\frac{2}{3} \cdot 0,72 \cdot\left[1-\left(\frac{0,94-0,20}{0,94}\right)^{1,5}\right]^{0,385} \cdot 0,20 \cdot 0,94^{1,5} \cdot \sqrt{2 \cdot 9,81} \\
Q_{H V}=0,26 \mathrm{~m}^{3} / \mathrm{s}
\end{gathered}
$$

Ya disponemos de la información necesaria para calcular el caudal relativo de atracción (Qatracción):

$$
\begin{aligned}
& Q_{\text {Ilamada }}=Q_{\text {escala }}+Q_{\text {auxiliar }} \\
& Q_{\text {atracción }}=\frac{Q_{\text {Ilamada }}}{Q_{\text {curso }}} \cdot 100
\end{aligned}
$$

donde $Q_{l l a m a d a}$ es el caudal total que atrae a los peces hacia las proximidades de la entrada del paso $\left(\mathrm{m}^{3} / \mathrm{s}\right), Q_{\text {escala }}$ es el que circula por el paso $\left(\mathrm{m}^{3} / \mathrm{s}\right), Q_{\text {auxiliar }}$ es el que ayuda a la atracción de los peces (puede ser el que circula sobre el azud, rebajes, toboganes, tuberías, salida de turbinas cercanas, etc.) $\left(\mathrm{m}^{3} / \mathrm{s}\right)$, Qatracción es la proporción que supone el caudal de llamada respecto del total que circula por esa sección del cauce (\%), y $Q_{\text {curso }}$ es el caudal que circula por el curso de agua en la sección en que se encuentra el paso para peces durante la evaluación. Así:

$$
Q_{\text {llamada }}=0,26+0,13=0,39 \mathrm{~m}^{3} / \mathrm{s}
$$




$$
Q_{\text {atracción }}=\frac{0,39}{0,80} \cdot 100=48,8 \%
$$

Por otro lado, se ha calculado la puntuación de la ubicación de la entrada $\left(U_{E}\right)$, haciendo una media aritmética de las puntuaciones de los parámetros analizados para esta variable:

Tabla A.3.7. Valoración de los aspectos relacionados con la ubicación de la entrada de peces $\left(U_{E}\right)$.

\begin{tabular}{ccc} 
PARÁMETRO & MEDICIÓN & PUNTUACIÓN \\
Ubicación próxima a la orilla & Muy adecuado & 10 \\
Emplazamiento aguas arriba & Muy adecuado & 10 \\
Colocación junto a la base del obstáculo & Muy adecuado & 10 \\
Instalación donde se concentre un mayor caudal & Muy adecuado & 10 \\
\hline Ubicación de la entrada $\left(U_{E}\right)$ & - & 10
\end{tabular}

Después, las variables fundamentales se han evaluado e interpretado de acuerdo con lo recogido en la metodología AEPS (Figura A.3.7 y tabla A.3.8):

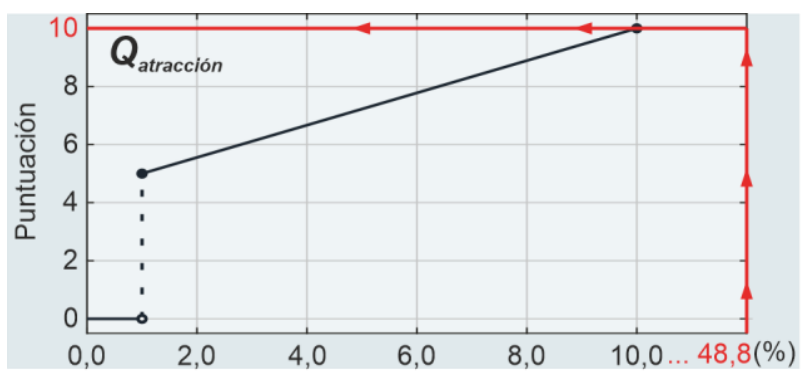

$\begin{array}{cc}\text { Nivel de idoneidad para la } \boldsymbol{U}_{\boldsymbol{E}} & \text { Punt. } \\ \text { Muy adecuado } & 10 \\ \text { Adecuado } & 6,7 \\ \text { Inadecuado } & 3,3 \\ \text { Muy inadecuado } & 0,0\end{array}$

Figura A.3.7. Puntuación de las variables fundamentales de la atracción (Qatracción - caudal relativo de atracción (\%) y $U_{E}-$ ubicación de la entrada para peces).

Tabla A.3.8. Evaluación de las variables fundamentales de la atracción.

\begin{tabular}{|c|c|c|c|c|}
\hline VARIABLE FUNDAMENTAL & VALOR & PUNTUACIÓN & EVALUACIÓN ( ${ }^{1}$ ) & $\begin{array}{l}\text { MODIFICACIONES } \\
\text { O MEJORAS }\left({ }^{1}\right)\end{array}$ \\
\hline $\begin{array}{l}\text { Caudal relativo de } \\
\text { atracción (Qatracción) }\end{array}$ & $48,8 \%$ & 10 & Muy favorable & Opcionales \\
\hline $\begin{array}{l}\text { Ubicación de la entrada de } \\
\text { peces }\left(U_{E}\right)\end{array}$ & Muy adecuado & 10 & Muy favorable & Opcionales \\
\hline
\end{tabular}




\section{A.3.3.1.2. ENTRADA}

Todas las variables estudiadas en la etapa de entrada han sido medidas directamente en campo. Así, su puntuación se ha calculado e interpretado sin necesidad de cálculos adicionales (Figura A.3.8 y tabla A.3.9):
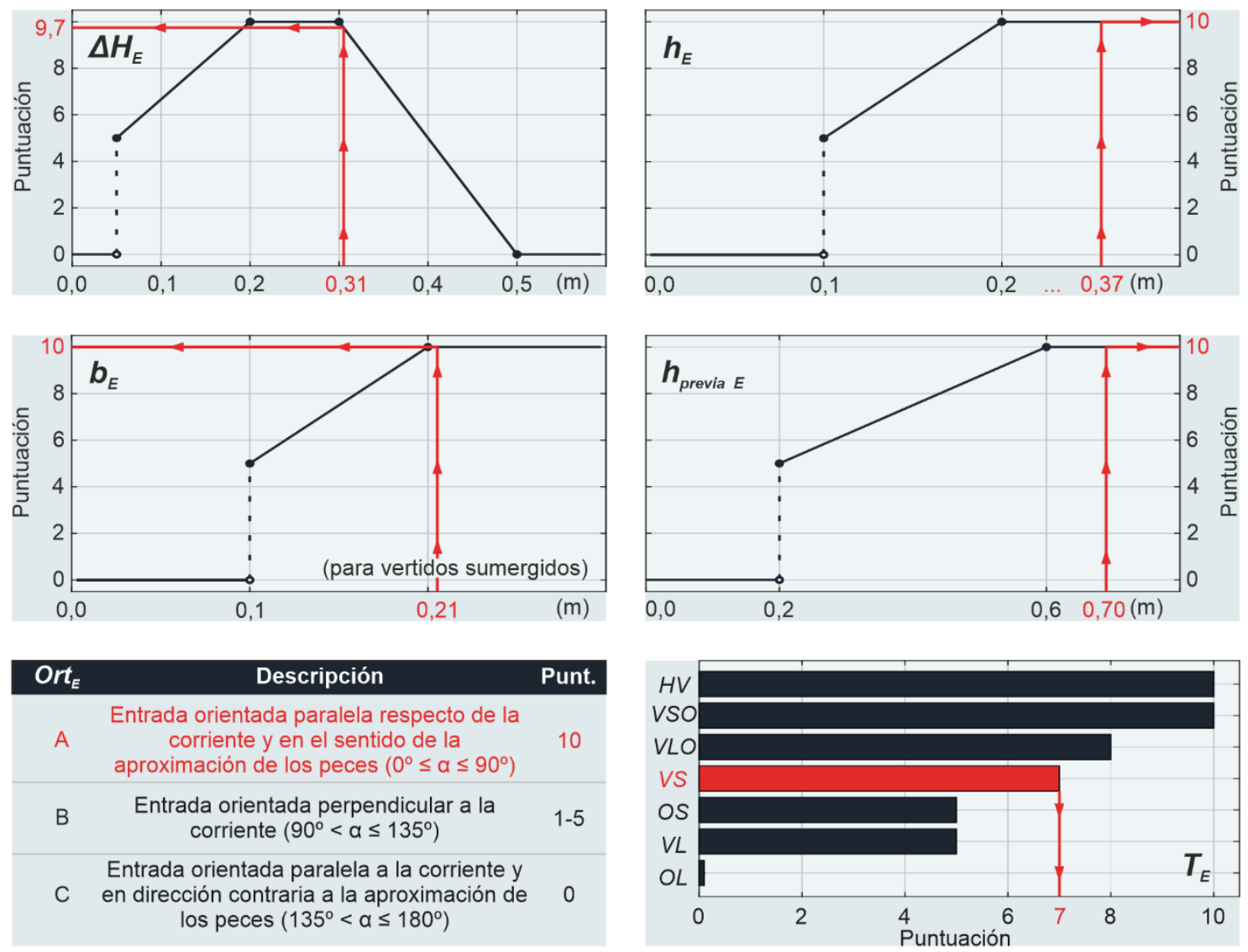

Figura A.3.8. Puntuación de las variables evaluadas en la entrada $\left(\Delta H_{E}\right.$ - desnivel entre la lámina de agua en el río y en el estanque inferior $(\mathrm{m}), h_{E}$ - profundidad de paso en la entrada $(\mathrm{m}), b_{E}$ - anchura de la entrada $(\mathrm{m}), h_{\text {previa } E}$ - profundidad previa a la entrada $(\mathrm{m}), \mathrm{Ort}_{E}$ - orientación de la entrada respecto del río $\left({ }^{\circ}\right), \alpha$ - ángulo que forma la entrada respecto del eje hidráulico del río, $T_{E}$ - tipo de entrada, $H V-$ hendidura vertical con o sin orificio y $p<0,25 \mathrm{~m}$, VSO - vertedero con vertido sumergido y orificio, VLO vertedero con vertido libre y orificio, $V S$ - vertedero con vertido sumergido, $O S$ - orificio sumergido, $V L$ - vertedero con vertido libre y $O L$ - orificio con vertido libre).

Tabla A.3.9. Evaluación de las variables fundamentales de la entrada.

\begin{tabular}{|ccccc}
\hline VARIABLE FUNDAMENTAL & VALOR & PUNTUACIÓN & EVALUACIÓN $\left({ }^{1}\right)$ & $\begin{array}{c}\text { MODIFICACIONES O } \\
\text { MEJORAS }\left({ }^{1}\right)\end{array}$ \\
\hline $\begin{array}{c}\text { Desnivel entre la lámina de } \\
\text { agua del río y del estanque } \\
\text { inferior }\left(\Delta H_{E}\right)\end{array}$ & $0,31 \mathrm{~m}$ & 9,7 & Muy favorable & Opcionales \\
$\begin{array}{c}\text { Profundidad en la entrada }\left(h_{E}\right) \\
0,37 \mathrm{~m}\end{array}$ & 10 & Muy favorable & Opcionales
\end{tabular}




\begin{tabular}{|c|c|c|c|c|}
\hline VARIABLE FUNDAMENTAL & VALOR & PUNTUACIÓN & EVALUACIÓN (1) & $\begin{array}{c}\text { MODIFICACIONES O } \\
\text { MEJORAS }\left({ }^{1}\right)\end{array}$ \\
\hline Anchura de la entrada $\left(b_{E}\right)$ & $0,21 \mathrm{~m}$ & 10 & Muy favorable & Opcionales \\
\hline $\begin{array}{l}\text { Profundidad previa a la } \\
\left.\text { entrada ( } h_{\text {previa }}\right)\end{array}$ & $0,70 \mathrm{~m}$ & 10 & Muy favorable & Opcionales \\
\hline $\begin{array}{l}\text { Orientación de la entrada } \\
\text { respecto del río }\left(O r t_{E}\right)\end{array}$ & $\begin{array}{c}\text { Zona A } \\
\left(0^{\circ} \leq \alpha \leq 90^{\circ}\right)\end{array}$ & 10 & Muy favorable & Opcionales \\
\hline Tipología de la entrada $\left(T_{E}\right)$ & $\begin{array}{l}\text { Vertedero } \\
\text { sumergido }\end{array}$ & 7,0 & Favorable & Recomendables \\
\hline
\end{tabular}

\section{A.3.3.1.3. PASAJE}

En el pasaje debemos calcular el tirante medio en los estanques $\left(t_{m e d}\right)$ y la potencia disipada por unidad de volumen $(N)$ a partir de la información recogida en campo. El tirante medio se ha calculado con de la siguiente expresión:

$$
t_{\text {med }}=\frac{p+h_{P_{s}}+p^{\prime}+h_{P_{s}}^{\prime}-\Delta H_{P_{s}}^{\prime}}{2}
$$

donde $t_{\text {med }}$ es el tirante medio en un estanque $(\mathrm{m}), p$ es la altura al umbral del elemento que conecta el estanque evaluado con el inferior $(m), h_{P_{s}}$ es la carga de vertido en la conexión con el estanque inferior $(m), p^{\prime}$ es la altura al umbral del elemento que conecta el estanque superior con el evaluado $(\mathrm{m}), h_{P_{s}}^{\prime}$ es la carga de vertido en la conexión con el estanque superior $(\mathrm{m})$, y $\Delta H_{P_{S}}^{\prime}$ es el desnivel entre las láminas de agua del estanque evaluado y del superior $(\mathrm{m})$. Aplicando los valores medidos en los estanques tipo y singulares, obtenemos:

Tabla A.3.10. Cálculo del tirante medio $\left(t_{m e d}\right)$ en los diferentes estanques.

$\begin{array}{cccc}\text { ESTANQUE } & \text { CÁLCULO } & \text { VALOR FINAL } \\ \text { Tipo } & t_{\text {med }}=\frac{0,0+0,93+0,0+0,93-0,20}{2} & 0,83 \mathrm{~m} \\ \text { Primer estanque singular } & t_{\text {med }}=\frac{0,0+0,91+0,0+0,91-0,26}{2} & 0,78 \mathrm{~m} \\ \text { Segundo estanque singular } & t_{\text {med }}=\frac{0,0+0,96+0,0+0,96-0,14}{2} & 0,89 \mathrm{~m}\end{array}$


Ahora se calcula la potencia disipada por unidad de volumen, que se estima con la siguiente expresión:

$$
N=\frac{g \cdot \rho \cdot Q_{\text {escala }} \cdot \Delta H_{P s}^{\prime}}{L \cdot B \cdot t_{\text {med }}}
$$

donde $N$ es la potencia disipada por unidad de volumen $\left(\mathrm{W} / \mathrm{m}^{3}\right), g$ es la aceleración de la gravedad $\left(9,81 \mathrm{~m} / \mathrm{s}^{2}\right), \rho$ es la densidad absoluta del agua $\left(\mathrm{kg} / \mathrm{m}^{3}\right), \Delta H_{P_{s}}^{\prime}$ es el desnivel entre la lámina de agua del estanque evaluado y del superior $(\mathrm{m}), L$ y $B$ son respectivamente la longitud y anchura del estanque evaluado $(\mathrm{m}), \mathrm{y} t_{\text {med }}$ es el tirante medio del estanque estudiado $(\mathrm{m})$. Sustituyendo los valores correspondientes a los estanques tipo y singulares, tenemos:

Tabla A.3.11. Cálculo de la potencia disipada por unidad de volumen $(N)$ en la escala.

$\begin{array}{ccc}\text { ESTANQUE } & \text { CÁLCULO } & \text { VALOR FINAL } \\ \text { Tipo } & N=\frac{9,81 \cdot 1000 \cdot 0,26 \cdot 0,20}{2,20 \cdot 1,70 \cdot 0,83} & 165,3 \mathrm{~W} / \mathrm{m}^{3} \\ \text { Primer estanque singular } & N=\frac{9,81 \cdot 1000 \cdot 0,26 \cdot 0,26}{3,35 \cdot 1,70 \cdot 0,78} & 149,3 \mathrm{~W} / \mathrm{m}^{3} \\ \text { Segundo estanque singular } & N=\frac{9,81 \cdot 1000 \cdot 0,26 \cdot 0,14}{2,45 \cdot 3,70 \cdot 0,89} & 44,3 \mathrm{~W} / \mathrm{m}^{3}\end{array}$

Después, se ha calculado la puntuación de todas las variables fundamentales de la etapa del pasaje (Figura A.3.9): 

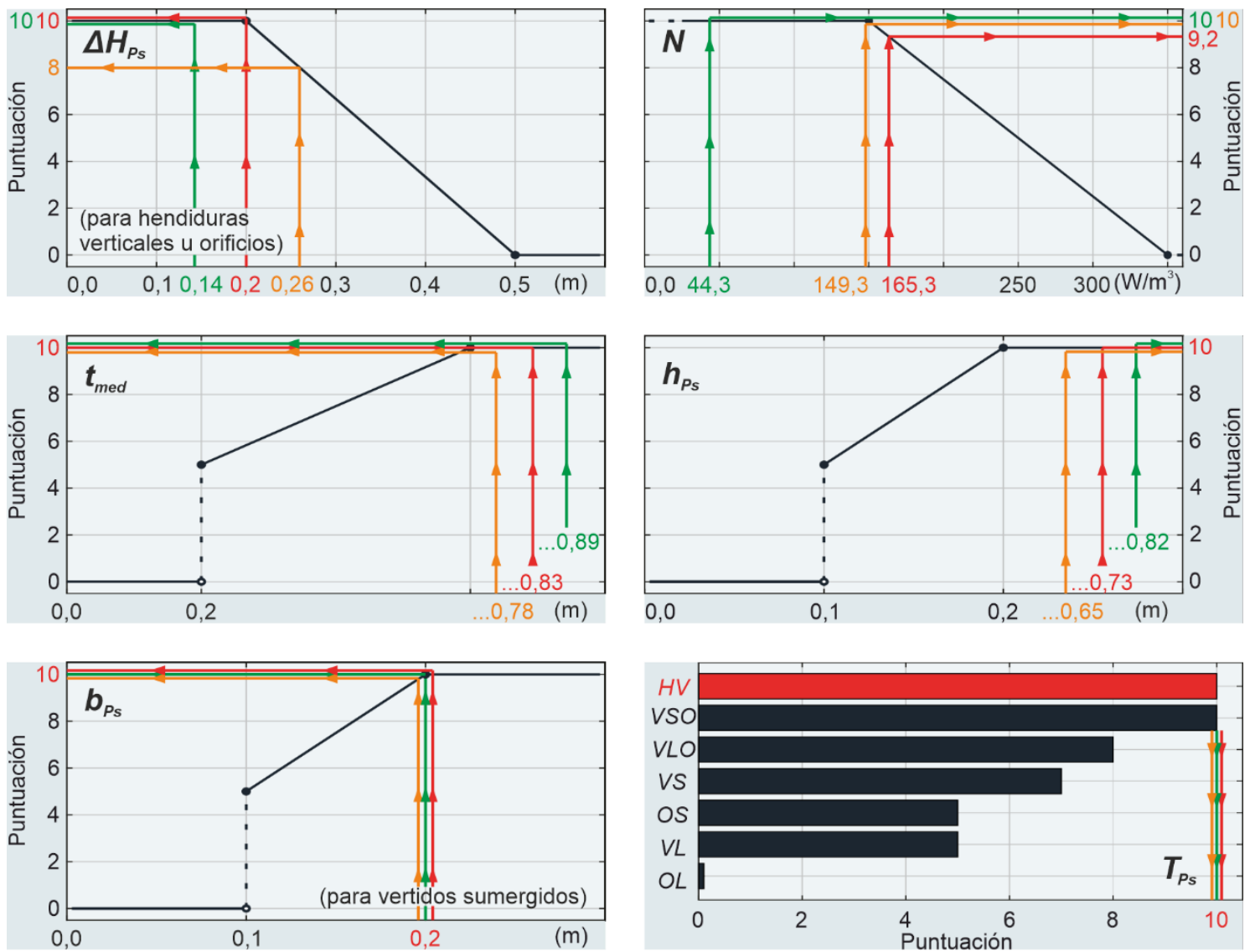

Figura A.3.9. Puntuación de las variables fundamentales del pasaje para el estanque tipo (en rojo), el inferior (en naranja) y en curva (en verde) $\left(\Delta H_{P_{s}}\right.$ - desnivel entre láminas de agua de estanques sucesivos (m), $N$ - potencia disipada por unidad de volumen $\left(\mathrm{W} / \mathrm{m}^{3}\right), t_{m e d}$ - tirante medio de los estanques $(\mathrm{m}), h_{P_{S}}$ - profundidad de paso entre estanques $(m), b_{P_{s}}$ - anchura de paso entre estanques $(\mathrm{m}), T_{P_{s}}$ - tipo de paso entre estanques, $H V$ - hendidura vertical con o sin orificio y $p<0,25 \mathrm{~m}$, VSO - vertedero con vertido sumergido y orificio, $V L O$ - vertedero con vertido libre y orificio, $V S$ - vertedero con vertido sumergido, $O S$ - orificio sumergido, $V L$ - vertedero con vertido libre y $O L$ - orificio con vertido libre).

Puesto que la escala que estamos estudiando tiene siete estanques tipo y dos singulares, debemos ponderar las puntuaciones de los parámetros estudiados en función del número de artesas de cada clase:

$$
\text { Punt }=\frac{N_{\text {tipo }} \cdot \text { Punt }_{\text {tipo }}+\sum \text { Punt }_{\text {singular }}}{N_{\text {estanques }}}
$$

donde Punt es la puntuación conjunta de una variable u observación del pasaje, $N_{\text {tipo }}$ es el número de estanques tipo, Punt tipo es la puntuación en los estanques tipo, Punt singular $_{\text {rip }}$ es la puntuación en los estanques singulares, y $N_{\text {estanques }}$ es el número total de estanques de la escala. En base a esto, las puntuaciones finales de las variables del pasaje han sido: 
Tabla A.3.12. Ponderación de las puntuaciones de las variables fundamentales del pasaje.

\begin{tabular}{|c|c|c|c|c|}
\hline \multirow[b]{2}{*}{ ESTANQUE } & \multicolumn{3}{|c|}{ PUNTUACIÓN ESTANQUES } & \multirow[b]{2}{*}{ PONDERADA } \\
\hline & TIPO & $\begin{array}{l}\text { PRIMER } \\
\text { SINGULAR }\end{array}$ & $\begin{array}{l}\text { SEGUNDO } \\
\text { SINGULAR }\end{array}$ & \\
\hline $\begin{array}{l}\text { Desnivel entre láminas de agua de } \\
\text { estanques sucesivos }\left(\Delta H_{P_{s}}\right)\end{array}$ & 10 & 8,0 & 10 & 9,8 \\
\hline $\begin{array}{l}\text { Potencia disipada por unidad de volumen } \\
\qquad(N)\end{array}$ & 9,2 & 10 & 10 & 9,4 \\
\hline Tirante medio en los estanques ( $\left.t_{\text {med }}\right)$ & 10 & 10 & 10 & 10 \\
\hline $\begin{array}{l}\text { Profundidad de paso entre estanques } \\
\qquad\left(h_{P_{S}}\right)\end{array}$ & 10 & 10 & 10 & 10 \\
\hline Anchura de paso entre estanques $\left(b_{P_{S}}\right)$ & 10 & 10 & 10 & 10 \\
\hline $\begin{array}{c}\text { Tipología del paso (conexión) entre } \\
\text { estanques }\left(T_{P S}\right)\end{array}$ & 10 & 10 & 10 & 10 \\
\hline
\end{tabular}

Después, se han evaluado e interpretado las puntuaciones ponderadas de cada variable:

Tabla A.3.13. Evaluación de las variables fundamentales del pasaje.

\begin{tabular}{|c|c|c|c|c|}
\hline VARIABLE FUNDAMENTAL & VALOR & $\begin{array}{l}\text { PUNTUACIÓN } \\
\text { PONDERADA }\end{array}$ & $\begin{array}{l}\text { EVALUACIÓN } \\
\left.\qquad{ }^{1}\right)\end{array}$ & $\begin{array}{c}\text { MODIFICACIONES } \\
\text { O MEJORAS }\left({ }^{1}\right)\end{array}$ \\
\hline $\begin{array}{c}\text { Desnivel entre láminas de } \\
\text { agua de estanques sucesivos } \\
\left(\Delta H_{P S}\right)\end{array}$ & $\begin{array}{c}0,20 \mathrm{~m}\left({ }^{2}\right), 0,26 \mathrm{~m} \\
\left({ }^{3}\right), 0,14 \mathrm{~m}\left({ }^{4}\right)\end{array}$ & 9,8 & Muy favorable & Opcionales \\
\hline $\begin{array}{l}\text { Potencia disipada por } \\
\text { unidad de volumen }(N)\end{array}$ & $\begin{array}{c}165,3 \mathrm{~W} / \mathrm{m}^{3}\left({ }^{2}\right) \\
149,3 \mathrm{~W} / \mathrm{m}^{3}\left({ }^{3}\right) \\
44,3 \mathrm{~W} / \mathrm{m}^{3}\left({ }^{4}\right)\end{array}$ & 9,4 & Muy favorable & Opcionales \\
\hline $\begin{array}{l}\text { Tirante medio en los } \\
\text { estanques }\left(t_{m e d}\right)\end{array}$ & $\begin{array}{c}0,83 \mathrm{~m}\left({ }^{2}\right), 0,78\left({ }^{3}\right) \\
0,89 \mathrm{~m}\left({ }^{4}\right)\end{array}$ & 10 & Muy favorable & Opcionales \\
\hline $\begin{array}{c}\text { Profundidad de paso entre } \\
\text { estanques }\left(h_{P_{S}}\right)\end{array}$ & $\begin{array}{l}0,73 \mathrm{~m}\left({ }^{2}\right), 0,65 \mathrm{~m} \\
\left({ }^{3}\right), 0,82 \mathrm{~m} \mathrm{({ } ^ { 4 } )}\end{array}$ & 10 & Muy favorable & Opcionales \\
\hline $\begin{array}{c}\text { Anchura de paso entre } \\
\text { estanques }\left(b_{P_{s}}\right)\end{array}$ & $0,20 \mathrm{~m}\left({ }^{2,3,4}\right)$ & 10 & Muy favorable & Opcionales \\
\hline $\begin{array}{c}\text { Tipología del paso } \\
\text { (conexión) entre estanques } \\
\left(T_{P_{s}}\right)\end{array}$ & $\begin{array}{l}\text { Hendidura vertical } \\
\qquad(2,3,4)\end{array}$ & 10 & Muy favorable & Opcionales \\
\hline $\begin{array}{l}\left({ }^{1}\right) \text { Calculado a partir de la t } \\
\left({ }^{2}\right) \text { Estanque tipo. } \\
\left({ }^{3}\right) \text { Estanque singular inferio } \\
\left({ }^{4}\right) \text { Estanque singular en cur }\end{array}$ & bla A.3.6. & & & \\
\hline
\end{tabular}




\section{A.3.3.1.4. SALIDA}

Las variables fundamentales de la salida se han valorado directamente con la información recogida en campo. A continuación, se muestran sus puntuaciones y evaluación (Figura A.3.10 y tabla A.3.14):
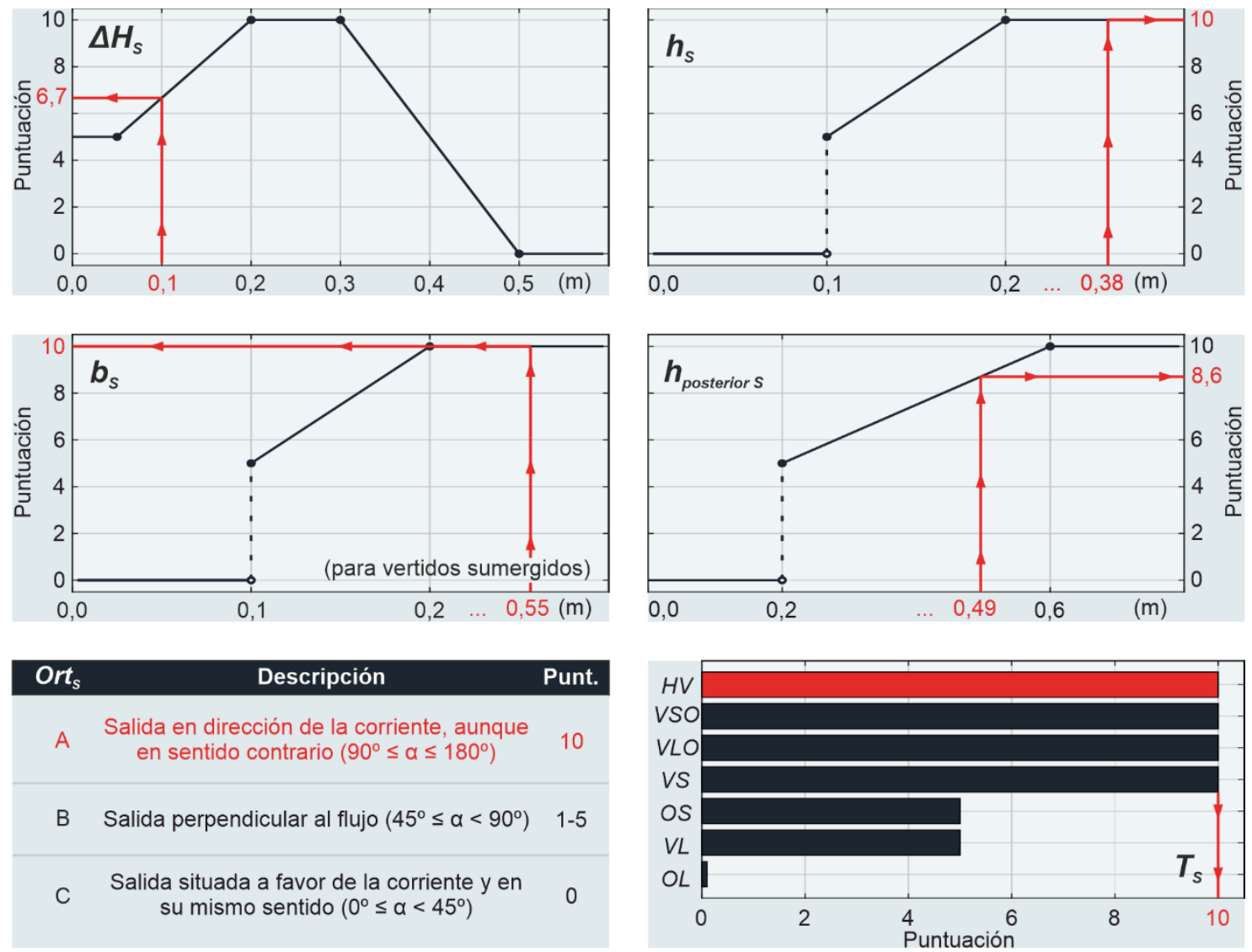

Figura A.3.10. Puntuación de las variables evaluadas en la salida $\left(\Delta H_{s}-\right.$ desnivel entre la lámina de agua en el río y en el estanque superior $(\mathrm{m}), h_{s}$ - profundidad de paso en la salida $(\mathrm{m}), b_{s}$ - anchura de la salida $(\mathrm{m}), h_{\text {posterior } s}$ - profundidad posterior a la salida $(\mathrm{m})$, Orts - orientación de la salida respecto del río $\left({ }^{\circ}\right), \alpha$-ángulo que forma la salida respecto del eje hidráulico del río, $T_{S}$ - tipo de salida, $H V-$ hendidura vertical con o sin orificio y $p<0,25 \mathrm{~m}, V S O$ - vertedero con vertido sumergido y orificio, VLO vertedero con vertido libre y orificio, VS - vertedero con vertido sumergido, OS - orificio sumergido, VL - vertedero con vertido libre y $O L$ - orificio con vertido libre).

Tabla A.3.14. Evaluación de las variables fundamentales de la salida.

$\begin{array}{ccccc}\text { VARIABLE FUNDAMENTAL } & \text { VALOR } & \text { PUNTUACIÓN } & \text { EVALUACIÓN }\left({ }^{1}\right) & \begin{array}{c}\text { MODIFICACIONES O } \\ \text { MEJORAS }\left({ }^{1}\right)\end{array} \\ \begin{array}{c}\text { Desnivel entre la lámina de } \\ \text { agua en el río y en el } \\ \text { estanque superior }\left(\Delta H_{s}\right)\end{array} & 0,10 \mathrm{~m} & 6,7 & \text { Favorable } & \text { Recomendables } \\ \begin{array}{c}\text { Profundidad en la salida }\left(h_{s}\right) \\ \text { Profundes }\end{array} & 0,38 \mathrm{~m} & 10 & \text { Muy favorable } & \text { Opcionales }\end{array}$




\begin{tabular}{|c|c|c|c|c|}
\hline VARIABLE FUNDAMENTAL & VALOR & PUNTUACIÓN & EVALUACIÓN ( $\left.{ }^{1}\right)$ & $\begin{array}{l}\text { MODIFICACIONES O } \\
\text { MEJORAS }\left({ }^{1}\right)\end{array}$ \\
\hline Anchura de la salida $\left(b_{s}\right)$ & $0,55 \mathrm{~m}$ & 10 & Muy favorable & Opcionales \\
\hline $\begin{array}{l}\text { Profundidad posterior a la } \\
\text { salida ( } h_{\text {posterior } s)}\end{array}$ & $0,49 \mathrm{~m}$ & 8,6 & Muy favorable & Opcionales \\
\hline $\begin{array}{l}\text { Orientación de la salida } \\
\text { respecto del río (Orts) }\end{array}$ & $\begin{array}{c}\text { Zona A } \\
\left(90^{\circ} \leq \alpha \leq 180^{\circ}\right)\end{array}$ & 10 & Muy favorable & Opcionales \\
\hline Tipología de la salida $\left(T_{s}\right)$ & $\begin{array}{l}\text { Hendidura } \\
\text { vertical }\end{array}$ & 10 & Muy favorable & Opcionales \\
\hline
\end{tabular}

\section{A.3.3.2. OBSERVACIONES DE RELEVANCIA}

La información recogida sobre las observaciones de relevancia ha permitido determinar su adecuación para los peces objetivo. De acuerdo con lo indicado por la metodología AEPS, las observaciones se han clasificado en tres categorías que tienen asociada una puntuación concreta. Esas puntuaciones han sido evaluadas empleando el siguiente criterio:

Tabla A.3.15. Criterio para evaluar las observaciones de relevancia por separado y en conjunto para cada etapa.

$\begin{array}{ccc}\text { PUNTUACIÓN } & \text { RESULTADO DE LA EVALUACIÓN } & \text { MODIFICACIONES O MEJORAS } \\ 0 \leq \text { Parámetro }<2 & \text { Muy desfavorable } & \text { Muy necesarias } \\ 2 \leq \text { Parámetro }<5 & \text { Desfavorable } & \text { Necesarias } \\ 5 \leq \text { Parámetro }<8 & \text { Favorable } & \text { Recomendables } \\ 8 \leq \text { Parámetro } \leq 10 & \text { Muy favorable } & \text { Opcionales }\end{array}$

Al igual que sucede con las variables fundamentales, las observaciones de relevancia del pasaje han sido ponderadas en función de su valoración en los diferentes estanques del paso (Ec. A.3.9). La información de las observaciones se muestra a continuación: 
Tabla A.3.16. Puntuación, evaluación y mejoras a realizar en las observaciones de relevancia de cada etapa ( $A$ - atracción, $E$ - entrada, $P s$ - pasaje, $S$ - salida).

\begin{tabular}{|c|c|c|c|c|c|}
\hline ETAPA & $\begin{array}{l}\text { OBSERVACIÓN } \\
\text { DE RELEVANCIA }\end{array}$ & $\begin{array}{l}\text { VALORACIÓN } \\
\text { EN CAMPO }\end{array}$ & PUNTUAC. & $\begin{array}{c}\text { EVALUACIÓN } \\
\text { (1) }\end{array}$ & $\begin{array}{l}\text { MODIFICACIONES O } \\
\text { MEJORAS }\left({ }^{1}\right)\end{array}$ \\
\hline \multirow[t]{2}{*}{$A$} & $\begin{array}{l}\text { Mantenimiento y } \\
\text { limpieza }\end{array}$ & Muy adecuado & 10 & Muy favorable & Opcionales \\
\hline & Accesibilidad & Muy adecuado & 10 & Muy favorable & Opcionales \\
\hline \multirow{6}{*}{$E$} & $\begin{array}{l}\text { Mantenimiento y } \\
\text { limpieza }\end{array}$ & Muy adecuado & 10 & Muy favorable & Opcionales \\
\hline & $\begin{array}{l}\text { Elementos para la } \\
\text { regulación del } \\
\text { salto entre } \\
\text { láminas de agua }\end{array}$ & Muy adecuado & 10 & Muy favorable & Opcionales \\
\hline & $\begin{array}{l}\text { Descargas de } \\
\text { flujo en la } \\
\text { entrada }\end{array}$ & Muy adecuado & 10 & Muy favorable & Opcionales \\
\hline & $\begin{array}{l}\text { Ausencia de otras } \\
\text { descargas que } \\
\text { alejen el pez }\end{array}$ & Muy adecuado & 10 & Muy favorable & Opcionales \\
\hline & $\begin{array}{l}\text { Aristas } \\
\text { redondeadas }\end{array}$ & Muy adecuado & 10 & Muy favorable & Opcionales \\
\hline & Accesibilidad & Muy adecuado & 10 & Muy favorable & Opcionales \\
\hline \multirow{9}{*}{ Ps } & $\begin{array}{l}\text { Mantenimiento y } \\
\text { limpieza }\end{array}$ & $\begin{array}{c}\text { Muy adecuado } \\
(2,3,4)\end{array}$ & $10\left({ }^{5}\right)$ & Muy favorable & Opcionales \\
\hline & $\begin{array}{l}\text { Forma de los } \\
\text { estanques }\end{array}$ & $\begin{array}{c}\text { Adecuado }\left({ }^{2}\right) \text {, } \\
\text { No adecuado } \\
\left({ }^{3,4}\right)\end{array}$ & $3,89\left(^{5}\right)$ & Favorable & Recomendables \\
\hline & $\begin{array}{l}\text { Deflectores en los } \\
\text { estanques }\end{array}$ & $\begin{array}{l}\text { Muy adecuado } \\
\qquad(2,3,4)\end{array}$ & $10\left(^{5}\right)$ & Muy favorable & Opcionales \\
\hline & $\begin{array}{l}\text { Conservación de } \\
\text { la estructura }\end{array}$ & $\begin{array}{l}\text { Muy adecuado } \\
\qquad(2,3,4)\end{array}$ & $10\left(^{5}\right)$ & Muy favorable & Opcionales \\
\hline & $\begin{array}{c}\text { Solera } \\
\text { naturalizada con } \\
\text { piedras }\end{array}$ & $\begin{array}{c}\text { Muy adecuado } \\
(2,3,4)\end{array}$ & $10\left({ }^{5}\right)$ & Muy favorable & Opcionales \\
\hline & $\begin{array}{l}\text { Aristas } \\
\text { redondeadas }\end{array}$ & $\begin{array}{c}\text { Adecuado } \\
(2,3,4)\end{array}$ & $5\left({ }^{5}\right)$ & Favorable & Recomendables \\
\hline & $\begin{array}{l}\text { Oscuridad por } \\
\text { elementos que } \\
\text { cubren la escala }\end{array}$ & $\begin{array}{c}\text { Muy adecuado } \\
(2,3,4)\end{array}$ & $10\left(^{5}\right)$ & Muy favorable & Opcionales \\
\hline & $\begin{array}{l}\text { Resguardo en los } \\
\text { estanques }\end{array}$ & $\begin{array}{l}\text { Muy adecuado } \\
\qquad(2,3,4)\end{array}$ & $10\left({ }^{5}\right)$ & Muy favorable & Opcionales \\
\hline & Accesibilidad & $\begin{array}{l}\text { Muy adecuado } \\
\qquad(2,3,4)\end{array}$ & $10\left({ }^{5}\right)$ & Muy favorable & Opcionales \\
\hline
\end{tabular}




\begin{tabular}{|c|c|c|c|c|c|}
\hline ETAPA & $\begin{array}{l}\text { OBSERVACIÓN } \\
\text { DE RELEVANCIA }\end{array}$ & $\begin{array}{l}\text { VALORACIÓN } \\
\text { EN CAMPO }\end{array}$ & PUNTUAC. & $\begin{array}{c}\text { EVALUACIÓN } \\
\left(^{1}\right)\end{array}$ & $\begin{array}{l}\text { MODIFICACIONES O } \\
\text { MEJORAS }\left({ }^{1}\right)\end{array}$ \\
\hline \multirow{6}{*}{$s$} & $\begin{array}{l}\text { Mantenimiento y } \\
\text { limpieza }\end{array}$ & Muy adecuado & 10 & Muy favorable & Opcionales \\
\hline & $\begin{array}{l}\text { Compuerta de } \\
\text { regulación de } \\
\text { caudales }\end{array}$ & Muy adecuado & 10 & Muy favorable & Opcionales \\
\hline & $\begin{array}{c}\text { Dispositivo contra } \\
\text { la entrada de } \\
\text { arrastres }\end{array}$ & Muy adecuado & 10 & Muy favorable & Opcionales \\
\hline & Salida segura & Muy adecuado & 10 & Muy favorable & Opcionales \\
\hline & $\begin{array}{l}\text { Aristas } \\
\text { redondeadas }\end{array}$ & Muy adecuado & 10 & Muy favorable & Opcionales \\
\hline & Accesibilidad & Muy adecuado & 10 & Muy favorable & Opcionales \\
\hline \multicolumn{6}{|c|}{ (1) Calculado a partir de la tabla A.3.15. } \\
\hline \multicolumn{6}{|c|}{${ }^{(2)}$ Estanque tipo. } \\
\hline \multicolumn{6}{|c|}{ (3) Estanque singular inferior. } \\
\hline \multicolumn{6}{|c|}{$\left({ }^{4}\right)$ Estanque singular en curva. } \\
\hline
\end{tabular}

\section{A.3.3.3. ETAPAS}

Determinada la puntuación de las variables fundamentales y observaciones de relevancia por separado, se ha calculado la puntuación de las etapas a superar por los peces. El cálculo a partir de las variables fundamentales se ha realizado con las siguientes medias geométricas:

$$
\begin{gathered}
A=\left(Q_{\text {atracción }} \cdot U_{E}\right)^{1 / 2} \\
E=\left(\Delta H_{E} \cdot h_{E} \cdot b_{E} \cdot h_{\text {previa } E} \cdot \text { Ort }_{E} \cdot T_{E}\right)^{1 / 6} \\
P S=\left(\Delta H_{P S} \cdot N \cdot t_{\text {med }} \cdot h_{P_{S}} \cdot b_{P_{S}} \cdot T_{P_{S}}\right)^{1 / 6} \\
S=\left(\Delta H_{S} \cdot h_{S} \cdot b_{S} \cdot h_{\text {posterior } S} \cdot \text { Ort }_{S} \cdot T_{S}\right)^{1 / 6}
\end{gathered}
$$


Sustituyendo las puntuaciones obtenidas:

$$
\begin{gathered}
A=(10 \cdot 10)^{1 / 2}=10 \\
E=(9,7 \cdot 10 \cdot 10 \cdot 10 \cdot 10 \cdot 7,0)^{1 / 6}=9,4 \\
P S=(9,8 \cdot 9,4 \cdot 10 \cdot 10 \cdot 10 \cdot 10)^{1 / 6}=9,9 \\
S=(6,7 \cdot 10 \cdot 10 \cdot 8,6 \cdot 10 \cdot 10)^{1 / 6}=9,1
\end{gathered}
$$

La puntuación de cada etapa a partir de las observaciones de relevancia se ha calculado como una media aritmética:

$$
O i=\frac{O_{1 i}+\ldots+O_{n i}}{N_{O i}}
$$

donde $O i$ es la puntuación de las observaciones de relevancia de una etapa $i$ en conjunto, $O_{1 i}$ y $O_{n i}$ son la puntuación de las observaciones 1 y $n$ de la etapa, respectivamente, y $N_{O i}$ es el número total de observaciones de esa etapa $i$. Con las puntuaciones calculadas se ha obtenido:

$$
\begin{gathered}
O_{A}=\frac{10+10}{2}=10 \\
O_{E}=\frac{10+10+10+10+10+10}{6}=10 \\
O_{P S}=\frac{10+3,89+10+10+10+5+10+10+10}{9}=8,8 \\
O_{S}=\frac{10+10+10+10+10+10}{6}=10
\end{gathered}
$$

En base a lo indicado por la metodología, cada etapa ha sido evaluada a partir de su puntuación, estableciendo la necesidad de realizar mejoras para facilitar el ascenso de los peces: 
Tabla A.3.17. Evaluación de las etapas a superar por los peces y la necesidad de realizar mejoras.

\begin{tabular}{|c|c|c|c|c|}
\hline ETAPA & PARÁMETROS & PUNTUAC. & EVALUACIÓN & $\begin{array}{c}\text { MODIFICACIONES } \\
\text { O MEJORAS }\end{array}$ \\
\hline \multirow{2}{*}{ Atracción } & Variables fundamentales & 10 & Muy favorable $\left({ }^{1}\right)$ & Opcionales $\left({ }^{1}\right)$ \\
\hline & Observaciones de relevancia & 10 & Muy favorable $\left({ }^{2}\right)$ & Opcionales $\left({ }^{2}\right)$ \\
\hline \multirow{2}{*}{ Entrada } & Variables fundamentales & 9,4 & Muy favorable $\left({ }^{1}\right)$ & Opcionales $\left({ }^{1}\right)$ \\
\hline & Observaciones de relevancia & 10 & Muy favorable $\left({ }^{2}\right)$ & Opcionales $\left({ }^{2}\right)$ \\
\hline \multirow{2}{*}{ Pasaje } & Variables fundamentales & 9,9 & Muy favorable $\left({ }^{1}\right)$ & Opcionales $\left({ }^{1}\right)$ \\
\hline & Observaciones de relevancia & 8,8 & Muy favorable $\left({ }^{2}\right)$ & Opcionales $\left({ }^{2}\right)$ \\
\hline \multirow{2}{*}{ Salida } & Variables fundamentales & 9,1 & Muy favorable $\left({ }^{1}\right)$ & Opcionales $\left({ }^{1}\right)$ \\
\hline & Observaciones de relevancia & 10 & Muy favorable $\left({ }^{2}\right)$ & Opcionales $\left({ }^{2}\right)$ \\
\hline
\end{tabular}

Los resultados indican que la escala para peces resulta muy favorable para el ascenso de las especies objetivo. Sin embargo, la metodología también muestra ciertos aspectos que cabe mejorar para facilitar el paso de la ictiofauna, a pesar de que en esta escala no sea en modo alguno necesario realizar tales intervenciones (Tabla A.3.17).

Además del mantenimiento y limpieza que en toda escala conviene realizar periódicamente, resulta muy positivo el hecho de que este paso permita regular caudales y niveles de agua gracias a poseer un vertedero de umbral móvil en la entrada y una compuerta en su salida. Así, y para la situación concreta del caudal circulante cuando se hizo la evaluación de la escala, se podría haber obtenido una puntuación aún mejor con tan solo cerrar ligeramente la compuerta y quitar uno de los tablones colocados a modo de umbral en el vertedero de entrada. 


\section{A.4. DESCRIPCIÓN Y EVALUACIÓN INDIVIDUAL DE LAS ESCALAS PARA PECES VISITADAS}




\section{A.4. DESCRIPCIÓN Y EVALUACIÓN INDIVIDUAL DE LAS ESCALAS PARA PECES VISITADAS}

A continuación, se presentan una serie de fichas que describen las características de las escalas para peces evaluadas en este trabajo. Además, esas fichas muestran los resultados obtenidos al aplicar la metodología AEPS a cada caso (Ver el apartado 4.2. Aplicación de la metodología AEPS):

ÍNDICE DEL ANEJO

\begin{tabular}{|c|}
\hline CUENCA HIDROGRÁFICA DEL RÍO DUERO \\
\hline ANDA I Y II.... \\
\hline CANALES DEL ARLANZÓN. \\
\hline L VERGUERAL..... \\
\hline GUMA ... \\
\hline LA PELOTERA \\
\hline LA RACHELA.. \\
\hline PUENTE DEL BULEVAR..... \\
\hline 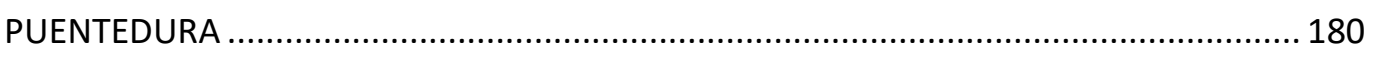 \\
\hline SAN MARTÍN DE RUBIALES II..... \\
\hline VADOCONDES... \\
\hline VILLAHOZ .......... \\
\hline VIRGEN DE LAS VIÑAS ................ \\
\hline LEÓN \\
\hline AMBASAGUAS DE CURUEÑO............. \\
\hline BOÑAR \\
\hline 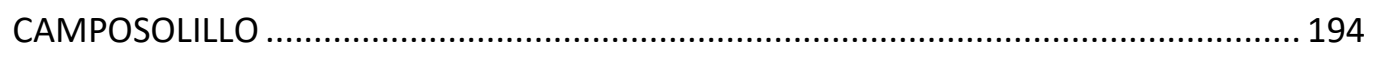 \\
\hline CANAL ALTO DE PAYUELOS ..... \\
\hline CANAL BAJO DE PAYUELOS ...... \\
\hline 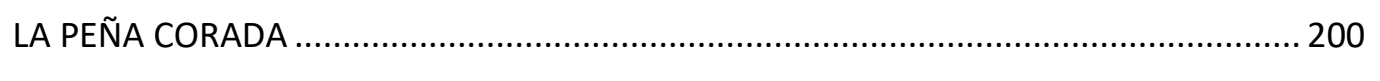 \\
\hline LA POLA DE GORDÓN ... \\
\hline LOS LEONES ..................... \\
\hline$\ldots 2$ \\
\hline
\end{tabular}




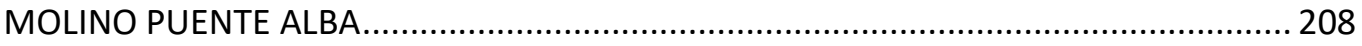

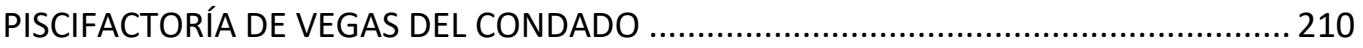

\section{PALENCIA}

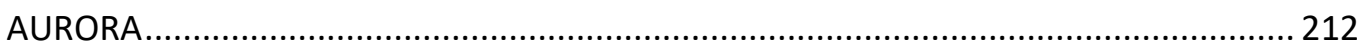

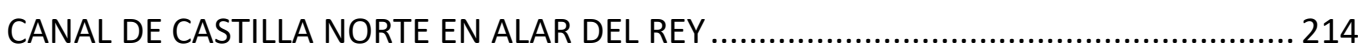

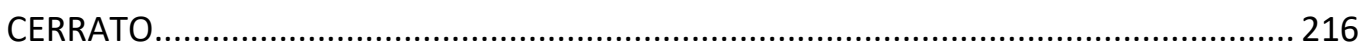

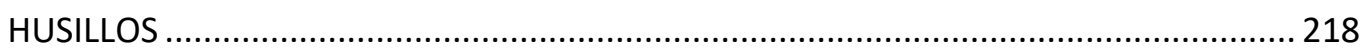

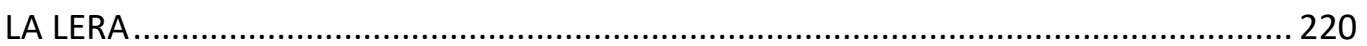

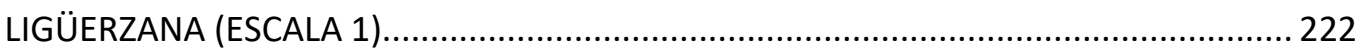

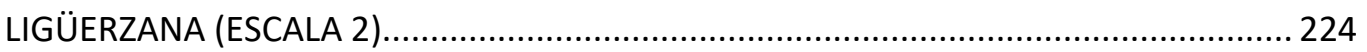

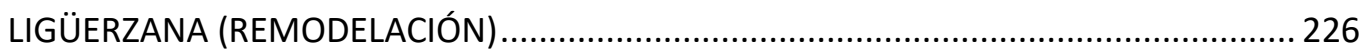

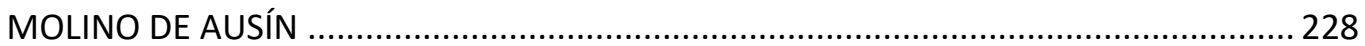

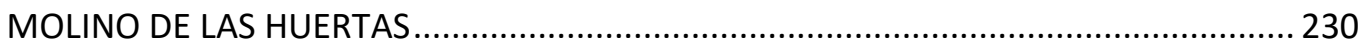

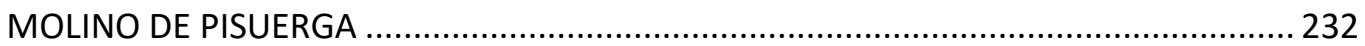

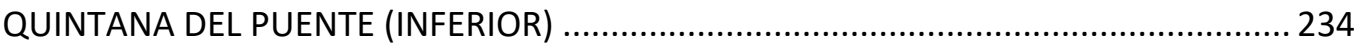

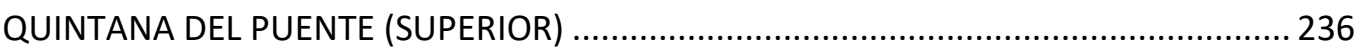

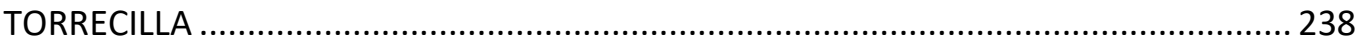

SALAMANCA

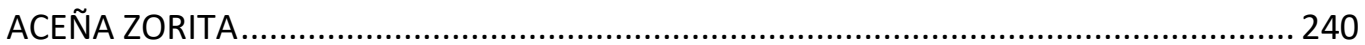

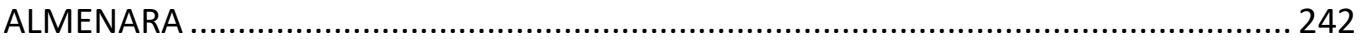

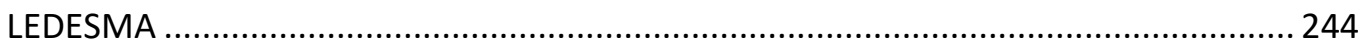

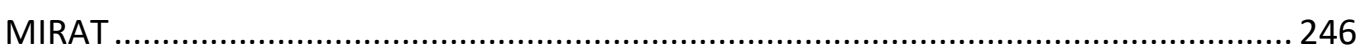

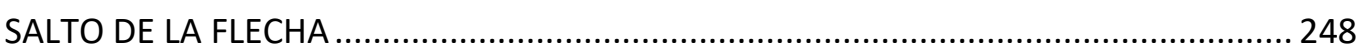

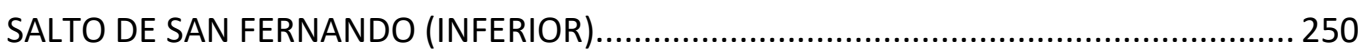

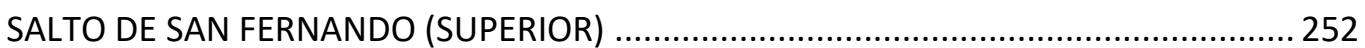

SEGOVIA

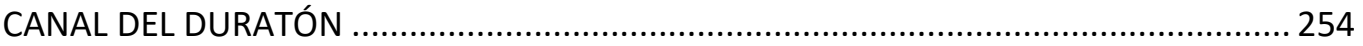

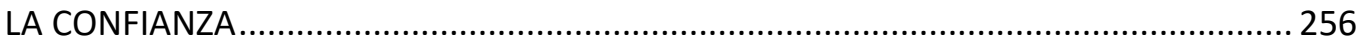

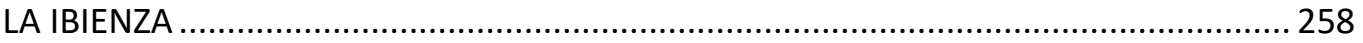

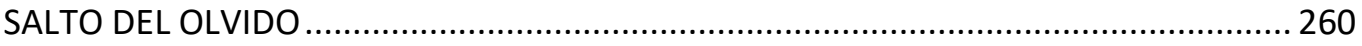

SORIA

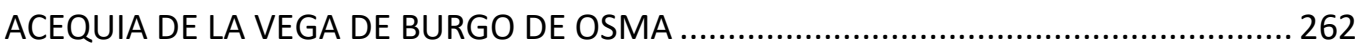

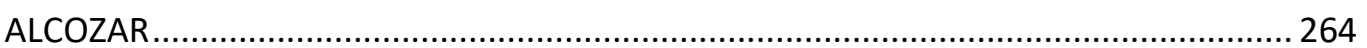

GORMAZ

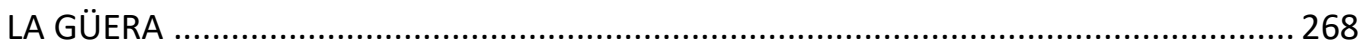




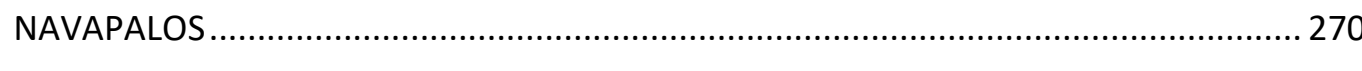

SAN ESTEBAN DE GORMAZ .................................................................. 272

VALLADOLID

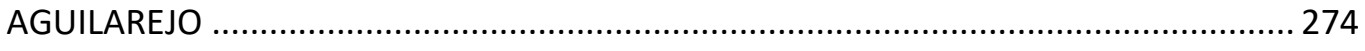

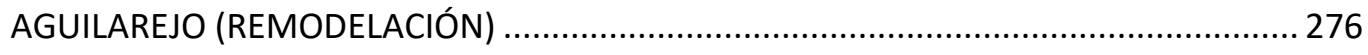

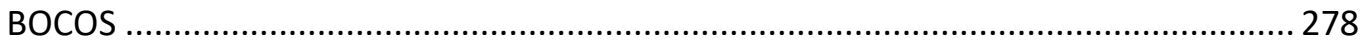

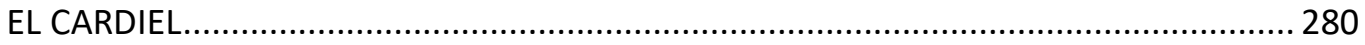

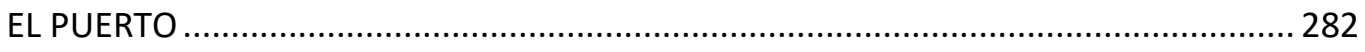

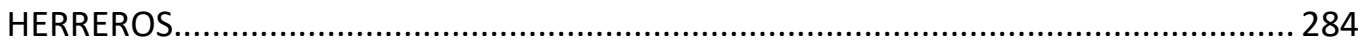

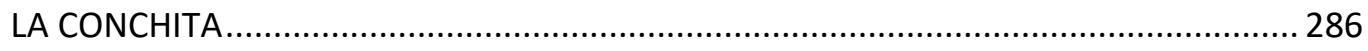

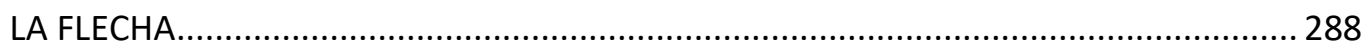

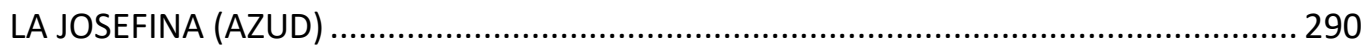

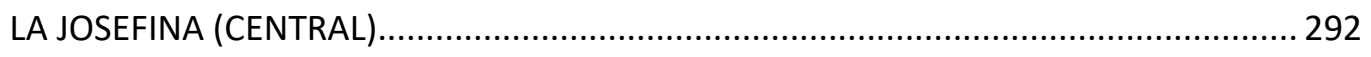

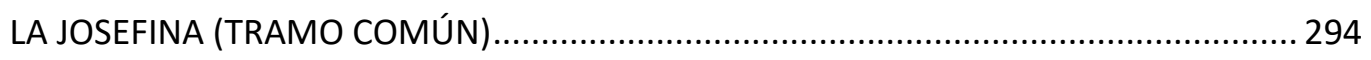

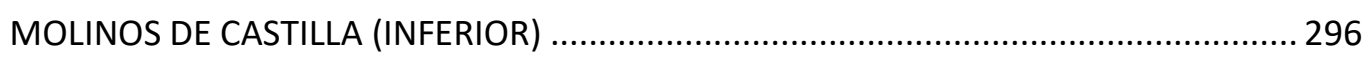

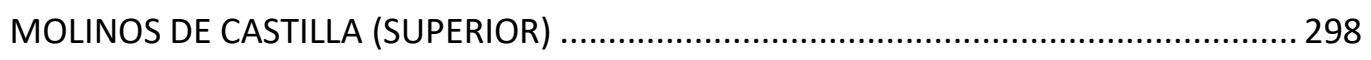

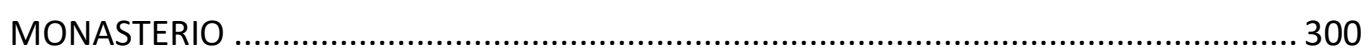

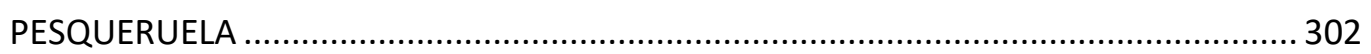

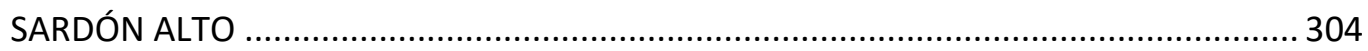

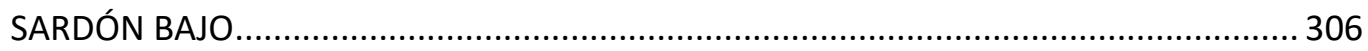

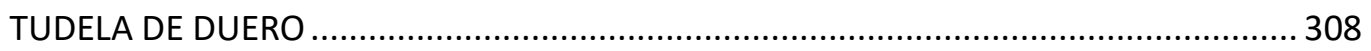

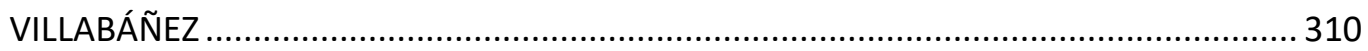

\section{ZAMORA}

NUESTRA SEÑORA DE LAS MERCEDES (AZUD) ................................................ 312

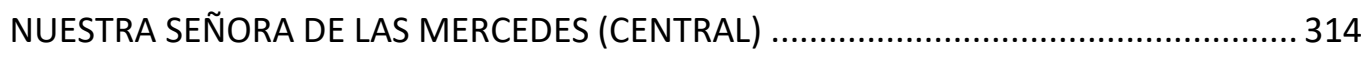

NUESTRA SEÑORA DE LAS MERCEDES (TRAMO COMÚN) ........................................ 316

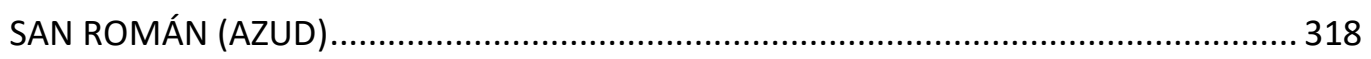

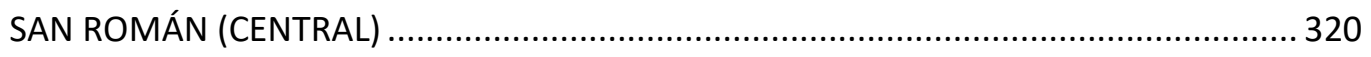

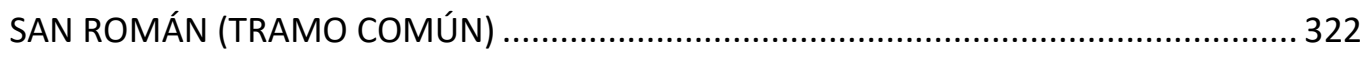

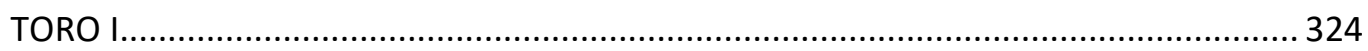

CUENCA HIDROGRÁFICA DEL RÍO MIERA

\section{CANTABRIA}

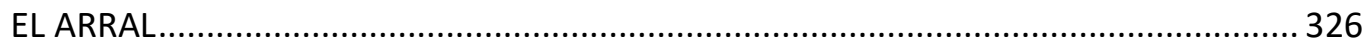

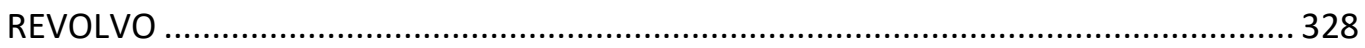




\section{CUENCA HIDROGRÁFICA DEL RÍO SEGURA}

\section{MURCIA}

CAÑAVEROSA 330

EL ESPARRAGAL 332

ELEVACIÓN ZONA 1 POST-TRASVASE . 334

SOTO DAMIÁN O EL JARRAL 336 


\section{PASO PARA PECES ASOCIADO AL AZUD DE LA CENTRAL HIDROELÉCTRICA DE ARANDA I Y II}

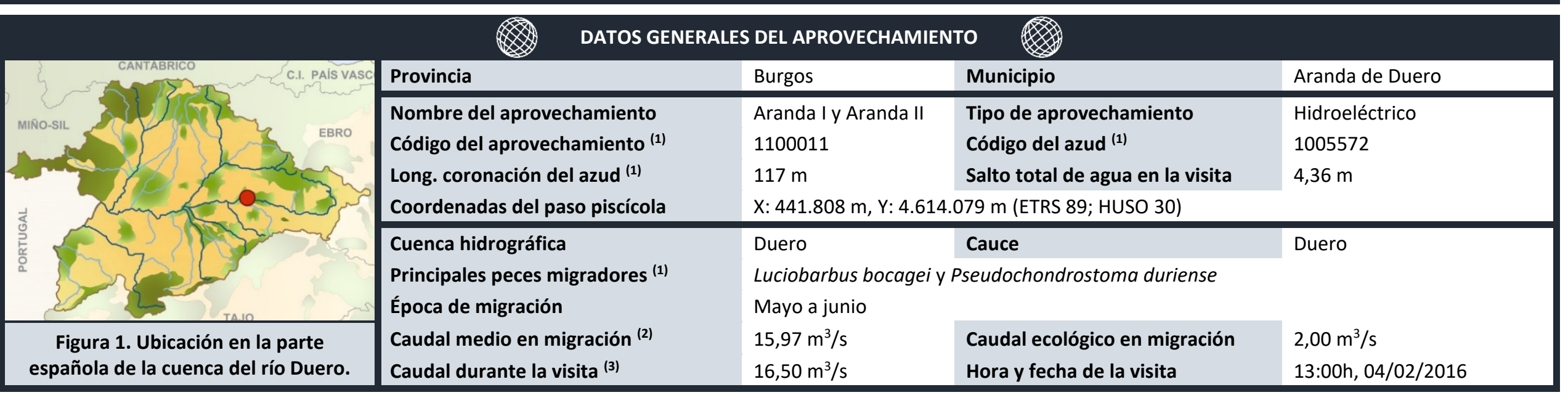

(1) Dato obtenido de MíRAME-IDE Duero. ${ }^{(2)}$ Dato obtenido del CEDEX Hidrológico. ${ }^{(3)}$ Dato obtenido del SAIH del Duero.

\begin{tabular}{|c|c|c|c|}
\hline \multicolumn{4}{|c|}{ OBSERVACIONES GENERALES DE LA ESCALA } \\
\hline $\begin{array}{l}\text { Estado de mantenimiento y limpieza durante la evaluación } \\
\text { Solera naturalizada (con piedras) } \\
\text { Vertedero de umbral móvil en la entrada de peces }\end{array}$ & $\begin{array}{l}\text { Adecuado } \\
\text { Sí } \\
\text { Sí }\end{array}$ & $\begin{array}{l}\text { Compuerta en la salida de peces } \\
\text { Dispositivo para evitar la entrada de arrastres } \\
\text { Salida de peces segura (alejada del azud, turbinas, ...) }\end{array}$ & $\begin{array}{l}\text { Sí } \\
\text { No } \\
\text { Sí }\end{array}$ \\
\hline
\end{tabular}

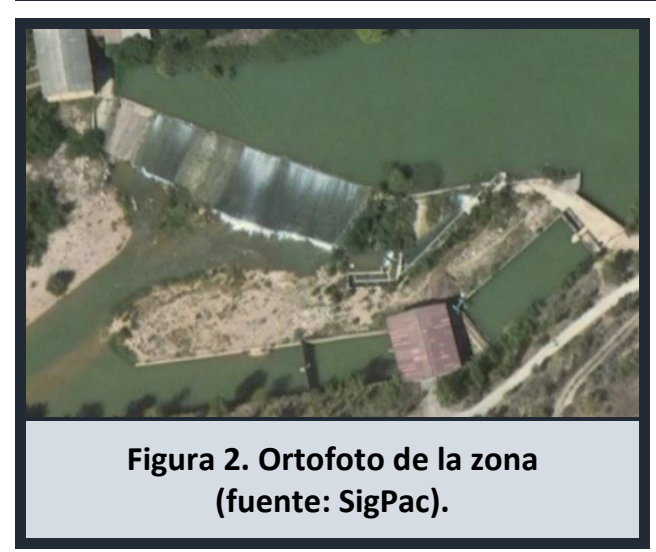

\begin{tabular}{lccl}
\multicolumn{4}{c}{ RESUMEN DE LA EVALUACIÓN DEL PASO PARA PECES } \\
& \multicolumn{2}{c}{ (CON LA METODOLOGÍA AEPS) } & \\
\hline Etapa o categoría & Puntuación & Evaluación & ¿Mejoras? \\
Atracción & 8,7 & Muy favorable & Opcionales \\
Entrada & 8,8 & Muy favorable & Opcionales \\
Pasaje & 9,9 & Muy favorable & Opcionales \\
Salida & 9,5 & Muy favorable & Opcionales \\
\hline
\end{tabular}

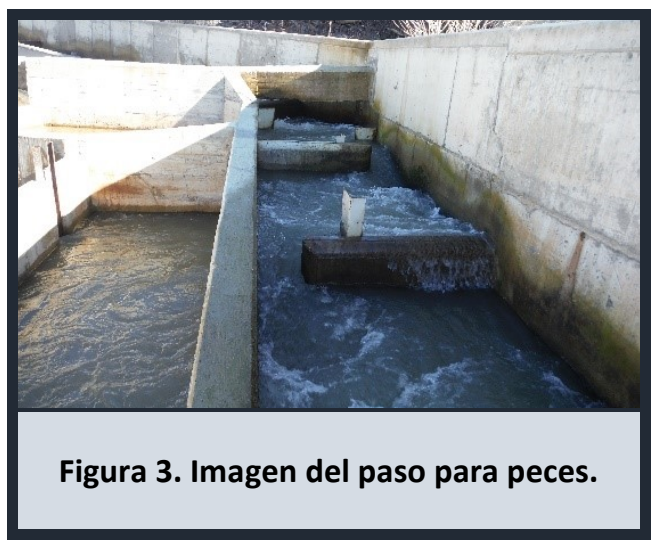




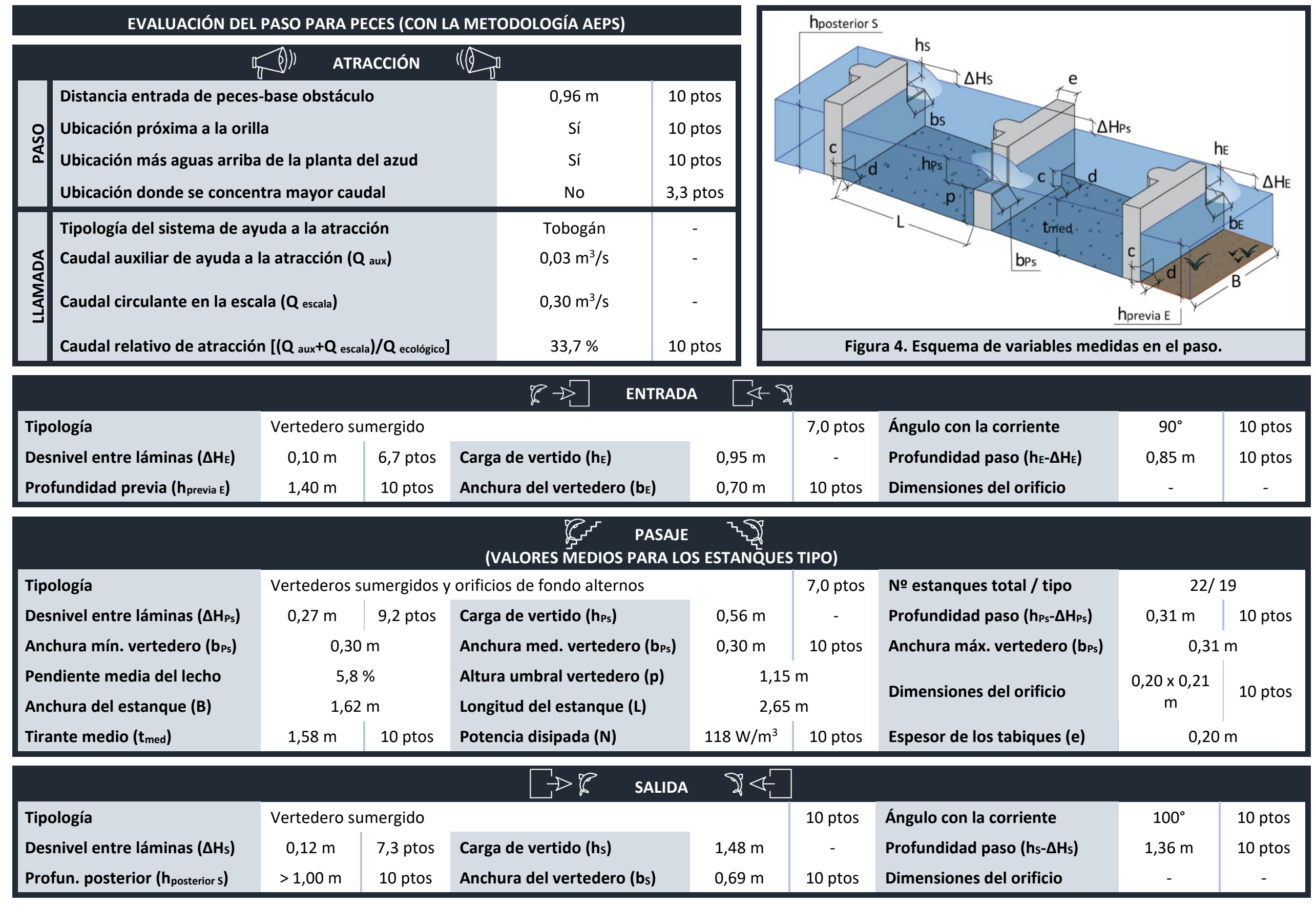




\section{PASO PARA PECES ASOCIADO AL AZUD DE CANALES DEL ARLANZÓN O DE LA FÁBRICA DE LA MONEDA}

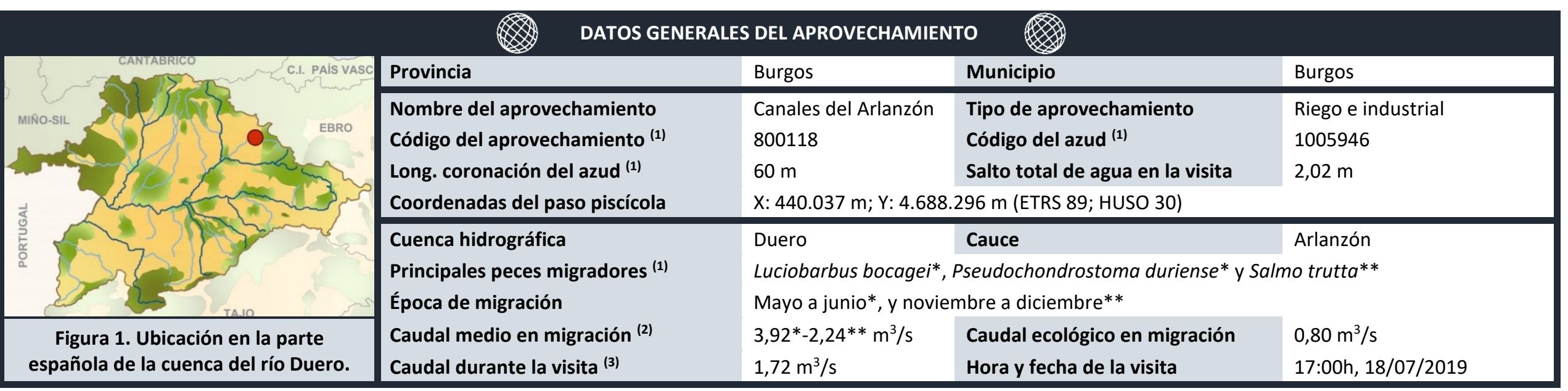

(1) Dato obtenido de MíRAME-IDE Duero. ${ }^{(2)}$ Dato obtenido del CEDEX Hidrológico. ${ }^{(3)}$ Dato obtenido del SAIH del Duero.

\begin{tabular}{|c|c|c|c|}
\hline Paso para peces de estanques & os conectados po & diduras verticales alineadas y sin orificios & \\
\hline $\begin{array}{l}\text { Estado de mantenimiento y limpieza durante la evaluación } \\
\text { Solera naturalizada (con piedras) } \\
\text { Vertedero de umbral móvil en la entrada de peces }\end{array}$ & $\begin{array}{l}\text { Muy adecuado } \\
\text { Sí } \\
\text { Sí }\end{array}$ & $\begin{array}{l}\text { Compuerta en la salida de peces } \\
\text { Dispositivo para evitar la entrada de arrastres } \\
\text { Salida de peces segura (alejada del azud, turbinas, ...) }\end{array}$ & $\begin{array}{l}\text { Sí } \\
\text { Sí } \\
\text { Sí }\end{array}$ \\
\hline
\end{tabular}

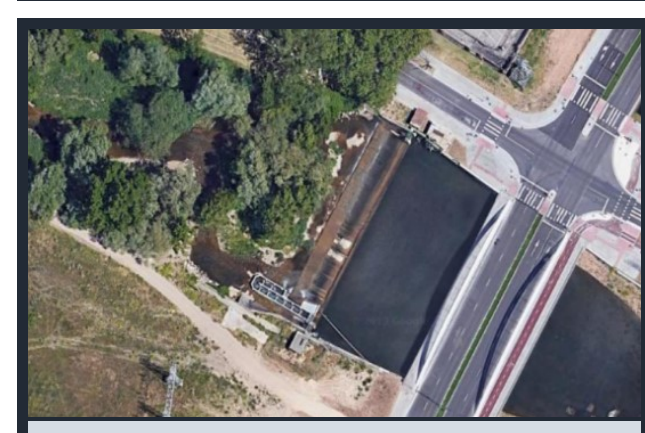

Figura 2. Ortofoto de la zona (fuente: Google Maps).

\begin{tabular}{lccl}
\multicolumn{4}{c}{ RESUMEN DE LA EVALUACIÓN DEL PASO PARA PECES } \\
(CON LA METODOLOGÍA AEPS) \\
Etapa o categoría & Puntuación & Evaluación & ¿Mejoras? \\
Atracción & 10,0 & Muy favorable & Opcionales \\
Entrada & 9,4 & Muy favorable & Opcionales \\
Pasaje & 9,9 & Muy favorable & Opcionales \\
Salida & 9,1 & Muy favorable & Opcionales \\
\hline
\end{tabular}

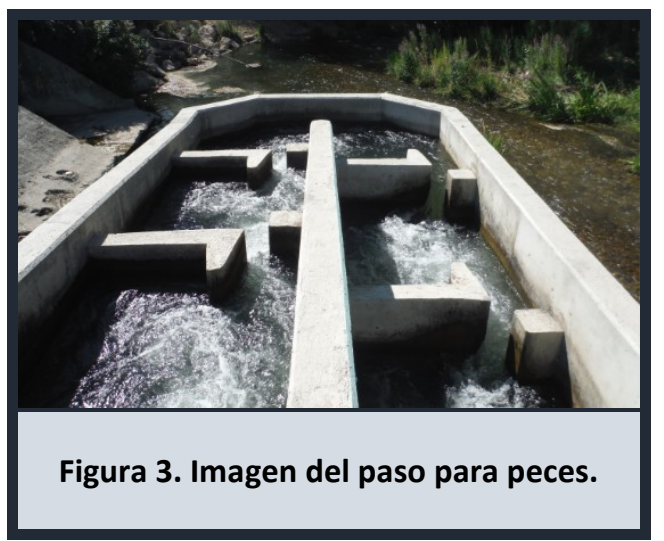




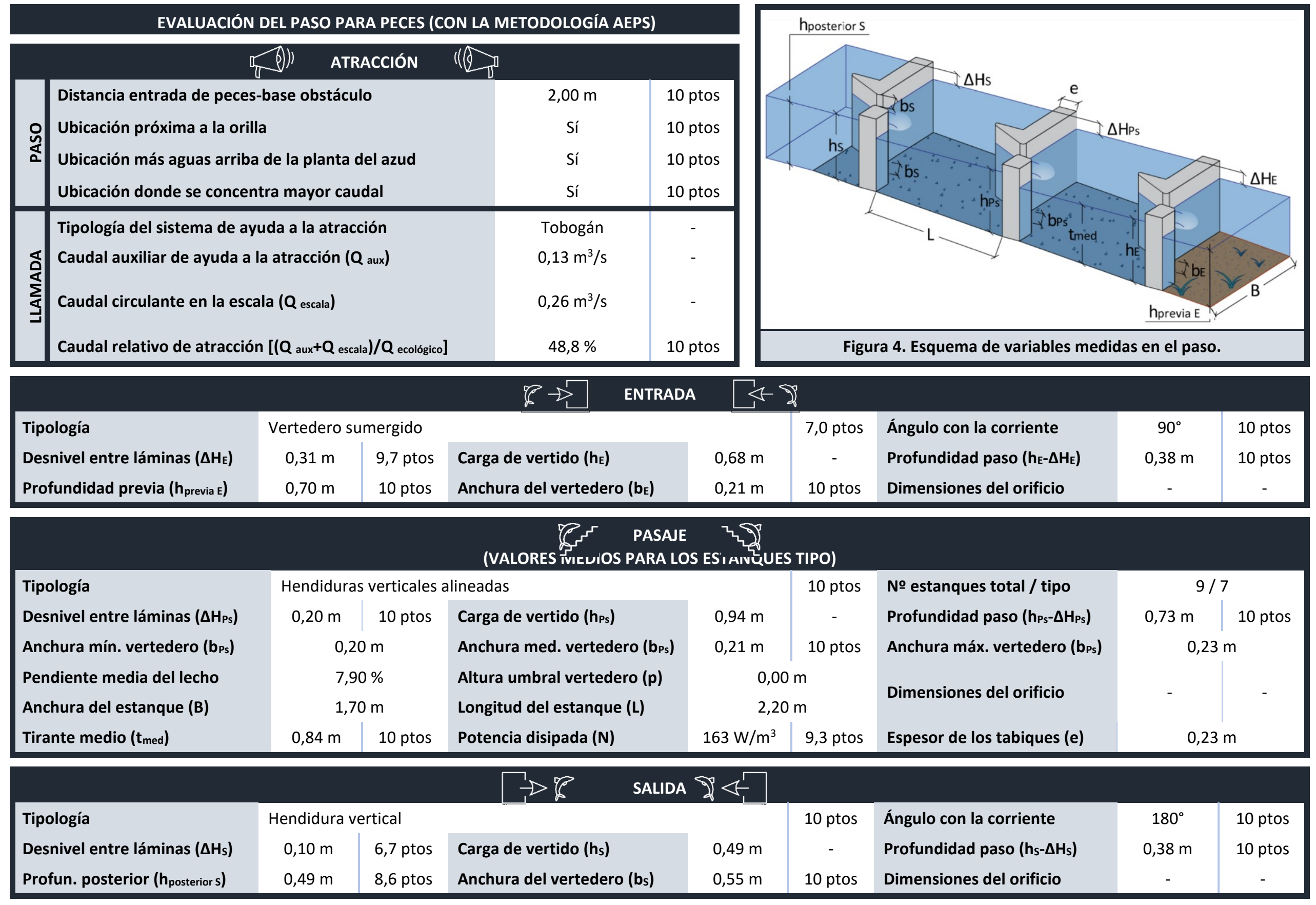




\section{PASO PARA PECES ASOCIADO AL AZUD DE LA CENTRAL HIDROELÉCTRICA DEL VERGUERAL}

\begin{tabular}{|c|c|c|c|c|}
\hline & Provincia & Burgos & Municipio & Mambrilla de Castrejón \\
\hline & $\begin{array}{l}\text { Nombre del aprovechamiento } \\
\text { Código del aprovechamiento } \\
\text { Long. coronación del azud } \\
\text { (1) } \\
\text { Coordenadas del paso piscícola }\end{array}$ & $\begin{array}{l}\text { El Vergueral } \\
1100017 \\
105 \mathrm{~m} \\
\mathrm{X}: 421.229 \mathrm{~m}, \mathrm{Y}: 4.613\end{array}$ & $\begin{array}{l}\text { Tipo de aprovechamiento } \\
\text { Código del azud (1) } \\
\text { Salto total de agua en la visita } \\
146 \text { m (ETRS 89; HUSO 30) }\end{array}$ & $\begin{array}{l}\text { Hidroeléctrico } \\
1005867 \\
3,20 \mathrm{~m}\end{array}$ \\
\hline & $\begin{array}{l}\text { Cuenca hidrográfica } \\
\text { Principales peces migradores }{ }^{(1)} \\
\text { Época de migración }\end{array}$ & $\begin{array}{l}\text { Duero } \\
\text { Luciobarbus bocagei } \\
\text { Mayo a junio }\end{array}$ & Cauce & Duero \\
\hline $\begin{array}{c}\text { Figura 1. Ubicación en la parte } \\
\text { española de la cuenca del río Duero. }\end{array}$ & $\begin{array}{l}\text { Caudal medio en migración (2) } \\
\text { Caudal durante la visita (3) }\end{array}$ & $\begin{array}{l}15,97 \mathrm{~m}^{3} / \mathrm{s} \\
16,50 \mathrm{~m}^{3} / \mathrm{s}\end{array}$ & $\begin{array}{l}\text { Caudal ecológico en migración } \\
\text { Hora y fecha de la visita }\end{array}$ & $\begin{array}{l}2,00 \mathrm{~m}^{3} / \mathrm{s} \\
17: 00 \mathrm{~h}, 04 / 02 / 2016\end{array}$ \\
\hline
\end{tabular}

(1) Dato obtenido de MíRAME-IDE Duero. ${ }^{(2)}$ Dato obtenido del CEDEX Hidrológico. ${ }^{(3)}$ Dato obtenido del SAIH del Duero.

\begin{tabular}{|c|c|c|c|}
\hline Paso para peces de estanques su & s conectados po & tederos sumergidos y orificios de fondo alternos & \\
\hline $\begin{array}{l}\text { Estado de mantenimiento y limpieza durante la evaluación } \\
\text { Solera naturalizada (con piedras) } \\
\text { Vertedero de umbral móvil en la entrada de peces }\end{array}$ & $\begin{array}{l}\text { Muy adecuado } \\
\text { No } \\
\text { Sí }\end{array}$ & $\begin{array}{l}\text { Compuerta en la salida de peces } \\
\text { Dispositivo para evitar la entrada de arrastres } \\
\text { Salida de peces segura (alejada del azud, turbinas, ...) }\end{array}$ & $\begin{array}{l}\text { No } \\
\text { Sí } \\
\text { No }\end{array}$ \\
\hline
\end{tabular}

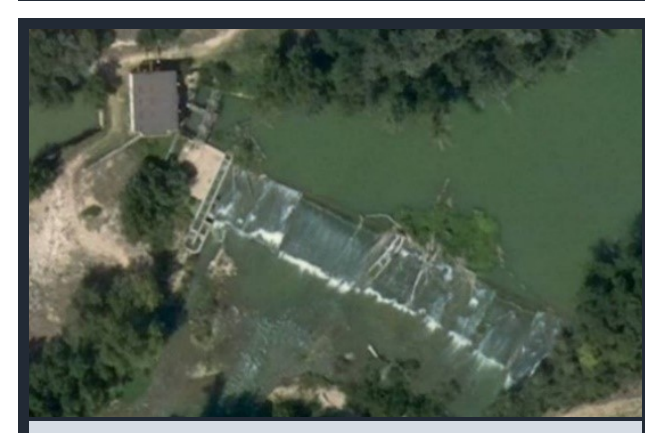

Figura 2. Ortofoto de la zona (fuente: SigPac).

\begin{tabular}{lccc}
\multicolumn{4}{c}{ RESUMEN DE LA EVALUACIÓN DEL PASO PARA PECES } \\
& \multicolumn{2}{c|}{ (CON LA METODOLOGÍA AEPS) } & \\
\hline Etapa o categoría & Puntuación & Evaluación & ¿Mejoras? \\
Atracción & 7,1 & Favorable & Recomendables \\
Entrada & 9,4 & Muy favorable & Opcionales \\
Pasaje & 10 & Muy favorable & Opcionales \\
Salida & 7,6 & Favorable & Recomendables \\
\hline
\end{tabular}

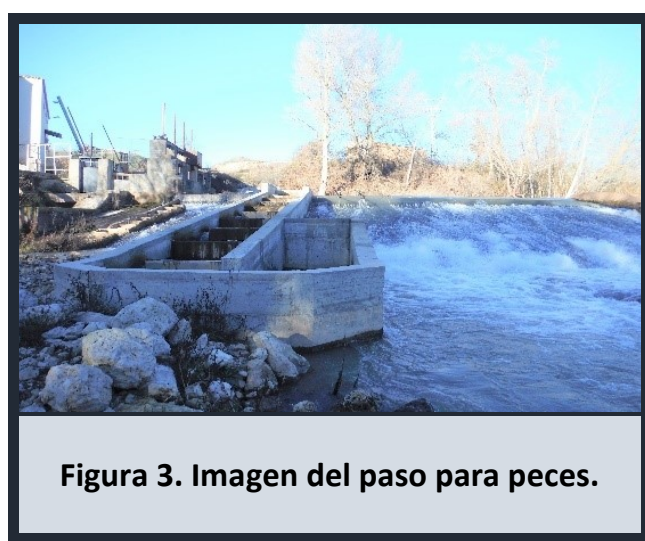




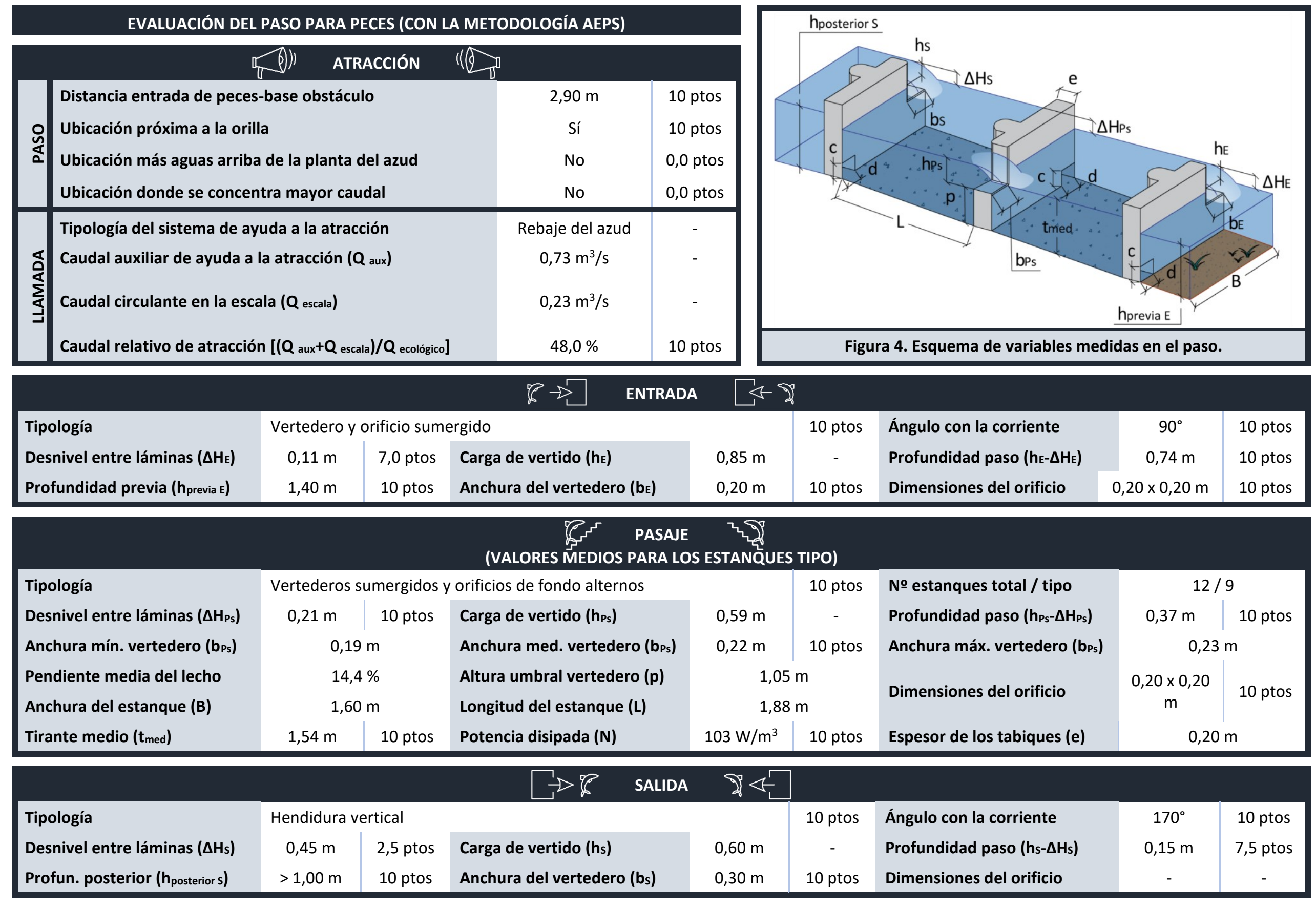




\section{PASO PARA PECES ASOCIADO AL AZUD DE LA CENTRAL HIDROELÉCTRICA DE GUMA}

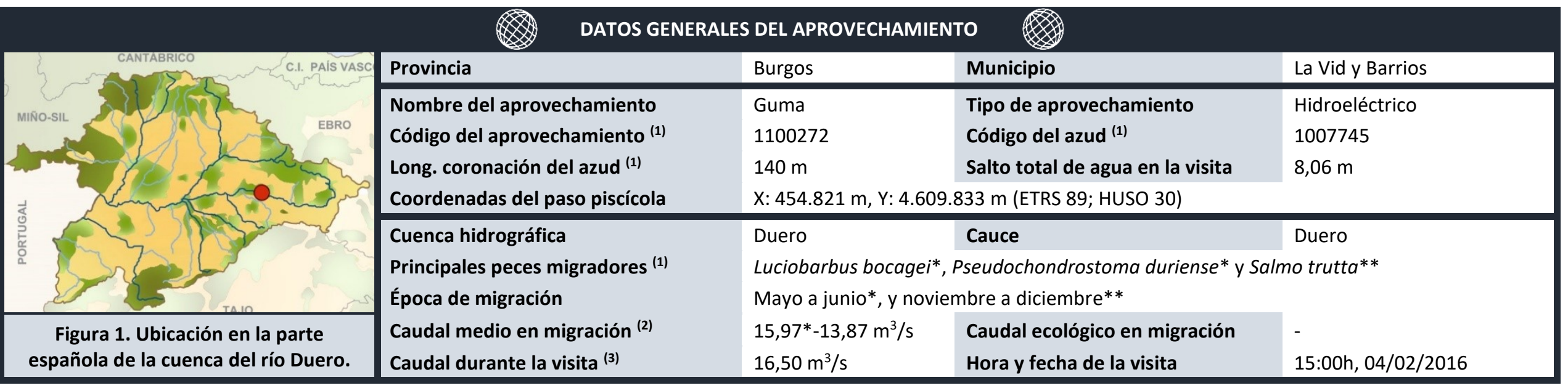

(1) Dato obtenido de MíRAME-IDE Duero. ${ }^{(2)}$ Dato obtenido del CEDEX Hidrológico. ${ }^{(3)}$ Dato obtenido del SAIH del Duero.

\begin{tabular}{|c|c|c|c|}
\hline Paso para peces de estanques $s$ & os conectado & tederos sumergidos y orificios de fondo alternos & \\
\hline $\begin{array}{l}\text { Estado de mantenimiento y limpieza durante la evaluación } \\
\text { Solera naturalizada (con piedras) } \\
\text { Vertedero de umbral móvil en la entrada de peces }\end{array}$ & $\begin{array}{l}\text { Adecuado } \\
\text { Sí } \\
\text { No }\end{array}$ & $\begin{array}{l}\text { Compuerta en la salida de peces } \\
\text { Dispositivo para evitar la entrada de arrastres } \\
\text { Salida de peces segura (alejada del azud, turbinas, ...) }\end{array}$ & $\begin{array}{l}\text { Sí } \\
\text { No } \\
\text { Sí }\end{array}$ \\
\hline
\end{tabular}

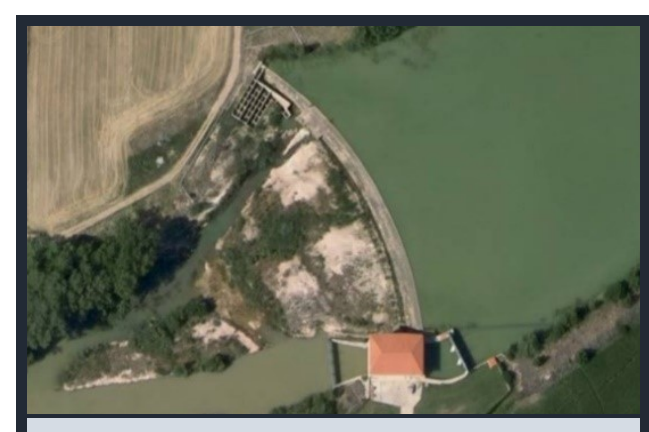

Figura 2. Ortofoto de la zona (fuente: SigPac).

\begin{tabular}{lccc}
\multicolumn{4}{c}{ RESUMEN DE LA EVALUACIÓN DEL PASO PARA PECES } \\
& \multicolumn{4}{c|}{ (CON LA METODOLOGÍA AEPS) } & \\
\hline Etapa o categoría & Puntuación & Evaluación & ¿Mejoras? \\
Atracción & 6,6 & Favorable & Recomendables \\
Entrada & 8,8 & Muy favorable & Opcionales \\
Pasaje & 10 & Muy favorable & Opcionales \\
Salida & 8,4 & Muy favorable & Opcionales \\
\hline
\end{tabular}

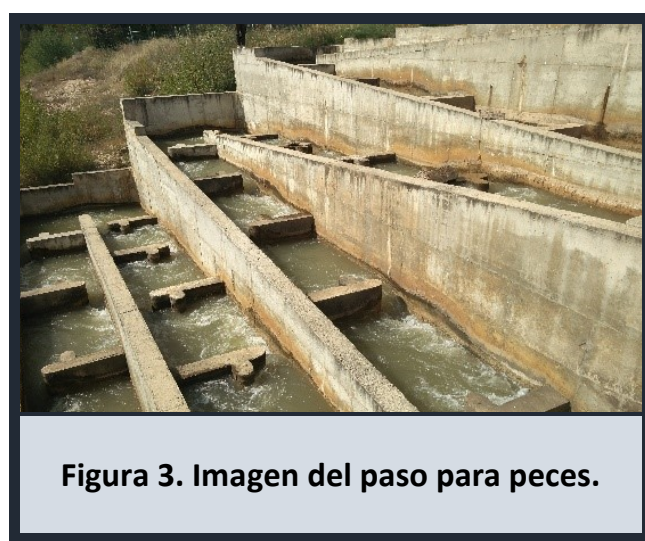




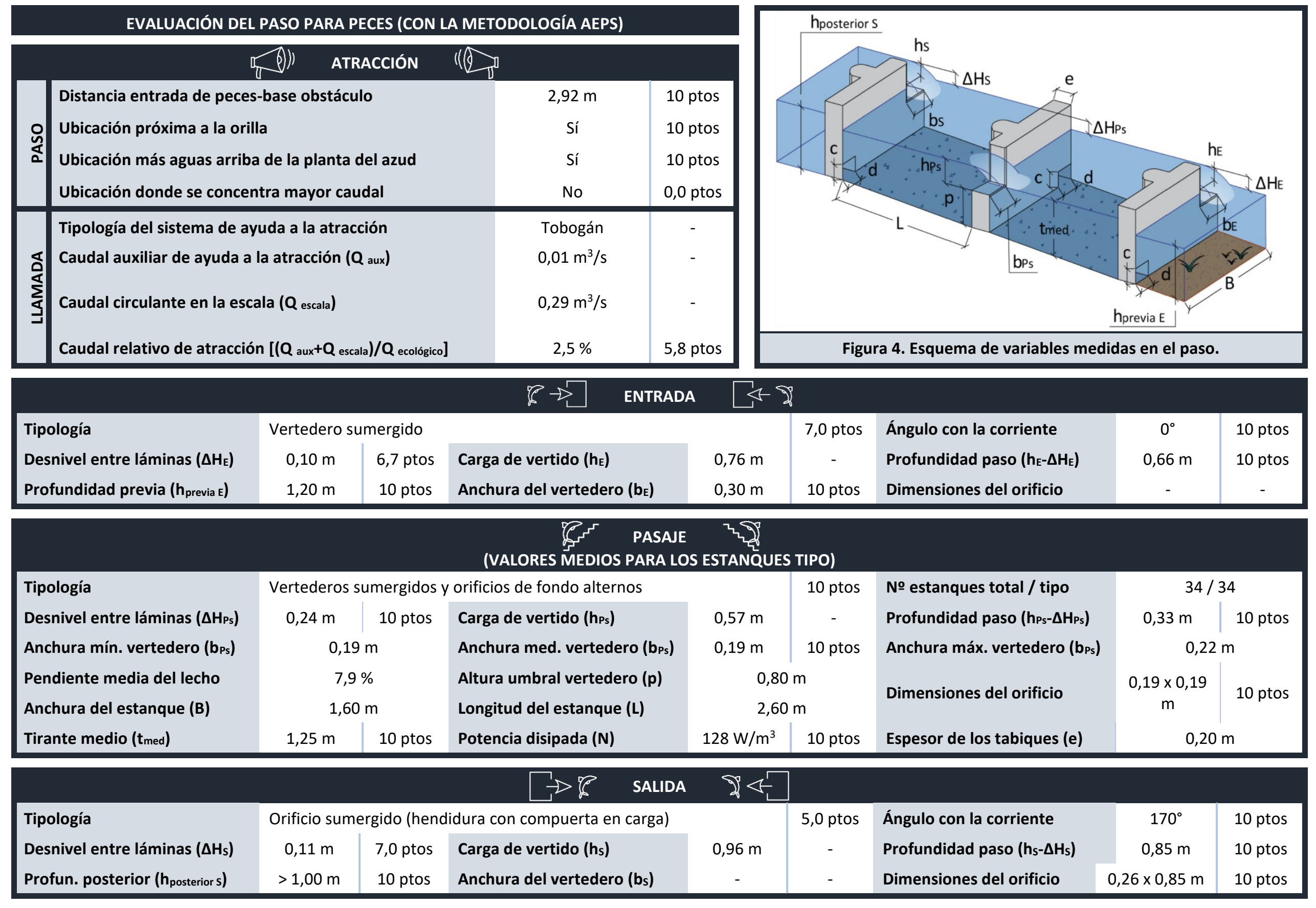




\section{PASO PARA PECES ASOCIADO AL AZUD DE LA CENTRAL HIDROELÉCTRICA DE LA PELOTERA}

\begin{tabular}{|c|c|c|c|c|}
\hline & Provincia & Burgos & Municipio & Barbadillo del Pez \\
\hline & $\begin{array}{l}\text { Nombre del aprovechamiento } \\
\text { Código del aprovechamiento } \\
\text { Long. coronación del azud } \\
\text { (1) } \\
\text { Coordenadas del paso piscícola }\end{array}$ & $\begin{array}{l}\text { La Pelotera } \\
1100077 \\
24 \mathrm{~m} \\
\mathrm{X:} 481.143 \mathrm{~m}, \mathrm{Y}: 4\end{array}$ & $\begin{array}{l}\text { Tipo de aprovechamiento } \\
\text { Código del azud (1) } \\
\text { Salto total de agua en la visita } \\
998 \text { m (ETRS 89; HUSO 30) }\end{array}$ & $\begin{array}{l}\text { Hidroeléctrico } \\
1005899 \\
1,26 \mathrm{~m}\end{array}$ \\
\hline & $\begin{array}{l}\text { Cuenca hidrográfica } \\
\text { Principales peces migradores }{ }^{(1)} \\
\text { Época de migración }\end{array}$ & $\begin{array}{l}\text { Duero } \\
\text { Luciobarbus bocag } \\
\text { Mayo a junio*, y n }\end{array}$ & $\begin{array}{l}\text { Cauce } \\
\text { Salmo trutta** } \\
\text { nbre a diciembre** }\end{array}$ & Pedroso \\
\hline $\begin{array}{l}\text { Figura 1. Ubicación en la parte } \\
\text { española de la cuenca del río Duero. }\end{array}$ & $\begin{array}{l}\text { Caudal medio en migración (2) } \\
\text { Caudal durante la visita }{ }^{(3)}\end{array}$ & $\begin{array}{l}3,95^{*}-4,12 * * \mathrm{~m}^{3} / \mathrm{s} \\
1,69 \mathrm{~m}^{3} / \mathrm{s}\end{array}$ & $\begin{array}{l}\text { Caudal ecológico en migración } \\
\text { Hora y fecha de la visita }\end{array}$ & $\begin{array}{l}0,60 \mathrm{~m}^{3} / \mathrm{s} \\
10: 00 \mathrm{~h}, 14 / 01 / 2015\end{array}$ \\
\hline
\end{tabular}

(1) Dato obtenido de MíRAME-IDE Duero. ${ }^{(2)}$ Dato obtenido del CEDEX Hidrológico. ${ }^{(3)}$ Dato obtenido del SAIH del Duero.

\begin{tabular}{|c|c|c|c|}
\hline Paso para peces de estanques su & os conectados po & diduras verticales alineadas y sin orificios & \\
\hline $\begin{array}{l}\text { Estado de mantenimiento y limpieza durante la evaluación } \\
\text { Solera naturalizada (con piedras) } \\
\text { Vertedero de umbral móvil en la entrada de peces }\end{array}$ & $\begin{array}{l}\text { Muy deficiente } \\
\text { Sí } \\
\text { No }\end{array}$ & $\begin{array}{l}\text { Compuerta en la salida de peces } \\
\text { Dispositivo para evitar la entrada de arrastres } \\
\text { Salida de peces segura (alejada del azud, turbinas, ...) }\end{array}$ & $\begin{array}{l}\text { Sí } \\
\text { No } \\
\text { Sí }\end{array}$ \\
\hline
\end{tabular}

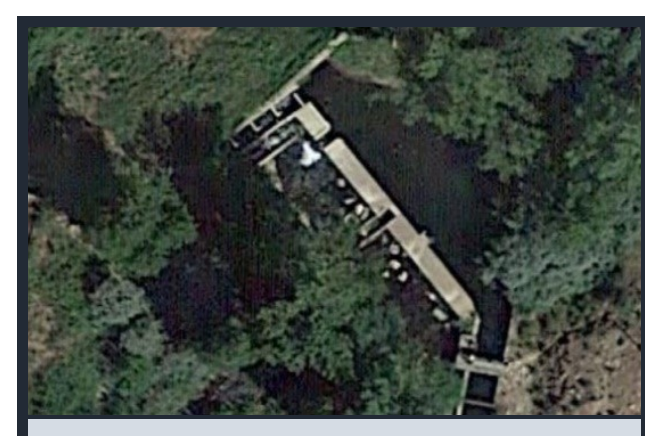

Figura 2. Ortofoto de la zona (fuente: Google Maps).

\begin{tabular}{|c|c|c|c|}
\hline \multicolumn{4}{|c|}{$\begin{array}{l}\text { RESUMEN DE LA EVALUACIÓN DEL PASO PARA PECES } \\
\text { (CON LA METODOLOGÍA AEPS) }\end{array}$} \\
\hline Etapa o categoría & Puntuación & Evaluación & ¿Mejoras? \\
\hline Atracción & 8,7 & Muy favorable & Opcionales \\
\hline Entrada & 9,5 & Muy favorable & Opcionales \\
\hline Pasaje & 9,7 & Muy favorable & Opcionales \\
\hline Salida & 10,0 & Muy favorable & Opcionales \\
\hline
\end{tabular}

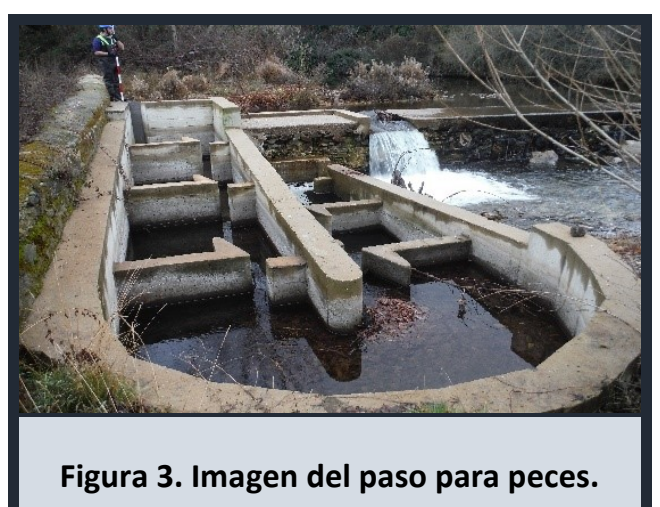




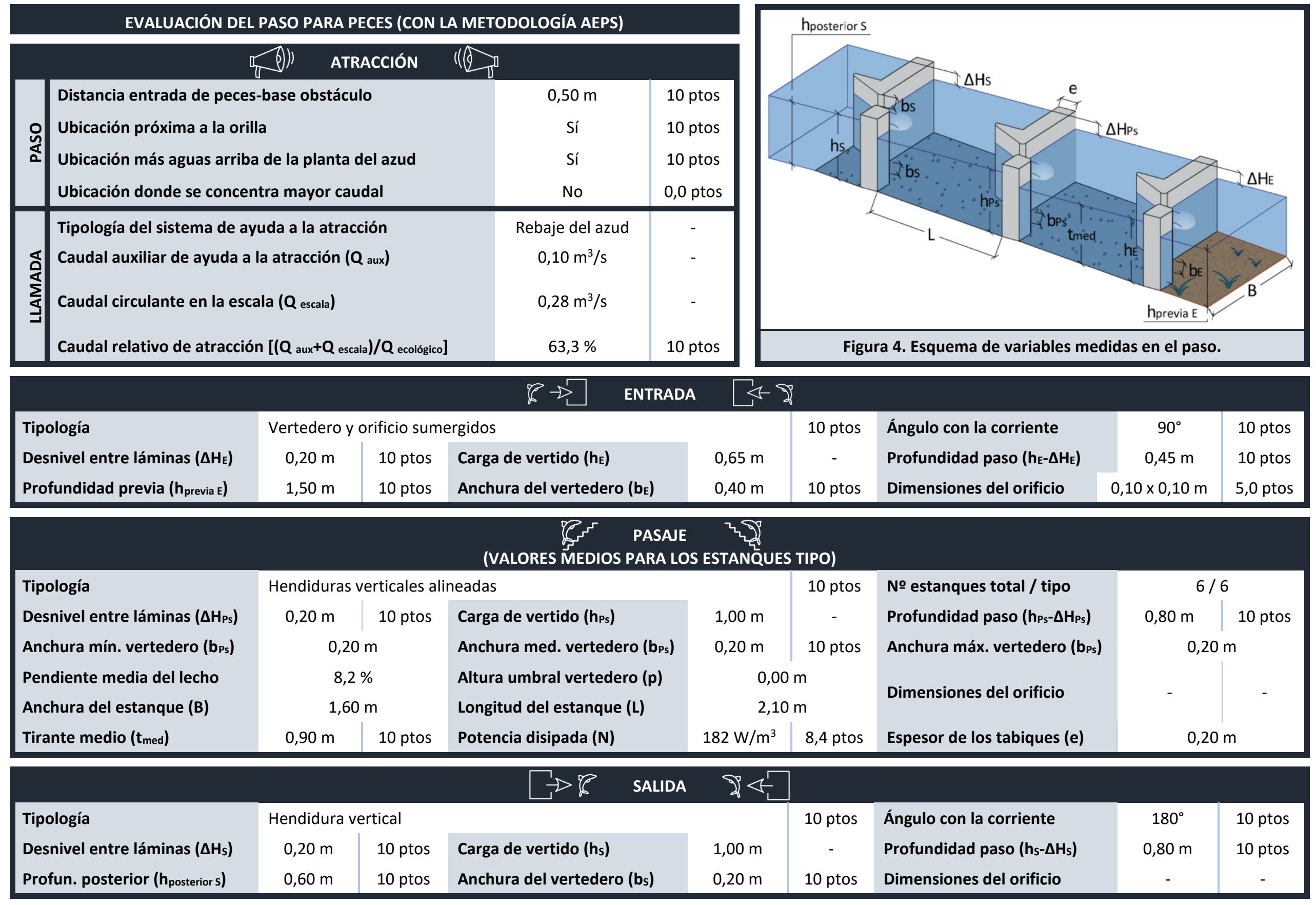




\section{PASO PARA PECES ASOCIADO AL AZUD DE LA CENTRAL HIDROELÉCTRICA DE LA RACHELA}

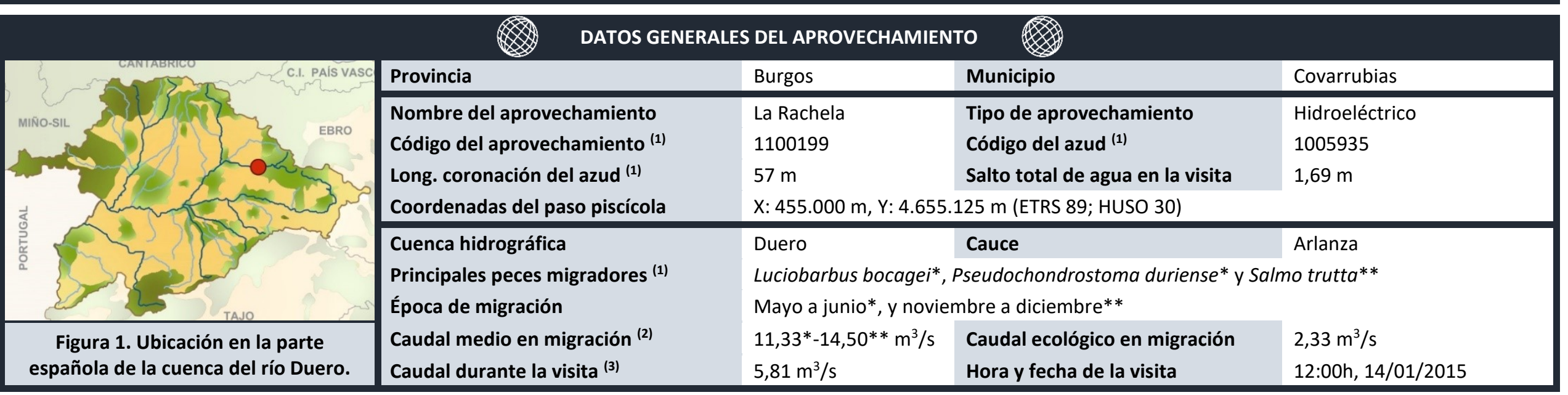

(1) Dato obtenido de MíRAME-IDE Duero. ${ }^{(2)}$ Dato obtenido del CEDEX Hidrológico. ${ }^{(3)}$ Dato obtenido del SAIH del Duero.

\begin{tabular}{|c|c|c|c|}
\hline \multicolumn{4}{|c|}{ OBSERVACIONES GENERALES DE LA ESCALA } \\
\hline $\begin{array}{l}\text { Estado de mantenimiento y limpieza durante la evaluación } \\
\text { Solera naturalizada (con piedras) } \\
\text { Vertedero de umbral móvil en la entrada de peces }\end{array}$ & $\begin{array}{l}\text { No adecuado } \\
\text { Sí } \\
\text { Sí }\end{array}$ & $\begin{array}{l}\text { Compuerta en la salida de peces } \\
\text { Dispositivo para evitar la entrada de arrastres } \\
\text { Salida de peces segura (alejada del azud, turbinas, ...) }\end{array}$ & $\begin{array}{l}\text { Sí } \\
\text { No } \\
\text { No }\end{array}$ \\
\hline
\end{tabular}

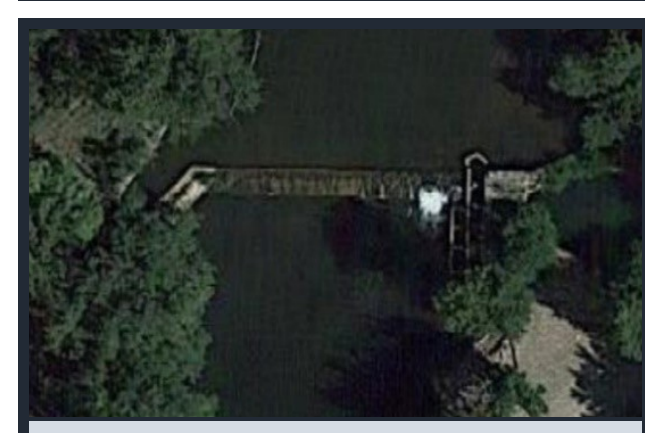

Figura 2. Ortofoto de la zona (fuente: Google Maps).

\begin{tabular}{lccc}
\multicolumn{4}{c}{ RESUMEN DE LA EVALUACIÓN DEL PASO PARA PECES } \\
& \multicolumn{2}{c|}{ (CON LA METODOLOGÍA AEPS) } & \\
\hline Etapa o categoría & Puntuación & Evaluación & ¿Mejoras? \\
Atracción & 6,9 & Favorable & Recomendables \\
Entrada & 9,4 & Muy favorable & Opcionales \\
Pasaje & 9,4 & Muy favorable & Opcionales \\
Salida & 7,7 & Favorable & Recomendables \\
\hline
\end{tabular}

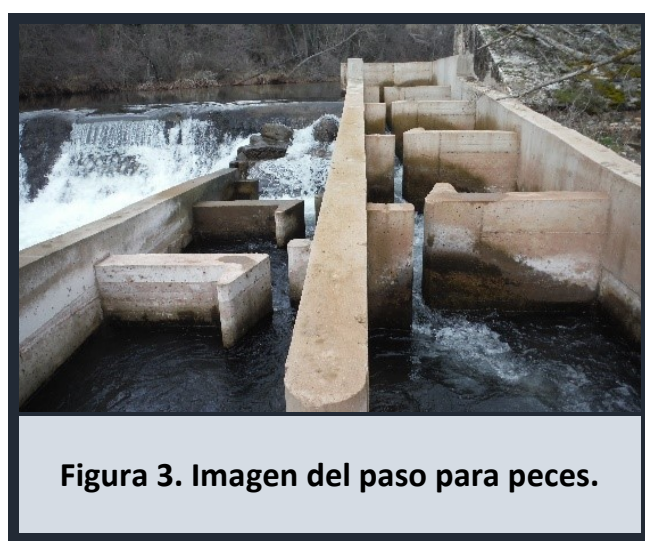




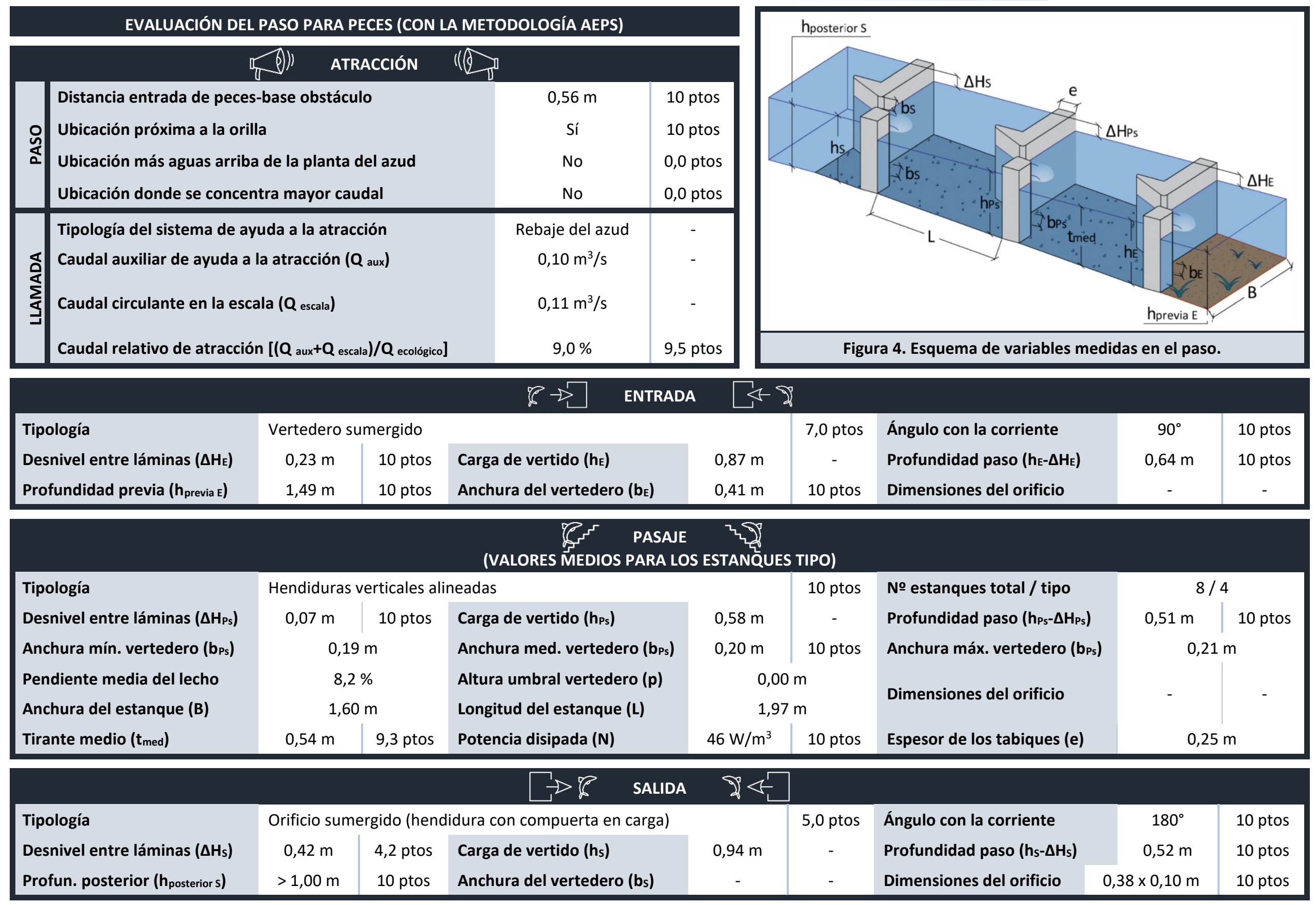




\section{PASO PARA PECES ASOCIADO AL OBSTÁCULO GENERADO POR EL NUEVO PUENTE DEL BULEVAR}

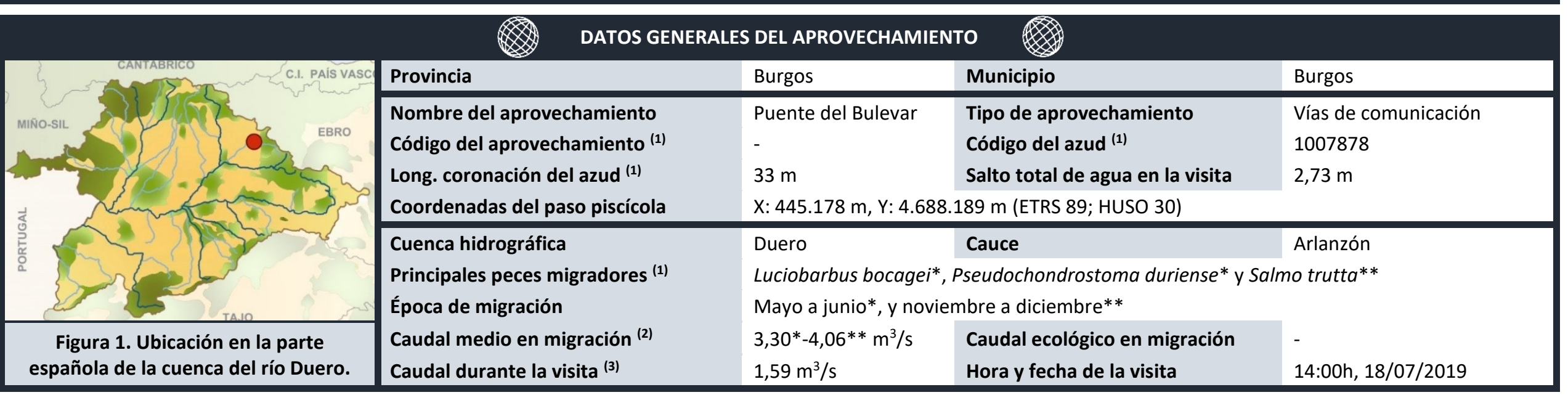

(1) Dato obtenido de MíRAME-IDE Duero. ${ }^{(2)}$ Dato obtenido del CEDEX Hidrológico. ${ }^{(3)}$ Dato obtenido del SAIH del Duero.

\begin{tabular}{|c|c|c|c|}
\hline Paso para peces de estanques & os conectad & tederos sumergidos y orificios de fondo alternos & \\
\hline $\begin{array}{l}\text { Estado de mantenimiento y limpieza durante la evaluación } \\
\text { Solera naturalizada (con piedras) } \\
\text { Vertedero de umbral móvil en la entrada de peces }\end{array}$ & $\begin{array}{l}\text { Adecuado } \\
\text { Sí } \\
\text { Sí }\end{array}$ & $\begin{array}{l}\text { Compuerta en la salida de peces } \\
\text { Dispositivo para evitar la entrada de arrastres } \\
\text { Salida de peces segura (alejada del azud, turbinas, ...) }\end{array}$ & $\begin{array}{l}\text { Sí } \\
\text { Sí } \\
\text { Sí }\end{array}$ \\
\hline
\end{tabular}

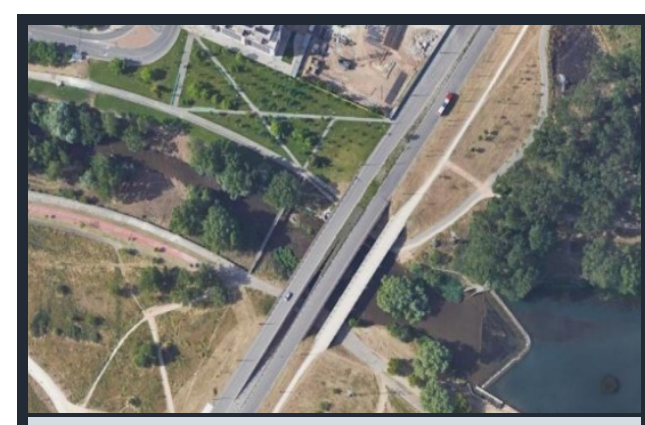

Figura 2. Ortofoto de la zona (fuente: Google Maps).

\begin{tabular}{lccc}
\multicolumn{4}{c}{ RESUMEN DE LA EVALUACIÓN DEL PASO PARA PECES } \\
& \multicolumn{4}{c|}{ (CON LA METODOLOGÍA AEPS) } & \\
\hline Etapa o categoría & Puntuación & Evaluación & ¿Mejoras? \\
Atracción & 7,8 & Favorable & Recomendables \\
Entrada & 9,4 & Muy favorable & Opcionales \\
Pasaje & 9,9 & Muy favorable & Opcionales \\
Salida & 9,2 & Muy favorable & Opcionales \\
\hline
\end{tabular}

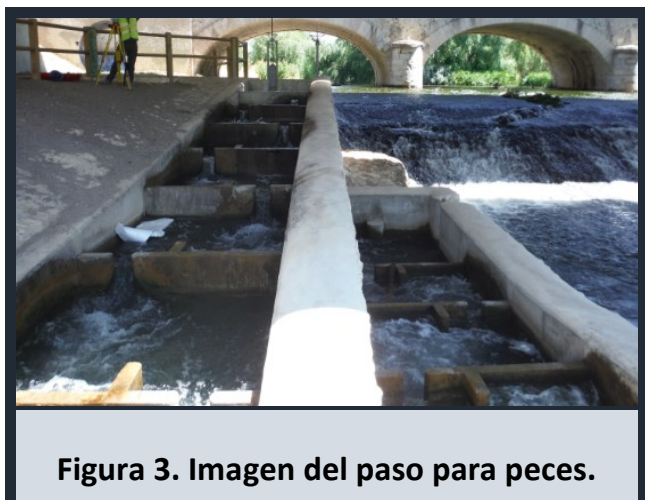




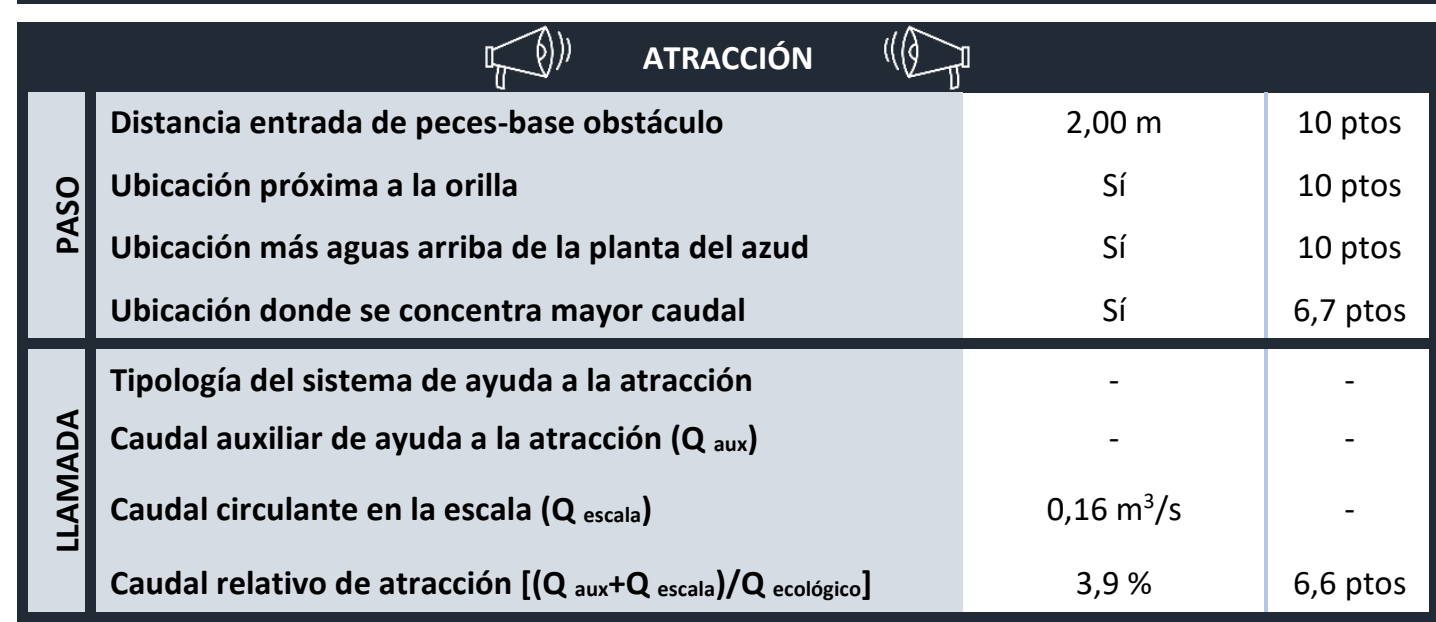

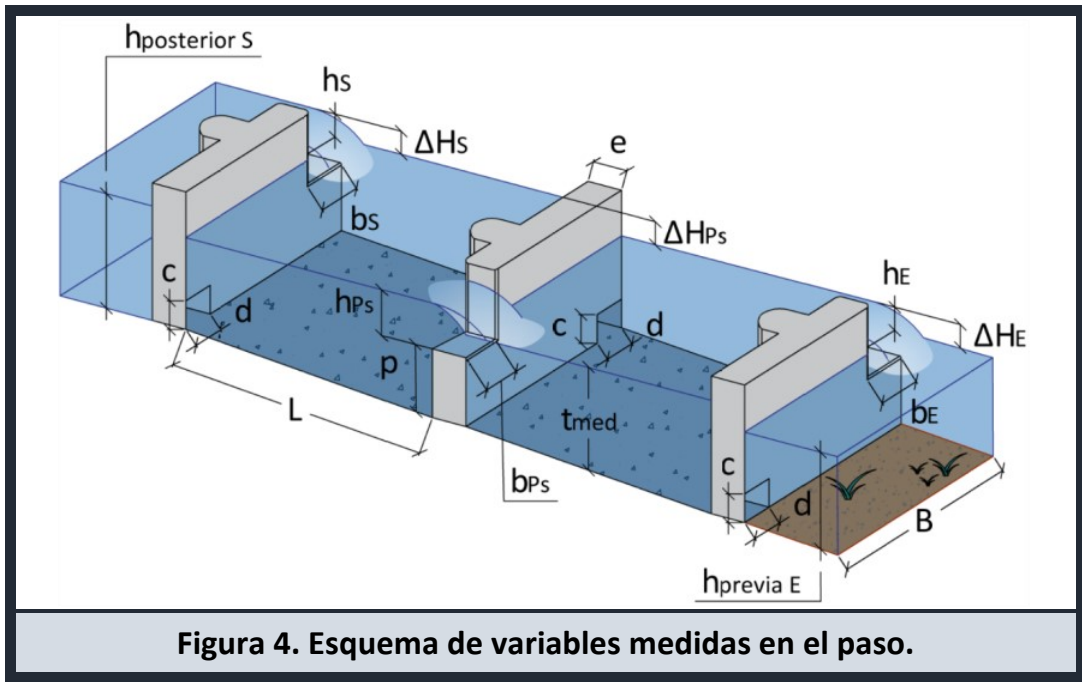

\begin{tabular}{|c|c|c|c|c|c|c|c|c|}
\hline & & & 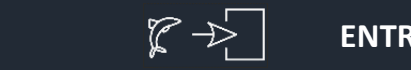 & & & & & \\
\hline Tipología & \multicolumn{3}{|c|}{ Vertedero y orificio sumergidos } & & 10 ptos & Ángulo con la corriente & $90^{\circ}$ & 10 ptos \\
\hline Desnivel entre láminas $\left(\Delta \mathrm{H}_{\mathrm{E}}\right)$ & $0,14 \mathrm{~m}$ & 8,0 ptos & Carga de vertido ( $\left.h_{E}\right)$ & $0,46 \mathrm{~m}$ & - & Profundidad paso $\left(h_{E}-\Delta H_{E}\right)$ & $0,32 \mathrm{~m}$ & 10 ptos \\
\hline Profundidad previa ( $h_{\text {previa } E)}$ & $0,78 \mathrm{~m}$ & 10 ptos & Anchura del vertedero $\left(b_{E}\right)$ & $0,28 \mathrm{~m}$ & 10 ptos & Dimensiones del orificio & $0,15 \times 0,15 \mathrm{~m}$ & 8,5 ptos \\
\hline
\end{tabular}

\begin{tabular}{|c|c|c|c|c|c|c|c|c|}
\hline Tipología & \multicolumn{3}{|c|}{ Vertederos sumergidos y orificios de fondo alternos } & & 10 ptos & № estanques total / tipo & \multicolumn{2}{|c|}{$12 / 11$} \\
\hline Desnivel entre láminas ( $\left.\Delta \mathrm{H}_{\mathrm{Ps}}\right)$ & $0,19 \mathrm{~m}$ & 10 ptos & Carga de vertido ( $\left.h_{\mathrm{Ps}}\right)$ & $0,47 \mathrm{~m}$ & - & Profundidad paso ( $\left.h_{\mathrm{Ps}_{\mathrm{s}}}-\Delta \mathrm{H}_{\mathrm{Ps}}\right)$ & $0,27 \mathrm{~m}$ & 10 ptos \\
\hline Anchura mín. vertedero ( $\left.b_{P_{s}}\right)$ & \multicolumn{2}{|c|}{$0,17 \mathrm{~m}$} & Anchura med. vertedero ( $\left.b_{P_{s}}\right)$ & $0,20 \mathrm{~m}$ & 10 ptos & Anchura máx. vertedero ( $\left.b_{P_{s}}\right)$ & \multicolumn{2}{|c|}{$0,20 \mathrm{~m}$} \\
\hline $\begin{array}{l}\text { Pendiente media del lecho } \\
\text { Anchura del estanque (B) }\end{array}$ & \multicolumn{2}{|c|}{$\begin{array}{l}11,04 \% \\
1,80 \mathrm{~m}\end{array}$} & $\begin{array}{l}\text { Altura umbral vertedero (p) } \\
\text { Longitud del estanque (L) }\end{array}$ & \multicolumn{2}{|c|}{$\begin{array}{l}0,60 \mathrm{~m} \\
1,70 \mathrm{~m}\end{array}$} & Dimensiones del orificio & $\begin{array}{c}0,17 \times 0,20 \\
m\end{array}$ & 8,3 ptos \\
\hline Tirante medio $\left(t_{\text {med }}\right)$ & $0,98 \mathrm{~m}$ & 10 ptos & Potencia disipada (N) & $100 \mathrm{~W} / \mathrm{m}^{3}$ & 10 ptos & Espesor de los tabiques (e) & 0,10 & \\
\hline
\end{tabular}

\begin{tabular}{|c|c|c|c|c|c|c|c|c|}
\hline Tipología & \multicolumn{3}{|c|}{ Orificio sumergido (vertedero con compuerta en carga) } & & \multirow{2}{*}{$\begin{array}{c}5 \text { ptos } \\
-\end{array}$} & \multirow{2}{*}{$\begin{array}{l}\text { Ángulo con la corriente } \\
\text { Profundidad paso }\left(\mathrm{h}_{\mathrm{s}}-\Delta \mathrm{H}_{\mathrm{s}}\right)\end{array}$} & \multirow{2}{*}{$\begin{array}{c}180^{\circ} \\
0,68 \mathrm{~m}\end{array}$} & \multirow{2}{*}{$\begin{array}{l}10 \text { ptos } \\
10 \text { ptos }\end{array}$} \\
\hline Desnivel entre láminas $\left(\Delta \mathrm{H}_{s}\right)$ & $0,20 \mathrm{~m}$ & 10 ptos & Carga de vertido (hs) & $0,87 \mathrm{~m}$ & & & & \\
\hline Profun. posterior ( $h_{\text {posterior }}$ ) & $0,30 \mathrm{~m}$ & 6,3 ptos & Anchura del vertedero (bs) & - & - & Dimensiones del orificio & $0,80 \times 0,20 \mathrm{~m}$ & 10 ptos \\
\hline
\end{tabular}




\section{PASO PARA PECES ASOCIADO AL AZUD DE LA CENTRAL HIDROELÉCTRICA DE PUENTEDURA}

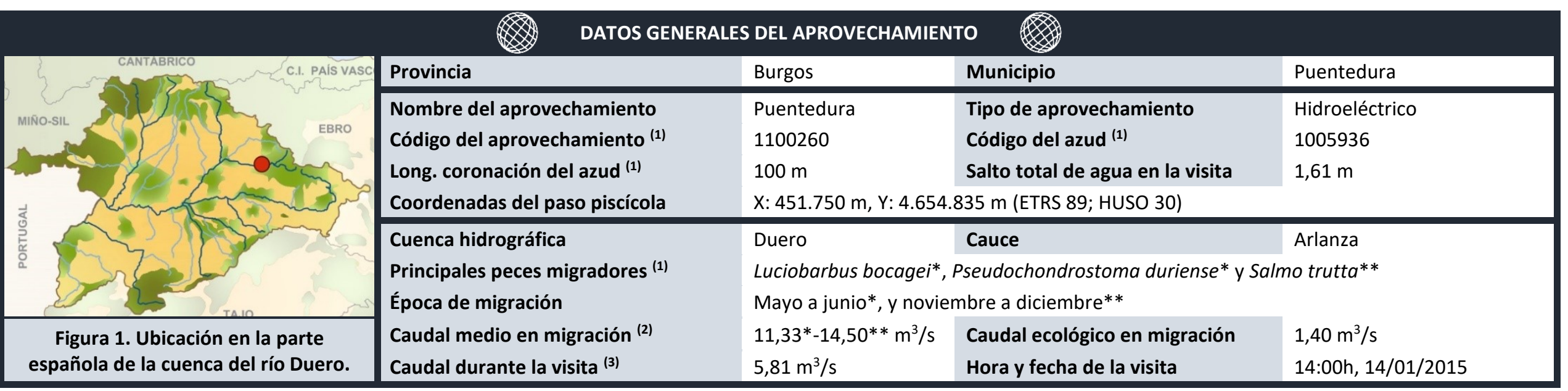

(1) Dato obtenido de MíRAME-IDE Duero. ${ }^{(2)}$ Dato obtenido del CEDEX Hidrológico. ${ }^{(3)}$ Dato obtenido del SAIH del Duero.

\begin{tabular}{|c|c|c|c|}
\hline \multicolumn{4}{|c|}{ OBSERVACIONES GENERALES DE LA ESCALA } \\
\hline $\begin{array}{l}\text { Estado de mantenimiento y limpieza durante la evaluación } \\
\text { Solera naturalizada (con piedras) } \\
\text { Vertedero de umbral móvil en la entrada de peces }\end{array}$ & $\begin{array}{l}\text { No adecuado } \\
\text { Sí } \\
\text { No }\end{array}$ & $\begin{array}{l}\text { Compuerta en la salida de peces } \\
\text { Dispositivo para evitar la entrada de arrastres } \\
\text { Salida de peces segura (alejada del azud, turbinas, ...) }\end{array}$ & $\begin{array}{l}\text { Sí } \\
\text { No } \\
\text { Sí }\end{array}$ \\
\hline
\end{tabular}

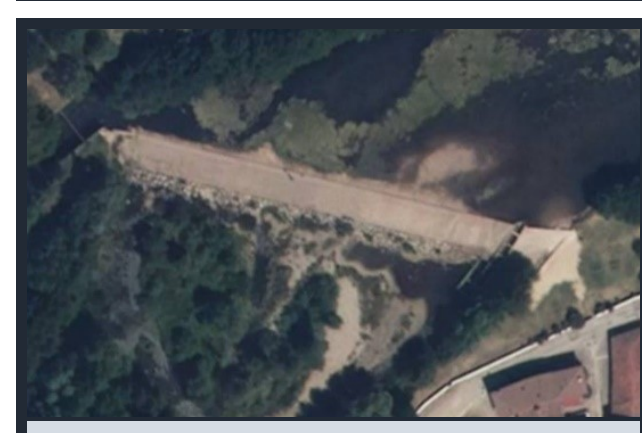

Figura 2. Ortofoto de la zona (fuente: SigPac).

\begin{tabular}{lccc|}
\hline \multicolumn{4}{c}{ RESUMEN DE LA EVALUACIÓN DEL PASO PARA PECES } \\
& \multicolumn{4}{c|}{ (CON LA METODOLOGÍA AEPS) } \\
\hline Etapa o categoría & Puntuación & Evaluación & ¿Mejoras? \\
Atracción & 8,7 & Muy favorable & Opcionales \\
Entrada & 0,0 & Muy desfavorable & Imprescindibles \\
Pasaje & 9,9 & Muy favorable & Opcionales \\
Salida & 9,7 & Muy favorable & Opcionales \\
\hline
\end{tabular}

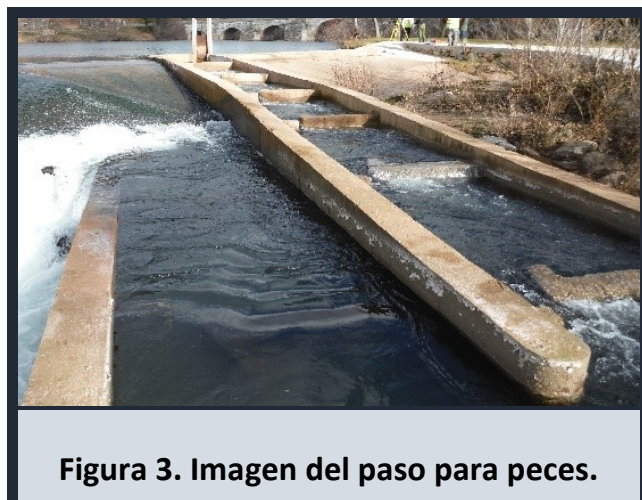




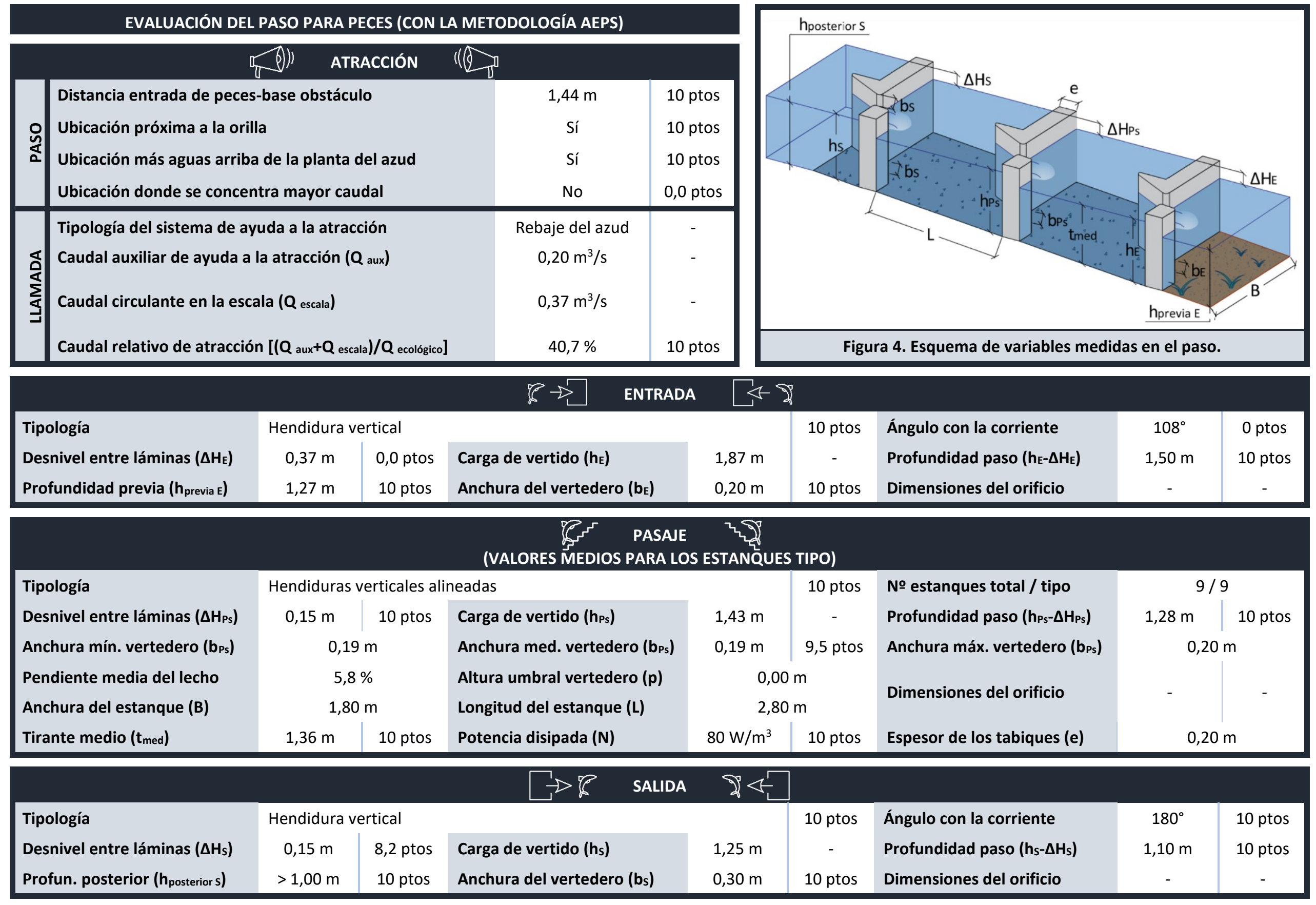




\section{PASO PARA PECES ASOCIADO AL AZUD DE LA CENTRAL DE SAN MARTÍN DE RUBIALES II}

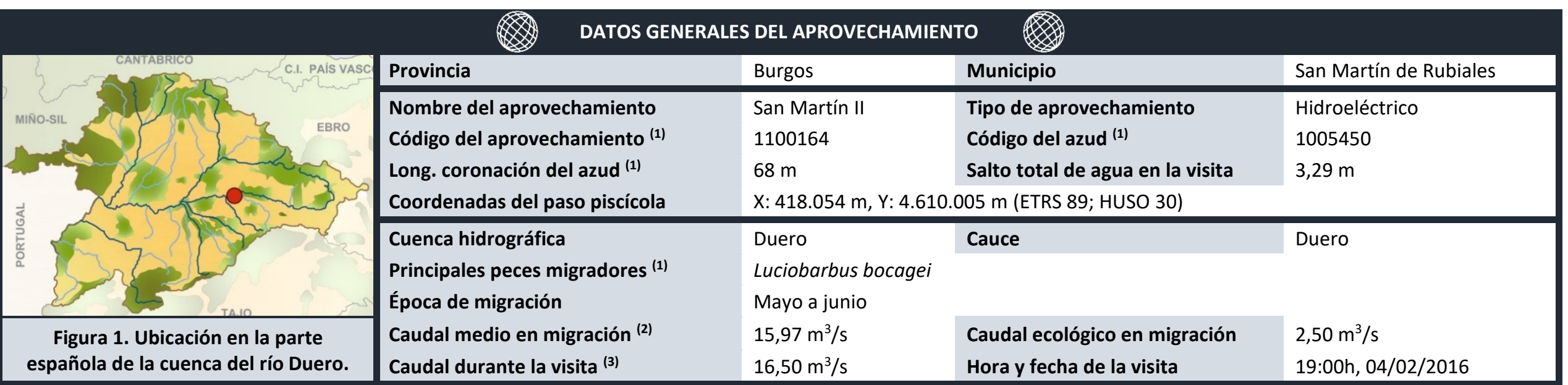

${ }^{(1)}$ Dato obtenido de MíRAME-IDE Duero. ${ }^{(2)}$ Dato obtenido del CEDEX Hidrológico. ${ }^{(3)}$ Dato obtenido del SAIH del Duero.

\begin{tabular}{|c|c|c|c|}
\hline Paso para peces de estanques $s$ & s conectados po & tederos sumergidos y orificios de fondo alternos & \\
\hline $\begin{array}{l}\text { Estado de mantenimiento y limpieza durante la evaluación } \\
\text { Solera naturalizada (con piedras) } \\
\text { Vertedero de umbral móvil en la entrada de peces }\end{array}$ & $\begin{array}{l}\text { Muy adecuado } \\
\text { Sí } \\
\text { Sí }\end{array}$ & $\begin{array}{l}\text { Compuerta en la salida de peces } \\
\text { Dispositivo para evitar la entrada de arrastres } \\
\text { Salida de peces segura (alejada del azud, turbinas, ...) }\end{array}$ & $\begin{array}{l}\text { No } \\
\text { Sí } \\
\text { Sí }\end{array}$ \\
\hline
\end{tabular}

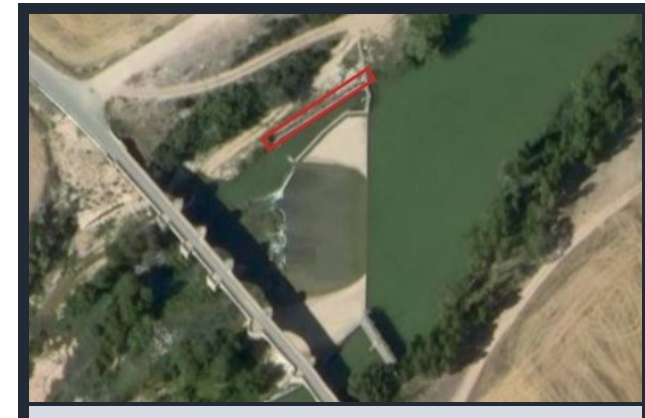

Figura 2. Ortofoto de la zona (fuente: SigPac).

\begin{tabular}{lccc}
\multicolumn{4}{c}{ RESUMEN DE LA EVALUACIÓN DEL PASO PARA PECES } \\
& \multicolumn{4}{c|}{ (CON LA METODOLOGÍA AEPS) } & \\
\hline Etapa o categoría & Puntuación & Evaluación & ¿Mejoras? \\
Atracción & 7,1 & Favorable & Recomendables \\
Entrada & 7,7 & Favorable & Recomendables \\
Pasaje & 9,8 & Muy favorable & Opcionales \\
Salida & 10,0 & Muy favorable & Opcionales \\
\hline
\end{tabular}

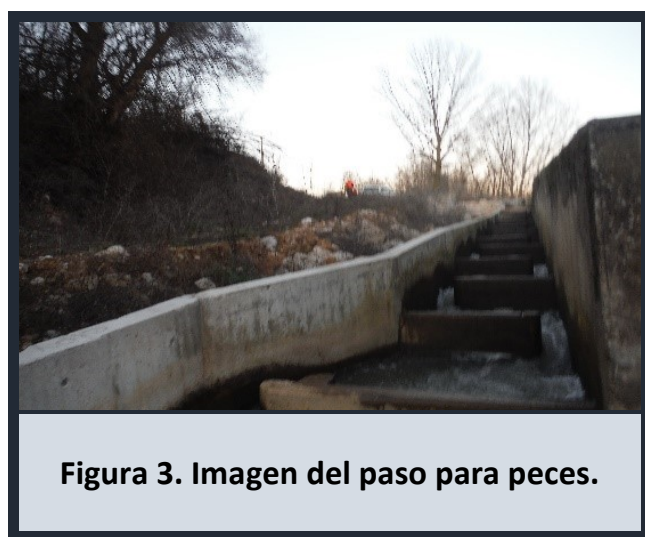




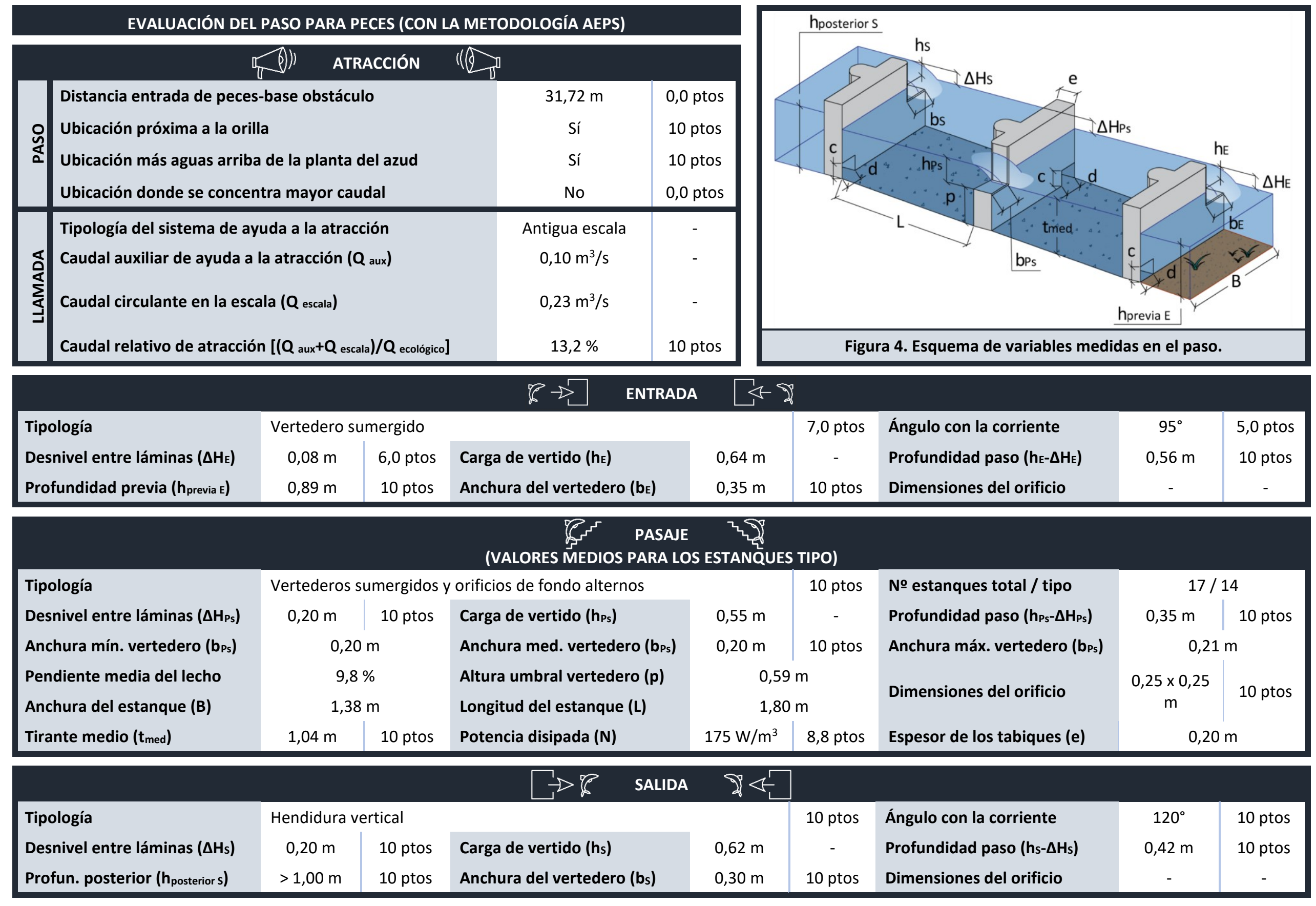




\section{PASO PARA PECES ASOCIADO AL AZUD DE VADOCONDES}

\begin{tabular}{|c|c|c|c|c|}
\hline & Provincia & Burgos & Municipio & Vadocondes \\
\hline 0 & $\begin{array}{l}\text { Nombre del aprovechamiento } \\
\text { Código del aprovechamiento } \\
\text { Long. coronación del azud } \\
\text { (1) } \\
\text { Coordenadas del paso piscícola }\end{array}$ & $\begin{array}{l}\text { Vadocondes } \\
1100028 \\
410 \mathrm{~m} \\
\mathrm{X}: 452.512 \mathrm{~m}\end{array}$ & $\begin{array}{l}\text { Tipo de aprovechamiento } \\
\text { Código del azud (1) } \\
\text { Salto total de agua en la visita } \\
27 \text { m (ETRS 89; HUSO 30) }\end{array}$ & $\begin{array}{l}\text { Hidroeléctrico } \\
1005569 \\
3,25 \mathrm{~m}\end{array}$ \\
\hline & $\begin{array}{l}\text { Cuenca hidrográfica } \\
\text { Principales peces migradores } \\
\text { Época de migración }\end{array}$ & $\begin{array}{l}\text { Duero } \\
\text { Pseudochono } \\
\text { Mayo a junio }\end{array}$ & $\begin{array}{l}\text { Cauce } \\
\text { uriense* y Salmo trutta** } \\
\text { nbre a diciembre** }\end{array}$ & Duero \\
\hline $\begin{array}{l}\text { Figura 1. Ubicación en la parte } \\
\text { española de la cuenca del río Duero. }\end{array}$ & $\begin{array}{l}\text { Caudal medio en migración }{ }^{(2)} \\
\text { Caudal durante la visita }{ }^{(3)}\end{array}$ & $\begin{array}{l}31,94 \mathrm{~m}^{3} / \mathrm{s} \\
16,50 \mathrm{~m}^{3} / \mathrm{s}\end{array}$ & $\begin{array}{l}\text { Caudal ecológico en migración } \\
\text { Hora y fecha de la visita }\end{array}$ & 14:00h, 04/02/2016 \\
\hline
\end{tabular}

(1) Dato obtenido de MíRAME-IDE Duero. ${ }^{(2)}$ Dato obtenido del CEDEX Hidrológico. ${ }^{(3)}$ Dato obtenido del SAIH del Duero.

\begin{tabular}{|c|c|c|c|}
\hline aso para peces de estanques su & s conectados po & diduras verticales alineadas y sin orificios & \\
\hline $\begin{array}{l}\text { Estado de mantenimiento y limpieza durante la evaluación } \\
\text { Solera naturalizada (con piedras) } \\
\text { Vertedero de umbral móvil en la entrada de peces }\end{array}$ & $\begin{array}{l}\text { Muy adecuado } \\
\text { Sí } \\
\text { No }\end{array}$ & $\begin{array}{l}\text { Compuerta en la salida de peces } \\
\text { Dispositivo para evitar la entrada de arrastres } \\
\text { Salida de peces segura (alejada del azud, turbinas, ...) }\end{array}$ & $\begin{array}{l}\text { Sí } \\
\text { No } \\
\text { Sí }\end{array}$ \\
\hline
\end{tabular}

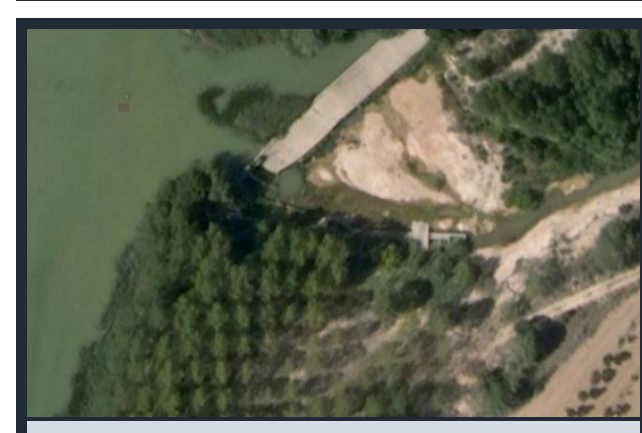

Figura 2. Ortofoto de la zona (fuente: SigPac).

\begin{tabular}{lccc}
\multicolumn{4}{c}{ RESUMEN DE LA EVALUACIÓN DEL PASO PARA PECES } \\
& \multicolumn{4}{c|}{ (CON LA METODOLOGíA AEPS) } & \\
\hline Etapa o categoría & Puntuación & Evaluación & ¿Mejoras? \\
Atracción & 6,6 & Favorable & Recomendables \\
Entrada & 9,3 & Muy favorable & Opcionales \\
Pasaje & 10,0 & Muy favorable & Opcionales \\
Salida & 8,5 & Muy favorable & Opcionales \\
\hline
\end{tabular}

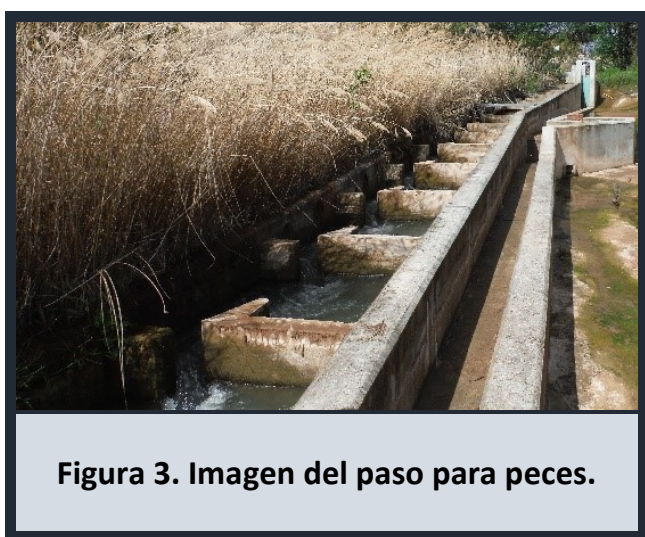




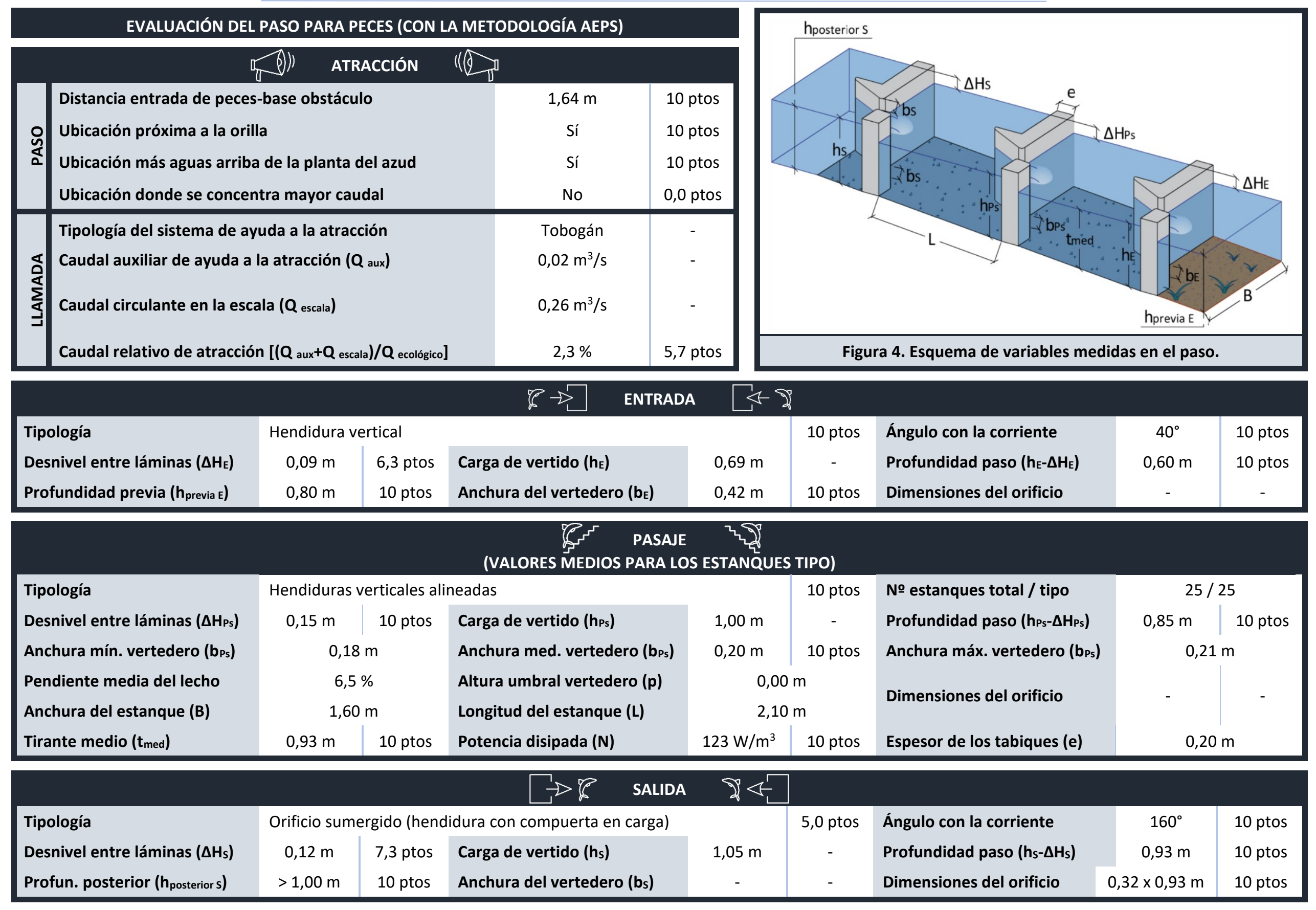




\section{PASO PARA PECES ASOCIADO AL AZUD DE LA CENTRAL HIDROELÉCTRICA DE VILLAHOZ}

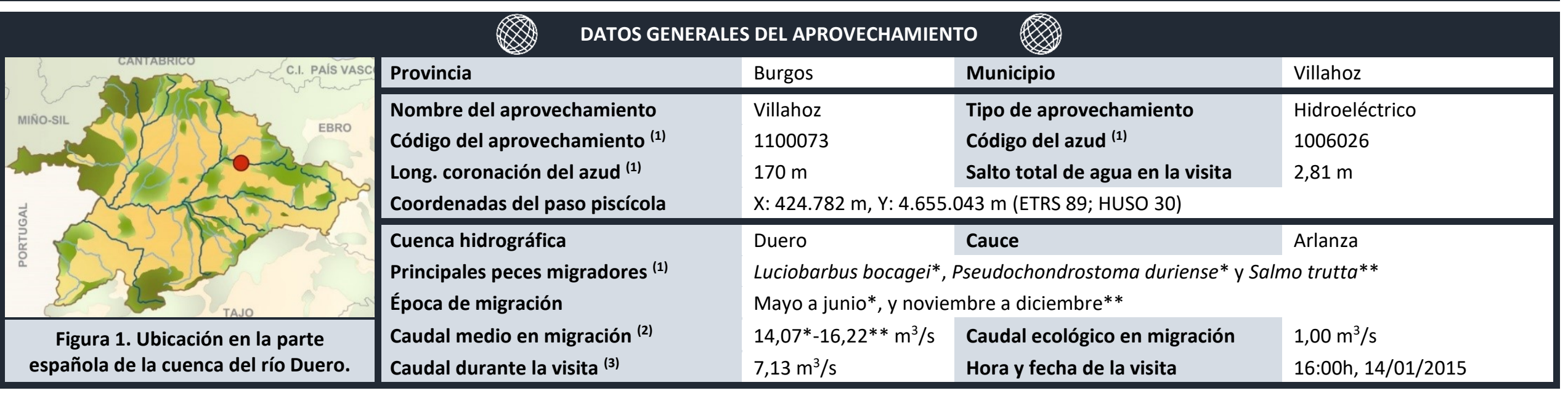

(1) Dato obtenido de MíRAME-IDE Duero. ${ }^{(2)}$ Dato obtenido del CEDEX Hidrológico. ${ }^{(3)}$ Dato obtenido del SAIH del Duero.

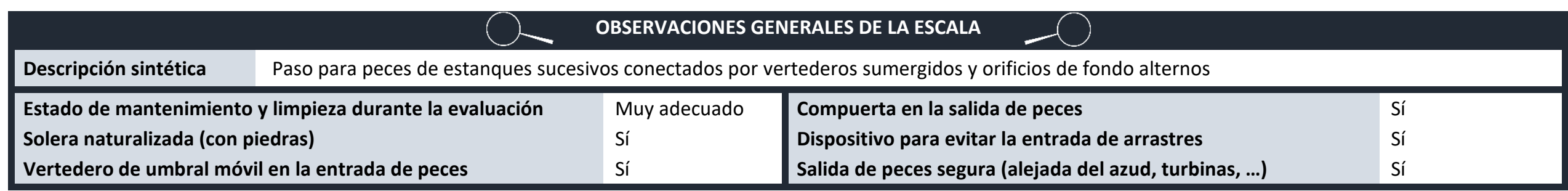

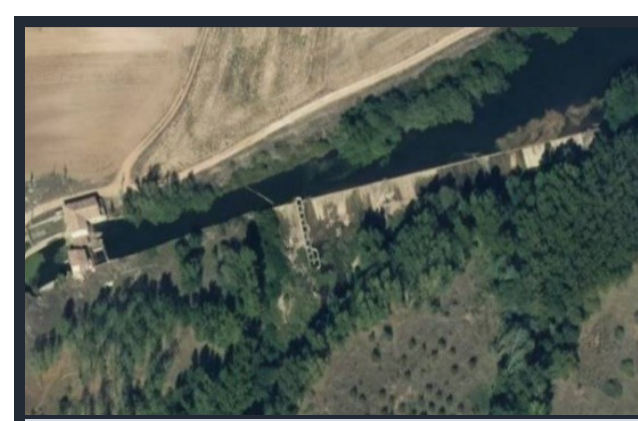

Figura 2. Ortofoto de la zona (fuente: SigPac).

\begin{tabular}{lccc}
\multicolumn{4}{c}{ RESUMEN DE LA EVALUACIÓN DEL PASO PARA PECES } \\
& \multicolumn{4}{c|}{ (CON LA METODOLOGÍA AEPS) } & \\
\hline Etapa o categoría & Puntuación & Evaluación & ¿Mejoras? \\
Atracción & 7,1 & Favorable & Recomendables \\
Entrada & 9,3 & Muy favorable & Opcionales \\
Pasaje & 10,0 & Muy favorable & Opcionales \\
Salida & 9,7 & Muy favorable & Opcionales \\
\hline
\end{tabular}

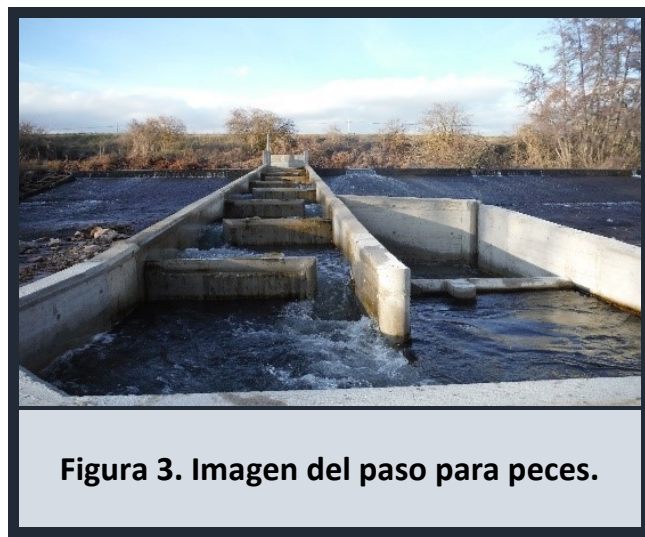




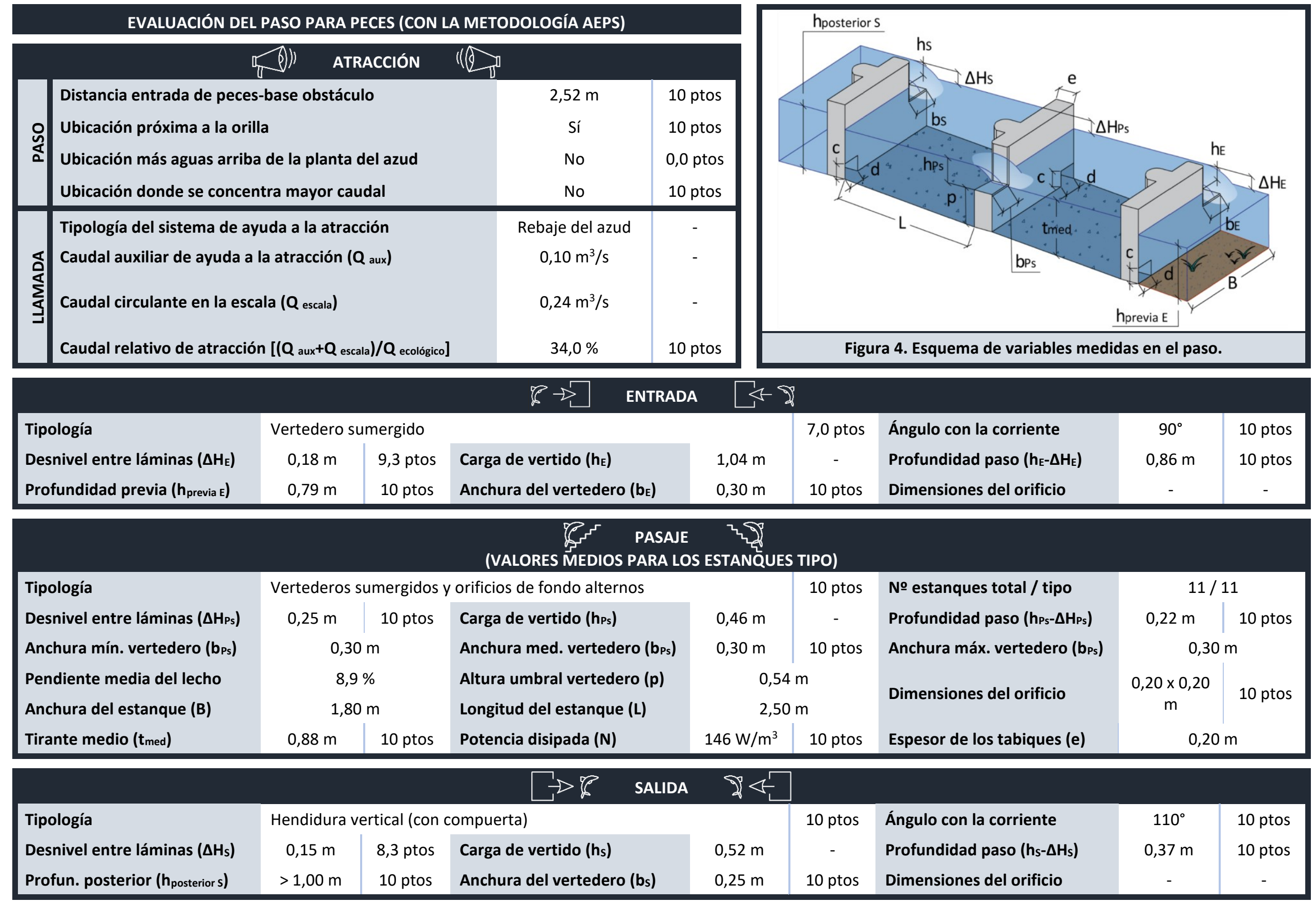




\section{PASO PARA PECES ASOCIADO AL AZUD DEL EMBALSE DE VIRGEN DE LAS VIÑAS}

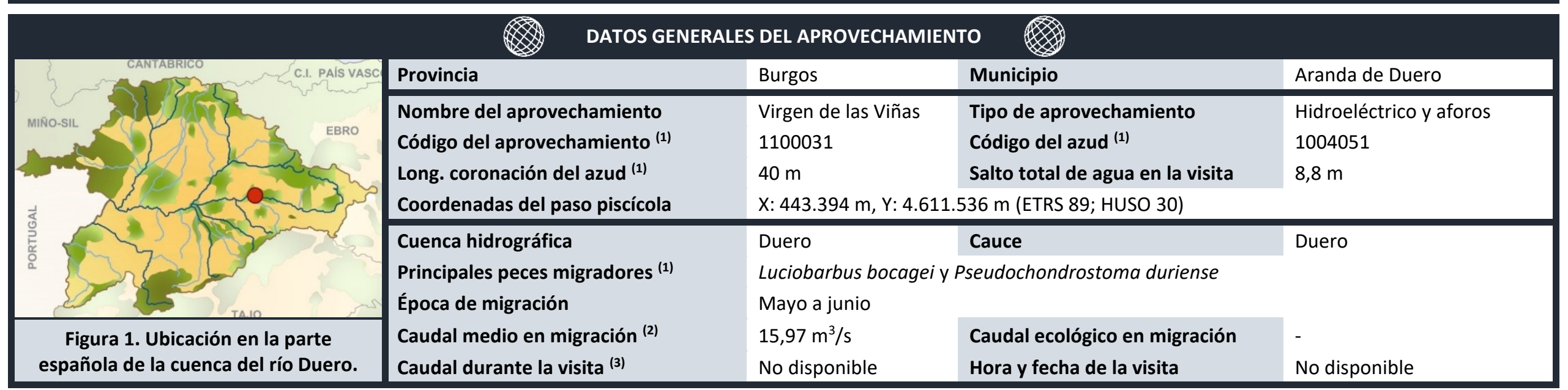

(1) Dato obtenido de MíRAME-IDE Duero. ${ }^{(2)}$ Dato obtenido del CEDEX Hidrológico. ${ }^{(3)}$ Dato obtenido del SAIH del Duero.

\begin{tabular}{|c|c|c|c|}
\hline Paso para peces de estanques st & os conectados $p$ & tederos no sumergidos y orificios de fondo alternos & \\
\hline $\begin{array}{l}\text { Estado de mantenimiento y limpieza durante la evaluación } \\
\text { Solera naturalizada (con piedras) } \\
\text { Vertedero de umbral móvil en la entrada de peces }\end{array}$ & $\begin{array}{l}\text { No adecuado } \\
\text { No } \\
\text { No }\end{array}$ & $\begin{array}{l}\text { Compuerta en la salida de peces } \\
\text { Dispositivo para evitar la entrada de arrastres } \\
\text { Salida de peces segura (alejada del azud, turbinas, ...) }\end{array}$ & $\begin{array}{l}\text { Sí } \\
\text { No } \\
\text { Sí }\end{array}$ \\
\hline
\end{tabular}

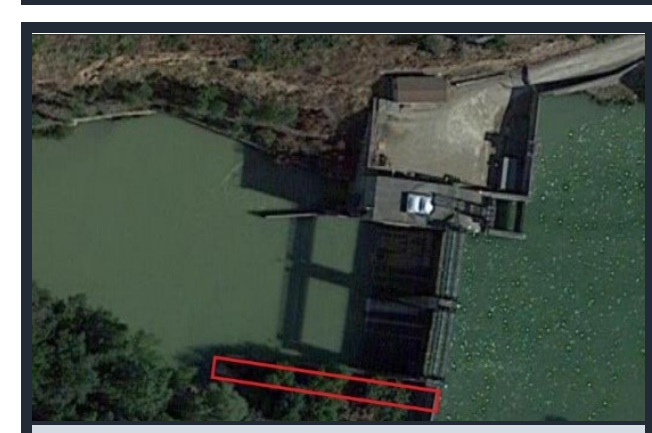

Figura 2. Ortofoto de la zona (fuente: Google Maps).

\begin{tabular}{lccc}
\multicolumn{4}{c}{ RESUMEN DE LA EVALUACIÓN DEL PASO PARA PECES } \\
& \multicolumn{2}{c|}{ (CON LA METODOLOGÍA AEPS) } & \\
\hline Etapa o categoría & Puntuación & Evaluación & ¿Mejoras? \\
Atracción & 5,1 & Desfavorable & Muy necesarias \\
Entrada & 0,0 & Muy desfavorable & Imprescindibles \\
Pasaje & 0,0 & Muy desfavorable & Imprescindibles \\
Salida & 0,0 & Muy desfavorable & Imprescindibles \\
\hline
\end{tabular}

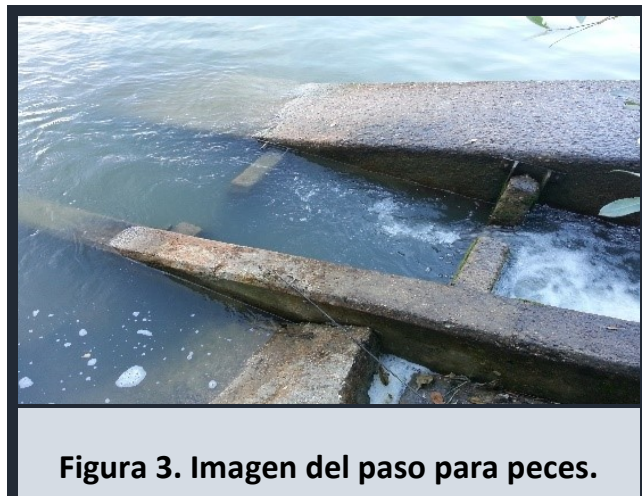




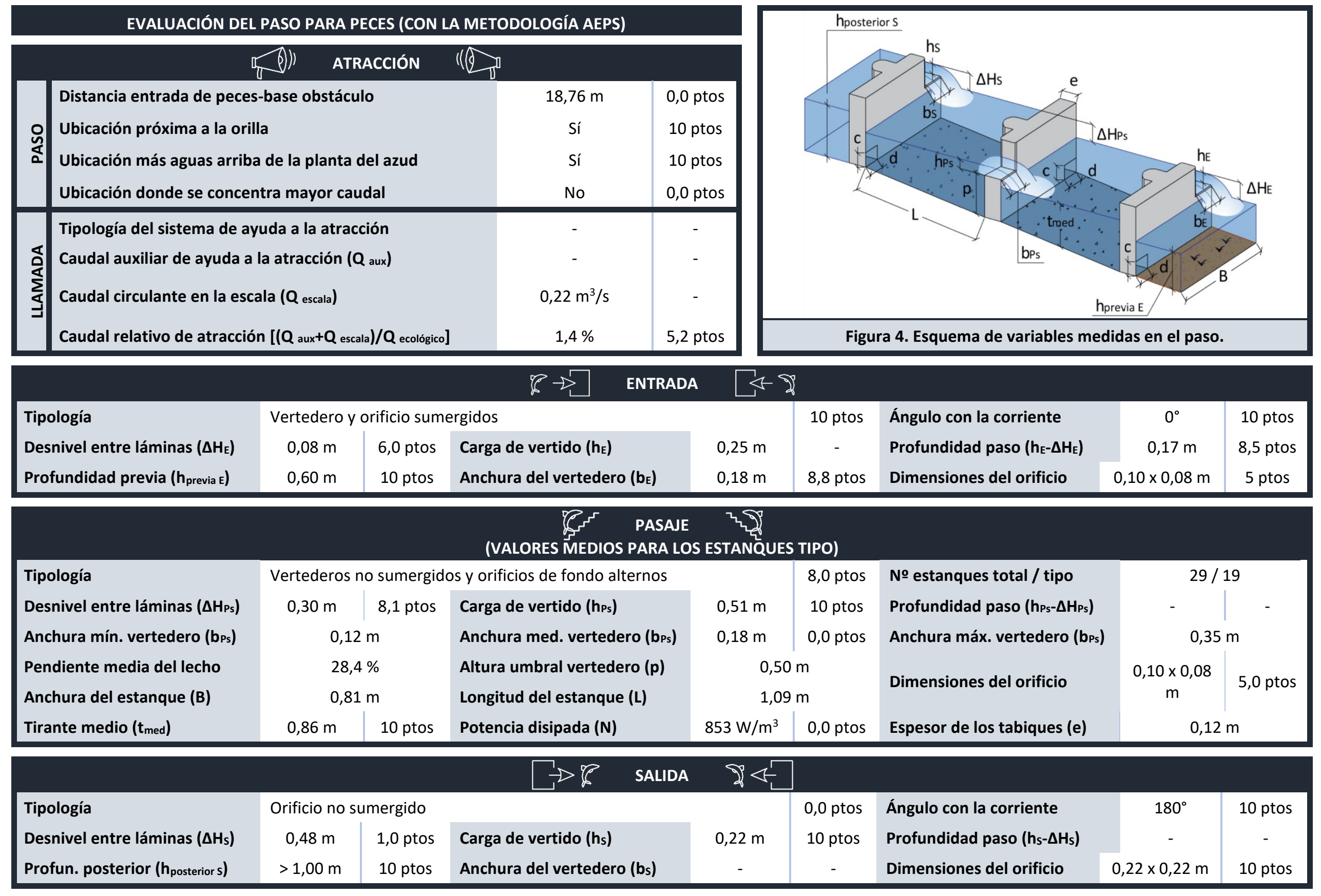




\section{PASO PARA PECES ASOCIADO AL AZUD DE LA CENTRAL HIDROELÉCTRICA DE AMBASAGUAS DE CURUEÑO}

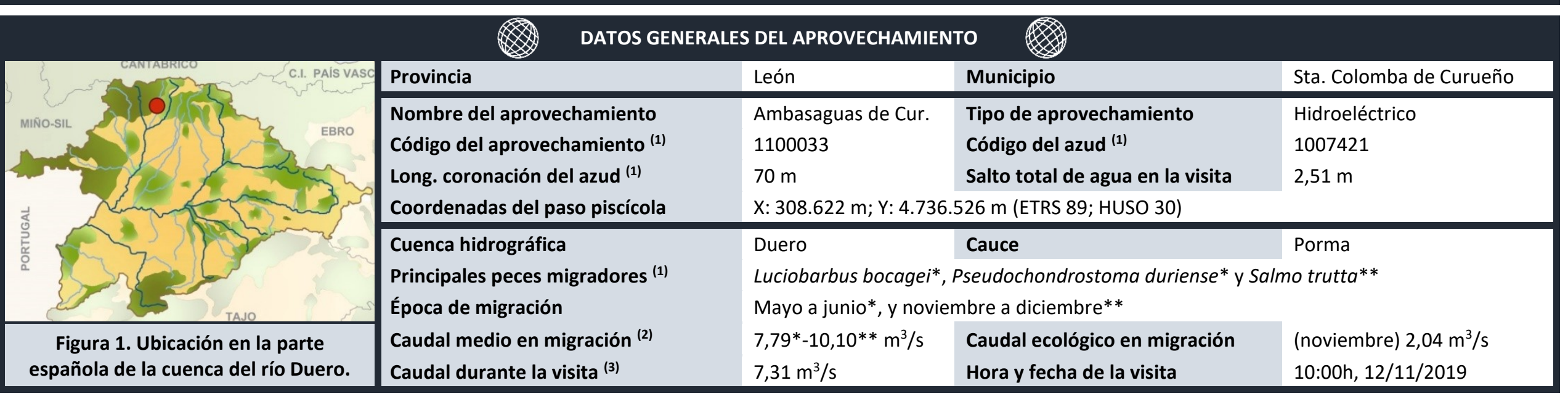

(1) Dato obtenido de MíRAME-IDE Duero. ${ }^{(2)}$ Dato obtenido del CEDEX Hidrológico. ${ }^{(3)}$ Dato obtenido del SAIH del Duero.

\begin{tabular}{|c|c|c|c|}
\hline \multicolumn{4}{|c|}{ OBSERVACIONES GENERALES DE LA ESCALA } \\
\hline $\begin{array}{l}\text { Estado de mantenimiento y limpieza durante la evaluación } \\
\text { Solera naturalizada (con piedras) } \\
\text { Vertedero de umbral móvil en la entrada de peces }\end{array}$ & $\begin{array}{l}\text { Adecuado } \\
\text { No } \\
\text { Sí }\end{array}$ & $\begin{array}{l}\text { Compuerta en la salida de peces } \\
\text { Dispositivo para evitar la entrada de arrastres } \\
\text { Salida de peces segura (alejada del azud, turbinas, ...) }\end{array}$ & $\begin{array}{l}\text { Sí } \\
\text { Sí } \\
\text { Sí }\end{array}$ \\
\hline
\end{tabular}

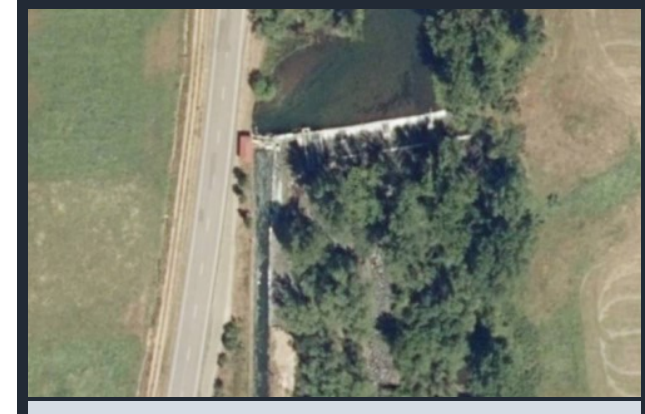

Figura 2. Ortofoto de la zona (fuente: SigPac).

\begin{tabular}{lccc}
\multicolumn{4}{c}{ RESUMEN DE LA EVALUACIÓN DEL PASO PARA PECES } \\
& \multicolumn{4}{c|}{ (CON LA METODOLOGÍA AEPS) } & \\
\hline Etapa o categoría & Puntuación & Evaluación & ¿Mejoras? \\
Atracción & 4,0 & Desfavorable & Muy necesarias \\
Entrada & 9,1 & Muy favorable & Opcionales \\
Pasaje & 9,5 & Muy favorable & Opcionales \\
Salida & 9,7 & Muy favorable & Opcionales \\
\hline
\end{tabular}

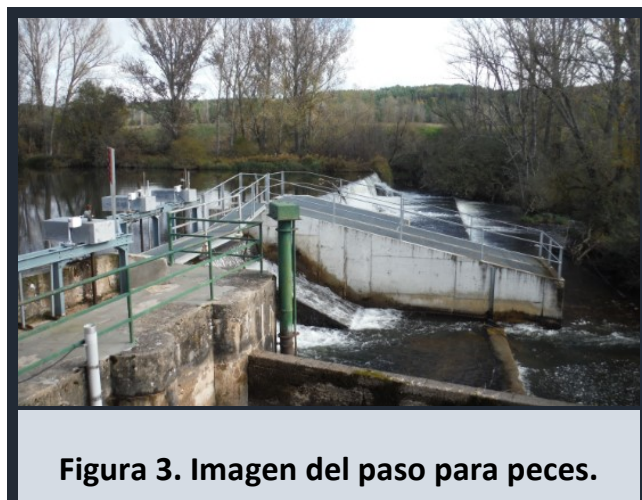




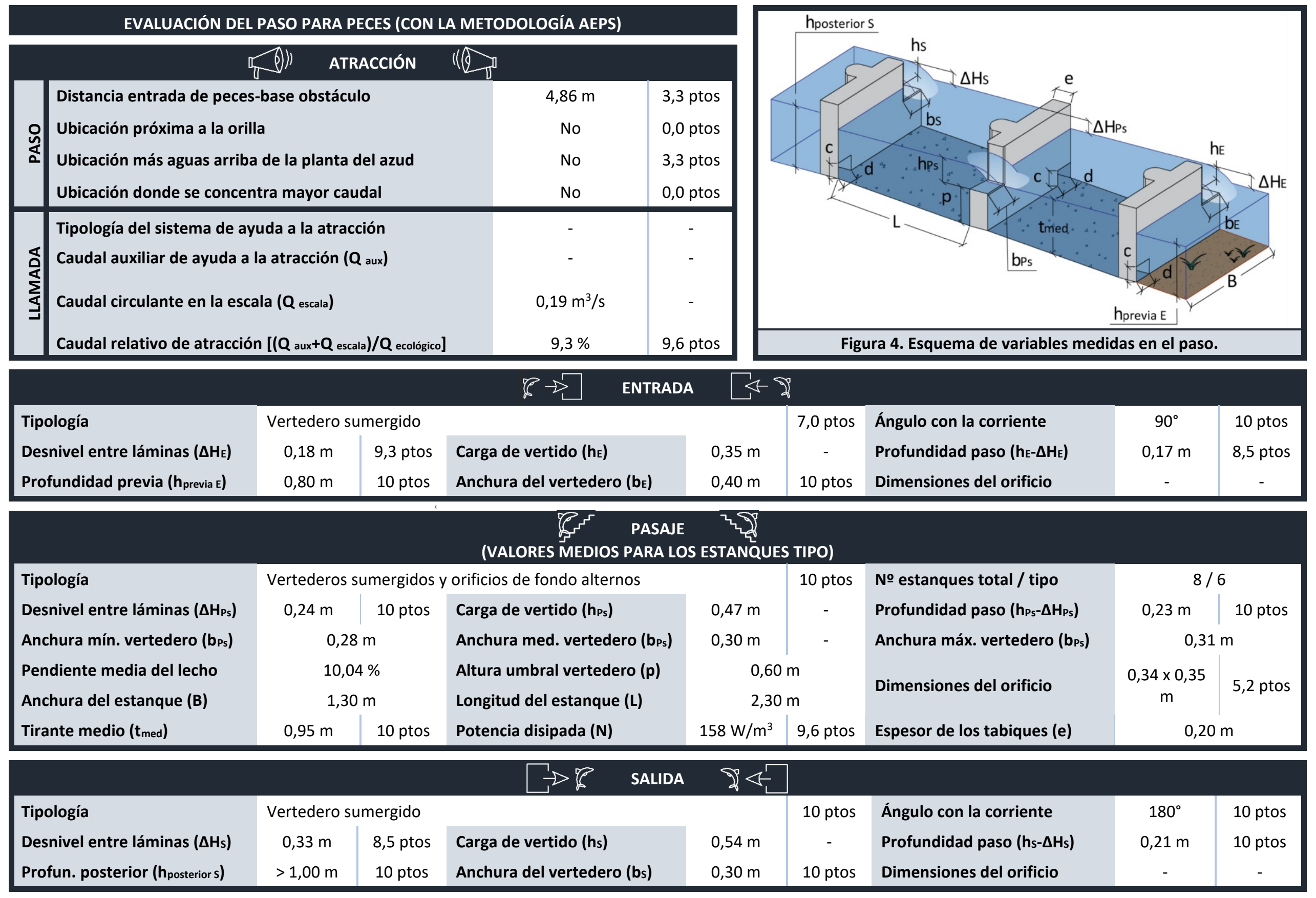




\section{PASO PARA PECES ASOCIADO AL AZUD DE LA CENTRAL HIDROELÉCTRICA DE BOÑAR}

\begin{tabular}{|c|c|c|c|c|}
\hline \multicolumn{5}{|c|}{ DATOS GENERALES DEL APROVECHAMIENTO } \\
\hline \multirow{8}{*}{$r$} & Provincia & León & Municipio & Boñar \\
\hline & \multirow{4}{*}{$\begin{array}{l}\text { Nombre del aprovechamiento } \\
\text { Código del aprovechamiento } \\
\text { Long. coronación del azud } \\
\text { (1) } \\
\text { Coordenadas del paso piscícola }\end{array}$} & Boñar & Tipo de aprovechamiento & Hidroeléctrico \\
\hline & & 1100108 & Código del azud (1) & 1007408 \\
\hline & & $86 \mathrm{~m}$ & Salto total de agua en la visita & $2,53 \mathrm{~m}$ \\
\hline & & \multicolumn{3}{|c|}{ X: 311.482 m; Y: 4.750 .359 m (ETRS 89; HUSO 30) } \\
\hline & Cuenca hidrográfica & Duero & Cauce & Porma \\
\hline & Principales peces migradores ${ }^{(1)}$ & \multirow{2}{*}{\multicolumn{3}{|c|}{$\begin{array}{l}\text { Luciobarbus bocagei*, Pseudochondrostoma duriense* y Salmo trutta** } \\
\text { Mayo a junio*, y noviembre a diciembre** }\end{array}$}} \\
\hline & Época de migración & & & \\
\hline \multirow{2}{*}{$\begin{array}{l}\text { Figura 1. Ubicación en la parte } \\
\text { española de la cuenca del río Duero. }\end{array}$} & Caudal medio en migración (2) & $10,56 *-7,22 * * \mathrm{~m}^{3} / \mathrm{s}$ & Caudal ecológico en migración & (noviembre) $2,20 \mathrm{~m}^{3} / \mathrm{s}$ \\
\hline & Caudal durante la visita ${ }^{(3)}$ & $2,03 \mathrm{~m}^{3} / \mathrm{s}$ & Hora y fecha de la visita & $13: 30 h, 12 / 11 / 2019$ \\
\hline
\end{tabular}

(1) Dato obtenido de MíRAME-IDE Duero. ${ }^{(2)}$ Dato obtenido del CEDEX Hidrológico. ${ }^{(3)}$ Dato obtenido del SAIH del Duero.

\begin{tabular}{|c|c|c|c|}
\hline Paso para peces de estanques su & $\begin{array}{l}\text { BSERVACIONES } \\
\text { S conectados po }\end{array}$ & $\begin{array}{l}\text { ERALES DE LA ESCALA } \\
\text { tederos sumergidos y orificios de fondo alternos }\end{array}$ & \\
\hline $\begin{array}{l}\text { Estado de mantenimiento y limpieza durante la evaluación } \\
\text { Solera naturalizada (con piedras) } \\
\text { Vertedero de umbral móvil en la entrada de peces }\end{array}$ & $\begin{array}{l}\text { Muy adecuado } \\
\text { No } \\
\text { No }\end{array}$ & $\begin{array}{l}\text { Compuerta en la salida de peces } \\
\text { Dispositivo para evitar la entrada de arrastres } \\
\text { Salida de peces segura (alejada del azud, turbinas, ...) }\end{array}$ & $\begin{array}{l}\text { Sí } \\
\text { No } \\
\text { Sí }\end{array}$ \\
\hline
\end{tabular}

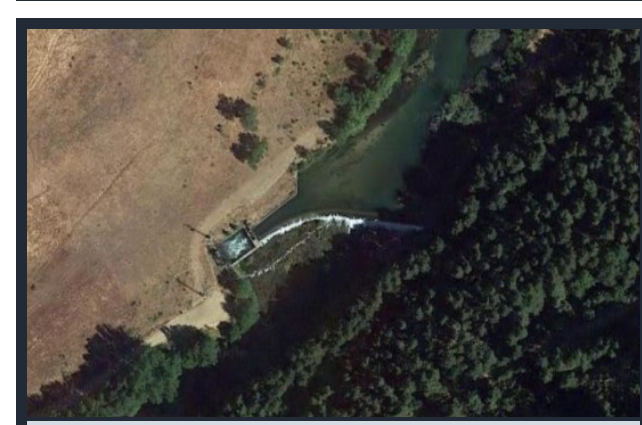

Figura 2. Ortofoto de la zona (fuente: Google Maps).

\begin{tabular}{lccc}
\multicolumn{4}{c}{ RESUMEN DE LA EVALUACIÓN DEL PASO PARA PECES } \\
& \multicolumn{4}{c|}{ (CON LA METODOLOGÍA AEPS) } & \\
\hline Etapa o categoría & Puntuación & Evaluación & ¿Mejoras? \\
Atracción & 9,1 & Muy favorable & Opcionales \\
Entrada & 0,0 & Muy desfavorable & Imprescindibles \\
Pasaje & 10,0 & Muy favorable & Opcionales \\
Salida & 10,0 & Muy favorable & Opcionales \\
\hline
\end{tabular}

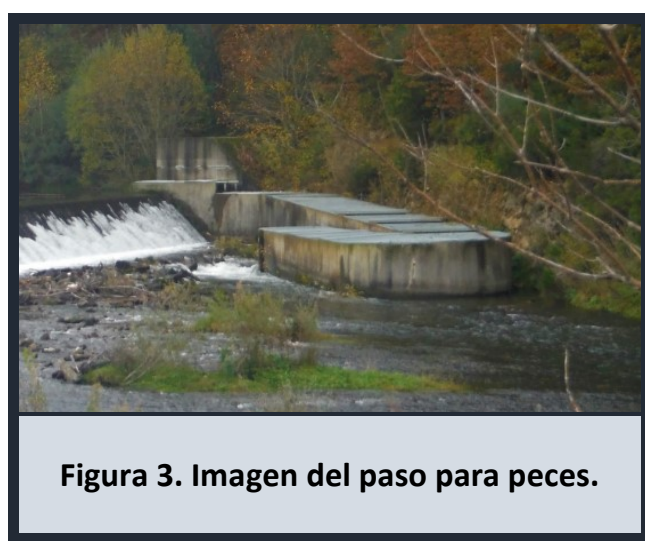




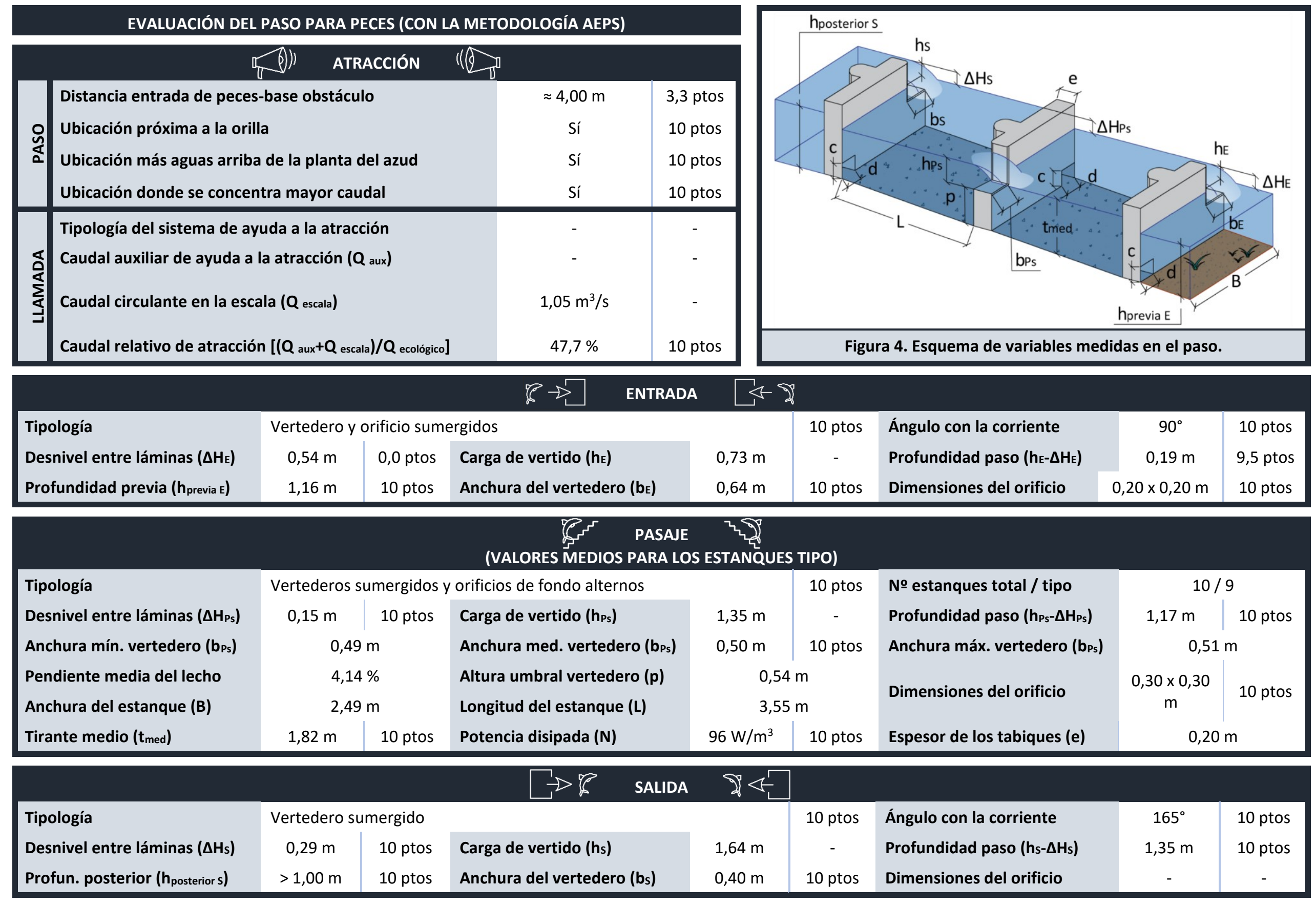




\section{PASO PARA PECES ASOCIADO AL AZUD DE LA CENTRAL HIDROELÉCTRICA DE CAMPOSOLILLO}

\begin{tabular}{|c|c|c|c|c|}
\hline & Provincia & León & Municipio & Puebla de Lillo \\
\hline & $\begin{array}{l}\text { Nombre del aprovechamiento } \\
\text { Código del aprovechamiento } \\
\text { Long. coronación del azud }\end{array}$ & $\begin{array}{l}\text { Camposolillo } \\
1100060 \\
16 \mathrm{~m} \\
X \cdot 315690 \mathrm{~m} Y \cdot 4762\end{array}$ & $\begin{array}{l}\text { Tipo de aprovechamiento } \\
\text { Código del azud (1) } \\
\text { Salto total de agua en la visita }\end{array}$ & $\begin{array}{l}\text { Hidroeléctrico } \\
1007398 \\
2,4 \mathrm{~m}\end{array}$ \\
\hline & $\begin{array}{l}\text { Cuenca hidrográfica } \\
\text { Principales peces migradores }{ }^{(1)} \\
\text { Época de migración }\end{array}$ & $\begin{array}{l}\text { Duero } \\
\text { Salmo trutta } \\
\text { Noviembre a diciembre }\end{array}$ & Cauce & Porma \\
\hline $\begin{array}{c}\text { Figura 1. Ubicación en la parte } \\
\text { española de la cuenca del río Duero. }\end{array}$ & $\begin{array}{l}\text { Caudal medio en migración (2) } \\
\text { Caudal durante la visita } \\
{ }^{(3)}\end{array}$ & $\begin{array}{l}6,73 \mathrm{~m}^{3} / \mathrm{s} \\
6,73 \mathrm{~m}^{3} / \mathrm{s}\end{array}$ & $\begin{array}{l}\text { Caudal ecológico en migración } \\
\text { Hora y fecha de la visita }\end{array}$ & $\begin{array}{l}\text { (enero) } 2,45 \mathrm{~m}^{3} / \mathrm{s} \\
17: 00 \mathrm{~h}, 23 / 01 / 2020\end{array}$ \\
\hline
\end{tabular}

(1) Dato obtenido de MíRAME-IDE Duero. ${ }^{(2)}$ Dato obtenido del CEDEX Hidrológico. ${ }^{(3)}$ Dato obtenido del SAIH del Duero.

\begin{tabular}{|c|c|c|c|}
\hline Paso para peces de estanques & os conectados po & tederos sumergidos y orificios de fondo alternos & \\
\hline $\begin{array}{l}\text { Estado de mantenimiento y limpieza durante la evaluación } \\
\text { Solera naturalizada (con piedras) } \\
\text { Vertedero de umbral móvil en la entrada de peces }\end{array}$ & $\begin{array}{l}\text { Muy adecuado } \\
\text { - } \\
\text { No }\end{array}$ & $\begin{array}{l}\text { Compuerta en la salida de peces } \\
\text { Dispositivo para evitar la entrada de arrastres } \\
\text { Salida de peces segura (alejada del azud, turbinas, ...) }\end{array}$ & $\begin{array}{l}\text { No } \\
\text { No } \\
\text { No }\end{array}$ \\
\hline
\end{tabular}

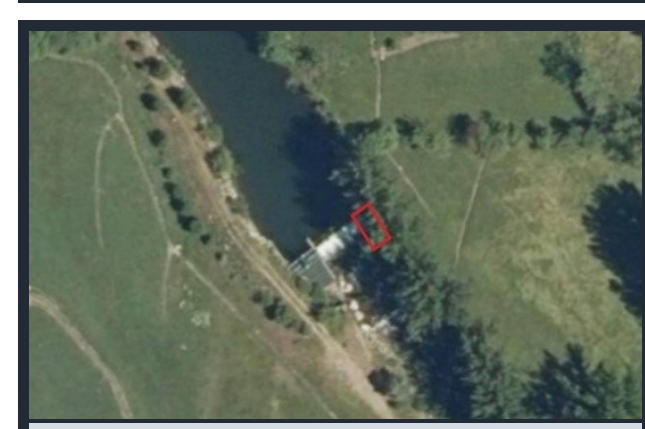

Figura 2. Ortofoto de la zona (fuente: SigPac).

\begin{tabular}{lccl}
\multicolumn{4}{c}{ RESUMEN DE LA EVALUACIÓN DEL PASO PARA PECES } \\
& \multicolumn{4}{c}{ (CON LA METODOLOGÍA AEPS) } & \\
\hline Etapa o categoría & Puntuación & Evaluación & ¿Mejoras? \\
Atracción & 8,1 & Muy favorable & Opcionales \\
Entrada & 9,9 & Muy favorable & Opcionales \\
Pasaje & 9,9 & Muy favorable & Opcionales \\
Salida & 10,0 & Muy favorable & Opcionales \\
\hline
\end{tabular}

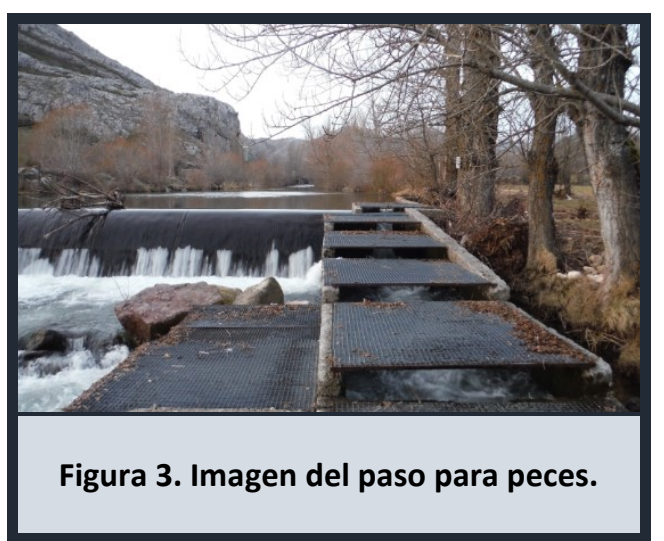




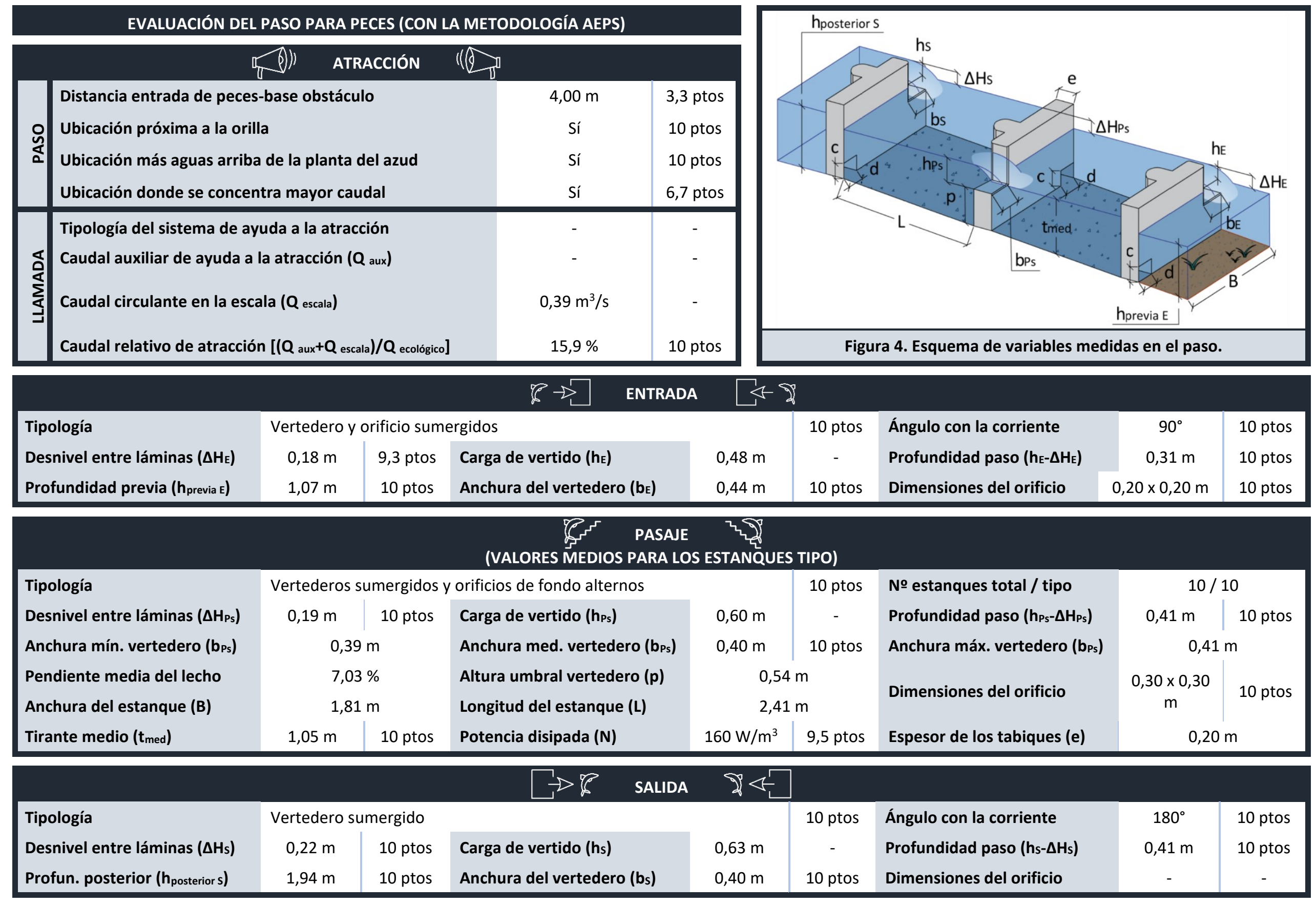




\section{PASO PARA PECES ASOCIADO AL AZUD DEL CANAL ALTO DE PAYUELOS}

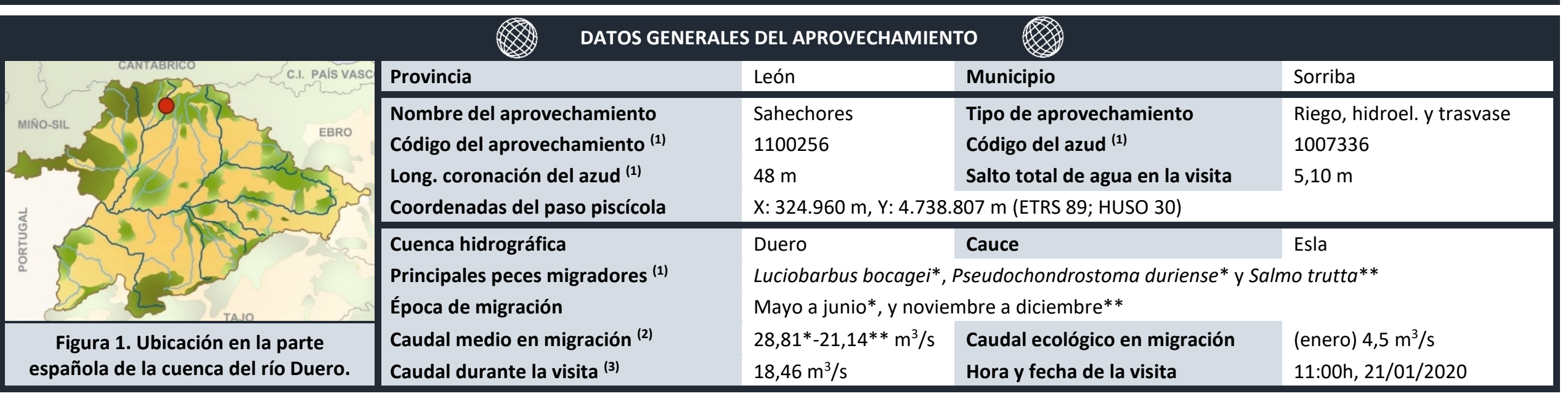

${ }^{(1)}$ Dato obtenido de MíRAME-IDE Duero. ${ }^{(2)}$ Dato obtenido del CEDEX Hidrológico. ${ }^{(3)}$ Dato obtenido del SAIH del Duero.

\begin{tabular}{|c|c|c|c|}
\hline Paso para peces de estanques su & s conectadc & tederos no sumergidos alternos y orificios de fondo aline & \\
\hline $\begin{array}{l}\text { Estado de mantenimiento y limpieza durante la evaluación } \\
\text { Solera naturalizada (con piedras) } \\
\text { Vertedero de umbral móvil en la entrada de peces }\end{array}$ & $\begin{array}{l}\text { Adecuado } \\
\text { No } \\
\text { No }\end{array}$ & $\begin{array}{l}\text { Compuerta en la salida de peces } \\
\text { Dispositivo para evitar la entrada de arrastres } \\
\text { Salida de peces segura (alejada del azud, turbinas, ...) }\end{array}$ & $\begin{array}{l}\text { No } \\
\text { No } \\
\text { Sí }\end{array}$ \\
\hline
\end{tabular}

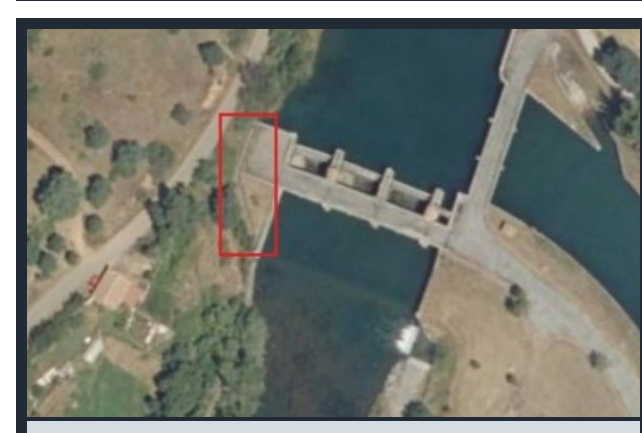

Figura 2. Ortofoto de la zona (fuente: SigPac).

\begin{tabular}{|c|c|c|c|}
\hline \multicolumn{4}{|c|}{$\begin{array}{l}\text { RESUMEN DE LA EVALUACIÓN DEL PASO PARA PECES } \\
\text { (CON LA METODOLOGÍA AEPS) }\end{array}$} \\
\hline Etapa o categoría & Puntuación & Evaluación & ¿Mejoras? \\
\hline Atracción & 5,9 & Desfavorable & Muy necesarias \\
\hline Entrada & 8,6 & Muy favorable & Opcionales \\
\hline Pasaje & 0,0 & Muy desfavorable & Imprescindibles \\
\hline Salida & 8,9 & Muy favorable & Opcionales \\
\hline
\end{tabular}

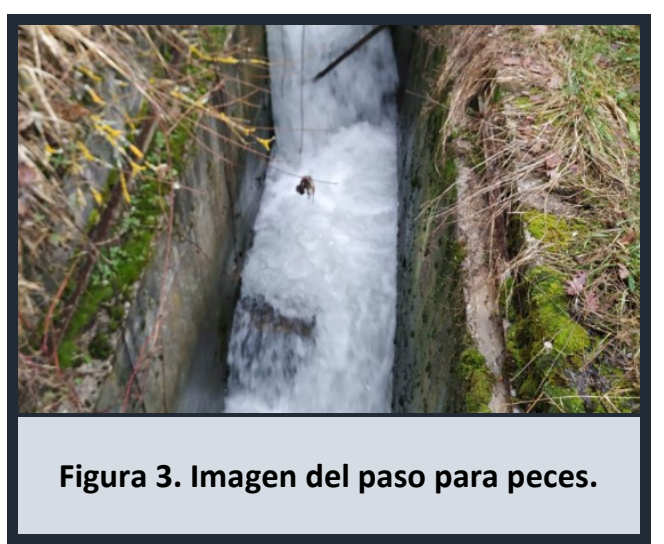




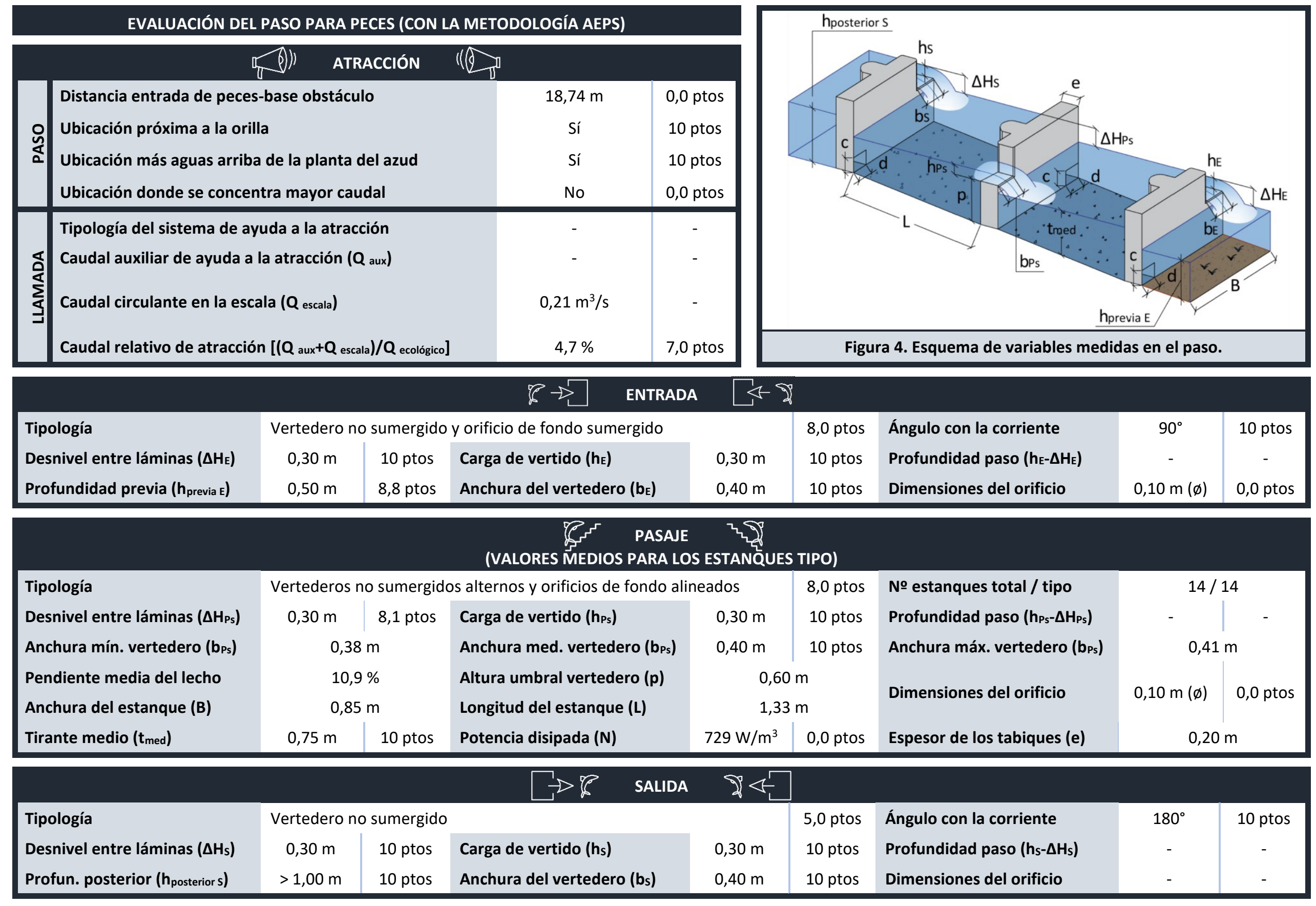




\section{PASO PARA PECES ASOCIADO A LA PRESA DEL AZUD DEL CANAL BAJO DE PAYUELOS}

\begin{tabular}{|c|c|c|c|c|}
\hline & Provincia & León & Municipio & Sahechores de Rueda \\
\hline & $\begin{array}{l}\text { Nombre del aprovechamiento } \\
\text { Código del aprovechamiento } \\
\text { Long. coronación del azud } \\
\text { (1) } \\
\text { Coordenadas del paso piscícola }\end{array}$ & $\begin{array}{l}\text { Canal Siete Pueblos } \\
- \\
98 \mathrm{~m} \\
\mathrm{X}: 318.873 \mathrm{~m}, \mathrm{Y}: 4.72\end{array}$ & $\begin{array}{l}\text { Tipo de aprovechamiento } \\
\text { Código del azud (1) } \\
\text { Salto total de agua en la visita } \\
55 \text { m (ETRS 89; HUSO 30) }\end{array}$ & $\begin{array}{l}\text { Riego } \\
1008763 \\
1,72 \mathrm{~m}\end{array}$ \\
\hline & $\begin{array}{l}\text { Cuenca hidrográfica } \\
\text { Principales peces migradores }{ }^{(1)} \\
\text { Época de migración }\end{array}$ & $\begin{array}{l}\text { Duero } \\
\text { Pseudochondrostom } \\
\text { Mayo a junio*, y nov }\end{array}$ & $\begin{array}{l}\text { Cauce } \\
\text { uriense* y Salmo trutta** } \\
\text { abre a diciembre** }\end{array}$ & Esla \\
\hline $\begin{array}{l}\text { Figura 1. Ubicación en la parte } \\
\text { española de la cuenca del río Duero. }\end{array}$ & $\begin{array}{l}\text { Caudal medio en migración (2) } \\
\text { Caudal durante la visita }{ }^{(3)}\end{array}$ & $\begin{array}{l}28,81 *-21,14^{* *} \mathrm{~m}^{3} / \mathrm{s} \\
29,61 \mathrm{~m}^{3} / \mathrm{s}\end{array}$ & $\begin{array}{l}\text { Caudal ecológico en migración } \\
\text { Hora y fecha de la visita }\end{array}$ & $\begin{array}{l}\text { (noviembre) 4,88 } \mathrm{m}^{3} / \mathrm{s} \\
11: 00 \mathrm{~h}, 02 / 11 / 2018\end{array}$ \\
\hline
\end{tabular}

(1) Dato obtenido de MíRAME-IDE Duero. ${ }^{(2)}$ Dato obtenido del CEDEX Hidrológico. ${ }^{(3)}$ Dato obtenido del SAIH del Duero.

\begin{tabular}{|c|c|c|c|}
\hline \multicolumn{4}{|c|}{$\begin{array}{l}\text { OBSERVACIONES GENERALES DE LA ESCALA } \\
\text { ivos conectados por vertederos ligeramente sumergic }\end{array}$} \\
\hline $\begin{array}{l}\text { Estado de mantenimiento y limpieza durante la evaluación } \\
\text { Solera naturalizada (con piedras) } \\
\text { Vertedero de umbral móvil en la entrada de peces }\end{array}$ & $\begin{array}{l}\text { Muy adecuado } \\
\text { No } \\
\text { No }\end{array}$ & $\begin{array}{l}\text { Compuerta en la salida de peces } \\
\text { Dispositivo para evitar la entrada de arrastres } \\
\text { Salida de peces segura (alejada del azud, turbinas, ...) }\end{array}$ & $\begin{array}{l}\text { No } \\
\text { Sí } \\
\text { Sí }\end{array}$ \\
\hline
\end{tabular}

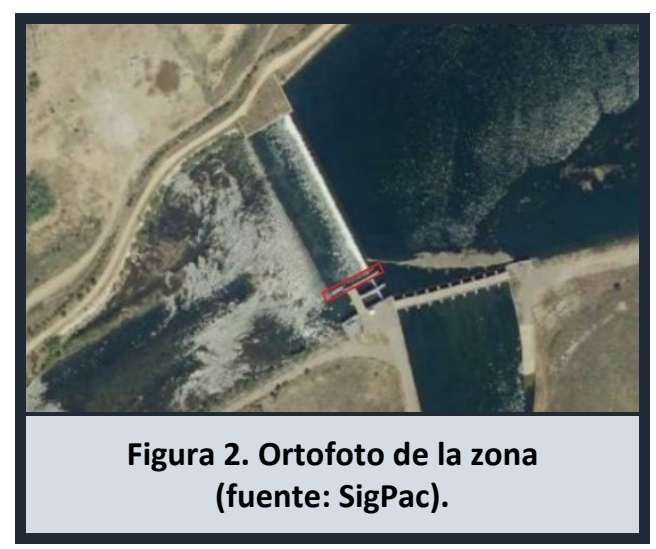

\begin{tabular}{lccc}
\multicolumn{4}{c}{ RESUMEN DE LA EVALUACIÓN DEL PASO PARA PECES } \\
& \multicolumn{4}{c|}{ (CON LA METODOLOGíA AEPS) } & \\
\hline Etapa o categoría & Puntuación & Evaluación & ¿Mejoras? \\
Atracción & 5,8 & Desfavorable & Muy necesarias \\
Entrada & 8,8 & Muy favorable & Opcionales \\
Pasaje & 9,4 & Muy favorable & Opcionales \\
Salida & 9,5 & Muy favorable & Opcionales \\
\hline
\end{tabular}

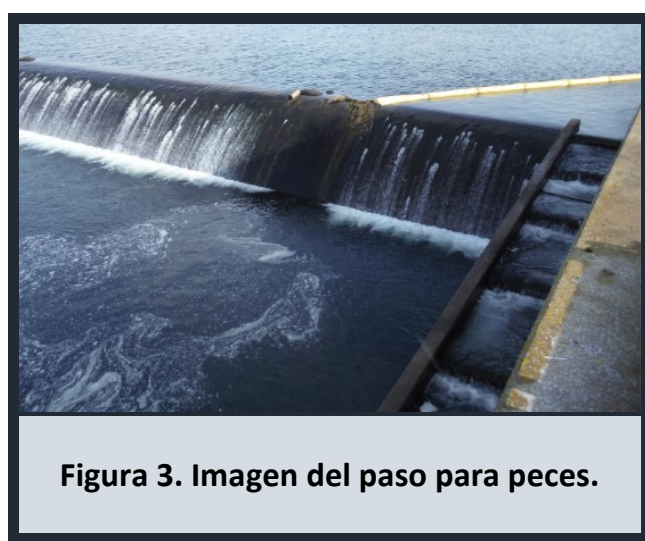




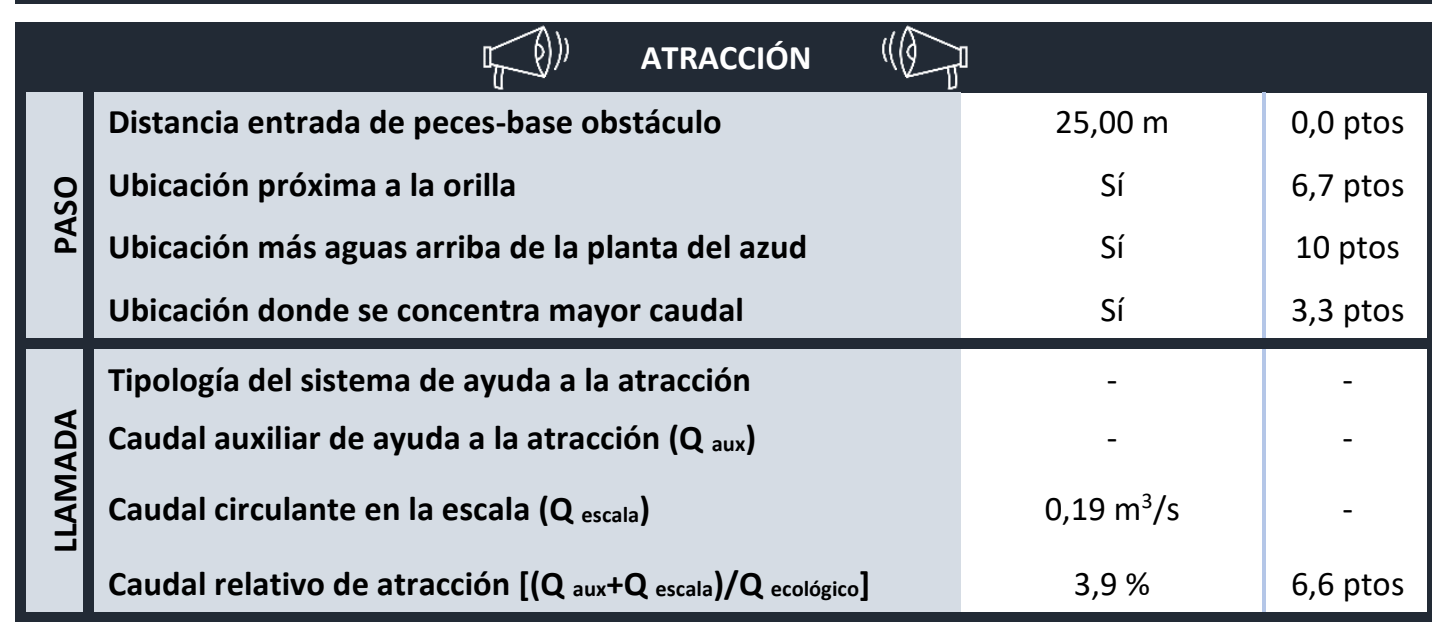

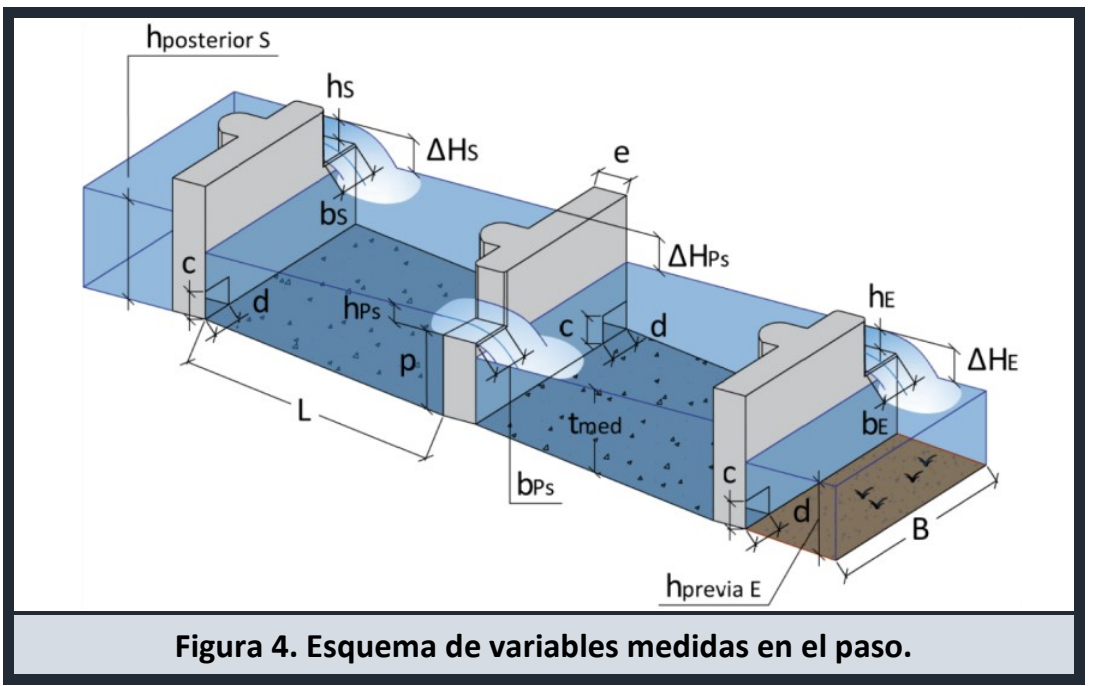

\begin{tabular}{|c|c|c|c|c|c|c|c|c|}
\hline & & & $b \rightarrow$ & & & & & \\
\hline Tipología & \multicolumn{3}{|c|}{ Vertedero no sumergido y orificio de fondo sumergido } & \multirow{3}{*}{$\begin{array}{l}0,17 \mathrm{~m} \\
0,60 \mathrm{~m}\end{array}$} & \multirow{3}{*}{$\begin{array}{l}8,0 \text { ptos } \\
8,5 \text { ptos } \\
10 \text { ptos }\end{array}$} & \multirow{3}{*}{$\begin{array}{l}\text { Ángulo con la corriente } \\
\text { Profundidad paso }\left(h_{E}-\Delta H_{E}\right) \\
\text { Dimensiones del orificio }\end{array}$} & \multirow{3}{*}{$\begin{array}{c}0^{\circ} \\
0,03 \mathrm{~m} \\
0,50 \times 0,15 \mathrm{~m}\end{array}$} & \multirow{3}{*}{$\begin{array}{l}10 \text { ptos } \\
- \\
10 \text { ptos }\end{array}$} \\
\hline Desnivel entre láminas $\left(\Delta \mathrm{H}_{\mathrm{E}}\right)$ & $0,10 \mathrm{~m}$ & 6,7 ptos & Carga de vertido $\left(h_{E}\right)$ & & & & & \\
\hline Profundidad previa (h $h_{\text {previa }}$ ) & $1,00 \mathrm{~m}$ & 10 ptos & Anchura del vertedero $\left(b_{E}\right)$ & & & & & \\
\hline
\end{tabular}

\begin{tabular}{|c|c|c|c|c|c|c|c|c|}
\hline Tipología & \multicolumn{3}{|c|}{ Vertederos no sumergidos y orificios de fondo alineados } & & 8,0 ptos & № estanques total / tipo & \multicolumn{2}{|c|}{$12 / 12$} \\
\hline Desnivel entre láminas $\left(\Delta H_{P_{s}}\right)$ & $0,14 \mathrm{~m}$ & 10 ptos & Carga de vertido ( $\left.h_{P s}\right)$ & $0,17 \mathrm{~m}$ & 8,5 ptos & Profundidad paso ( $\mathrm{h}_{\left.\mathrm{Ps}_{\mathrm{s}}-\Delta \mathrm{H}_{\mathrm{Ps}}\right)}$ & $0,03 \mathrm{~m}$ & - \\
\hline Anchura mín. vertedero ( bPs $_{\text {s }}$ ) & \multicolumn{2}{|c|}{$0,59 \mathrm{~m}$} & Anchura med. vertedero ( $\left.b_{P_{s}}\right)$ & $0,60 \mathrm{~m}$ & 10 ptos & Anchura máx. vertedero ( $\left.b_{P_{s}}\right)$ & \multicolumn{2}{|c|}{$0,61 \mathrm{~m}$} \\
\hline Pendiente media del lecho & \multicolumn{2}{|c|}{$6,51 \%$} & Altura umbral vertedero (p) & \multicolumn{2}{|c|}{$0,92 \mathrm{~m}$} & Dimancianes dol rrificin & $0,50 \times 0,15$ & $10 n+0$ \\
\hline Anchura del estanque (B) & \multicolumn{2}{|c|}{$1,75 \mathrm{~m}$} & Longitud del estanque (L) & \multicolumn{2}{|c|}{$2,30 \mathrm{~m}$} & 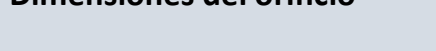 & $m$ & 年 \\
\hline Tirante medio $\left(t_{\text {med }}\right)$ & $0,92 \mathrm{~m}$ & 10 ptos & Potencia disipada (N) & $85 \mathrm{~W} / \mathrm{m}^{3}$ & 10 ptos & Espesor de los tabiques (e) & \multicolumn{2}{|c|}{$0,20 \mathrm{~m}$} \\
\hline
\end{tabular}

\begin{tabular}{|c|c|c|c|c|c|c|c|c|}
\hline Tipología & \multicolumn{3}{|c|}{ Vertedero no sumergido y orificio de fondo sumergido } & & 10 ptos & Ángulo con la corriente & $180^{\circ}$ & 10 ptos \\
\hline Desnivel entre láminas $\left(\Delta \mathrm{H}_{\mathrm{s}}\right)$ & $0,14 \mathrm{~m}$ & 8,0 ptos & Carga de vertido ( $h_{s}$ ) & $0,18 \mathrm{~m}$ & 9,0 ptos & Profundidad paso $\left(\mathrm{h}_{\mathrm{s}}-\Delta \mathrm{H}_{\mathrm{s}}\right)$ & $0,04 \mathrm{~m}$ & - \\
\hline Profun. posterior ( $\mathrm{h}_{\text {posterior } \mathrm{s} \text { ) }}$ & $0,90 \mathrm{~m}$ & 10 ptos & Anchura del vertedero (bs) & $0,60 \mathrm{~m}$ & 10 ptos & Dimensiones del orificio & $0,50 \times 0,15 \mathrm{~m}$ & 10 ptos \\
\hline
\end{tabular}




\section{PASO PARA PECES ASOCIADO AL AZUD DE LA CENTRAL HIDROELÉCTRICA DE LA PEÑA CORADA}

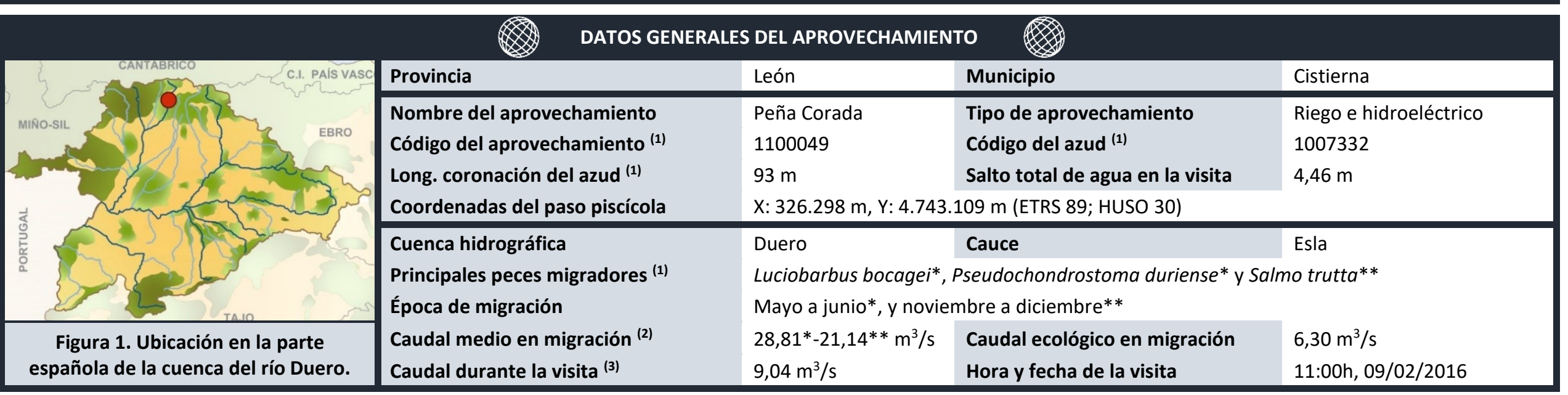

(1) Dato obtenido de MíRAME-IDE Duero. ${ }^{(2)}$ Dato obtenido del CEDEX Hidrológico. ${ }^{(3)}$ Dato obtenido del SAIH del Duero.

\begin{tabular}{|c|c|c|c|}
\hline Paso para peces de estanques su & os conectad & tederos sumergidos y orificios de fondo alternos & \\
\hline $\begin{array}{l}\text { Estado de mantenimiento y limpieza durante la evaluación } \\
\text { Solera naturalizada (con piedras) } \\
\text { Vertedero de umbral móvil en la entrada de peces }\end{array}$ & $\begin{array}{l}\text { Deficiente } \\
\text { No } \\
\text { No }\end{array}$ & $\begin{array}{l}\text { Compuerta en la salida de peces } \\
\text { Dispositivo para evitar la entrada de arrastres } \\
\text { Salida de peces segura (alejada del azud, turbinas, ...) }\end{array}$ & $\begin{array}{l}\text { Sí } \\
\text { No } \\
\text { Sí }\end{array}$ \\
\hline
\end{tabular}

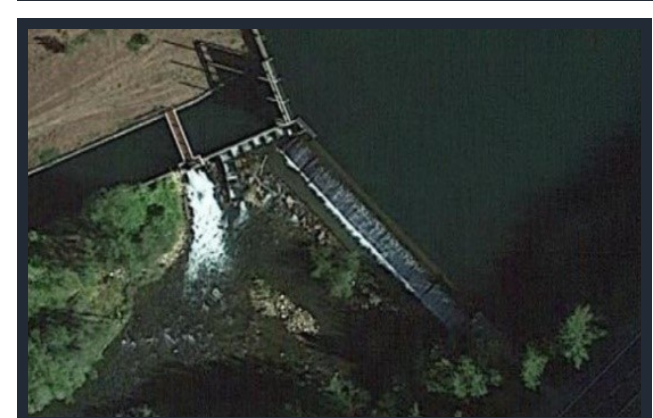

Figura 2. Ortofoto de la zona (fuente: Google Maps).

\begin{tabular}{lccc}
\multicolumn{4}{c}{ RESUMEN DE LA EVALUACIÓN DEL PASO PARA PECES } \\
& \multicolumn{4}{c|}{ (CON LA METODOLOGÍA AEPS) } & \\
\hline Etapa o categoría & Puntuación & Evaluación & ¿Mejoras? \\
Atracción & 5,0 & Desfavorable & Muy necesarias \\
Entrada & 8,5 & Muy favorable & Opcionales \\
Pasaje & 0,0 & Muy desfavorable & Imprescindibles \\
Salida & 7,9 & Favorable & Recomendables \\
\hline
\end{tabular}

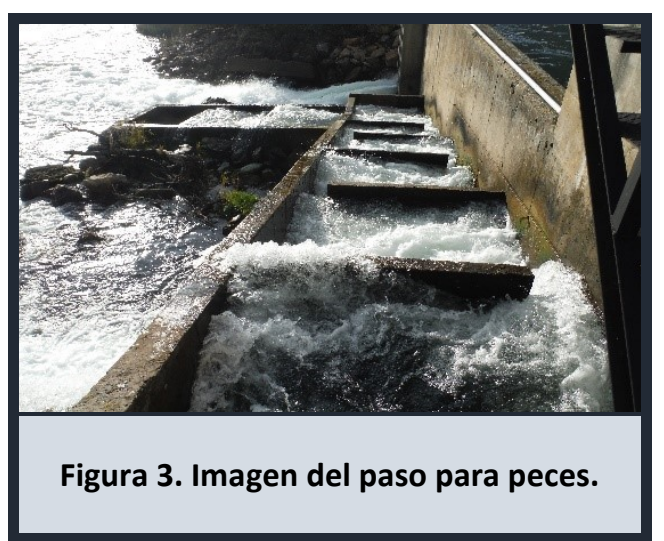




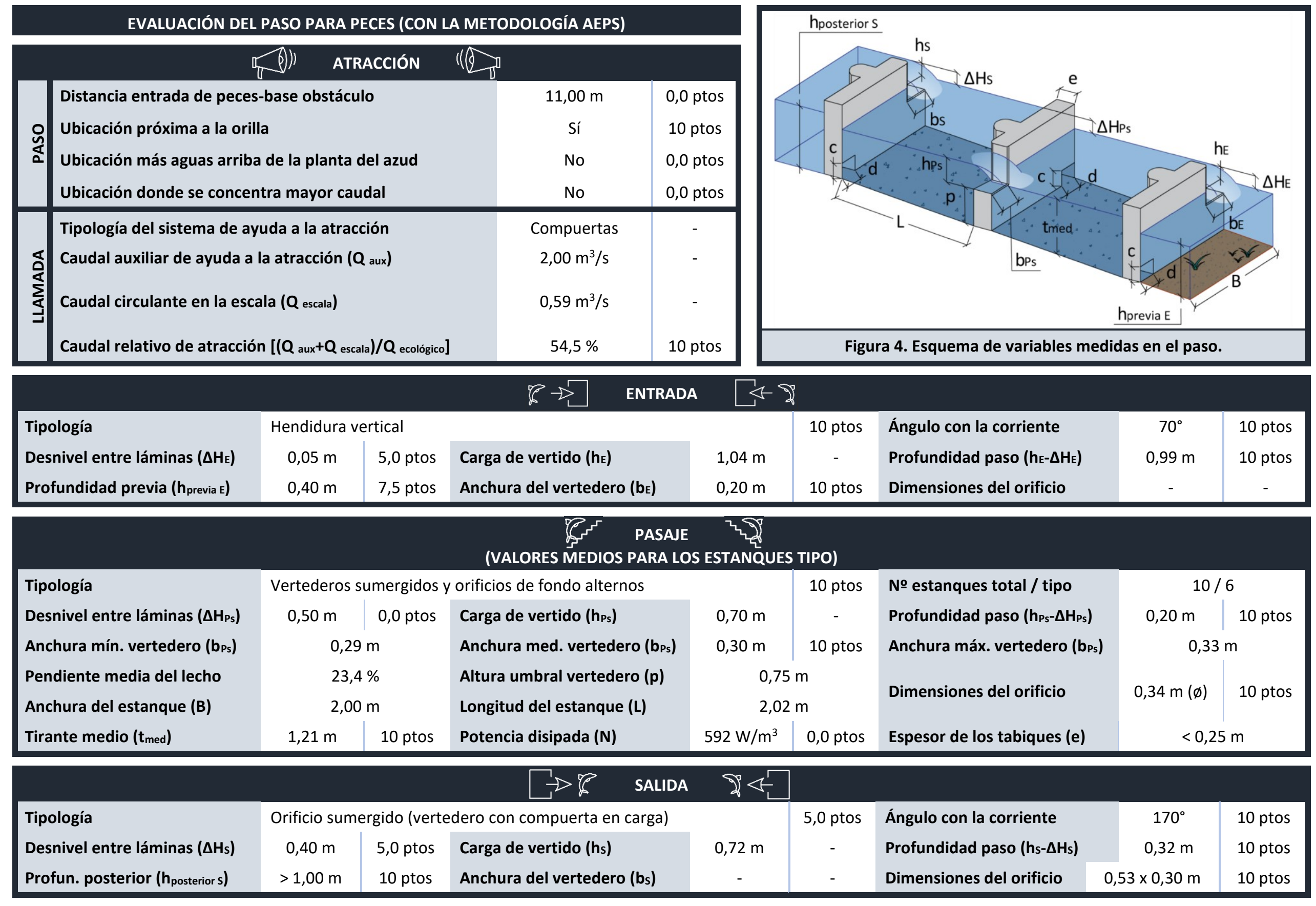




\section{PASO PARA PECES ASOCIADO AL AZUD DE LA CENTRAL HIDROELÉCTRICA DE LA POLA DE GORDÓN}

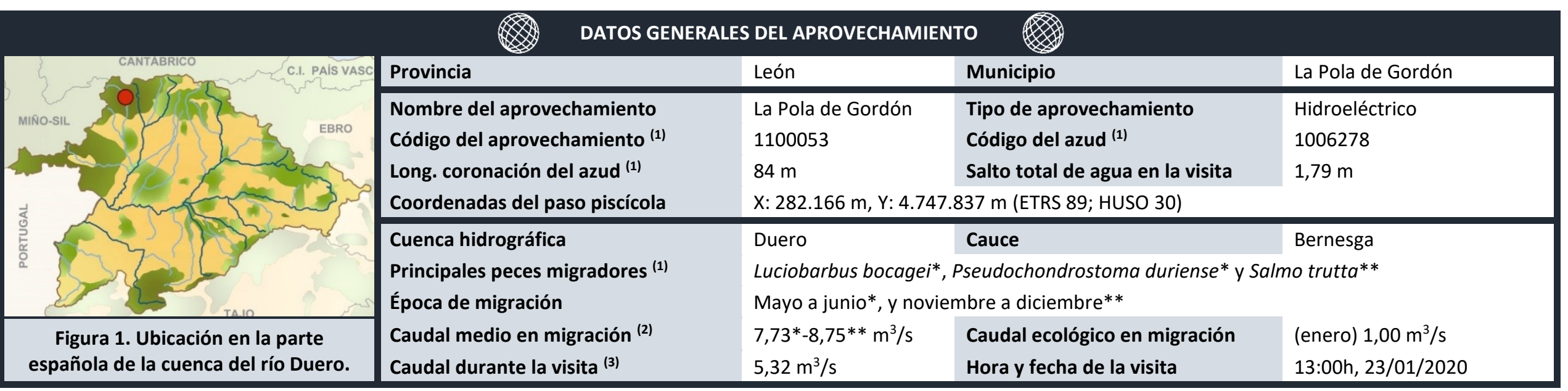

(1) Dato obtenido de MíRAME-IDE Duero. ${ }^{(2)}$ Dato obtenido del CEDEX Hidrológico. ${ }^{(3)}$ Dato obtenido del SAIH del Duero.

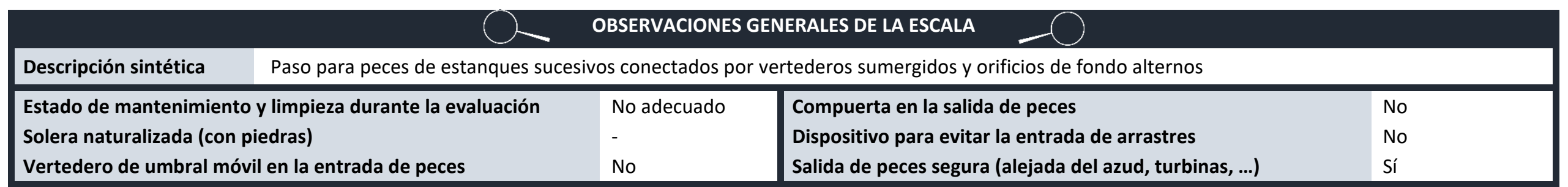

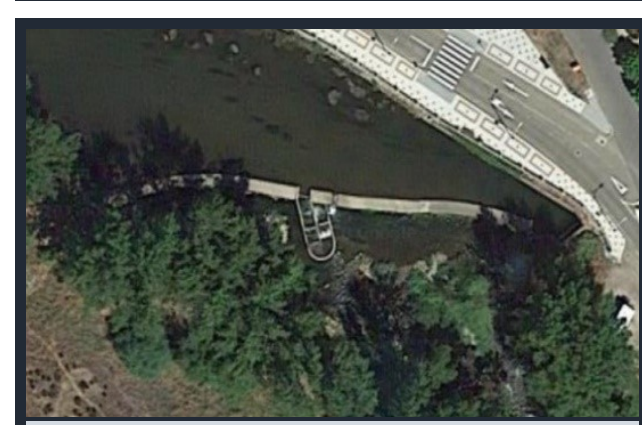

Figura 2. Ortofoto de la zona (fuente: Google Maps).

\begin{tabular}{lccc}
\multicolumn{4}{c}{ RESUMEN DE LA EVALUACIÓN DEL PASO PARA PECES } \\
& \multicolumn{2}{c|}{ (CON LA METODOLOGÍA AEPS) } & \\
\hline Etapa o categoría & Puntuación & Evaluación & ¿Mejoras? \\
Atracción & 7,1 & Favorable & Recomendables \\
Entrada & 0,0 & Muy desfavorable & Imprescindibles \\
Pasaje & 10,0 & Muy favorable & Opcionales \\
Salida & 0,0 & Muy desfavorable & Imprescindibles \\
\hline
\end{tabular}

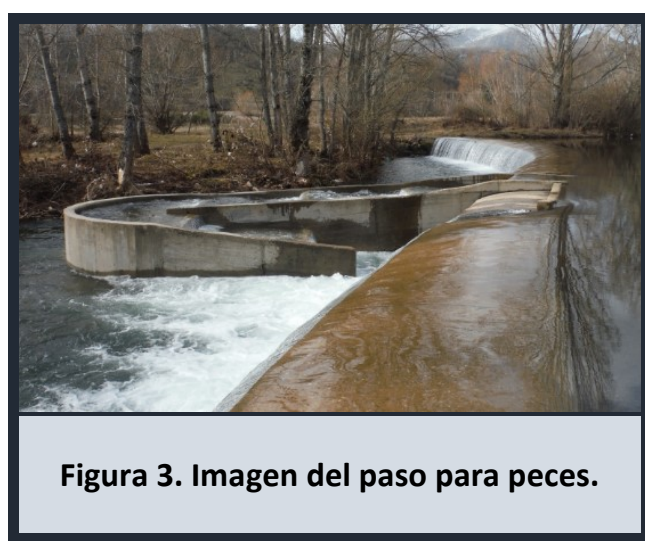




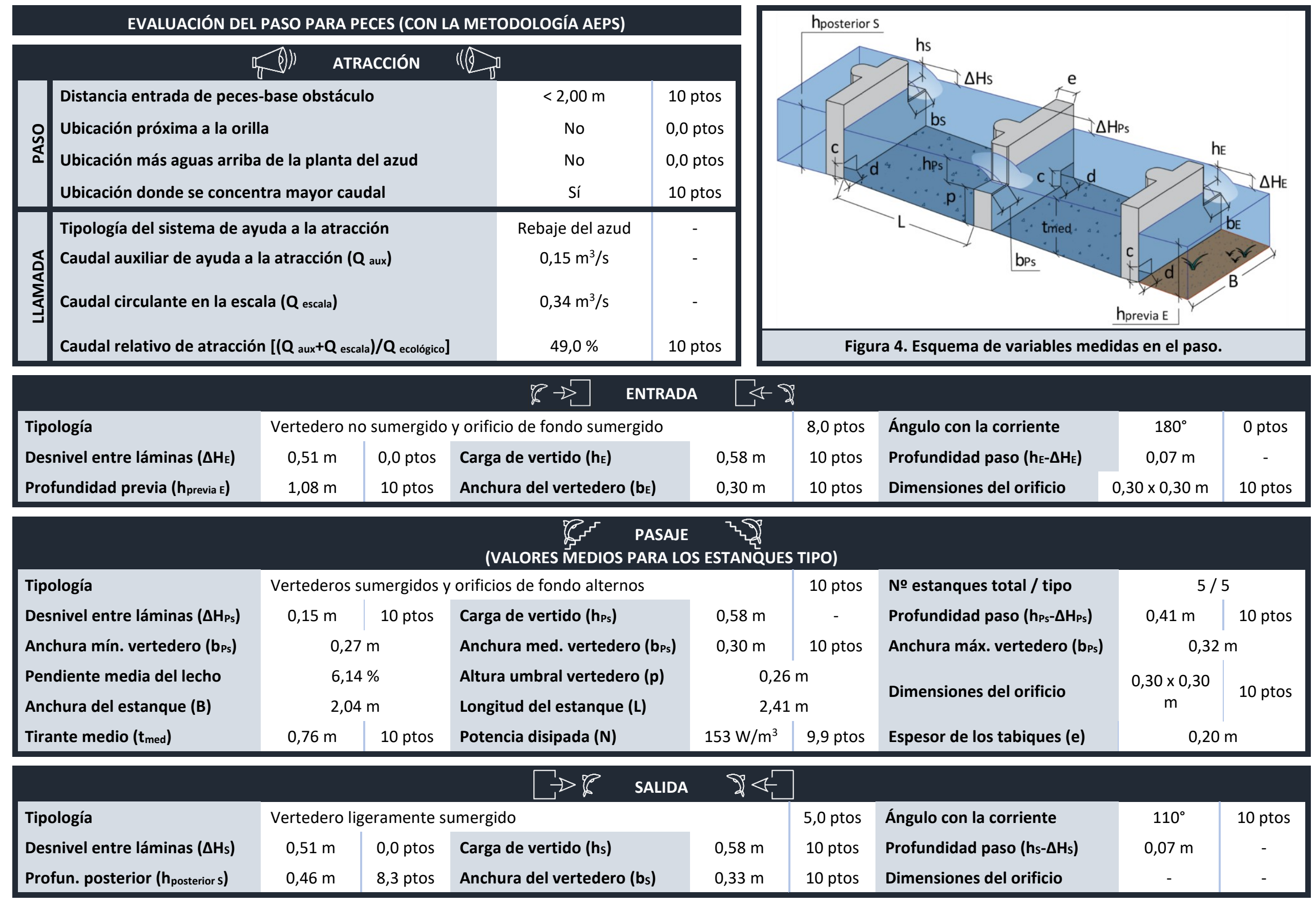




\section{PASO PARA PECES ASOCIADO AL AZUD DE LA MINICENTRAL DE LOS LEONES}

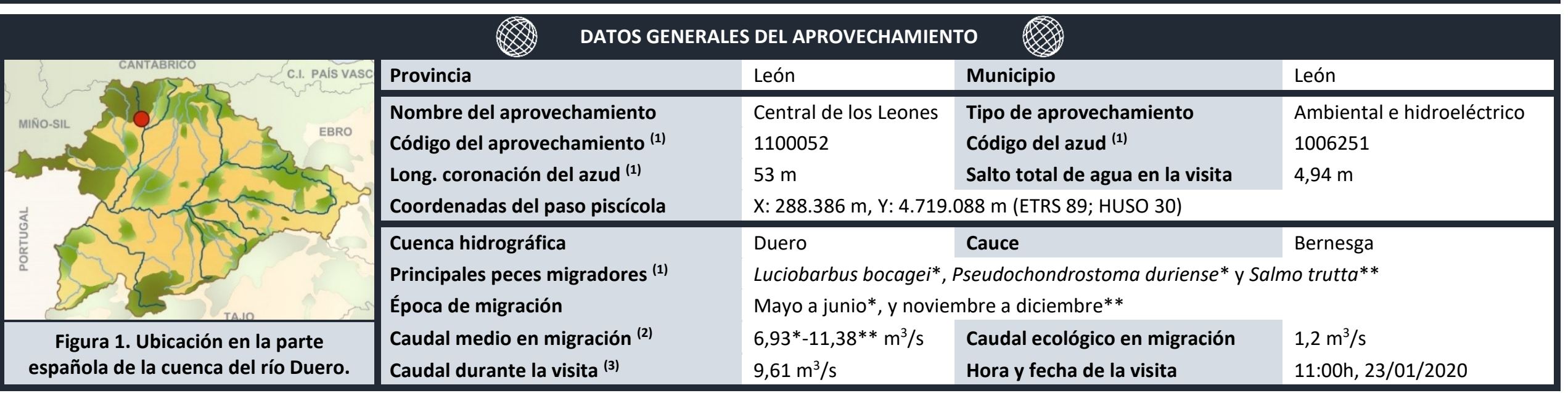

(1) Dato obtenido de MíRAME-IDE Duero. ${ }^{(2)}$ Dato obtenido del CEDEX Hidrológico. ${ }^{(3)}$ Dato obtenido del SAIH del Duero.

\begin{tabular}{|c|c|c|c|}
\hline Paso para peces de estanques su & os conectados $p$ & tederos no sumergidos y orificios de fondo alineados & \\
\hline $\begin{array}{l}\text { Estado de mantenimiento y limpieza durante la evaluación } \\
\text { Solera naturalizada (con piedras) } \\
\text { Vertedero de umbral móvil en la entrada de peces }\end{array}$ & $\begin{array}{l}\text { No adecuado } \\
\text { No } \\
\text { No }\end{array}$ & $\begin{array}{l}\text { Compuerta en la salida de peces } \\
\text { Dispositivo para evitar la entrada de arrastres } \\
\text { Salida de peces segura (alejada del azud, turbinas, ...) }\end{array}$ & $\begin{array}{l}\text { No } \\
\text { Sí } \\
\text { Sí }\end{array}$ \\
\hline
\end{tabular}

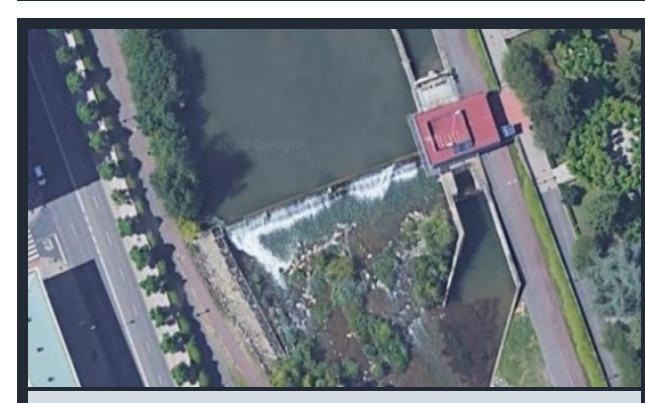

Figura 2. Ortofoto de la zona (fuente: Google Maps).

\begin{tabular}{lccc}
\hline \multicolumn{4}{c}{ RESUMEN DE LA EVALUACIÓN DEL PASO PARA PECES } \\
& \multicolumn{2}{c|}{ (CON LA METODOLOGíA AEPS) } & \\
\hline Etapa o categoría & Puntuación & Evaluación & ¿Mejoras? \\
Atracción & 7,1 & Favorable & Recomendables \\
Entrada & 0,0 & Muy desfavorable & Imprescindibles \\
Pasaje & 0,0 & Muy desfavorable & Imprescindibles \\
Salida & 9,0 & Muy favorable & Opcionales \\
\hline
\end{tabular}

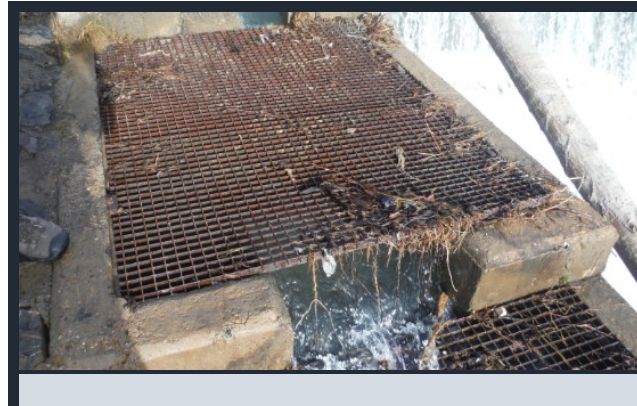

Figura 3. Imagen del paso para peces. 


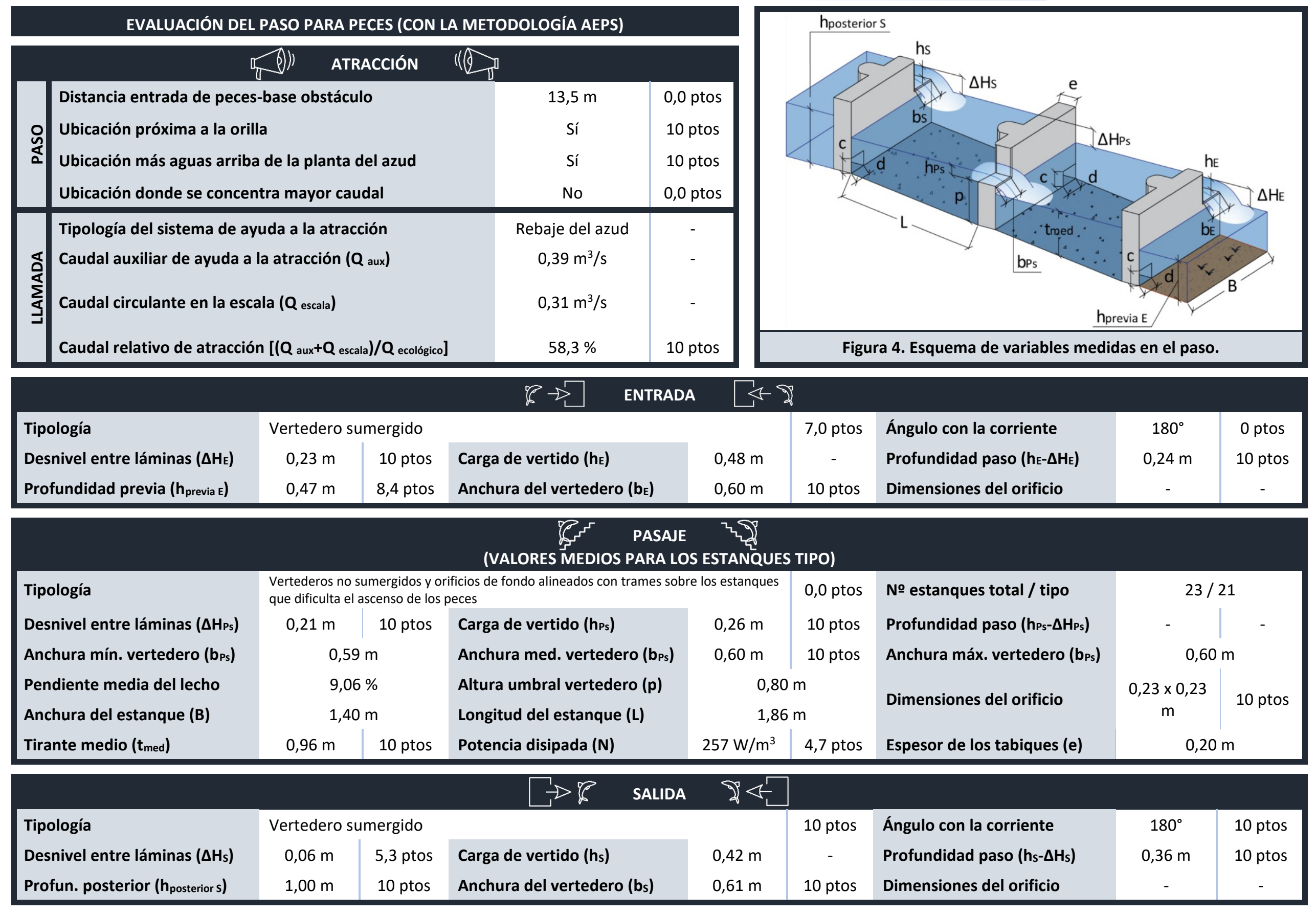

$\begin{array}{ll}\text { Jorge Valbuena Castro } & 205\end{array}$ 


\section{PASO PARA PECES ASOCIADO AL AZUD DE LA CENTRAL HIDROELÉCTRICA DE MATALLANA DE TORÍO}

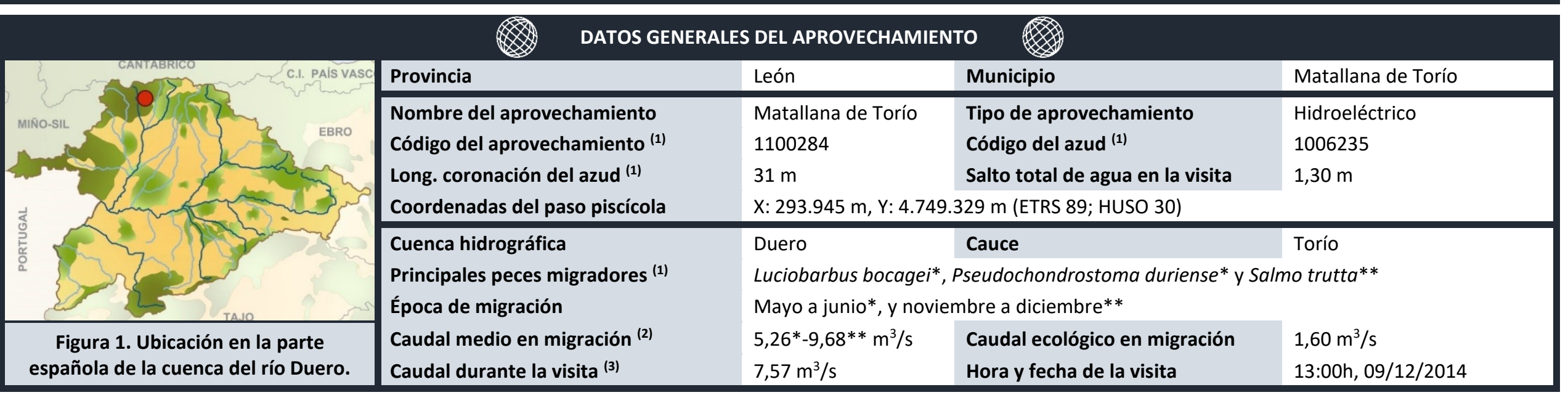

(1) Dato obtenido de MíRAME-IDE Duero. ${ }^{(2)}$ Dato obtenido del CEDEX Hidrológico. ${ }^{(3)}$ Dato obtenido del SAIH del Duero.

\begin{tabular}{|c|c|c|c|}
\hline Paso para peces de estanques st & os conectados $p$ & rtederos sumergidos y orifcios de fondo alternos & \\
\hline $\begin{array}{l}\text { Estado de mantenimiento y limpieza durante la evaluación } \\
\text { Solera naturalizada (con piedras) } \\
\text { Vertedero de umbral móvil en la entrada de peces }\end{array}$ & $\begin{array}{l}\text { No adecuado } \\
\text { No } \\
\text { No }\end{array}$ & $\begin{array}{l}\text { Compuerta en la salida de peces } \\
\text { Dispositivo para evitar la entrada de arrastres } \\
\text { Salida de peces segura (alejada del azud, turbinas, ...) }\end{array}$ & $\begin{array}{l}\text { No } \\
\text { No } \\
\text { Sí }\end{array}$ \\
\hline
\end{tabular}

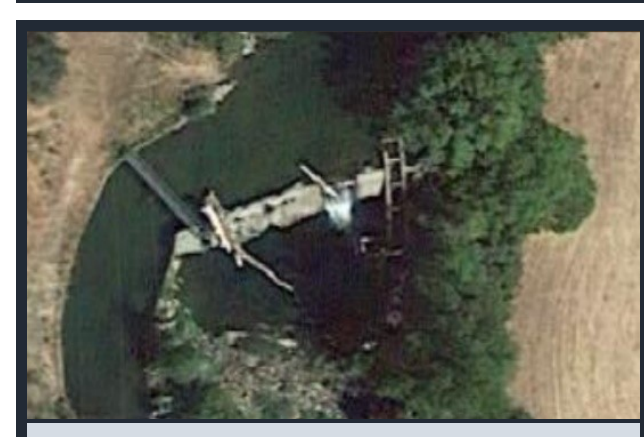

Figura 2. Ortofoto de la zona (fuente: Google Maps).

\begin{tabular}{lccc}
\multicolumn{4}{c}{ RESUMEN DE LA EVALUACIÓN DEL PASO PARA PECES } \\
& \multicolumn{4}{c|}{ (CON LA METODOLOGÍA AEPS) } & \\
\hline Etapa o categoría & Puntuación & Evaluación & ¿Mejoras? \\
Atracción & 7,1 & Favorable & Recomendables \\
Entrada & 9,1 & Muy favorable & Opcionales \\
Pasaje & 9,4 & Muy favorable & Opcionales \\
Salida & 7,6 & Favorable & Recomendables \\
\hline
\end{tabular}

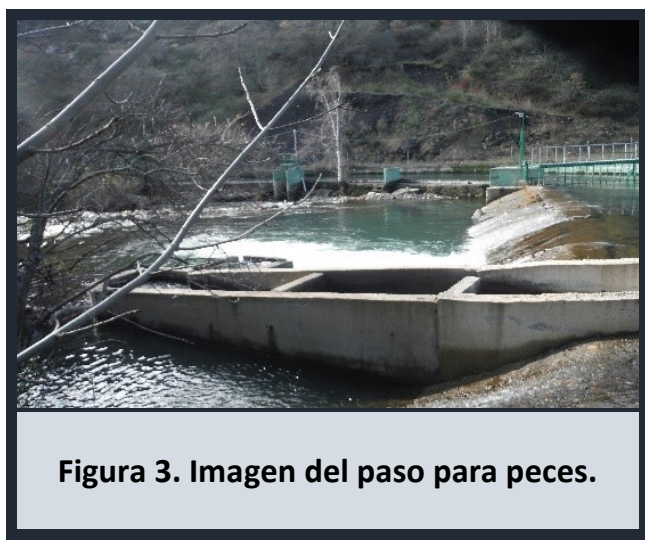




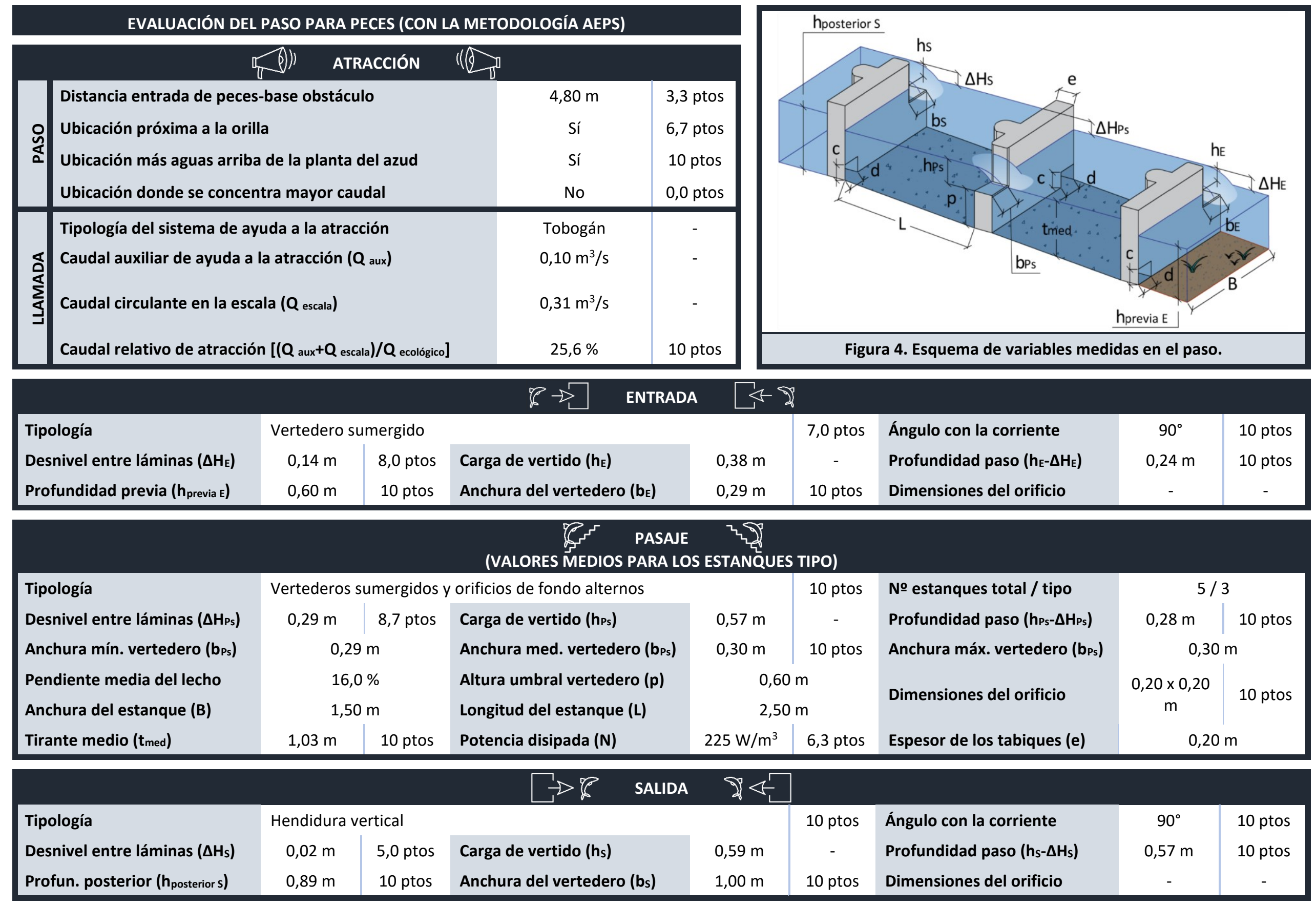




\section{PASO PARA PECES ASOCIADO AL AZUD DE LA CENTRAL HIDROELÉCTRICA DE MOLINO PUENTE ALBA}

\begin{tabular}{|c|c|c|c|c|}
\hline & Provincia & León & Municipio & La Robla \\
\hline & $\begin{array}{l}\text { Nombre del aprovechamiento } \\
\text { Código del aprovechamiento } \\
\text { Long. coronación del azud } \\
\text { (1) } \\
\text { Coordenadas del paso piscícola }\end{array}$ & $\begin{array}{l}\text { Molino Puente Alba } \\
1100145 \\
27 \mathrm{~m} \\
\mathrm{X}: 284.257 \mathrm{~m}, \mathrm{Y}: 4.74\end{array}$ & $\begin{array}{l}\text { Tipo de aprovechamiento } \\
\text { Código del azud (1) } \\
\text { Salto total de agua en la visita } \\
475 \text { m (ETRS 89; HUSO 30) }\end{array}$ & $\begin{array}{l}\text { Hidroeléctrico } \\
1006279 \\
2,46 \mathrm{~m}\end{array}$ \\
\hline & $\begin{array}{l}\text { Cuenca hidrográfica } \\
\text { Principales peces migradores }{ }^{(1)} \\
\text { Época de migración }\end{array}$ & \multicolumn{3}{|c|}{$\begin{array}{l}\text { Luciobarbus bocagei*, Pseudochondrostoma duriense* y Salmo trutta** } \\
\text { Mayo a junio*, y noviembre a diciembre** }\end{array}$} \\
\hline $\begin{array}{l}\text { Figura 1. Ubicación en la parte } \\
\text { española de la cuenca del río Duero. }\end{array}$ & $\begin{array}{l}\text { Caudal medio en migración (2) } \\
\text { Caudal durante la visita }{ }^{(3)}\end{array}$ & $\begin{array}{l}7,73 *-8,75^{* *} \mathrm{~m}^{3} / \mathrm{s} \\
6,10 \mathrm{~m}^{3} / \mathrm{s}\end{array}$ & $\begin{array}{l}\text { Caudal ecológico en migración } \\
\text { Hora y fecha de la visita }\end{array}$ & $\begin{array}{l}\text { (enero) } 1,80 \mathrm{~m}^{3} / \mathrm{s} \\
14: 00 \mathrm{~h}, 23 / 01 / 2020\end{array}$ \\
\hline
\end{tabular}

(1) Dato obtenido de MíRAME-IDE Duero. ${ }^{(2)}$ Dato obtenido del CEDEX Hidrológico. ${ }^{(3)}$ Dato obtenido del SAIH del Duero.

\begin{tabular}{|c|c|c|c|}
\hline Paso para peces de estanques su & os conectados $p$ & ndiduras verticales alineadas y sin orificios & \\
\hline $\begin{array}{l}\text { Estado de mantenimiento y limpieza durante la evaluación } \\
\text { Solera naturalizada (con piedras) } \\
\text { Vertedero de umbral móvil en la entrada de peces }\end{array}$ & $\begin{array}{l}\text { No adecuado } \\
\text { Sí } \\
\text { No }\end{array}$ & $\begin{array}{l}\text { Compuerta en la salida de peces } \\
\text { Dispositivo para evitar la entrada de arrastres } \\
\text { Salida de peces segura (alejada del azud, turbinas, ...) }\end{array}$ & $\begin{array}{l}\text { Sí } \\
\text { Sí } \\
\text { Sí }\end{array}$ \\
\hline
\end{tabular}

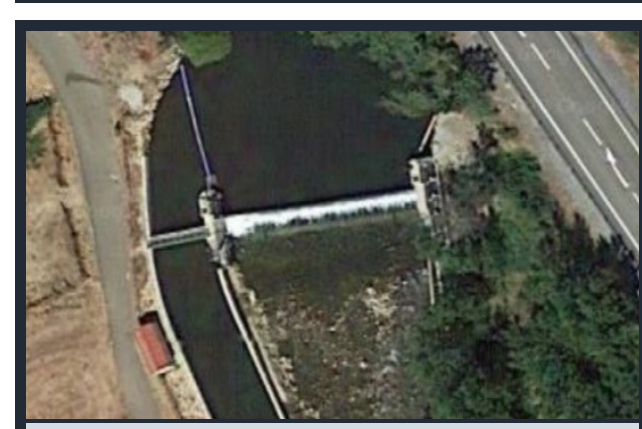

Figura 2. Ortofoto de la zona (fuente: Google Maps).

\begin{tabular}{lccl}
\multicolumn{4}{c}{ RESUMEN DE LA EVALUACIÓN DEL PASO PARA PECES } \\
& \multicolumn{4}{c}{ (CON LA METODOLOGÍA AEPS) } & \\
\hline Etapa o categoría & Puntuación & Evaluación & ¿Mejoras? \\
Atracción & 9,6 & Muy favorable & Opcionales \\
Entrada & 8,4 & Muy favorable & Opcionales \\
Pasaje & 10,0 & Muy favorable & Opcionales \\
Salida & 10,0 & Muy favorable & Opcionales \\
\hline
\end{tabular}

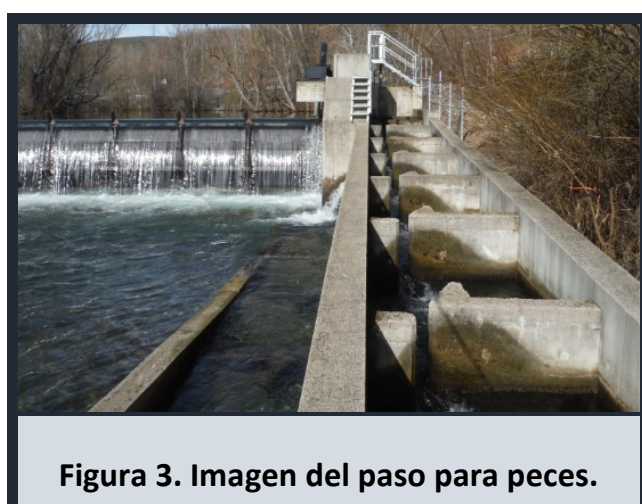




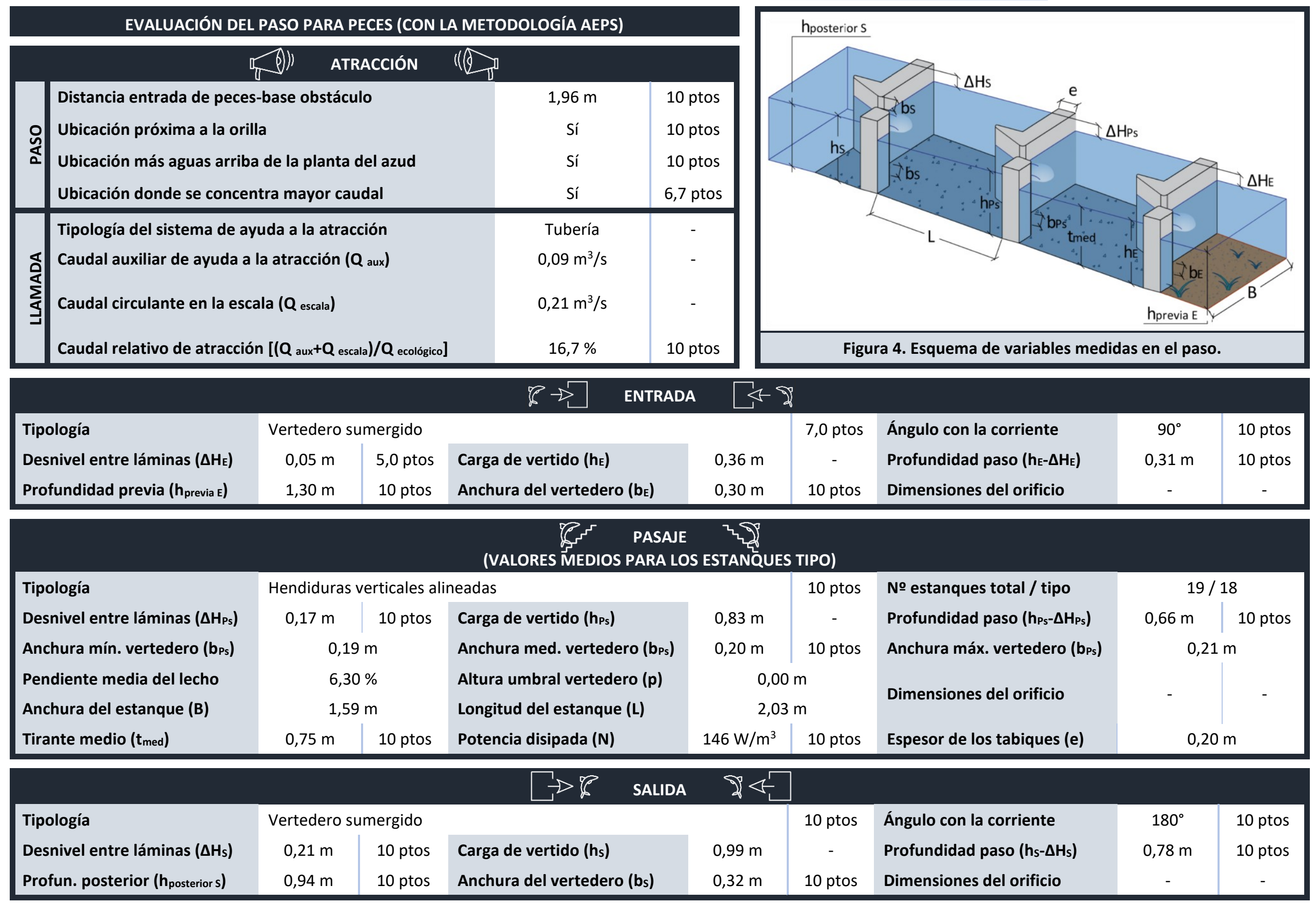




\section{PASO PARA PECES ASOCIADO AL AZUD DE LA PISCIFACTORÍA DE VEGAS DEL CONDADO}

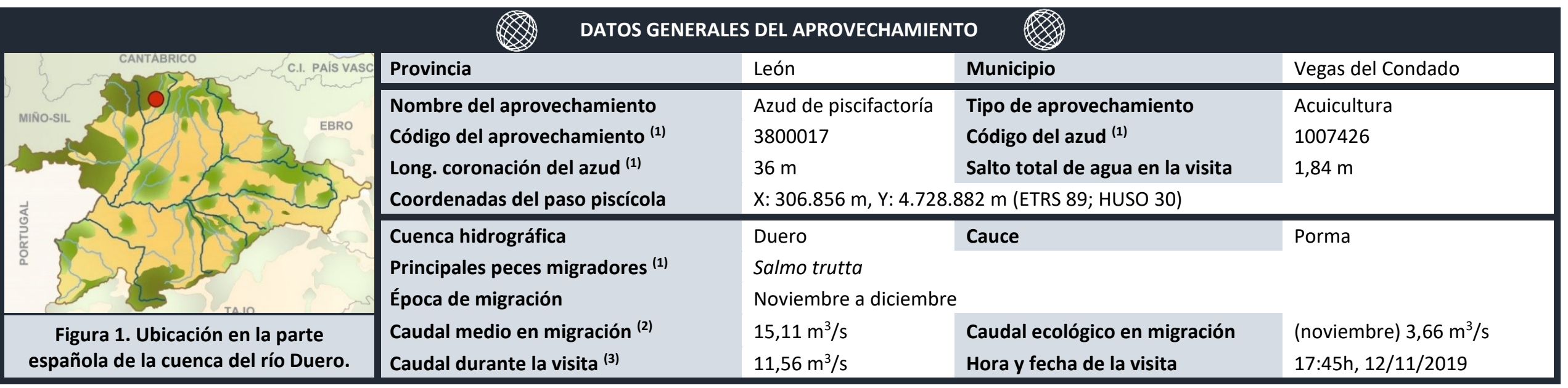

(1) Dato obtenido de MíRAME-IDE Duero. ${ }^{(2)}$ Dato obtenido del CEDEX Hidrológico. ${ }^{(3)}$ Dato obtenido del SAIH del Duero.

\begin{tabular}{|c|c|c|c|}
\hline \multicolumn{4}{|c|}{ OBSERVACIONES GENERALES DE LA ESCALA } \\
\hline $\begin{array}{l}\text { Estado de mantenimiento y limpieza durante la evaluación } \\
\text { Solera naturalizada (con piedras) } \\
\text { Vertedero de umbral móvil en la entrada de peces }\end{array}$ & $\begin{array}{l}\text { Muy deficiente } \\
\text { Sí } \\
\text { No }\end{array}$ & $\begin{array}{l}\text { Compuerta en la salida de peces } \\
\text { Dispositivo para evitar la entrada de arrastres } \\
\text { Salida de peces segura (alejada del azud, turbinas, ...) }\end{array}$ & $\begin{array}{l}\text { Sí } \\
\text { No } \\
\text { Sí }\end{array}$ \\
\hline
\end{tabular}

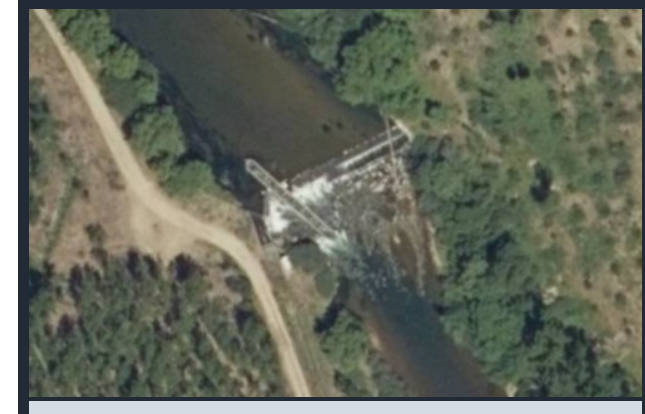

Figura 2. Ortofoto de la zona (fuente: SigPac).

\begin{tabular}{lccl}
\multicolumn{5}{c}{ RESUMEN DE LA EVALUACIÓN DEL PASO PARA PECES } \\
(CON LA METODOLOGÍA AEPS)
\end{tabular}

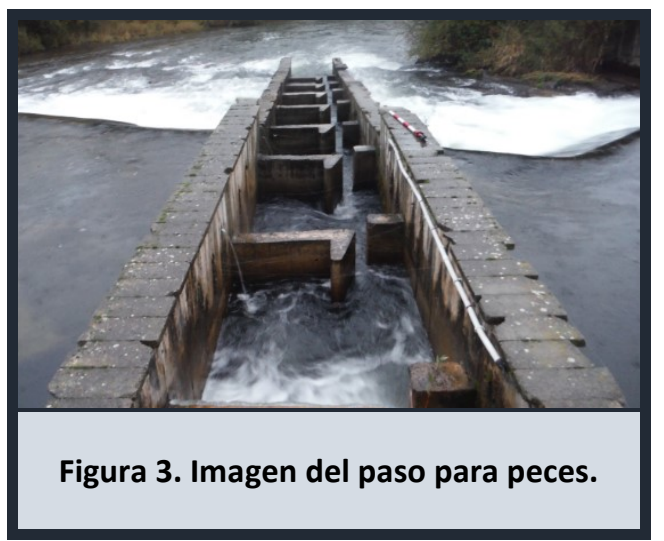




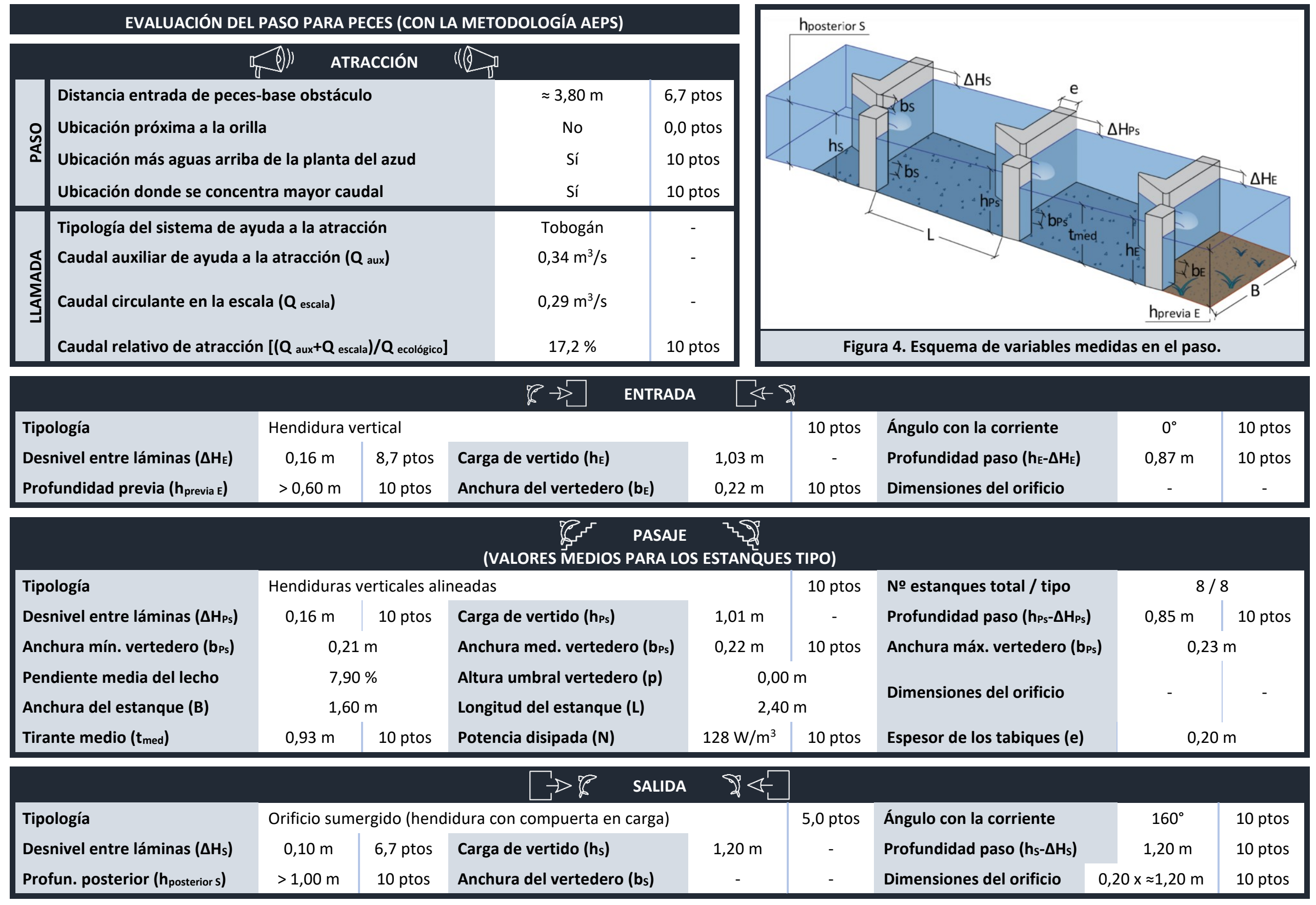




\section{PASO PARA PECES ASOCIADO AL AZUD DE LA CENTRAL HIDROELÉCTRICA DE AURORA}

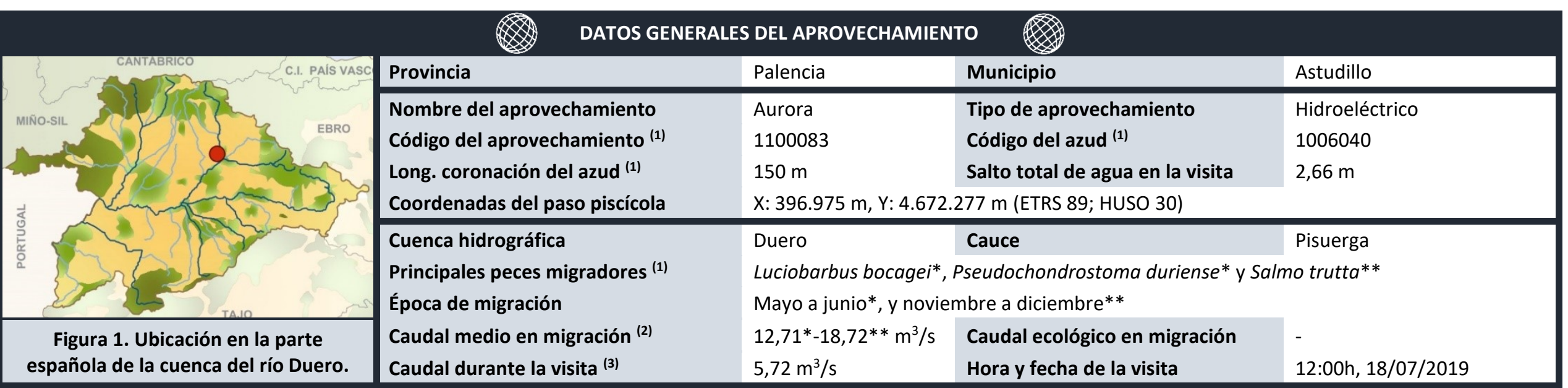

${ }^{(1)}$ Dato obtenido de MíRAME-IDE Duero. ${ }^{(2)}$ Dato obtenido del CEDEX Hidrológico. ${ }^{(3)}$ Dato obtenido del SAIH del Duero.

\begin{tabular}{|c|c|c|c|}
\hline Paso para peces de estanques & os conectado & ederos no sumergidos alineados y sin orificios de fondo & \\
\hline $\begin{array}{l}\text { Estado de mantenimiento y limpieza durante la evaluación } \\
\text { Solera naturalizada (con piedras) } \\
\text { Vertedero de umbral móvil en la entrada de peces }\end{array}$ & $\begin{array}{l}\text { Deficiente } \\
\text { No } \\
\text { No }\end{array}$ & $\begin{array}{l}\text { Compuerta en la salida de peces } \\
\text { Dispositivo para evitar la entrada de arrastres } \\
\text { Salida de peces segura (alejada del azud, turbinas, ...) }\end{array}$ & $\begin{array}{l}\text { No } \\
\text { No } \\
\text { Sí }\end{array}$ \\
\hline
\end{tabular}

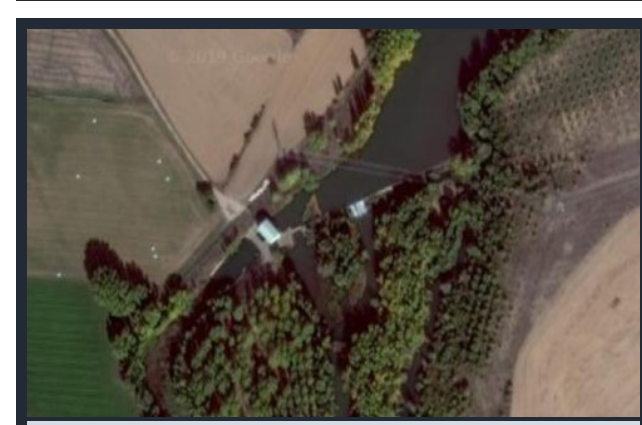

Figura 2. Ortofoto de la zona (fuente: Google Maps).

\begin{tabular}{lccc}
\multicolumn{4}{c}{ RESUMEN DE LA EVALUACIÓN DEL PASO PARA PECES } \\
& \multicolumn{4}{c|}{ (CON LA METODOLOGÍA AEPS) } & \\
\hline Etapa o categoría & Puntuación & Evaluación & ¿Mejoras? \\
Atracción & 4,6 & Desfavorable & Muy necesarias \\
Entrada & 0,0 & Muy desfavorable & Imprescindibles \\
Pasaje & 0,0 & Muy desfavorable & Imprescindibles \\
Salida & 8,5 & Muy favorable & Opcionales \\
\hline
\end{tabular}

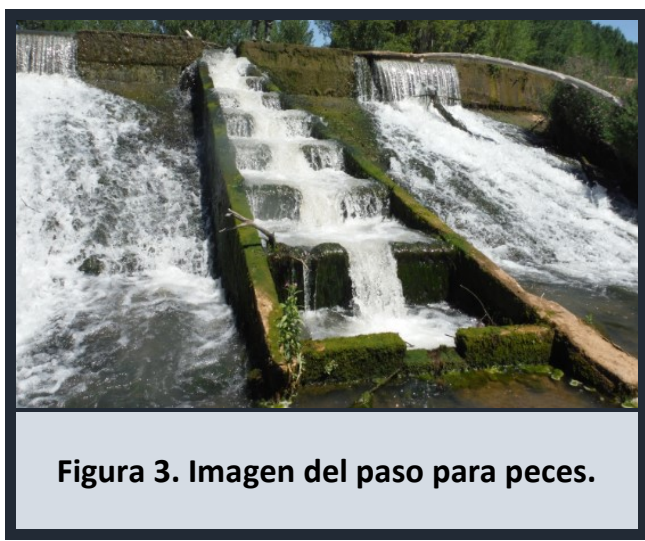




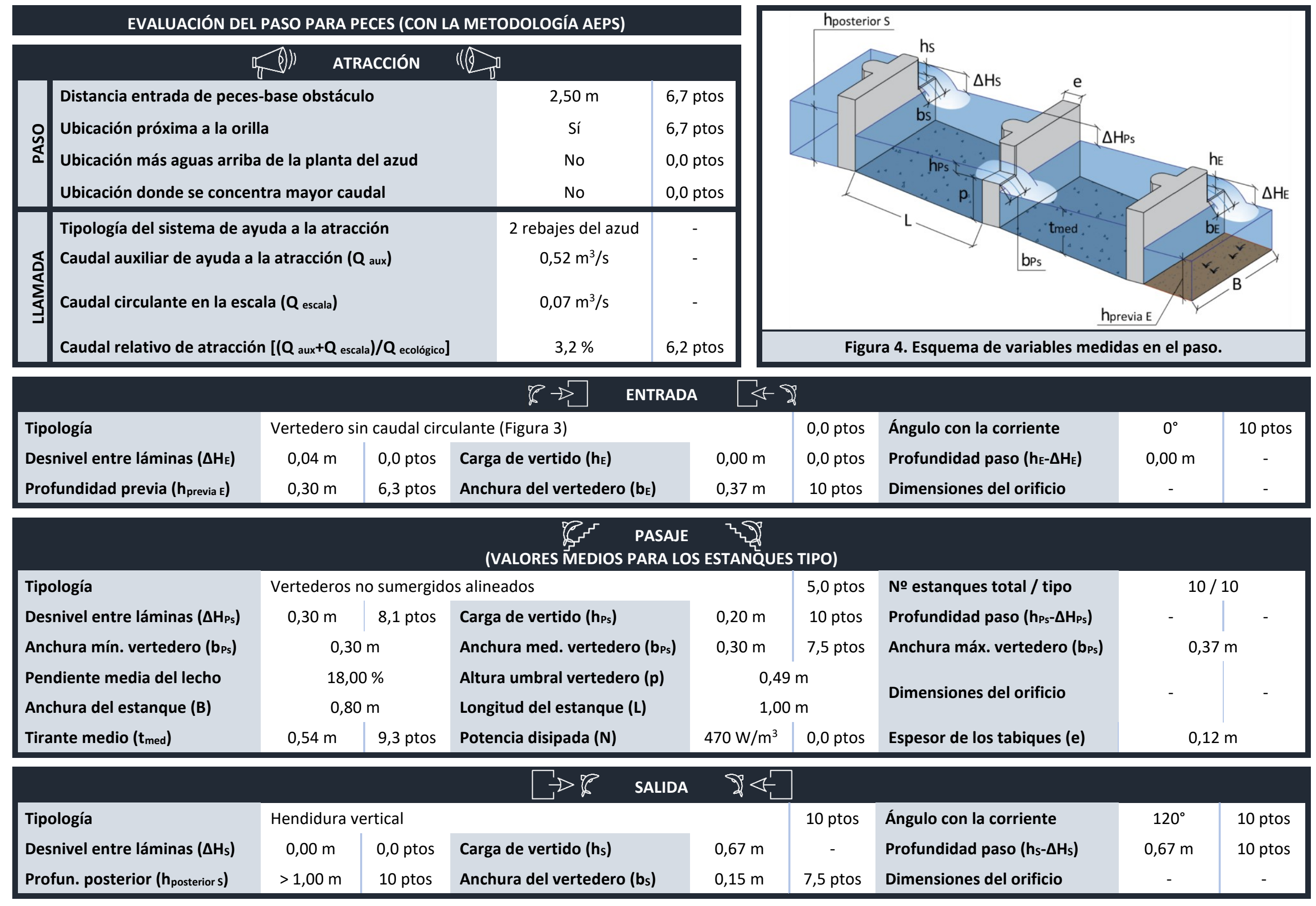




\section{PASO PARA PECES ASOCIADO AL AZUD DEL CANAL DE CASTILLA NORTE EN ALAR DEL REY}

\begin{tabular}{|c|c|c|c|c|}
\hline & Provincia & Palencia & Municipio & Alar del Rey \\
\hline & $\begin{array}{l}\text { Nombre del aprovechamiento } \\
\text { Código del aprovechamiento } \\
\text { Long. coronación del azud } \\
\text { (1) } \\
\text { Coordenadas del paso piscícola }\end{array}$ & $\begin{array}{l}\text { El Pisón } \\
1100303 \\
155 \mathrm{~m} \\
X: 393.045 \mathrm{~m}, \mathrm{Y}: 4.724 . C\end{array}$ & $\begin{array}{l}\text { Tipo de aprovechamiento } \\
\text { Código del azud (1) } \\
\text { Salto total de agua en la visita } \\
19 \text { m (ETRS 89; HUSO 30) }\end{array}$ & $\begin{array}{l}\text { Riego e hidroeléctrico } \\
1006051 \\
2,87 \mathrm{~m}\end{array}$ \\
\hline & $\begin{array}{l}\text { Cuenca hidrográfica } \\
\text { Principales peces migradores }{ }^{(1)} \\
\text { Época de migración }\end{array}$ & $\begin{array}{l}\text { Duero } \\
\text { Salmo trutta } \\
\text { Noviembre a diciembre }\end{array}$ & Cauce & Pisuerga \\
\hline $\begin{array}{l}\text { Figura 1. Ubicación en la parte } \\
\text { española de la cuenca del río Duero. }\end{array}$ & $\begin{array}{l}\text { Caudal medio en migración (2) } \\
\text { Caudal durante la visita }{ }^{(3)}\end{array}$ & $\begin{array}{l}10,41 \mathrm{~m}^{3} / \mathrm{s} \\
3,12 \mathrm{~m}^{3} / \mathrm{s}\end{array}$ & $\begin{array}{l}\text { Caudal ecológico en migración } \\
\text { Hora y fecha de la visita }\end{array}$ & 11:00h, 07/11/2019 \\
\hline
\end{tabular}

(1) Dato obtenido de MíRAME-IDE Duero. ${ }^{(2)}$ Dato obtenido del CEDEX Hidrológico. ${ }^{(3)}$ Dato obtenido del SAIH del Duero.

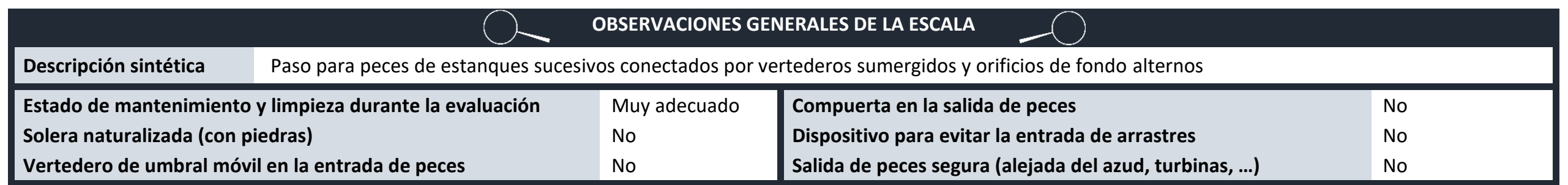

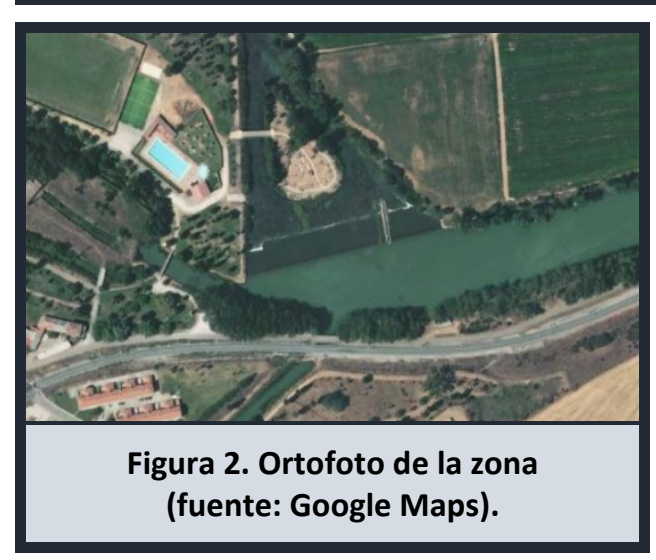

\begin{tabular}{|c|c|c|c|}
\hline \multicolumn{4}{|c|}{$\begin{array}{l}\text { RESUMEN DE LA EVALUACIÓN DEL PASO PARA PECES } \\
\text { (CON LA METODOLOGÍA AEPS) }\end{array}$} \\
\hline Etapa o categoría & Puntuación & Evaluación & ¿Mejoras? \\
\hline Atracción & 5,8 & Desfavorable & Muy necesarias \\
\hline Entrada & 5,4 & Desfavorable & Muy necesarias \\
\hline Pasaje & 9,7 & Muy favorable & Opcionales \\
\hline Salida & 9,3 & Muy favorable & Opcionales \\
\hline
\end{tabular}

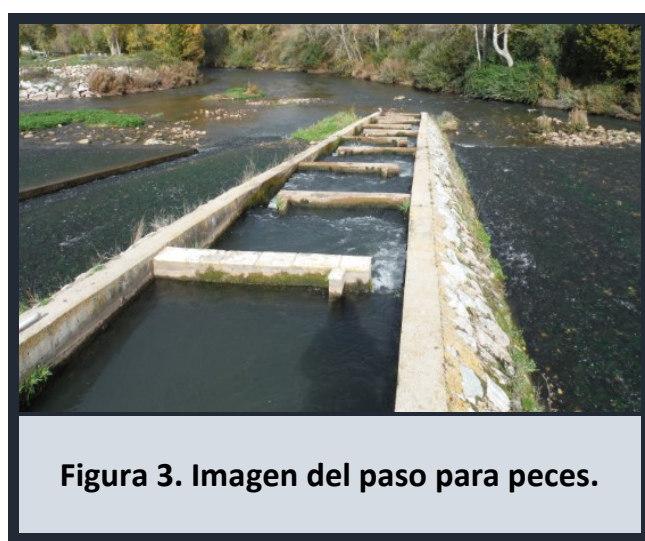




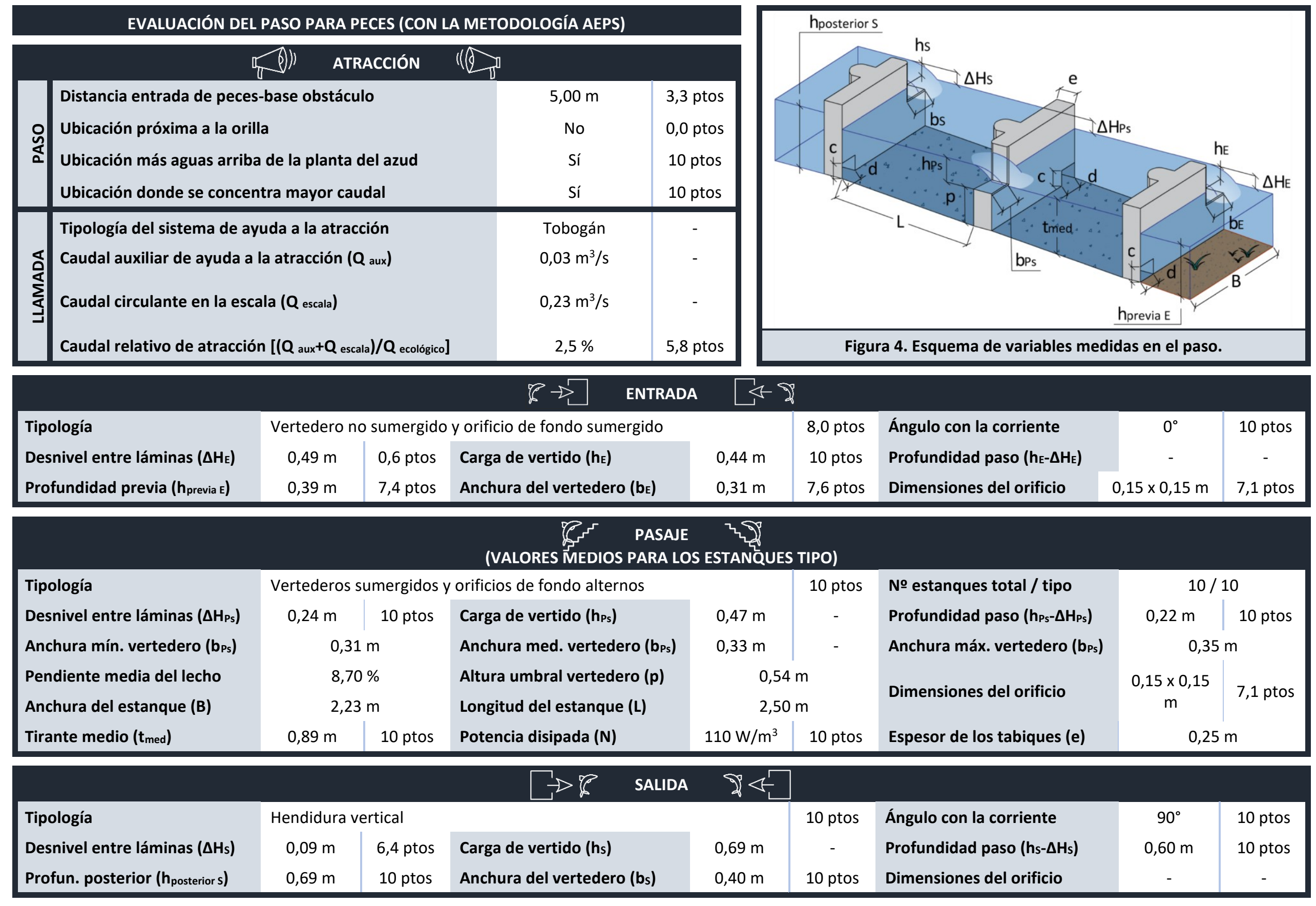




\section{PASO PARA PECES ASOCIADO AL AZUD DE LA CENTRAL DE CERRATO}

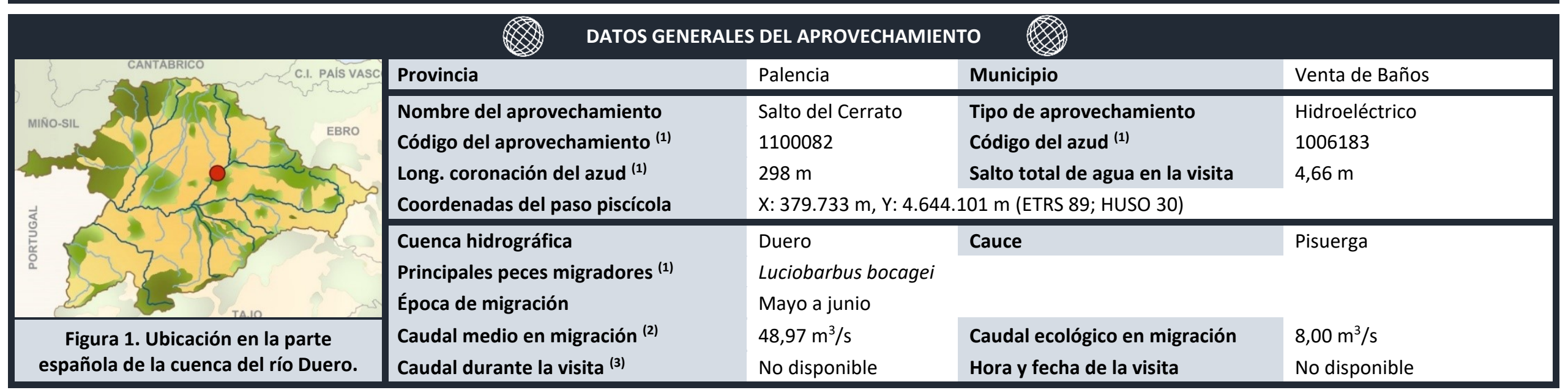

(1) Dato obtenido de MíRAME-IDE Duero. ${ }^{(2)}$ Dato obtenido del CEDEX Hidrológico. ${ }^{(3)}$ Dato obtenido del SAIH del Duero.

\begin{tabular}{|c|c|c|c|}
\hline Paso para peces de estanques st & os conectad & tederos sumergidos alternos & \\
\hline $\begin{array}{l}\text { Estado de mantenimiento y limpieza durante la evaluación } \\
\text { Solera naturalizada (con piedras) } \\
\text { Vertedero de umbral móvil en la entrada de peces }\end{array}$ & $\begin{array}{l}\text { Adecuado } \\
\text { Sí } \\
\text { No }\end{array}$ & $\begin{array}{l}\text { Compuerta en la salida de peces } \\
\text { Dispositivo para evitar la entrada de arrastres } \\
\text { Salida de peces segura (alejada del azud, turbinas, ...) }\end{array}$ & $\begin{array}{l}\text { No } \\
\text { Sí } \\
\text { Sí }\end{array}$ \\
\hline
\end{tabular}

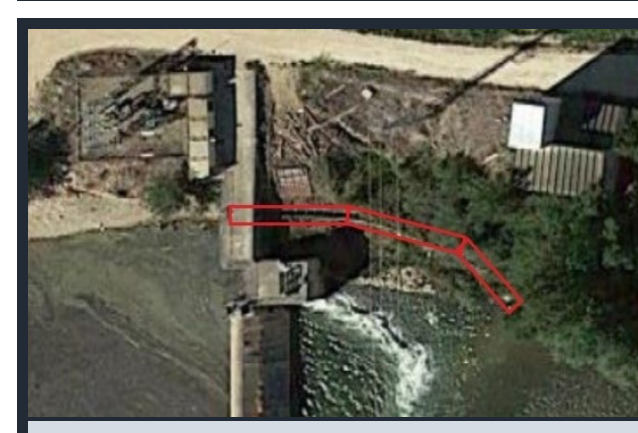

Figura 2. Ortofoto de la zona (fuente: Google Maps).

\begin{tabular}{|c|c|c|c|}
\hline \multicolumn{4}{|c|}{$\begin{array}{l}\text { RESUMEN DE LA EVALUACIÓN DEL PASO PARA PECES } \\
\text { (CON LA METODOLOGÍA AEPS) }\end{array}$} \\
\hline Etapa o categoría & Puntuación & Evaluación & ¿Mejoras? \\
\hline Atracción & 4,6 & Desfavorable & Muy necesarias \\
\hline Entrada & 8,4 & Muy favorable & Opcionales \\
\hline Pasaje & 8,1 & Muy favorable & Opcionales \\
\hline Salida & 8,9 & Muy favorable & Opcionales \\
\hline
\end{tabular}

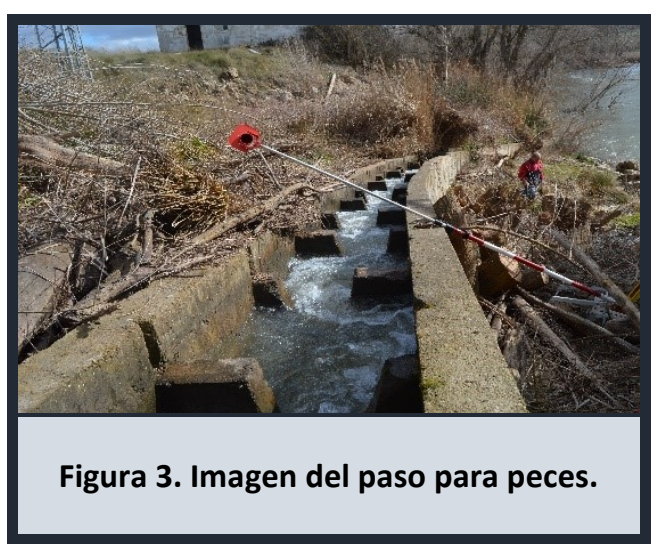




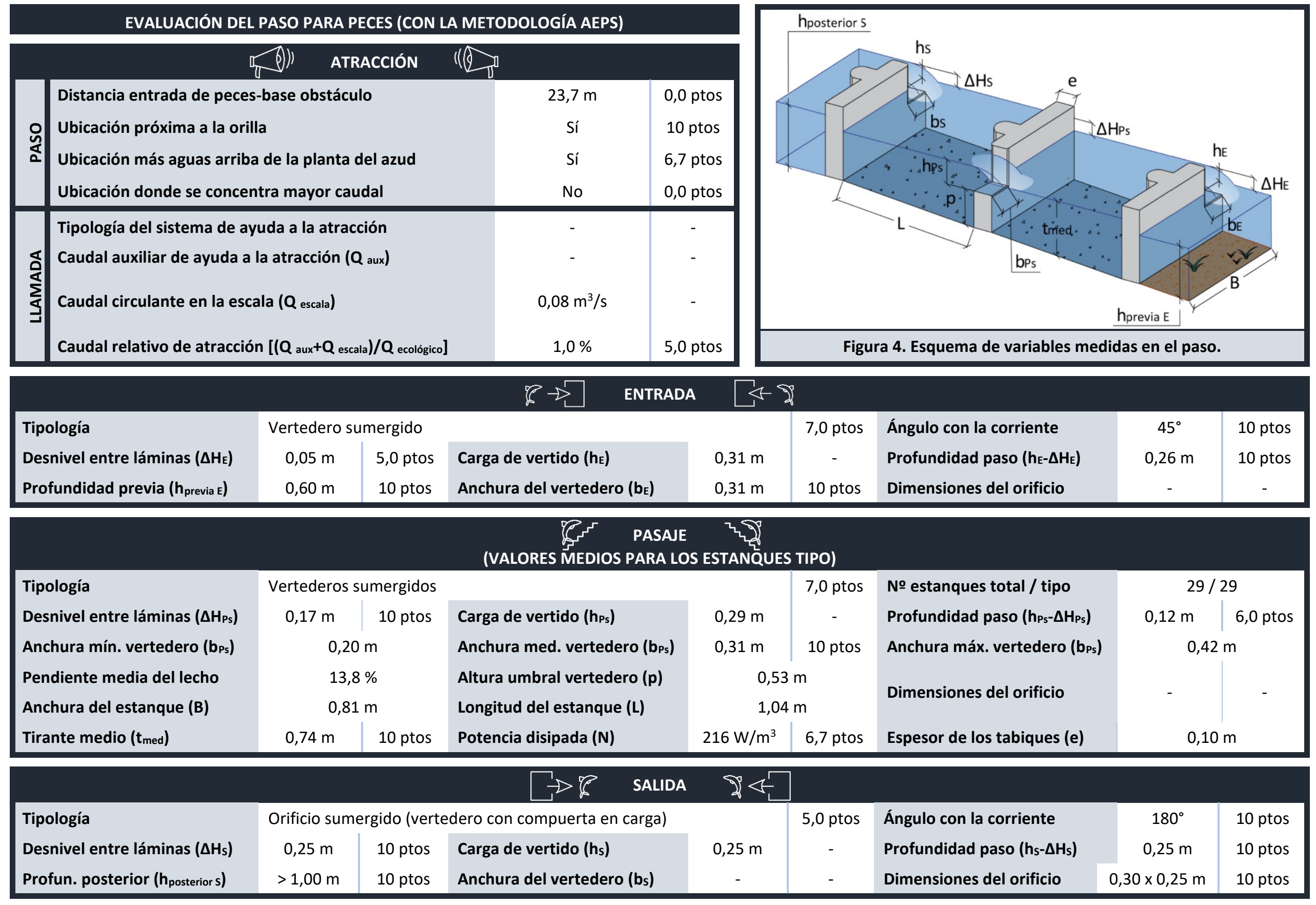




\section{PASO PARA PECES ASOCIADO AL AZUD DE LA CENTRAL HIDROELÉCTRICA DE HUSILLOS}

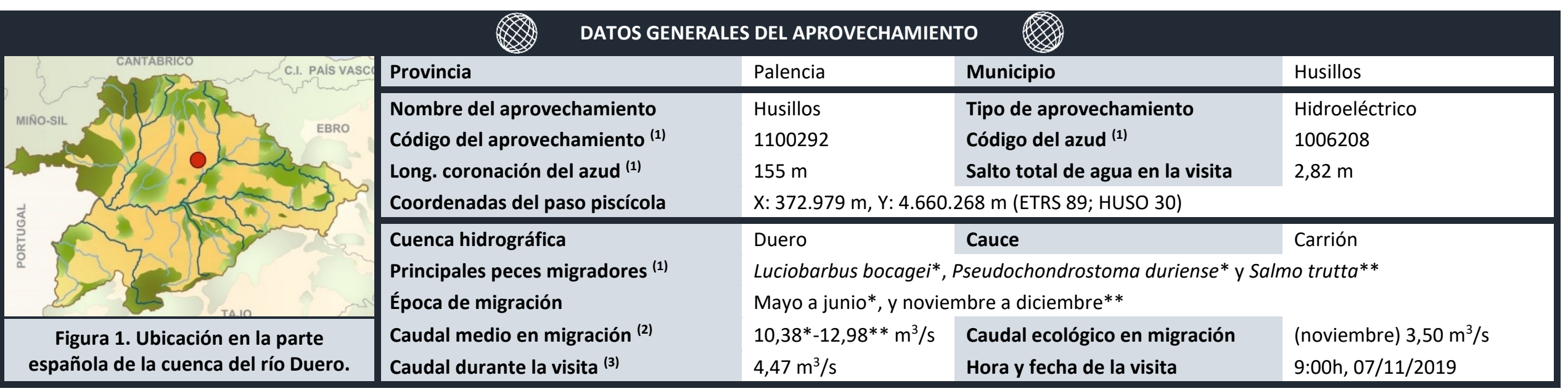

${ }^{(1)}$ Dato obtenido de MíRAME-IDE Duero. ${ }^{(2)}$ Dato obtenido del CEDEX Hidrológico. ${ }^{(3)}$ Dato obtenido del SAIH del Duero.

\begin{tabular}{|c|c|c|c|}
\hline \multicolumn{4}{|c|}{ OBSERVACIONES GENERALES DE LA ESCALA } \\
\hline $\begin{array}{l}\text { Estado de mantenimiento y limpieza durante la evaluación } \\
\text { Solera naturalizada (con piedras) } \\
\text { Vertedero de umbral móvil en la entrada de peces }\end{array}$ & $\begin{array}{l}\text { Muy deficiente } \\
\text { No } \\
\text { No }\end{array}$ & $\begin{array}{l}\text { Compuerta en la salida de peces } \\
\text { Dispositivo para evitar la entrada de arrastres } \\
\text { Salida de peces segura (alejada del azud, turbinas, ...) }\end{array}$ & $\begin{array}{l}\text { No } \\
\text { No } \\
\text { Sí }\end{array}$ \\
\hline
\end{tabular}

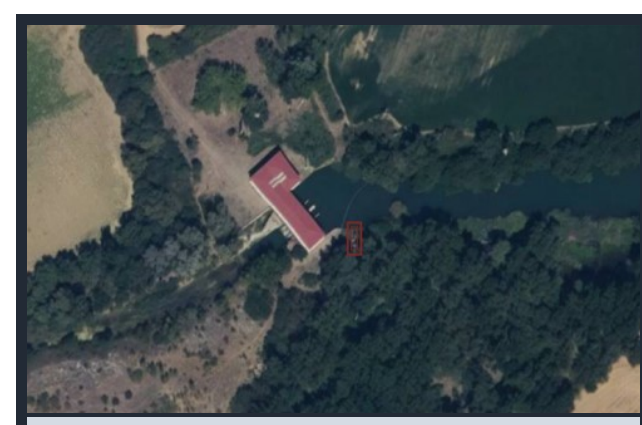

Figura 2. Ortofoto de la zona (fuente: SigPac).

\begin{tabular}{lccc}
\multicolumn{4}{c}{ RESUMEN DE LA EVALUACIÓN DEL PASO PARA PECES } \\
& \multicolumn{2}{c|}{ (CON LA METODOLOGÍA AEPS) } & \\
\hline $\begin{array}{l}\text { Etapa o categoría } \\
\text { Atracción }\end{array}$ & $\begin{array}{l}\text { Puntuación } \\
\text { Entrada }\end{array}$ & Evaluación & ¿Mejoras? \\
Pasaje & 0,0 & Muy desfavorable & Imprescindibles \\
Salida & 0,0 & Muy desfavorable & Imprescindibles \\
\hline
\end{tabular}

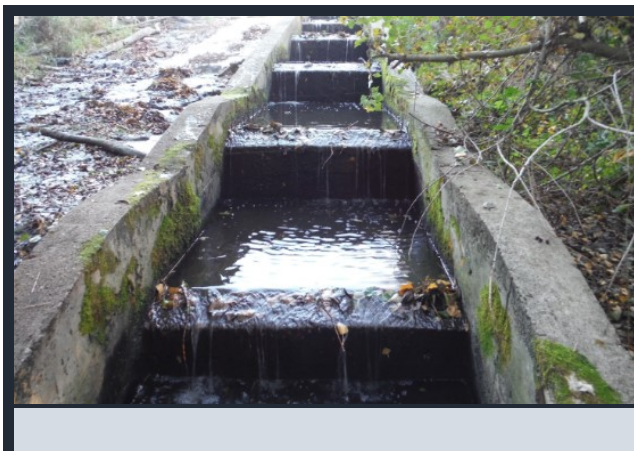

Figura 3. Imagen del paso para peces. 


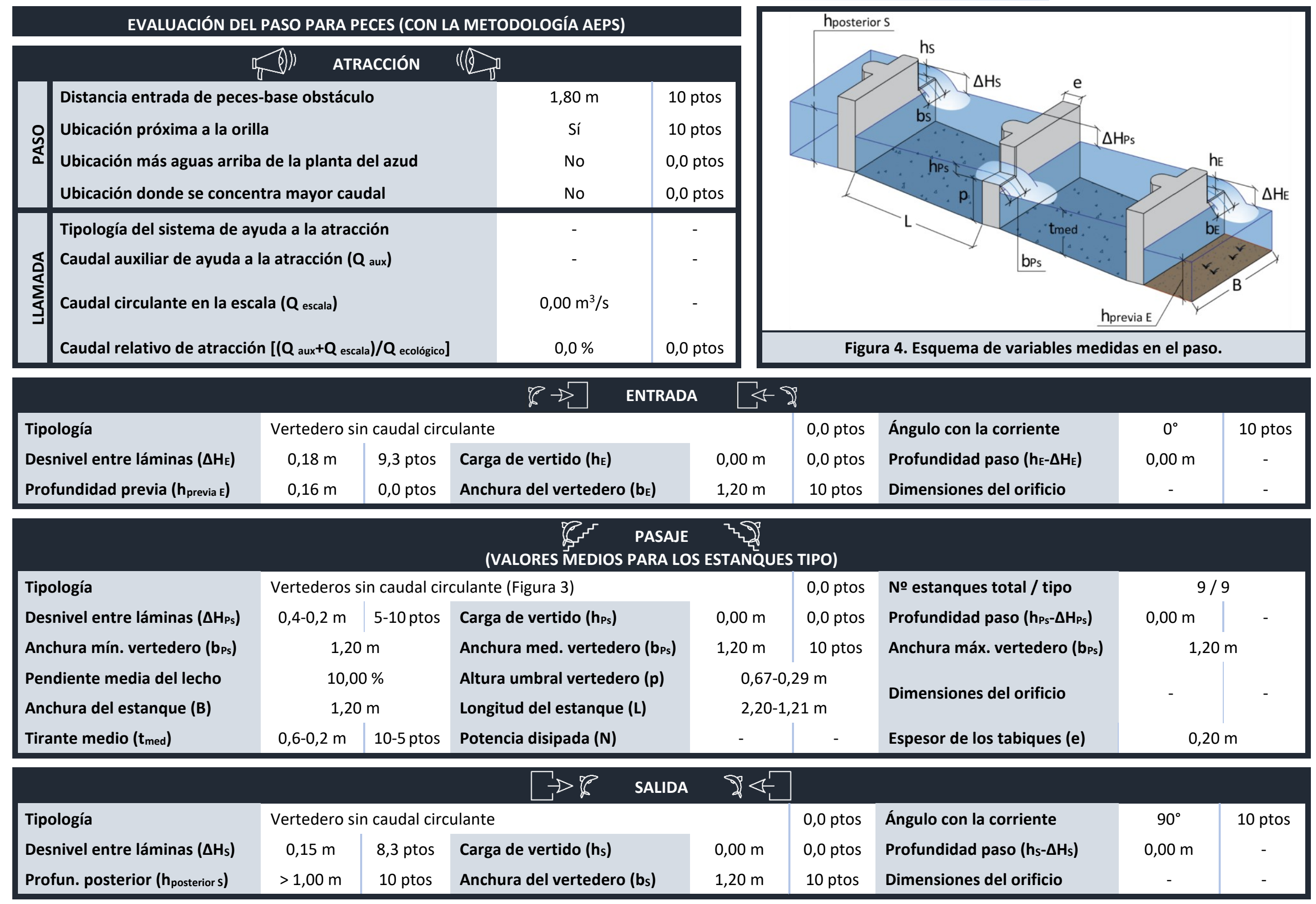




\section{PASO PARA PECES ASOCIADO AL AZUD DE LA CENTRAL HIDROELÉCTRICA DE LA LERA}

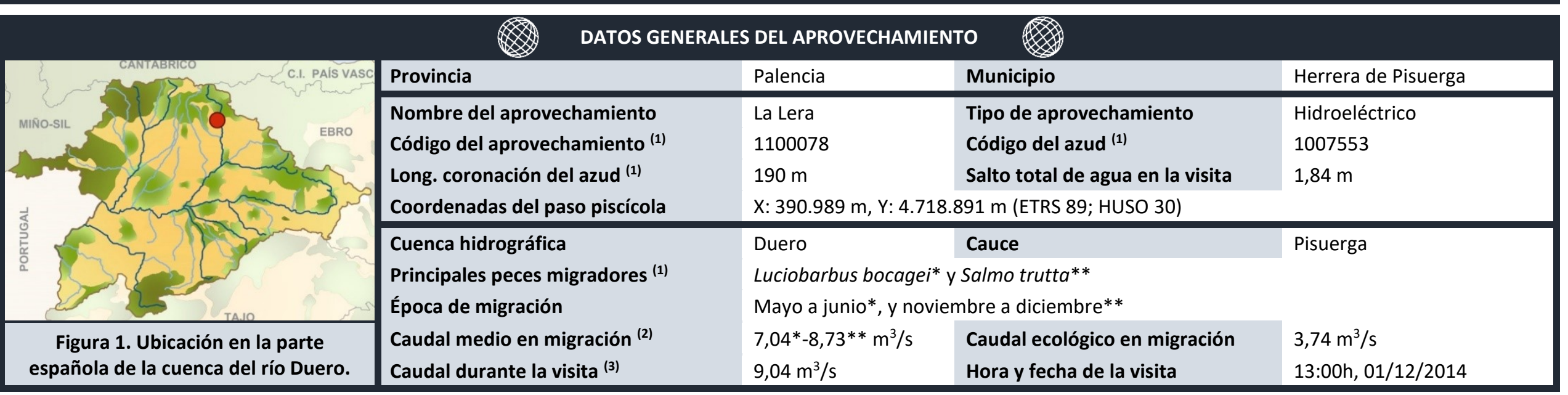

${ }^{(1)}$ Dato obtenido de MíRAME-IDE Duero. ${ }^{(2)}$ Dato obtenido del CEDEX Hidrológico. ${ }^{(3)}$ Dato obtenido del SAIH del Duero.

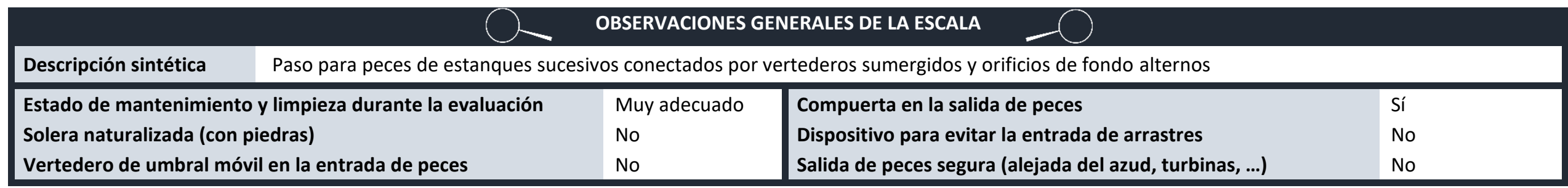

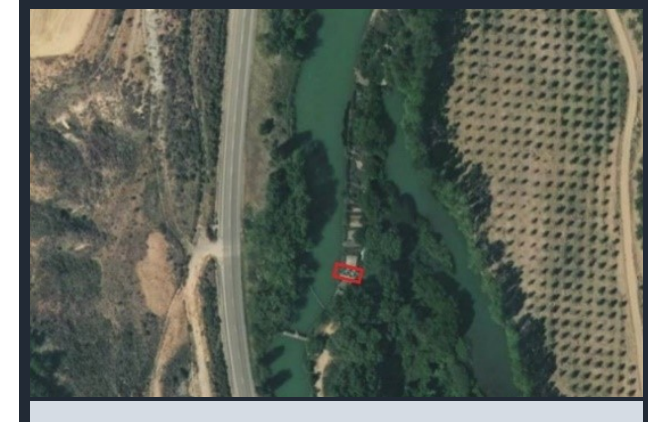

Figura 2. Ortofoto de la zona (fuente: SigPac).

\begin{tabular}{lccc}
\multicolumn{4}{c}{ RESUMEN DE LA EVALUACIÓN DEL PASO PARA PECES } \\
& \multicolumn{2}{c|}{ (CON LA METODOLOGÍA AEPS) } & \\
\hline Etapa o categoría & Puntuación & Evaluación & ¿Mejoras? \\
Atracción & 6,2 & Favorable & Recomendables \\
Entrada & 9,2 & Muy favorable & Opcionales \\
Pasaje & 9,1 & Muy favorable & Opcionales \\
Salida & 8,9 & Muy favorable & Opcionales \\
\hline
\end{tabular}

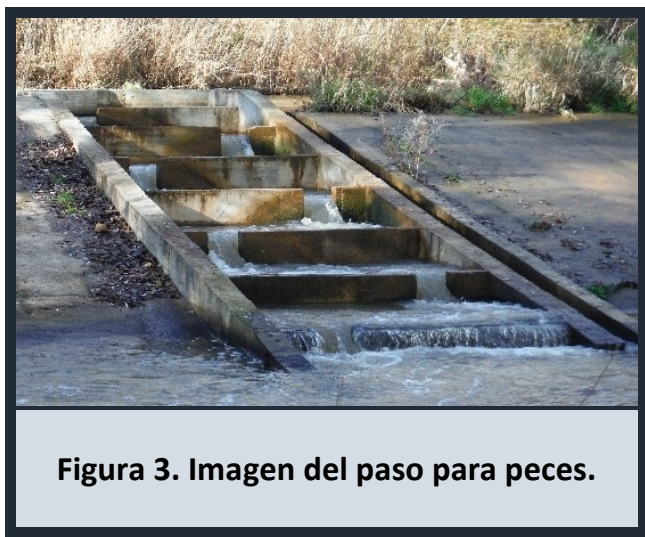




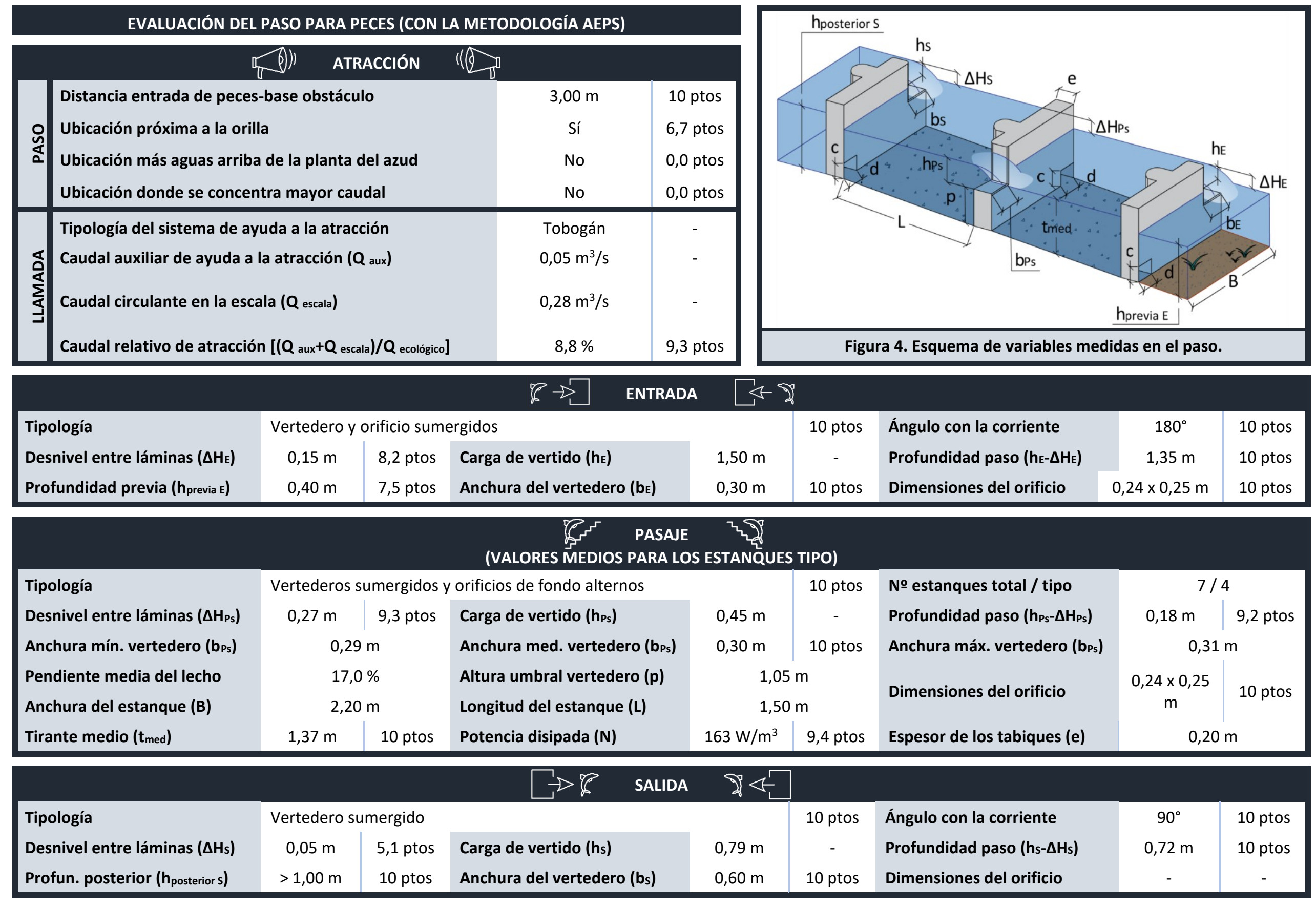




\section{PASO PARA PECES ASOCIADO AL AZUD DE LA CENTRAL HIDROELÉCTRICA DE LIGÜERZANA (ESCALA 1)}

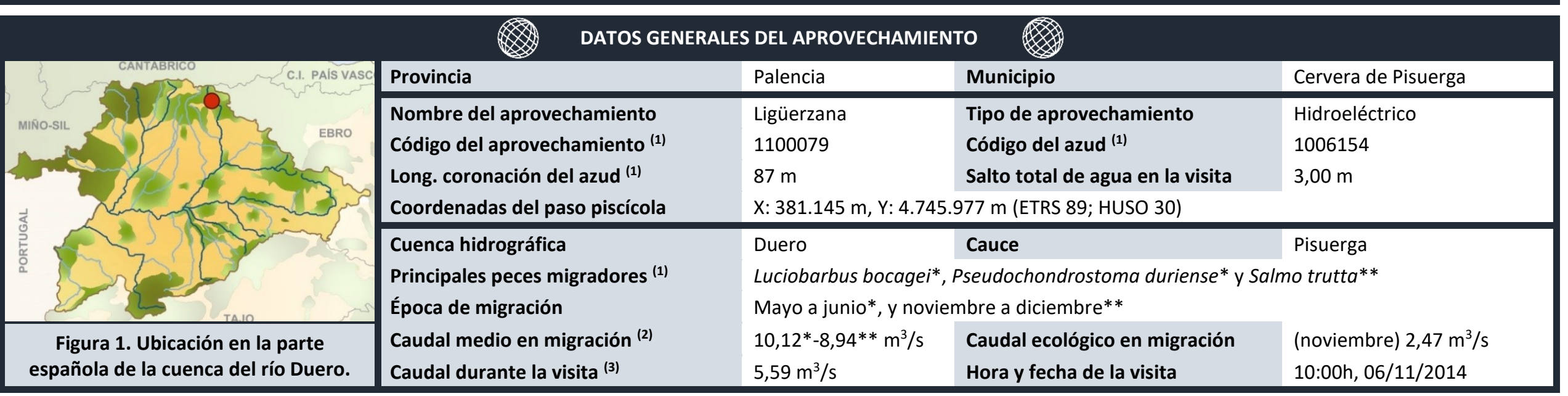

(1) Dato obtenido de MíRAME-IDE Duero. ${ }^{(2)}$ Dato obtenido del CEDEX Hidrológico. ${ }^{(3)}$ Dato obtenido del SAIH del Duero.

\begin{tabular}{|c|c|c|c|}
\hline Paso para peces de estanques st & os conectado & tederos no sumergidos alternos & \\
\hline $\begin{array}{l}\text { Estado de mantenimiento y limpieza durante la evaluación } \\
\text { Solera naturalizada (con piedras) } \\
\text { Vertedero de umbral móvil en la entrada de peces }\end{array}$ & $\begin{array}{l}\text { Adecuado } \\
\text { - } \\
\text { No }\end{array}$ & $\begin{array}{l}\text { Compuerta en la salida de peces } \\
\text { Dispositivo para evitar la entrada de arrastres } \\
\text { Salida de peces segura (alejada del azud, turbinas, ...) }\end{array}$ & $\begin{array}{l}\text { No } \\
\text { No } \\
\text { No }\end{array}$ \\
\hline
\end{tabular}

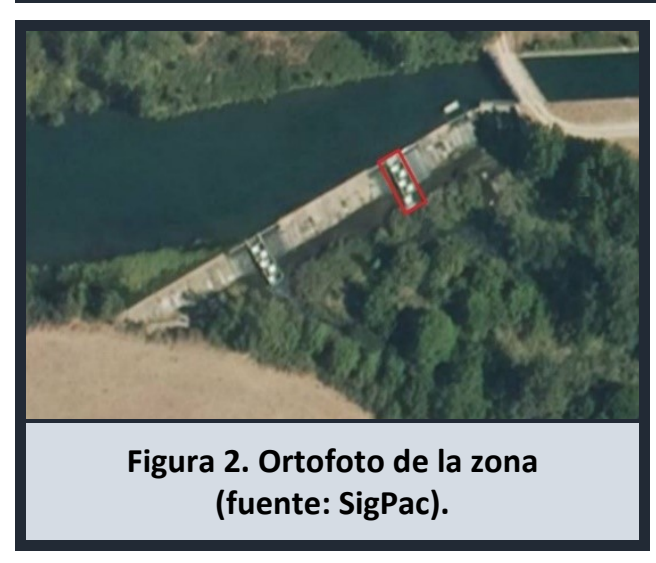

\begin{tabular}{|c|c|c|c|}
\hline \multicolumn{4}{|c|}{$\begin{array}{l}\text { RESUMEN DE LA EVALUACIÓN DEL PASO PARA PECES } \\
\text { (CON LA METODOLOGÍA AEPS) }\end{array}$} \\
\hline Etapa o categoría & Puntuación & Evaluación & ¿Mejoras? \\
\hline Atracción & 6,5 & Favorable & Recomendables \\
\hline Entrada & 0,0 & Muy desfavorable & Imprescindibles \\
\hline Pasaje & 0,0 & Muy desfavorable & Imprescindibles \\
\hline Salida & 5,6 & Desfavorable & Muy necesarias \\
\hline
\end{tabular}

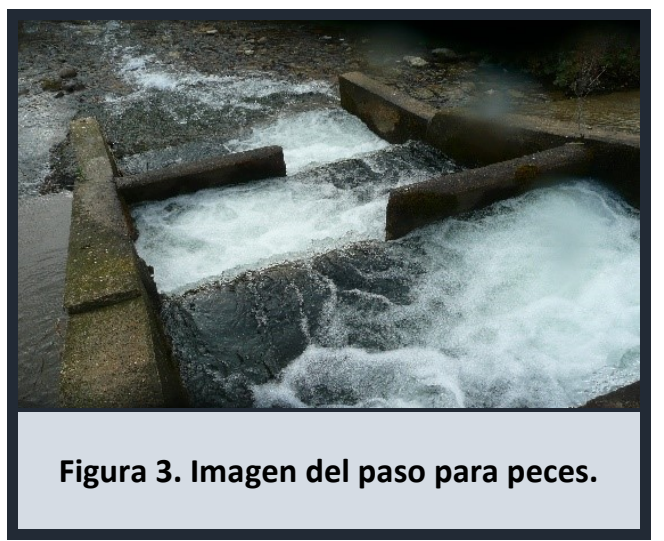




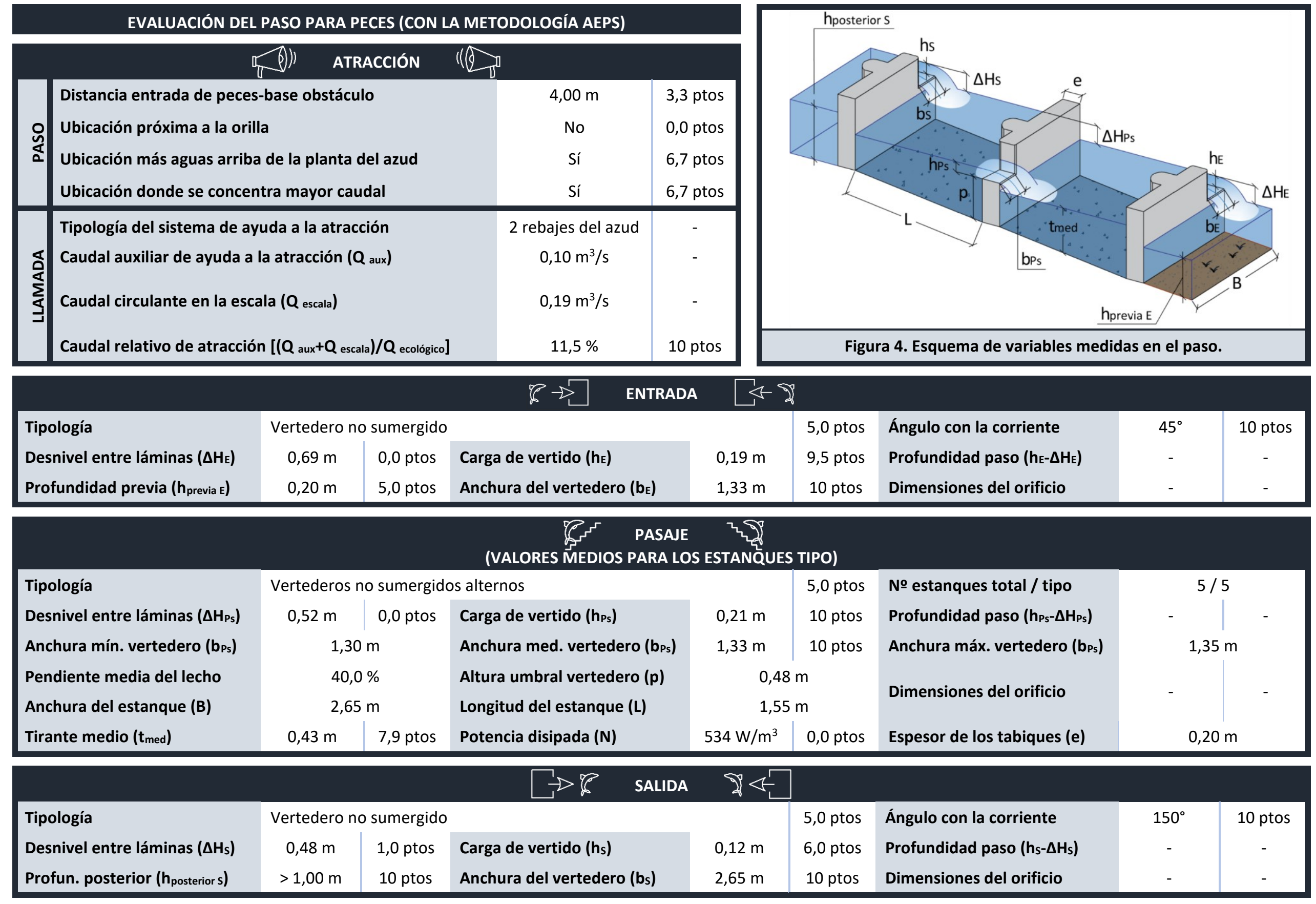




\section{PASO PARA PECES ASOCIADO AL AZUD DE LA CENTRAL HIDROELÉCTRICA DE LIGÜERZANA (ESCALA 2)}

\begin{tabular}{|c|c|c|c|c|}
\hline & Provincia & Palencia & Municipio & Cervera de Pisuerga \\
\hline & $\begin{array}{l}\text { Nombre del aprovechamiento } \\
\text { Código del aprovechamiento } \\
\text { Long. coronación del azud } \\
\text { (1) } \\
\text { Coordenadas del paso piscícola }\end{array}$ & $\begin{array}{l}\text { Ligüerzana } \\
1100079 \\
87 \mathrm{~m} \\
\mathrm{X}: 381.114 \mathrm{~m}, \mathrm{Y}: 4.7\end{array}$ & $\begin{array}{l}\text { Tipo de aprovechamiento } \\
\text { Código del azud (1) } \\
\text { Salto total de agua en la visita } \\
960 \text { m (ETRS 89; HUSO 30) }\end{array}$ & $\begin{array}{l}\text { Hidroeléctrico } \\
1006154 \\
3,00 \mathrm{~m}\end{array}$ \\
\hline & $\begin{array}{l}\text { Cuenca hidrográfica } \\
\text { Principales peces migradores }{ }^{(1)} \\
\text { Época de migración }\end{array}$ & \multicolumn{3}{|c|}{$\begin{array}{l}\text { Luciobarbus bocagei*, Pseudochondrostoma duriense* y Salmo trutta** } \\
\text { Mayo a junio*, y noviembre a diciembre** }\end{array}$} \\
\hline $\begin{array}{l}\text { Figura 1. Ubicación en la parte } \\
\text { española de la cuenca del río Duero. }\end{array}$ & $\begin{array}{l}\text { Caudal medio en migración (2) } \\
\text { Caudal durante la visita }{ }^{(3)}\end{array}$ & $\begin{array}{l}10,12 *-8,94 * * \mathrm{~m}^{3} / \mathrm{s} \\
5,59 \mathrm{~m}^{3} / \mathrm{s}\end{array}$ & $\begin{array}{l}\text { Caudal ecológico en migración } \\
\text { Hora y fecha de la visita }\end{array}$ & $\begin{array}{l}\text { (noviembre) } 2,47 \mathrm{~m}^{3} / \mathrm{s} \\
10: 00 \mathrm{~h}, 06 / 11 / 2014\end{array}$ \\
\hline
\end{tabular}

(1) Dato obtenido de MíRAME-IDE Duero. ${ }^{(2)}$ Dato obtenido del CEDEX Hidrológico. ${ }^{(3)}$ Dato obtenido del SAIH del Duero.

\begin{tabular}{|c|c|c|c|}
\hline Paso para peces de estanques & os conectados po & tederos no sumergidos alternos & \\
\hline $\begin{array}{l}\text { Estado de mantenimiento y limpieza durante la evaluación } \\
\text { Solera naturalizada (con piedras) } \\
\text { Vertedero de umbral móvil en la entrada de peces }\end{array}$ & $\begin{array}{l}\text { Muy adecuado } \\
\text { - } \\
\text { No }\end{array}$ & $\begin{array}{l}\text { Compuerta en la salida de peces } \\
\text { Dispositivo para evitar la entrada de arrastres } \\
\text { Salida de peces segura (alejada del azud, turbinas, ...) }\end{array}$ & $\begin{array}{l}\text { No } \\
\text { No } \\
\text { No }\end{array}$ \\
\hline
\end{tabular}

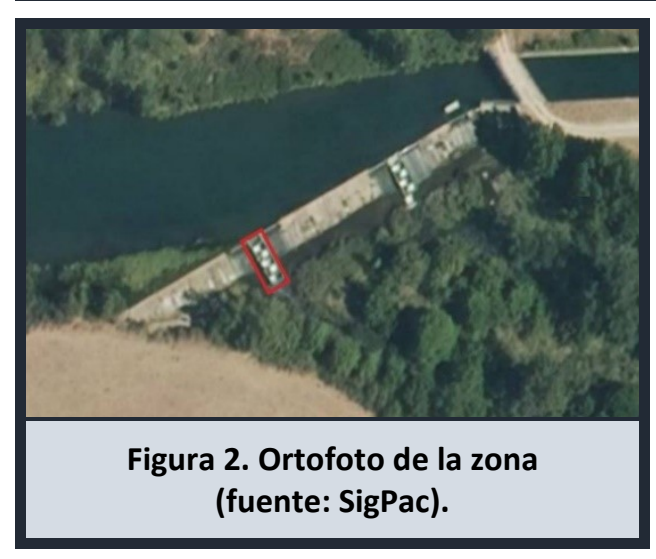

\begin{tabular}{|c|c|c|c|}
\hline \multicolumn{4}{|c|}{$\begin{array}{l}\text { RESUMEN DE LA EVALUACIÓN DEL PASO PARA PECES } \\
\text { (CON LA METODOLOGÍA AEPS) }\end{array}$} \\
\hline Etapa o categoría & Puntuación & Evaluación & ¿Mejoras? \\
\hline Atracción & 4,1 & Desfavorable & Muy necesarias \\
\hline Entrada & 0,0 & Muy desfavorable & Imprescindibles \\
\hline Pasaje & 0,0 & Muy desfavorable & Imprescindibles \\
\hline Salida & 7,7 & Favorable & Recomendables \\
\hline
\end{tabular}

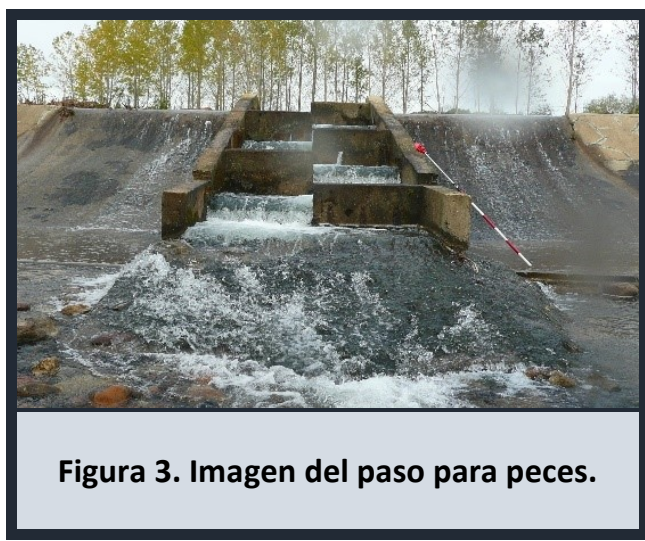




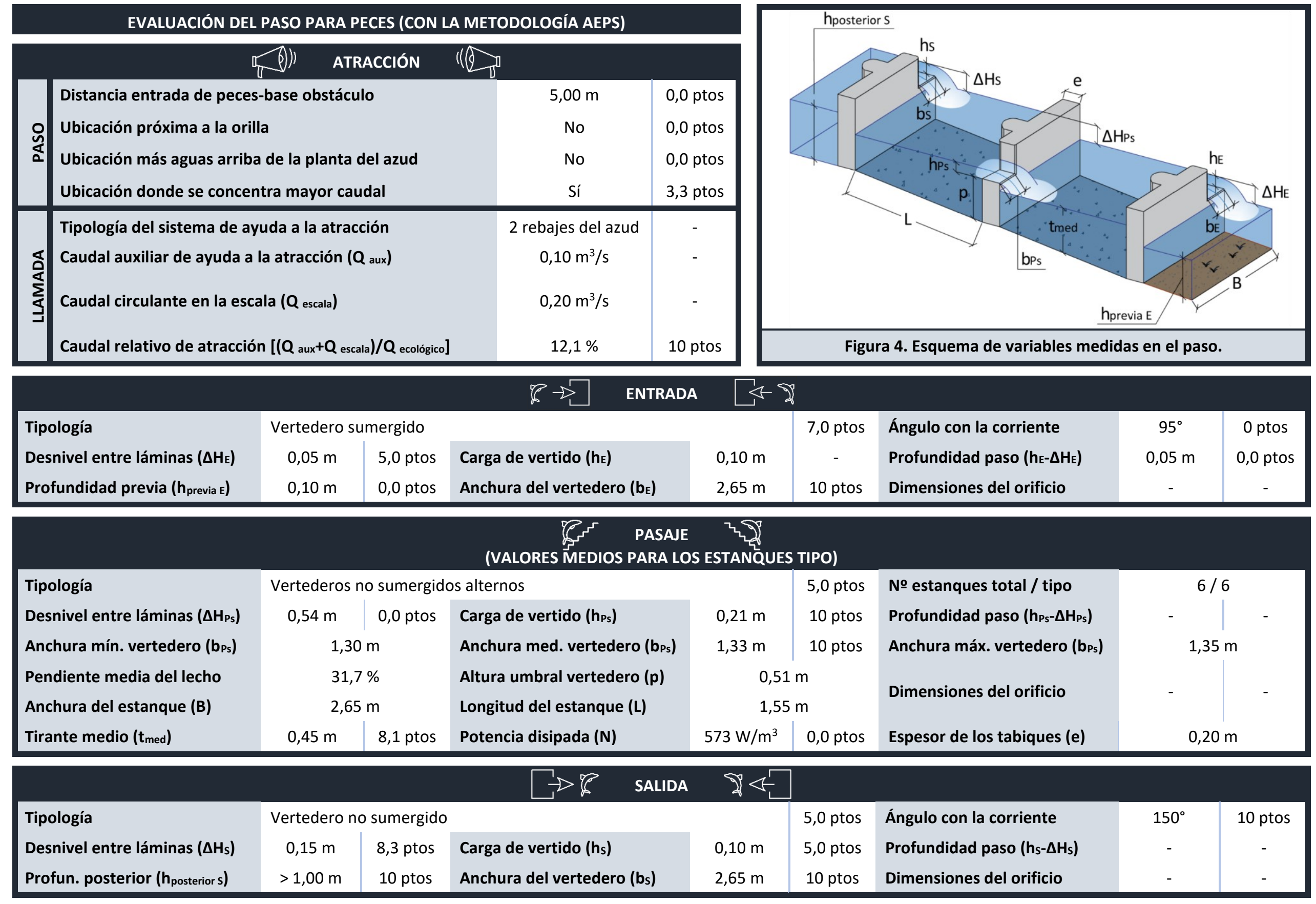




\section{PASO PARA PECES ASOCIADO AL AZUD DE LA CENTRAL HIDROELÉCTRICA DE LIGÜERZANA (REMODELACIÓN)}

\begin{tabular}{|c|c|c|c|c|}
\hline & Provincia & Palencia & Municipio & Cervera de Pisuerga \\
\hline & $\begin{array}{l}\text { Nombre del aprovechamiento } \\
\text { Código del aprovechamiento } \\
\text { Long. coronación del azud } \\
{ }^{(1)} \\
\text { Coordenadas del paso piscícola }\end{array}$ & $\begin{array}{l}\text { Ligüerzana } \\
1100079 \\
87 \mathrm{~m} \\
\mathrm{X}: 381.145 \mathrm{~m}, \mathrm{Y}: 4.7\end{array}$ & $\begin{array}{l}\text { Tipo de aprovechamiento } \\
\text { Código del azud (1) } \\
\text { Salto total de agua en la visita } \\
977 \text { m (ETRS 89; HUSO 30) }\end{array}$ & $\begin{array}{l}\text { Hidroeléctrico } \\
1006154 \\
3,00 \mathrm{~m}\end{array}$ \\
\hline & $\begin{array}{l}\text { Cuenca hidrográfica } \\
\text { Principales peces migradores }{ }^{(1)} \\
\text { Época de migración }\end{array}$ & \multirow{2}{*}{\multicolumn{3}{|c|}{ 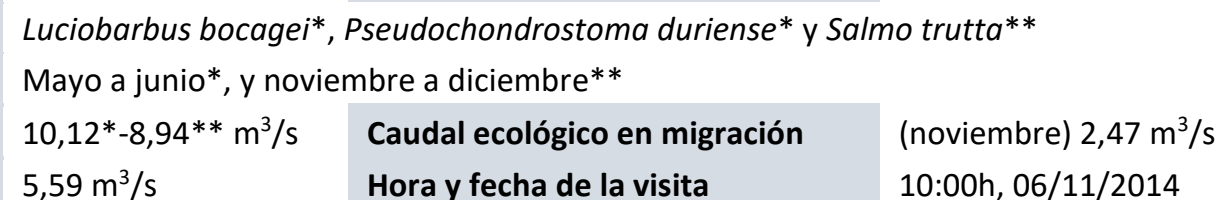 }} \\
\hline $\begin{array}{c}\text { Figura 1. Ubicación en la parte } \\
\text { española de la cuenca del río Duero. }\end{array}$ & $\begin{array}{l}\text { Caudal medio en migración (2) } \\
\text { Caudal durante la visita }{ }^{(3)}\end{array}$ & & & \\
\hline
\end{tabular}

(1) Dato obtenido de MíRAME-IDE Duero. ${ }^{(2)}$ Dato obtenido del CEDEX Hidrológico. ${ }^{(3)}$ Dato obtenido del SAIH del Duero.

\begin{tabular}{|c|c|c|c|}
\hline Paso para peces de estanques su & os conectados po & tederos sumergidos y orificios de fondo alternos & \\
\hline $\begin{array}{l}\text { Estado de mantenimiento y limpieza durante la evaluación } \\
\text { Solera naturalizada (con piedras) } \\
\text { Vertedero de umbral móvil en la entrada de peces }\end{array}$ & $\begin{array}{l}\text { Muy adecuado } \\
\text { Sí } \\
\text { Sí }\end{array}$ & $\begin{array}{l}\text { Compuerta en la salida de peces } \\
\text { Dispositivo para evitar la entrada de arrastres } \\
\text { Salida de peces segura (alejada del azud, turbinas, ...) }\end{array}$ & $\begin{array}{l}\text { Sí } \\
\text { Sí } \\
\text { Sí }\end{array}$ \\
\hline
\end{tabular}

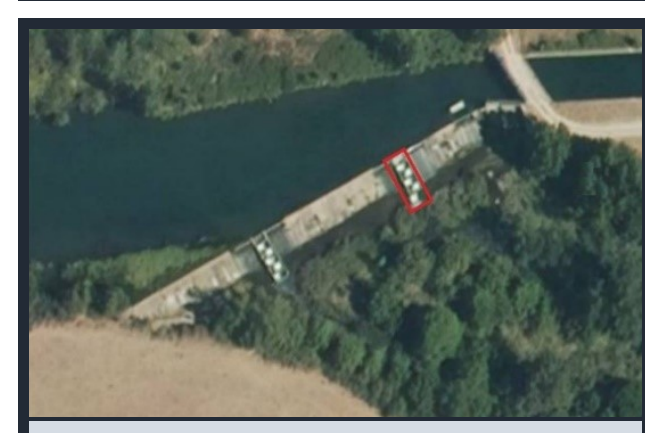

Figura 2. Ortofoto de la zona (fuente: SigPac).

\begin{tabular}{lccc}
\multicolumn{4}{c}{ RESUMEN DE LA EVALUACIÓN DEL PASO PARA PECES } \\
& \multicolumn{4}{c|}{ (CON LA METODOLOGÍA AEPS) } & \\
\hline Etapa o categoría & Puntuación & Evaluación & ¿Mejoras? \\
Atracción & 7,6 & Favorable & Recomendables \\
Entrada & 9,7 & Muy favorable & Opcionales \\
Pasaje & 10,0 & Muy favorable & Opcionales \\
Salida & 8,9 & Muy favorable & Opcionales \\
\hline
\end{tabular}

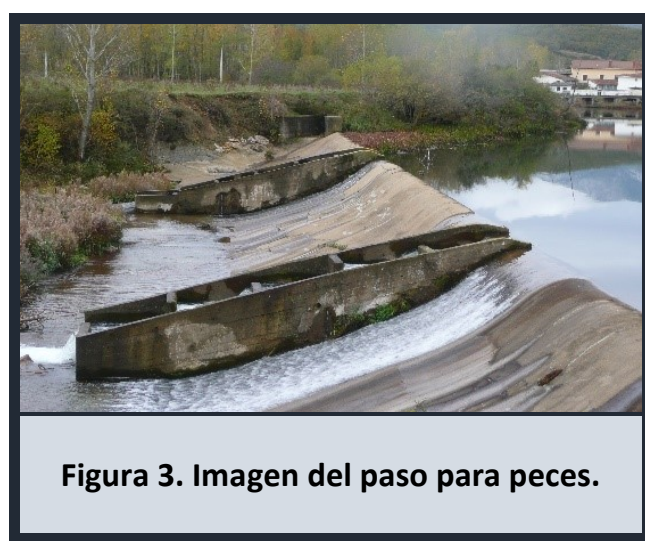




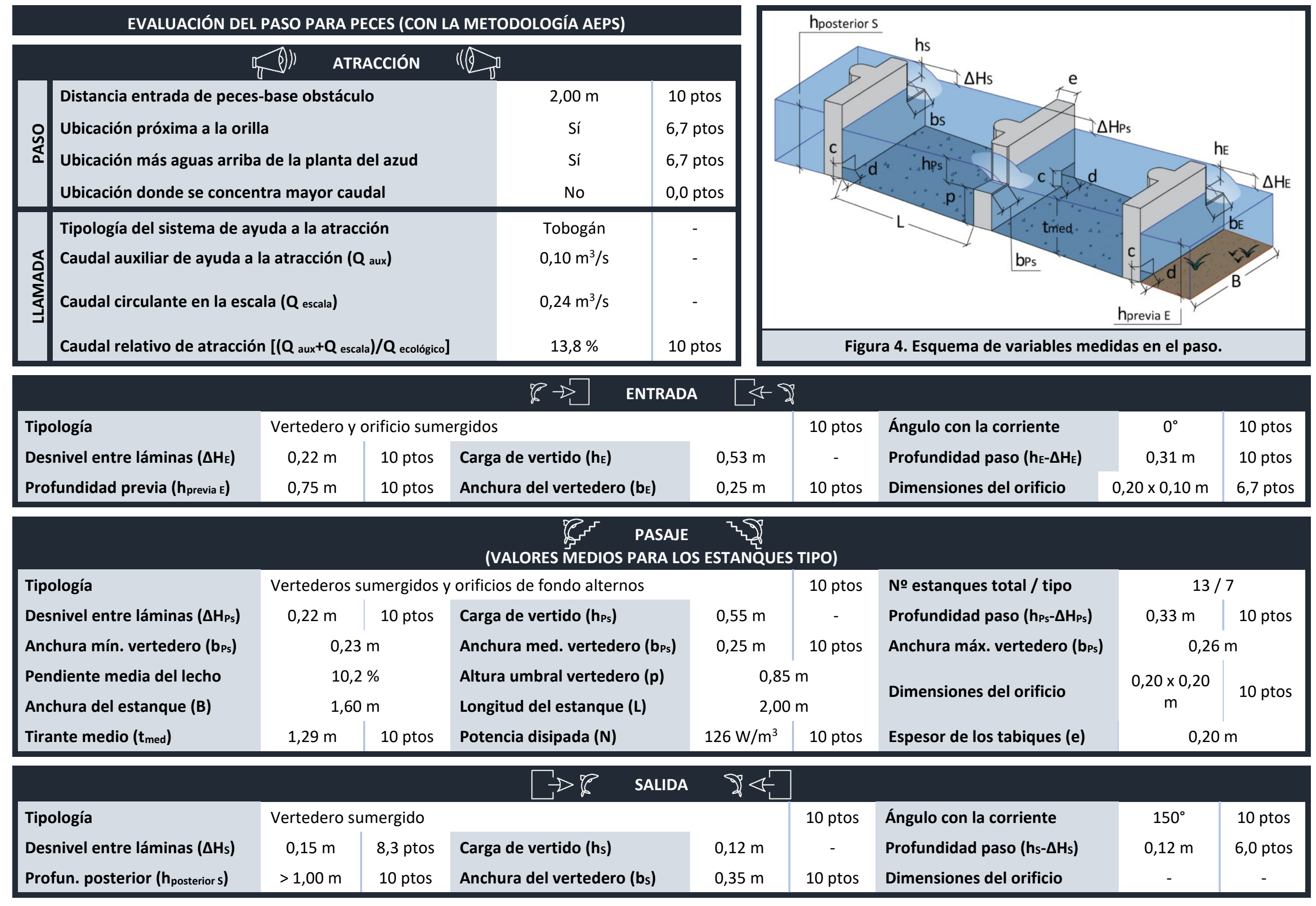




\section{PASO PARA PECES ASOCIADO AL AZUD DE LA CENTRAL HIDROELÉCTRICA DE MOLINO DE AUSíN}

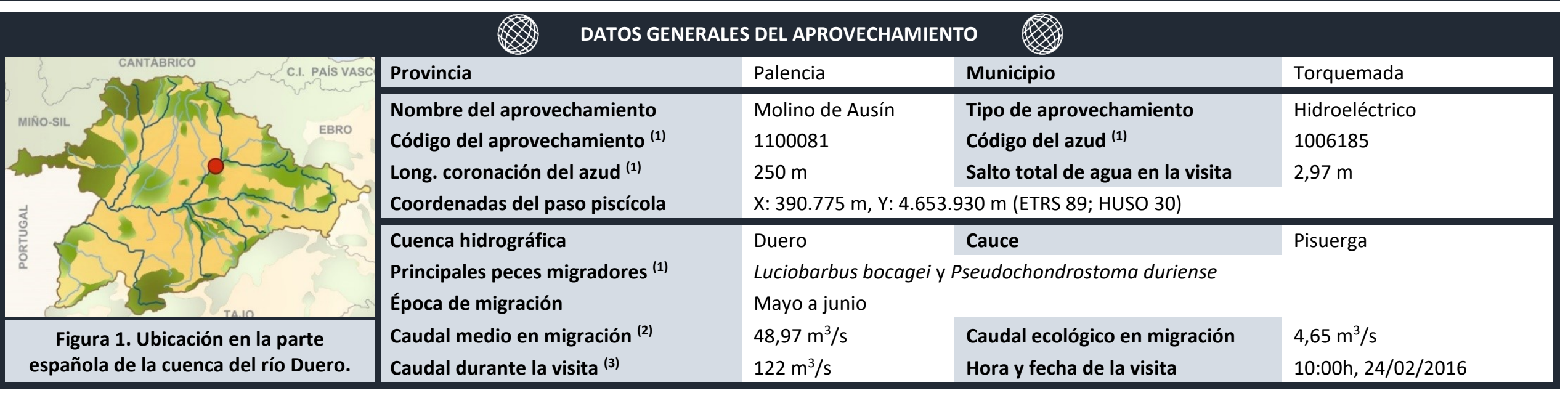

(1) Dato obtenido de MíRAME-IDE Duero. ${ }^{(2)}$ Dato obtenido del CEDEX Hidrológico. ${ }^{(3)}$ Dato obtenido del SAIH del Duero.

\begin{tabular}{|c|c|c|c|}
\hline \multicolumn{4}{|c|}{ OBSERVACIONES GENERALES DE LA ESCALA } \\
\hline $\begin{array}{l}\text { Estado de mantenimiento y limpieza durante la evaluación } \\
\text { Solera naturalizada (con piedras) } \\
\text { Vertedero de umbral móvil en la entrada de peces }\end{array}$ & $\begin{array}{l}\text { Adecuado } \\
\text { Sí } \\
\text { No }\end{array}$ & $\begin{array}{l}\text { Compuerta en la salida de peces } \\
\text { Dispositivo para evitar la entrada de arrastres } \\
\text { Salida de peces segura (alejada del azud, turbinas, ...) }\end{array}$ & $\begin{array}{l}\text { Sí } \\
\text { No } \\
\text { Sí }\end{array}$ \\
\hline
\end{tabular}

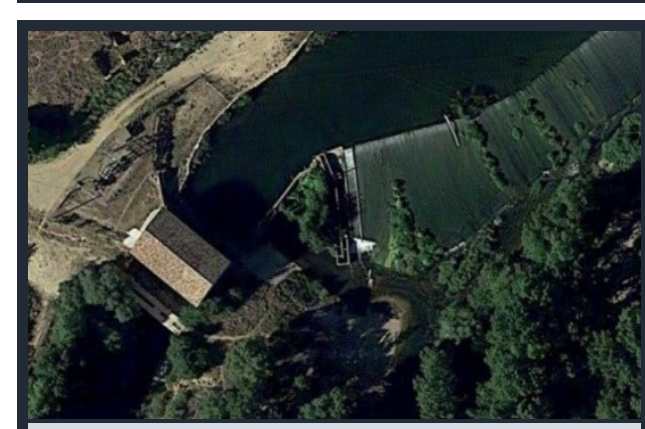

Figura 2. Ortofoto de la zona (fuente: Google Maps).

\begin{tabular}{lccl}
\multicolumn{5}{c}{$\begin{array}{c}\text { RESUMEN DE LA EVALUACIÓN DEL PASO PARA PECES } \\
\text { (CON LA METODOLOGÍA AEPS) }\end{array}$} \\
\hline $\begin{array}{l}\text { Etapa o categoría } \\
\text { Atracción }\end{array}$ & $\begin{array}{c}\text { Puntuación } \\
\text { Entrada }\end{array}$ & Evaluación & ¿Mejoras? \\
Pasaje & 8,7 & Muy favorable & Opcionales \\
Salida & 8,4 & Muy favorable & Opcionales \\
& 9,5 & Muy favorable & Opcionales \\
\hline
\end{tabular}

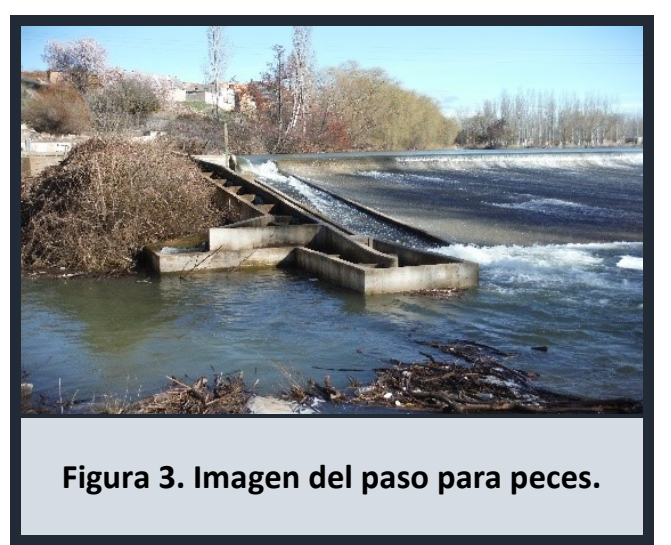




\section{EVALUACIÓN DEL PASO PARA PECES (CON LA METODOLOGíA AEPS)}

\begin{tabular}{|c|c|c|c|}
\hline \multirow[b]{2}{*}{ 음 } & ATRACCIÓN & & \\
\hline & $\begin{array}{l}\text { Distancia entrada de peces-base obstáculo } \\
\text { Ubicación próxima a la orilla } \\
\text { Ubicación más aguas arriba de la planta del azud } \\
\text { Ubicación donde se concentra mayor caudal }\end{array}$ & $\begin{array}{l}0,50 \mathrm{~m} \\
\text { Sí } \\
\text { No } \\
\text { Sí }\end{array}$ & $\begin{array}{l}10 \text { ptos } \\
10 \text { ptos } \\
0,0 \text { ptos } \\
10 \text { ptos }\end{array}$ \\
\hline 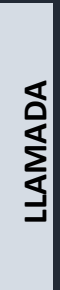 & $\begin{array}{l}\text { Tipología del sistema de ayuda a la atracción } \\
\left.\text { Caudal auxiliar de ayuda a la atracción ( } Q_{\text {aux }}\right) \\
\left.\text { Caudal circulante en la escala ( } Q_{\text {escala }}\right) \\
\text { Caudal relativo de atracción }\left[\left(Q_{\text {aux }}+Q_{\text {escala }}\right) / Q_{\text {ecológico }}\right.\end{array}$ & $\begin{array}{l}\text { Tobogán } \\
0,65 \mathrm{~m}^{3} / \mathrm{s} \\
0,14 \mathrm{~m}^{3} / \mathrm{s} \\
17,0 \%\end{array}$ & $\begin{array}{c}- \\
- \\
- \\
10 \text { ptos }\end{array}$ \\
\hline
\end{tabular}

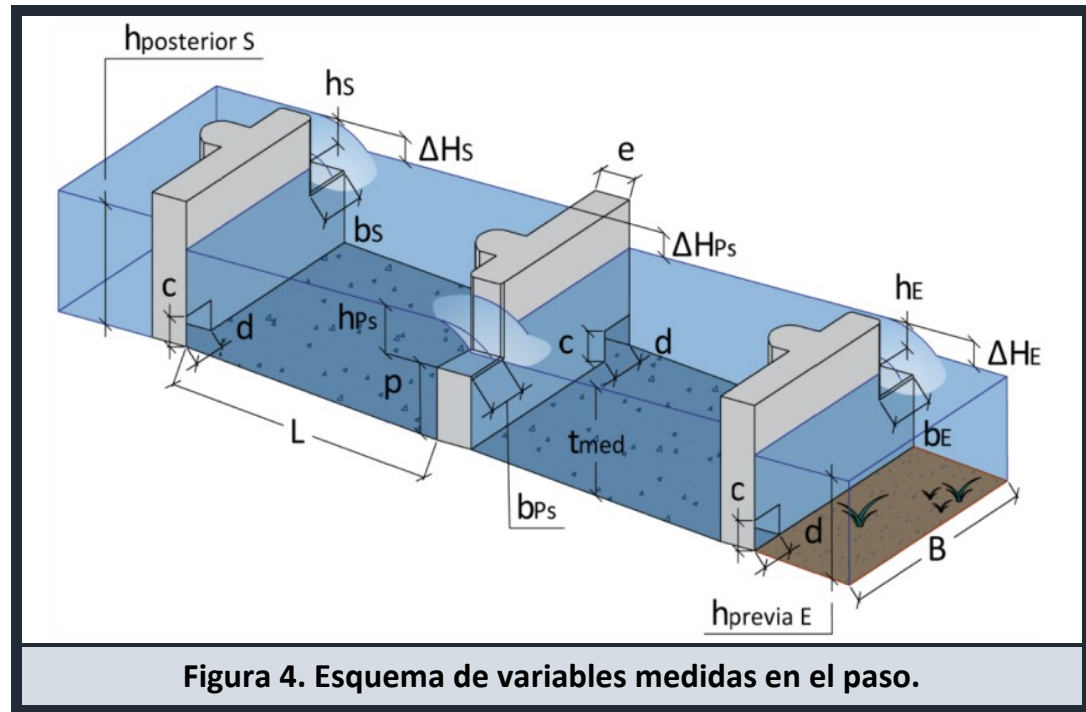

\begin{tabular}{|c|c|c|c|c|c|c|c|c|}
\hline & & & $b \rightarrow$ & & & & & \\
\hline Tipología & Vertederc & nergido & & & 7,0 ptos & Ángulo con la corriente & $70^{\circ}$ & 10 ptos \\
\hline Desnivel entre láminas $\left(\Delta \mathrm{H}_{\mathrm{E}}\right)$ & $0,05 \mathrm{~m}$ & 5,0 ptos & Carga de vertido $\left(h_{E}\right)$ & $1,08 \mathrm{~m}$ & - & Profundidad paso $\left(h_{E}-\Delta H_{E}\right)$ & $1,03 \mathrm{~m}$ & 10 ptos \\
\hline Profundidad previa ( $h_{\text {previa }}$ ) & $1,25 \mathrm{~m}$ & 10 ptos & Anchura del vertedero $\left(b_{E}\right)$ & $0,20 \mathrm{~m}$ & 10 ptos & Dimensiones del orificio & - & - \\
\hline
\end{tabular}

\begin{tabular}{|c|c|c|c|c|c|c|c|c|}
\hline Tipología & \multicolumn{3}{|c|}{ Vertederos sumergidos y orificios de fondo alternos } & & 10 ptos & № estanques total / tipo & \multicolumn{2}{|c|}{$16 / 15$} \\
\hline Desnivel entre láminas ( $\left.\Delta \mathrm{H}_{\mathrm{Ps}}\right)$ & $0,24 \mathrm{~m}$ & 10 ptos & Carga de vertido (hPs) & $0,49 \mathrm{~m}$ & - & Profundidad paso (hps $\left.-\Delta \mathrm{H}_{\mathrm{Ps}}\right)$ & $0,24 \mathrm{~m}$ & 10 ptos \\
\hline Anchura mín. vertedero (bPs) & \multicolumn{2}{|c|}{$0,18 \mathrm{~m}$} & Anchura med. vertedero ( $\left.b_{P s}\right)$ & $0,20 \mathrm{~m}$ & - & Anchura máx. vertedero ( $\left.b_{P s}\right)$ & \multicolumn{2}{|c|}{$0,22 \mathrm{~m}$} \\
\hline Pendiente media del lecho & \multicolumn{2}{|c|}{$10,0 \%$} & Altura umbral vertedero ( $p)$ & \multicolumn{2}{|c|}{$0,67 \mathrm{~m}$} & Dimonsiones dol arificio & $0,10 \times 0,10$ & $75 n+o c$ \\
\hline Anchura del estanque (B) & \multicolumn{2}{|c|}{$1,05 \mathrm{~m}$} & Longitud del estanque (L) & \multicolumn{2}{|c|}{$1,90 \mathrm{~m}$} & (2). & $\mathrm{m}$ & (1) \\
\hline Tirante medio $\left(t_{\text {med }}\right)$ & $1,04 \mathrm{~m}$ & 10 ptos & Potencia disipada (N) & $159 \mathrm{~W} / \mathrm{m}^{3}$ & 9,6 ptos & Espesor de los tabiques (e) & \multicolumn{2}{|c|}{$0,20 \mathrm{~m}$} \\
\hline
\end{tabular}

\begin{tabular}{|c|c|c|c|c|c|c|c|c|}
\hline Tipología & Orificio su & gido & & & 5,0 ptos & Ángulo con la corriente & $160^{\circ}$ & 10 ptos \\
\hline Desnivel entre láminas $\left(\Delta \mathrm{H}_{s}\right)$ & $0,26 \mathrm{~m}$ & 10 ptos & Carga de vertido (hs) & $0,40 \mathrm{~m}$ & - & Profundidad paso (hs- $\left.\Delta \mathrm{H}_{\mathrm{s}}\right)$ & $0,40 \mathrm{~m}$ & 10 ptos \\
\hline Profun. posterior ( $h_{\text {posterior } s)}$ & $>1,50 \mathrm{~m}$ & 10 ptos & Anchura del vertedero ( $\left.b_{s}\right)$ & - & - & Dimensiones del orificio & $0,30 \times 0,40 \mathrm{~m}$ & 10 ptos \\
\hline
\end{tabular}


Desarrollo y aplicación de una nueva metodología para la evaluación de pasos para peces de estanques sucesivos

PASO PARA PECES ASOCIADO AL AZUD DE LA CENTRAL HIDROELÉCTRICA DE MOLINO DE LAS HUERTAS

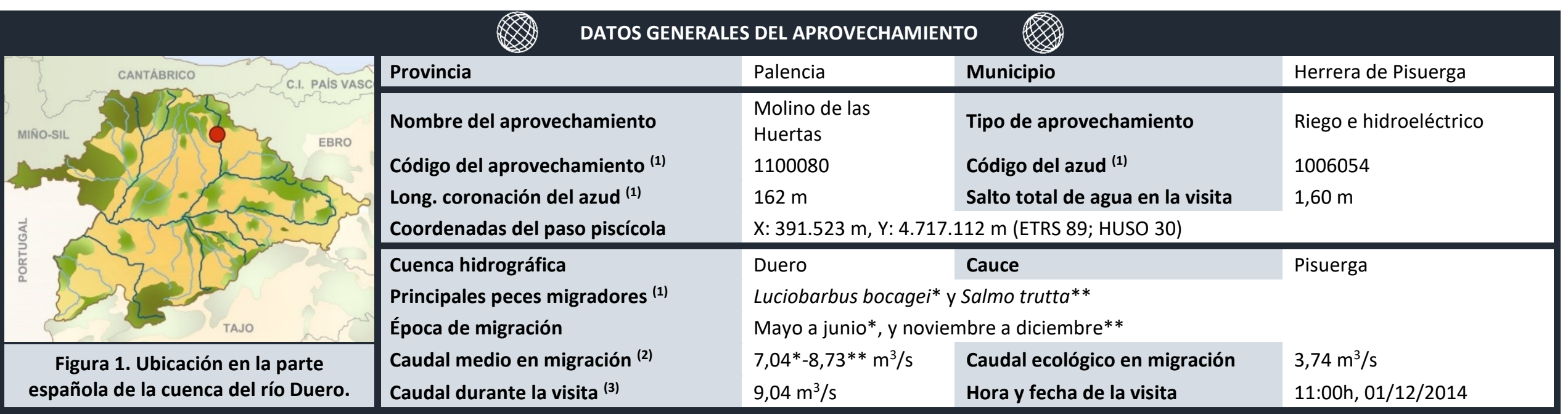

(1) Dato obtenido de MÍRAME-IDE Duero. ${ }^{(2)}$ Dato obtenido del CEDEX Hidrológico. ${ }^{(3)}$ Dato obtenido del SAIH del Duero.

\begin{tabular}{|c|c|c|c|}
\hline Paso para peces de estanques su & os conectados po & tederos sumergidos y orificios de fondo alternos & \\
\hline $\begin{array}{l}\text { Estado de mantenimiento y limpieza durante la evaluación } \\
\text { Solera naturalizada (con piedras) } \\
\text { Vertedero de umbral móvil en la entrada de peces }\end{array}$ & $\begin{array}{l}\text { Muy adecuado } \\
\text { Sí } \\
\text { No }\end{array}$ & $\begin{array}{l}\text { Compuerta en la salida de peces } \\
\text { Dispositivo para evitar la entrada de arrastres } \\
\text { Salida de peces segura (alejada del azud, turbinas, ...) }\end{array}$ & $\begin{array}{l}\text { Sí } \\
\text { No } \\
\text { No }\end{array}$ \\
\hline
\end{tabular}

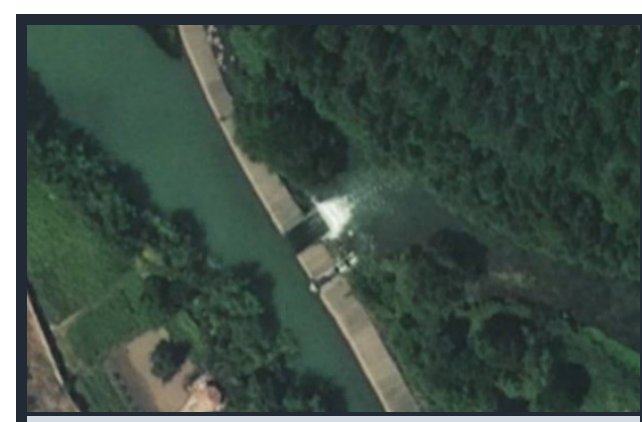

Figura 2. Ortofoto de la zona (fuente: SigPac).

\begin{tabular}{lccc}
\multicolumn{4}{c}{ RESUMEN DE LA EVALUACIÓN DEL PASO PARA PECES } \\
& \multicolumn{2}{c}{ (CON LA METODOLOGÍA AEPS) } & \\
\hline Etapa o categoría & Puntuación & Evaluación & ¿Mejoras? \\
Atracción & 4,1 & Desfavorable & Muy necesarias \\
Entrada & 0,0 & Muy desfavorable & Imprescindibles \\
Pasaje & 0,0 & Muy desfavorable & Imprescindibles \\
Salida & 10,0 & Muy favorable & Opcionales \\
\hline
\end{tabular}

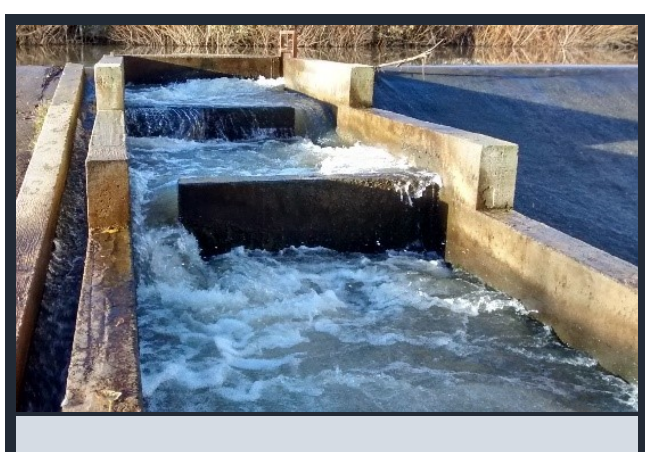

Figura 3. Imagen del paso para peces. 


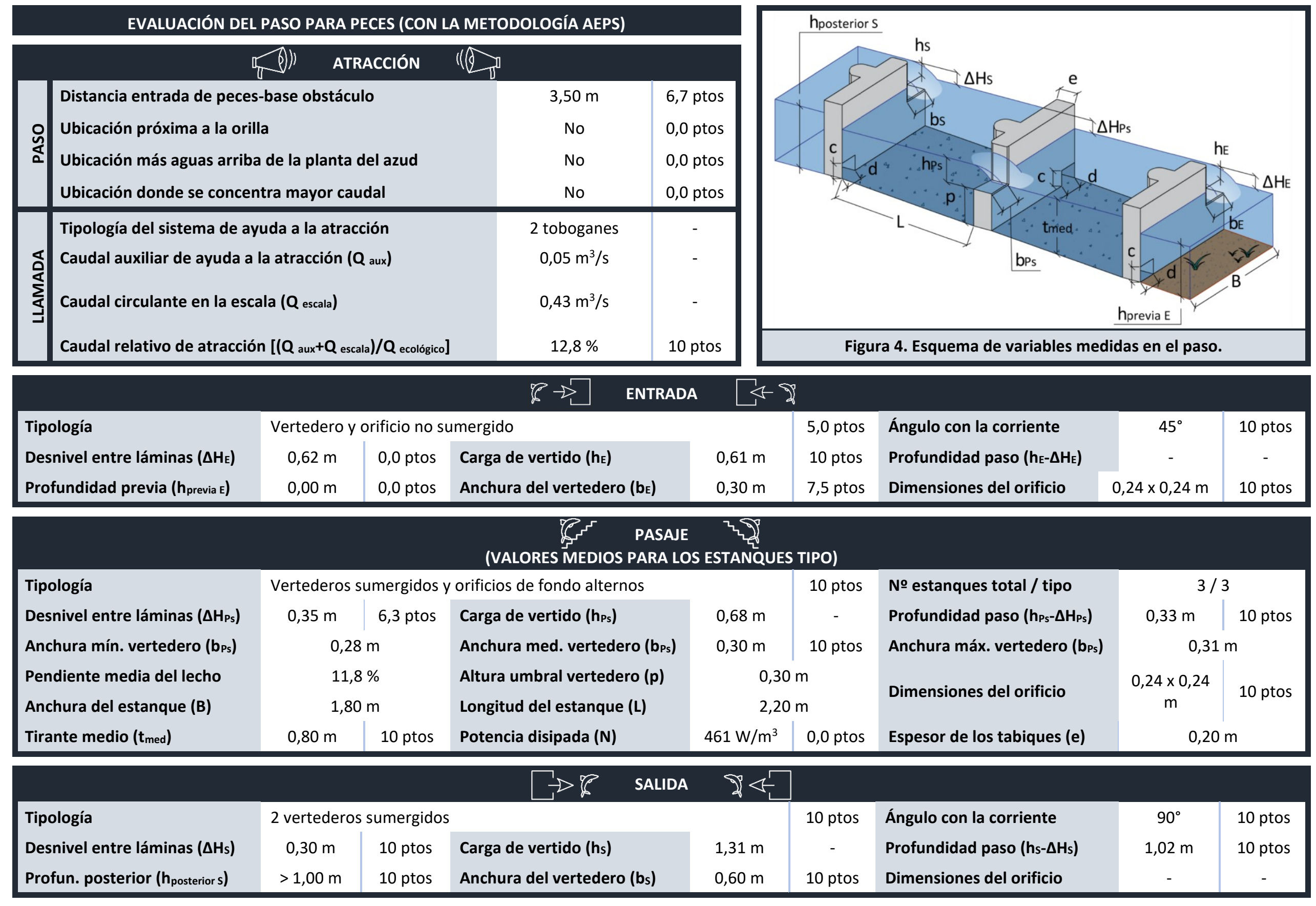




\section{PASO PARA PECES ASOCIADO AL AZUD DE LA CENTRAL HIDROELÉCTRICA DE MOLINO DE PISUERGA}

\begin{tabular}{|c|c|c|c|c|}
\hline & Provincia & Palencia & Municipio & Astudillo \\
\hline & $\begin{array}{l}\text { Nombre del aprovechamiento } \\
\text { Código del aprovechamiento } \\
\text { Long. coronación del azud } \\
\text { (1) } \\
\text { Coordenadas del paso piscícola }\end{array}$ & $\begin{array}{l}\text { Molino de Pisuerga } \\
1100160 \\
261 \mathrm{~m} \\
X: 397.430 \mathrm{~m}, \mathrm{Y}: 4.67\end{array}$ & $\begin{array}{l}\text { Tipo de aprovechamiento } \\
\text { Código del azud (1) } \\
\text { Salto total de agua en la visita } \\
53 \text { m (ETRS 89; HUSO 30) }\end{array}$ & $\begin{array}{l}\text { Hidroeléctrico } \\
1006042 \\
2,13 \mathrm{~m}\end{array}$ \\
\hline & $\begin{array}{l}\text { Cuenca hidrográfica } \\
\text { Principales peces migradores }{ }^{(1)} \\
\text { Época de migración }\end{array}$ & \multicolumn{3}{|c|}{$\begin{array}{l}\text { Luciobarbus bocagei* }{ }^{*} \text { Pseudochondrostoma duriense* y Salmo trutta** } \\
\text { Mayo a junio*, y noviembre a diciembre** }\end{array}$} \\
\hline $\begin{array}{l}\text { Figura 1. Ubicación en la parte } \\
\text { española de la cuenca del río Duero. }\end{array}$ & $\begin{array}{l}\text { Caudal medio en migración (2) } \\
\text { Caudal durante la visita }{ }^{(3)}\end{array}$ & $\begin{array}{l}12,71 *-18,72 * * \mathrm{~m}^{3} / \mathrm{s} \\
8,10 \mathrm{~m}^{3} / \mathrm{s}\end{array}$ & $\begin{array}{l}\text { Caudal ecológico en migración } \\
\text { Hora y fecha de la visita }\end{array}$ & $\begin{array}{l}\text { (noviembre) 6,39 } \mathrm{m}^{3} / \mathrm{s} \\
\text { 13:00h, 07/11/2019 }\end{array}$ \\
\hline
\end{tabular}

(1) Dato obtenido de MíRAME-IDE Duero. ${ }^{(2)}$ Dato obtenido del CEDEX Hidrológico. ${ }^{(3)}$ Dato obtenido del SAIH del Duero.

\begin{tabular}{|c|c|c|c|}
\hline \multicolumn{4}{|c|}{ OBSERVACIONES GENERALES DE LA ESCALA } \\
\hline $\begin{array}{l}\text { Estado de mantenimiento y limpieza durante la evaluación } \\
\text { Solera naturalizada (con piedras) } \\
\text { Vertedero de umbral móvil en la entrada de peces }\end{array}$ & $\begin{array}{l}\text { Muy adecuado } \\
\text { No } \\
\text { No }\end{array}$ & $\begin{array}{l}\text { Compuerta en la salida de peces } \\
\text { Dispositivo para evitar la entrada de arrastres } \\
\text { Salida de peces segura (alejada del azud, turbinas, ...) }\end{array}$ & $\begin{array}{l}\text { No } \\
\text { No } \\
\text { No }\end{array}$ \\
\hline
\end{tabular}

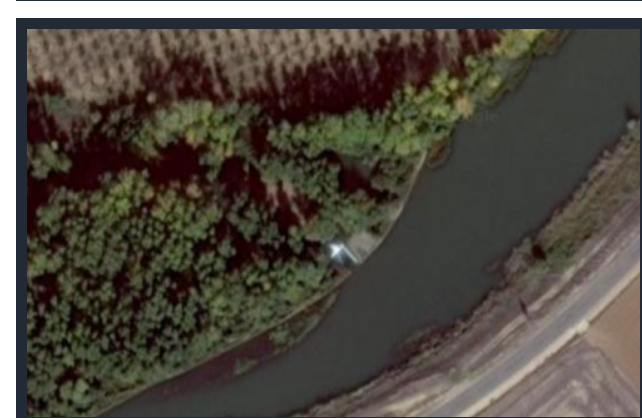

Figura 2. Ortofoto de la zona (fuente: Google Maps).

\begin{tabular}{lccc}
\multicolumn{4}{c}{ RESUMEN DE LA EVALUACIÓN DEL PASO PARA PECES } \\
& \multicolumn{2}{c|}{ (CON LA METODOLOGÍA AEPS) } & \\
\hline $\begin{array}{l}\text { Etapa o categoría } \\
\text { Atracción }\end{array}$ & $\begin{array}{l}\text { Puntuación } \\
\text { Entrada }\end{array}$ & Evaluación & ¿Mejoras? \\
Pasaje & 8,2 & Muy favorable & Opcionales \\
Salida & 0,0 & Muy desfavorable & Imprescindibles \\
& 0,0 & Muy desfavorable & Imprescindibles \\
\hline
\end{tabular}

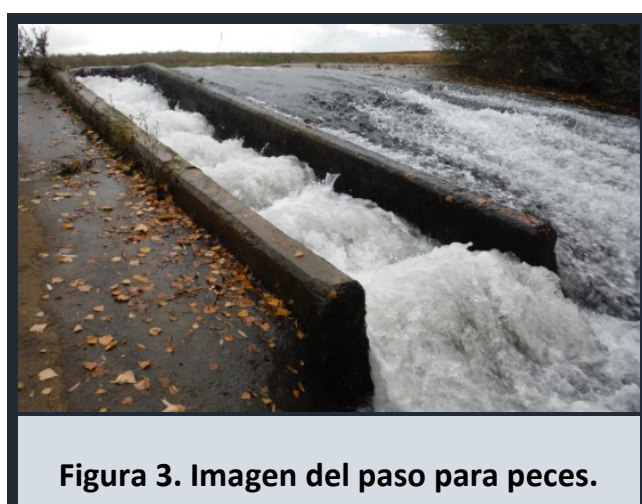




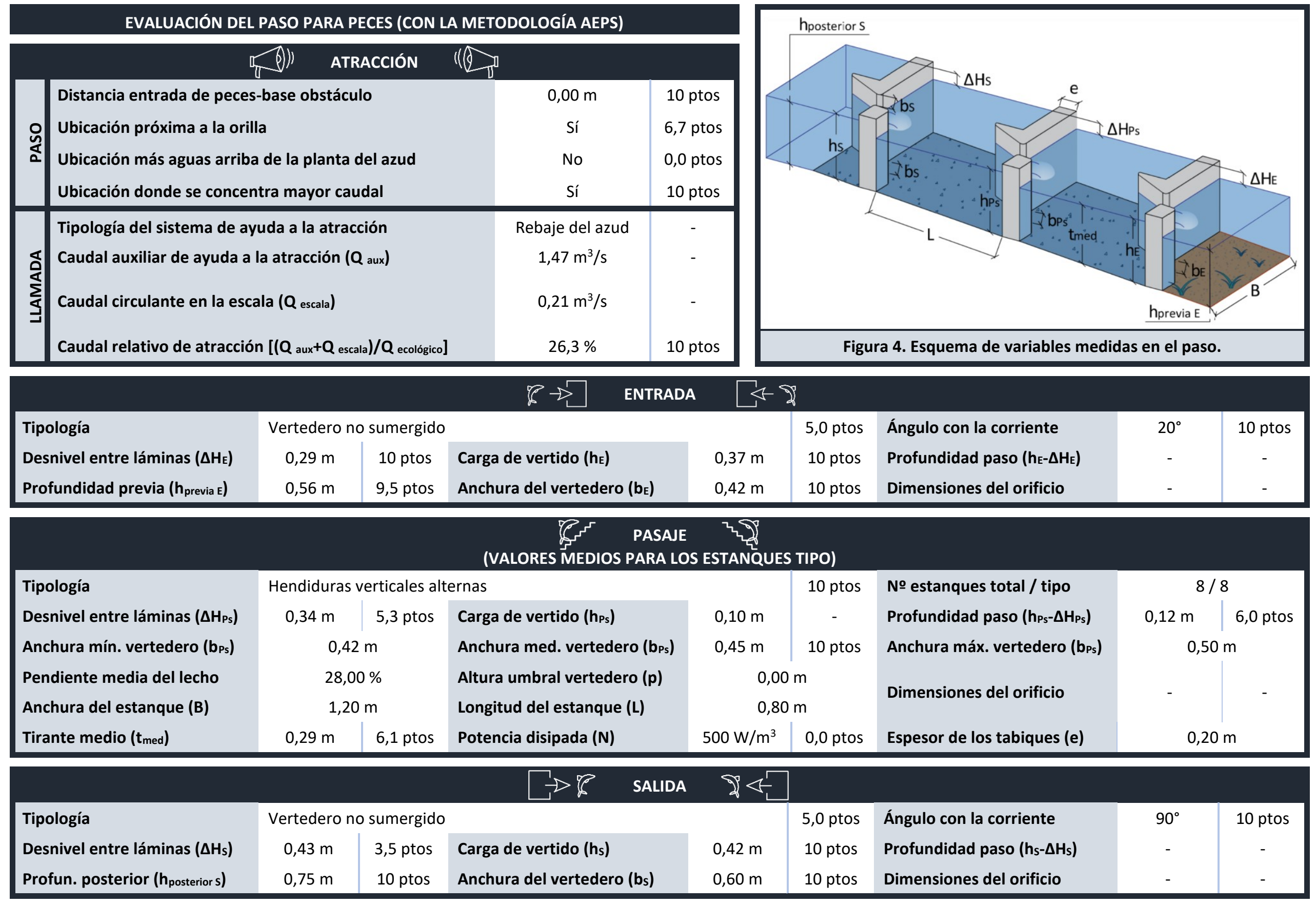




\section{PASO PARA PECES ASOCIADO AL AZUD DE LA CENTRAL HIDROELÉCTRICA DE QUINTANA DEL PUENTE (INFERIOR)}

\begin{tabular}{|c|c|c|c|c|}
\hline & Provincia & Palencia & Municipio & Herrera de Valdecañas \\
\hline & $\begin{array}{l}\text { Nombre del aprovechamiento } \\
\text { Código del aprovechamiento } \\
\text { Long. coronación del azud } \\
\text { Coordenadas del paso piscícola }\end{array}$ & $\begin{array}{l}\text { Quintana del Puente } \\
1100069 \\
145 \mathrm{~m} \\
X: 399.270 \mathrm{~m}, \mathrm{Y}: 4.658\end{array}$ & $\begin{array}{l}\text { Tipo de aprovechamiento } \\
\text { Código del azud (1) } \\
\text { Salto total de agua en la visita } \\
908 \text { m (ETRS 89; HUSO 30) }\end{array}$ & $\begin{array}{l}\text { Hidroeléctrico } \\
1005993 \\
3,35 \mathrm{~m}\end{array}$ \\
\hline & $\begin{array}{l}\text { Cuenca hidrográfica } \\
\text { Principales peces migradores }{ }^{(1)} \\
\text { Época de migración }\end{array}$ & $\begin{array}{l}\text { Duero } \\
\text { Luciobarbus bocagei y } \\
\text { Mayo a junio }\end{array}$ & $\begin{array}{l}\text { Cauce } \\
\text { seudochondrostoma duriense }\end{array}$ & Arlanza \\
\hline $\begin{array}{c}\text { Figura 1. Ubicación en la parte } \\
\text { española de la cuenca del río Duero. }\end{array}$ & $\begin{array}{l}\text { Caudal medio en migración }{ }^{(2)} \\
\text { Caudal durante la visita }{ }^{(3)}\end{array}$ & $\begin{array}{l}26,25 \mathrm{~m}^{3} / \mathrm{s} \\
\text { No disponible }\end{array}$ & $\begin{array}{l}\text { Caudal ecológico en migración } \\
\text { Hora y fecha de la visita }\end{array}$ & $\begin{array}{l}2,5 \mathrm{~m}^{3} / \mathrm{s} \\
\text { No disponible }\end{array}$ \\
\hline
\end{tabular}

(1) Dato obtenido de MíRAME-IDE Duero. ${ }^{(2)}$ Dato obtenido del CEDEX Hidrológico. ${ }^{(3)}$ Dato obtenido del SAIH del Duero.

\begin{tabular}{|c|c|c|c|}
\hline Paso para peces de estanques su & os conectad & tederos sumergidos y orificios de fondo alternos & \\
\hline $\begin{array}{l}\text { Estado de mantenimiento y limpieza durante la evaluación } \\
\text { Solera naturalizada (con piedras) } \\
\text { Vertedero de umbral móvil en la entrada de peces }\end{array}$ & $\begin{array}{l}\text { Adecuado } \\
\text { Sí } \\
\text { No }\end{array}$ & $\begin{array}{l}\text { Compuerta en la salida de peces } \\
\text { Dispositivo para evitar la entrada de arrastres } \\
\text { Salida de peces segura (alejada del azud, turbinas, ...) }\end{array}$ & $\begin{array}{l}\text { Sí } \\
\text { Sí } \\
\text { Sí }\end{array}$ \\
\hline
\end{tabular}

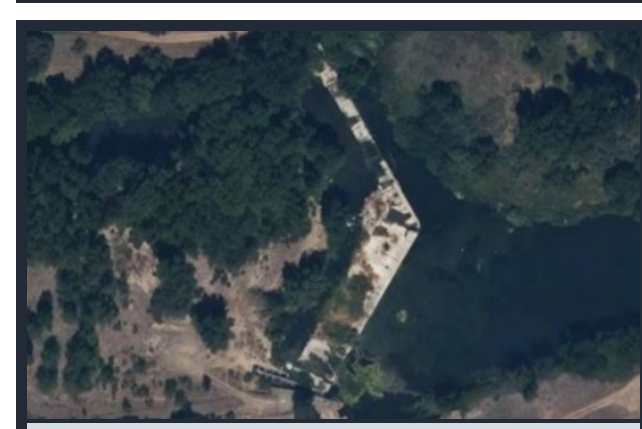

Figura 2. Ortofoto de la zona (fuente: SigPac).

\begin{tabular}{lccc}
\multicolumn{4}{c}{ RESUMEN DE LA EVALUACIÓN DEL PASO PARA PECES } \\
& \multicolumn{4}{c}{ (CON LA METODOLOGÍA AEPS) } \\
\hline Etapa o categoría & Puntuación & Evaluación & ¿Mejoras? \\
Atracción & 10,0 & Muy favorable & Opcionales \\
Entrada & 9,4 & Muy favorable & Opcionales \\
Pasaje & 10,0 & Muy favorable & Opcionales \\
Salida & 0,0 & Muy desfavorable & Imprescindibles
\end{tabular}

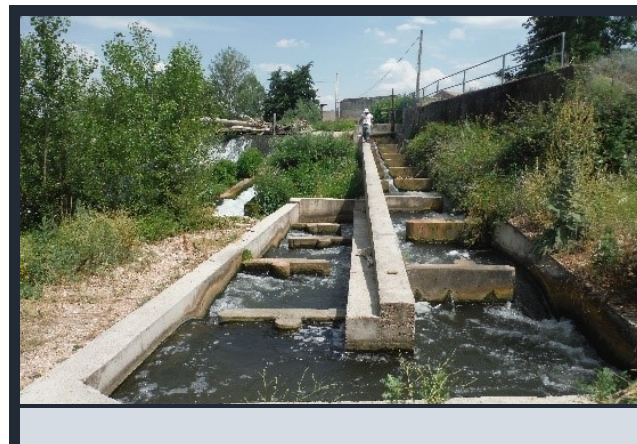

Figura 3. Imagen del paso para peces. 


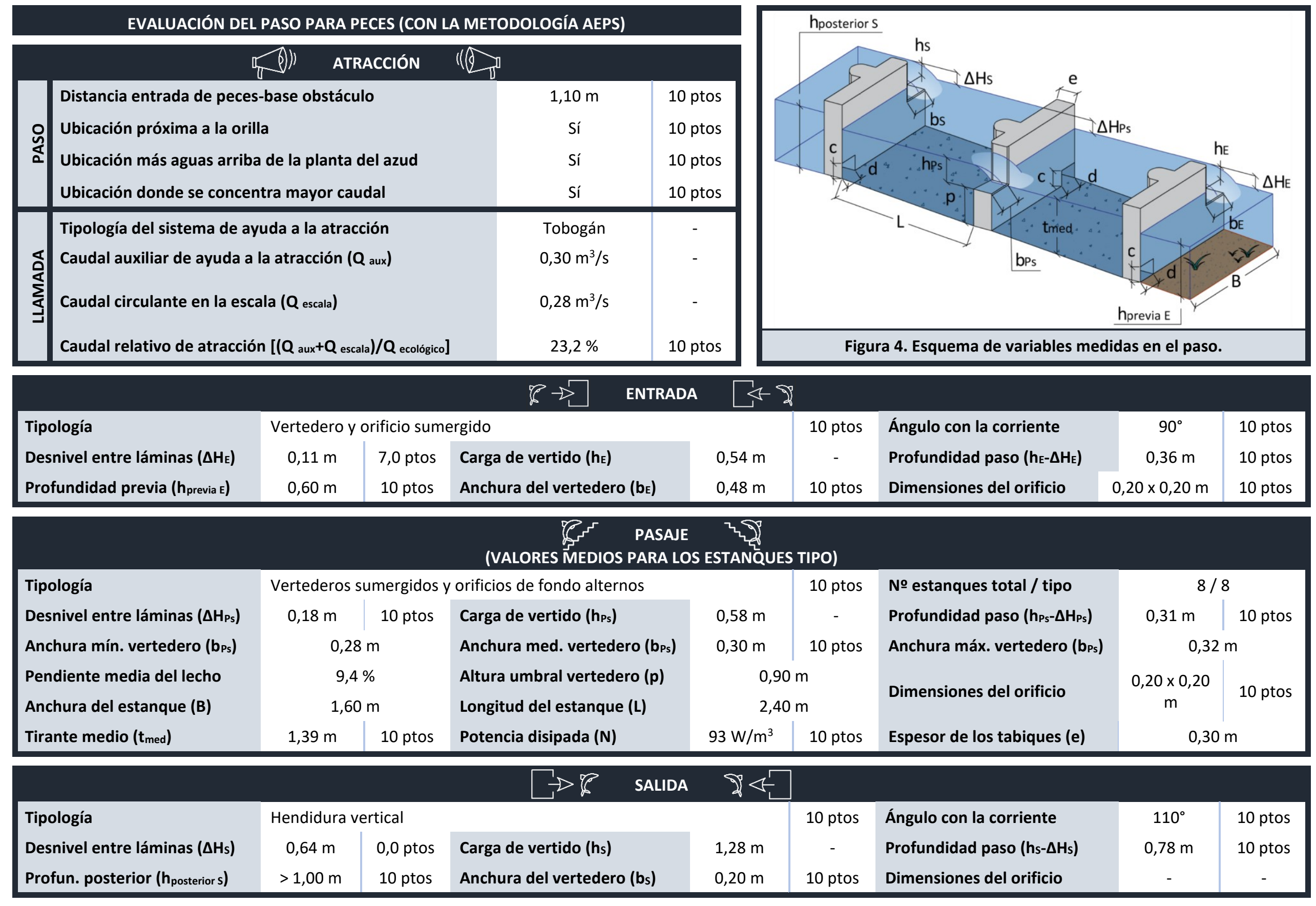




\section{PASO PARA PECES ASOCIADO AL AZUD DE LA CENTRAL HIDROELÉCTRICA DE QUINTANA DEL PUENTE (SUPERIOR)}

\begin{tabular}{|c|c|c|c|c|}
\hline & Provincia & Palencia & Municipio & Herrera de Valdecañas \\
\hline & $\begin{array}{l}\text { Nombre del aprovechamiento } \\
\text { Código del aprovechamiento } \\
\text { Long. coronación del azud } \\
\text { Coordenadas del paso piscícola }\end{array}$ & $\begin{array}{l}\text { Quintana del Puente } \\
1100069 \\
145 \mathrm{~m} \\
\mathrm{X}: 399.270 \mathrm{~m}, \mathrm{Y:}: 4.658\end{array}$ & $\begin{array}{l}\text { Tipo de aprovechamiento } \\
\text { Código del azud (1) } \\
\text { Salto total de agua en la visita } \\
908 \text { m (ETRS 89; HUSO 30) }\end{array}$ & $\begin{array}{l}\text { Hidroeléctrico } \\
1005993 \\
3,35 \mathrm{~m}\end{array}$ \\
\hline 0 & $\begin{array}{l}\text { Cuenca hidrográfica } \\
\text { Principales peces migradores }{ }^{(1)} \\
\text { Época de migración }\end{array}$ & $\begin{array}{l}\text { Duero } \\
\text { Luciobarbus bocagei y } \\
\text { Mayo a junio }\end{array}$ & $\begin{array}{l}\text { Cauce } \\
\text { seudochondrostoma duriense }\end{array}$ & Arlanza \\
\hline $\begin{array}{l}\text { Figura 1. Ubicación en la parte } \\
\text { española de la cuenca del río Duero. }\end{array}$ & $\begin{array}{l}\text { Caudal medio en migración (2) } \\
\text { Caudal durante la visita }{ }^{(3)}\end{array}$ & $\begin{array}{l}26,25 \mathrm{~m}^{3} / \mathrm{s} \\
\text { No disponible }\end{array}$ & $\begin{array}{l}\text { Caudal ecológico en migración } \\
\text { Hora y fecha de la visita }\end{array}$ & $\begin{array}{l}2,5 \mathrm{~m}^{3} / \mathrm{s} \\
\text { No disponible }\end{array}$ \\
\hline
\end{tabular}

(1) Dato obtenido de MíRAME-IDE Duero. ${ }^{(2)}$ Dato obtenido del CEDEX Hidrológico. ${ }^{(3)}$ Dato obtenido del SAIH del Duero.

\begin{tabular}{|c|c|c|c|}
\hline \multicolumn{4}{|c|}{ OBSERVACIONES GENERALES DE LA ESCALA } \\
\hline $\begin{array}{l}\text { Estado de mantenimiento y limpieza durante la evaluación } \\
\text { Solera naturalizada (con piedras) } \\
\text { Vertedero de umbral móvil en la entrada de peces }\end{array}$ & $\begin{array}{l}\text { Adecuado } \\
\text { Sí } \\
\text { No }\end{array}$ & $\begin{array}{l}\text { Compuerta en la salida de peces } \\
\text { Dispositivo para evitar la entrada de arrastres } \\
\text { Salida de peces segura (alejada del azud, turbinas, ...) }\end{array}$ & $\begin{array}{l}\text { Sí } \\
\text { Sí } \\
\text { Sí }\end{array}$ \\
\hline
\end{tabular}

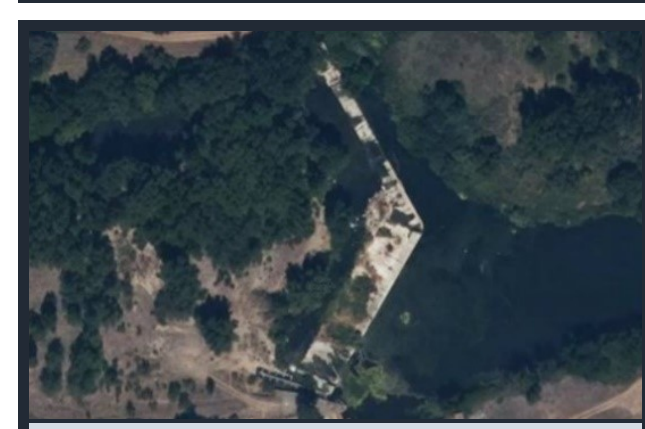

Figura 2. Ortofoto de la zona (fuente: SigPac).

\begin{tabular}{lccc}
\multicolumn{4}{c}{ RESUMEN DE LA EVALUACIÓN DEL PASO PARA PECES } \\
(CON LA METODOLOGÍA AEPS) & \\
\hline Etapa o categoría & Puntuación & Evaluación & ¿Mejoras? \\
Atracción & 10,0 & Muy favorable & Opcionales \\
Entrada & 9,4 & Muy favorable & Opcionales \\
Pasaje & 9,6 & Muy favorable & Opcionales \\
Salida & 0,0 & Muy desfavorable & Imprescindibles \\
\hline
\end{tabular}

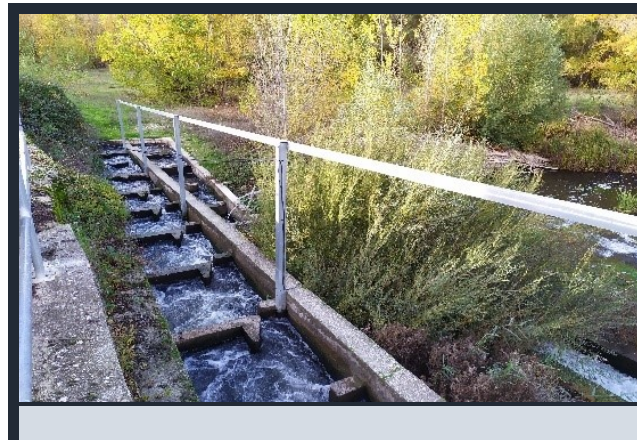

Figura 3. Imagen del paso para peces. 


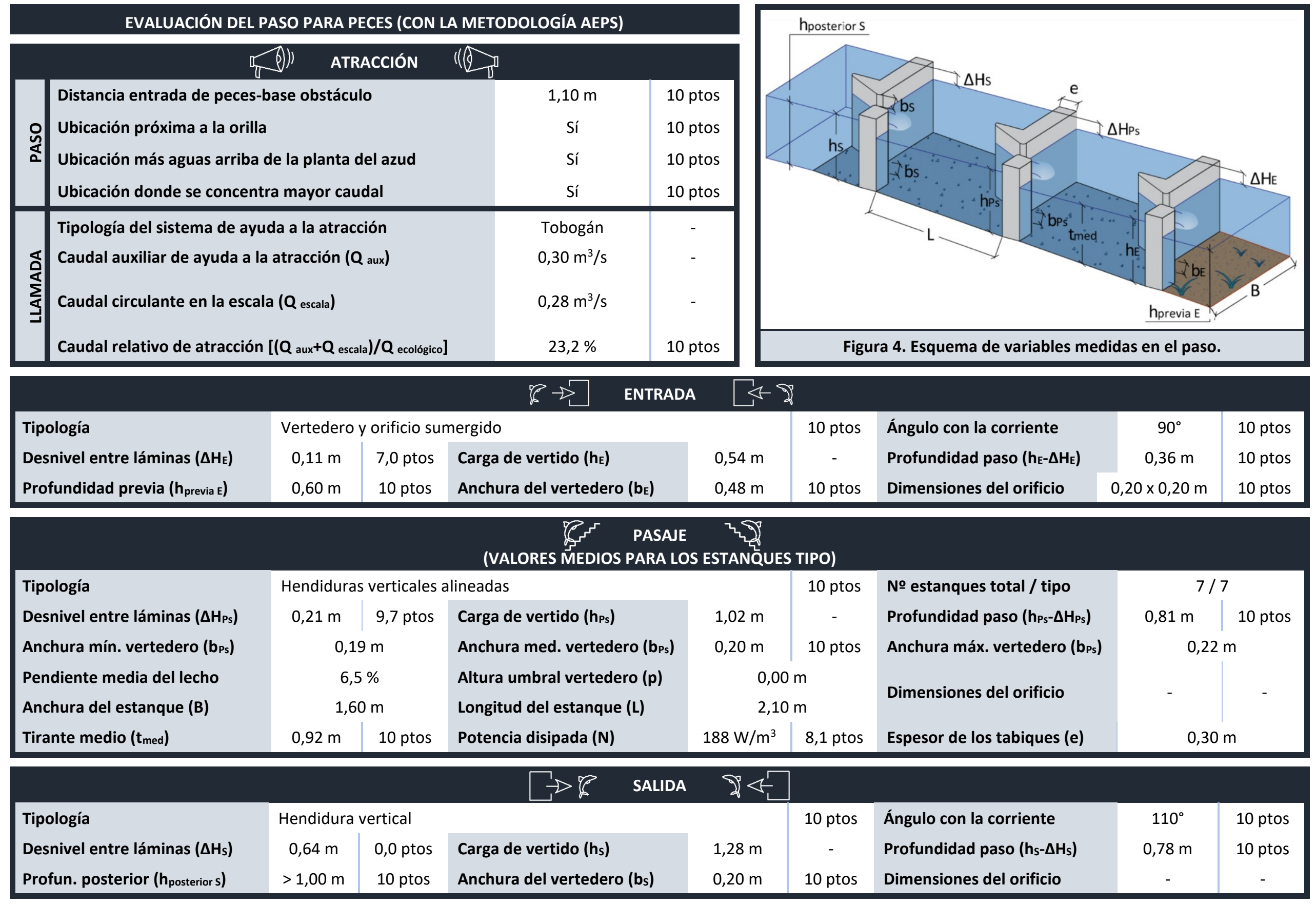




\section{PASO PARA PECES ASOCIADO AL AZUD DE TORRECILLA}

\begin{tabular}{|c|c|c|c|c|}
\hline \multicolumn{5}{|c|}{ DATOS GENERALES DEL APROVECHAMIENTO } \\
\hline \multirow{5}{*}{ \{rivo } & Provincia & Palencia & Municipio & Dueñas \\
\hline & $\begin{array}{l}\text { Nombre del aprovechamiento } \\
\text { Código del aprovechamiento } \\
\text { Long. coronación del azud }^{(1)}\end{array}$ & $\begin{array}{l}\text { Torrecilla I y II } \\
1100213 \\
137 \mathrm{~m}\end{array}$ & $\begin{array}{l}\text { Tipo de aprovechamiento } \\
\text { Código del azud (1) } \\
\text { Salto total de agua en la visita }\end{array}$ & \multirow[t]{2}{*}{$\begin{array}{l}\text { Hidroeléctrico } \\
1005256 \\
3,87 \mathrm{~m}\end{array}$} \\
\hline & Coordenadas del paso piscícola & \multicolumn{2}{|c|}{ X: 371.798 m, Y: 4.635 .412 m (ETRS 89; HUSO 30) } & \\
\hline & Cuenca hidrográfica & Duero & Cauce & Pisuerga \\
\hline & $\begin{array}{l}\text { Principales peces migradores }{ }^{(1)} \\
\text { Época de migración }\end{array}$ & \multicolumn{2}{|c|}{$\begin{array}{l}\text { Luciobarbus bocagei y Pseudochondrostoma duriense } \\
\text { Mayo a junio }\end{array}$} & \\
\hline $\begin{array}{l}\text { Figura 1. Ubicación en la parte } \\
\text { española de la cuenca del río Duero. }\end{array}$ & $\begin{array}{l}\text { Caudal medio en migración } \\
\text { Caudal durante la visita } \\
{ }^{(3)}\end{array}$ & $\begin{array}{l}59,35 \mathrm{~m}^{3} / \mathrm{s} \\
142,93 \mathrm{~m}^{3} / \mathrm{s}\end{array}$ & $\begin{array}{l}\text { Caudal ecológico en migración } \\
\text { Hora y fecha de la visita }\end{array}$ & 14:00h, 24/02/2016 \\
\hline
\end{tabular}

(1) Dato obtenido de MíRAME-IDE Duero. ${ }^{(2)}$ Dato obtenido del CEDEX Hidrológico. ${ }^{(3)}$ Dato obtenido del SAIH del Duero.

\begin{tabular}{|c|c|c|c|}
\hline Paso para peces de estanques su & os conectados po & tederos sumergidos y orifcios de fondo alternos & \\
\hline $\begin{array}{l}\text { Estado de mantenimiento y limpieza durante la evaluación } \\
\text { Solera naturalizada (con piedras) } \\
\text { Vertedero de umbral móvil en la entrada de peces }\end{array}$ & $\begin{array}{l}\text { Muy adecuado } \\
\text { Sí } \\
\text { No }\end{array}$ & $\begin{array}{l}\text { Compuerta en la salida de peces } \\
\text { Dispositivo para evitar la entrada de arrastres } \\
\text { Salida de peces segura (alejada del azud, turbinas, ...) }\end{array}$ & $\begin{array}{l}\text { Sí } \\
\text { No } \\
\text { No }\end{array}$ \\
\hline
\end{tabular}

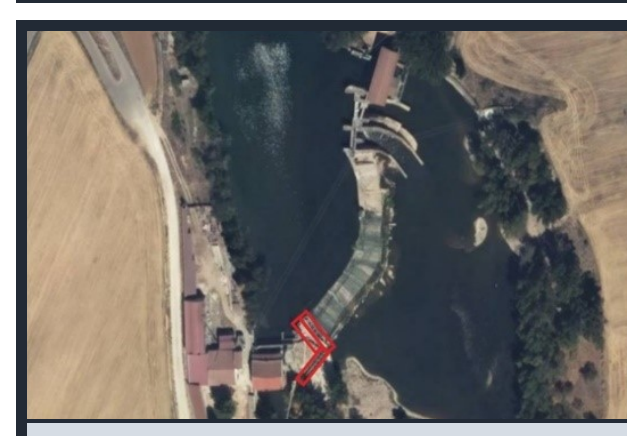

Figura 2. Ortofoto de la zona (fuente: SigPac).

\begin{tabular}{lccc}
\multicolumn{4}{c}{ RESUMEN DE LA EVALUACIÓN DEL PASO PARA PECES } \\
& \multicolumn{4}{c}{ (CON LA METODOLOGÍA AEPS) } & \\
\hline Etapa o categoría & Puntuación & Evaluación & ¿Mejoras? \\
Atracción & 5,1 & Desfavorable & Muy necesarias \\
Entrada & 9,5 & Muy favorable & Opcionales \\
Pasaje & 9,9 & Muy favorable & Opcionales \\
Salida & 8,9 & Muy favorable & Opcionales \\
\hline
\end{tabular}

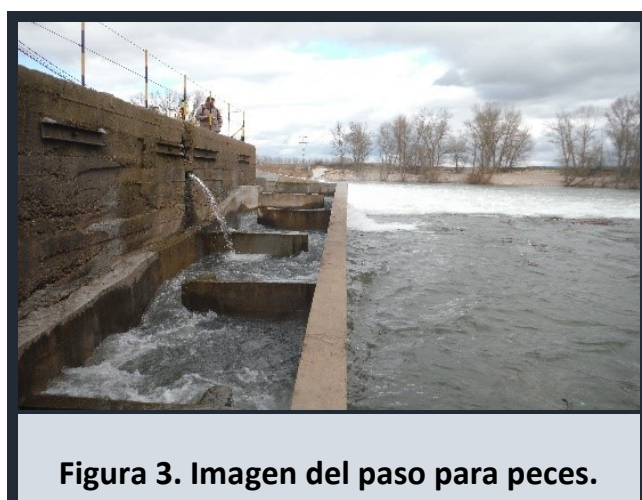




\begin{tabular}{|c|c|c|c|}
\hline & ATRACCIÓN & & \\
\hline 음 & $\begin{array}{l}\text { Distancia entrada de peces-base obstáculo } \\
\text { Ubicación próxima a la orilla } \\
\text { Ubicación más aguas arriba de la planta del azud } \\
\text { Ubicación donde se concentra mayor caudal }\end{array}$ & $\begin{array}{l}1,50 \mathrm{~m} \\
\text { Sí } \\
\text { No } \\
\text { No }\end{array}$ & $\begin{array}{l}10 \text { ptos } \\
10 \text { ptos } \\
0,0 \text { ptos } \\
0,0 \text { ptos }\end{array}$ \\
\hline 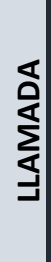 & $\begin{array}{l}\text { Tipología del sistema de ayuda a la atracción } \\
\left.\text { Caudal auxiliar de ayuda a la atracción ( } Q_{\text {aux }}\right) \\
\left.\text { Caudal circulante en la escala ( } Q_{\text {escala }}\right) \\
\left.\left.\text { Caudal relativo de atracción [( } Q_{\text {aux }}+Q_{\text {escala }}\right) / Q_{\text {ecológico }}\right]\end{array}$ & $\begin{array}{c}\text { Tobogán } \\
0,03 \mathrm{~m}^{3} / \mathrm{s} \\
0,34 \mathrm{~m}^{3} / \mathrm{s} \\
1,3 \%\end{array}$ & $\begin{array}{c}- \\
- \\
- \\
5,2 \text { ptos }\end{array}$ \\
\hline
\end{tabular}

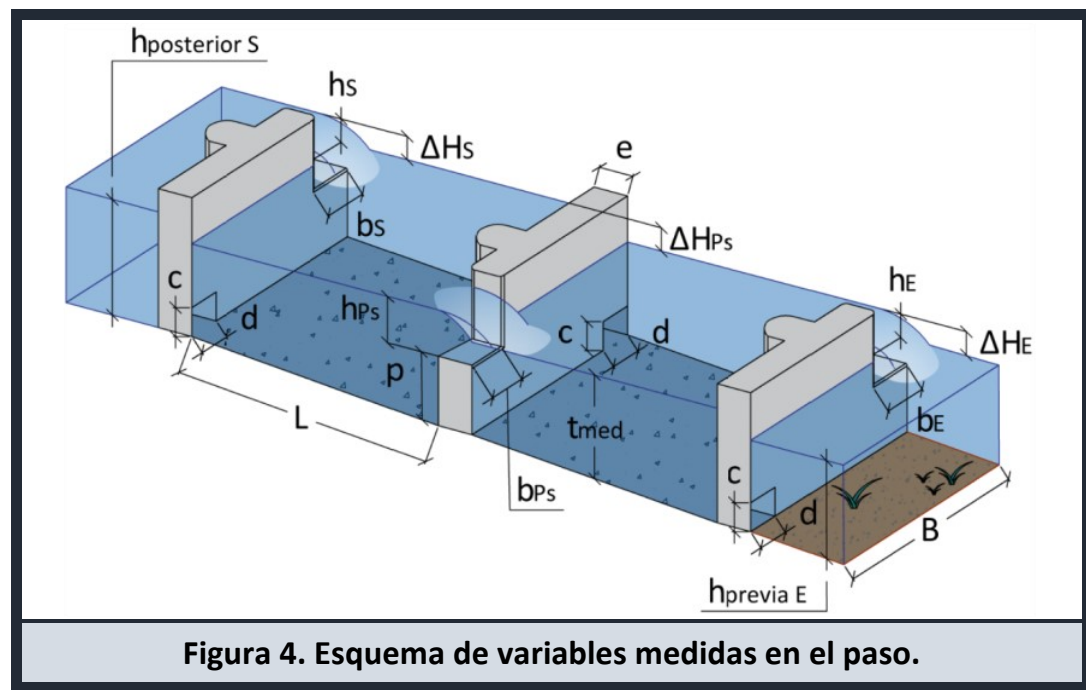

\begin{tabular}{|c|c|c|c|c|c|c|c|c|}
\hline & & & $b \rightarrow$ & 5 & & & & \\
\hline Tipología & Vertedero & -ificio sun & rgido & & 10 ptos & Ángulo con la corriente & $90^{\circ}$ & 10 ptos \\
\hline Desnivel entre láminas $\left(\Delta \mathrm{H}_{\mathrm{E}}\right)$ & $0,12 \mathrm{~m}$ & 7,3 ptos & Carga de vertido $\left(h_{E}\right)$ & $0,86 \mathrm{~m}$ & - & Profundidad paso $\left(\mathrm{h}_{\mathrm{E}}-\Delta \mathrm{H}_{\mathrm{E}}\right)$ & $0,74 \mathrm{~m}$ & 10 ptos \\
\hline Profundidad previa ( $h_{\text {previa E }}$ ) & $1,00 \mathrm{~m}$ & 10 ptos & Anchura del vertedero $\left(b_{E}\right)$ & $0,30 \mathrm{~m}$ & 10 ptos & Dimensiones del orificio & $0,20 \times 0,20 \mathrm{~m}$ & 10 ptos \\
\hline
\end{tabular}

\begin{tabular}{|c|c|c|c|c|c|c|c|c|}
\hline Tipología & \multicolumn{3}{|c|}{ Vertederos sumergidos y orificios de fondo alternos } & & 10 ptos & № estanques total / tipo & \multicolumn{2}{|c|}{$23 / 22$} \\
\hline Desnivel entre láminas ( $\left.\Delta \mathrm{H}_{\mathrm{Ps}}\right)$ & $0,24 \mathrm{~m}$ & 10 ptos & Carga de vertido (hPs) & $0,60 \mathrm{~m}$ & - & Profundidad paso (hPs $\left.-\Delta \mathrm{HPs}_{\mathrm{Ps}}\right)$ & $0,35 \mathrm{~m}$ & 10 ptos \\
\hline Anchura mín. vertedero ( $\left.b_{P_{s}}\right)$ & \multicolumn{2}{|c|}{$0,30 \mathrm{~m}$} & Anchura med. vertedero $\left(b_{P_{s}}\right)$ & $0,31 \mathrm{~m}$ & 10 ptos & Anchura máx. vertedero $\left(b_{P_{s}}\right)$ & \multicolumn{2}{|c|}{$0,34 \mathrm{~m}$} \\
\hline Pendiente media del lecho & \multicolumn{2}{|c|}{$9,0 \%$} & Altura umbral vertedero (p) & \multicolumn{2}{|c|}{$1,20 \mathrm{~m}$} & Dimensiones del orificio & $0,20 \times 0,20$ & 10 ptos \\
\hline Anchura del estanque (B) & \multicolumn{2}{|c|}{$1,60 \mathrm{~m}$} & Longitud del estanque (L) & \multicolumn{2}{|c|}{$2,67 \mathrm{~m}$} & 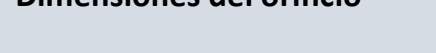 & $\mathrm{m}$ & 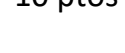 \\
\hline Tirante medio $\left(t_{\text {med }}\right)$ & $1,68 \mathrm{~m}$ & 10 ptos & Potencia disipada (N) & $112 \mathrm{~W} / \mathrm{m}^{3}$ & 10 ptos & Espesor de los tabiques (e) & \multicolumn{2}{|c|}{$0,20 \mathrm{~m}$} \\
\hline
\end{tabular}

\begin{tabular}{|c|c|c|c|c|c|c|c|c|}
\hline Tipología & \multicolumn{3}{|c|}{ Orificio sumergido (hendidura con compuerta en carga) } & \multirow{3}{*}{$1,44 \mathrm{~m}$} & \multirow{3}{*}{$\begin{array}{c}5,0 \text { ptos } \\
-\end{array}$} & \multirow{3}{*}{$\begin{array}{l}\text { Ángulo con la corriente } \\
\left.\text { Profundidad paso (hs- } \Delta \mathrm{H}_{\mathrm{s}}\right) \\
\text { Dimensiones del orificio }\end{array}$} & \multirow{3}{*}{$\begin{array}{c}160^{\circ} \\
1,24 \mathrm{~m} \\
0,20 \times 1,20 \mathrm{~m}\end{array}$} & \multirow{3}{*}{$\begin{array}{l}10 \text { ptos } \\
10 \text { ptos } \\
10 \text { ptos }\end{array}$} \\
\hline Desnivel entre láminas $\left(\Delta H_{s}\right)$ & $0,20 \mathrm{~m}$ & 10 ptos & Carga de vertido (hs) & & & & & \\
\hline Profun. posterior ( $h_{\text {posterior } s)}$ & $>1,00 \mathrm{~m}$ & 10 ptos & Anchura del vertedero (bs) & & & & & \\
\hline
\end{tabular}




\section{PASO PARA PECES ASOCIADO AL AZUD DE ACEÑA ZORITA}

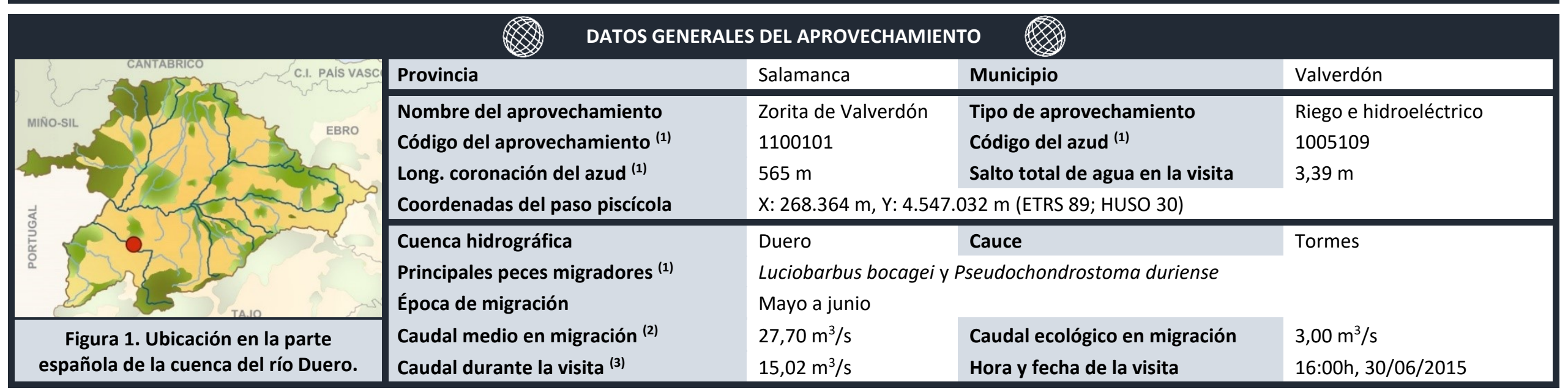

(1) Dato obtenido de MíRAME-IDE Duero. ${ }^{(2)}$ Dato obtenido del CEDEX Hidrológico. ${ }^{(3)}$ Dato obtenido del SAIH del Duero.

\begin{tabular}{|c|c|c|c|}
\hline Paso para peces de estanques su & s conectados po & tederos no sumergidos y orificios de fondo alternos & \\
\hline $\begin{array}{l}\text { Estado de mantenimiento y limpieza durante la evaluación } \\
\text { Solera naturalizada (con piedras) } \\
\text { Vertedero de umbral móvil en la entrada de peces }\end{array}$ & $\begin{array}{l}\text { Muy adecuado } \\
\text { No } \\
\text { No }\end{array}$ & $\begin{array}{l}\text { Compuerta en la salida de peces } \\
\text { Dispositivo para evitar la entrada de arrastres } \\
\text { Salida de peces segura (alejada del azud, turbinas, ...) }\end{array}$ & $\begin{array}{l}\text { No } \\
\text { No } \\
\text { Sí }\end{array}$ \\
\hline
\end{tabular}

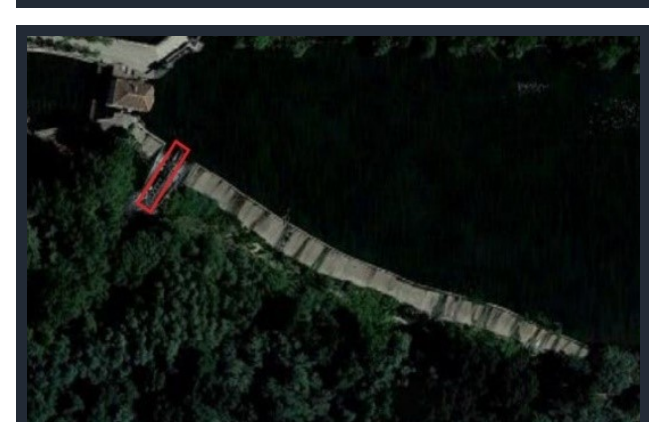

Figura 2. Ortofoto de la zona (fuente: Google Maps).

\begin{tabular}{|c|c|c|c|}
\hline \multicolumn{4}{|c|}{$\begin{array}{l}\text { RESUMEN DE LA EVALUACIÓN DEL PASO PARA PECES } \\
\text { (CON LA METODOLOGÍA AEPS) }\end{array}$} \\
\hline Etapa o categoría & Puntuación & Evaluación & ¿Mejoras? \\
\hline Atracción & 4,1 & Desfavorable & Muy necesarias \\
\hline Entrada & 8,3 & Muy favorable & Opcionales \\
\hline Pasaje & 0,0 & Muy desfavorable & Imprescindibles \\
\hline Salida & 9,0 & Muy favorable & Opcionales \\
\hline
\end{tabular}

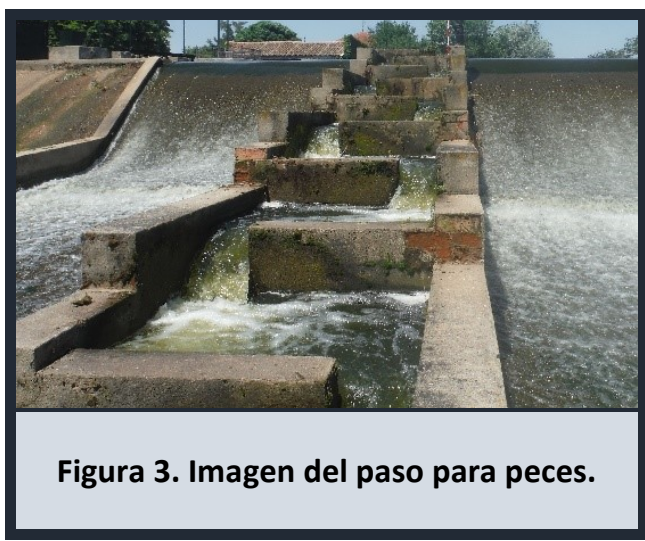




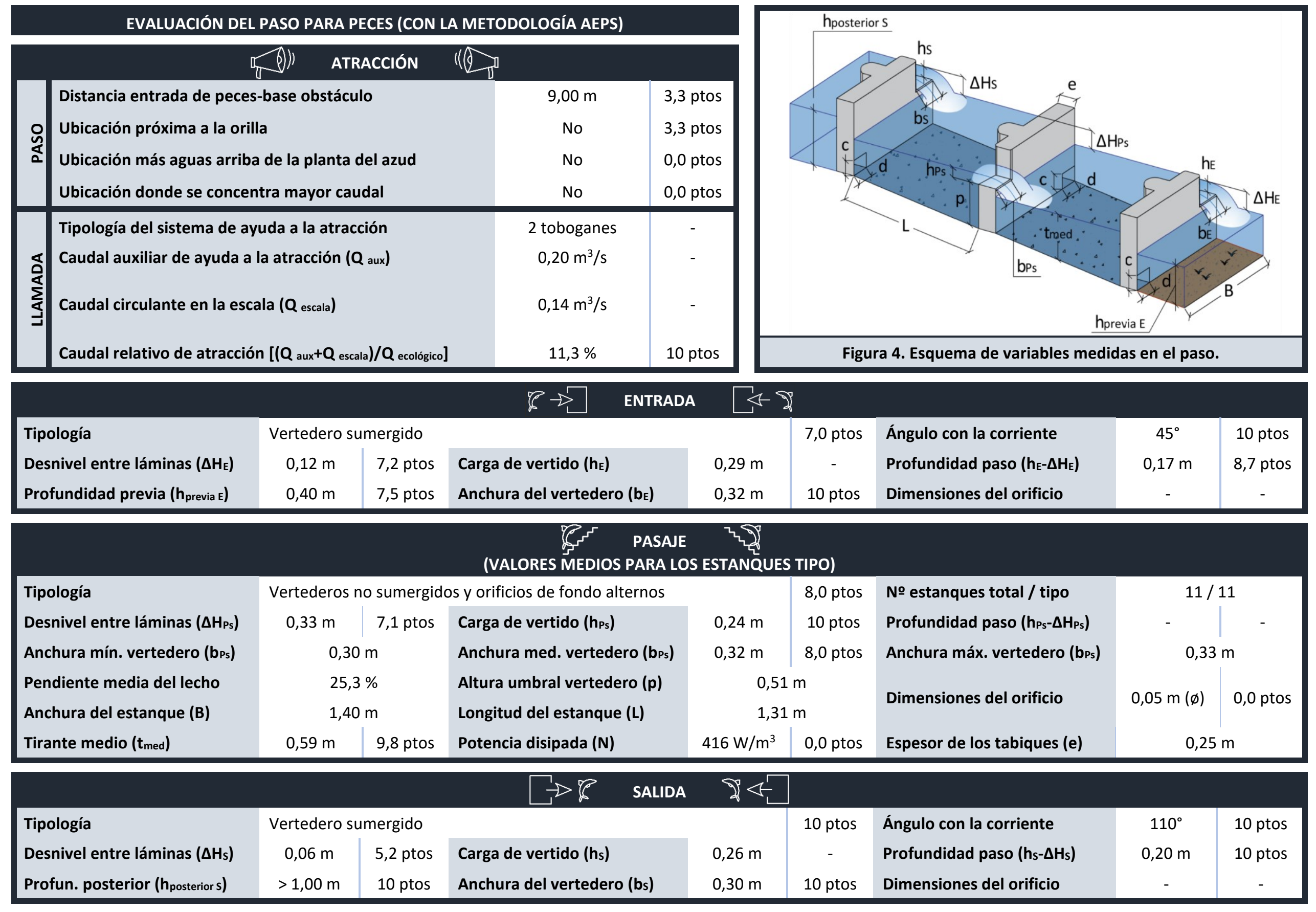

$\begin{array}{ll}\text { Jorge Valbuena Castro } & 241\end{array}$ 


\section{PASO PARA PECES ASOCIADO AL AZUD DE LA CENTRAL HIDROELÉCTRICA DE ALMENARA}

\begin{tabular}{|c|c|c|c|c|}
\hline & Provincia & Salamanca & Municipio & Almenara de Tormes \\
\hline & $\begin{array}{l}\text { Nombre del aprovechamiento } \\
\text { Código del aprovechamiento } \\
\text { Long. coronación del azud } \\
\text { (1) } \\
\text { Coordenadas del paso piscícola }\end{array}$ & $\begin{array}{l}\text { Almenara } \\
1100095 \\
230 \mathrm{~m} \\
X: 262.773\end{array}$ & $\begin{array}{l}\text { Tipo de aprovechamiento } \\
\text { Código del azud (1) } \\
\text { Salto total de agua en la visita } \\
277 \text { m (ETRS 89; HUSO 30) }\end{array}$ & $\begin{array}{l}\text { Hidroeléctrico } \\
1005111 \\
1,93 \mathrm{~m}\end{array}$ \\
\hline & $\begin{array}{l}\text { Cuenca hidrográfica } \\
\text { Principales peces migradores }{ }^{(1)} \\
\text { Época de migración }\end{array}$ & $\begin{array}{l}\text { Duero } \\
\text { Luciobarbus } \\
\text { Mayo a juni }\end{array}$ & $\begin{array}{l}\text { Cauce } \\
\text { seudochondrostoma duriense }\end{array}$ & Tormes \\
\hline $\begin{array}{l}\text { Figura 1. Ubicación en la parte } \\
\text { española de la cuenca del río Duero. }\end{array}$ & $\begin{array}{l}\text { Caudal medio en migración (2) } \\
\text { Caudal durante la visita }{ }^{(3)}\end{array}$ & $\begin{array}{l}27,70 \mathrm{~m}^{3} / \mathrm{s} \\
17,99 \mathrm{~m}^{3} / \mathrm{s}\end{array}$ & $\begin{array}{l}\text { Caudal ecológico en migración } \\
\text { Hora y fecha de la visita }\end{array}$ & $\begin{array}{l}21,10 \mathrm{~m}^{3} / \mathrm{s} \\
13: 00 \mathrm{~h}, 30 / 06 / 2015\end{array}$ \\
\hline
\end{tabular}

${ }^{(1)}$ Dato obtenido de MíRAME-IDE Duero. ${ }^{(2)}$ Dato obtenido del CEDEX Hidrológico. ${ }^{(3)}$ Dato obtenido del SAIH del Duero.

\begin{tabular}{|c|c|c|c|}
\hline Paso para peces de estanques & os conectad & diduras verticales alineadas y sin orificios & \\
\hline $\begin{array}{l}\text { Estado de mantenimiento y limpieza durante la evaluación } \\
\text { Solera naturalizada (con piedras) } \\
\text { Vertedero de umbral móvil en la entrada de peces }\end{array}$ & $\begin{array}{l}\text { Adecuado } \\
\text { - } \\
\text { No }\end{array}$ & $\begin{array}{l}\text { Compuerta en la salida de peces } \\
\text { Dispositivo para evitar la entrada de arrastres } \\
\text { Salida de peces segura (alejada del azud, turbinas, ...) }\end{array}$ & $\begin{array}{l}\text { Sí } \\
\text { Sí } \\
\text { Sí }\end{array}$ \\
\hline
\end{tabular}

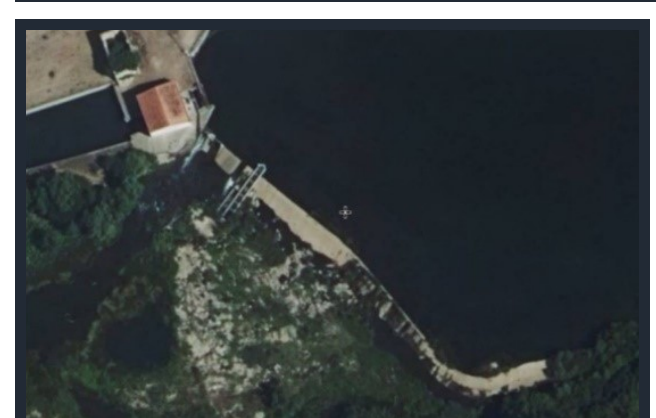

Figura 2. Ortofoto de la zona (fuente: SigPac).

\begin{tabular}{lccl}
\multicolumn{5}{c}{ RESUMEN DE LA EVALUACIÓN DEL PASO PARA PECES } \\
(CON LA METODOLOGÍA AEPS) \\
Etapa o categoría & Puntuación & Evaluación & ¿Mejoras? \\
Atracción & 8,7 & Muy favorable & Opcionales \\
Entrada & 9,6 & Muy favorable & Opcionales \\
Pasaje & 10,0 & Muy favorable & Opcionales \\
Salida & 8,9 & Muy favorable & Opcionales \\
\hline
\end{tabular}

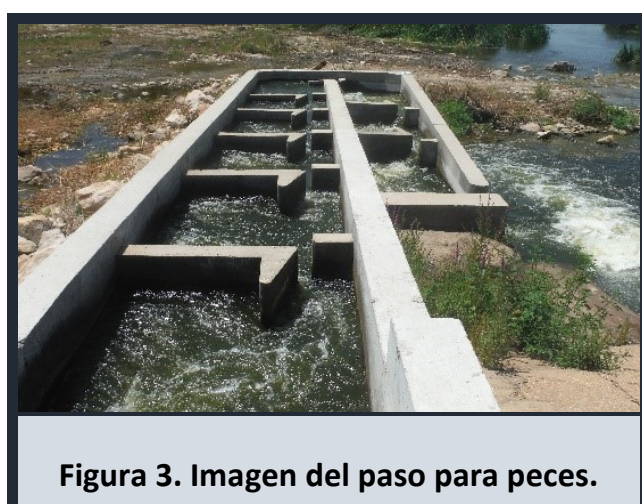




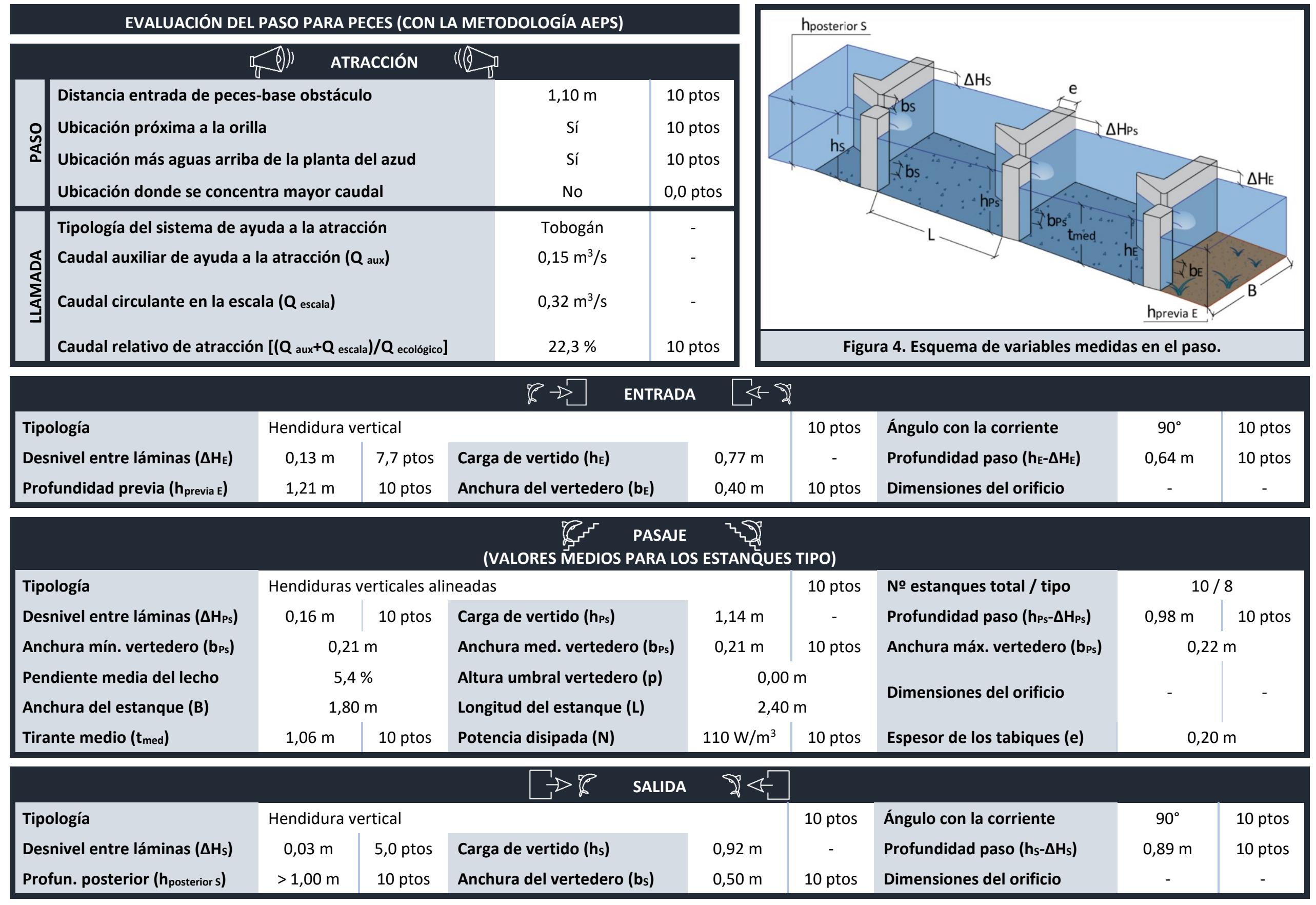




\section{PASO PARA PECES ASOCIADO AL AZUD DE LA CENTRAL HIDROELÉCTRICA DE LEDESMA}

\begin{tabular}{|c|c|c|c|c|}
\hline & Provincia & Salamanca & Municipio & Ledesma \\
\hline & $\begin{array}{l}\text { Nombre del aprovechamiento } \\
\text { Código del aprovechamiento } \\
\text { Long. coronación del azud } \\
\text { (1) } \\
\text { Coordenadas del paso piscícola }\end{array}$ & $\begin{array}{l}\text { Ledesma } \\
1100097 \\
118 \mathrm{~m} \\
X: 249.704\end{array}$ & $\begin{array}{l}\text { Tipo de aprovechamiento } \\
\text { Código del azud (1) } \\
\text { Salto total de agua en la visita } \\
231 \text { m (ETRS 89; HUSO 30) }\end{array}$ & $\begin{array}{l}\text { Hidroeléctrico } \\
1005184 \\
5,41 \mathrm{~m}\end{array}$ \\
\hline & $\begin{array}{l}\text { Cuenca hidrográfica } \\
\text { Principales peces migradores }{ }^{(1)} \\
\text { Época de migración }\end{array}$ & $\begin{array}{l}\text { Duero } \\
\text { Luciobarbus } \\
\text { Mayo a juni }\end{array}$ & $\begin{array}{l}\text { Cauce } \\
\text { seudochondrostoma duriense }\end{array}$ & Tormes \\
\hline $\begin{array}{c}\text { Figura 1. Ubicación en la parte } \\
\text { española de la cuenca del río Duero. }\end{array}$ & $\begin{array}{l}\text { Caudal medio en migración (2) } \\
\text { Caudal durante la visita (3) }\end{array}$ & $\begin{array}{l}27,70 \mathrm{~m}^{3} / \mathrm{s} \\
16,24 \mathrm{~m}^{3} / \mathrm{s}\end{array}$ & $\begin{array}{l}\text { Caudal ecológico en migración } \\
\text { Hora y fecha de la visita }\end{array}$ & 11:00h, 30/06/2015 \\
\hline
\end{tabular}

${ }^{(1)}$ Dato obtenido de MíRAME-IDE Duero. ${ }^{(2)}$ Dato obtenido del CEDEX Hidrológico. ${ }^{(3)}$ Dato obtenido del SAIH del Duero.

\begin{tabular}{|c|c|c|c|}
\hline \multicolumn{4}{|c|}{$\begin{array}{l}\text { OBSERVACIONES GENERALES DE LA ESCALA } \\
\text { vos conectados por vertederos sumergidos alternos }\end{array}$} \\
\hline $\begin{array}{l}\text { Estado de mantenimiento y limpieza durante la evaluación } \\
\text { Solera naturalizada (con piedras) } \\
\text { Vertedero de umbral móvil en la entrada de peces }\end{array}$ & $\begin{array}{l}\text { No adecuado } \\
\text { Sí } \\
\text { No }\end{array}$ & $\begin{array}{l}\text { Compuerta en la salida de peces } \\
\text { Dispositivo para evitar la entrada de arrastres } \\
\text { Salida de peces segura (alejada del azud, turbinas, ...) }\end{array}$ & $\begin{array}{l}\text { No } \\
\text { No } \\
\text { No }\end{array}$ \\
\hline
\end{tabular}

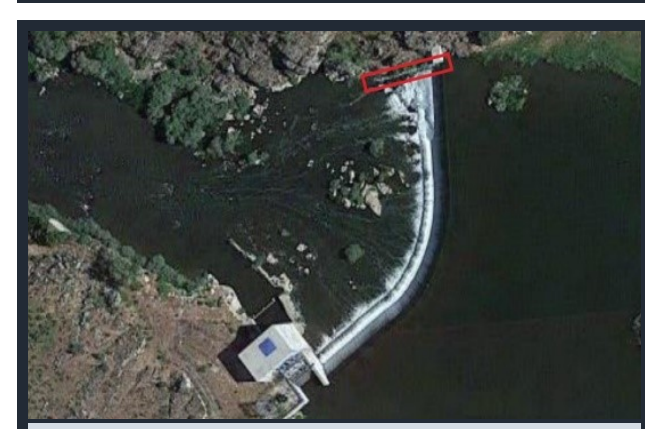

Figura 2. Ortofoto de la zona (fuente: Google Maps).

\begin{tabular}{lccc}
\multicolumn{4}{c}{ RESUMEN DE LA EVALUACIÓN DEL PASO PARA PECES } \\
& \multicolumn{2}{c|}{ (CON LA METODOLOGíA AEPS) } & \\
\hline Etapa o categoría & Puntuación & Evaluación & ¿Mejoras? \\
Atracción & 0,0 & Muy desfavorable & Imprescindibles \\
Entrada & 9,2 & Muy favorable & Opcionales \\
Pasaje & 0,0 & Muy desfavorable & Imprescindibles \\
Salida & 7,8 & Favorable & Recomendables \\
\hline
\end{tabular}

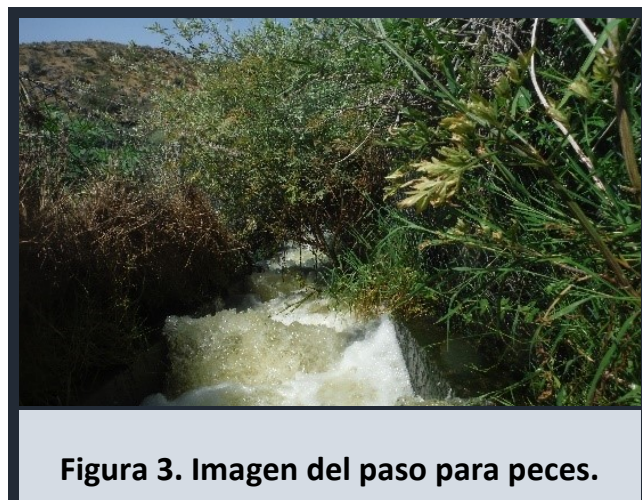




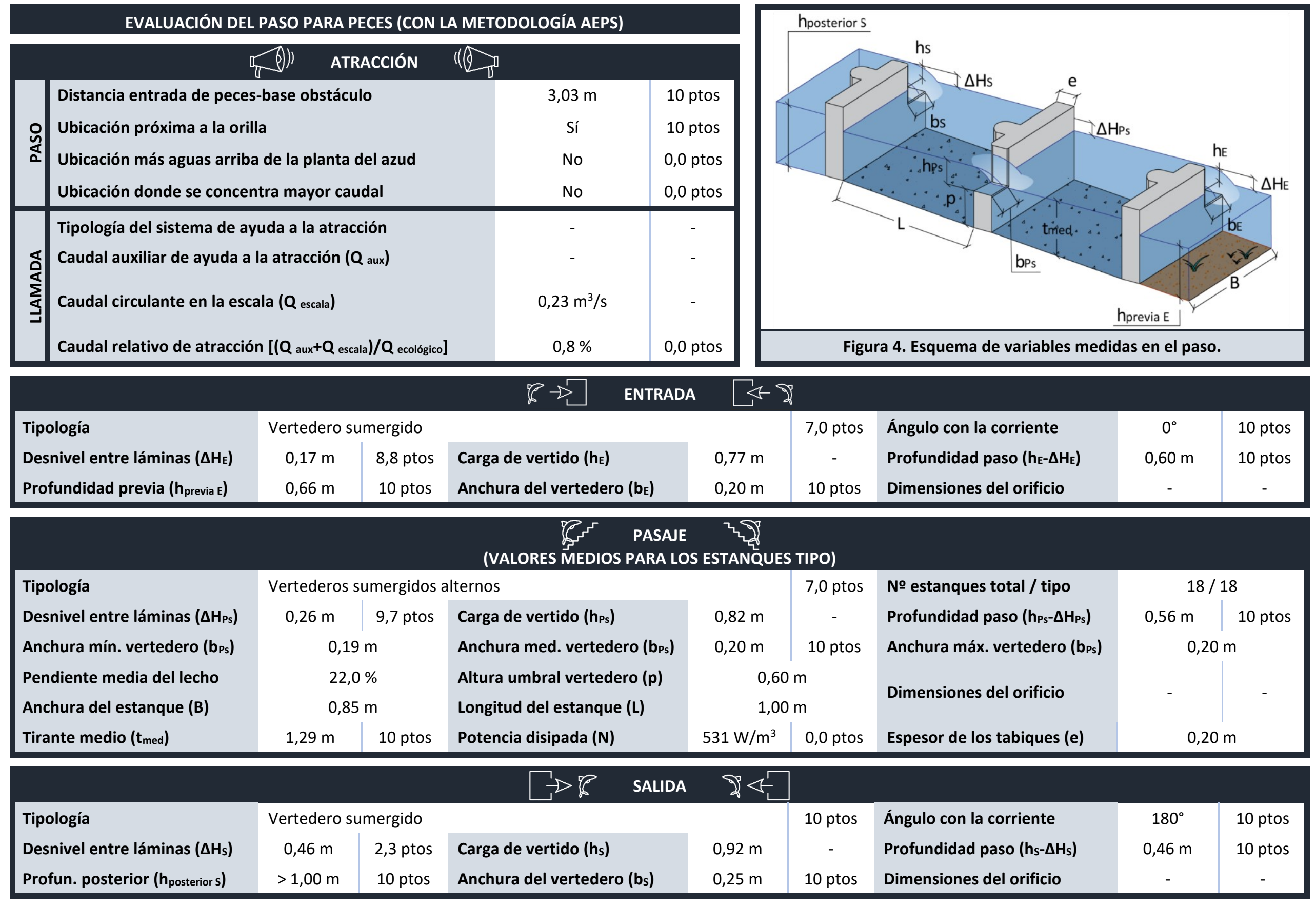




\section{PASO PARA PECES ASOCIADO AL AZUD DE LA CENTRAL HIDROELÉCTRICA DE MIRAT}

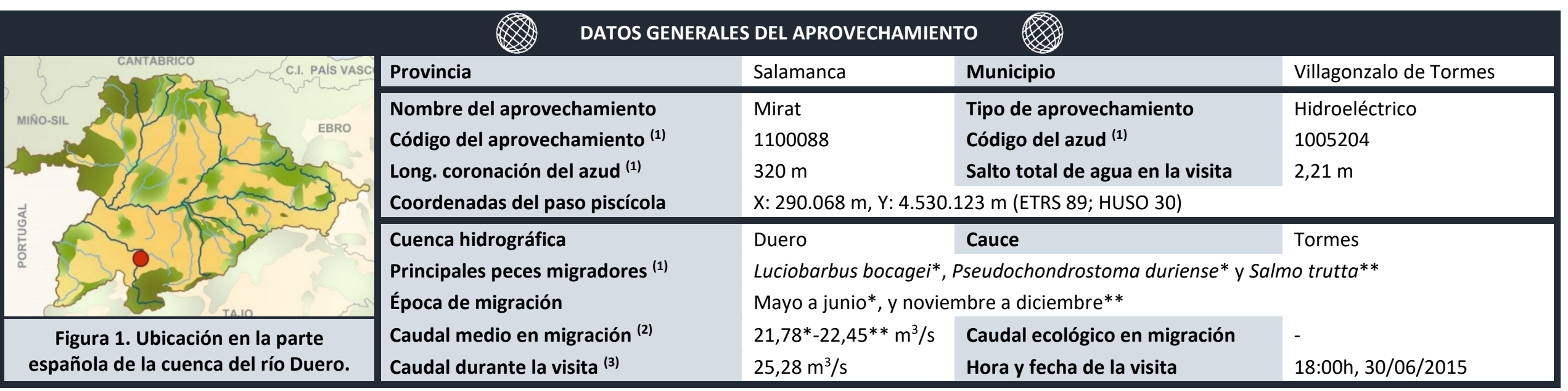

(1) Dato obtenido de MíRAME-IDE Duero. ${ }^{(2)}$ Dato obtenido del CEDEX Hidrológico. ${ }^{(3)}$ Dato obtenido del SAIH del Duero.

\begin{tabular}{|c|c|c|c|}
\hline Paso para peces de estanques & os conectados po & tederos sumergidos y orificios de fondo alternos & \\
\hline $\begin{array}{l}\text { Estado de mantenimiento y limpieza durante la evaluación } \\
\text { Solera naturalizada (con piedras) } \\
\text { Vertedero de umbral móvil en la entrada de peces }\end{array}$ & $\begin{array}{l}\text { Muy adecuado } \\
\text { Sí } \\
\text { No }\end{array}$ & $\begin{array}{l}\text { Compuerta en la salida de peces } \\
\text { Dispositivo para evitar la entrada de arrastres } \\
\text { Salida de peces segura (alejada del azud, turbinas, ...) }\end{array}$ & $\begin{array}{l}\text { Sí } \\
\text { No } \\
\text { Sí }\end{array}$ \\
\hline
\end{tabular}

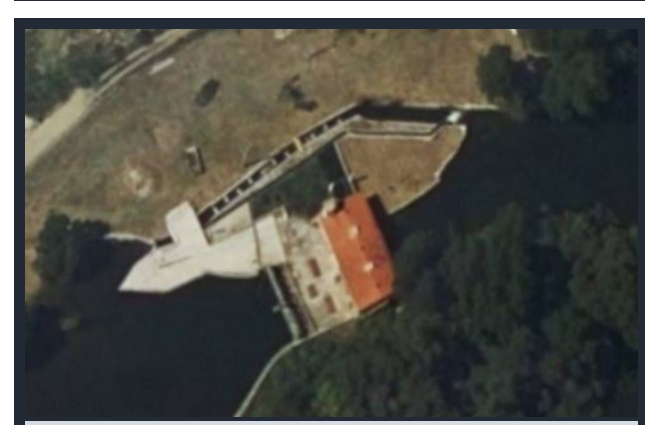

Figura 2. Ortofoto de la zona (fuente: SigPac).

\begin{tabular}{lccc}
\multicolumn{4}{c}{ RESUMEN DE LA EVALUACIÓN DEL PASO PARA PECES } \\
& \multicolumn{4}{c|}{ (CON LA METODOLOGÍA AEPS) } & \\
\hline Etapa o categoría & Puntuación & Evaluación & ¿Mejoras? \\
Atracción & 4,3 & Desfavorable & Muy necesarias \\
Entrada & 9,3 & Muy desfavorable & Imprescindibles \\
Pasaje & 9,6 & Muy desfavorable & Imprescindibles \\
Salida & 9,4 & Muy desfavorable & Imprescindibles \\
\hline
\end{tabular}

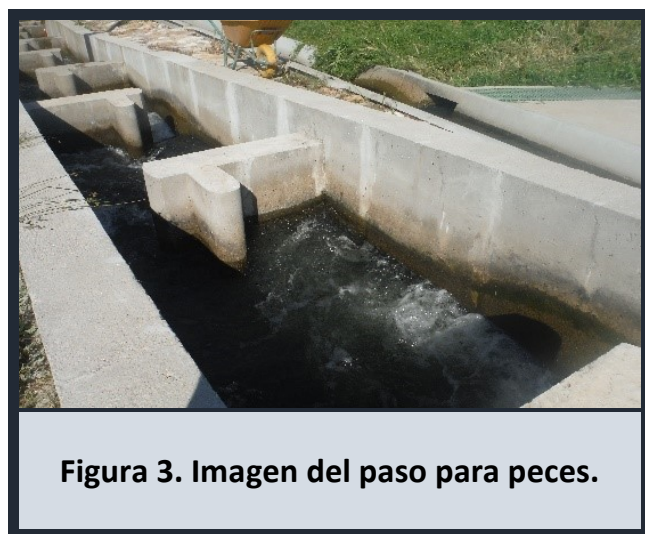




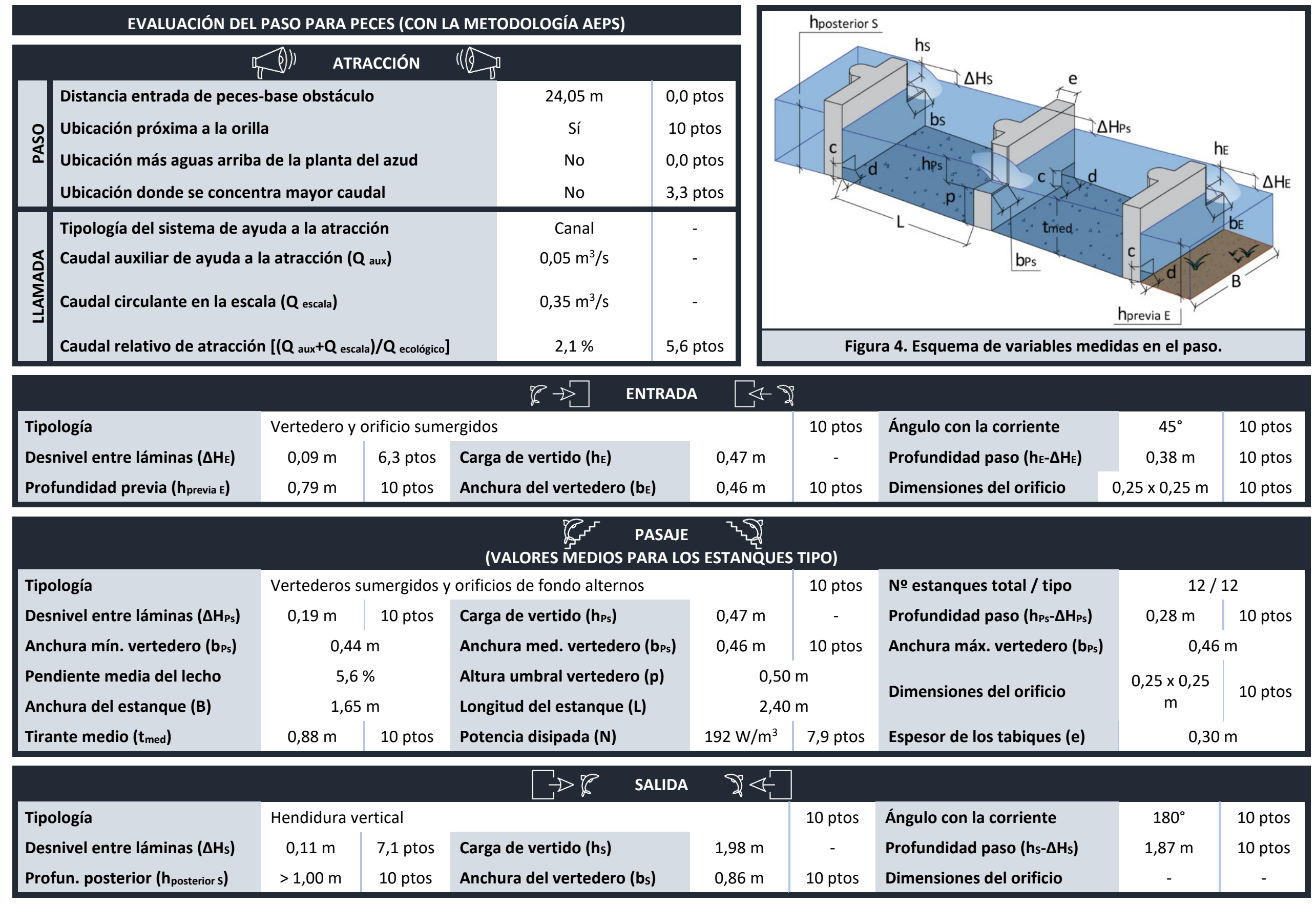




\section{PASO PARA PECES ASOCIADO AL AZUD DE LA CENTRAL HIDROELÉCTRICA DE SALTO DE LA FLECHA}

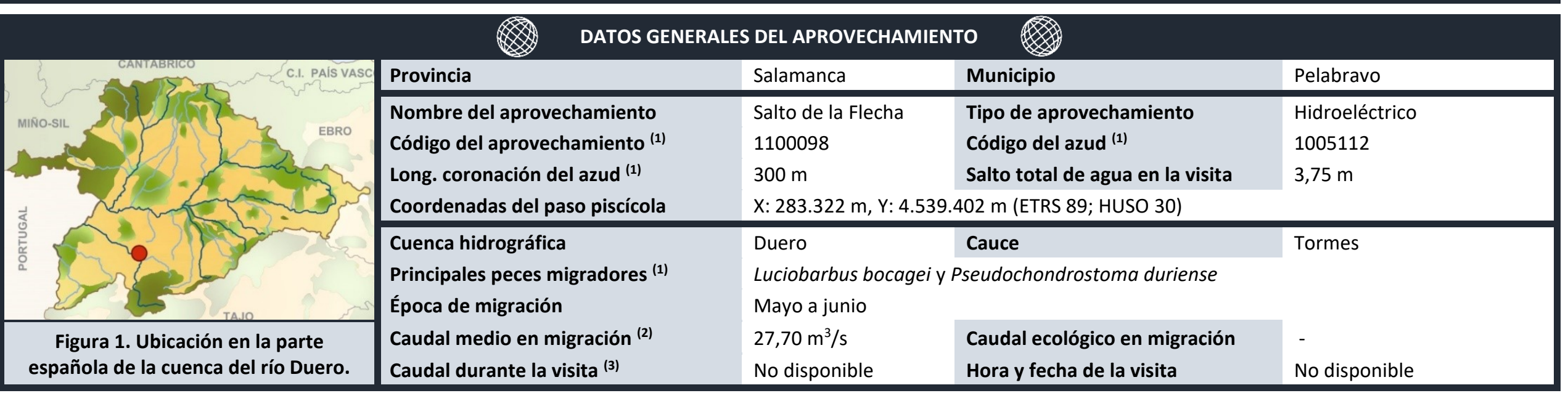

(1) Dato obtenido de MíRAME-IDE Duero. ${ }^{(2)}$ Dato obtenido del CEDEX Hidrológico. ${ }^{(3)}$ Dato obtenido del SAIH del Duero.

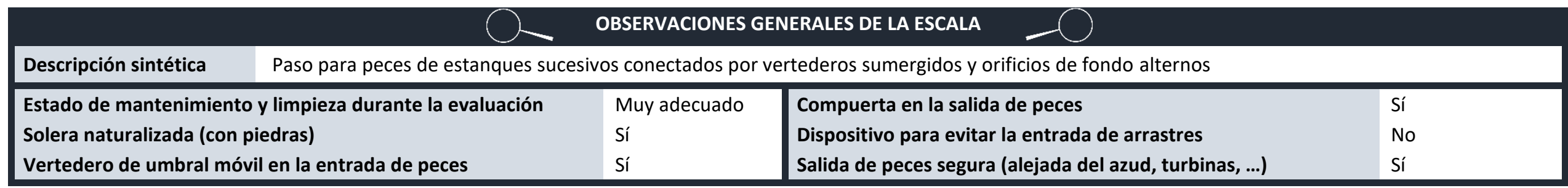

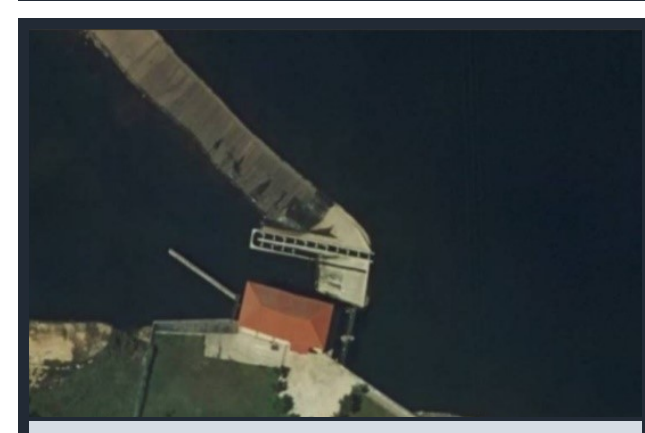

Figura 2. Ortofoto de la zona (fuente: SigPac).

\begin{tabular}{|c|c|c|c|}
\hline \multicolumn{4}{|c|}{$\begin{array}{l}\text { RESUMEN DE LA EVALUACIÓN DEL PASO PARA PECES } \\
\text { (CON LA METODOLOGÍA AEPS) }\end{array}$} \\
\hline Etapa o categoría & Puntuación & Evaluación & ¿Mejoras? \\
\hline Atracción & 7,2 & Favorable & Recomendables \\
\hline Entrada & 9,4 & Muy favorable & Opcionales \\
\hline Pasaje & 10,0 & Muy favorable & Opcionales \\
\hline Salida & 9,7 & Muy favorable & Opcionales \\
\hline
\end{tabular}

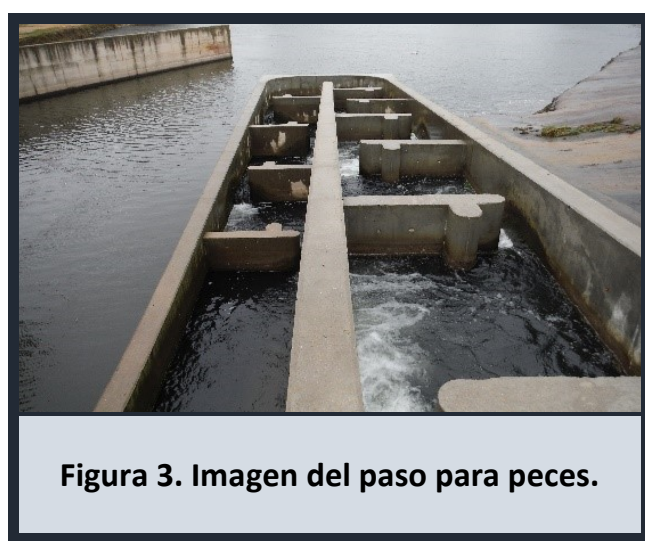




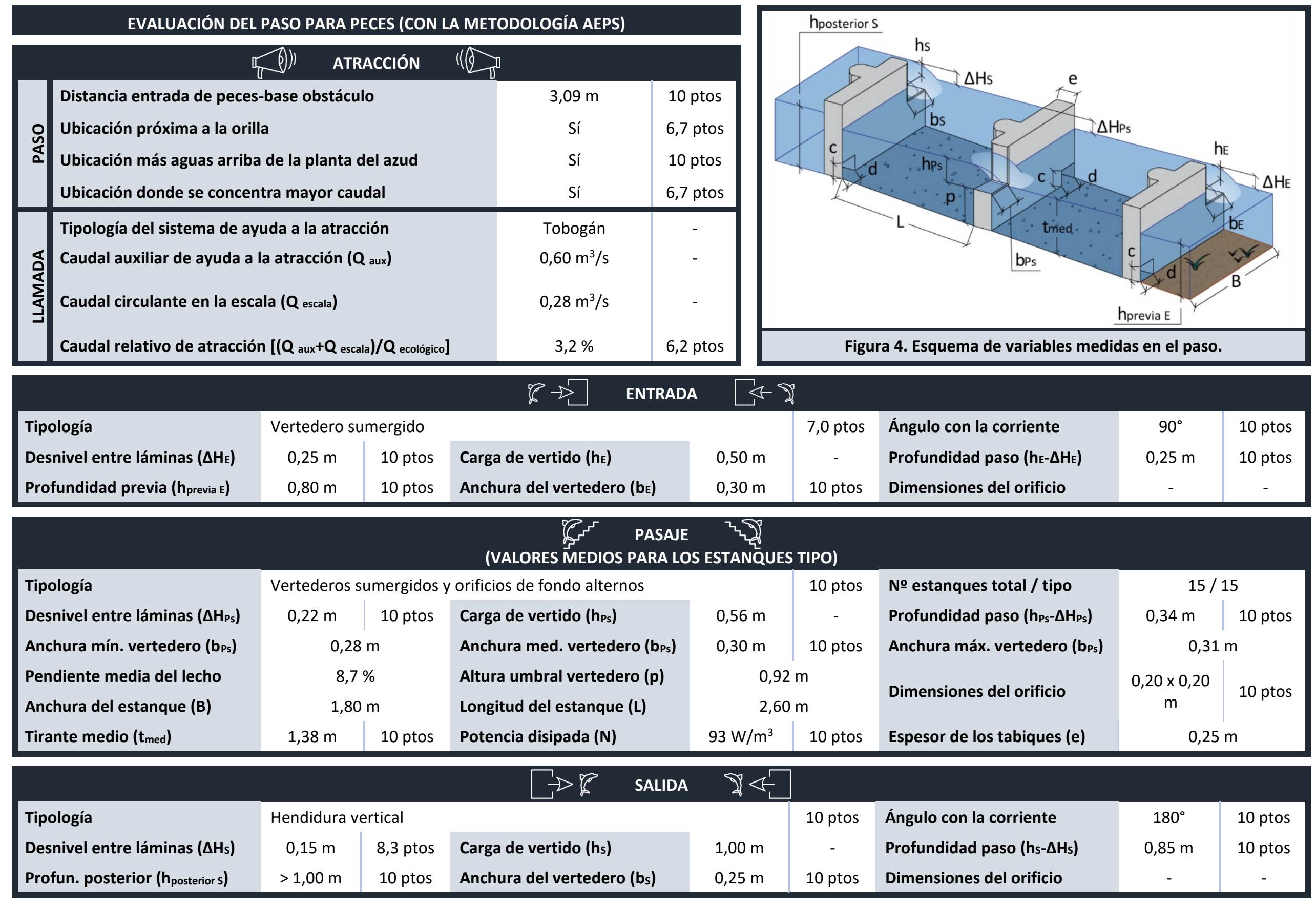




\section{PASO PARA PECES ASOCIADO AL AZUD DEL SALTO DE SAN FERNANDO (INFERIOR)}

\begin{tabular}{|c|c|c|c|c|}
\hline & Provincia & Salamanca & Municipio & Cespedosa de Tormes \\
\hline & $\begin{array}{l}\text { Nombre del aprovechamiento } \\
\text { Código del aprovechamiento } \\
\text { Long. coronación del azud } \\
\text { (1) } \\
\text { Coordenadas del paso piscícola }\end{array}$ & $\begin{array}{l}\text { Salto San Fernando } \\
1100181 \\
141 \mathrm{~m} \\
\mathrm{X}: 282.565 \mathrm{~m}, \mathrm{Y}: 4.48\end{array}$ & $\begin{array}{l}\text { Tipo de aprovechamiento } \\
\text { Código del azud (1) } \\
\text { Salto total de agua en la visita } \\
944 \text { m (ETRS 89; HUSO 30) }\end{array}$ & $\begin{array}{l}\text { Hidroeléctrico } \\
1004078 \\
13,4 \mathrm{~m}\end{array}$ \\
\hline & $\begin{array}{l}\text { Cuenca hidrográfica } \\
\text { Principales peces migradores }{ }^{(1)} \\
\text { Época de migración }\end{array}$ & \multicolumn{3}{|c|}{$\begin{array}{l}\text { Luciobarbus bocagei*, Pseudochondrostoma duriense* y Salmo trutta** } \\
\text { Mayo a junio*, y noviembre a diciembre** }\end{array}$} \\
\hline $\begin{array}{l}\text { Figura 1. Ubicación en la parte } \\
\text { española de la cuenca del río Duero. }\end{array}$ & $\begin{array}{l}\text { Caudal medio en migración (2) } \\
\text { Caudal durante la visita }{ }^{(3)}\end{array}$ & $\begin{array}{l}22,17 *-36.53 * * \mathrm{~m}^{3} / \mathrm{s} \\
\text { No disponible }\end{array}$ & $\begin{array}{l}\text { Caudal ecológico en migración } \\
\text { Hora y fecha de la visita }\end{array}$ & $\begin{array}{l}2,50 *-1,50 * * \mathrm{~m}^{3} / \mathrm{s} \\
\text { No disponible }\end{array}$ \\
\hline
\end{tabular}

(1) Dato obtenido de MíRAME-IDE Duero. ${ }^{(2)}$ Dato obtenido del CEDEX Hidrológico. ${ }^{(3)}$ Dato obtenido del SAIH del Duero.

\begin{tabular}{|c|c|c|c|}
\hline \multicolumn{4}{|c|}{ OBSERVACIONES GENERALES DE LA ESCALA } \\
\hline $\begin{array}{l}\text { Estado de mantenimiento y limpieza durante la evaluación } \\
\text { Solera naturalizada (con piedras) } \\
\text { Vertedero de umbral móvil en la entrada de peces }\end{array}$ & $\begin{array}{l}\text { Adecuado } \\
\text { Sí } \\
\text { Sí }\end{array}$ & $\begin{array}{l}\text { Compuerta en la salida de peces } \\
\text { Dispositivo para evitar la entrada de arrastres } \\
\text { Salida de peces segura (alejada del azud, turbinas, ...) }\end{array}$ & $\begin{array}{l}\text { Sí } \\
\text { Sí } \\
\text { Sí }\end{array}$ \\
\hline
\end{tabular}

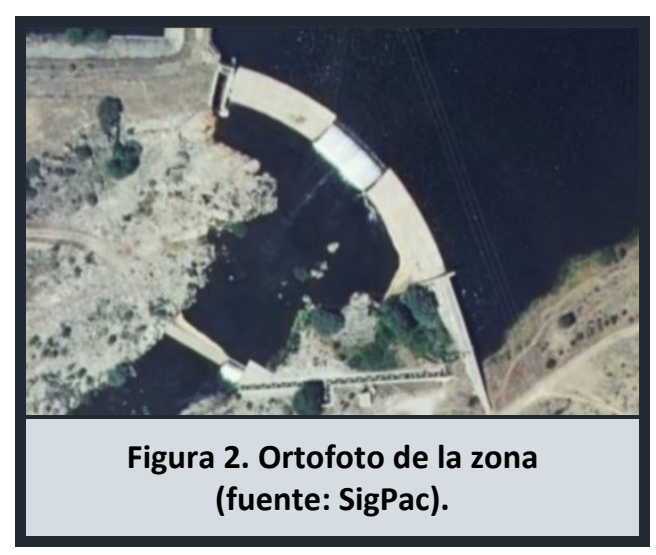

\begin{tabular}{lccl}
\multicolumn{5}{c}{ RESUMEN DE LA EVALUACIÓN DEL PASO PARA PECES } \\
(CON LA METODOLOGÍA AEPS) & \\
\hline $\begin{array}{l}\text { Etapa o categoría } \\
\text { Atracción }\end{array}$ & $\begin{array}{l}\text { Puntuación } \\
\text { Entrada }\end{array}$ & Evaluación & ¿Mejoras? \\
Pasaje & 10,0 & Muy favorable & Opcionales \\
Salida & 9,9 & Muy favorable & Opcionales \\
& 9,5 & Muy favorable & Opcionales \\
\end{tabular}

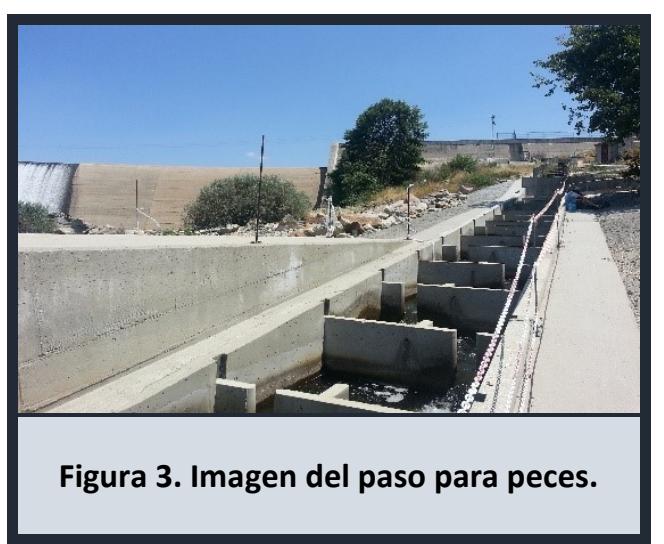




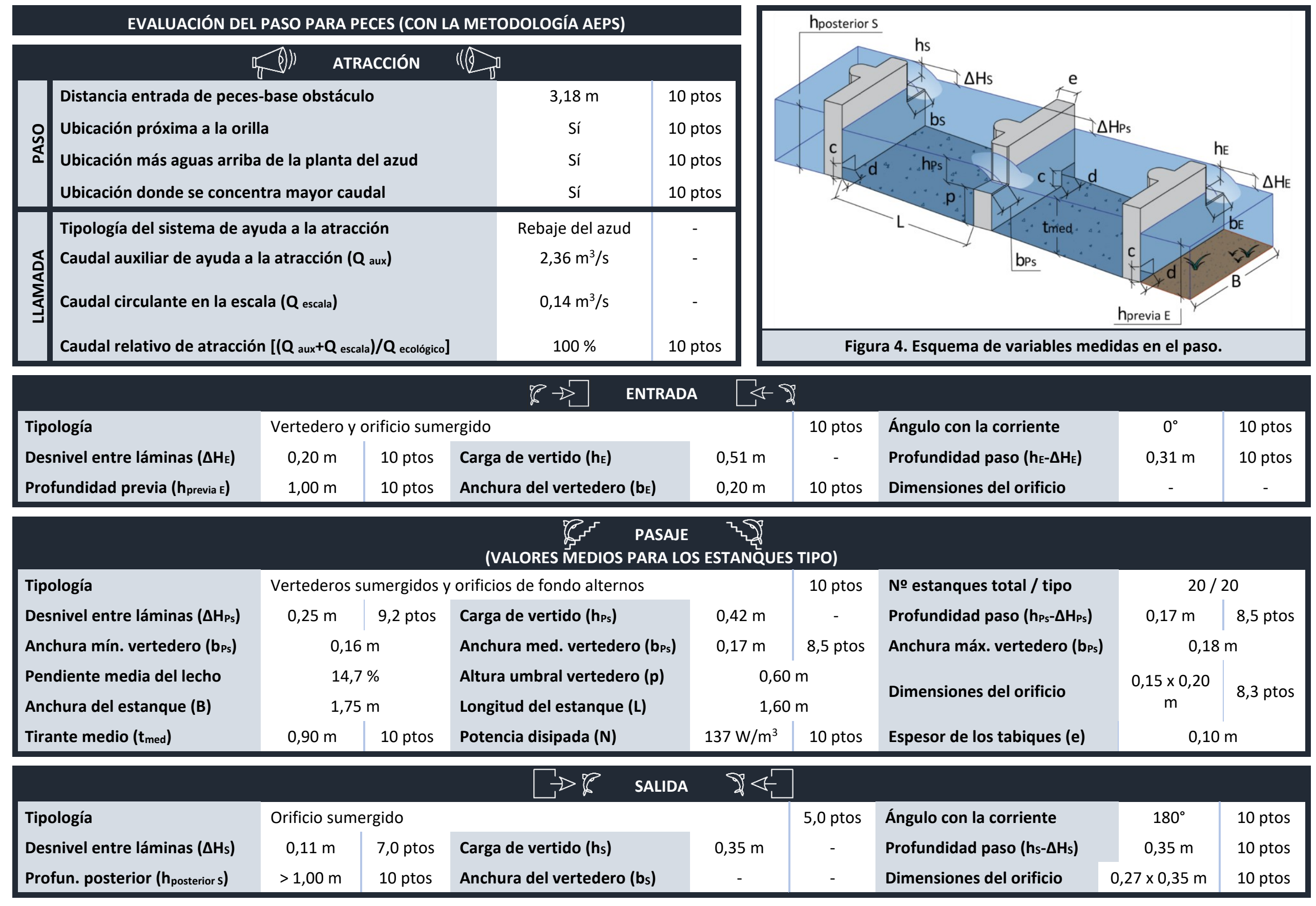




\section{PASO PARA PECES ASOCIADO AL AZUD DEL SALTO DE SAN FERNANDO (SUPERIOR)}

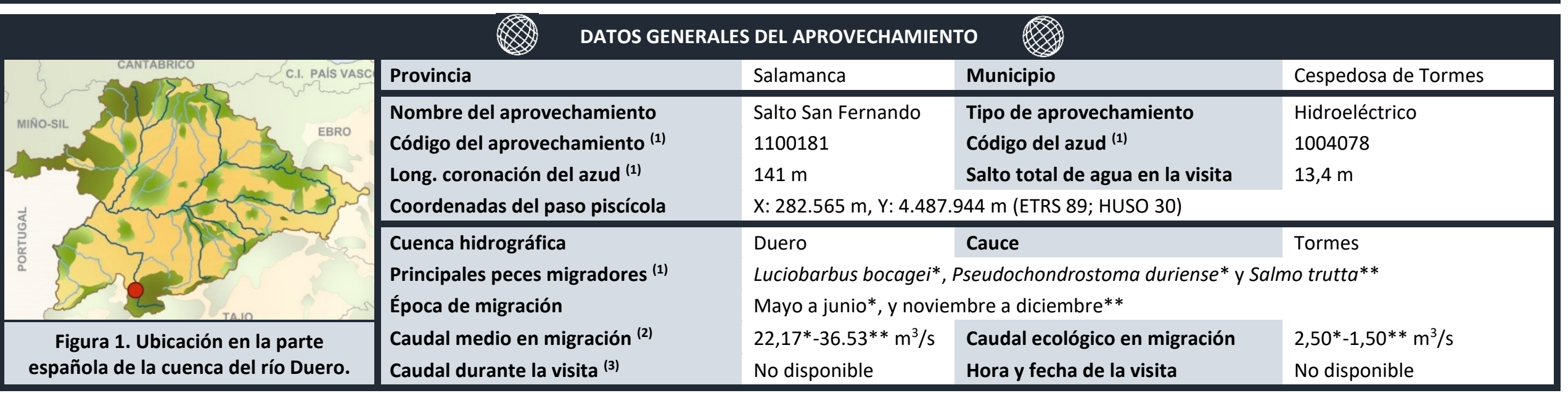

(1) Dato obtenido de MíRAME-IDE Duero. ${ }^{(2)}$ Dato obtenido del CEDEX Hidrológico. ${ }^{(3)}$ Dato obtenido del SAIH del Duero.

\begin{tabular}{|c|c|c|c|}
\hline \multicolumn{4}{|c|}{ OBSERVACIONES GENERALES DE LA ESCALA } \\
\hline $\begin{array}{l}\text { Estado de mantenimiento y limpieza durante la evaluación } \\
\text { Solera naturalizada (con piedras) } \\
\text { Vertedero de umbral móvil en la entrada de peces }\end{array}$ & $\begin{array}{l}\text { Adecuado } \\
\text { Sí } \\
\text { Sí }\end{array}$ & $\begin{array}{l}\text { Compuerta en la salida de peces } \\
\text { Dispositivo para evitar la entrada de arrastres } \\
\text { Salida de peces segura (alejada del azud, turbinas, ...) }\end{array}$ & $\begin{array}{l}\text { Sí } \\
\text { Sí } \\
\text { Sí }\end{array}$ \\
\hline
\end{tabular}

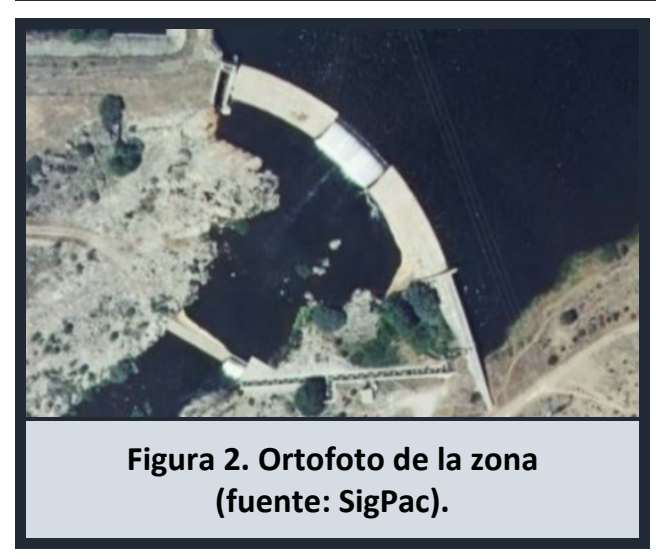

\begin{tabular}{|c|c|c|c|}
\hline \multicolumn{4}{|c|}{$\begin{array}{l}\text { RESUMEN DE LA EVALUACIÓN DEL PASO PARA PECES } \\
\text { (CON LA METODOLOGÍA AEPS) }\end{array}$} \\
\hline Etapa o categoría & Puntuación & Evaluación & ¿Mejoras? \\
\hline Atracción & 10,0 & Muy favorable & Opcionales \\
\hline Entrada & 9,9 & Muy favorable & Opcionales \\
\hline Pasaje & 8,9 & Muy favorable & Opcionales \\
\hline Salida & 8,4 & Muy favorable & Opcionales \\
\hline
\end{tabular}

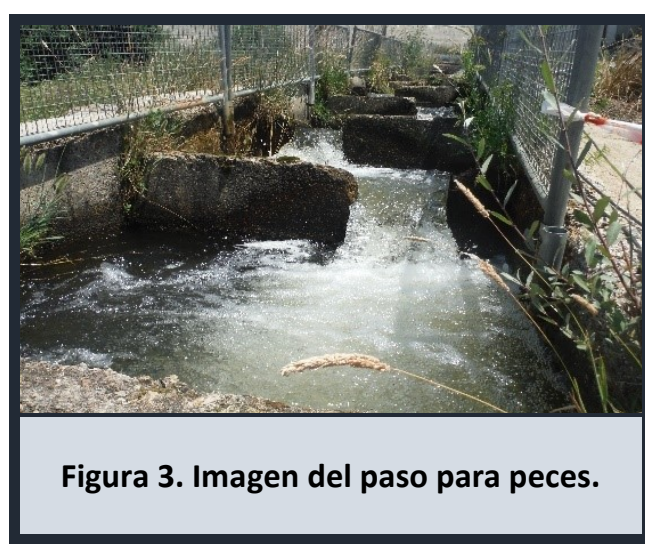




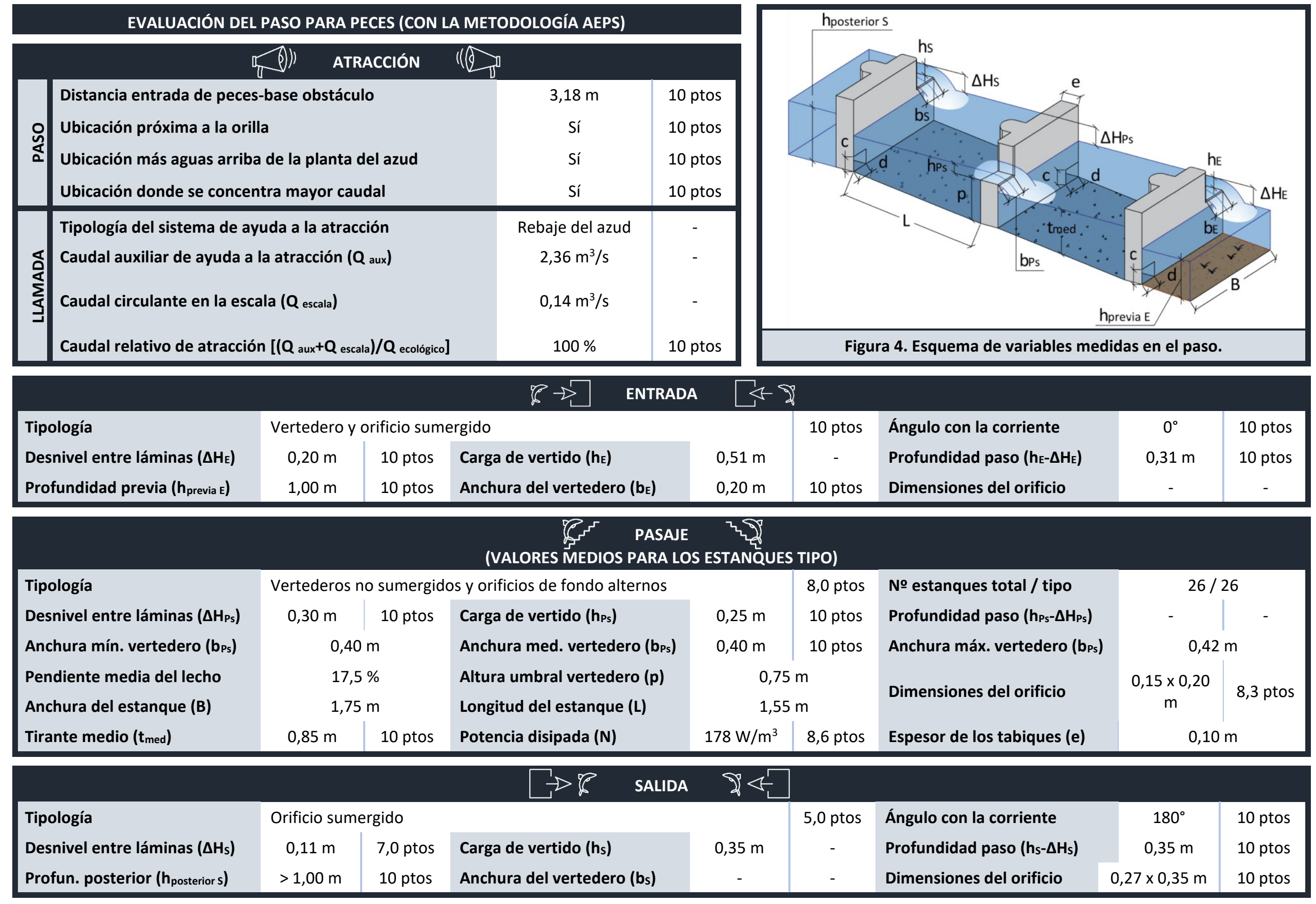




\section{PASO PARA PECES ASOCIADO AL AZUD DEL CANAL DEL DURATÓN}

\begin{tabular}{|c|c|c|c|c|}
\hline & Provincia & Segovia & Municipio & Laguna de Contreras \\
\hline & $\begin{array}{l}\text { Nombre del aprovechamiento } \\
\text { Código del aprovechamiento } \\
\text { Long. coronación del azud } \\
\text { (1) } \\
\text { Coordenadas del paso piscícola }\end{array}$ & $\begin{array}{l}\text { Salto de Valteína } \\
1100029 \\
54 \mathrm{~m} \\
\text { X: } 414.309 \text { m, Y: } 4 .\end{array}$ & $\begin{array}{l}\text { Tipo de aprovechamiento } \\
\text { Código del azud (1) } \\
\text { Salto total de agua en la visita } \\
21 \text { m (ETRS 89; HUSO 30) }\end{array}$ & $\begin{array}{l}\text { Riego e hidroeléctrico } \\
1005438 \\
1,35 \mathrm{~m}\end{array}$ \\
\hline & $\begin{array}{l}\text { Cuenca hidrográfica } \\
\text { Principales peces migradores }{ }^{(1)} \\
\text { Época de migración }\end{array}$ & $\begin{array}{l}\text { Duero } \\
\text { Luciobarbus bocag } \\
\text { Mayo a junio*, y n }\end{array}$ & $\begin{array}{l}\text { Cauce } \\
\text { Salmo trutta** } \\
\text { nbre a diciembre** }\end{array}$ & Duratón \\
\hline $\begin{array}{l}\text { Figura 1. Ubicación en la parte } \\
\text { española de la cuenca del río Duero. }\end{array}$ & $\begin{array}{l}\text { Caudal medio en migración (2) } \\
\text { Caudal durante la visita }{ }^{(3)}\end{array}$ & $\begin{array}{l}2,25 *-2,40 * * \mathrm{~m}^{3} / \mathrm{s} \\
4,66 \mathrm{~m}^{3} / \mathrm{s}\end{array}$ & $\begin{array}{l}\text { Caudal ecológico en migración } \\
\text { Hora y fecha de la visita }\end{array}$ & $\begin{array}{l}0,40 \mathrm{~m}^{3} / \mathrm{s} \\
12: 30 \mathrm{~h}, 15 / 03 / 2016\end{array}$ \\
\hline
\end{tabular}

(1) Dato obtenido de MíRAME-IDE Duero. ${ }^{(2)}$ Dato obtenido del CEDEX Hidrológico. ${ }^{(3)}$ Dato obtenido del SAIH del Duero.

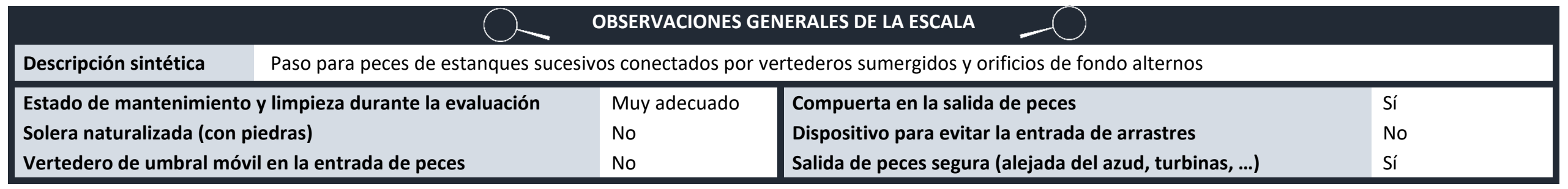

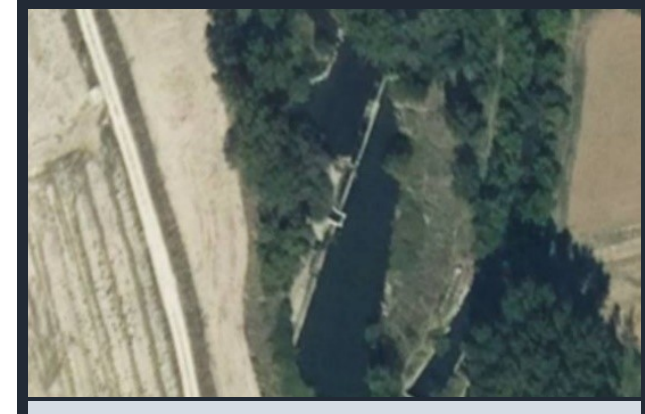

Figura 2. Ortofoto de la zona (fuente: SigPac).

\begin{tabular}{lccc}
\multicolumn{4}{c}{ RESUMEN DE LA EVALUACIÓN DEL PASO PARA PECES } \\
& \multicolumn{4}{c|}{ (CON LA METODOLOGÍA AEPS) } \\
\hline Etapa o categoría & Puntuación & Evaluación & ¿Mejoras? \\
Atracción & 5,0 & Desfavorable & Muy necesarias \\
Entrada & 8,7 & Muy favorable & Opcionales \\
Pasaje & 9,1 & Muy favorable & Opcionales \\
Salida & 8,2 & Muy favorable & Opcionales \\
\hline
\end{tabular}

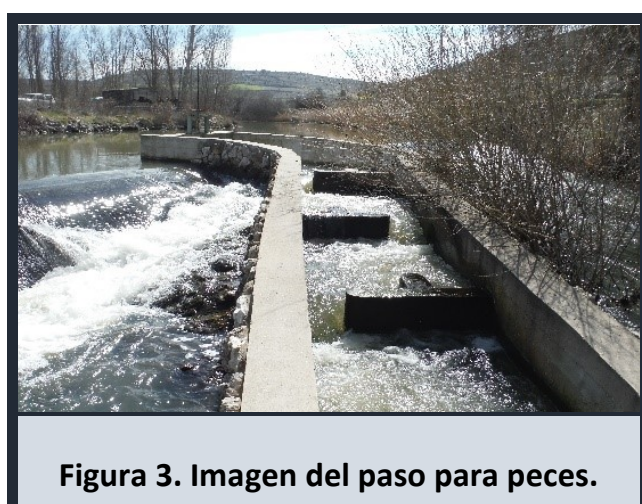




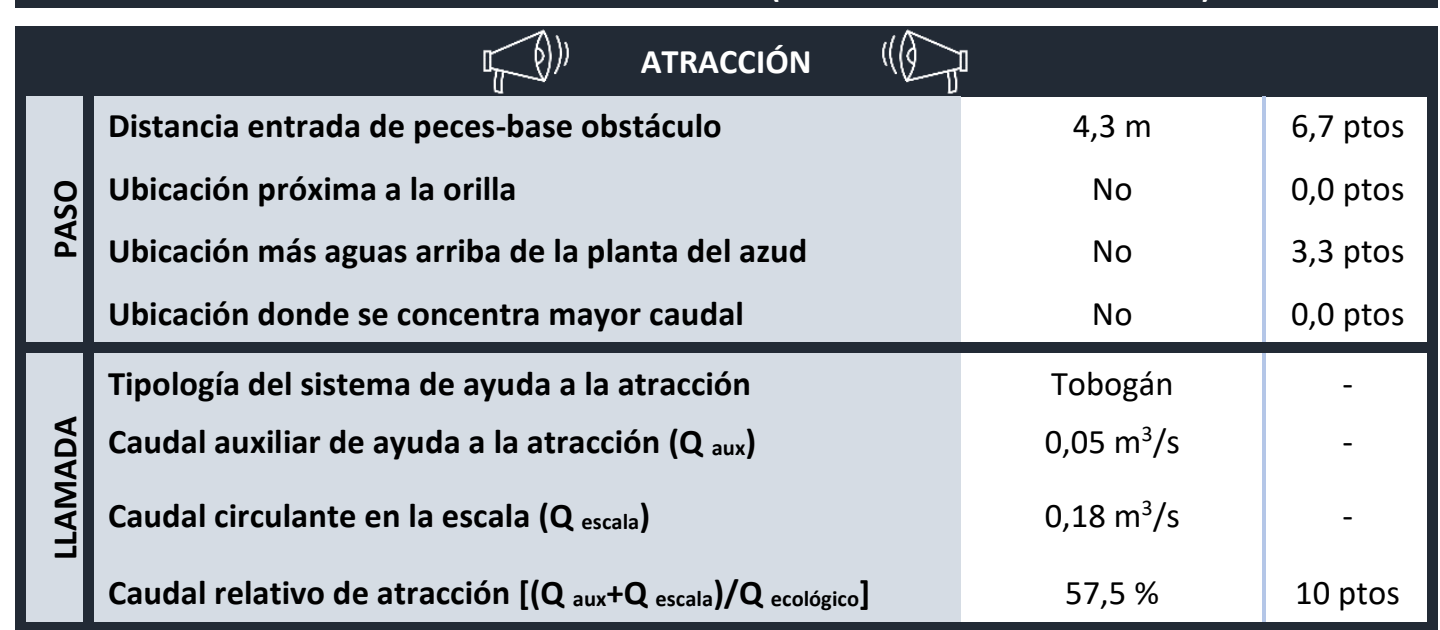

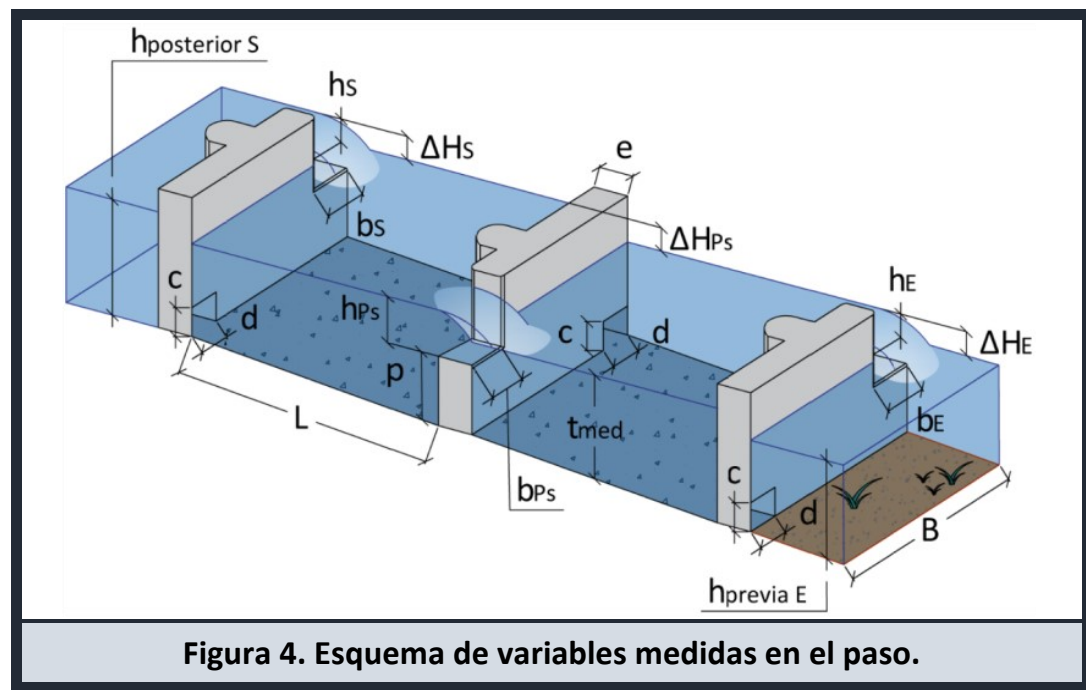

\begin{tabular}{|c|c|c|c|c|c|c|c|c|}
\hline & & & $b \rightarrow$ & & & & & \\
\hline Tipología & Vertedero & rificio sum & rgido & & 10 ptos & Ángulo con la corriente & $0^{\circ}$ & 10 ptos \\
\hline Desnivel entre láminas $\left(\Delta H_{\mathrm{E}}\right)$ & $0,06 \mathrm{~m}$ & 5,3 ptos & Carga de vertido $\left(h_{E}\right)$ & $0,53 \mathrm{~m}$ & - & Profundidad paso $\left(\mathrm{h}_{\mathrm{E}}-\Delta \mathrm{H}_{\mathrm{E}}\right)$ & $0,47 \mathrm{~m}$ & 10 ptos \\
\hline Profundidad previa ( $h_{\text {previa }}$ ) & $0,52 \mathrm{~m}$ & 9,0 ptos & Anchura del vertedero $\left(b_{E}\right)$ & $0,24 \mathrm{~m}$ & 10 ptos & Dimensiones del orificio & $0,15 \times 0,20 \mathrm{~m}$ & 8,3 ptos \\
\hline
\end{tabular}

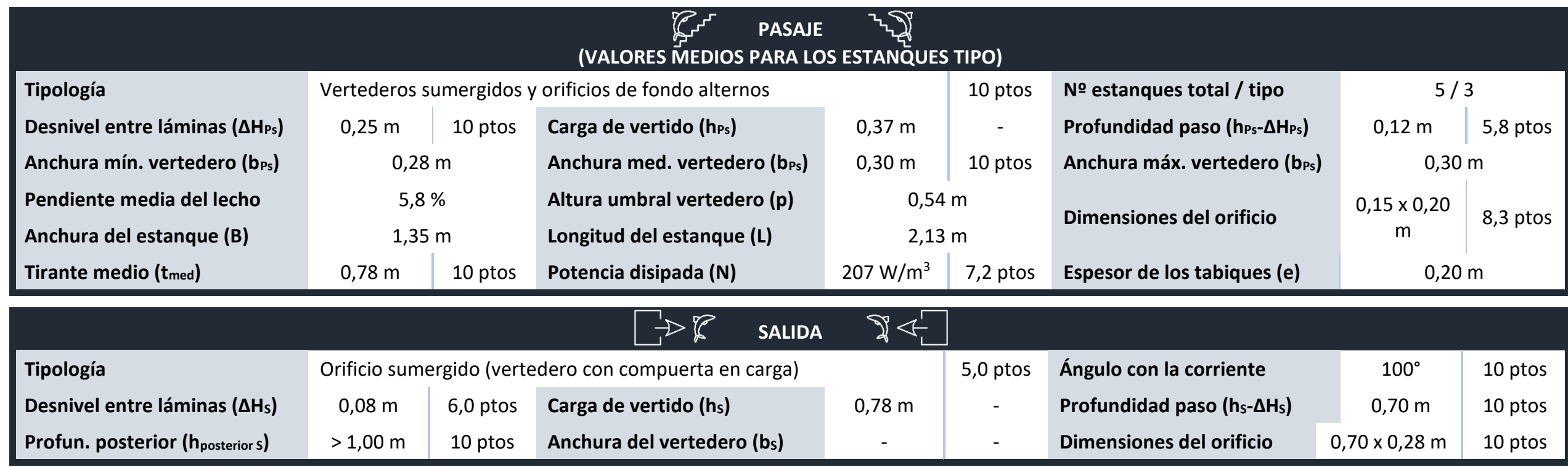




\section{PASO PARA PECES ASOCIADO AL AZUD DE LA CENTRAL HIDROELÉCTRICA DE LA CONFIANZA}

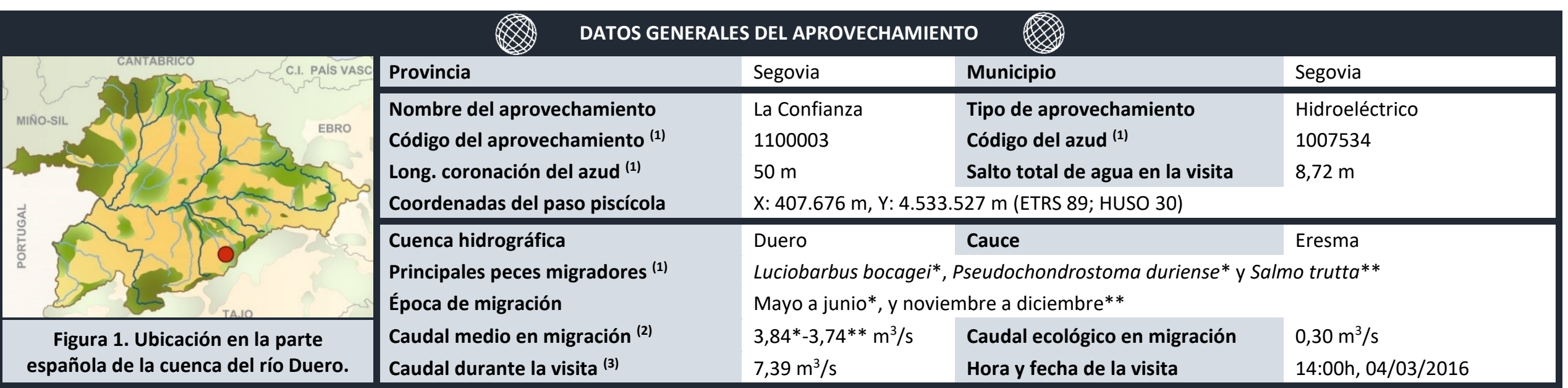

${ }^{(1)}$ Dato obtenido de MíRAME-IDE Duero. ${ }^{(2)}$ Dato obtenido del CEDEX Hidrológico. ${ }^{(3)}$ Dato obtenido del SAIH del Duero.

\begin{tabular}{|c|c|c|c|}
\hline Paso para peces de estanques & os conectado & tederos sumergidos y orifcios de fondo alternos & \\
\hline $\begin{array}{l}\text { Estado de mantenimiento y limpieza durante la evaluación } \\
\text { Solera naturalizada (con piedras) } \\
\text { Vertedero de umbral móvil en la entrada de peces }\end{array}$ & $\begin{array}{l}\text { Deficiente } \\
\text { No } \\
\text { No }\end{array}$ & $\begin{array}{l}\text { Compuerta en la salida de peces } \\
\text { Dispositivo para evitar la entrada de arrastres } \\
\text { Salida de peces segura (alejada del azud, turbinas, ...) }\end{array}$ & $\begin{array}{l}\text { No } \\
\text { Sí } \\
\text { No }\end{array}$ \\
\hline
\end{tabular}

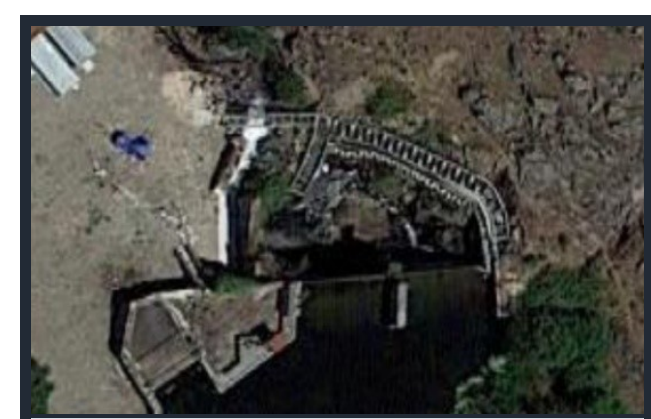

Figura 2. Ortofoto de la zona (fuente: Google Maps).

\begin{tabular}{|c|c|c|c|}
\hline \multicolumn{4}{|c|}{$\begin{array}{l}\text { RESUMEN DE LA EVALUACIÓN DEL PASO PARA PECES } \\
\text { (CON LA METODOLOGÍA AEPS) }\end{array}$} \\
\hline Etapa o categoría & Puntuación & Evaluación & ¿Mejoras? \\
\hline Atracción & 5,8 & Desfavorable & Muy necesarias \\
\hline Entrada & 8,8 & Muy favorable & Opcionales \\
\hline Pasaje & 0,0 & Muy desfavorable & Imprescindibles \\
\hline Salida & 8,6 & Muy favorable & Opcionales \\
\hline
\end{tabular}

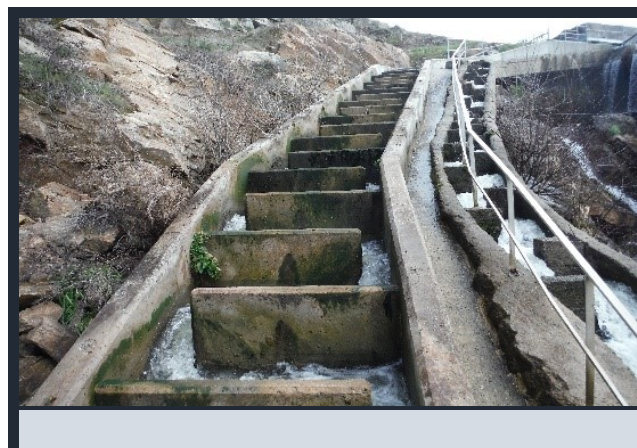

Figura 3. Imagen del paso para peces. 


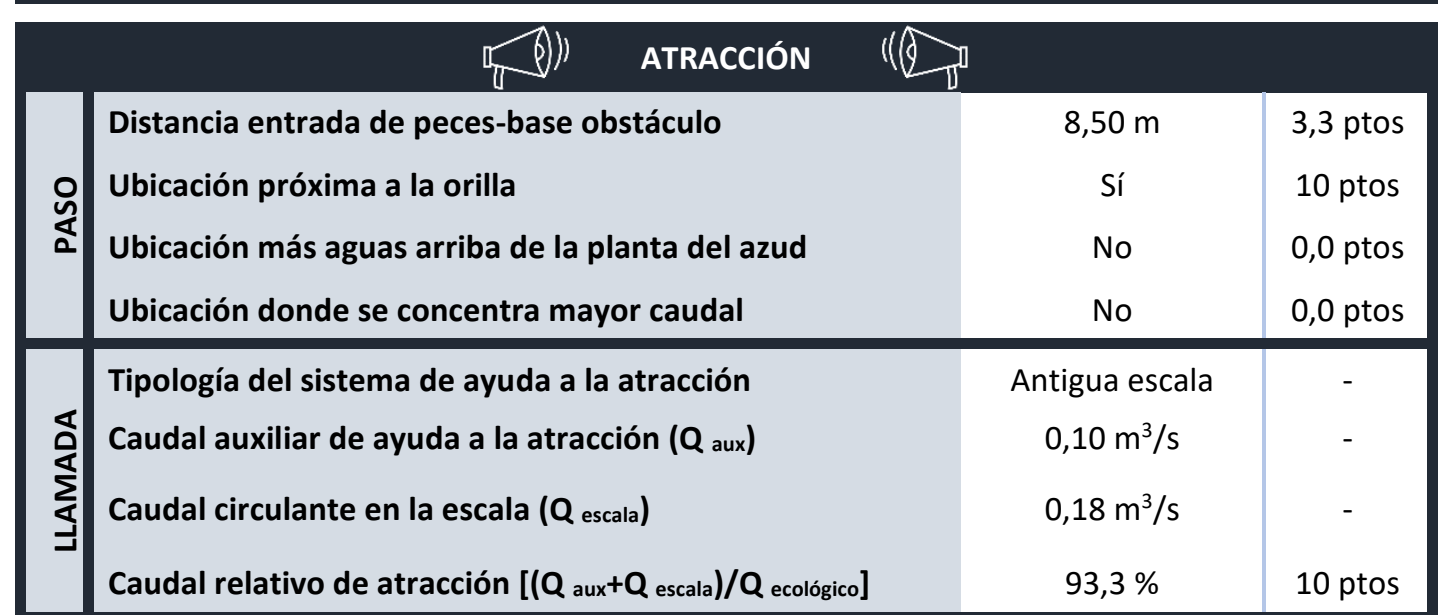

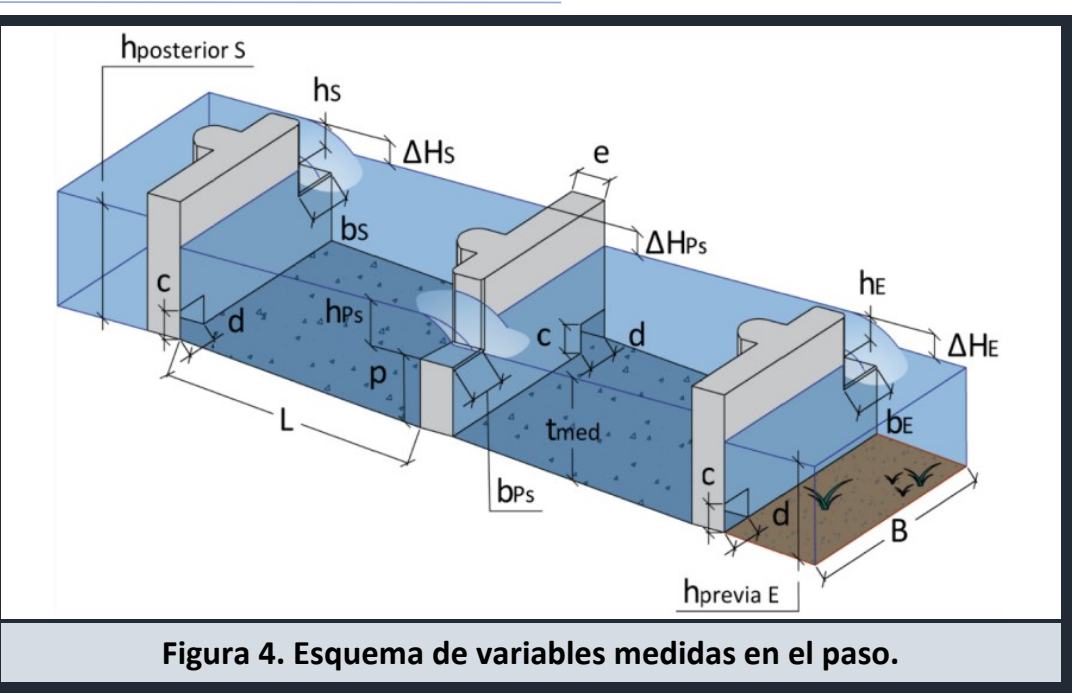

\begin{tabular}{|c|c|c|c|c|c|c|c|c|}
\hline & & & $\sqrt{6} \rightarrow$ & 5 & & & & \\
\hline Tipología & Vertedero & nergido & & & 7,0 ptos & Ángulo con la corriente & $70^{\circ}$ & 10 ptos \\
\hline Desnivel entre láminas $\left(\Delta \mathrm{H}_{\mathrm{E}}\right)$ & $0,10 \mathrm{~m}$ & 6,7 ptos & Carga de vertido $\left(h_{E}\right)$ & $0,79 \mathrm{~m}$ & - & Profundidad paso $\left(h_{E}-\Delta H_{E}\right)$ & $0,69 \mathrm{~m}$ & 10 ptos \\
\hline Profundidad previa ( $h_{\text {previa }}$ ) & $0,83 \mathrm{~m}$ & 10 ptos & Anchura del vertedero $\left(b_{E}\right)$ & $0,20 \mathrm{~m}$ & 10 ptos & Dimensiones del orificio & - & - \\
\hline
\end{tabular}

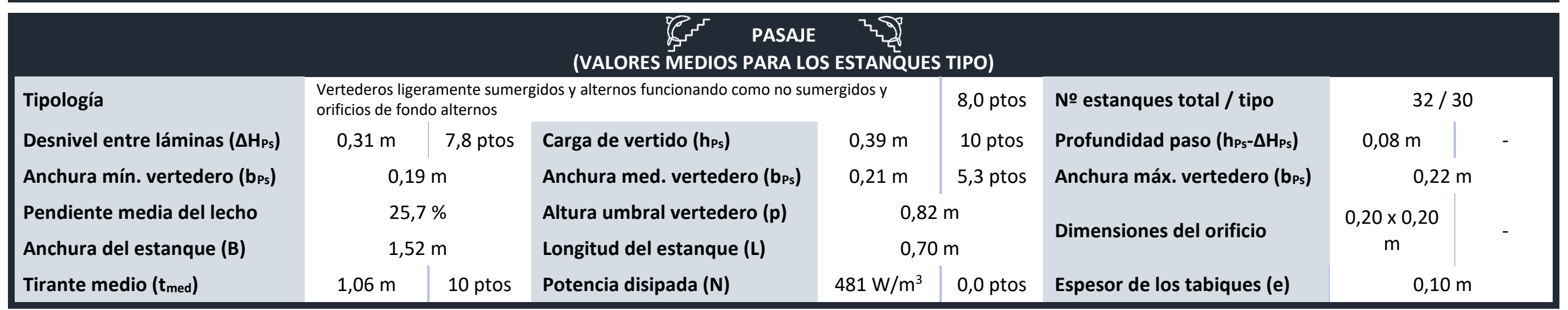

\begin{tabular}{|c|c|c|c|c|c|c|c|c|}
\hline Tipología & Vertedero & nergido & & & 10 ptos & Ángulo con la corriente & $180^{\circ}$ & 10 ptos \\
\hline Desnivel entre láminas $\left(\Delta \mathrm{H}_{s}\right)$ & $0,10 \mathrm{~m}$ & 6,7 ptos & Carga de vertido (hs) & $0,37 \mathrm{~m}$ & - & Profundidad paso (hs- $\left.\Delta H_{s}\right)$ & $0,27 \mathrm{~m}$ & 10 ptos \\
\hline Profun. posterior ( $h_{\text {posterior } s)}$ & $0,27 \mathrm{~m}$ & 5,9 ptos & Anchura del vertedero (bs) & $0,70 \mathrm{~m}$ & 10 ptos & Dimensiones del orificio & - & - \\
\hline
\end{tabular}




\section{PASO PARA PECES ASOCIADO AL AZUD DEL EMBALSE DE LA IBIENZA}

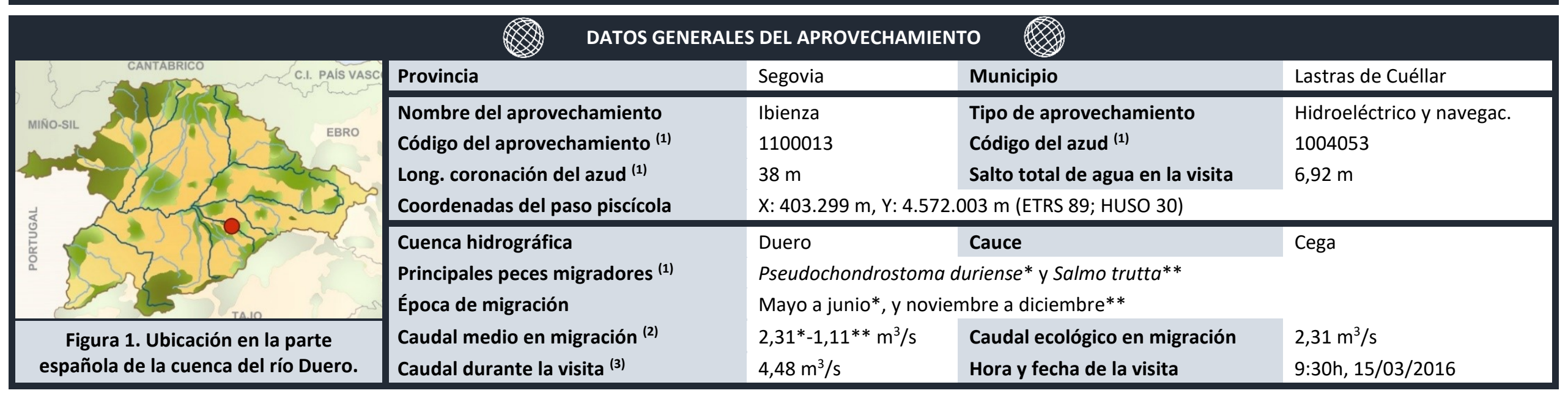

(1) Dato obtenido de MíRAME-IDE Duero. ${ }^{(2)}$ Dato obtenido del CEDEX Hidrológico. ${ }^{(3)}$ Dato obtenido del SAIH del Duero.

\begin{tabular}{|c|c|c|c|}
\hline Paso para peces de estanques st & os conectad & tederos sumergidos y orificios de fondo alternos & \\
\hline $\begin{array}{l}\text { Estado de mantenimiento y limpieza durante la evaluación } \\
\text { Solera naturalizada (con piedras) } \\
\text { Vertedero de umbral móvil en la entrada de peces }\end{array}$ & $\begin{array}{l}\text { Adecuado } \\
\text { Sí } \\
\text { No }\end{array}$ & $\begin{array}{l}\text { Compuerta en la salida de peces } \\
\text { Dispositivo para evitar la entrada de arrastres } \\
\text { Salida de peces segura (alejada del azud, turbinas, ...) }\end{array}$ & $\begin{array}{l}\text { Sí } \\
\text { No } \\
\text { Sí }\end{array}$ \\
\hline
\end{tabular}

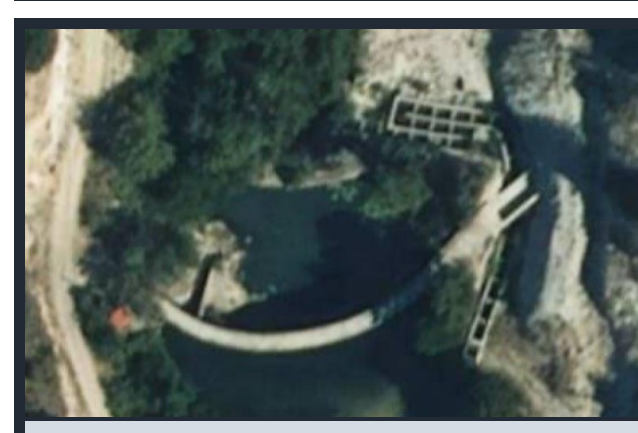

Figura 2. Ortofoto de la zona (fuente: SigPac).

\begin{tabular}{lccc}
\multicolumn{4}{c}{ RESUMEN DE LA EVALUACIÓN DEL PASO PARA PECES } \\
& \multicolumn{4}{c|}{ (CON LA METODOLOGÍA AEPS) } & \\
\hline Etapa o categoría & Puntuación & Evaluación & ¿Mejoras? \\
Atracción & 8,7 & Muy favorable & Opcionales \\
Entrada & 7,9 & Favorable & Recomendables \\
Pasaje & 0,0 & Muy desfavorable & Imprescindibles \\
Salida & 9,4 & Muy favorable & Opcionales \\
\hline
\end{tabular}

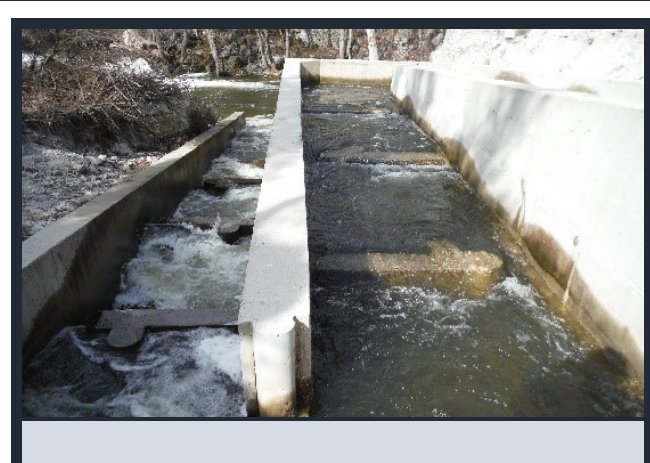

Figura 3. Imagen del paso para peces. 


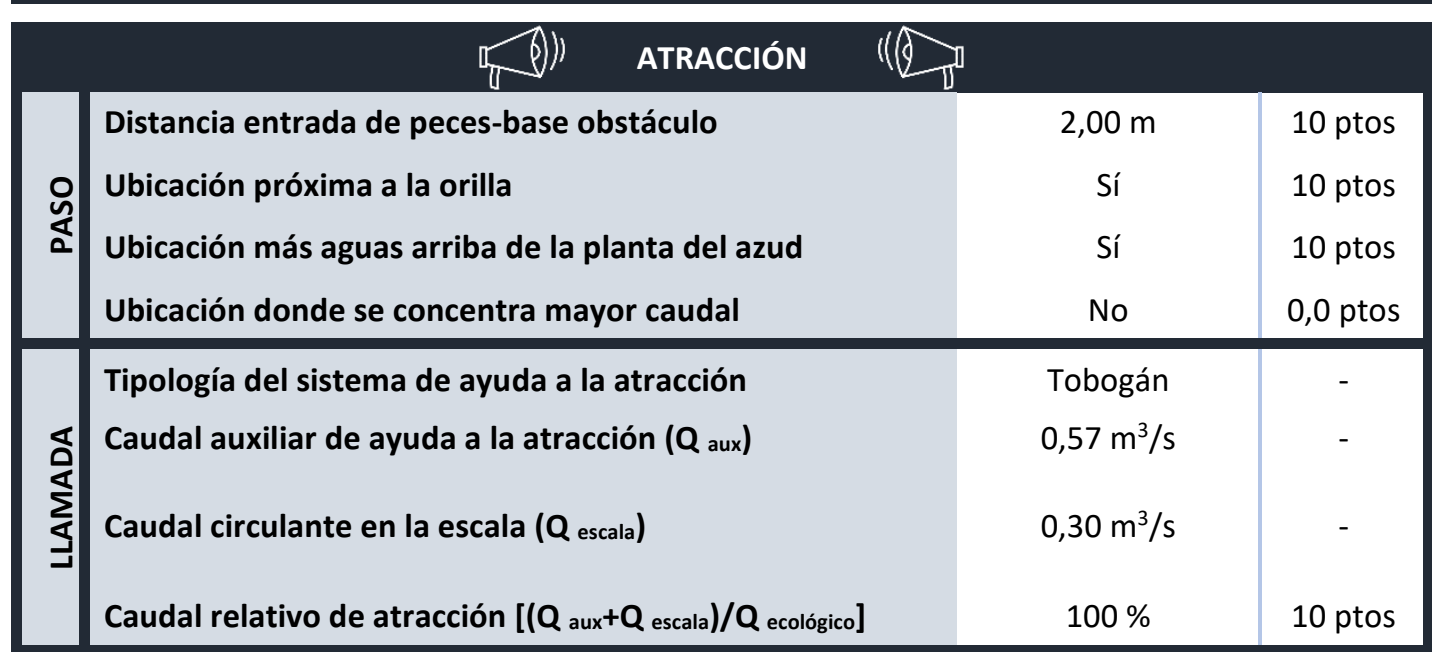

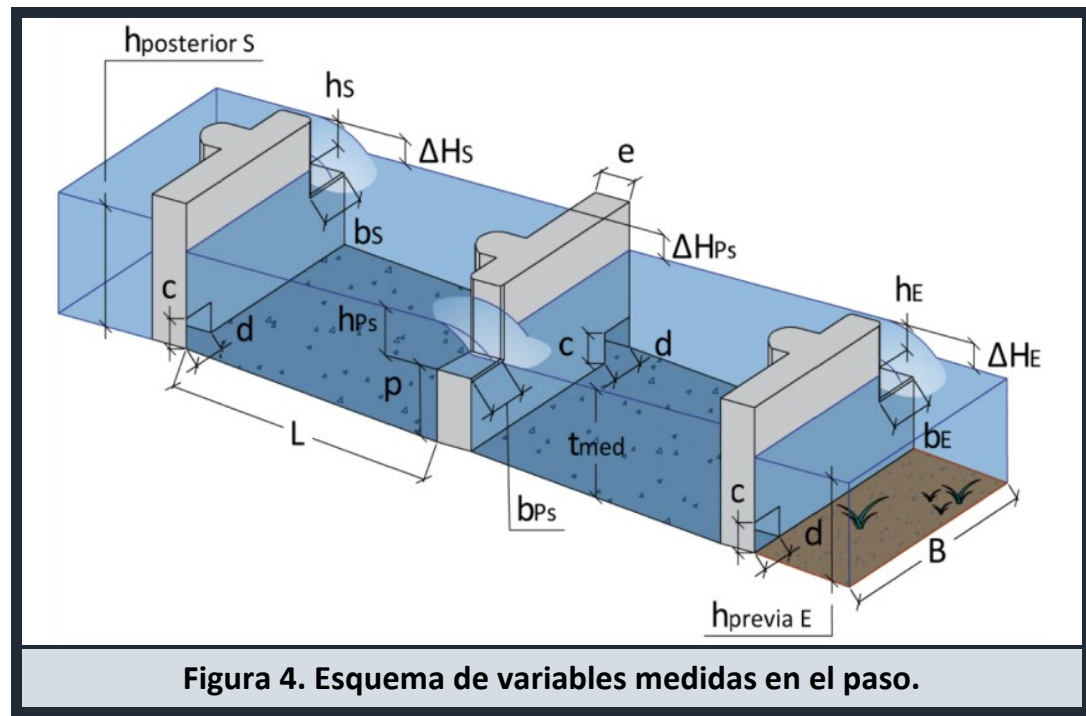

\begin{tabular}{|c|c|c|c|c|c|c|c|c|}
\hline & & & $b \rightarrow$ & & & & & \\
\hline Tipología & \multicolumn{3}{|c|}{ Vertedero y orificio sumergido } & \multirow{3}{*}{$\begin{array}{l}0,92 \mathrm{~m} \\
0,23 \mathrm{~m}\end{array}$} & \multirow{3}{*}{$\begin{array}{c}10 \text { ptos } \\
- \\
10 \text { ptos }\end{array}$} & \multirow{3}{*}{$\begin{array}{l}\text { Ángulo con la corriente } \\
\text { Profundidad paso }\left(h_{E}-\Delta H_{E}\right) \\
\text { Dimensiones del orificio }\end{array}$} & \multirow{3}{*}{$\begin{array}{c}80^{\circ} \\
0,47 \mathrm{~m} \\
0,20 \times 0,20 \mathrm{~m}\end{array}$} & \multirow{3}{*}{$\begin{array}{l}10 \text { ptos } \\
10 \text { ptos } \\
10 \text { ptos }\end{array}$} \\
\hline Desnivel entre láminas $\left(\Delta \mathrm{H}_{\mathrm{E}}\right)$ & $0,45 \mathrm{~m}$ & 2,4 ptos & Carga de vertido $\left(h_{E}\right)$ & & & & & \\
\hline Profundidad previa ( $h_{\text {previa E }}$ ) & $1,05 \mathrm{~m}$ & 10 ptos & Anchura del vertedero $\left(b_{E}\right)$ & & & & & \\
\hline
\end{tabular}

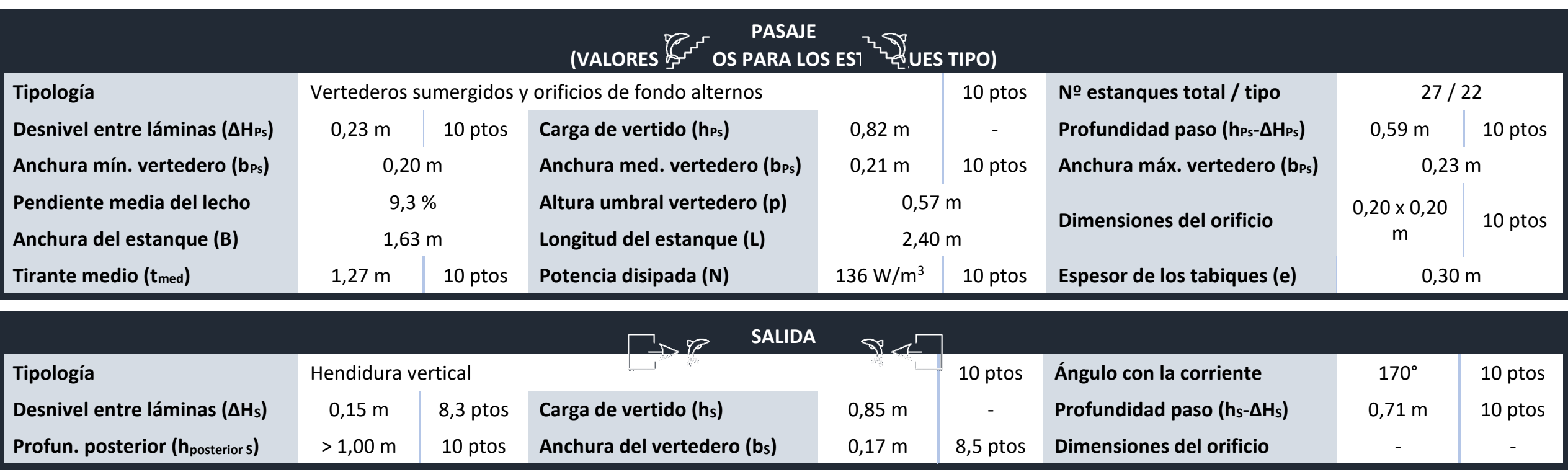




\section{PASO PARA PECES ASOCIADO AL AZUD DE LA CENTRAL DE SALTO DEL OLVIDO}

\begin{tabular}{|c|c|c|c|c|}
\hline & Provincia & Segovia & Municipio & Sitio de San Ildefonso \\
\hline & $\begin{array}{l}\text { Nombre del aprovechamiento } \\
\text { Código del aprovechamiento } \\
\text { Long. coronación del azud } \\
\text { (1) } \\
\text { Coordenadas del paso piscícola }\end{array}$ & $\begin{array}{l}\text { Salto del Olvido } \\
1100002 \\
67 \mathrm{~m} \\
\mathrm{X}: 413.982 \mathrm{~m}, \mathrm{Y}: 4.525 .9\end{array}$ & $\begin{array}{l}\text { Tipo de aprovechamiento } \\
\text { Código del azud (1) } \\
\text { Salto total de agua en la visita } \\
939 \text { m (ETRS 89; HUSO 30) }\end{array}$ & $\begin{array}{l}\text { Hidroeléctrico } \\
1005361 \\
11,86 \mathrm{~m}\end{array}$ \\
\hline & $\begin{array}{l}\text { Cuenca hidrográfica } \\
\text { Principales peces migradores }{ }^{(1)} \\
\text { Época de migración }\end{array}$ & $\begin{array}{l}\text { Duero } \\
\text { Salmo trutta } \\
\text { Noviembre a diciembre }\end{array}$ & Cauce & Eresma \\
\hline $\begin{array}{c}\text { Figura 1. Ubicación en la parte } \\
\text { española de la cuenca del río Duero. }\end{array}$ & $\begin{array}{l}\text { Caudal medio en migración (2) } \\
\text { Caudal durante la visita }{ }^{(3)}\end{array}$ & $\begin{array}{l}3,84 \mathrm{~m}^{3} / \mathrm{s} \\
7,19 \mathrm{~m}^{3} / \mathrm{s}\end{array}$ & $\begin{array}{l}\text { Caudal ecológico en migración } \\
\text { Hora y fecha de la visita }\end{array}$ & $11: 00 h, 04 / 03 / 2016$ \\
\hline
\end{tabular}

${ }^{(1)}$ Dato obtenido de MíRAME-IDE Duero. ${ }^{(2)}$ Dato obtenido del CEDEX Hidrológico. ${ }^{(3)}$ Dato obtenido del SAIH del Duero.

\begin{tabular}{|c|c|c|c|}
\hline \multicolumn{4}{|c|}{ OBSERVACIONES GENERALES DE LA ESCALA } \\
\hline $\begin{array}{l}\text { Estado de mantenimiento y limpieza durante la evaluación } \\
\text { Solera naturalizada (con piedras) } \\
\text { Vertedero de umbral móvil en la entrada de peces }\end{array}$ & $\begin{array}{l}\text { No adecuado } \\
\text { Sí } \\
\text { No }\end{array}$ & $\begin{array}{l}\text { Compuerta en la salida de peces } \\
\text { Dispositivo para evitar la entrada de arrastres } \\
\text { Salida de peces segura (alejada del azud, turbinas, ...) }\end{array}$ & $\begin{array}{l}\text { No } \\
\text { No } \\
\text { Sí }\end{array}$ \\
\hline
\end{tabular}

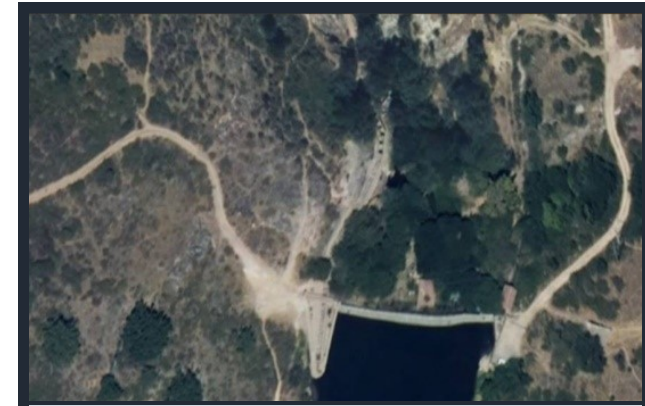

Figura 2. Ortofoto de la zona (fuente: SigPac).

\begin{tabular}{lccc}
\multicolumn{4}{c}{ RESUMEN DE LA EVALUACIÓN DEL PASO PARA PECES } \\
& \multicolumn{4}{c|}{ (CON LA METODOLOGÍA AEPS) } \\
\hline Etapa o categoría & Puntuación & Evaluación & ¿Mejoras? \\
Atracción & 4,2 & Desfavorable & Muy necesarias \\
Entrada & 0,0 & Muy desfavorable & Imprescindibles \\
Pasaje & 8,4 & Muy favorable & Opcionales \\
Salida & 8,9 & Muy favorable & Opcionales \\
\hline
\end{tabular}

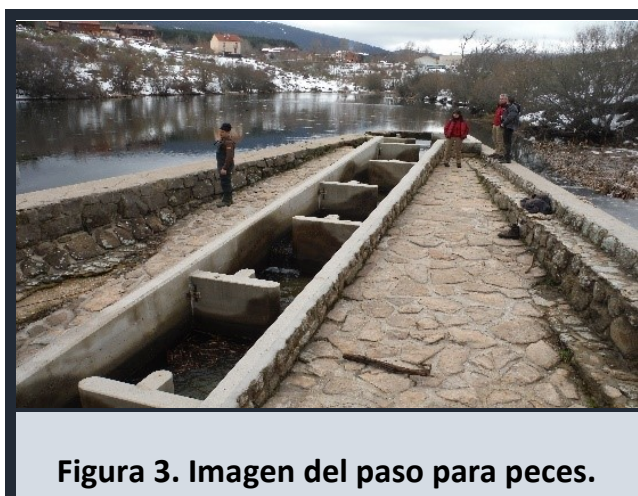




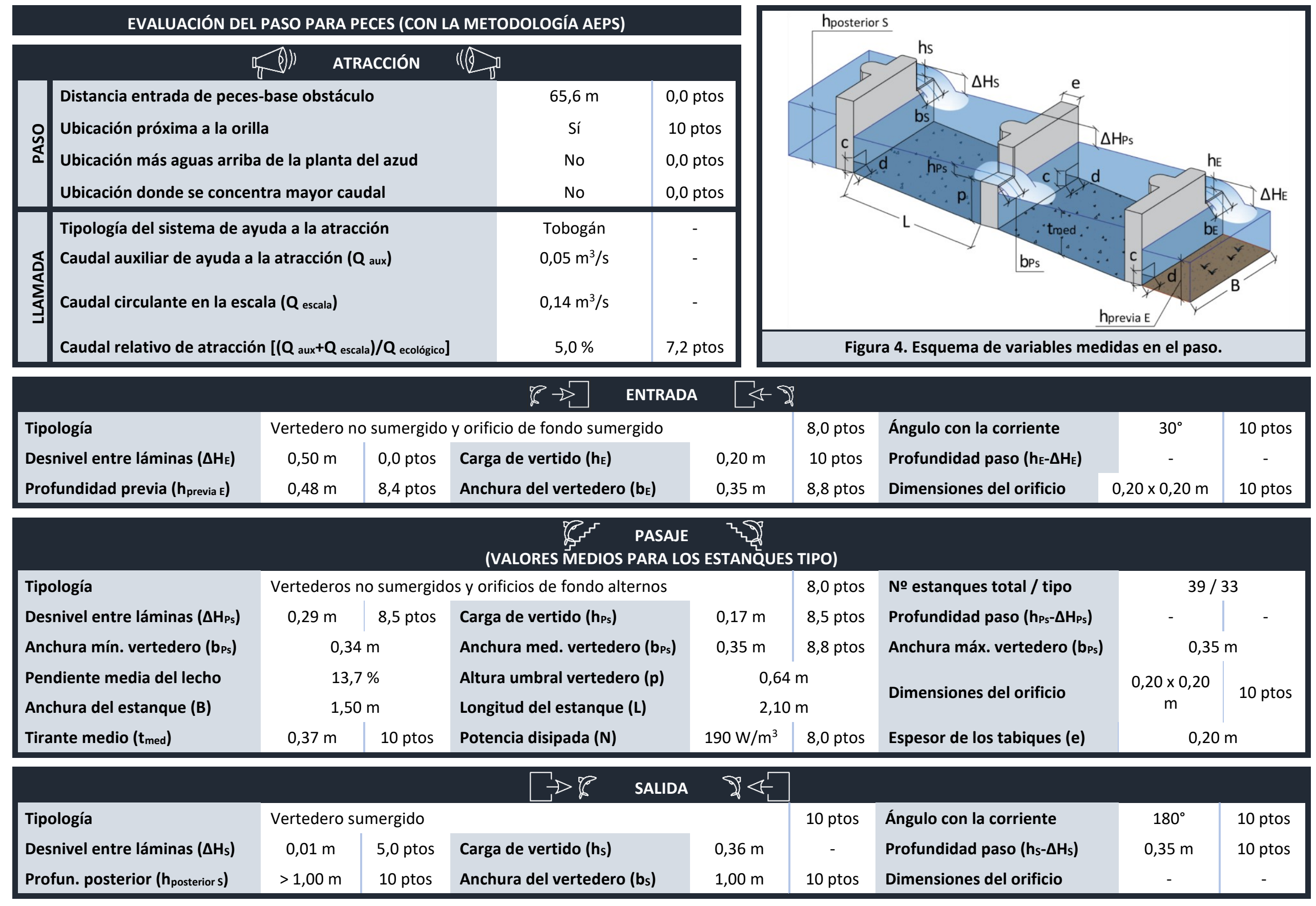




\section{PASO PARA PECES ASOCIADO AL AZUD DE LA ACEQUIA DE LA VEGA DE BURGO DE OSMA}

\begin{tabular}{|c|c|c|c|c|}
\hline & Provincia & Soria & Municipio & Ucero \\
\hline & $\begin{array}{l}\text { Nombre del aprovechamiento } \\
\text { Código del aprovechamiento } \\
\text { Long. coronación del azud } \\
\text { (1) } \\
\text { Coordenadas del paso piscícola }\end{array}$ & $\begin{array}{l}\text { Ucero } \\
1100206 \\
58 \mathrm{~m} \\
X: 495.056 \mathrm{~m}, \mathrm{Y}: 4.608 . C\end{array}$ & $\begin{array}{l}\text { Tipo de aprovechamiento } \\
\text { Código del azud }{ }^{(1)} \\
\text { Salto total de agua en la visita } \\
05 \text { m (ETRS 89; HUSO 30) }\end{array}$ & $\begin{array}{l}\text { Riego e hidroeléctrico } \\
1005678 \\
1,34 \mathrm{~m}\end{array}$ \\
\hline & $\begin{array}{l}\text { Cuenca hidrográfica } \\
\text { Principales peces migradores }{ }^{(1)} \\
\text { Época de migración }\end{array}$ & $\begin{array}{l}\text { Duero } \\
\text { Salmo trutta } \\
\text { Noviembre a diciembre }\end{array}$ & Cauce & Ucero \\
\hline $\begin{array}{l}\text { Figura 1. Ubicación en la parte } \\
\text { española de la cuenca del río Duero. }\end{array}$ & $\begin{array}{l}\text { Caudal medio en migración (2) } \\
\text { Caudal durante la visita }{ }^{(3)}\end{array}$ & $\begin{array}{l}2,25 \mathrm{~m}^{3} / \mathrm{s} \\
1,76 \mathrm{~m}^{3} / \mathrm{s}\end{array}$ & $\begin{array}{l}\text { Caudal ecológico en migración } \\
\text { Hora y fecha de la visita }\end{array}$ & $\begin{array}{l}\text { (febrero) } 0,52 \mathrm{~m}^{3} / \mathrm{s} \\
16: 00 \mathrm{~h}, 18 / 02 / 2020\end{array}$ \\
\hline
\end{tabular}

(1) Dato obtenido de MíRAME-IDE Duero. ${ }^{(2)}$ Dato obtenido del CEDEX Hidrológico. ${ }^{(3)}$ Dato obtenido del SAIH del Duero.

\begin{tabular}{|c|c|c|c|}
\hline \multicolumn{4}{|c|}{ OBSERVACIONES GENERALES DE LA ESCALA } \\
\hline $\begin{array}{l}\text { Estado de mantenimiento y limpieza durante la evaluación } \\
\text { Solera naturalizada (con piedras) } \\
\text { Vertedero de umbral móvil en la entrada de peces }\end{array}$ & $\begin{array}{l}\text { Adecuado } \\
\text { No } \\
\text { No }\end{array}$ & $\begin{array}{l}\text { Compuerta en la salida de peces } \\
\text { Dispositivo para evitar la entrada de arrastres } \\
\text { Salida de peces segura (alejada del azud, turbinas, ...) }\end{array}$ & $\begin{array}{l}\text { No } \\
\text { No } \\
\text { No }\end{array}$ \\
\hline
\end{tabular}

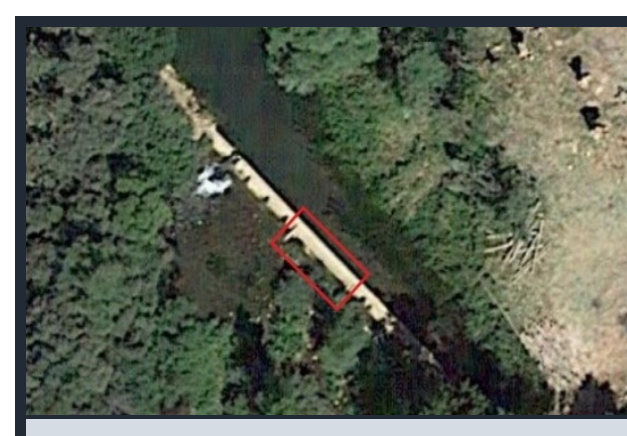

Figura 2. Ortofoto de la zona (fuente: Google Maps).

\begin{tabular}{lccc}
\multicolumn{4}{c}{ RESUMEN DE LA EVALUACIÓN DEL PASO PARA PECES } \\
& \multicolumn{2}{c|}{ (CON LA METODOLOGÍA AEPS) } & \\
\hline Etapa o categoría & Puntuación & Evaluación & ¿Mejoras? \\
Atracción & 3,8 & Muy desfavorable & Imprescindibles \\
Entrada & 0,0 & Muy desfavorable & Imprescindibles \\
Pasaje & 0,0 & Muy desfavorable & Imprescindibles \\
Salida & 0,0 & Muy desfavorable & Imprescindibles \\
\hline
\end{tabular}

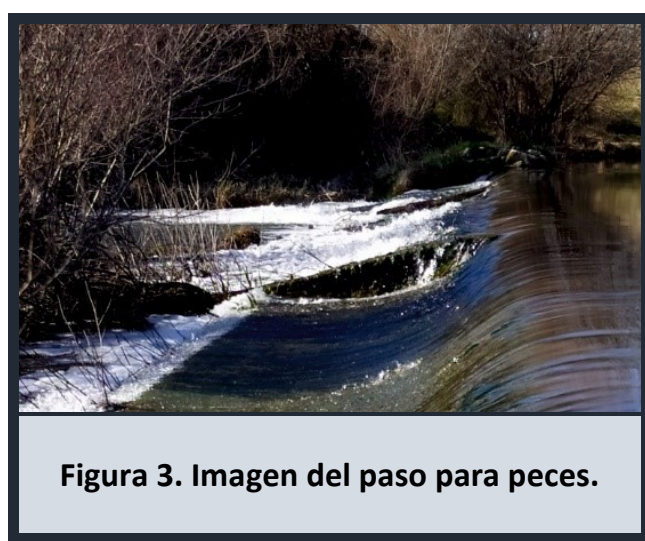




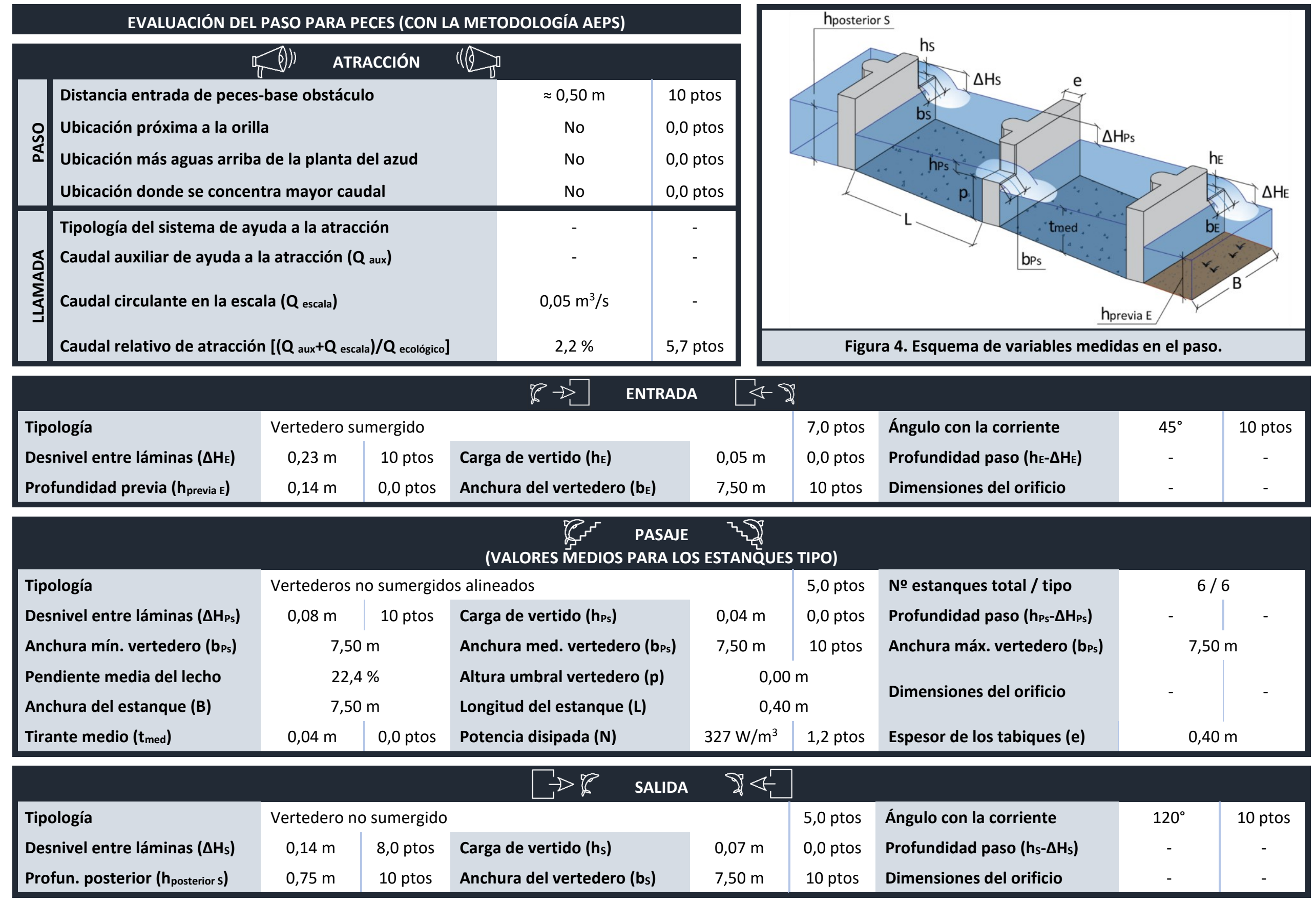




\section{PASO PARA PECES ASOCIADO AL AZUD DE LA CENTRAL HIDROELÉCTRICA DE ALCOZAR}

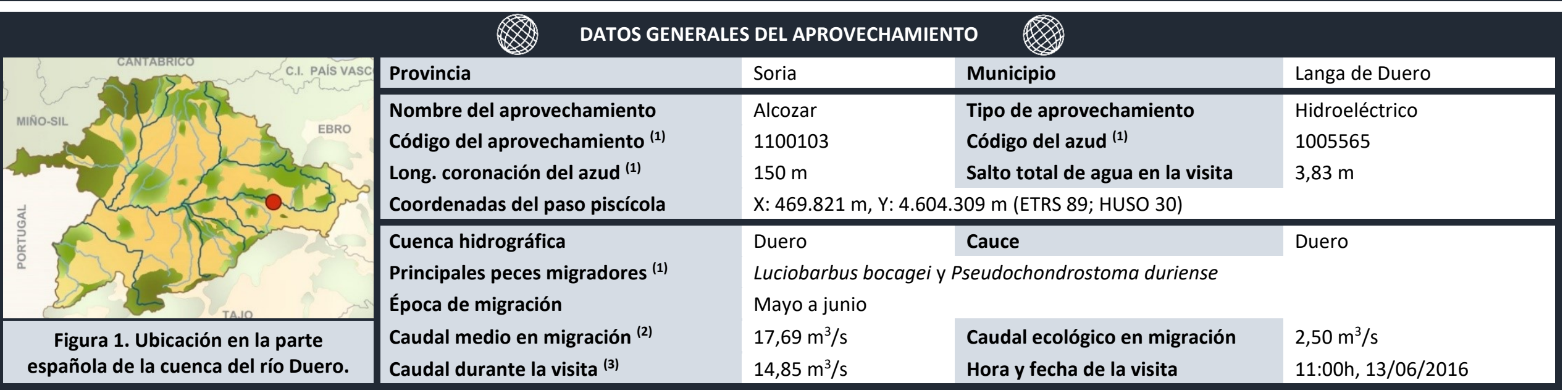

(1) Dato obtenido de MíRAME-IDE Duero. ${ }^{(2)}$ Dato obtenido del CEDEX Hidrológico. ${ }^{(3)}$ Dato obtenido del SAIH del Duero.

\begin{tabular}{|c|c|c|c|}
\hline Paso para peces de estanques & s conectad & tederos sumergidos y orifcios de fondo alternos & \\
\hline $\begin{array}{l}\text { Estado de mantenimiento y limpieza durante la evaluación } \\
\text { Solera naturalizada (con piedras) } \\
\text { Vertedero de umbral móvil en la entrada de peces }\end{array}$ & $\begin{array}{l}\text { Adecuado } \\
\text { No } \\
\text { No }\end{array}$ & $\begin{array}{l}\text { Compuerta en la salida de peces } \\
\text { Dispositivo para evitar la entrada de arrastres } \\
\text { Salida de peces segura (alejada del azud, turbinas, ...) }\end{array}$ & $\begin{array}{l}\text { Sí } \\
\text { No } \\
\text { Sí }\end{array}$ \\
\hline
\end{tabular}

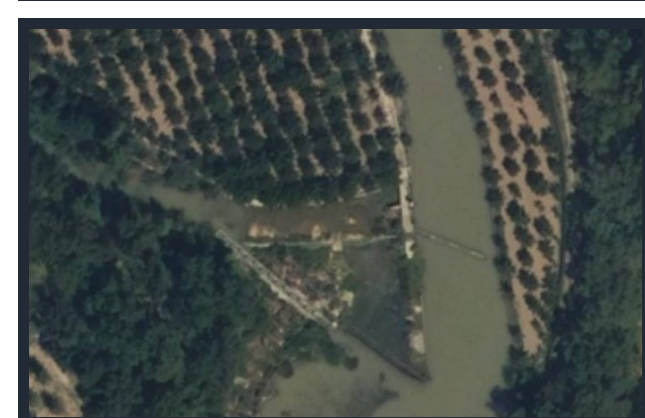

Figura 2. Ortofoto de la zona (fuente: SigPac).

\begin{tabular}{lccc}
\multicolumn{4}{c}{ RESUMEN DE LA EVALUACIÓN DEL PASO PARA PECES } \\
& \multicolumn{2}{c}{ (CON LA METODOLOGÍA AEPS) } & \\
\hline Etapa o categoría & Puntuación & Evaluación & ¿Mejoras? \\
Atracción & 5,8 & Desfavorable & Muy necesarias \\
Entrada & 7,5 & Favorable & Recomendables \\
Pasaje & 9,3 & Muy favorable & Opcionales \\
Salida & 8,9 & Muy favorable & Opcionales \\
\hline
\end{tabular}

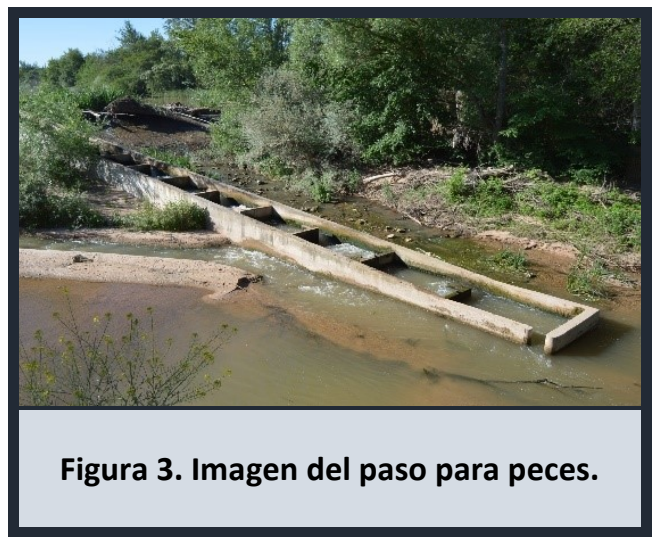




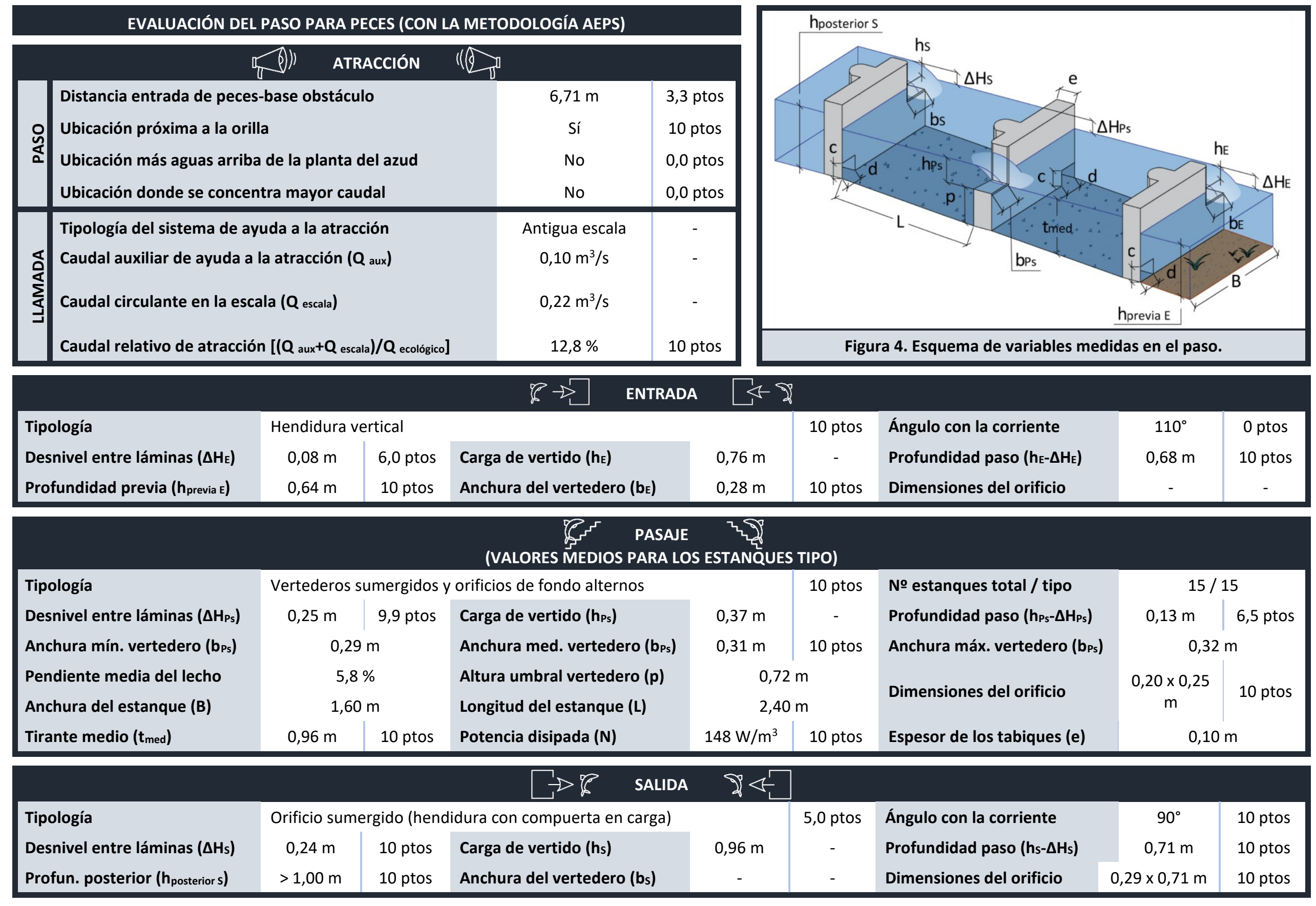




\section{PASO PARA PECES ASOCIADO AL AZUD DE LA CENTRAL HIDROELÉCTRICA DE GORMAZ}

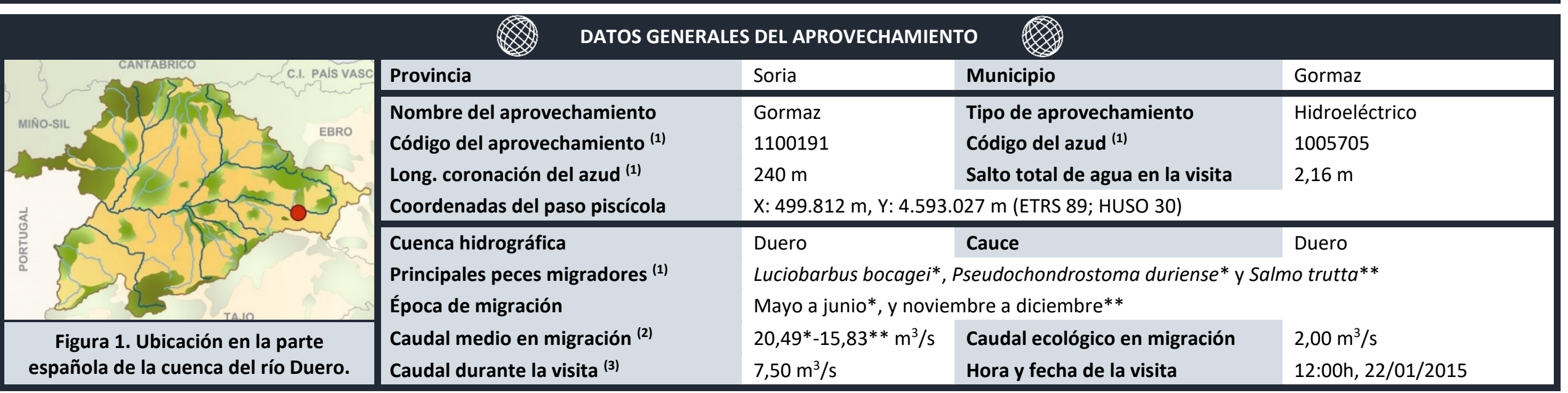

(1) Dato obtenido de MíRAME-IDE Duero. ${ }^{(2)}$ Dato obtenido del CEDEX Hidrológico. ${ }^{(3)}$ Dato obtenido del SAIH del Duero.

\begin{tabular}{|c|c|c|c|}
\hline Paso para peces de estanques st & os conectados po & tederos sumergidos y orificios de fondo alternos & \\
\hline $\begin{array}{l}\text { Estado de mantenimiento y limpieza durante la evaluación } \\
\text { Solera naturalizada (con piedras) } \\
\text { Vertedero de umbral móvil en la entrada de peces }\end{array}$ & $\begin{array}{l}\text { Muy adecuado } \\
\text { No } \\
\text { No }\end{array}$ & $\begin{array}{l}\text { Compuerta en la salida de peces } \\
\text { Dispositivo para evitar la entrada de arrastres } \\
\text { Salida de peces segura (alejada del azud, turbinas, ...) }\end{array}$ & $\begin{array}{l}\text { Sí } \\
\text { Sí } \\
\text { Sí }\end{array}$ \\
\hline
\end{tabular}

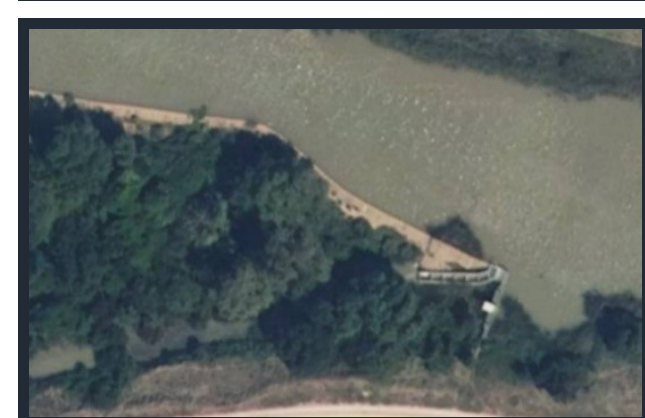

Figura 2. Ortofoto de la zona (fuente: SigPac).

\begin{tabular}{lccc}
\multicolumn{5}{c}{ RESUMEN DE LA EVALUACIÓN DEL PASO PARA PECES } \\
& \multicolumn{4}{c|}{ (CON LA METODOLOGÍA AEPS) } & \\
\hline Etapa o categoría & Puntuación & Evaluación & ¿Mejoras? \\
Atracción & 8,2 & Muy favorable & Opcionales \\
Entrada & 9,4 & Muy favorable & Opcionales \\
Pasaje & 0,0 & Muy desfavorable & Imprescindibles \\
Salida & 0,0 & Muy desfavorable & Imprescindibles \\
\hline
\end{tabular}

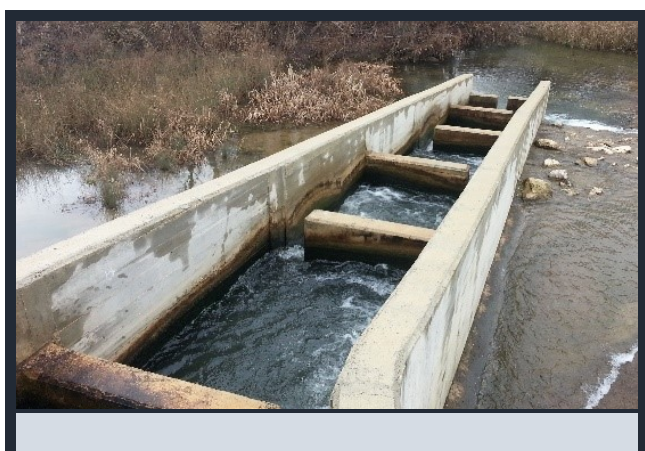

Figura 3. Imagen del paso para peces. 


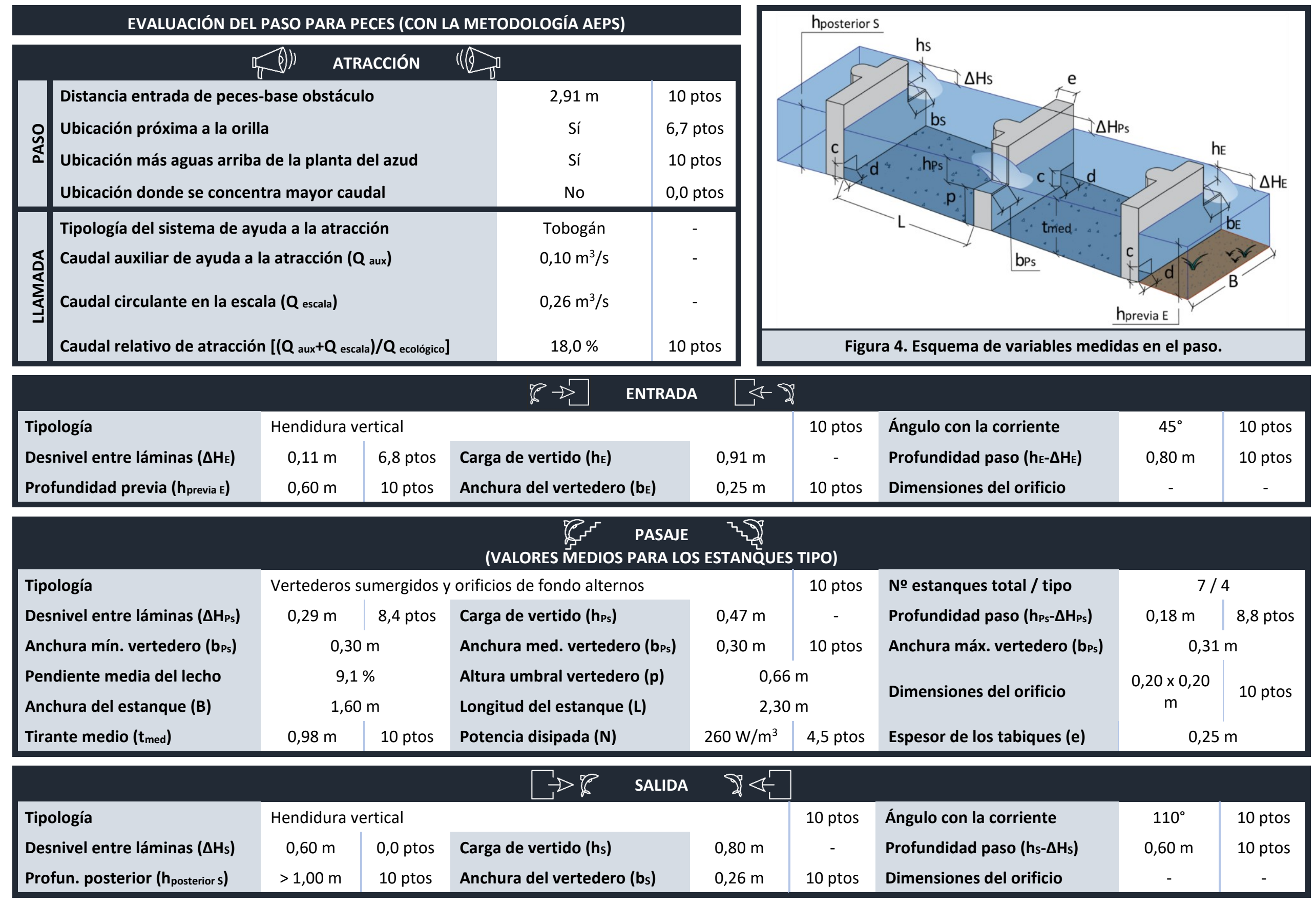




\section{PASO PARA PECES ASOCIADO AL AZUD DE LA CENTRAL HIDROELÉCTRICA DE LA GÜERA}

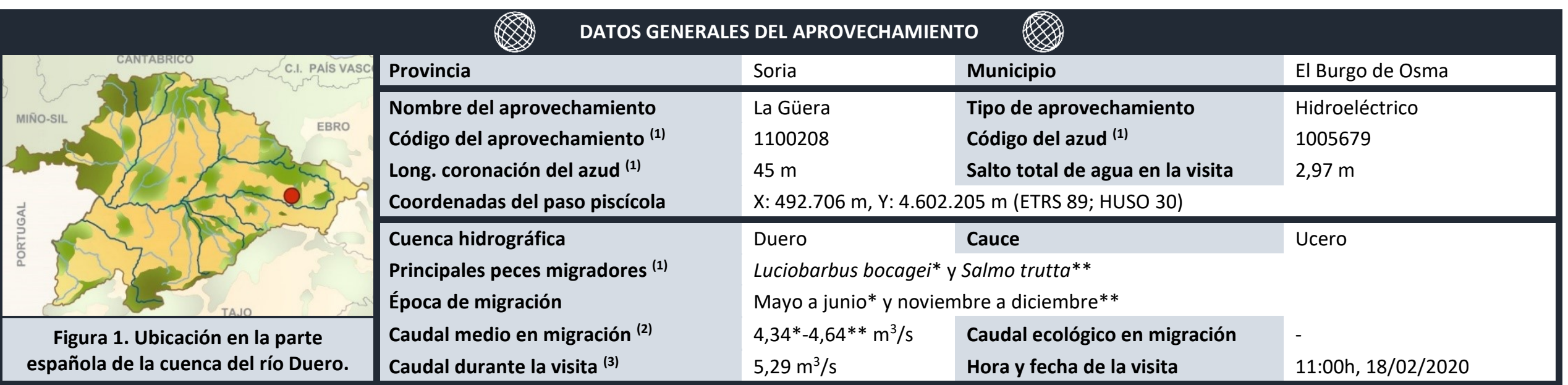

(1) Dato obtenido de MíRAME-IDE Duero. ${ }^{(2)}$ Dato obtenido del CEDEX Hidrológico. ${ }^{(3)}$ Dato obtenido del SAIH del Duero.

\begin{tabular}{|c|c|c|c|}
\hline \multicolumn{4}{|c|}{ OBSERVACIONES GENERALES DE LA ESCALA } \\
\hline $\begin{array}{l}\text { Estado de mantenimiento y limpieza durante la evaluación } \\
\text { Solera naturalizada (con piedras) } \\
\text { Vertedero de umbral móvil en la entrada de peces }\end{array}$ & $\begin{array}{l}\text { No adecuado } \\
\text { Sí } \\
\text { Sí }\end{array}$ & $\begin{array}{l}\text { Compuerta en la salida de peces } \\
\text { Dispositivo para evitar la entrada de arrastres } \\
\text { Salida de peces segura (alejada del azud, turbinas, ...) }\end{array}$ & $\begin{array}{l}\text { No } \\
\text { Sí } \\
\text { Sí }\end{array}$ \\
\hline
\end{tabular}

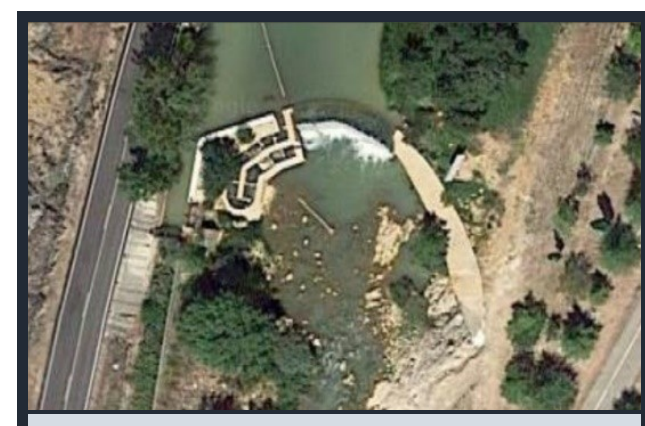

Figura 2. Ortofoto de la zona (fuente: Google Maps).

\begin{tabular}{lccc}
\multicolumn{4}{c}{ RESUMEN DE LA EVALUACIÓN DEL PASO PARA PECES } \\
& \multicolumn{4}{c|}{ (CON LA METODOLOGÍA AEPS) } & \\
\hline Etapa o categoría & Puntuación & Evaluación & ¿Mejoras? \\
Atracción & 7,7 & Favorable & Recomendables \\
Entrada & 7,0 & Favorable & Recomendables \\
Pasaje & 9,8 & Muy favorable & Opcionales \\
Salida & 9,5 & Muy favorable & Opcionales \\
\hline
\end{tabular}

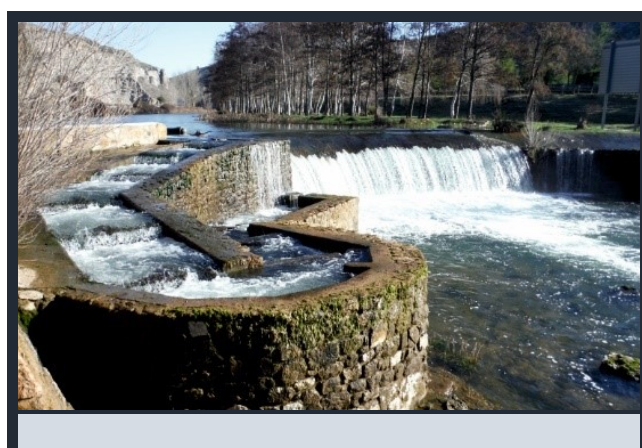

Figura 3. Imagen del paso para peces. 


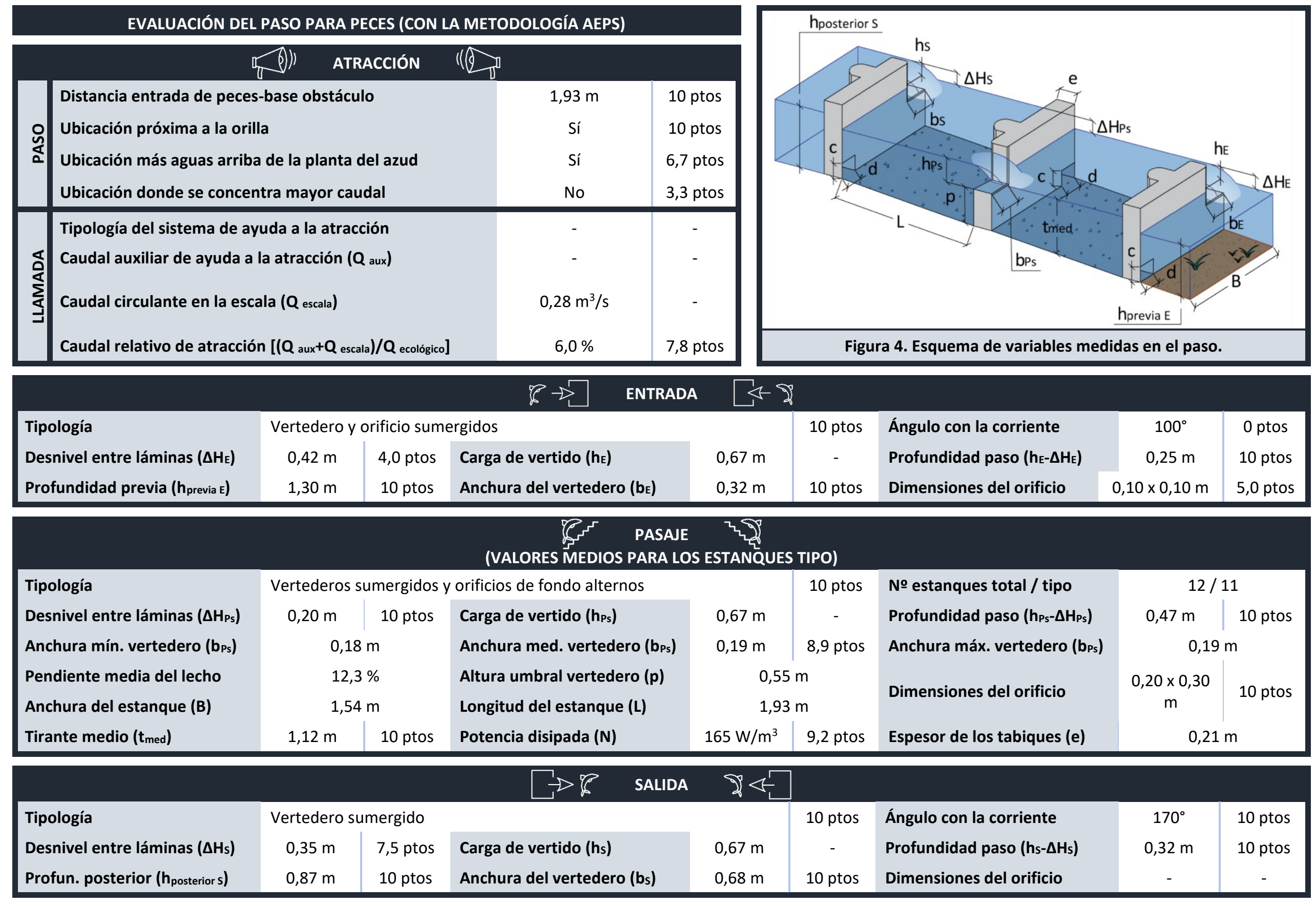




\section{PASO PARA PECES ASOCIADO AL AZUD DE LA CENTRAL HIDROELÉCTRICA DE NAVAPALOS}

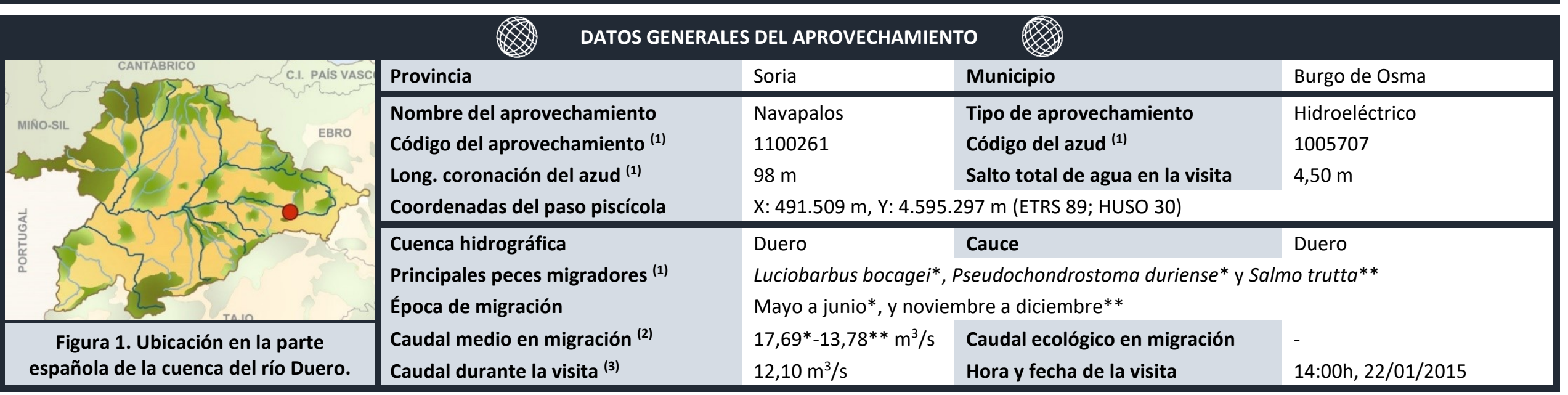

(1) Dato obtenido de MíRAME-IDE Duero. ${ }^{(2)}$ Dato obtenido del CEDEX Hidrológico. ${ }^{(3)}$ Dato obtenido del SAIH del Duero.

\begin{tabular}{|c|c|c|c|}
\hline Paso para peces de estanques su & s conectadc & tederos sumergidos y orificios de fondo alternos & \\
\hline $\begin{array}{l}\text { Estado de mantenimiento y limpieza durante la evaluación } \\
\text { Solera naturalizada (con piedras) } \\
\text { Vertedero de umbral móvil en la entrada de peces }\end{array}$ & $\begin{array}{l}\text { Adecuado } \\
\text { No } \\
\text { No }\end{array}$ & $\begin{array}{l}\text { Compuerta en la salida de peces } \\
\text { Dispositivo para evitar la entrada de arrastres } \\
\text { Salida de peces segura (alejada del azud, turbinas, ...) }\end{array}$ & $\begin{array}{l}\text { Sí } \\
\text { No } \\
\text { Sí }\end{array}$ \\
\hline
\end{tabular}

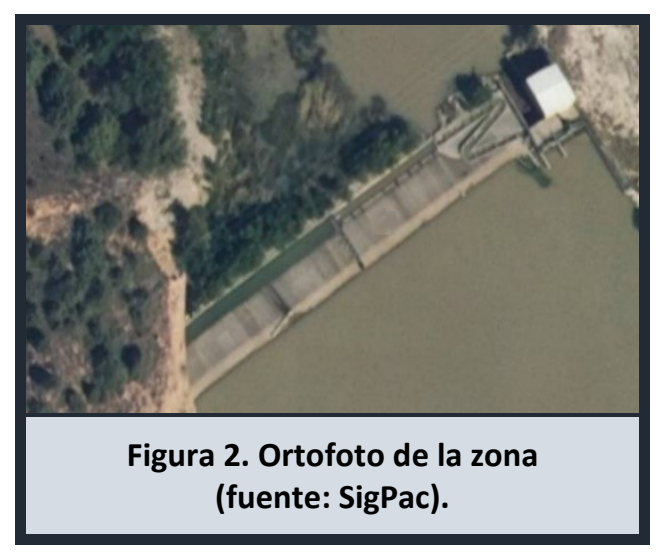

\begin{tabular}{|c|c|c|c|}
\hline \multicolumn{4}{|c|}{$\begin{array}{l}\text { RESUMEN DE LA EVALUACIÓN DEL PASO PARA PECES } \\
\text { (CON LA METODOLOGÍA AEPS) }\end{array}$} \\
\hline Etapa o categoría & Puntuación & Evaluación & ¿Mejoras? \\
\hline Atracción & 6,7 & Favorable & Recomendables \\
\hline Entrada & 0,0 & Muy desfavorable & Imprescindibles \\
\hline Pasaje & 9,3 & Muy favorable & Opcionales \\
\hline Salida & 10,0 & Muy favorable & Opcionales \\
\hline
\end{tabular}

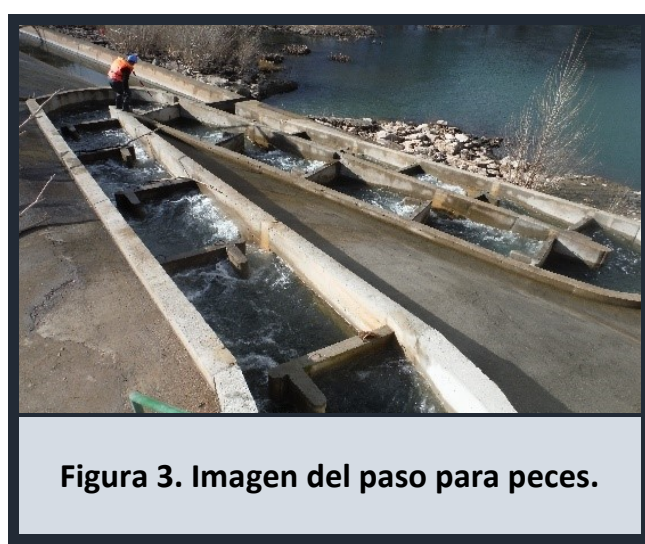




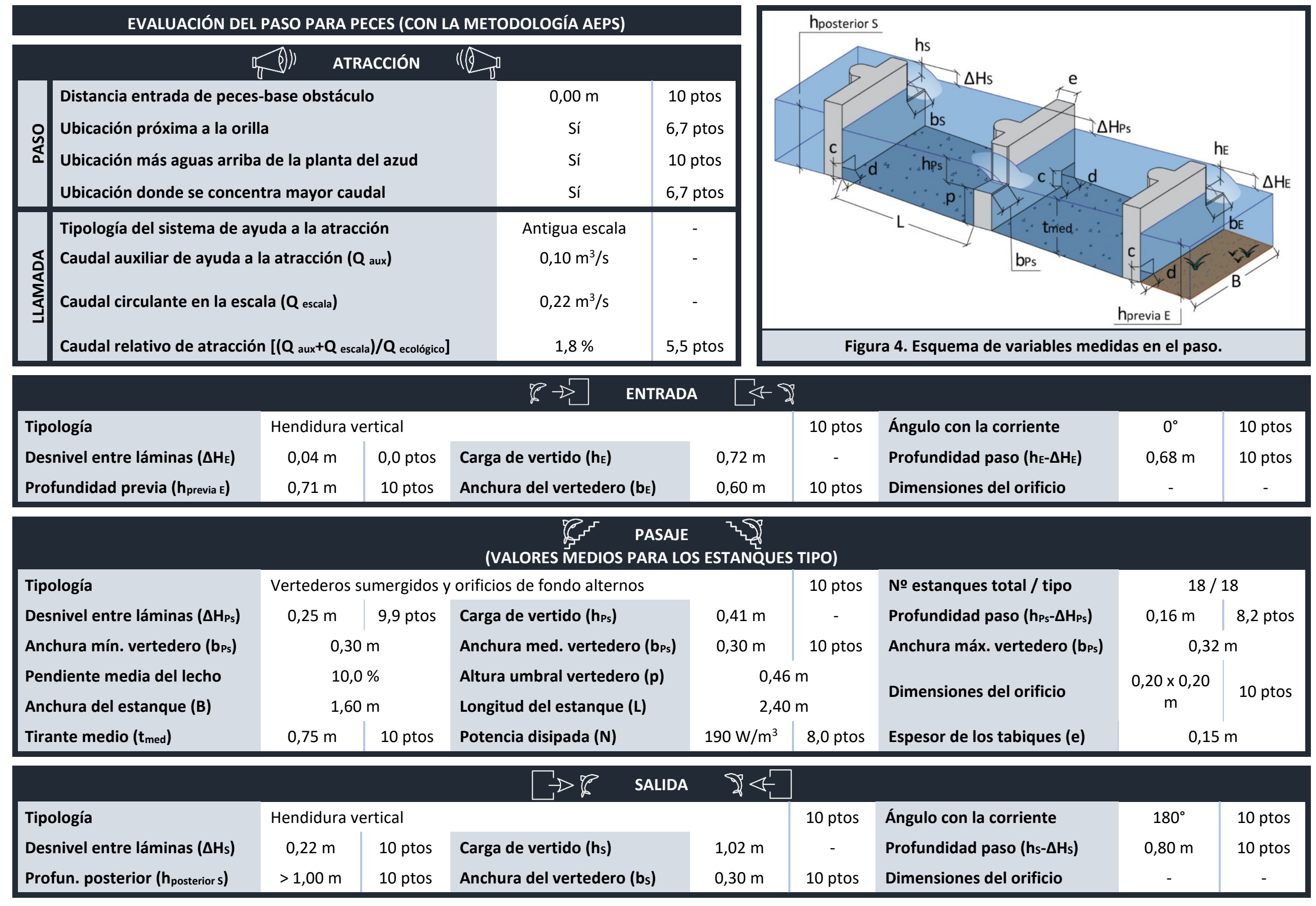




\section{PASO PARA PECES ASOCIADO AL AZUD DE LA CENTRAL HIDROELÉCTRICA DE SAN ESTEBAN DE GORMAZ}

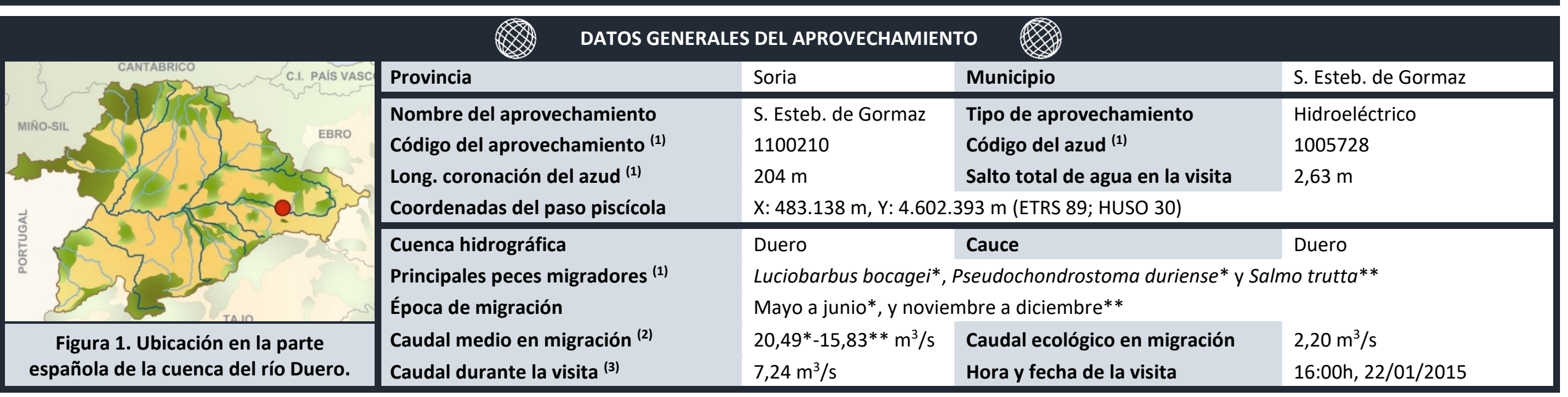

(1) Dato obtenido de MíRAME-IDE Duero. ${ }^{(2)}$ Dato obtenido del CEDEX Hidrológico. ${ }^{(3)}$ Dato obtenido del SAIH del Duero.

\begin{tabular}{|c|c|c|c|}
\hline Paso para peces de estanques st & os conectad & diduras verticales alineadas y sin orificios & \\
\hline $\begin{array}{l}\text { Estado de mantenimiento y limpieza durante la evaluación } \\
\text { Solera naturalizada (con piedras) } \\
\text { Vertedero de umbral móvil en la entrada de peces }\end{array}$ & $\begin{array}{l}\text { Adecuado } \\
\text { Sí } \\
\text { No }\end{array}$ & $\begin{array}{l}\text { Compuerta en la salida de peces } \\
\text { Dispositivo para evitar la entrada de arrastres } \\
\text { Salida de peces segura (alejada del azud, turbinas, ...) }\end{array}$ & $\begin{array}{l}\text { No } \\
\text { Sí } \\
\text { Sí }\end{array}$ \\
\hline
\end{tabular}

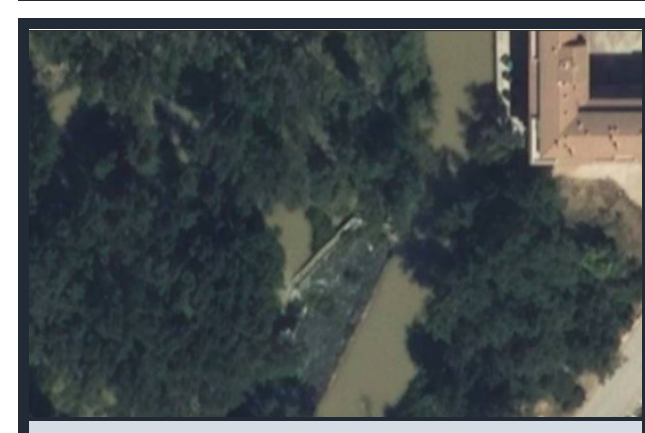

Figura 2. Ortofoto de la zona (fuente: SigPac).

\begin{tabular}{lccc}
\multicolumn{4}{c}{ RESUMEN DE LA EVALUACIÓN DEL PASO PARA PECES } \\
& \multicolumn{4}{c|}{ (CON LA METODOLOGÍA AEPS) } & \\
\hline Etapa o categoría & Puntuación & Evaluación & ¿Mejoras? \\
Atracción & 7,6 & Favorable & Recomendables \\
Entrada & 9,5 & Muy favorable & Opcionales \\
Pasaje & 9,7 & Muy favorable & Opcionales \\
Salida & 9,1 & Muy favorable & Opcionales \\
\hline
\end{tabular}

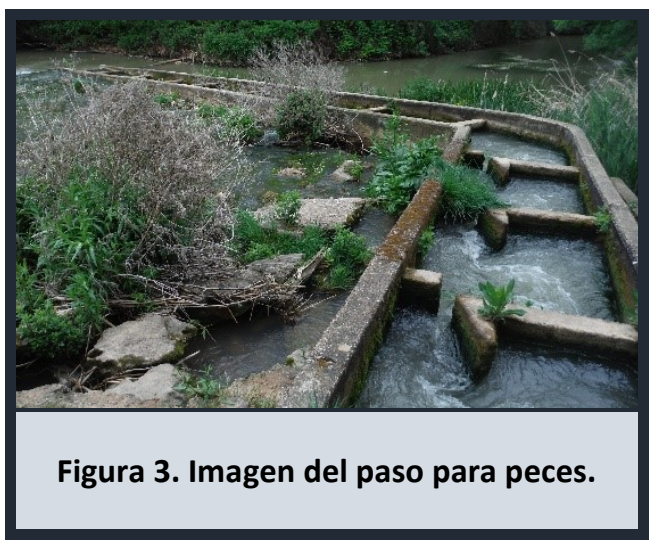




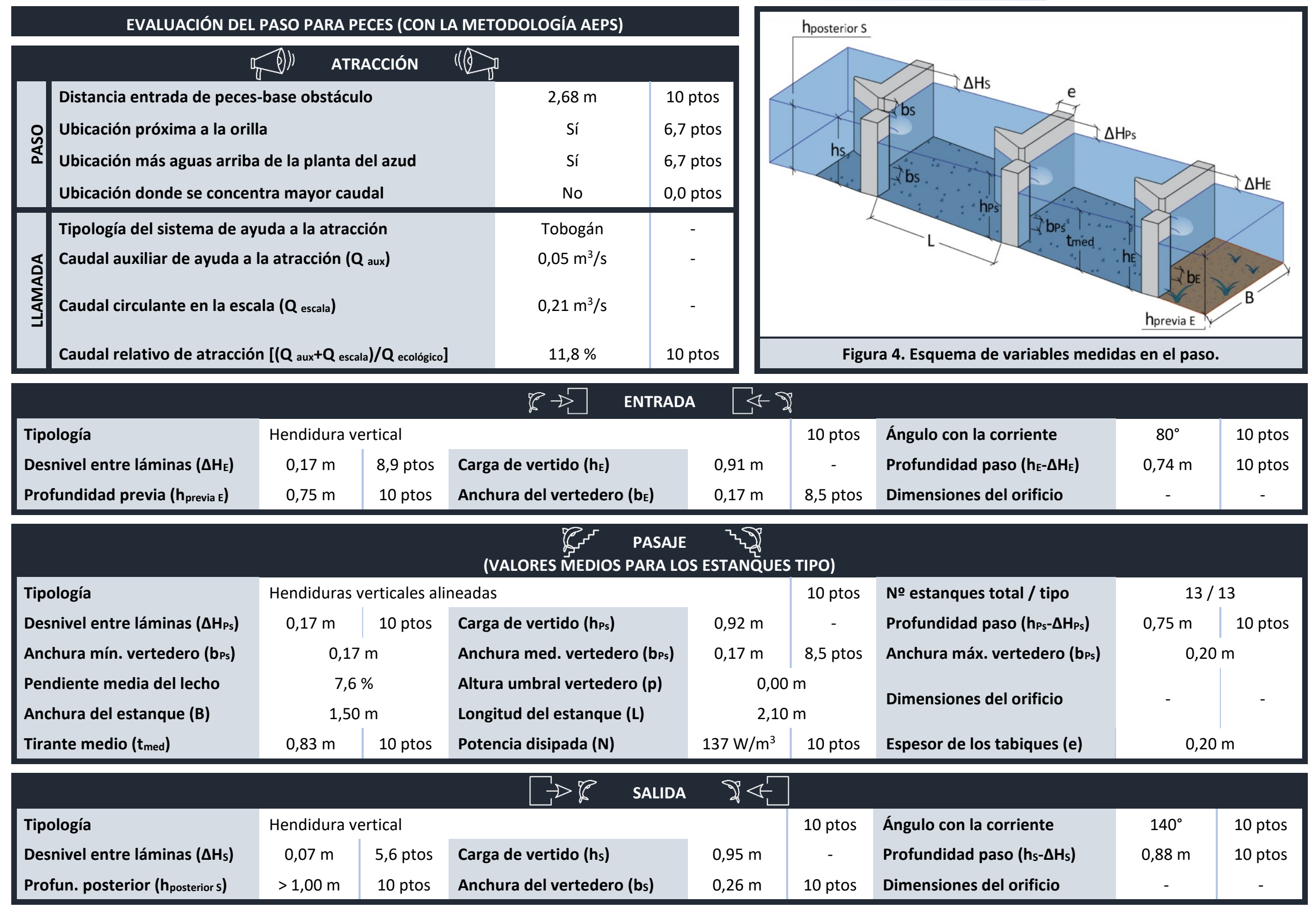

$\begin{array}{ll}\text { Jorge Valbuena Castro } & 273\end{array}$ 


\section{PASO PARA PECES ASOCIADO AL AZUD DE LA CENTRAL HIDROELÉCTRICA DE AGUILAREJO}

\begin{tabular}{|c|c|c|c|c|}
\hline & Provincia & Valladolid & Municipio & Corcos \\
\hline & $\begin{array}{l}\text { Nombre del aprovechamiento } \\
\text { Código del aprovechamiento }{ }^{(1)} \\
\text { Long. coronación del azud (1) }\end{array}$ & $\begin{array}{l}\text { Aguilarejo } \\
1100086 \\
105 \mathrm{~m} \\
\mathrm{x} \cdot 365268 \mathrm{~m} \cdot 462\end{array}$ & $\begin{array}{l}\text { Tipo de aprovechamiento } \\
\text { Código del azud (1) } \\
\text { Salto total de agua en la visita }\end{array}$ & $\begin{array}{l}\text { Hidroeléctrico } \\
1005260 \\
2,99 \mathrm{~m}\end{array}$ \\
\hline & $\begin{array}{l}\text { Cuenca hidrográfica } \\
\text { Principales peces migradores }{ }^{(1)} \\
\text { Época de migración }\end{array}$ & $\begin{array}{l}\text { Duero } \\
\text { Luciobarbus bocagei } \\
\text { Mayo a junio }\end{array}$ & Cauce & Pisuerga \\
\hline $\begin{array}{l}\text { Figura 1. Ubicación en la parte } \\
\text { española de la cuenca del río Duero. }\end{array}$ & $\begin{array}{l}\text { Caudal medio en migración }{ }^{(2)} \\
\text { Caudal durante la visita }\end{array}$ & $\begin{array}{l}59,35 \mathrm{~m}^{3} / \mathrm{s} \\
21,47 \mathrm{~m}^{3} / \mathrm{s}\end{array}$ & $\begin{array}{l}\text { Caudal ecológico en migración } \\
\text { Hora y fecha de la visita }\end{array}$ & $\begin{array}{l}1,50 \mathrm{~m}^{3} / \mathrm{s} \\
10: 00 \mathrm{~h}, 16 / 07 / 2015\end{array}$ \\
\hline
\end{tabular}

(1) Dato obtenido de MíRAME-IDE Duero. ${ }^{(2)}$ Dato obtenido del CEDEX Hidrológico. ${ }^{(3)}$ Dato obtenido del SAIH del Duero.

\begin{tabular}{|c|c|c|c|}
\hline Paso para peces de estanques su & s conectadc & tederos no sumergidos y orificios de fondo alternos & \\
\hline $\begin{array}{l}\text { Estado de mantenimiento y limpieza durante la evaluación } \\
\text { Solera naturalizada (con piedras) } \\
\text { Vertedero de umbral móvil en la entrada de peces }\end{array}$ & $\begin{array}{l}\text { Adeucado } \\
\text { No } \\
\text { Sí }\end{array}$ & $\begin{array}{l}\text { Compuerta en la salida de peces } \\
\text { Dispositivo para evitar la entrada de arrastres } \\
\text { Salida de peces segura (alejada del azud, turbinas, ...) }\end{array}$ & $\begin{array}{l}\text { Sí } \\
\text { No } \\
\text { Sí }\end{array}$ \\
\hline
\end{tabular}

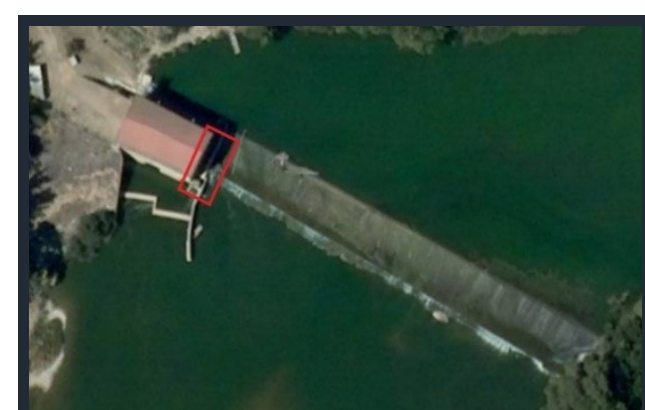

Figura 2. Ortofoto de la zona (fuente: SigPac).

\begin{tabular}{lccc}
\multicolumn{4}{c}{ RESUMEN DE LA EVALUACIÓN DEL PASO PARA PECES } \\
& \multicolumn{4}{c|}{ (CON LA METODOLOGÍA AEPS) } & \\
\hline Etapa o categoría & Puntuación & Evaluación & ¿Mejoras? \\
Atracción & 7,7 & Favorable & Recomendables \\
Entrada & 8,7 & Muy favorable & Opcionales \\
Pasaje & 0,0 & Muy desfavorable & Imprescindibles \\
Salida & 0,0 & Muy desfavorable & Imprescindibles \\
\hline
\end{tabular}

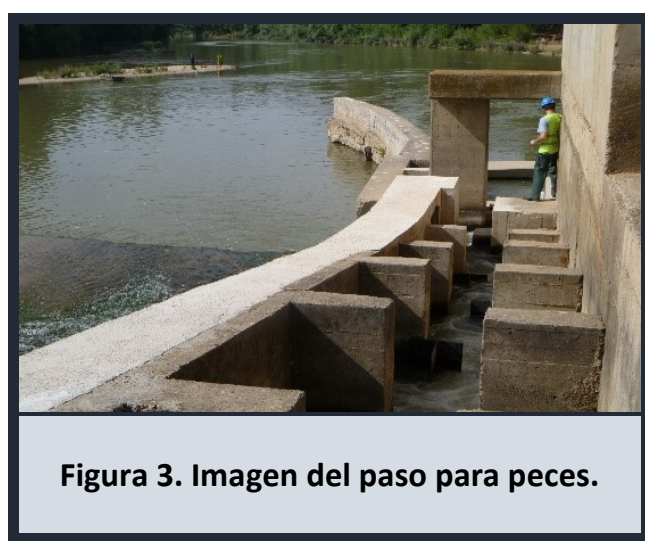




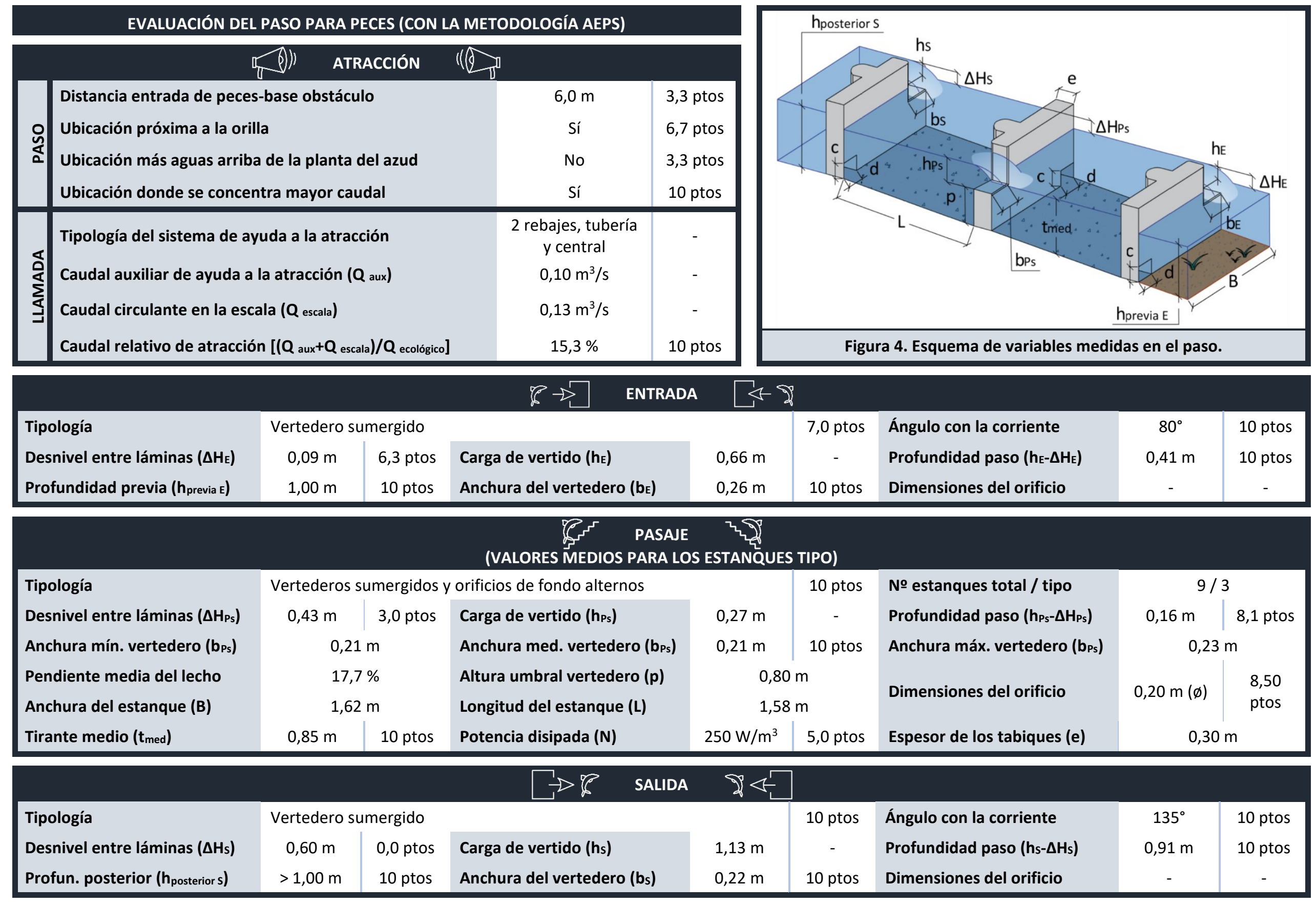




\section{PASO PARA PECES ASOCIADO AL AZUD DE LA CENTRAL HIDROELÉCTRICA DE AGUILAREJO (REMODELACIÓN)}

\begin{tabular}{|c|c|c|c|c|}
\hline & Provincia & Valladolid & Municipio & Corcos \\
\hline & $\begin{array}{l}\text { Nombre del aprovechamiento } \\
\text { Código del aprovechamiento } \\
\text { Long. coronación del azud } \\
\text { (1) } \\
\text { Coordenadas del paso piscícola }\end{array}$ & $\begin{array}{l}\text { Aguilarejo } \\
1100086 \\
105 \mathrm{~m} \\
X: 365.244\end{array}$ & $\begin{array}{l}\text { Tipo de aprovechamiento } \\
\text { Código del azud (1) } \\
\text { Salto total de agua en la visita } \\
504 \text { m (ETRS 89; HUSO 30) }\end{array}$ & $\begin{array}{l}\text { Hidroeléctrico } \\
1005260 \\
3,25 \mathrm{~m}\end{array}$ \\
\hline & $\begin{array}{l}\text { Cuenca hidrográfica } \\
\text { Principales peces migradores }{ }^{(1)} \\
\text { Época de migración }\end{array}$ & $\begin{array}{l}\text { Duero } \\
\text { Luciobarbus } \\
\text { Mayo a juni }\end{array}$ & $\begin{array}{l}\text { Cauce } \\
\text { seudochondrostoma duriense }\end{array}$ & Pisuerga \\
\hline $\begin{array}{l}\text { Figura 1. Ubicación en la parte } \\
\text { española de la cuenca del río Duero. }\end{array}$ & $\begin{array}{l}\text { Caudal medio en migración (2) } \\
\text { Caudal durante la visita }{ }^{(3)}\end{array}$ & $\begin{array}{l}59,35 \mathrm{~m}^{3} / \mathrm{s} \\
25,00 \mathrm{~m}^{3} / \mathrm{s}\end{array}$ & $\begin{array}{l}\text { Caudal ecológico en migración } \\
\text { Hora y fecha de la visita }\end{array}$ & $\begin{array}{l}1,50 \mathrm{~m}^{3} / \mathrm{s} \\
\text { No disponible }\end{array}$ \\
\hline
\end{tabular}

(1) Dato obtenido de MíRAME-IDE Duero. ${ }^{(2)}$ Dato obtenido del CEDEX Hidrológico. ${ }^{(3)}$ Dato obtenido del SAIH del Duero.

\begin{tabular}{|c|c|c|c|}
\hline Paso para peces de estanques $s$ & os conectados po & tederos sumergidos y orificios de fondo alternos & \\
\hline $\begin{array}{l}\text { Estado de mantenimiento y limpieza durante la evaluación } \\
\text { Solera naturalizada (con piedras) } \\
\text { Vertedero de umbral móvil en la entrada de peces }\end{array}$ & $\begin{array}{l}\text { Muy adecuado } \\
\text { No } \\
\text { Sí }\end{array}$ & $\begin{array}{l}\text { Compuerta en la salida de peces } \\
\text { Dispositivo para evitar la entrada de arrastres } \\
\text { Salida de peces segura (alejada del azud, turbinas, ...) }\end{array}$ & $\begin{array}{l}\text { Sí } \\
\text { No } \\
\text { Sí }\end{array}$ \\
\hline
\end{tabular}

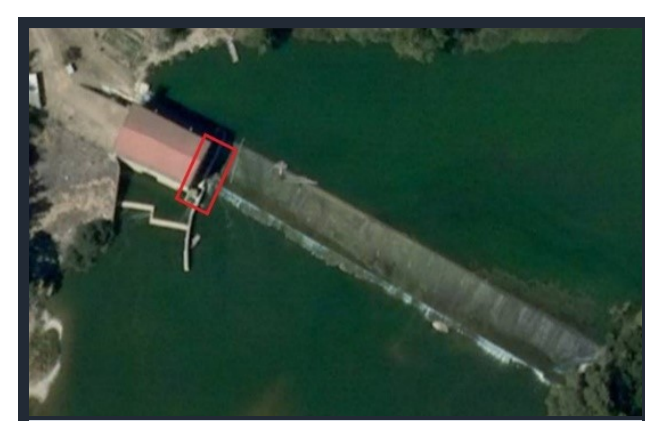

Figura 2. Ortofoto de la zona (fuente: SigPac).

\begin{tabular}{lccl}
\multicolumn{5}{c}{ RESUMEN DE LA EVALUACIÓN DEL PASO PARA PECES } \\
(CON LA METODOLOGÍA AEPS) \\
\hline Etapa o categoría & Puntuación & Evaluación & ¿Mejoras? \\
Atracción & 8,7 & Muy favorable & Opcionales \\
Entrada & 9,9 & Muy favorable & Opcionales \\
Pasaje & 8,4 & Muy favorable & Opcionales \\
Salida & 7,2 & Muy favorable & Opcionales \\
\hline
\end{tabular}

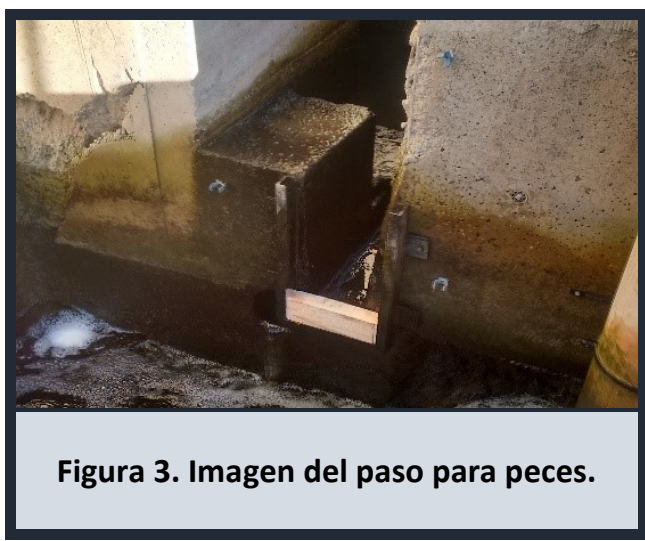




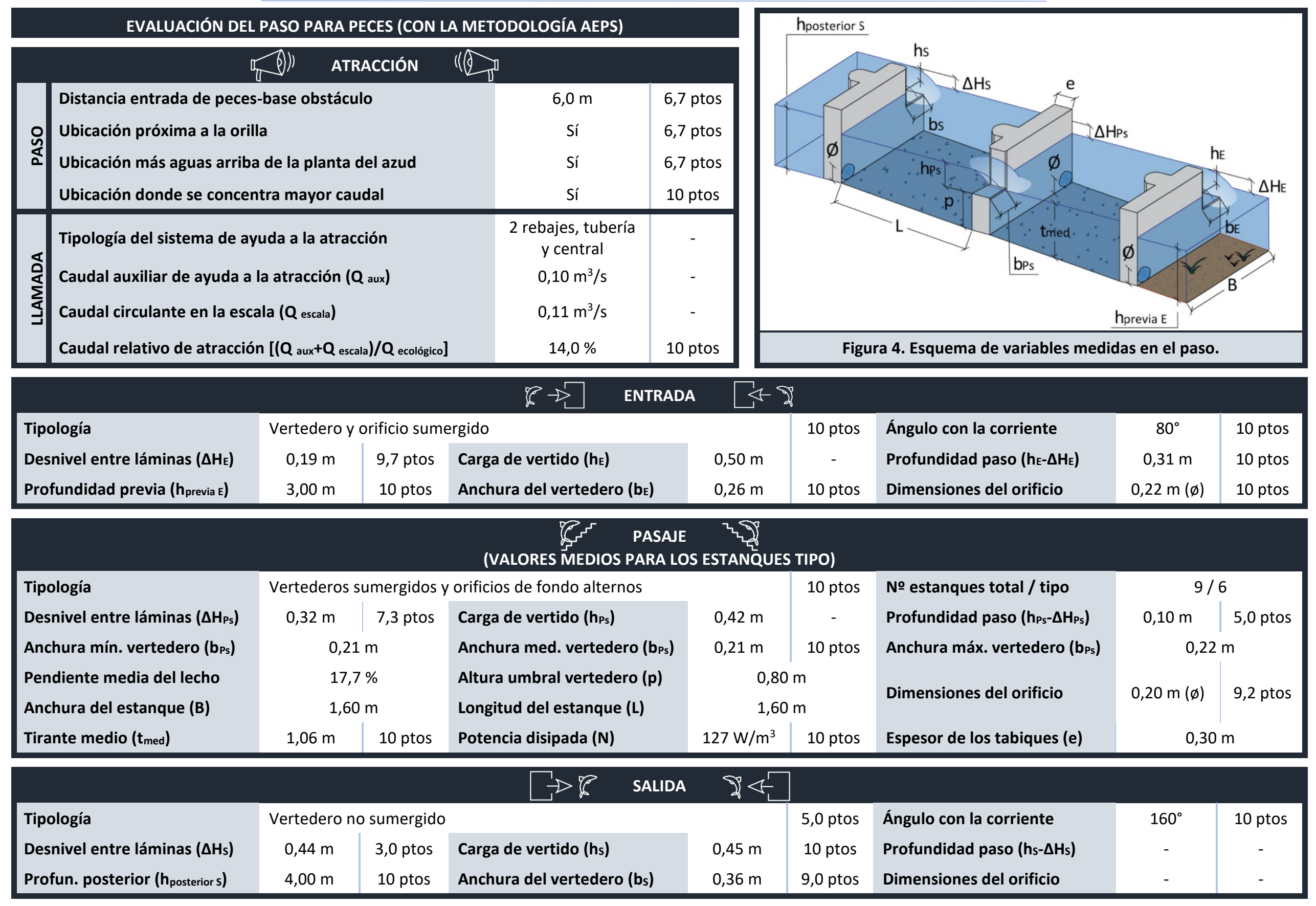




\section{PASO PARA PECES ASOCIADO AL AZUD DE LA CENTRAL HIDROELÉCTRICA DE BOCOS}

\begin{tabular}{|c|c|c|c|c|}
\hline & Provincia & Valladolid & Municipio & Bocos de Duero \\
\hline & $\begin{array}{l}\text { Nombre del aprovechamiento } \\
\text { Código del aprovechamiento } \\
\text { Long. coronación del azud } \\
\text { (1) } \\
\text { Coordenadas del paso piscícola }\end{array}$ & $\begin{array}{l}\text { Bocos } \\
1100012 \\
40 \mathrm{~m} \\
X: 411.305 \mathrm{~m}, \mathrm{Y}: 4.60\end{array}$ & $\begin{array}{l}\text { Tipo de aprovechamiento } \\
\text { Código del azud (1) } \\
\text { Salto total de agua en la visita } \\
462 \text { m (ETRS 89; HUSO 30) }\end{array}$ & $\begin{array}{l}\text { Hidroeléctrico } \\
1005451 \\
4,82 \mathrm{~m}\end{array}$ \\
\hline & $\begin{array}{l}\text { Cuenca hidrográfica } \\
\text { Principales peces migradores }{ }^{(1)} \\
\text { Época de migración }\end{array}$ & $\begin{array}{l}\text { Duero } \\
\text { Luciobarbus bocagei } \\
\text { Mayo a junio }\end{array}$ & Cauce & Duero \\
\hline $\begin{array}{l}\text { Figura 1. Ubicación en la parte } \\
\text { española de la cuenca del río Duero. }\end{array}$ & $\begin{array}{l}\text { Caudal medio en migración (2) } \\
\text { Caudal durante la visita }{ }^{(3)}\end{array}$ & $\begin{array}{l}25,79 \mathrm{~m}^{3} / \mathrm{s} \\
60,44 \mathrm{~m}^{3} / \mathrm{s}\end{array}$ & $\begin{array}{l}\text { Caudal ecológico en migración } \\
\text { Hora y fecha de la visita }\end{array}$ & 10:00h, 22/03/2016 \\
\hline
\end{tabular}

(1) Dato obtenido de MíRAME-IDE Duero. ${ }^{(2)}$ Dato obtenido del CEDEX Hidrológico. ${ }^{(3)}$ Dato obtenido del SAIH del Duero.

\begin{tabular}{|c|c|c|c|}
\hline \multicolumn{4}{|c|}{ OBSERVACIONES GENERALES DE LA ESCALA } \\
\hline $\begin{array}{l}\text { Estado de mantenimiento y limpieza durante la evaluación } \\
\text { Solera naturalizada (con piedras) } \\
\text { Vertedero de umbral móvil en la entrada de peces }\end{array}$ & $\begin{array}{l}\text { No adecuado } \\
\text { No } \\
\text { No }\end{array}$ & $\begin{array}{l}\text { Compuerta en la salida de peces } \\
\text { Dispositivo para evitar la entrada de arrastres } \\
\text { Salida de peces segura (alejada del azud, turbinas, ...) }\end{array}$ & $\begin{array}{l}\text { No } \\
\text { No } \\
\text { No }\end{array}$ \\
\hline
\end{tabular}

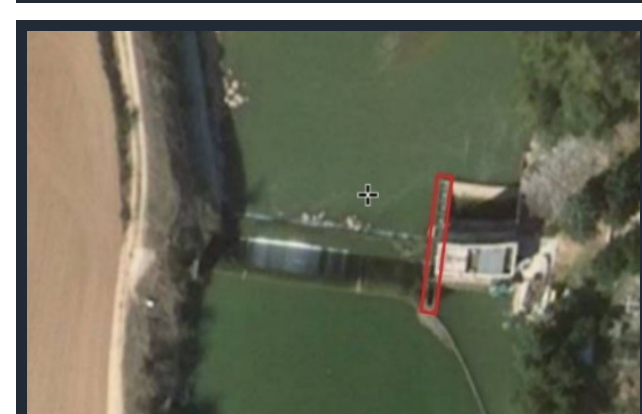

Figura 2. Ortofoto de la zona (fuente: SigPac).

\begin{tabular}{lccc}
\multicolumn{4}{c}{ RESUMEN DE LA EVALUACIÓN DEL PASO PARA PECES } \\
& \multicolumn{4}{c|}{ (CON LA METODOLOGÍA AEPS) } & \\
\hline Etapa o categoría & Puntuación & Evaluación & ¿Mejoras? \\
Atracción & 4,9 & Desfavorable & Muy necesarias \\
Entrada & 8,1 & Muy favorable & Opcionales \\
Pasaje & 6,2 & Favorable & Recomendables \\
Salida & 8,9 & Muy favorable & Opcionales \\
\hline
\end{tabular}

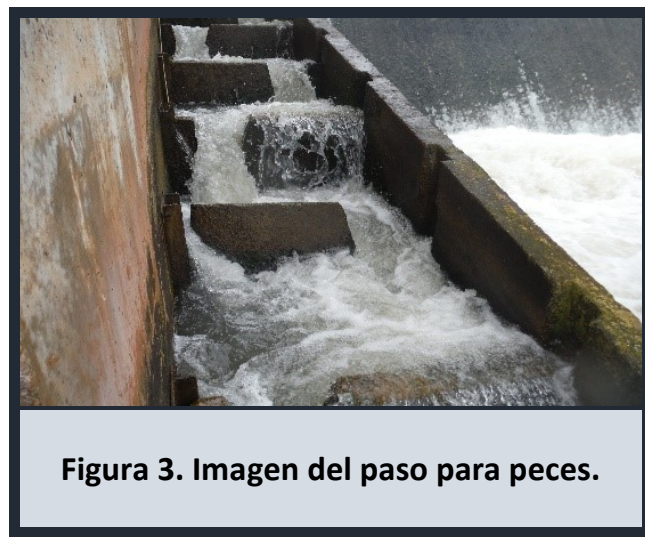




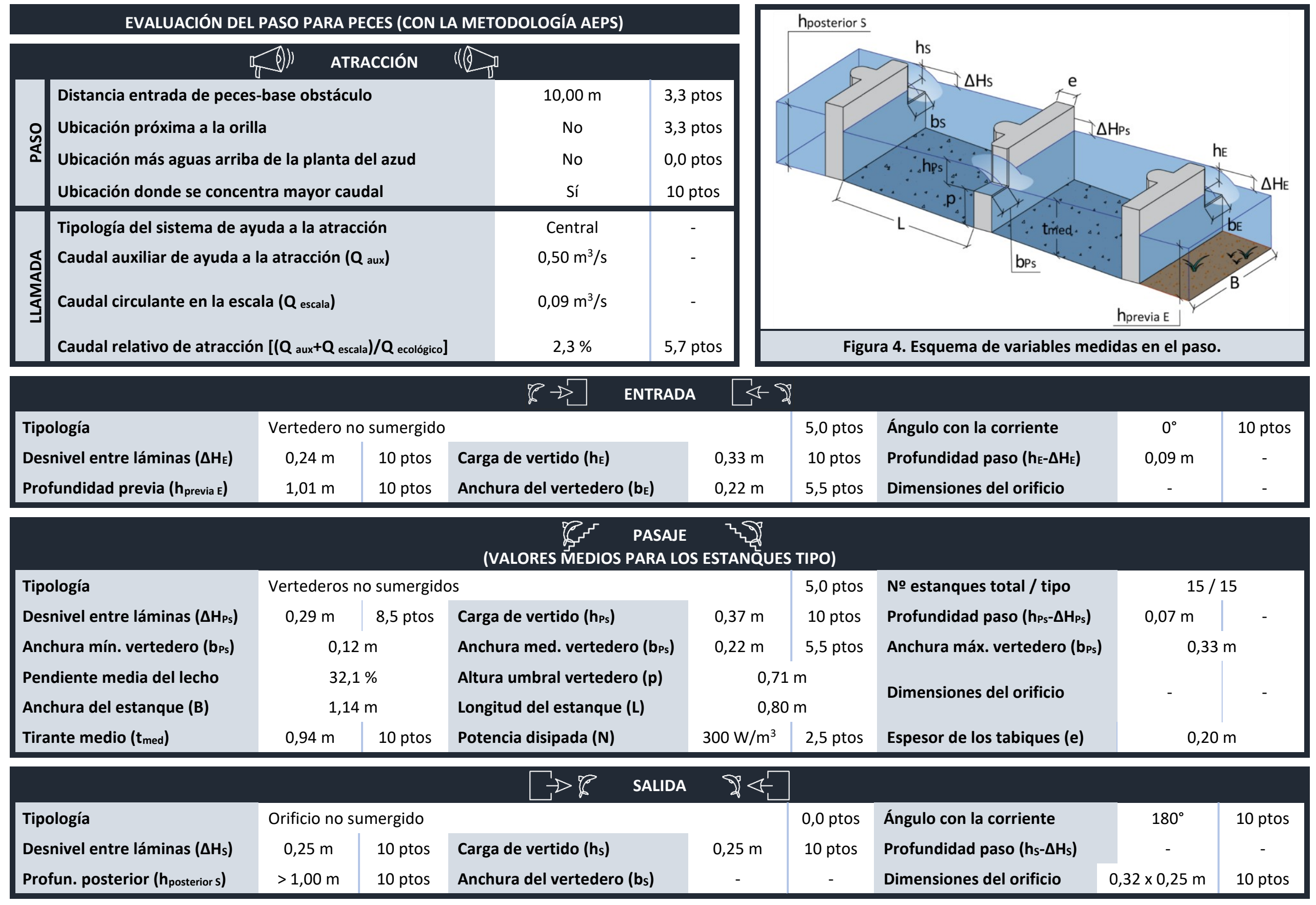




\section{PASO PARA PECES ASOCIADO AL AZUD DE LA CENTRAL HIDROELÉCTRICA DEL CARDIEL}

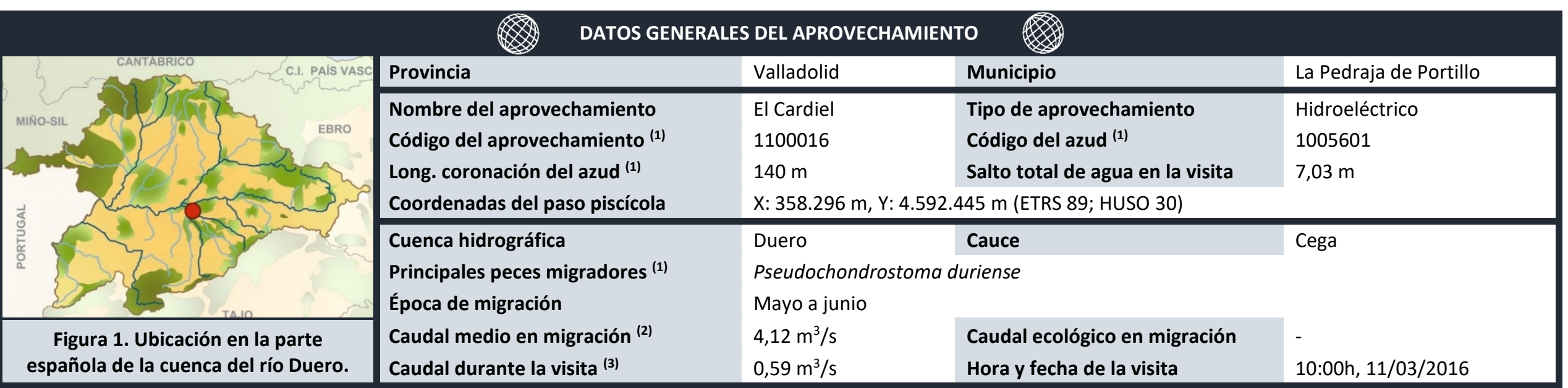

${ }^{(1)}$ Dato obtenido de MíRAME-IDE Duero. ${ }^{(2)}$ Dato obtenido del CEDEX Hidrológico. ${ }^{(3)}$ Dato obtenido del SAIH del Duero.

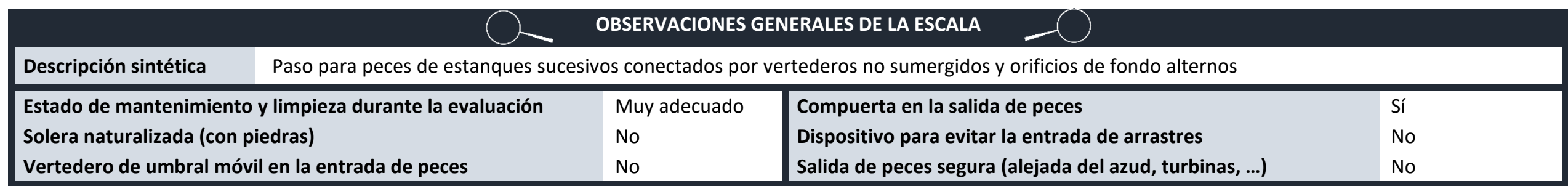

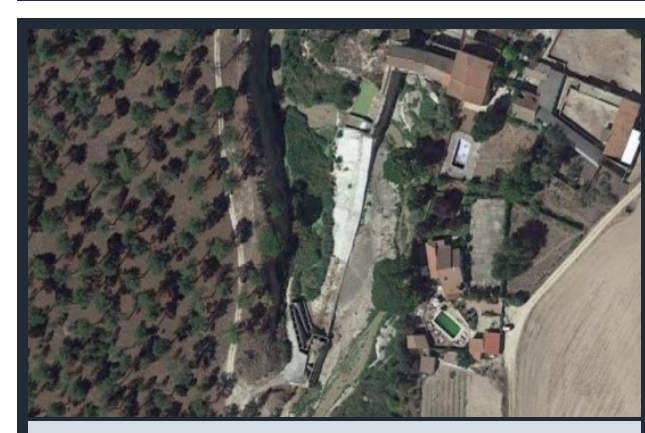

Figura 2. Ortofoto de la zona (fuente: Google Maps).

\begin{tabular}{lccl}
\multicolumn{5}{c}{ RESUMEN DE LA EVALUACIÓN DEL PASO PARA PECES } \\
& \multicolumn{4}{c}{ (CON LA METODOLOGíA AEPS) } \\
\hline Etapa o categoría & Puntuación & Evaluación & ¿Mejoras? \\
Atracción & 8,7 & Muy favorable & Opcionales \\
Entrada & 9,2 & Muy favorable & Opcionales \\
Pasaje & 8,8 & Muy favorable & Opcionales \\
Salida & 8,9 & Muy favorable & Opcionales \\
\hline
\end{tabular}

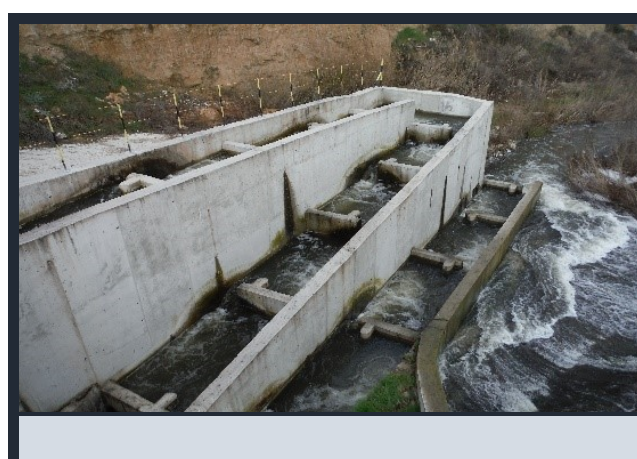

Figura 3. Imagen del paso para peces. 


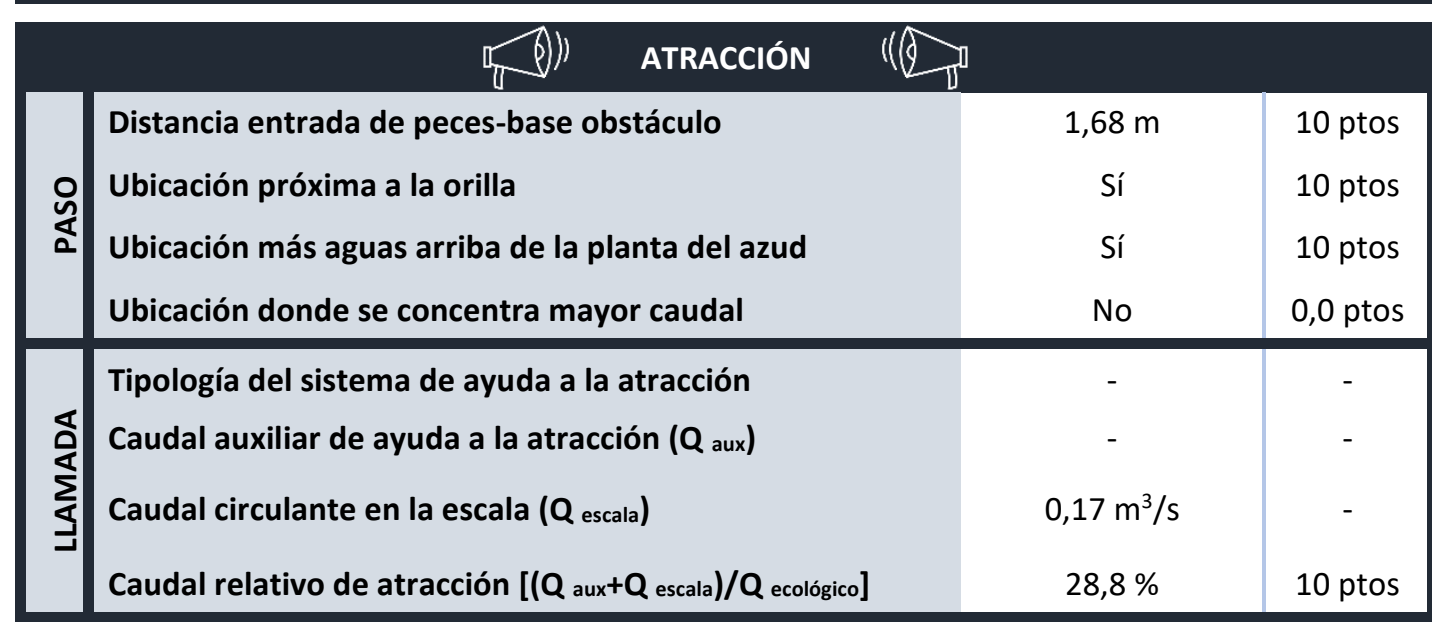

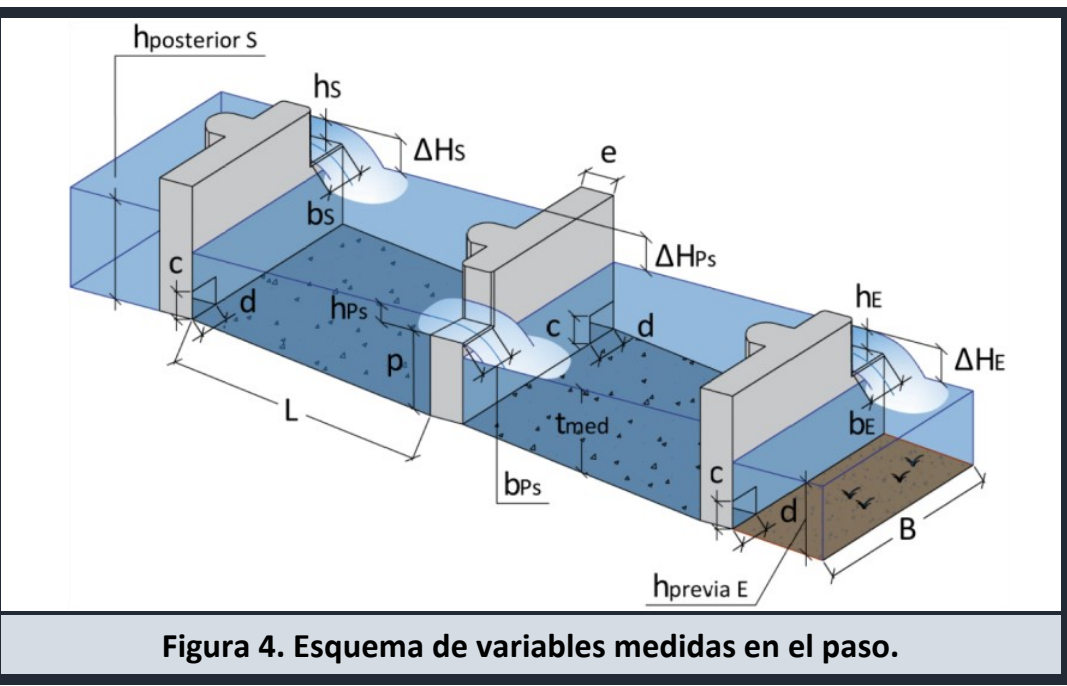

\begin{tabular}{|c|c|c|c|c|c|c|c|c|}
\hline & & & $b \rightarrow$ & & & & & \\
\hline Tipología & \multicolumn{3}{|c|}{ Vertedero no sumergido y orificio de fondo sumergido } & \multirow{3}{*}{$\begin{array}{l}0,21 \mathrm{~m} \\
0,31 \mathrm{~m}\end{array}$} & \multirow{3}{*}{$\begin{array}{l}8,0 \text { ptos } \\
10 \text { ptos } \\
7,8 \text { ptos }\end{array}$} & \multirow{3}{*}{$\begin{array}{l}\text { Ángulo con la corriente } \\
\text { Profundidad paso }\left(\mathrm{h}_{\mathrm{E}}-\Delta \mathrm{H}_{\mathrm{E}}\right) \\
\text { Dimensiones del orificio }\end{array}$} & \multirow{2}{*}{$0^{\circ}$} & \multirow{2}{*}{$\begin{array}{c}10 \text { ptos } \\
-\end{array}$} \\
\hline Desnivel entre láminas $\left(\Delta H_{E}\right)$ & $0,33 \mathrm{~m}$ & 8,4 ptos & Carga de vertido $\left(h_{E}\right)$ & & & & & \\
\hline Profundidad previa ( $h_{\text {previa }}$ ) & $0,87 \mathrm{~m}$ & 10 ptos & Anchura del vertedero ( $\left.b_{E}\right)$ & & & & $0,20 \times 0,20 \mathrm{~m}$ & 10 ptos \\
\hline
\end{tabular}

\begin{tabular}{|c|c|c|c|c|c|c|c|}
\hline Tipología & \multicolumn{3}{|c|}{ Vertederos no sumergidos y orificios de fondo alternos } & & 8,0 ptos & № estanques total / tipo & $22 / 17$ \\
\hline Desnivel entre láminas $\left(\Delta \mathrm{H}_{\mathrm{Ps}}\right)$ & $0,29 \mathrm{~m}$ & 8,5 ptos & Carga de vertido ( $\left.\mathrm{h}_{\mathrm{Ps}}\right)$ & $0,23 \mathrm{~m}$ & 10 ptos & Profundidad paso ( $\left.h_{\mathrm{Ps}_{\mathrm{s}}}-\Delta \mathrm{H}_{\mathrm{Ps}}\right)$ & - \\
\hline Anchura mín. vertedero ( $\left.b_{P s}\right)$ & \multicolumn{2}{|c|}{$0,30 \mathrm{~m}$} & Anchura med. vertedero ( $\left.b_{p_{s}}\right)$ & $0,31 \mathrm{~m}$ & 7,8 ptos & Anchura máx. vertedero ( $\left.b_{P_{s}}\right)$ & $0,32 \mathrm{~m}$ \\
\hline Pendiente media del lecho & \multicolumn{2}{|c|}{$13,8 \%$} & Altura umbral vertedero ( $p)$ & \multicolumn{2}{|c|}{$0,63 \mathrm{~m}$} & Dimencinnoc dalorificin & \multirow{2}{*}{$\begin{array}{c}0,20 \times 0,20 \\
m\end{array}$} \\
\hline Anchura del estanque (B) & \multicolumn{2}{|c|}{$1,50 \mathrm{~m}$} & Longitud del estanque (L) & \multicolumn{2}{|c|}{$2,50 \mathrm{~m}$} & 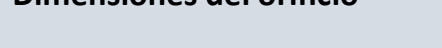 & \\
\hline Tirante medio $\left(t_{\text {med }}\right)$ & $0,72 \mathrm{~m}$ & 10 ptos & Potencia disipada (N) & $180 \mathrm{~W} / \mathrm{m}^{3}$ & 8,5 ptos & Espesor de los tabiques (e) & 0,23 \\
\hline
\end{tabular}

\begin{tabular}{|c|c|c|c|c|c|c|c|c|}
\hline Tipología & \multicolumn{3}{|c|}{ Orificio sumergido (hendidura con compuerta en carga) } & \multirow{3}{*}{$\begin{array}{c}1,04 \mathrm{~m} \\
-\end{array}$} & \multirow{3}{*}{$\begin{array}{c}5,0 \text { ptos } \\
- \\
-\end{array}$} & \multirow{3}{*}{$\begin{array}{l}\text { Ángulo con la corriente } \\
\text { Profundidad paso }\left(h_{s}-\Delta H_{s}\right) \\
\text { Dimensiones del orificio }\end{array}$} & \multirow{3}{*}{$\begin{array}{c}90^{\circ} \\
0,81 \mathrm{~m} \\
0,20 \times 0,25 \mathrm{~m}\end{array}$} & \multirow{3}{*}{$\begin{array}{l}10 \text { ptos } \\
10 \text { ptos } \\
10 \text { ptos }\end{array}$} \\
\hline Desnivel entre láminas $\left(\Delta \mathrm{H}_{s}\right)$ & $0,23 \mathrm{~m}$ & 10 ptos & Carga de vertido (hs) & & & & & \\
\hline Profun. posterior ( $h_{\text {posterior }}$ ) & $>1,00 \mathrm{~m}$ & 10 ptos & Anchura del vertedero (bs) & & & & & \\
\hline
\end{tabular}




\section{PASO PARA PECES ASOCIADO AL AZUD EL PUERTO}

\begin{tabular}{|c|c|c|c|c|}
\hline & Provincia & Valladolid & Municipio & Tordesillas \\
\hline & $\begin{array}{l}\text { Nombre del aprovechamiento } \\
\text { Código del aprovechamiento } \\
\text { Long. coronación del azud } \\
\text { (1) } \\
\text { Coordenadas del paso piscícola }\end{array}$ & $\begin{array}{l}\text { San Miguel del Pino } \\
1100165 \\
310 \mathrm{~m} \\
X: 340.114 \mathrm{~m}, \mathrm{Y}: 4.59\end{array}$ & $\begin{array}{l}\text { Tipo de aprovechamiento } \\
\text { Código del azud (1) } \\
\text { Salto total de agua en la visita } \\
372 \text { m (ETRS 89; HUSO 30) }\end{array}$ & $\begin{array}{l}\text { Riego e hidroeléctrico } \\
1005289 \\
3,65 \mathrm{~m}\end{array}$ \\
\hline & $\begin{array}{l}\text { Cuenca hidrográfica } \\
\text { Principales peces migradores } \\
\text { Época de migración }\end{array}$ & $\begin{array}{l}\text { Duero } \\
\text { Luciobarbus bocagei } \\
\text { Mayo a junio }\end{array}$ & Cauce & Duero \\
\hline $\begin{array}{l}\text { Figura 1. Ubicación en la parte } \\
\text { española de la cuenca del río Duero. }\end{array}$ & $\begin{array}{l}\text { Caudal medio en migración }{ }^{(2)} \\
\text { Caudal durante la visita }{ }^{(3)}\end{array}$ & $\begin{array}{l}104,01 \mathrm{~m}^{3} / \mathrm{s} \\
20,05 \mathrm{~m}^{3} / \mathrm{s}\end{array}$ & $\begin{array}{l}\text { Caudal ecológico en migración } \\
\text { Hora y fecha de la visita }\end{array}$ & $\begin{array}{l}1,00 \mathrm{~m}^{3} / \mathrm{s} \\
11: 00 \mathrm{~h}, 13 / 09 / 2016\end{array}$ \\
\hline
\end{tabular}

(1) Dato obtenido de MíRAME-IDE Duero. ${ }^{(2)}$ Dato obtenido del CEDEX Hidrológico. ${ }^{(3)}$ Dato obtenido del SAIH del Duero.

\begin{tabular}{|c|c|c|c|}
\hline aso para peces de estanques su & s conectados po & tederos sumergidos y orificios de fondo alternos & \\
\hline $\begin{array}{l}\text { Estado de mantenimiento y limpieza durante la evaluación } \\
\text { Solera naturalizada (con piedras) } \\
\text { Vertedero de umbral móvil en la entrada de peces }\end{array}$ & $\begin{array}{l}\text { Muy adecuado } \\
\text { Sí } \\
\text { Sí }\end{array}$ & $\begin{array}{l}\text { Compuerta en la salida de peces } \\
\text { Dispositivo para evitar la entrada de arrastres } \\
\text { Salida de peces segura (alejada del azud, turbinas, ...) }\end{array}$ & $\begin{array}{l}\text { Sí } \\
\text { No } \\
\text { Sí }\end{array}$ \\
\hline
\end{tabular}

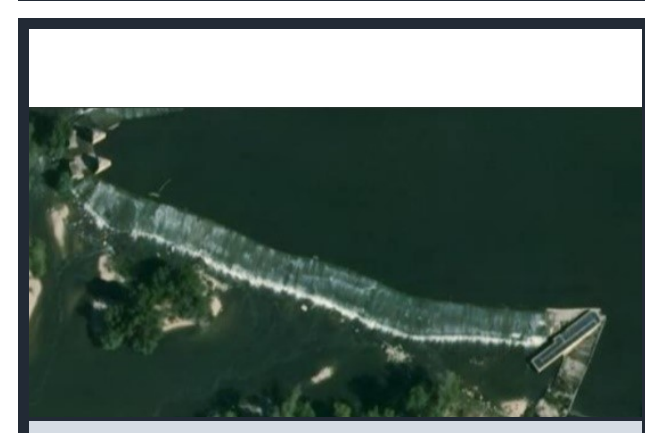

Figura 2. Ortofoto de la zona (fuente: SigPac).

\begin{tabular}{lccl}
\multicolumn{4}{c}{ RESUMEN DE LA EVALUACIÓN DEL PASO PARA PECES } \\
(CON LA METODOLOGÍA AEPS) \\
Etapa o categoría & Puntuación & Evaluación & ¿Mejoras? \\
Atracción & 8,2 & Muy favorable & Opcionales \\
Entrada & 9,1 & Muy favorable & Opcionales \\
Pasaje & 9,1 & Muy favorable & Opcionales \\
Salida & 8,5 & Muy favorable & Opcionales \\
\hline
\end{tabular}

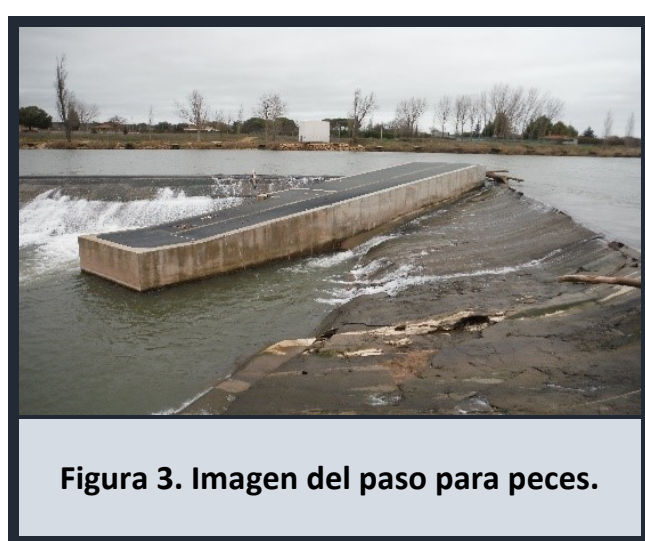




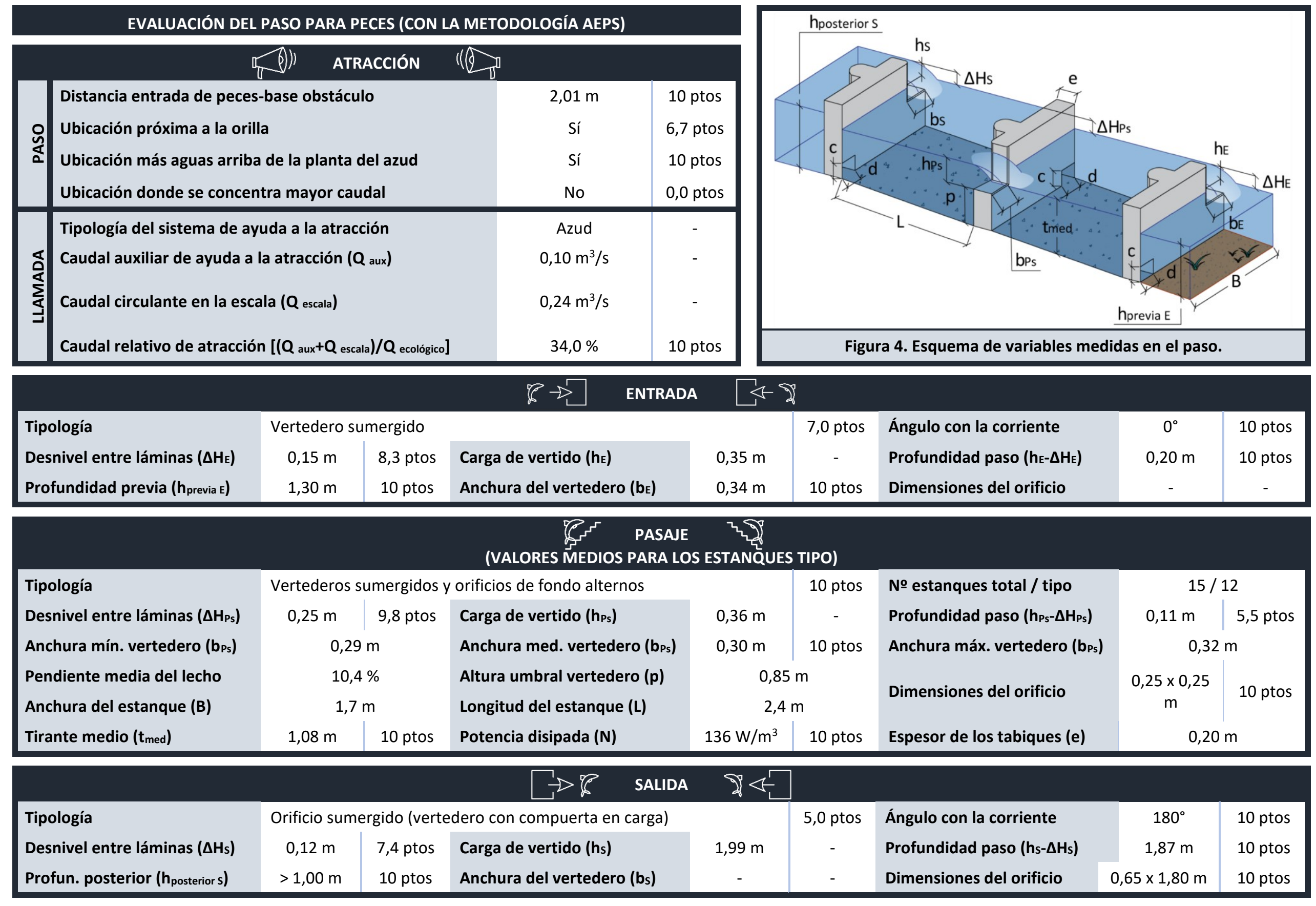




\section{PASO PARA PECES ASOCIADO AL AZUD DE LA CENTRAL HIDROELÉCTRICA DE HERREROS}

\begin{tabular}{|c|c|c|c|c|}
\hline & Provincia & Valladolid & Municipio & Pollos \\
\hline & $\begin{array}{l}\text { Nombre del aprovechamiento } \\
\text { Código del aprovechamiento } \\
\text { Long. coronación del azud } \\
\text { (1) } \\
\text { Coordenadas del paso piscícola }\end{array}$ & $\begin{array}{l}\text { Herreros } \\
1100182 \\
425 \mathrm{~m} \\
X: 326.634 \mathrm{~m}, \mathrm{Y}: 4.593\end{array}$ & $\begin{array}{l}\text { Tipo de aprovechamiento } \\
\text { Código del azud (1) } \\
\text { Salto total de agua en la visita } \\
493 \text { m (ETRS 89; HUSO 30) }\end{array}$ & $\begin{array}{l}\text { Riego e hidroeléctrico } \\
1005294 \\
1,68 \mathrm{~m}\end{array}$ \\
\hline & $\begin{array}{l}\text { Cuenca hidrográfica } \\
\text { Principales peces migradores }{ }^{(1)} \\
\text { Época de migración }\end{array}$ & $\begin{array}{l}\text { Duero } \\
\text { Luciobarbus bocagei } \\
\text { Mayo a junio }\end{array}$ & Cauce & Duero \\
\hline $\begin{array}{c}\text { Figura 1. Ubicación en la parte } \\
\text { española de la cuenca del río Duero. }\end{array}$ & $\begin{array}{l}\text { Caudal medio en migración (2) } \\
\text { Caudal durante la visita (3) }\end{array}$ & $\begin{array}{l}104,01 \mathrm{~m}^{3} / \mathrm{s} \\
239,41 \mathrm{~m}^{3} / \mathrm{s}\end{array}$ & $\begin{array}{l}\text { Caudal ecológico en migración } \\
\text { Hora y fecha de la visita }\end{array}$ & $\begin{array}{l}104,00 \mathrm{~m}^{3} / \mathrm{s} \\
17: 00 \mathrm{~h}, 11 / 03 / 2016\end{array}$ \\
\hline
\end{tabular}

(1) Dato obtenido de MíRAME-IDE Duero. ${ }^{(2)}$ Dato obtenido del CEDEX Hidrológico. ${ }^{(3)}$ Dato obtenido del SAIH del Duero.

\begin{tabular}{|c|c|c|c|}
\hline Paso para peces de estanques su & os conectad & tederos ligeramente sumergidos y alineados & \\
\hline $\begin{array}{l}\text { Estado de mantenimiento y limpieza durante la evaluación } \\
\text { Solera naturalizada (con piedras) } \\
\text { Vertedero de umbral móvil en la entrada de peces }\end{array}$ & $\begin{array}{l}\text { Deficiente } \\
\text { No } \\
\text { No }\end{array}$ & $\begin{array}{l}\text { Compuerta en la salida de peces } \\
\text { Dispositivo para evitar la entrada de arrastres } \\
\text { Salida de peces segura (alejada del azud, turbinas, ...) }\end{array}$ & $\begin{array}{l}\text { No } \\
\text { No } \\
\text { Sí }\end{array}$ \\
\hline
\end{tabular}

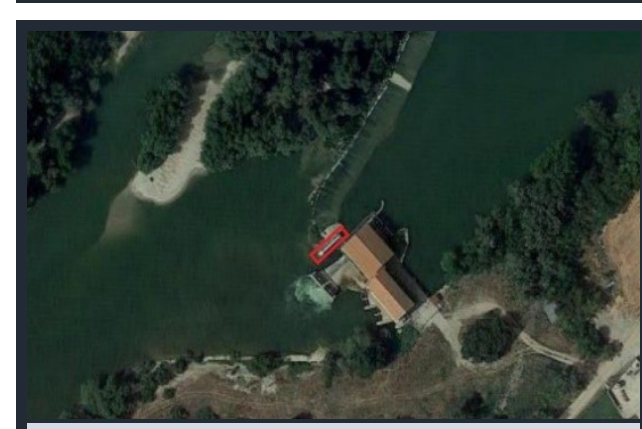

Figura 2. Ortofoto de la zona (fuente: Google Maps).

\begin{tabular}{|c|c|c|c|}
\hline \multicolumn{4}{|c|}{$\begin{array}{l}\text { RESUMEN DE LA EVALUACIÓN DEL PASO PARA PECES } \\
\text { (CON LA METODOLOGÍA AEPS) }\end{array}$} \\
\hline Etapa o categoría & Puntuación & Evaluación & ¿Mejoras? \\
\hline Atracción & 5,8 & Desfavorable & Muy necesarias \\
\hline Entrada & 8,8 & Muy favorable & Opcionales \\
\hline Pasaje & 0,0 & Muy desfavorable & Imprescindibles \\
\hline Salida & 8,9 & Muy favorable & Opcionales \\
\hline
\end{tabular}

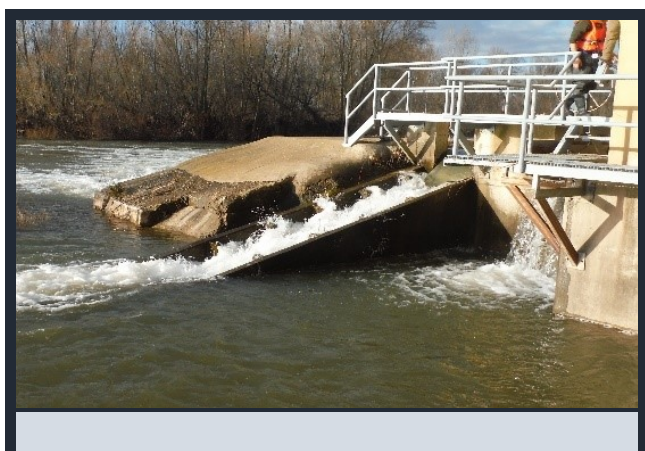

Figura 3. Imagen del paso para peces. 


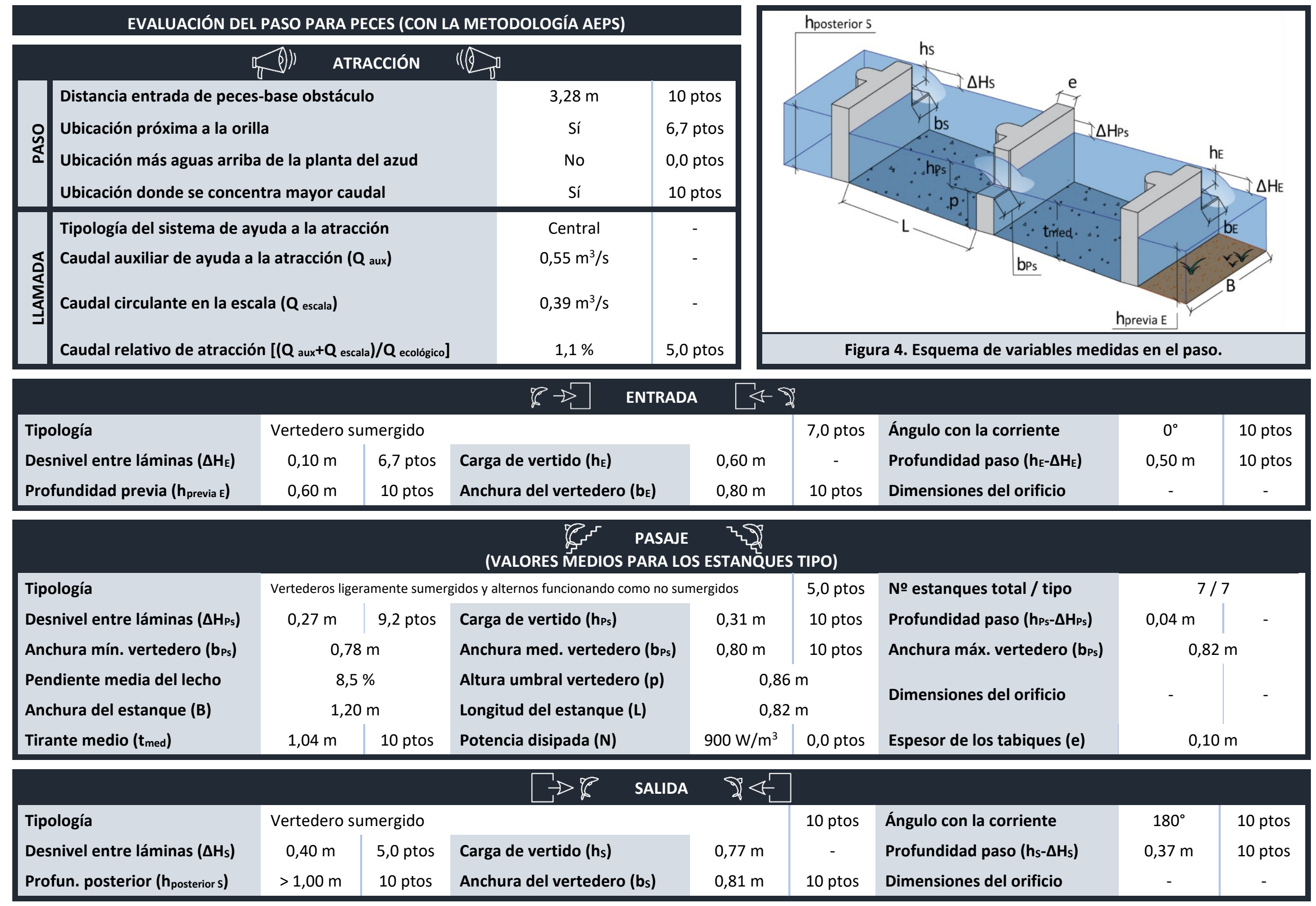




\section{PASO PARA PECES ASOCIADO AL AZUD DE LA CENTRAL HIDROELÉCTRICA DE LA CONCHITA}

\begin{tabular}{|c|c|c|c|c|}
\hline & Provincia & Valladolid & Municipio & Tudela de Duero \\
\hline & $\begin{array}{l}\text { Nombre del aprovechamiento } \\
\text { Código del aprovechamiento } \\
\text { Long. coronación del azud } \\
\text { Coordenadas del paso piscícola }\end{array}$ & $\begin{array}{l}\text { La Conchita } \\
1100018 \\
163 m \\
X: 368.130 n\end{array}$ & $\begin{array}{l}\text { Tipo de aprovechamiento } \\
\text { Código del azud (1) } \\
\text { Salto total de agua en la visita } \\
240 \text { m (ETRS 89; HUSO 30) }\end{array}$ & $\begin{array}{l}\text { Hidroeléctrico } \\
1005585 \\
3,13 \mathrm{~m}\end{array}$ \\
\hline & $\begin{array}{l}\text { Cuenca hidrográfica } \\
\text { Principales peces migradores }{ }^{(1)} \\
\text { Época de migración }\end{array}$ & $\begin{array}{l}\text { Duero } \\
\text { Luciobarbus } \\
\text { Mayo a juni }\end{array}$ & $\begin{array}{l}\text { Cauce } \\
\text { seudochondrostoma duriense }\end{array}$ & Duero \\
\hline $\begin{array}{c}\text { Figura 1. Ubicación en la parte } \\
\text { española de la cuenca del río Duero. }\end{array}$ & $\begin{array}{l}\text { Caudal medio en migración (2) } \\
\text { Caudal durante la visita }{ }^{(3)}\end{array}$ & $\begin{array}{l}32,02 \mathrm{~m}^{3} / \mathrm{s} \\
75,85 \mathrm{~m}^{3} / \mathrm{s}\end{array}$ & $\begin{array}{l}\text { Caudal ecológico en migración } \\
\text { Hora y fecha de la visita }\end{array}$ & $\begin{array}{l}4,00 \mathrm{~m}^{3} / \mathrm{s} \\
12: 30 \mathrm{~h}, 11 / 03 / 2016\end{array}$ \\
\hline
\end{tabular}

(1) Dato obtenido de MíRAME-IDE Duero. ${ }^{(2)}$ Dato obtenido del CEDEX Hidrológico. ${ }^{(3)}$ Dato obtenido del SAIH del Duero.

\begin{tabular}{|c|c|c|c|}
\hline Paso para peces de estanques su & os conectad & tederos no sumergidos alternos y sin orificios & \\
\hline $\begin{array}{l}\text { Estado de mantenimiento y limpieza durante la evaluación } \\
\text { Solera naturalizada (con piedras) } \\
\text { Vertedero de umbral móvil en la entrada de peces }\end{array}$ & $\begin{array}{l}\text { Adecuado } \\
\text { No } \\
\text { No }\end{array}$ & $\begin{array}{l}\text { Compuerta en la salida de peces } \\
\text { Dispositivo para evitar la entrada de arrastres } \\
\text { Salida de peces segura (alejada del azud, turbinas, ...) }\end{array}$ & $\begin{array}{l}\text { No } \\
\text { No } \\
\text { No }\end{array}$ \\
\hline
\end{tabular}

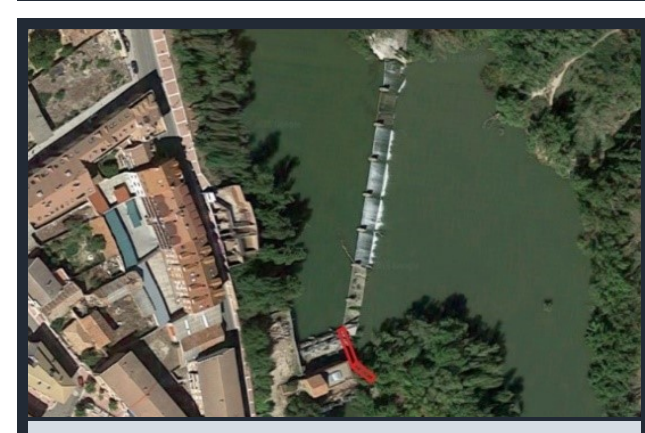

Figura 2. Ortofoto de la zona (fuente: SigPac).

\begin{tabular}{lcccc}
\multicolumn{4}{c}{ RESUMEN DE LA EVALUACIÓN DEL PASO PARA PECES } \\
& \multicolumn{2}{c|}{ (CON LA METODOLOGÍA AEPS) } & \\
\hline Etapa o categoría & Puntuación & Evaluación & ¿Mejoras? \\
Atracción & 3,6 & Muy desfavorable & Imprescindibles \\
Entrada & 7,8 & Favorable & Recomendables \\
Pasaje & 7,4 & Favorable & Recomendables \\
Salida & 0,0 & Muy desfavorable & Imprescindibles \\
\hline
\end{tabular}

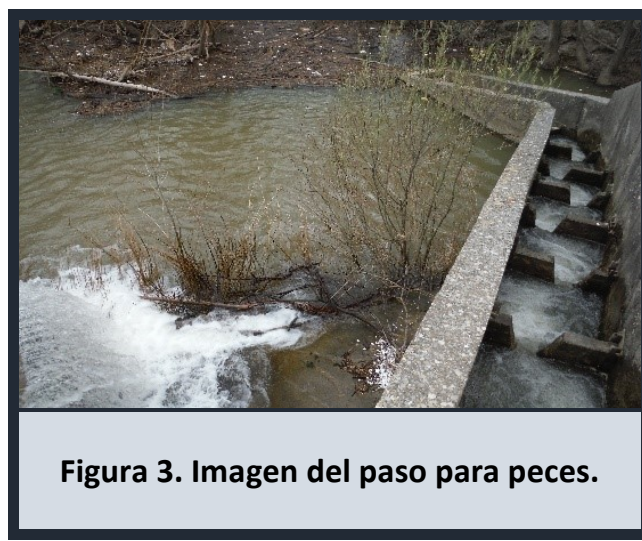




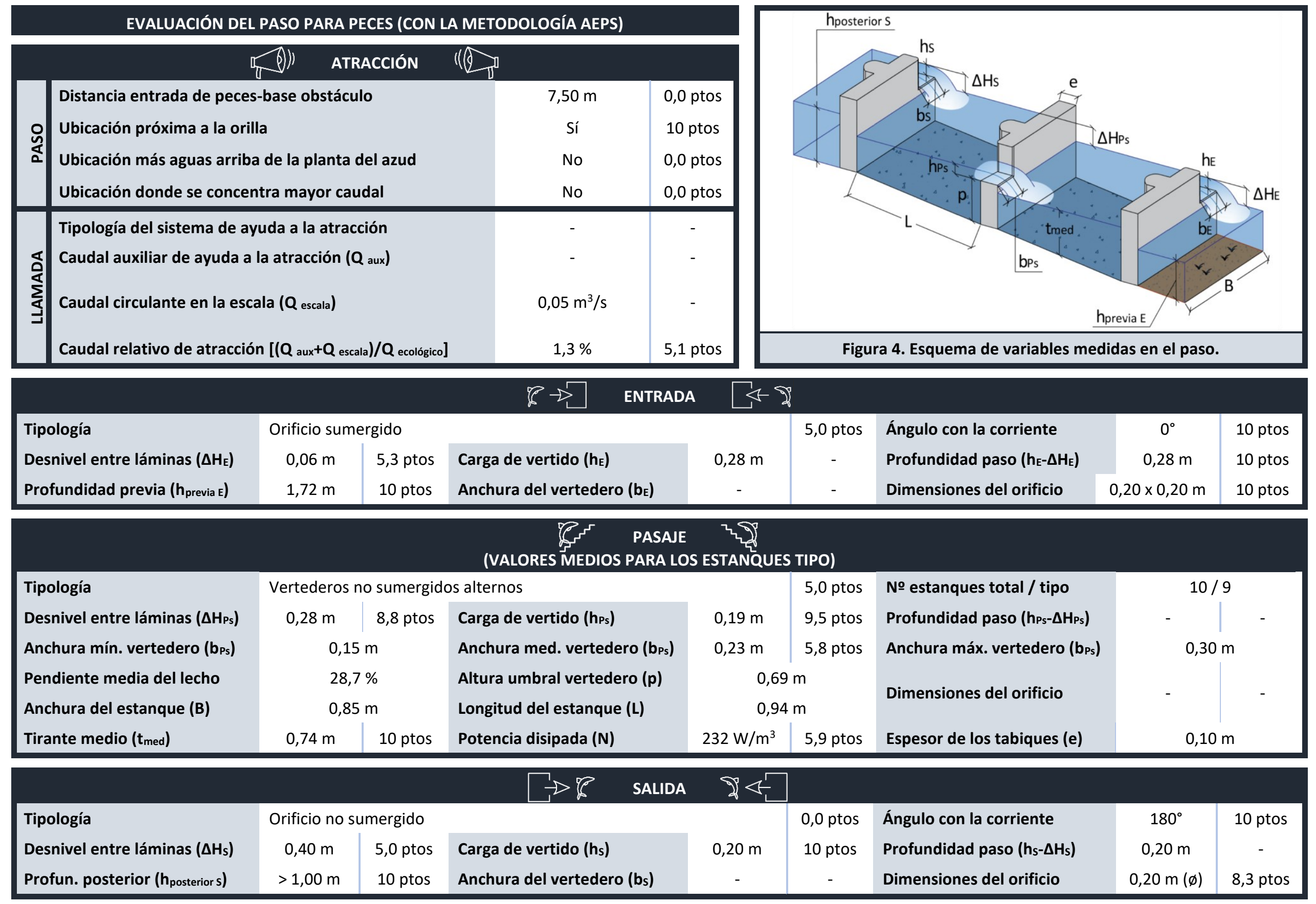




\section{PASO PARA PECES ASOCIADO AL AZUD DE LA CENTRAL HIDROELÉCTRICA DE SALTO DE LA FLECHA}

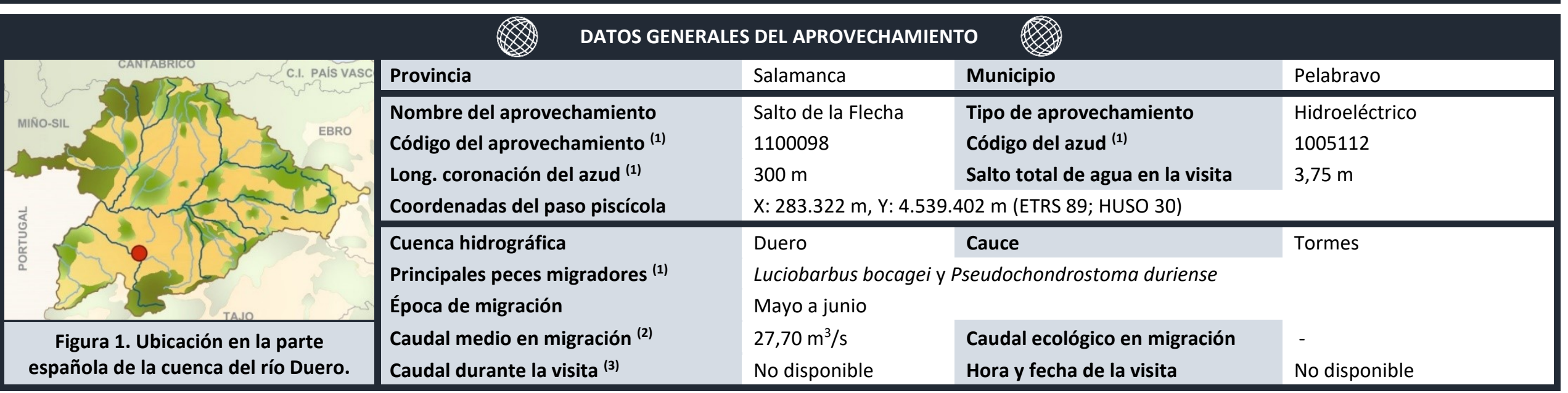

(1) Dato obtenido de MíRAME-IDE Duero. ${ }^{(2)}$ Dato obtenido del CEDEX Hidrológico. ${ }^{(3)}$ Dato obtenido del SAIH del Duero.

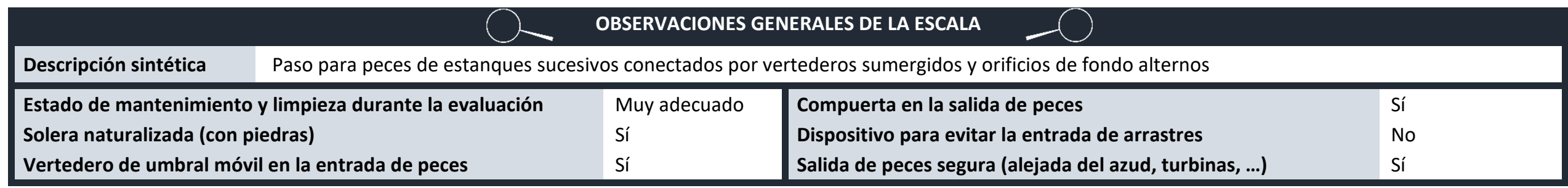

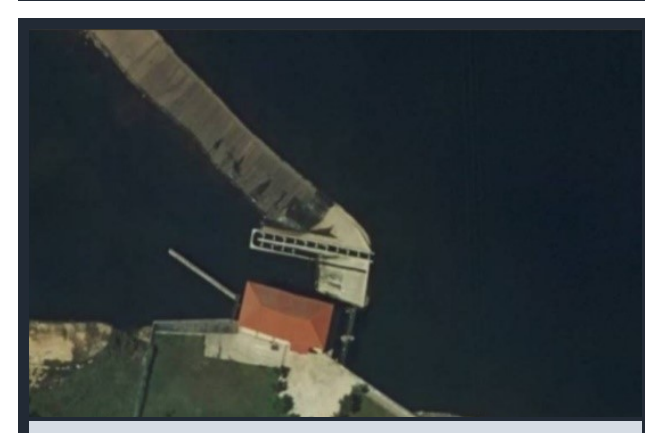

Figura 2. Ortofoto de la zona (fuente: SigPac).

\begin{tabular}{|c|c|c|c|}
\hline \multicolumn{4}{|c|}{$\begin{array}{l}\text { RESUMEN DE LA EVALUACIÓN DEL PASO PARA PECES } \\
\text { (CON LA METODOLOGÍA AEPS) }\end{array}$} \\
\hline Etapa o categoría & Puntuación & Evaluación & ¿Mejoras? \\
\hline Atracción & 7,2 & Favorable & Recomendables \\
\hline Entrada & 9,4 & Muy favorable & Opcionales \\
\hline Pasaje & 10,0 & Muy favorable & Opcionales \\
\hline Salida & 9,7 & Muy favorable & Opcionales \\
\hline
\end{tabular}

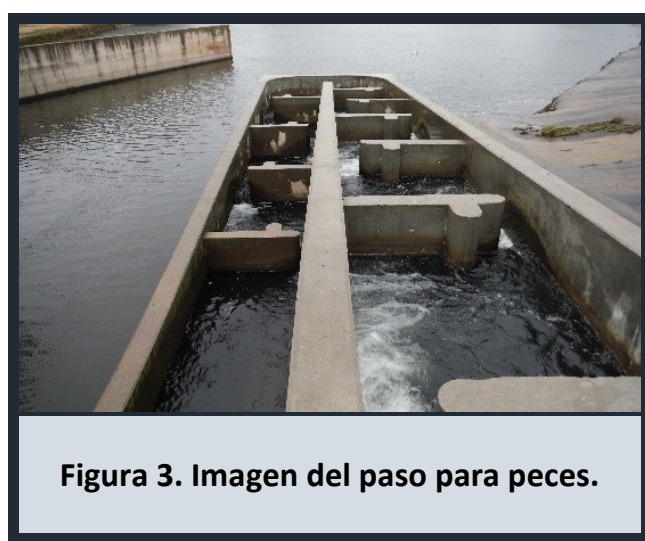




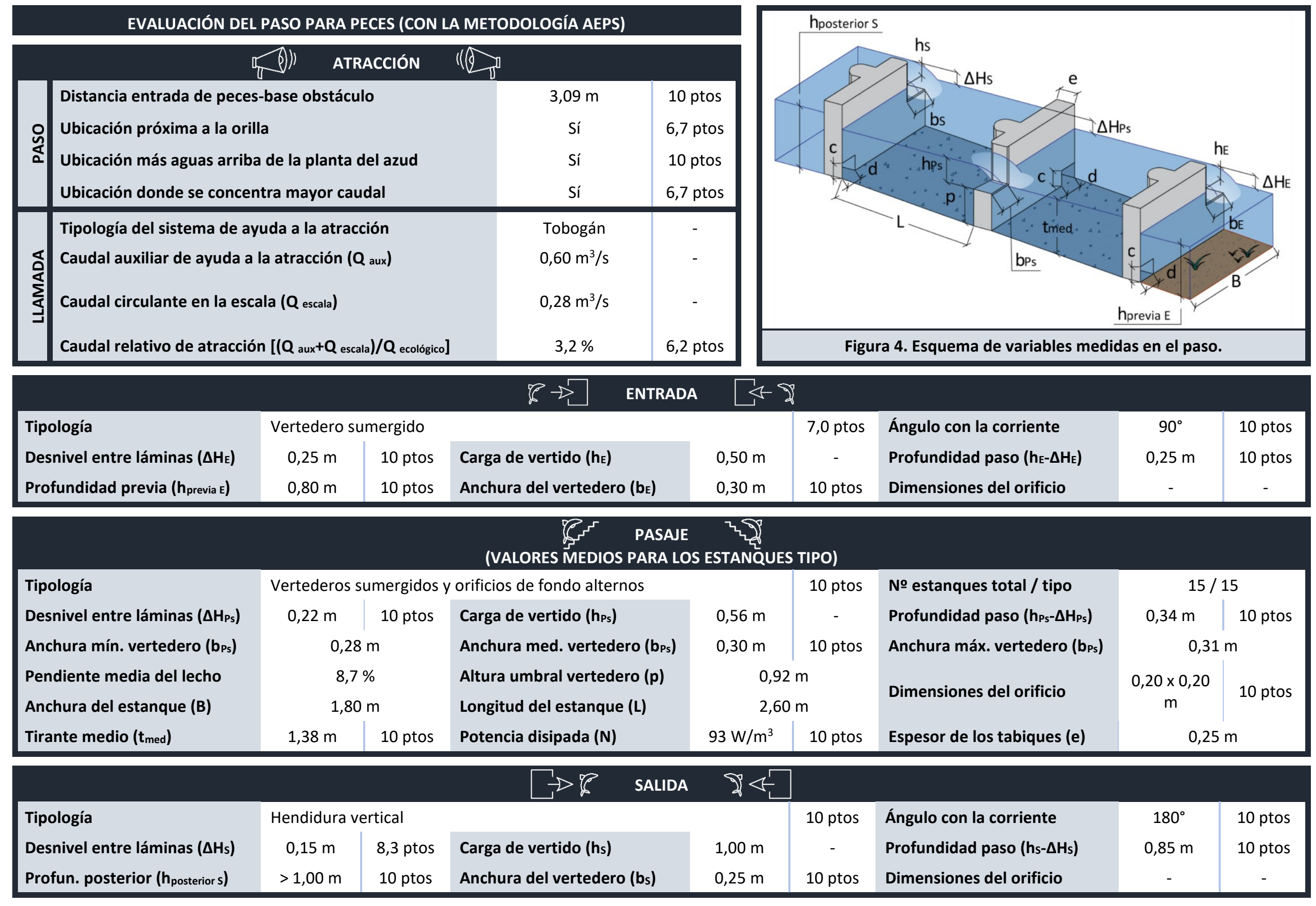




\section{PASO PARA PECES ASOCIADO AL AZUD DE LA CENTRAL HIDROELÉCTRICA DE LA JOSEFINA (AZUD)}

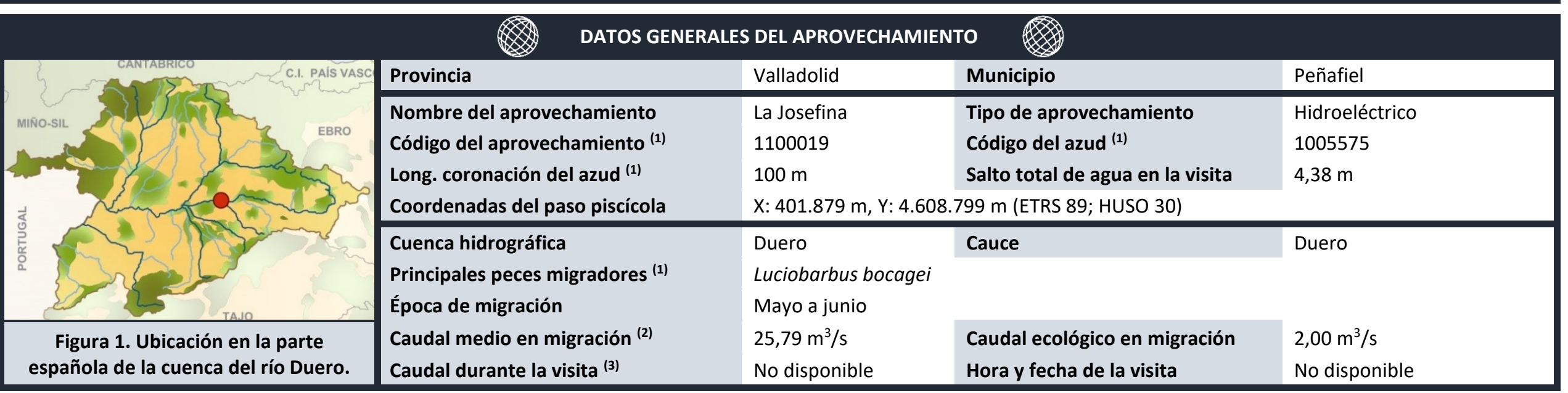

(1) Dato obtenido de MíRAME-IDE Duero. ${ }^{(2)}$ Dato obtenido del CEDEX Hidrológico. ${ }^{(3)}$ Dato obtenido del SAIH del Duero.

\begin{tabular}{|c|c|c|c|}
\hline Paso para peces de estanques $s$ & os conectad & tederos sumergidos y orificios de fondo alternos & \\
\hline $\begin{array}{l}\text { Estado de mantenimiento y limpieza durante la evaluación } \\
\text { Solera naturalizada (con piedras) } \\
\text { Vertedero de umbral móvil en la entrada de peces }\end{array}$ & $\begin{array}{l}\text { Adecuado } \\
\text { Sí } \\
\text { Sí }\end{array}$ & $\begin{array}{l}\text { Compuerta en la salida de peces } \\
\text { Dispositivo para evitar la entrada de arrastres } \\
\text { Salida de peces segura (alejada del azud, turbinas, ...) }\end{array}$ & $\begin{array}{l}\text { Sí } \\
\text { No } \\
\text { Sí }\end{array}$ \\
\hline
\end{tabular}

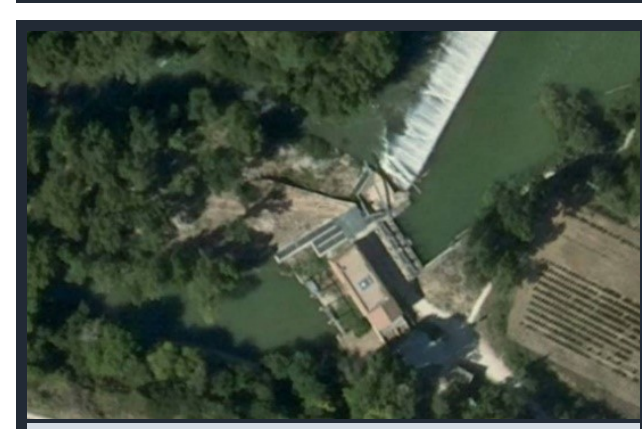

Figura 2. Ortofoto de la zona (fuente: SigPac).

\begin{tabular}{lccl}
\multicolumn{5}{c}{ RESUMEN DE LA EVALUACIÓN DEL PASO PARA PECES } \\
(CON LA METODOLOGÍA AEPS) & \\
\hline Etapa o categoría & Puntuación & Evaluación & ¿Mejoras? \\
Atracción & 9,6 & Muy favorable & Opcionales \\
Entrada & 9,7 & Muy favorable & Opcionales \\
Pasaje & 9,7 & Muy favorable & Opcionales \\
Salida & 8,9 & Muy favorable & Opcionales \\
\hline
\end{tabular}

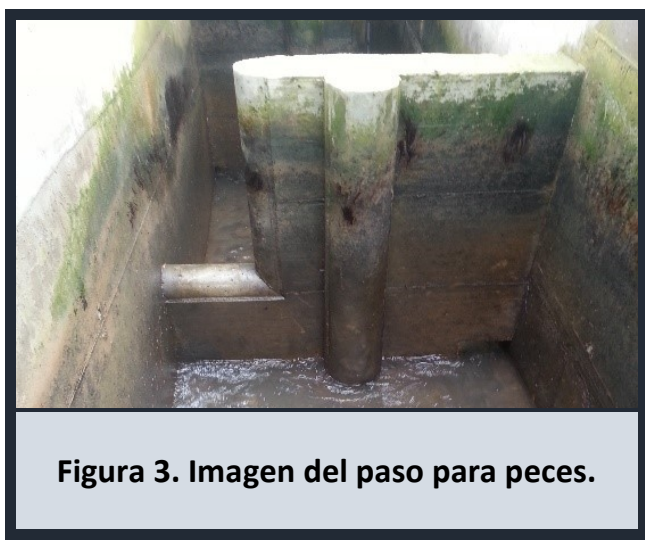




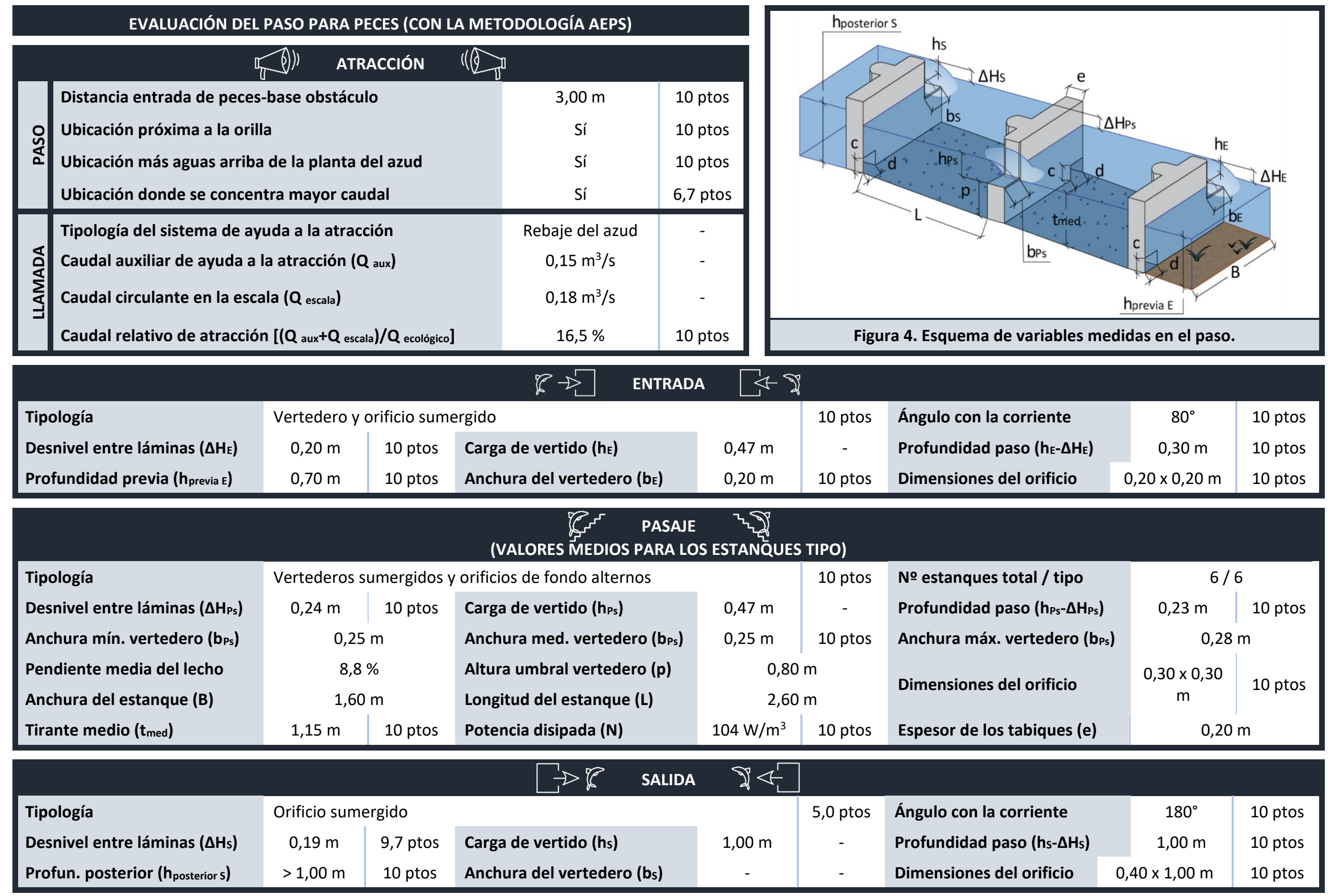




\section{PASO PARA PECES ASOCIADO AL AZUD DE LA CENTRAL HIDROELÉCTRICA DE LA JOSEFINA (CENTRAL)}

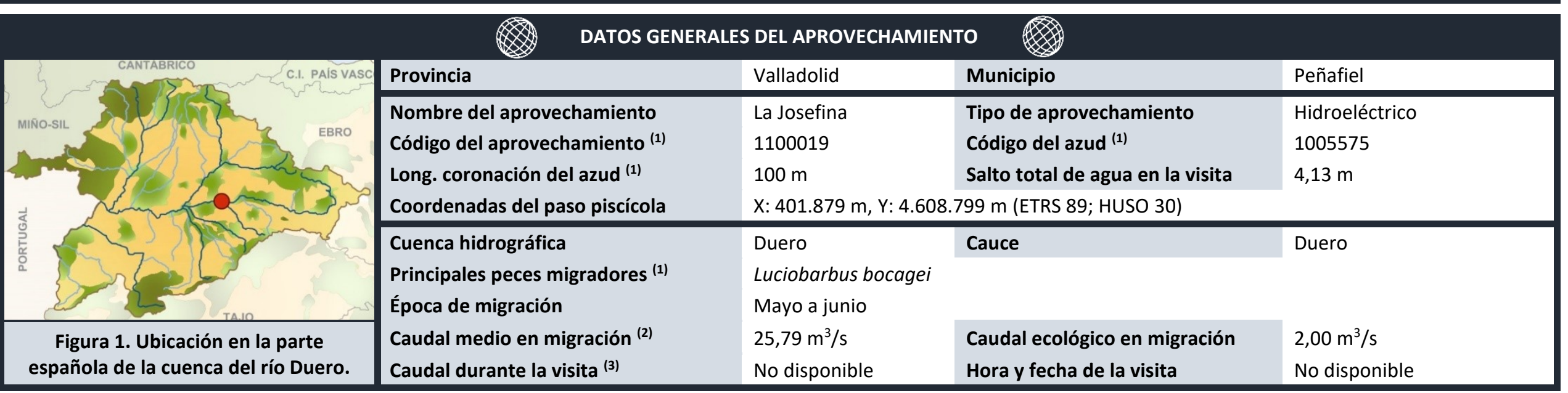

(1) Dato obtenido de MíRAME-IDE Duero. ${ }^{(2)}$ Dato obtenido del CEDEX Hidrológico. ${ }^{(3)}$ Dato obtenido del SAIH del Duero.

\begin{tabular}{|c|c|c|c|}
\hline Paso para peces de estanques su & os conectad & tederos sumergidos y orificios de fondo alternos & \\
\hline $\begin{array}{l}\text { Estado de mantenimiento y limpieza durante la evaluación } \\
\text { Solera naturalizada (con piedras) } \\
\text { Vertedero de umbral móvil en la entrada de peces }\end{array}$ & $\begin{array}{l}\text { Adecuado } \\
\text { Sí } \\
\text { Sí }\end{array}$ & $\begin{array}{l}\text { Compuerta en la salida de peces } \\
\text { Dispositivo para evitar la entrada de arrastres } \\
\text { Salida de peces segura (alejada del azud, turbinas, ...) }\end{array}$ & $\begin{array}{l}\text { Sí } \\
\text { No } \\
\text { Sí }\end{array}$ \\
\hline
\end{tabular}

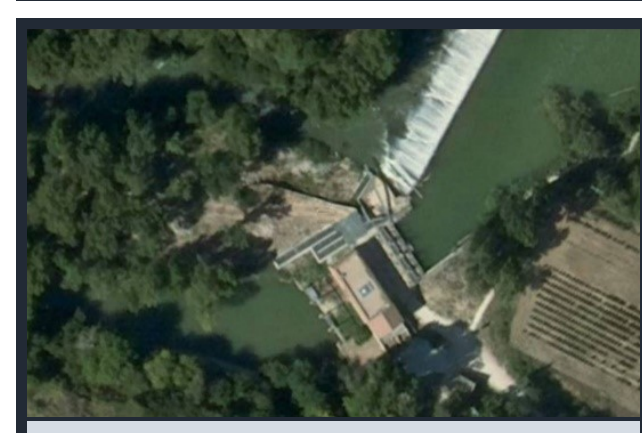

Figura 2. Ortofoto de la zona (fuente: SigPac).

\begin{tabular}{lccc}
\multicolumn{4}{c}{ RESUMEN DE LA EVALUACIÓN DEL PASO PARA PECES } \\
& \multicolumn{4}{c|}{ (CON LA METODOLOGÍA AEPS) } & \\
\hline Etapa o categoría & Puntuación & Evaluación & ¿Mejoras? \\
Atracción & 7,4 & Favorable & Recomendables \\
Entrada & 9,7 & Muy favorable & Opcionales \\
Pasaje & 9,7 & Muy favorable & Opcionales \\
Salida & 8,9 & Muy favorable & Opcionales \\
\hline
\end{tabular}

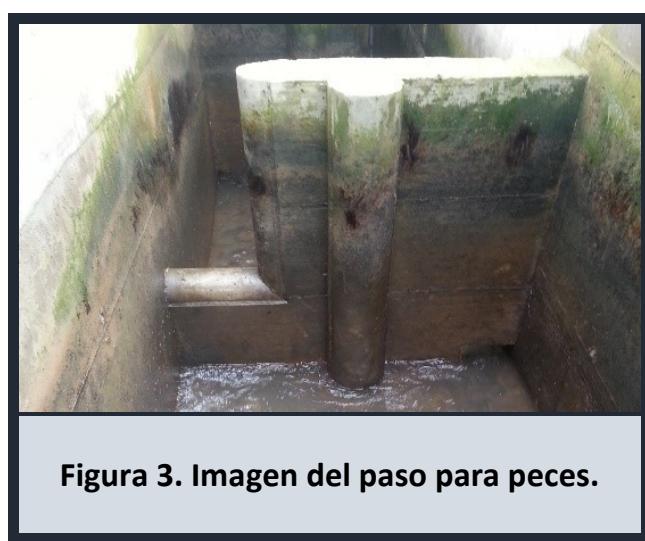




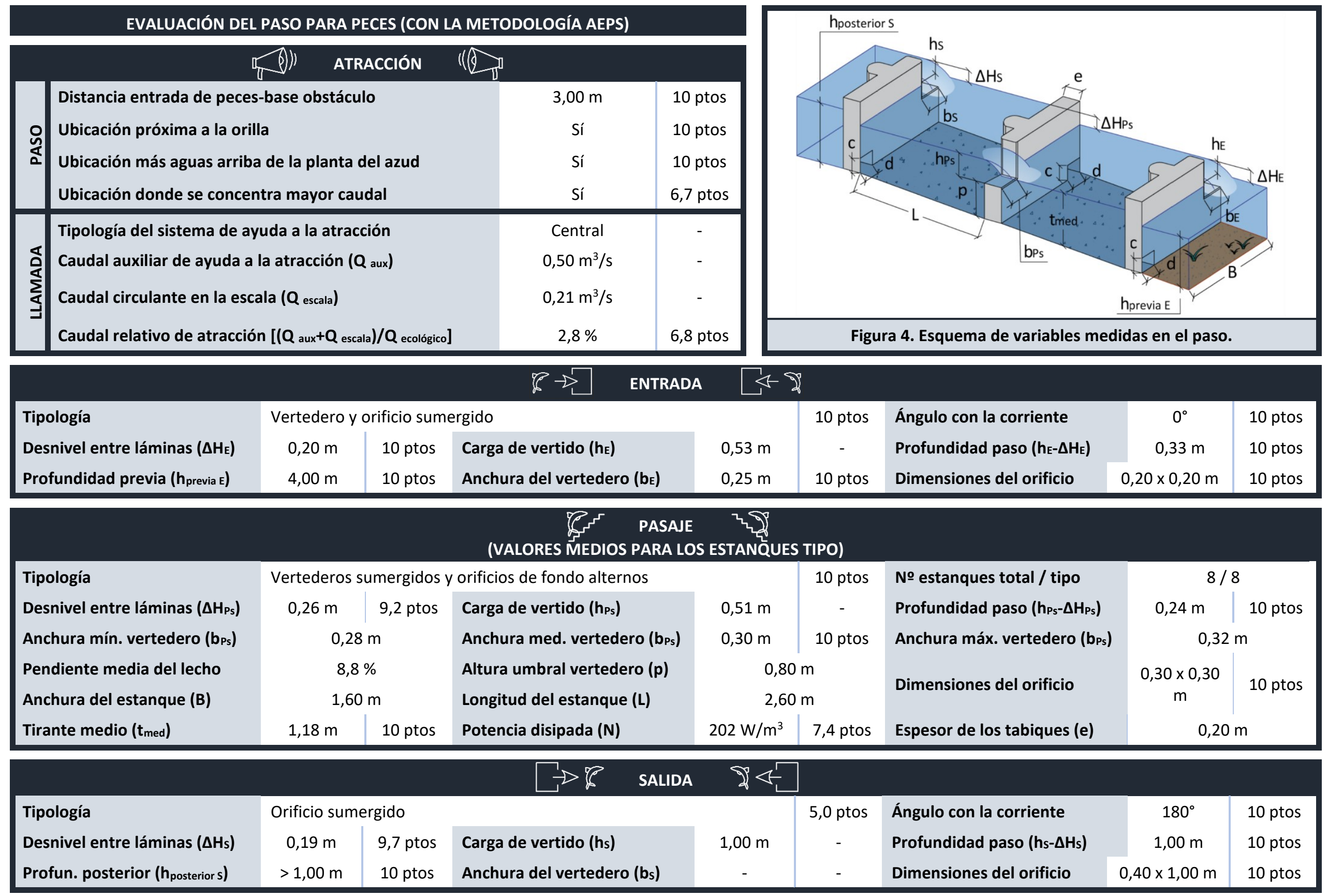




\section{PASO PARA PECES ASOCIADO AL AZUD DE LA CENTRAL HIDROELÉCTRICA DE LA JOSEFINA (TRAMO COMÚN)}

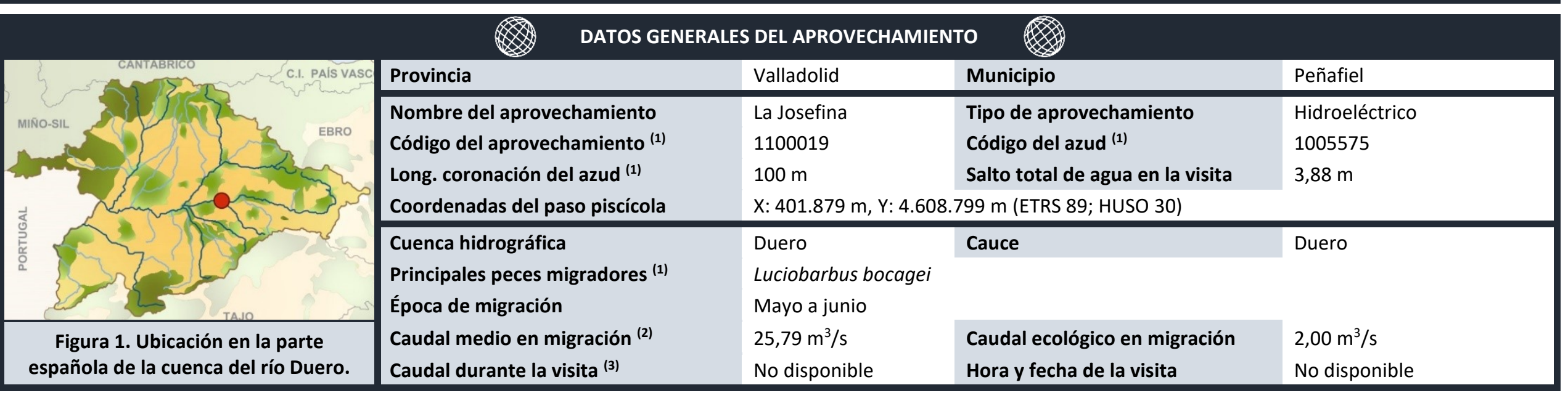

(1) Dato obtenido de MíRAME-IDE Duero. ${ }^{(2)}$ Dato obtenido del CEDEX Hidrológico. ${ }^{(3)}$ Dato obtenido del SAIH del Duero.

\begin{tabular}{|c|c|c|c|}
\hline Paso para peces de estanques $s$ & os conectad & tederos sumergidos y orificios de fondo alternos & \\
\hline $\begin{array}{l}\text { Estado de mantenimiento y limpieza durante la evaluación } \\
\text { Solera naturalizada (con piedras) } \\
\text { Vertedero de umbral móvil en la entrada de peces }\end{array}$ & $\begin{array}{l}\text { Adecuado } \\
\text { Sí } \\
\text { Sí }\end{array}$ & $\begin{array}{l}\text { Compuerta en la salida de peces } \\
\text { Dispositivo para evitar la entrada de arrastres } \\
\text { Salida de peces segura (alejada del azud, turbinas, ...) }\end{array}$ & $\begin{array}{l}\text { Sí } \\
\text { No } \\
\text { Sí }\end{array}$ \\
\hline
\end{tabular}

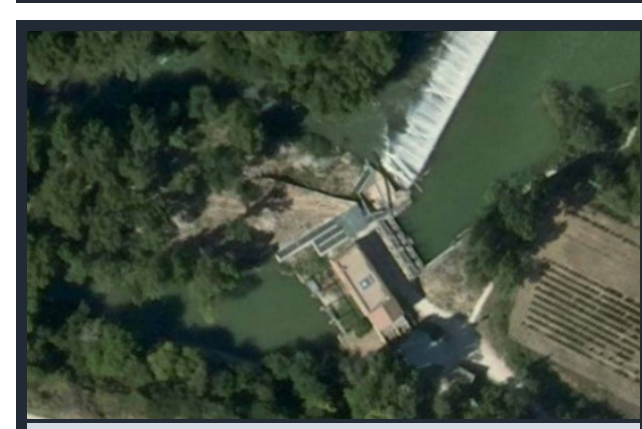

Figura 2. Ortofoto de la zona (fuente: SigPac).

\begin{tabular}{lccl}
\multicolumn{5}{c}{ RESUMEN DE LA EVALUACIÓN DEL PASO PARA PECES } \\
(CON LA METODOLOGÍA AEPS)
\end{tabular}

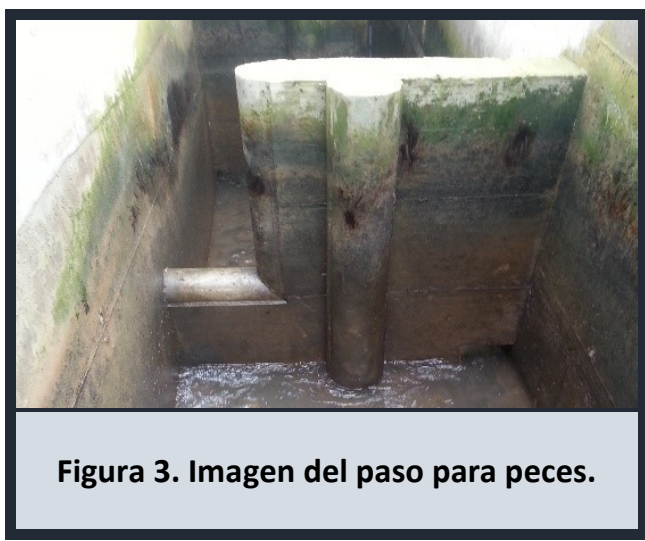




\section{EVALUACIÓN DEL PASO PARA PECES (CON LA METODOLOGíA AEPS)}

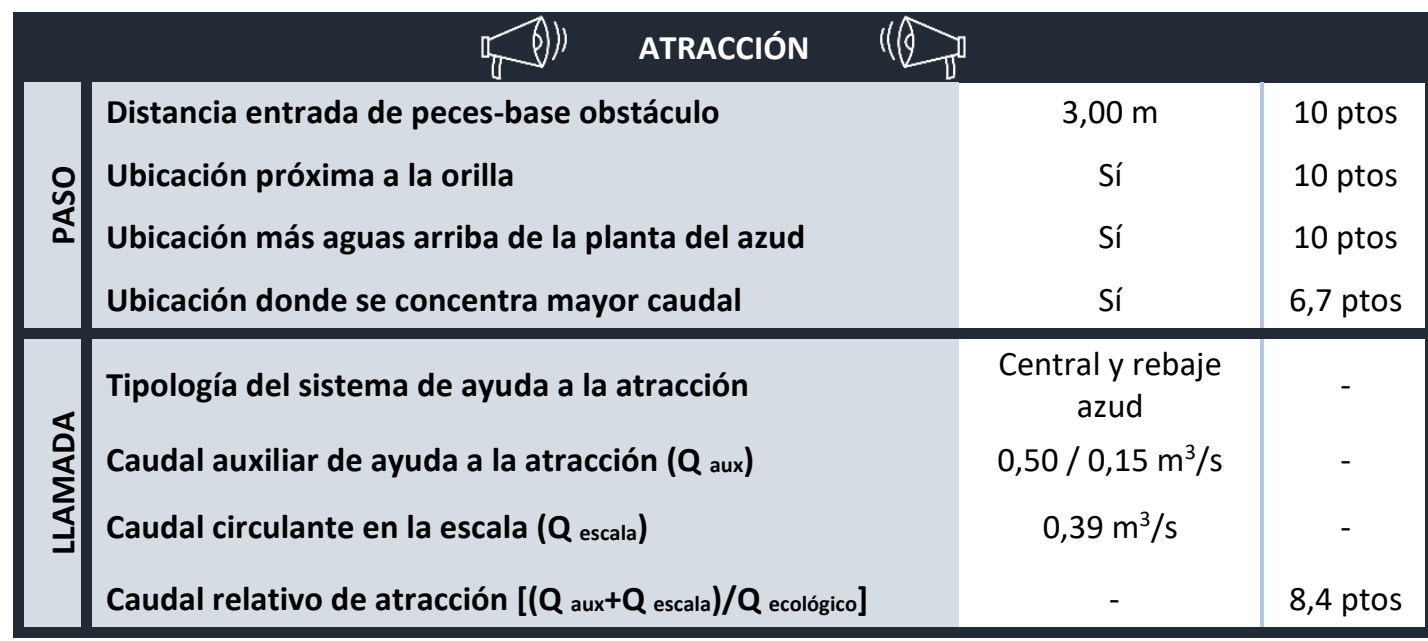

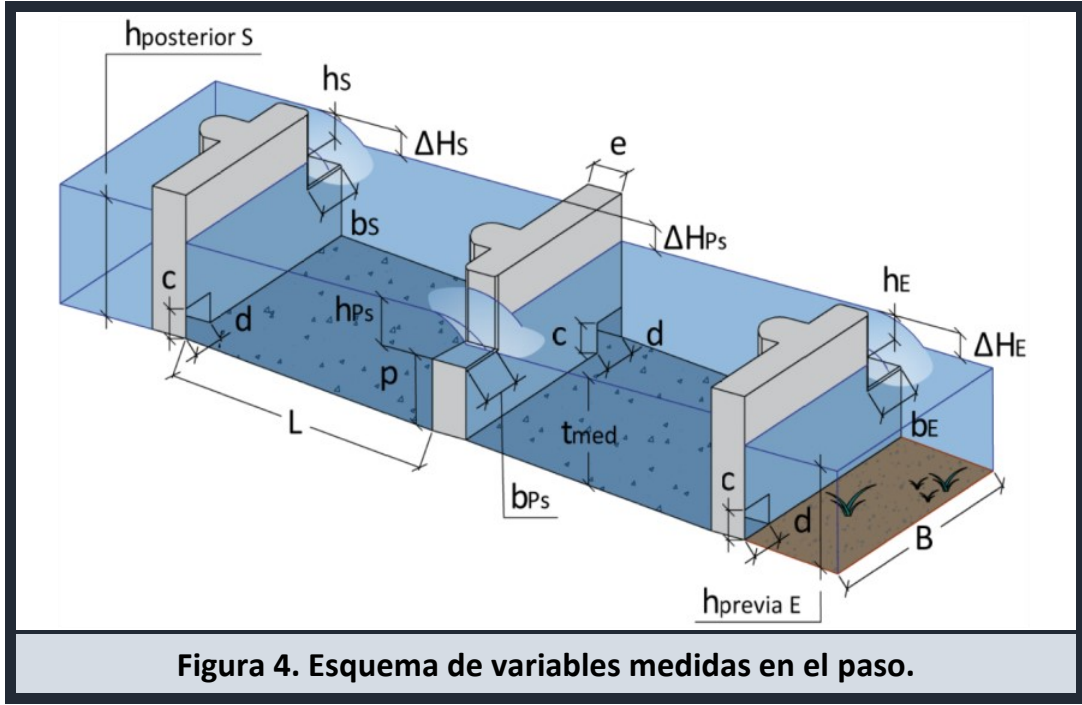

\begin{tabular}{|c|c|c|c|c|c|c|c|c|}
\hline & & & $b \rightarrow$ & 5 & & & & \\
\hline Tipología & Vertedero & rificio sun & rgido & & 10 ptos & Ángulo con la corriente & $80^{\circ}$ & 10 ptos \\
\hline Desnivel entre láminas $\left(\Delta H_{\mathrm{E}}\right)$ & $0,20 \mathrm{~m}$ & 10 ptos & Carga de vertido $\left(h_{E}\right)$ & $0,47 \mathrm{~m}$ & - & Profundidad paso $\left(h_{E}-\Delta H_{E}\right)$ & $0,30 \mathrm{~m}$ & 10 ptos \\
\hline Profundidad previa ( $h_{\text {previa }}$ ) & $0,70 \mathrm{~m}$ & 10 ptos & Anchura del vertedero $\left(b_{E}\right)$ & $0,20 \mathrm{~m}$ & 10 ptos & Dimensiones del orificio & $0,20 \times 0,20 \mathrm{~m}$ & 10 ptos \\
\hline
\end{tabular}

\begin{tabular}{|c|c|c|c|c|c|c|c|c|}
\hline Tipología & \multicolumn{3}{|c|}{ Vertederos sumergidos y orificios de fondo alternos } & & 10 ptos & № estanques total / tipo & \multicolumn{2}{|c|}{$9 / 9$} \\
\hline Desnivel entre láminas ( $\left.\Delta \mathrm{H}_{\mathrm{Ps}}\right)$ & $0,24 \mathrm{~m}$ & 10 ptos & Carga de vertido ( $\mathrm{h}_{\mathrm{Ps}}$ ) & $0,47 \mathrm{~m}$ & 10 ptos & Profundidad paso $\left(h_{P_{s}}-\Delta H_{P_{s}}\right)$ & $0,23 \mathrm{~m}$ & 10 ptos \\
\hline Anchura mín. vertedero ( $\left.b_{P_{s}}\right)$ & \multicolumn{2}{|c|}{$0,25 \mathrm{~m}$} & Anchura med. vertedero ( $\left.b_{P s}\right)$ & $0,25 \mathrm{~m}$ & 10 ptos & Anchura máx. vertedero ( $\left.b_{P_{s}}\right)$ & \multicolumn{2}{|c|}{$0,32 \mathrm{~m}$} \\
\hline $\begin{array}{l}\text { Pendiente media del lecho } \\
\text { Anchura del estanque (B) }\end{array}$ & \multicolumn{2}{|c|}{$9,8 \%$} & $\begin{array}{l}\text { Altura umbral vertedero (p) } \\
\text { Longitud del estanque (L) }\end{array}$ & \multicolumn{2}{|c|}{$0,80 \mathrm{~m}$} & Dimensiones del orificio & $\begin{array}{c}0,30 \times 0,30 \\
\mathrm{~m}\end{array}$ & 10 ptos \\
\hline Tirante medio $\left(t_{\text {med }}\right)$ & $1,15 \mathrm{~m}$ & 10 ptos & Potencia disipada (N) & $98 \mathrm{~W} / \mathrm{m}^{3}$ & 10 ptos & Espesor de los tabiques (e) & \multicolumn{2}{|c|}{$0,20 \mathrm{~m}$} \\
\hline
\end{tabular}

\begin{tabular}{|c|c|c|c|c|c|c|c|c|}
\hline Tipología & Orificio sur & gido & & & 5,0 ptos & Ángulo con la corriente & $180^{\circ}$ & 10 ptos \\
\hline Desnivel entre láminas $\left(\Delta H_{s}\right)$ & $0,19 \mathrm{~m}$ & 9,7 ptos & Carga de vertido (hs) & $1,00 \mathrm{~m}$ & - & Profundidad paso (hs- $\Delta \mathrm{H}_{\mathrm{s}}$ ) & $1,00 \mathrm{~m}$ & 10 ptos \\
\hline Profun. posterior ( $h_{\text {posterior } s)}$ & $>1,00 \mathrm{~m}$ & 10 ptos & Anchura del vertedero (bs) & - & - & Dimensiones del orificio & $0,40 \times 1,00 \mathrm{~m}$ & 10 ptos \\
\hline
\end{tabular}




\section{PASO PARA PECES ASOCIADO AL AZUD DE LA CENTRAL HIDROELÉCTRICA DE MOLINOS DE CASTILLA (INFERIOR)}

\begin{tabular}{|c|c|c|c|c|}
\hline & Provincia & Valladolid & Municipio & Peñafiel \\
\hline & $\begin{array}{l}\text { Nombre del aprovechamiento } \\
\text { Código del aprovechamiento } \\
\text { Long. coronación del azud } \\
\text { (1) } \\
\text { Coordenadas del paso piscícola }\end{array}$ & $\begin{array}{l}\text { Molinos de Castilla } \\
1100147 \\
135 \mathrm{~m} \\
X: 407.339 \mathrm{~m}, \mathrm{Y}: 4.60\end{array}$ & $\begin{array}{l}\text { Tipo de aprovechamiento } \\
\text { Código del azud (1) } \\
\text { Salto total de agua en la visita } \\
294 \text { m (ETRS 89; HUSO 30) }\end{array}$ & $\begin{array}{l}\text { Hidroeléctrico } \\
1007544 \\
5,6 \mathrm{~m}\end{array}$ \\
\hline & $\begin{array}{l}\text { Cuenca hidrográfica } \\
\text { Principales peces migradores }{ }^{(1)} \\
\text { Época de migración }\end{array}$ & $\begin{array}{l}\text { Duero } \\
\text { Luciobarbus bocagei } \\
\text { Mayo a junio }\end{array}$ & Cauce & Duero \\
\hline $\begin{array}{c}\text { Figura 1. Ubicación en la parte } \\
\text { española de la cuenca del río Duero. }\end{array}$ & $\begin{array}{l}\text { Caudal medio en migración (2) } \\
\text { Caudal durante la visita }{ }^{(3)}\end{array}$ & $\begin{array}{l}25,79 \mathrm{~m}^{3} / \mathrm{s} \\
\text { No disponible }\end{array}$ & $\begin{array}{l}\text { Caudal ecológico en migración } \\
\text { Hora y fecha de la visita }\end{array}$ & $\begin{array}{l}4,00 \mathrm{~m}^{3} / \mathrm{s} \\
\text { No disponible }\end{array}$ \\
\hline
\end{tabular}

(1) Dato obtenido de MíRAME-IDE Duero. ${ }^{(2)}$ Dato obtenido del CEDEX Hidrológico. ${ }^{(3)}$ Dato obtenido del SAIH del Duero.

\begin{tabular}{|c|c|c|c|}
\hline Paso para peces de estanques su & os conectad & diduras verticales alineadas y sin orificios & \\
\hline $\begin{array}{l}\text { Estado de mantenimiento y limpieza durante la evaluación } \\
\text { Solera naturalizada (con piedras) } \\
\text { Vertedero de umbral móvil en la entrada de peces }\end{array}$ & $\begin{array}{l}\text { Adecuado } \\
\text { Sí } \\
\text { No }\end{array}$ & $\begin{array}{l}\text { Compuerta en la salida de peces } \\
\text { Dispositivo para evitar la entrada de arrastres } \\
\text { Salida de peces segura (alejada del azud, turbinas, ...) }\end{array}$ & $\begin{array}{l}\text { Sí } \\
\text { No } \\
\text { Sí }\end{array}$ \\
\hline
\end{tabular}

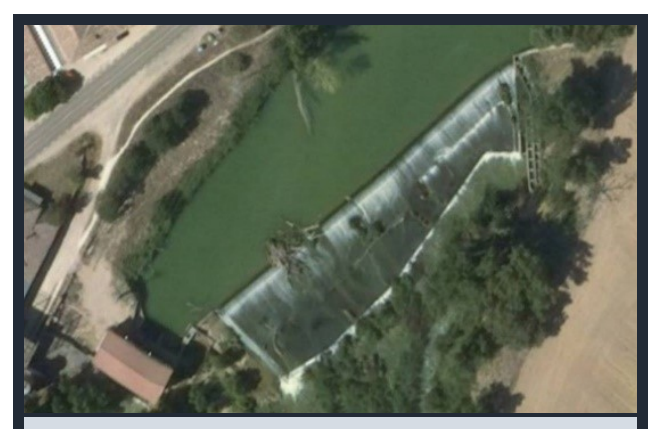

Figura 2. Ortofoto de la zona (fuente: SigPac).

\begin{tabular}{lccc}
\multicolumn{4}{c}{ RESUMEN DE LA EVALUACIÓN DEL PASO PARA PECES } \\
& \multicolumn{4}{c|}{ (CON LA METODOLOGÍA AEPS) } & \\
\hline Etapa o categoría & Puntuación & Evaluación & ¿Mejoras? \\
Atracción & 7,9 & Favorable & Recomendables \\
Entrada & 10,0 & Muy favorable & Opcionales \\
Pasaje & 9,8 & Muy favorable & Opcionales \\
Salida & 8,9 & Muy favorable & Opcionales \\
\hline
\end{tabular}

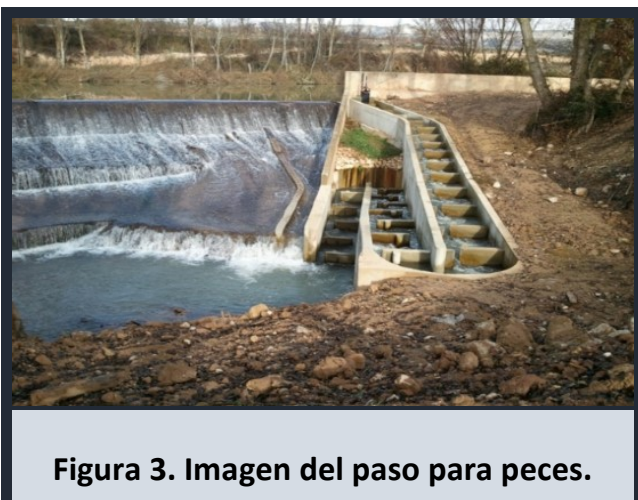




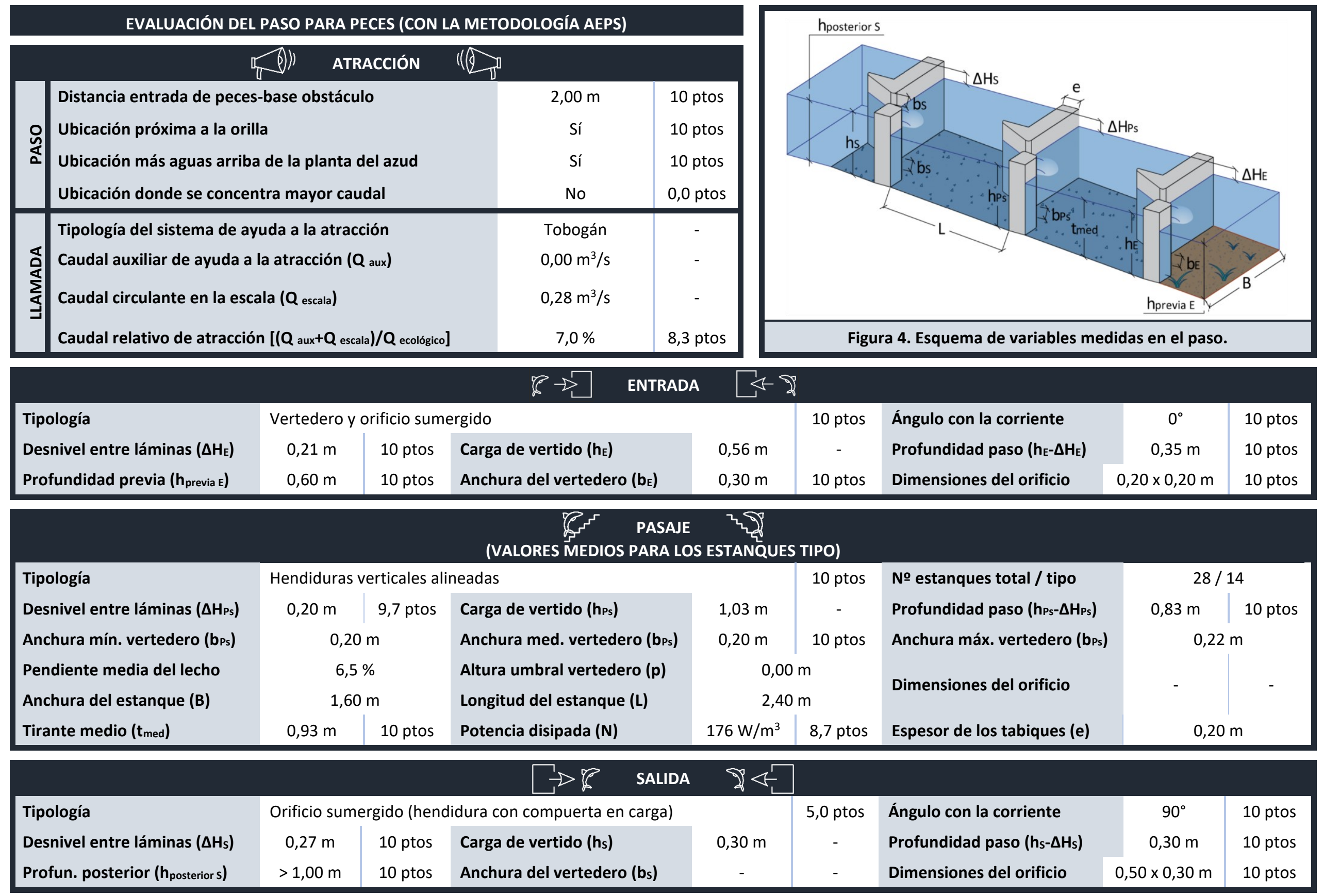




\section{PASO PARA PECES ASOCIADO AL AZUD DE LA CENTRAL HIDROELÉCTRICA DE MOLINOS DE CASTILLA (SUPERIOR)}

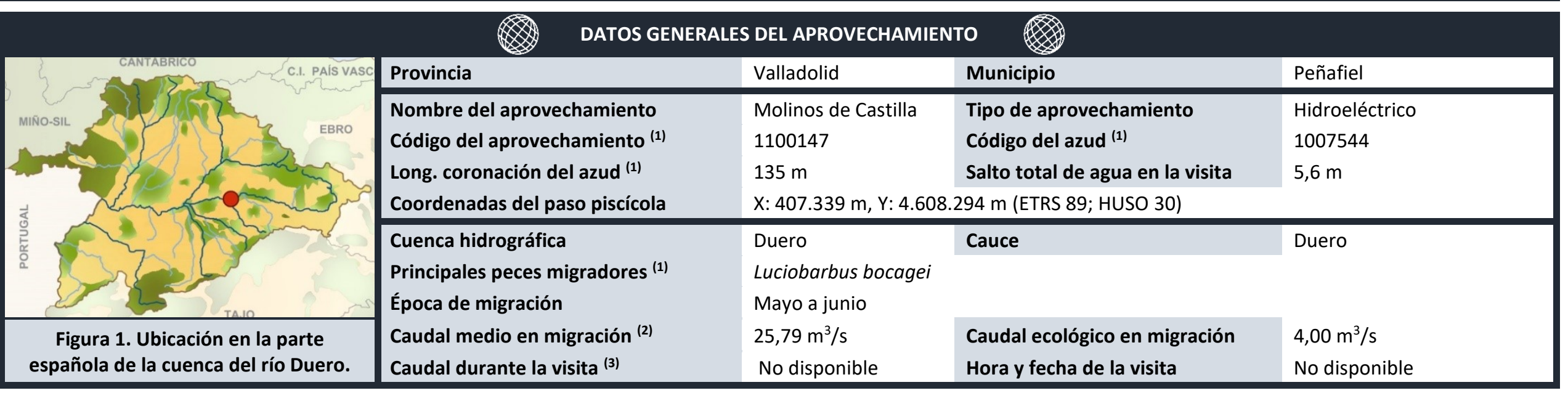

(1) Dato obtenido de MíRAME-IDE Duero. ${ }^{(2)}$ Dato obtenido del CEDEX Hidrológico. ${ }^{(3)}$ Dato obtenido del SAIH del Duero.

\begin{tabular}{|c|c|c|c|}
\hline \multicolumn{4}{|c|}{$\begin{array}{l}\text { OBSERVACIONES GENERALES DE LA ESCALA } \\
\text { ivos conectados por vertederos sumergidos y orificios de fondo alternos }\end{array}$} \\
\hline $\begin{array}{l}\text { Estado de mantenimiento y limpieza durante la evaluación } \\
\text { Solera naturalizada (con piedras) } \\
\text { Vertedero de umbral móvil en la entrada de peces }\end{array}$ & $\begin{array}{l}\text { Adecuado } \\
\text { Sí } \\
\text { No }\end{array}$ & $\begin{array}{l}\text { Compuerta en la salida de peces } \\
\text { Dispositivo para evitar la entrada de arrastres } \\
\text { Salida de peces segura (alejada del azud, turbinas, ...) }\end{array}$ & $\begin{array}{l}\text { Sí } \\
\text { No } \\
\text { Sí }\end{array}$ \\
\hline
\end{tabular}

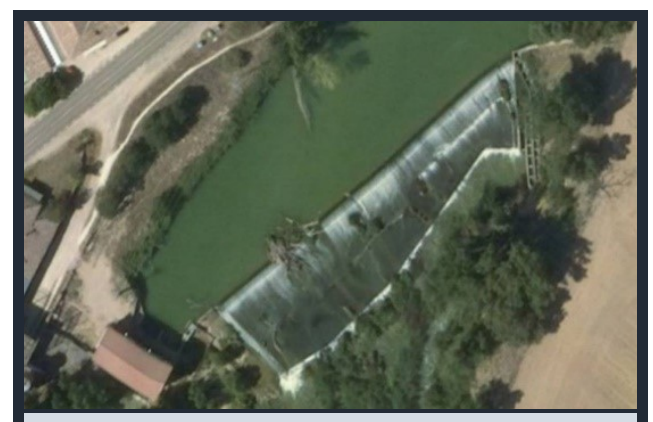

Figura 2. Ortofoto de la zona (fuente: SigPac).

\begin{tabular}{lccc}
\multicolumn{4}{c}{ RESUMEN DE LA EVALUACIÓN DEL PASO PARA PECES } \\
& \multicolumn{4}{c|}{ (CON LA METODOLOGÍA AEPS) } & \\
\hline Etapa o categoría & Puntuación & Evaluación & ¿Mejoras? \\
Atracción & 7,9 & Favorable & Recomendables \\
Entrada & 10,0 & Muy favorable & Opcionales \\
Pasaje & 10,0 & Muy favorable & Opcionales \\
Salida & 8,9 & Muy favorable & Opcionales \\
\hline
\end{tabular}

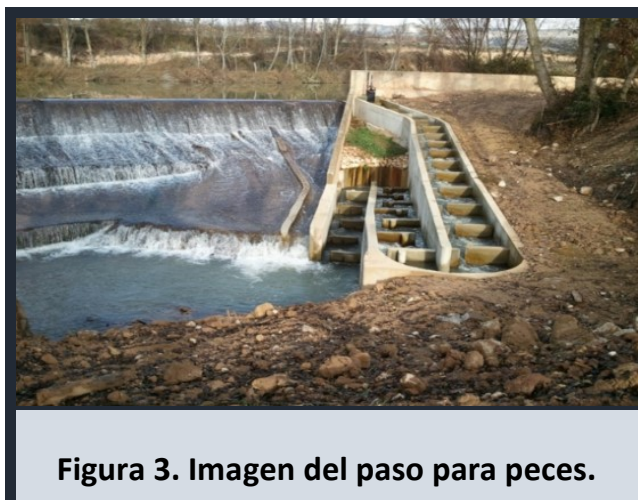




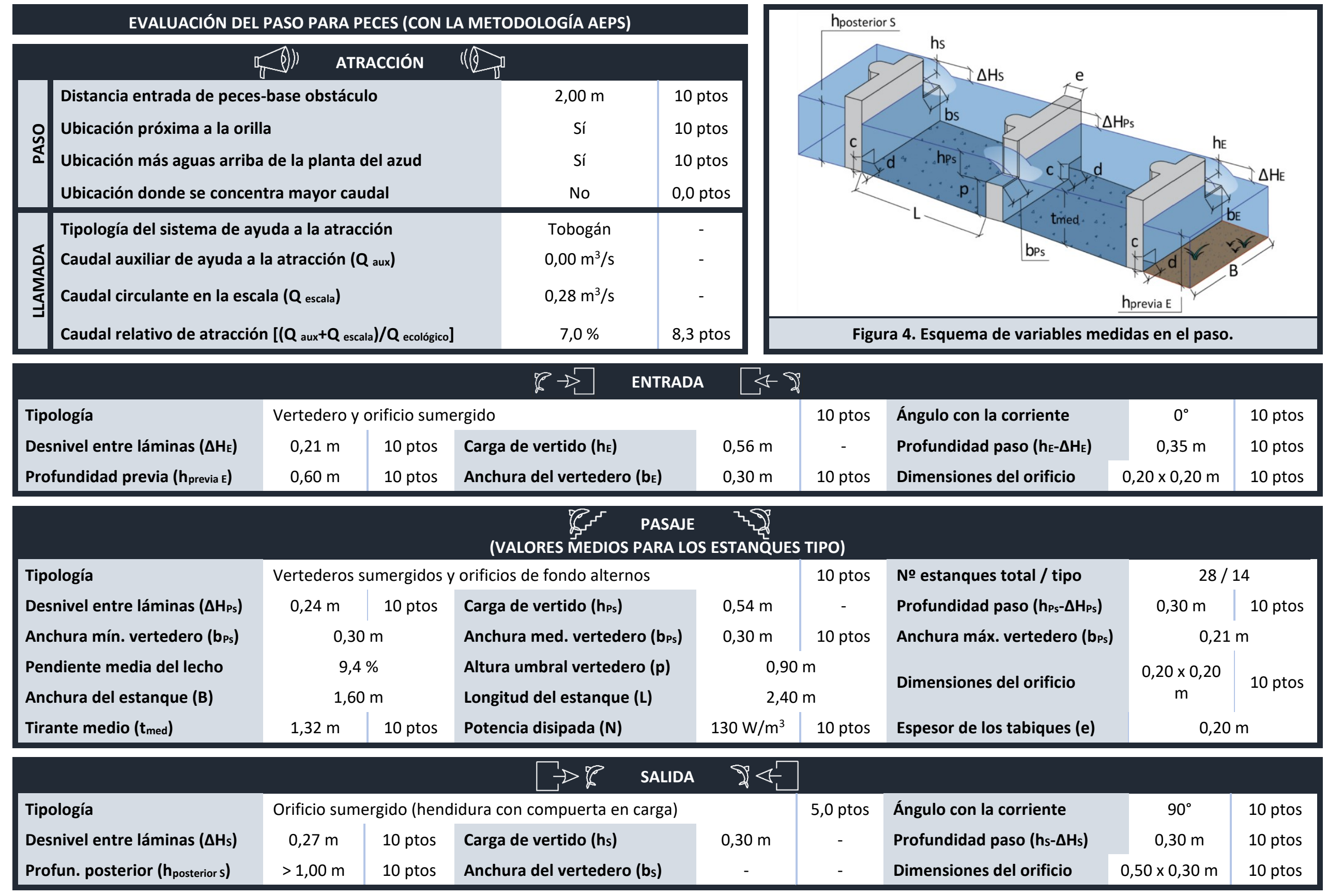




\section{PASO PARA PECES ASOCIADO AL AZUD DE LA CENTRAL HIDROELÉCTRICA DE MONASTERIO}

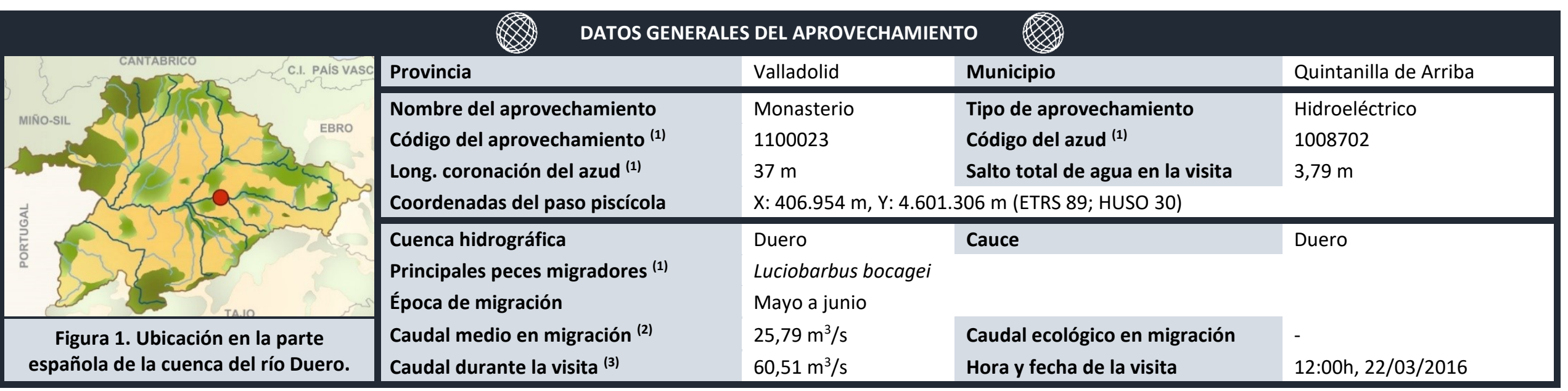

${ }^{(1)}$ Dato obtenido de MíRAME-IDE Duero. ${ }^{(2)}$ Dato obtenido del CEDEX Hidrológico. ${ }^{(3)}$ Dato obtenido del SAIH del Duero.

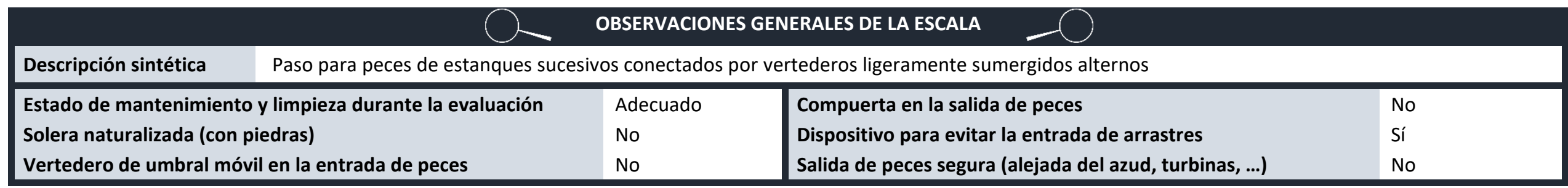

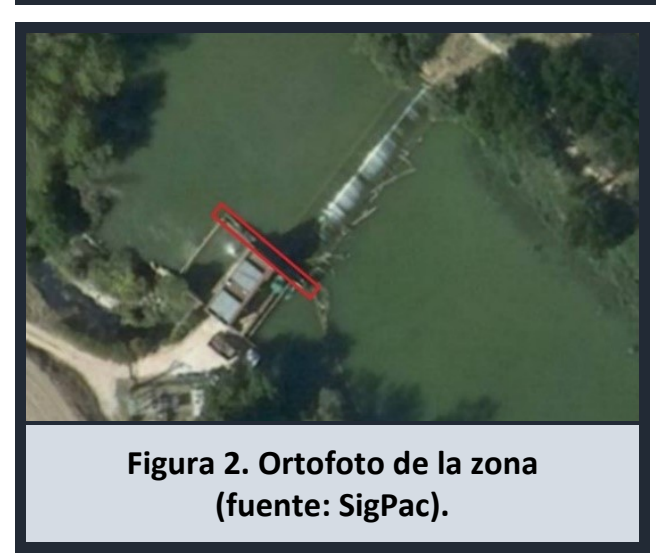

\begin{tabular}{|c|c|c|c|}
\hline \multicolumn{4}{|c|}{$\begin{array}{l}\text { RESUMEN DE LA EVALUACIÓN DEL PASO PARA PECES } \\
\text { (CON LA METODOLOGÍA AEPS) }\end{array}$} \\
\hline Etapa o categoría & Puntuación & Evaluación & ¿Mejoras? \\
\hline Atracción & 5,8 & Desfavorable & Muy necesarias \\
\hline Entrada & 9,4 & Muy favorable & Opcionales \\
\hline Pasaje & 0,0 & Muy desfavorable & Imprescindibles \\
\hline Salida & 7,9 & Favorable & Recomendables \\
\hline
\end{tabular}

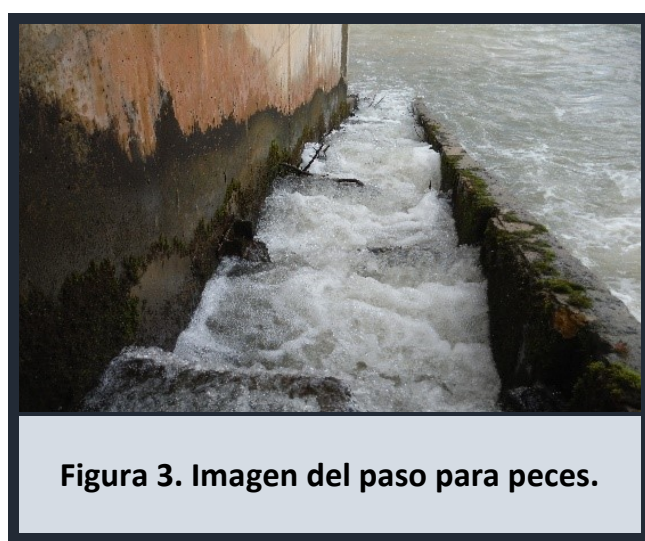




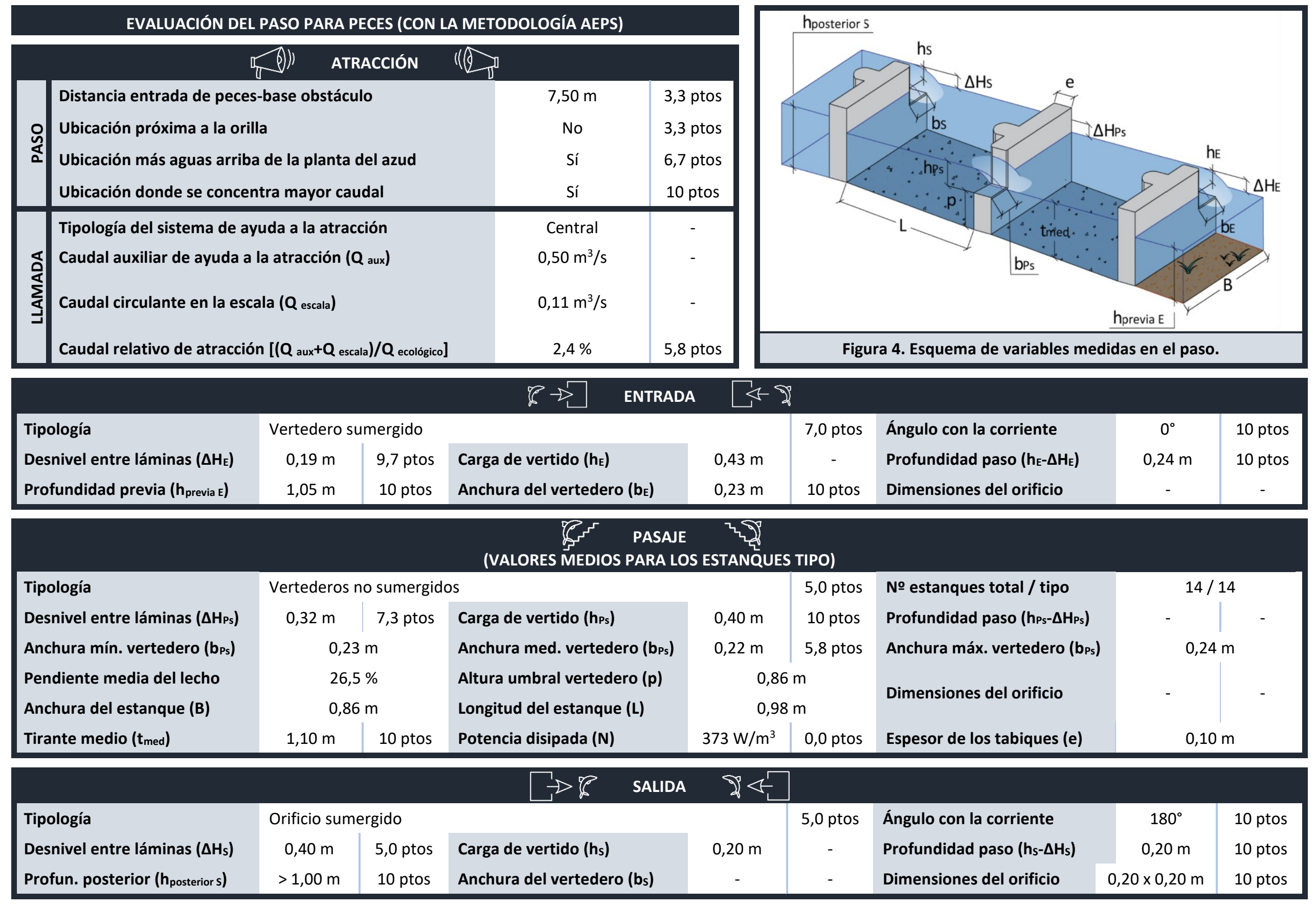




\section{PASO PARA PECES ASOCIADO AL AZUD DE PESQUERUELA}

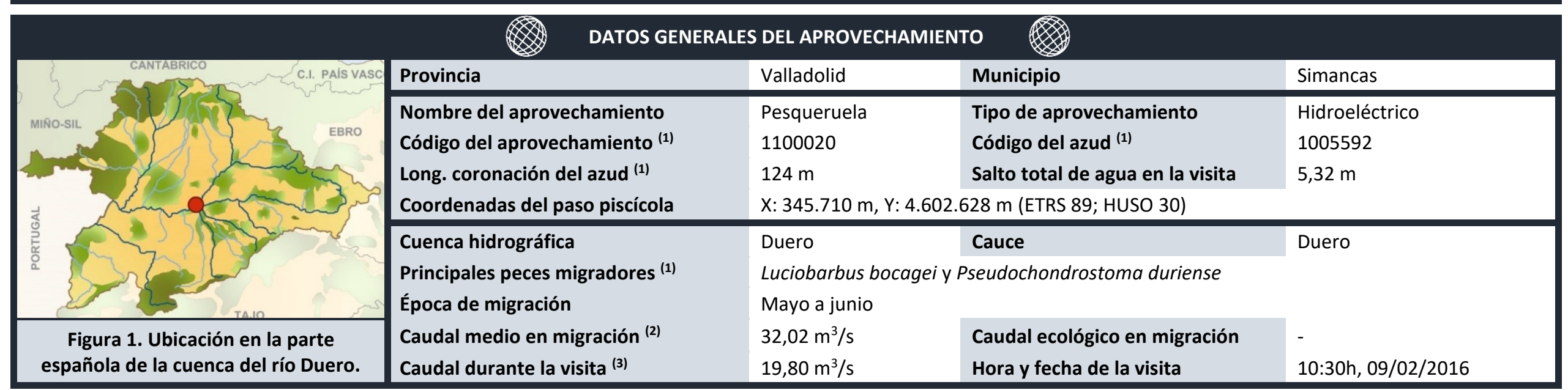

(1) Dato obtenido de MíRAME-IDE Duero. ${ }^{(2)}$ Dato obtenido del CEDEX Hidrológico. ${ }^{(3)}$ Dato obtenido del SAIH del Duero.

\begin{tabular}{|c|c|c|c|}
\hline Paso para peces de estanques st & os conectados po & tederos sumergidos y orificios de fondo alternos & \\
\hline $\begin{array}{l}\text { Estado de mantenimiento y limpieza durante la evaluación } \\
\text { Solera naturalizada (con piedras) } \\
\text { Vertedero de umbral móvil en la entrada de peces }\end{array}$ & $\begin{array}{l}\text { Muy adecuado } \\
\text { Sí } \\
\text { Sí }\end{array}$ & $\begin{array}{l}\text { Compuerta en la salida de peces } \\
\text { Dispositivo para evitar la entrada de arrastres } \\
\text { Salida de peces segura (alejada del azud, turbinas, ...) }\end{array}$ & $\begin{array}{l}\text { Sí } \\
\text { No } \\
\text { Sí }\end{array}$ \\
\hline
\end{tabular}

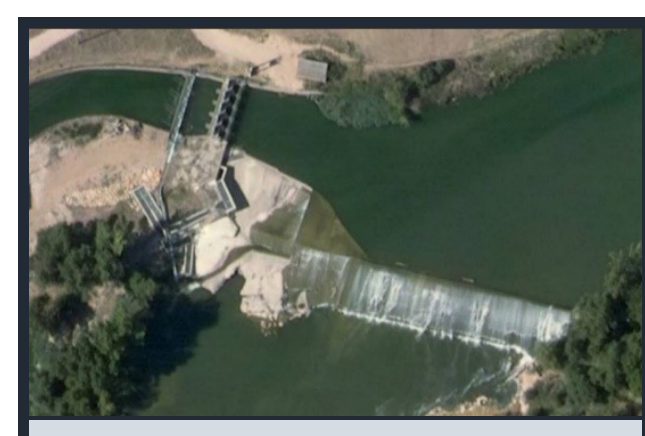

Figura 2. Ortofoto de la zona (fuente: SigPac).

\begin{tabular}{lccc}
\multicolumn{4}{c}{ RESUMEN DE LA EVALUACIÓN DEL PASO PARA PECES } \\
& \multicolumn{4}{c|}{ (CON LA METODOLOGÍA AEPS) } & \\
\hline Etapa o categoría & Puntuación & Evaluación & ¿Mejoras? \\
Atracción & 7,0 & Favorable & Recomendables \\
Entrada & 9,7 & Muy favorable & Opcionales \\
Pasaje & 9,8 & Muy favorable & Opcionales \\
Salida & 7,1 & Favorable & Recomendables \\
\hline
\end{tabular}

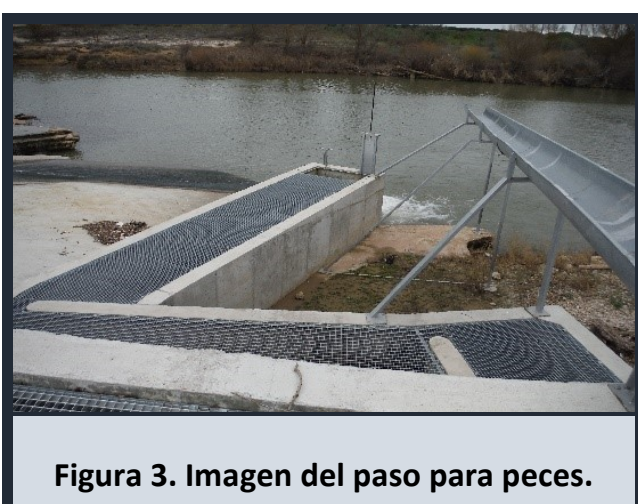




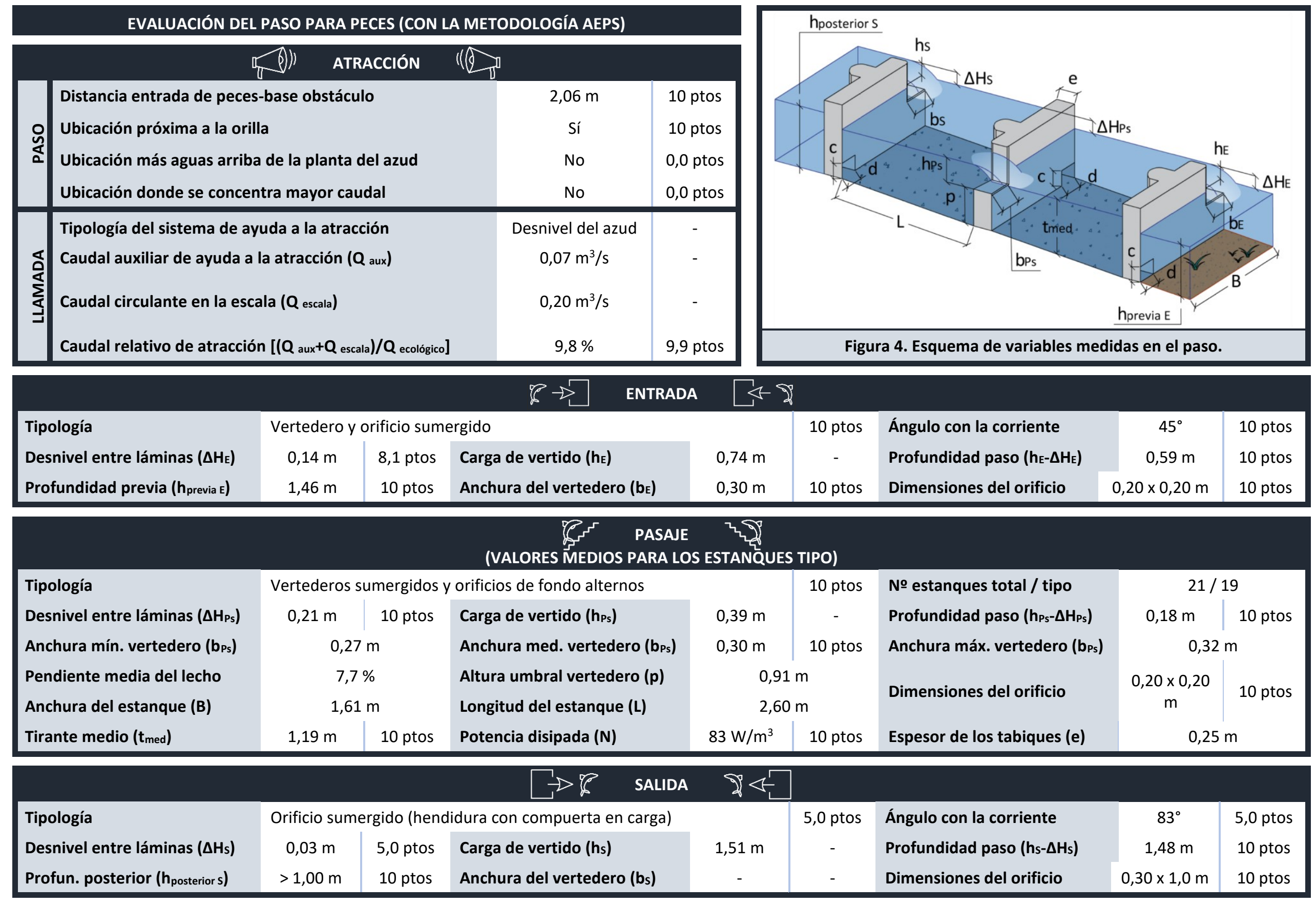




\section{PASO PARA PECES ASOCIADO AL AZUD DE LA CENTRAL DE SARDÓN ALTO}

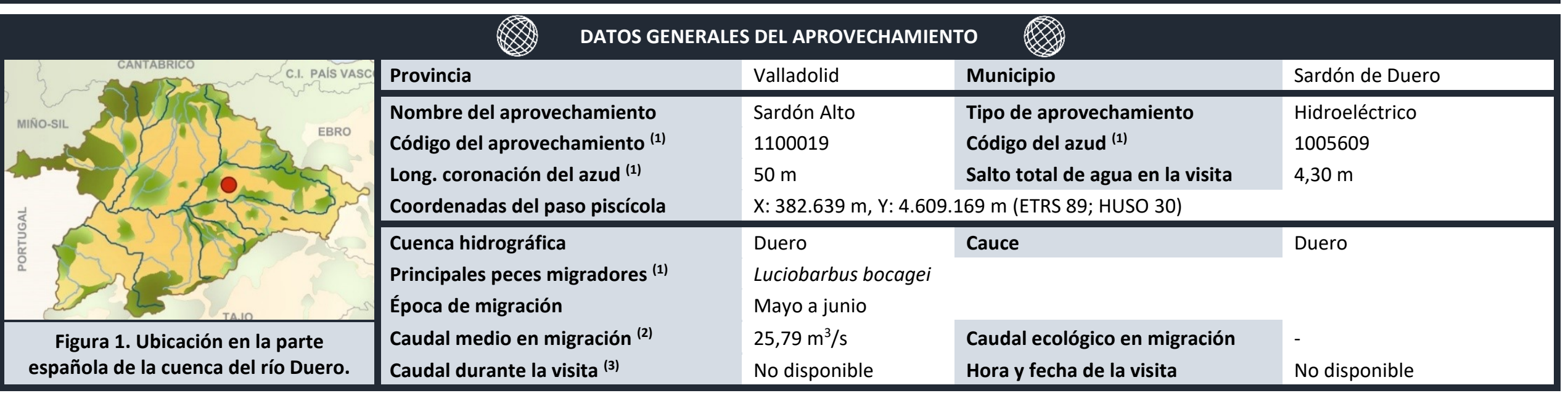

(1) Dato obtenido de MíRAME-IDE Duero. ${ }^{(2)}$ Dato obtenido del CEDEX Hidrológico. ${ }^{(3)}$ Dato obtenido del SAIH del Duero.

\begin{tabular}{|c|c|c|c|}
\hline Paso para peces de estanques & os conectados po & tederos sumergidos y orificios de fondo alternos & \\
\hline $\begin{array}{l}\text { Estado de mantenimiento y limpieza durante la evaluación } \\
\text { Solera naturalizada (con piedras) } \\
\text { Vertedero de umbral móvil en la entrada de peces }\end{array}$ & $\begin{array}{l}\text { Muy adecuado } \\
\text { Sí } \\
\text { Sí }\end{array}$ & $\begin{array}{l}\text { Compuerta en la salida de peces } \\
\text { Dispositivo para evitar la entrada de arrastres } \\
\text { Salida de peces segura (alejada del azud, turbinas, ...) }\end{array}$ & $\begin{array}{l}\text { Sí } \\
\text { Sí } \\
\text { Sí }\end{array}$ \\
\hline
\end{tabular}

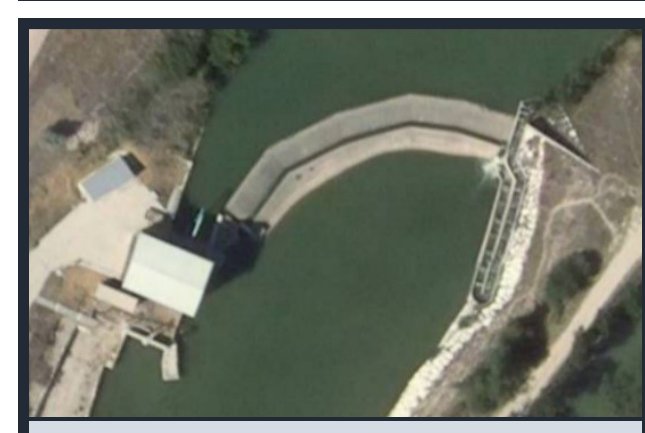

Figura 2. Ortofoto de la zona (fuente: SigPac).

\begin{tabular}{lccc}
\multicolumn{5}{c}{ RESUMEN DE LA EVALUACIÓN DEL PASO PARA PECES } \\
& \multicolumn{2}{c|}{ (CON LA METODOLOGíA AEPS) } & \\
\hline $\begin{array}{l}\text { Etapa o categoría } \\
\text { Atracción }\end{array}$ & $\begin{array}{c}\text { Puntuación } \\
\text { Entrada }\end{array}$ & Evaluación & ¿Mejoras? \\
Pasaje & 10,5 & Favorable & Recomendables \\
Salida & 10,0 & Muy favorable & Opcionales \\
\hline
\end{tabular}

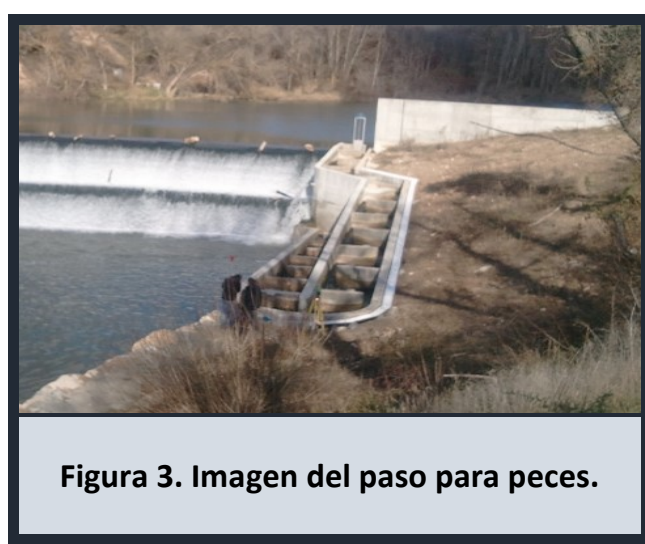




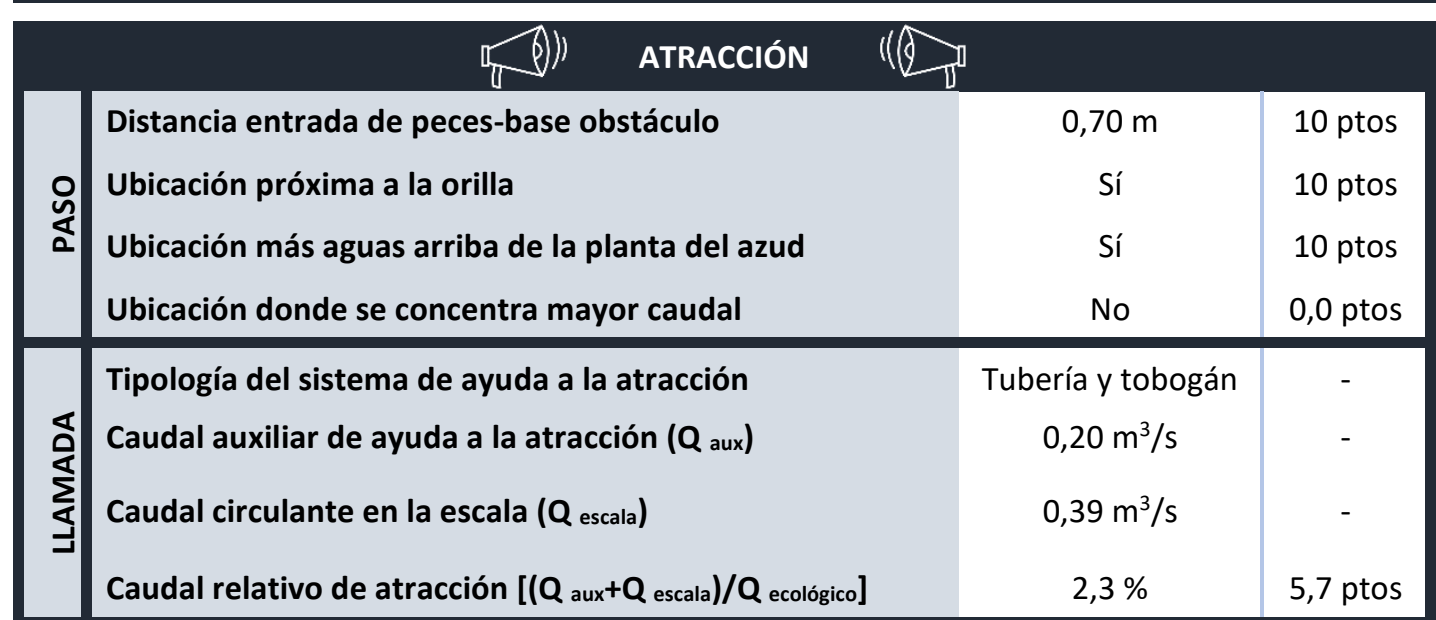

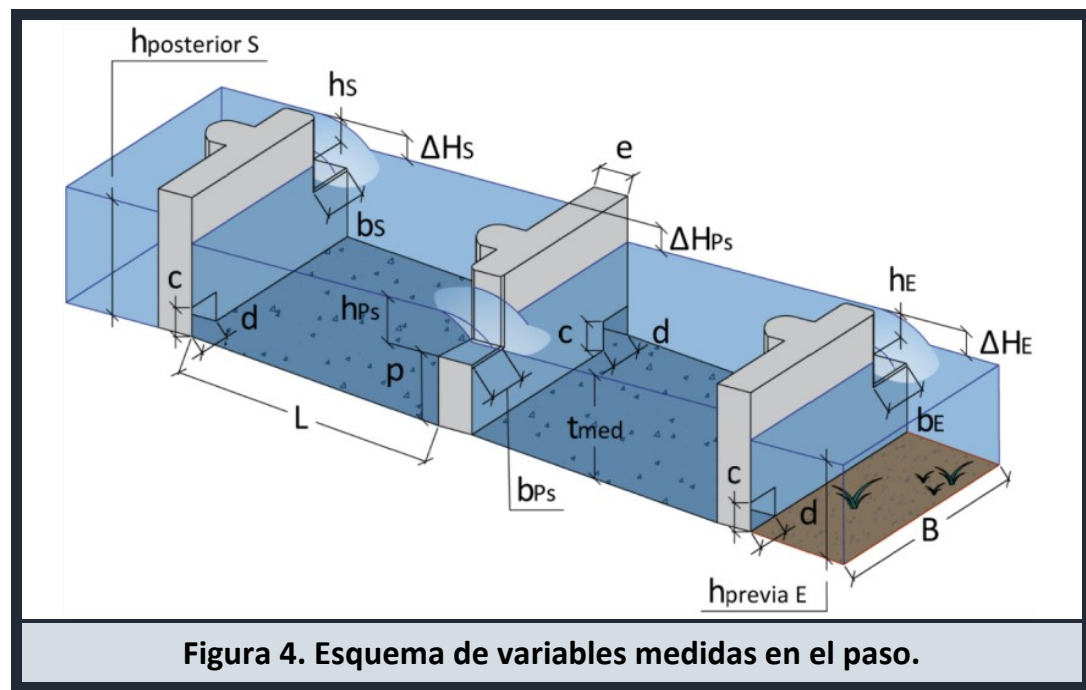

\begin{tabular}{|c|c|c|c|c|c|c|c|c|}
\hline \multicolumn{9}{|c|}{$\sqrt[6]{6} \rightarrow \sqrt{5}$} \\
\hline Tipología & \multicolumn{3}{|c|}{ Vertedero y orificio sumergido } & & 10 ptos & Ángulo con la corriente & $90^{\circ}$ & 10 ptos \\
\hline Desnivel entre láminas $\left(\Delta \mathrm{H}_{\mathrm{E}}\right)$ & $0,23 \mathrm{~m}$ & 10 ptos & Carga de vertido $\left(h_{E}\right)$ & $0,84 \mathrm{~m}$ & - & Profundidad paso ( $\left.h_{E}-\Delta H_{E}\right)$ & $0,61 \mathrm{~m}$ & 10 ptos \\
\hline Profundidad previa ( $h_{\text {previa }}$ ) & $1,00 \mathrm{~m}$ & 10 ptos & Anchura del vertedero $\left(b_{E}\right)$ & $0,30 \mathrm{~m}$ & 10 ptos & Dimensiones del orificio & $0,25 \times 0,25 \mathrm{~m}$ & 10 ptos \\
\hline
\end{tabular}

\begin{tabular}{|c|c|c|c|c|c|c|c|c|}
\hline Tipología & \multicolumn{3}{|c|}{ Vertederos sumergidos y orificios de fondo alternos } & & 10 ptos & № estanques total / tipo & \multicolumn{2}{|c|}{$19 / 19$} \\
\hline Desnivel entre láminas ( $\left.\Delta \mathrm{H}_{\mathrm{Ps}}\right)$ & $0,22 \mathrm{~m}$ & 10 ptos & Carga de vertido (hPs) & $0,78 \mathrm{~m}$ & - & Profundidad paso ( $\left.\mathrm{h}_{\mathrm{Ps}}-\Delta \mathrm{H}_{\mathrm{Ps}}\right)$ & $0,56 \mathrm{~m}$ & 10 ptos \\
\hline Anchura mín. vertedero ( $\left.b_{P_{s}}\right)$ & \multicolumn{2}{|c|}{$0,29 \mathrm{~m}$} & Anchura med. vertedero ( $\left.b_{P s}\right)$ & $0,30 \mathrm{~m}$ & 10 ptos & Anchura máx. vertedero (bPs) & \multicolumn{2}{|c|}{$0,30 \mathrm{~m}$} \\
\hline $\begin{array}{l}\text { Pendiente media del lecho } \\
\text { Anchura del estanque (B) }\end{array}$ & \multicolumn{2}{|c|}{$\begin{array}{r}7,4 \% \\
1,80 \mathrm{~m}\end{array}$} & $\begin{array}{l}\text { Altura umbral vertedero (p) } \\
\text { Longitud del estanque (L) }\end{array}$ & \multicolumn{2}{|c|}{$\begin{array}{l}0,70 \mathrm{~m} \\
2,80 \mathrm{~m}\end{array}$} & Dimensiones del orificio & $\begin{array}{c}0,25 \times 0,25 \\
\mathrm{~m}\end{array}$ & 10 ptos \\
\hline Tirante medio $\left(t_{\text {med }}\right)$ & $1,37 \mathrm{~m}$ & 10 ptos & Potencia disipada (N) & $122 \mathrm{~W} / \mathrm{m}^{3}$ & 10 ptos & Espesor de los tabiques (e) & 0,2 & \\
\hline
\end{tabular}

\begin{tabular}{|c|c|c|c|c|c|c|c|c|}
\hline Tipología & \multicolumn{3}{|c|}{ Orificio sumergido (hendidura con compuerta en carga) } & & 5,0 ptos & Ángulo con la corriente & $170^{\circ}$ & 10 ptos \\
\hline Desnivel entre láminas $\left(\Delta \mathrm{H}_{s}\right)$ & $0,24 \mathrm{~m}$ & 10 ptos & Carga de vertido (hs) & $0,24 \mathrm{~m}$ & - & Profundidad paso (hs- $\left.\Delta H_{s}\right)$ & $0,24 \mathrm{~m}$ & 10 ptos \\
\hline Profun. posterior (h $h_{\text {posterior } s)}$ & $>1,00 \mathrm{~m}$ & 10 ptos & Anchura del vertedero (bs) & - & - & Dimensiones del orificio & $0,50 \times 0,24 \mathrm{~m}$ & 10 ptos \\
\hline
\end{tabular}




\section{PASO PARA PECES ASOCIADO AL AZUD DE SARDÓN BAJO}

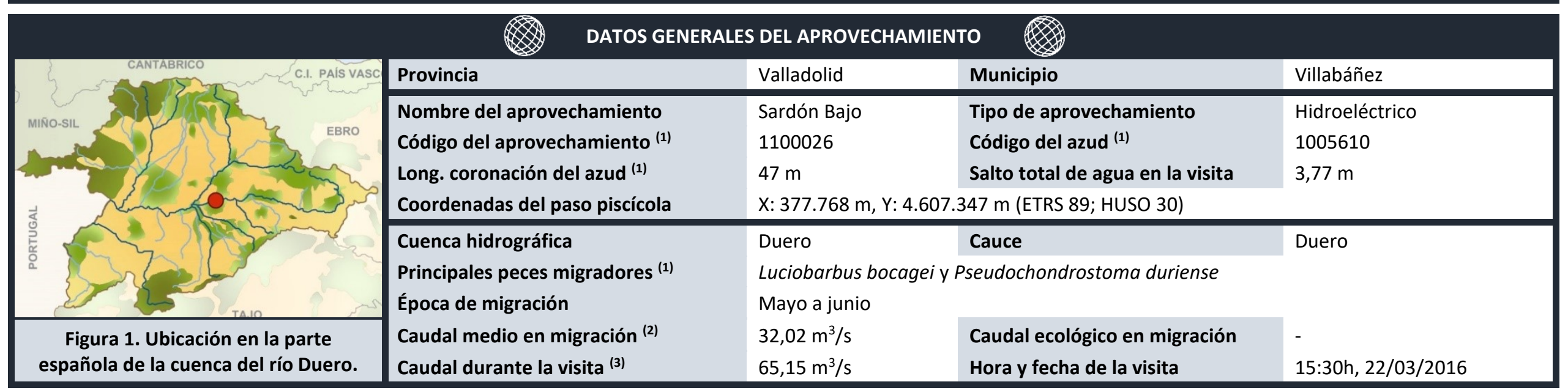

(1) Dato obtenido de MíRAME-IDE Duero. ${ }^{(2)}$ Dato obtenido del CEDEX Hidrológico. ${ }^{(3)}$ Dato obtenido del SAIH del Duero.

\begin{tabular}{|c|c|c|c|}
\hline Paso para peces de estanques su & os conectad & tederos sumergidos alternos & \\
\hline $\begin{array}{l}\text { Estado de mantenimiento y limpieza durante la evaluación } \\
\text { Solera naturalizada (con piedras) } \\
\text { Vertedero de umbral móvil en la entrada de peces }\end{array}$ & $\begin{array}{l}\text { Adecuado } \\
\text { Sí } \\
\text { No }\end{array}$ & $\begin{array}{l}\text { Compuerta en la salida de peces } \\
\text { Dispositivo para evitar la entrada de arrastres } \\
\text { Salida de peces segura (alejada del azud, turbinas, ...) }\end{array}$ & $\begin{array}{l}\text { No } \\
\text { Sí } \\
\text { No }\end{array}$ \\
\hline
\end{tabular}

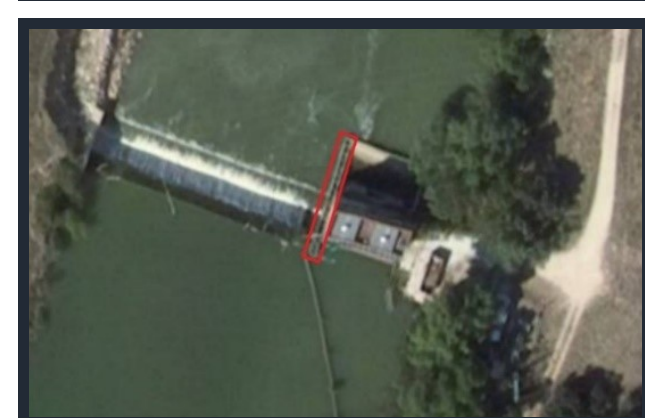

Figura 2. Ortofoto de la zona (fuente: SigPac).

\begin{tabular}{|c|c|c|c|}
\hline \multicolumn{4}{|c|}{$\begin{array}{l}\text { RESUMEN DE LA EVALUACIÓN DEL PASO PARA PECES } \\
\text { (CON LA METODOLOGÍA AEPS) }\end{array}$} \\
\hline Etapa o categoría & Puntuación & Evaluación & ¿Mejoras? \\
\hline Atracción & 5,3 & Desfavorable & Muy necesarias \\
\hline Entrada & 9,0 & Muy favorable & Opcionales \\
\hline Pasaje & 0,0 & Muy desfavorable & Imprescindibles \\
\hline Salida & 7,9 & Favorable & Recomendables \\
\hline
\end{tabular}

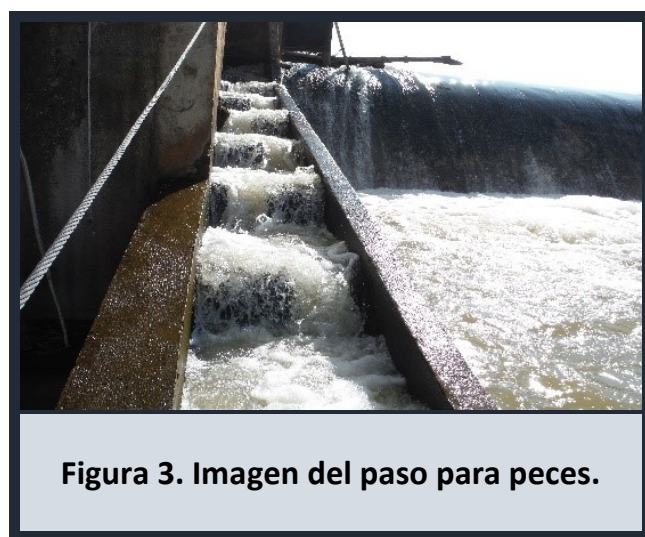




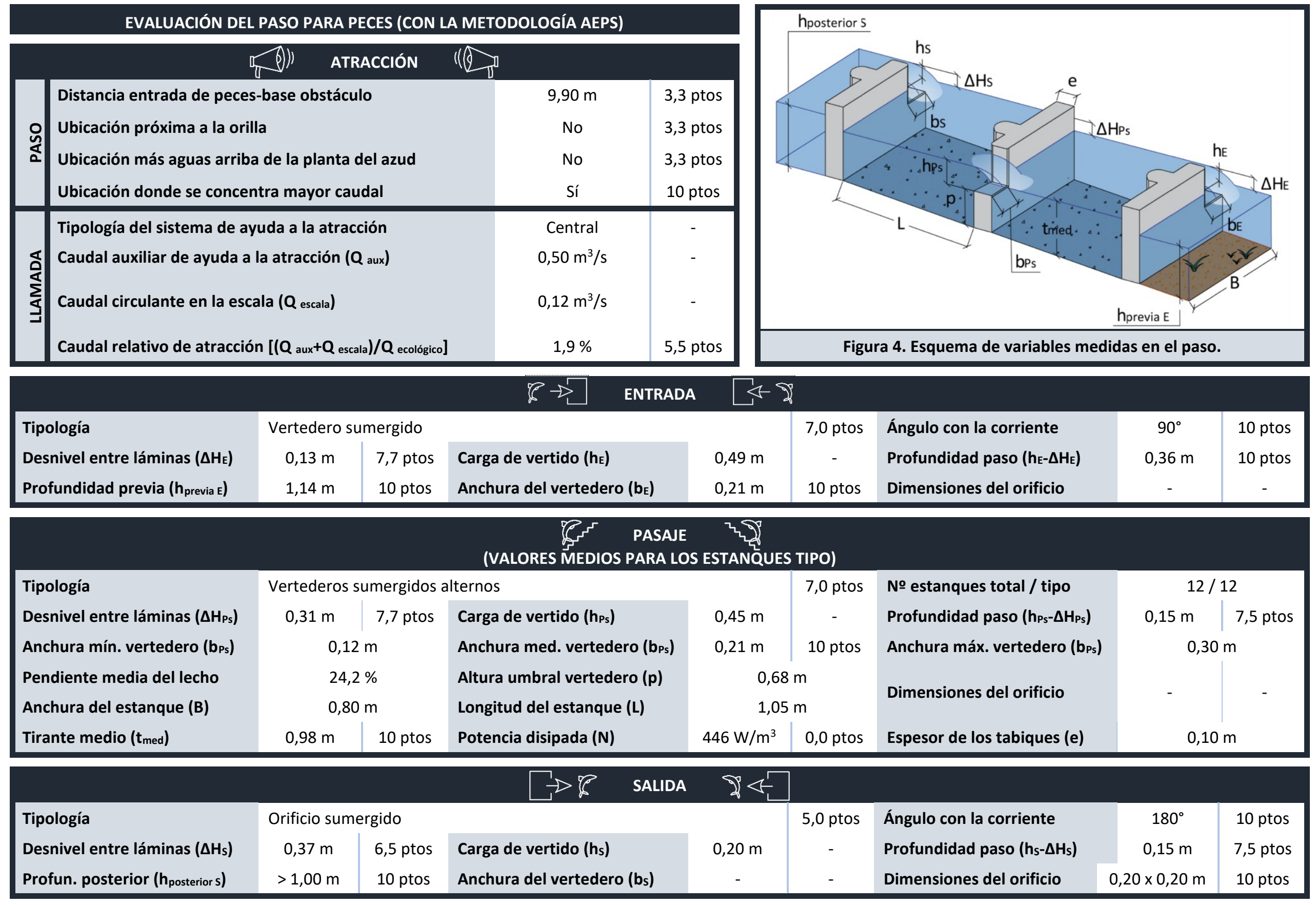




\section{PASO PARA PECES ASOCIADO AL AZUD DE LA CENTRAL DE TUDELA DE DUERO}

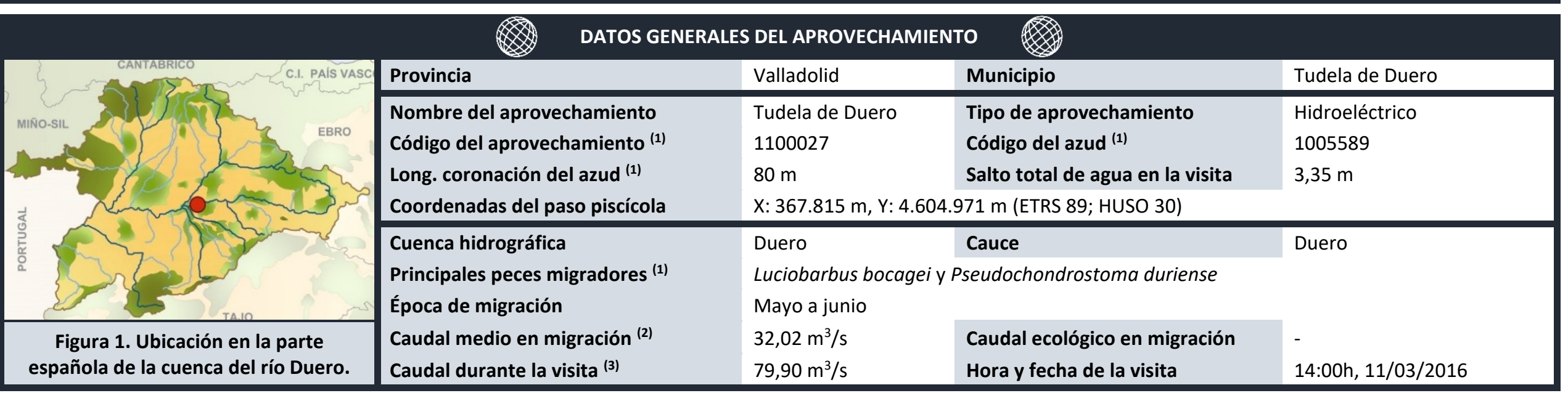

${ }^{(1)}$ Dato obtenido de MíRAME-IDE Duero. ${ }^{(2)}$ Dato obtenido del CEDEX Hidrológico. ${ }^{(3)}$ Dato obtenido del SAIH del Duero.

\begin{tabular}{|c|c|c|c|}
\hline Paso para peces de estanques su & os conectad & tederos sumergidos y no sumergidos alternos & \\
\hline $\begin{array}{l}\text { Estado de mantenimiento y limpieza durante la evaluación } \\
\text { Solera naturalizada (con piedras) } \\
\text { Vertedero de umbral móvil en la entrada de peces }\end{array}$ & $\begin{array}{l}\text { Adecuado } \\
\text { Sí } \\
\text { No }\end{array}$ & $\begin{array}{l}\text { Compuerta en la salida de peces } \\
\text { Dispositivo para evitar la entrada de arrastres } \\
\text { Salida de peces segura (alejada del azud, turbinas, ...) }\end{array}$ & $\begin{array}{l}\text { No } \\
\text { No } \\
\text { No }\end{array}$ \\
\hline
\end{tabular}

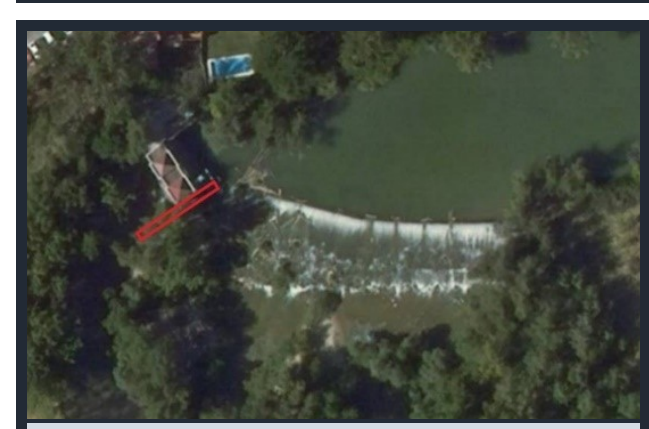

Figura 2. Ortofoto de la zona (fuente: SigPac).

\begin{tabular}{lccc}
\multicolumn{4}{c}{ RESUMEN DE LA EVALUACIÓN DEL PASO PARA PECES } \\
& \multicolumn{2}{c}{ (CON LA METODOLOGÍA AEPS) } & \\
\hline Etapa o categoría & Puntuación & Evaluación & ¿Mejoras? \\
Atracción & 6,4 & Favorable & Recomendables \\
Entrada & 0,0 & Muy desfavorable & Imprescindibles \\
Pasaje & 7,1 & Favorable & Recomendables \\
Salida & 7,9 & Favorable & Recomendables \\
\hline
\end{tabular}

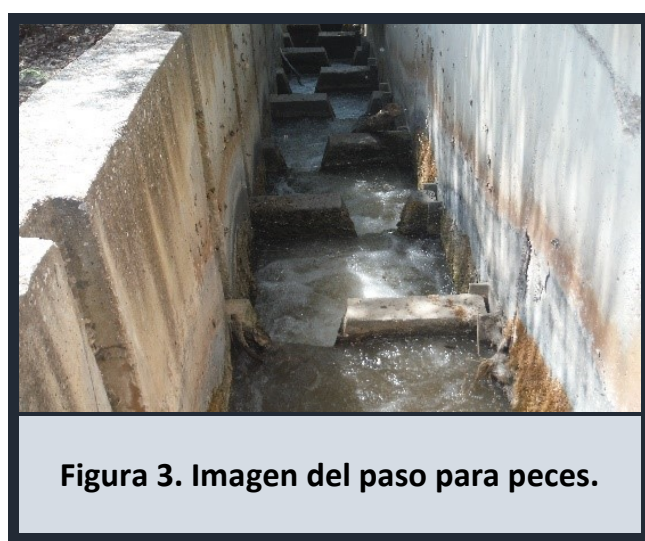




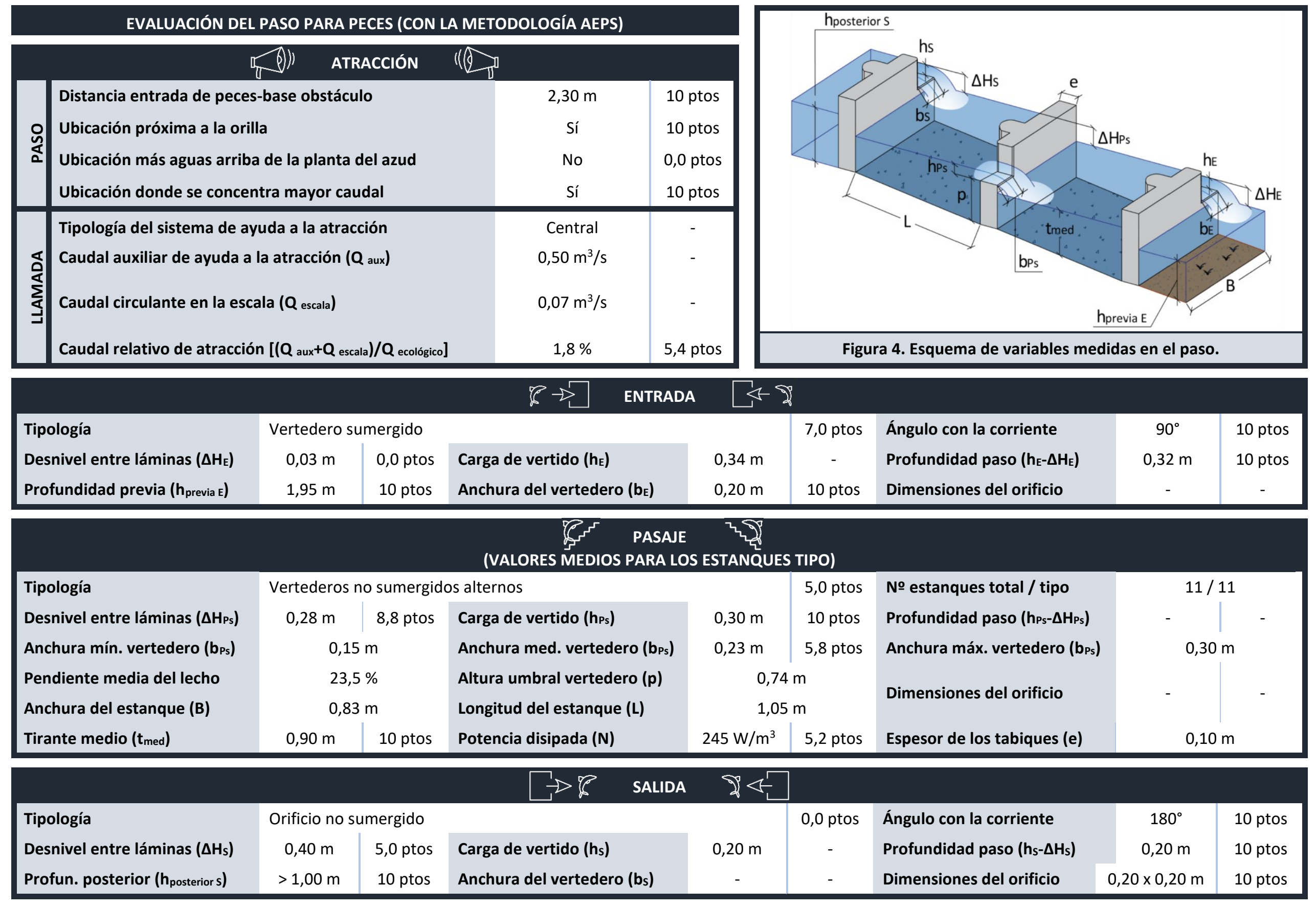




\section{PASO PARA PECES ASOCIADO AL AZUD DE SOFOENSA VILLABÁÑEZ}

\begin{tabular}{|c|c|c|c|c|}
\hline & Provincia & Valladolid & Municipio & Villabáñez \\
\hline & $\begin{array}{l}\text { Nombre del aprovechamiento } \\
\text { Código del aprovechamiento } \\
\text { Long. coronación del azud } \\
\text { (1) } \\
\text { Coordenadas del paso piscícola }\end{array}$ & $\begin{array}{l}\text { Villabáñez } \\
1100030 \\
98 \mathrm{~m} \\
\text { X: } 373.609\end{array}$ & $\begin{array}{l}\text { Tipo de aprovechamiento } \\
\text { Código del azud (1) } \\
\text { Salto total de agua en la visita } \\
980 \text { m (ETRS 89; HUSO 30) }\end{array}$ & $\begin{array}{l}\text { Hidroeléctrico } \\
1005606 \\
3,42 \mathrm{~m}\end{array}$ \\
\hline & $\begin{array}{l}\text { Cuenca hidrográfica } \\
\text { Principales peces migradores }{ }^{(1)} \\
\text { Época de migración }\end{array}$ & $\begin{array}{l}\text { Duero } \\
\text { Luciobarbus } \\
\text { Mayo a juni }\end{array}$ & $\begin{array}{l}\text { Cauce } \\
\text { seudochondrostoma duriense }\end{array}$ & Duero \\
\hline $\begin{array}{l}\text { Figura 1. Ubicación en la parte } \\
\text { española de la cuenca del río Duero. }\end{array}$ & $\begin{array}{l}\text { Caudal medio en migración (2) } \\
\text { Caudal durante la visita }{ }^{(3)}\end{array}$ & $\begin{array}{l}25,79 \mathrm{~m}^{3} / \mathrm{s} \\
62,12 \mathrm{~m}^{3} / \mathrm{s}\end{array}$ & $\begin{array}{l}\text { Caudal ecológico en migración } \\
\text { Hora y fecha de la visita }\end{array}$ & $\begin{array}{l}4,00 \mathrm{~m}^{3} / \mathrm{s} \\
17: 00 \mathrm{~h}, 15 / 03 / 2016\end{array}$ \\
\hline
\end{tabular}

(1) Dato obtenido de MíRAME-IDE Duero. ${ }^{(2)}$ Dato obtenido del CEDEX Hidrológico. ${ }^{(3)}$ Dato obtenido del SAIH del Duero.

\begin{tabular}{|c|c|c|c|}
\hline Paso para peces de estanques st & os conectados $p$ & tederos sumergidos alternos & \\
\hline $\begin{array}{l}\text { Estado de mantenimiento y limpieza durante la evaluación } \\
\text { Solera naturalizada (con piedras) } \\
\text { Vertedero de umbral móvil en la entrada de peces }\end{array}$ & $\begin{array}{l}\text { No adecuado } \\
\text { Sí } \\
\text { No }\end{array}$ & $\begin{array}{l}\text { Compuerta en la salida de peces } \\
\text { Dispositivo para evitar la entrada de arrastres } \\
\text { Salida de peces segura (alejada del azud, turbinas, ...) }\end{array}$ & $\begin{array}{l}\text { No } \\
\text { No } \\
\text { Sí }\end{array}$ \\
\hline
\end{tabular}

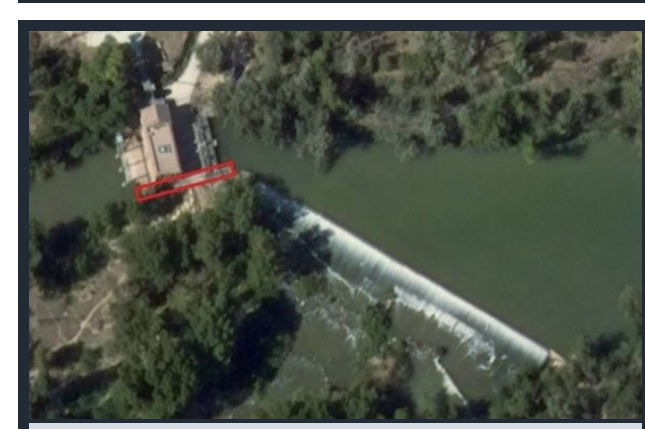

Figura 2. Ortofoto de la zona (fuente: SigPac).

\begin{tabular}{lccc}
\multicolumn{4}{c}{ RESUMEN DE LA EVALUACIÓN DEL PASO PARA PECES } \\
& \multicolumn{4}{c|}{ (CON LA METODOLOGÍA AEPS) } & \\
\hline Etapa o categoría & Puntuación & Evaluación & ¿Mejoras? \\
Atracción & 6,7 & Favorable & Recomendables \\
Entrada & 8,8 & Muy favorable & Opcionales \\
Pasaje & 0,0 & Muy desfavorable & Imprescindibles \\
Salida & 8,9 & Muy favorable & Opcionales \\
\hline
\end{tabular}

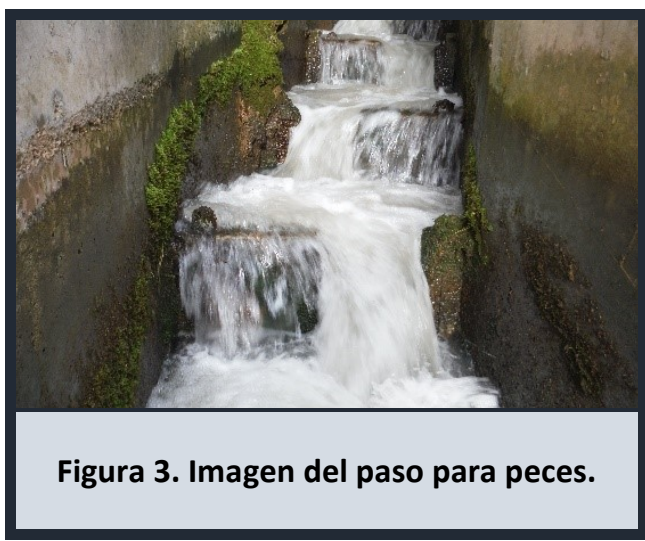




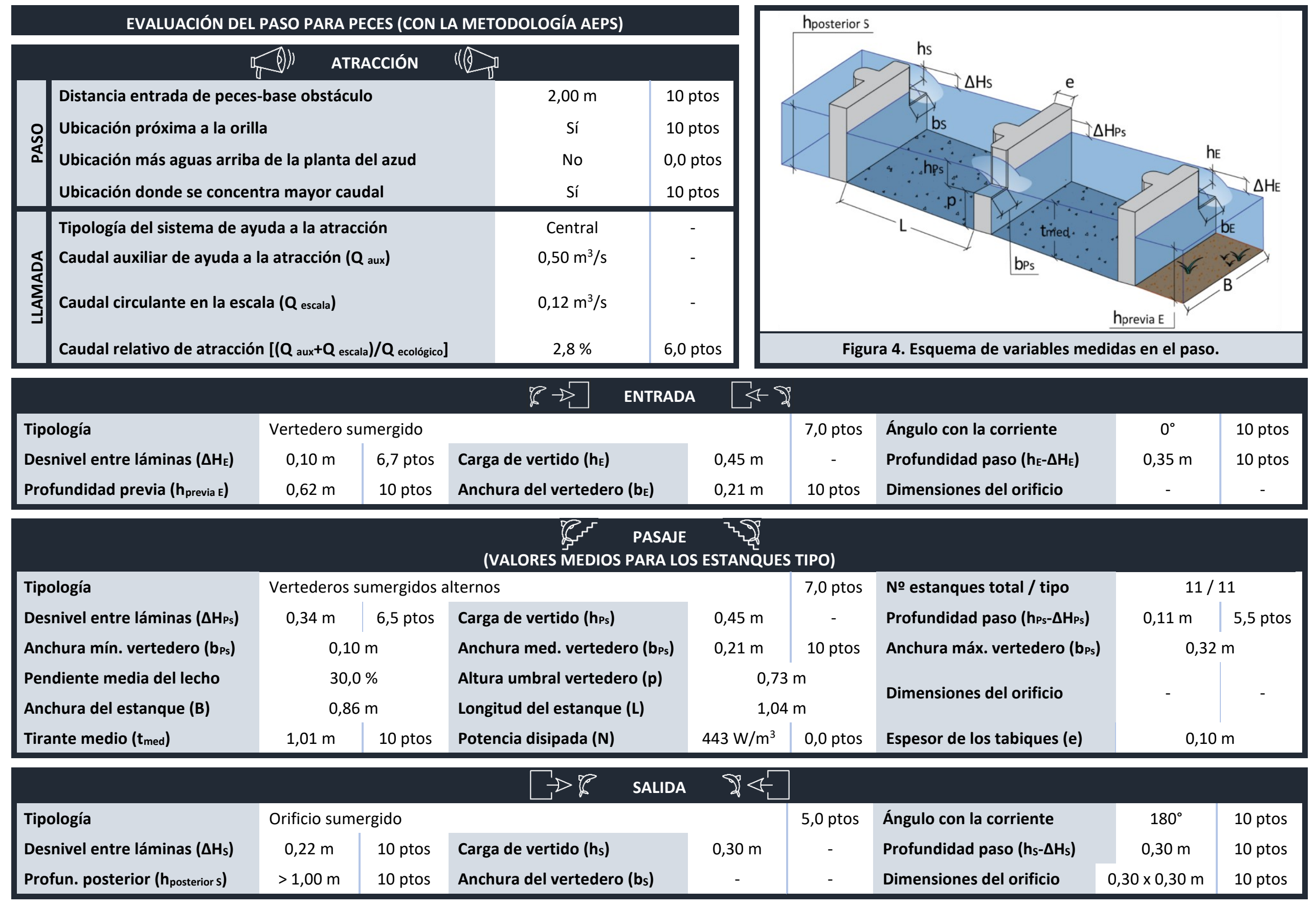




\section{PASO PARA PECES ASOCIADO AL AZUD DE LA CENTRAL DE NUESTRA SEÑORA DE LAS MERCEDES (AZUD)}

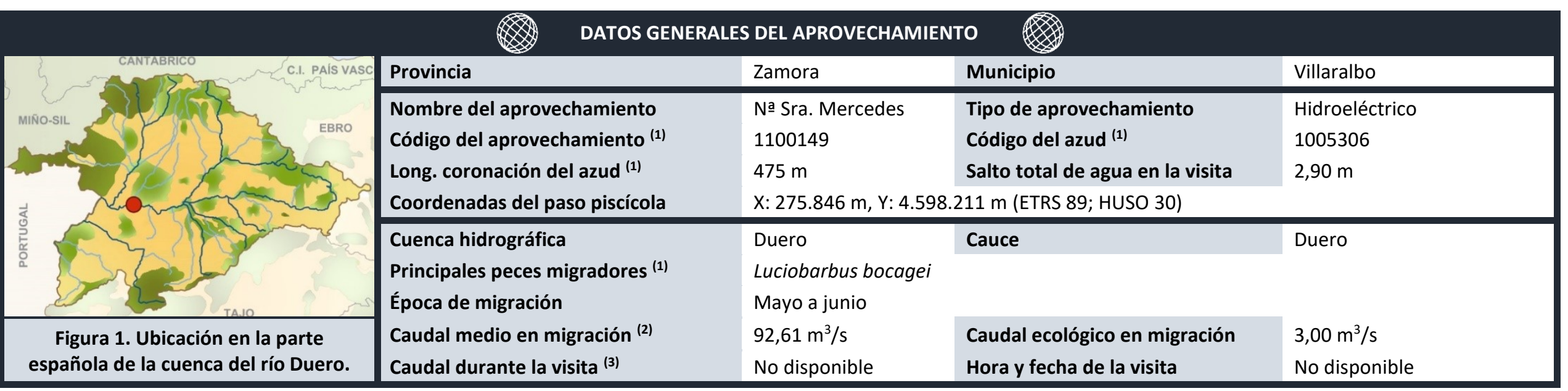

(1) Dato obtenido de MíRAME-IDE Duero. ${ }^{(2)}$ Dato obtenido del CEDEX Hidrológico. ${ }^{(3)}$ Dato obtenido del SAIH del Duero.

\begin{tabular}{|c|c|c|c|}
\hline Paso para peces de estanques su & os conectados po & diduras verticales alineadas y sin orificios & \\
\hline $\begin{array}{l}\text { Estado de mantenimiento y limpieza durante la evaluación } \\
\text { Solera naturalizada (con piedras) } \\
\text { Vertedero de umbral móvil en la entrada de peces }\end{array}$ & $\begin{array}{l}\text { Muy adecuado } \\
\text { Sí } \\
\text { No }\end{array}$ & $\begin{array}{l}\text { Compuerta en la salida de peces } \\
\text { Dispositivo para evitar la entrada de arrastres } \\
\text { Salida de peces segura (alejada del azud, turbinas, ...) }\end{array}$ & $\begin{array}{l}\text { Sí } \\
\text { Sí } \\
\text { Sí }\end{array}$ \\
\hline
\end{tabular}

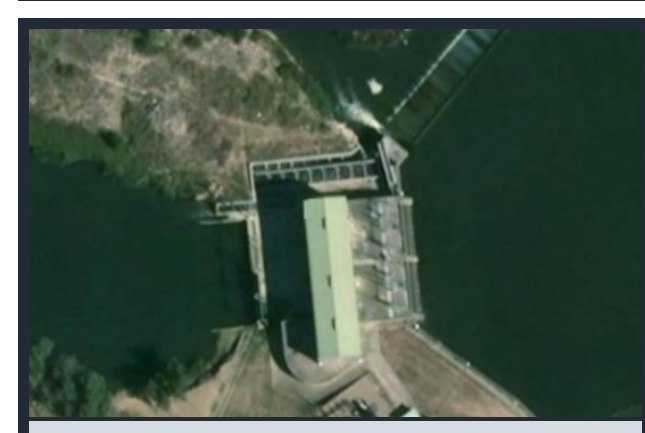

Figura 2. Ortofoto de la zona (fuente: SigPac).

\begin{tabular}{lccc}
\multicolumn{4}{c}{ RESUMEN DE LA EVALUACIÓN DEL PASO PARA PECES } \\
(CON LA METODOLOGÍA AEPS) & \\
\hline Etapa o categoría & Puntuación & Evaluación & ¿Mejoras? \\
Atracción & 7,5 & Favorable & Recomendables \\
Entrada & 9,1 & Muy favorable & Opcionales \\
Pasaje & 10,0 & Muy favorable & Opcionales \\
Salida & 8,9 & Muy favorable & Opcionales \\
\hline
\end{tabular}

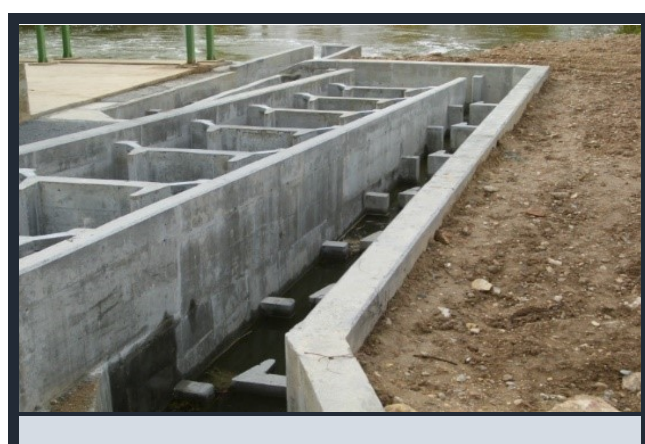

Figura 3. Imagen del paso para peces. 


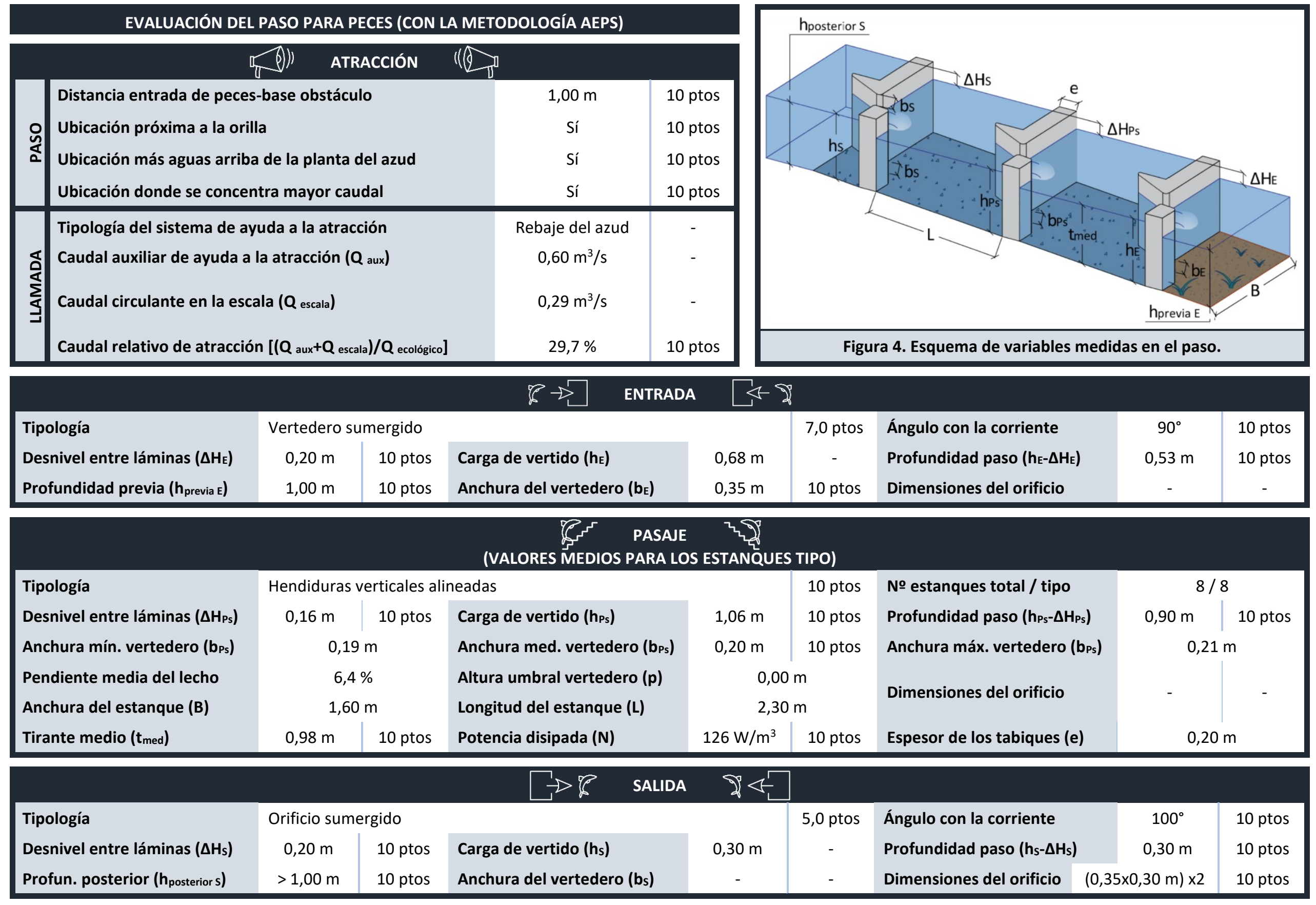


Desarrollo y aplicación de una nueva metodología para la evaluación de pasos para peces de estanques sucesivos

\section{PASO PARA PECES ASOCIADO AL AZUD DE LA CENTRAL DE NUESTRA SEÑORA DE LAS MERCEDES (CENTRAL)}

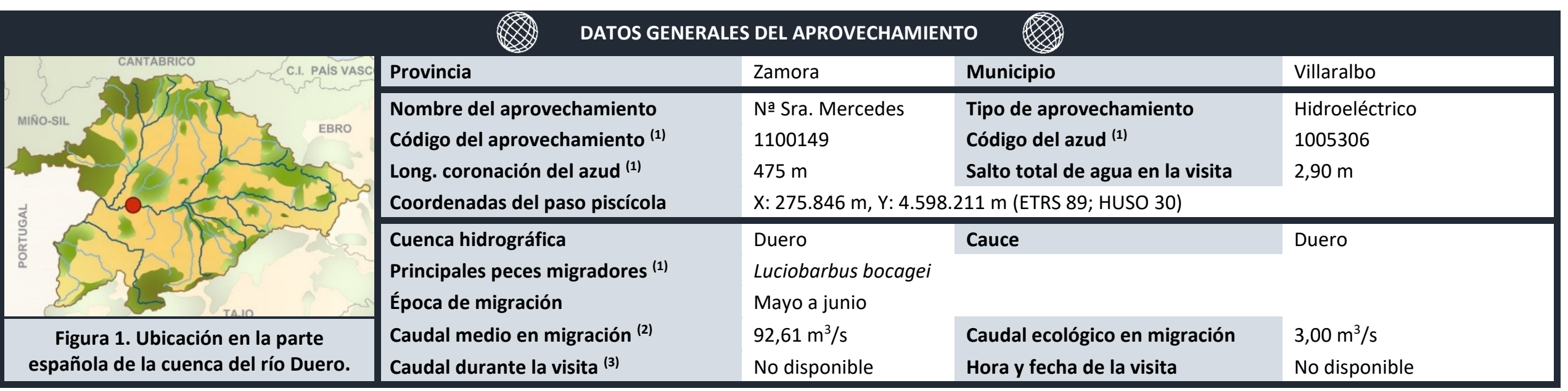

(1) Dato obtenido de MíRAME-IDE Duero. ${ }^{(2)}$ Dato obtenido del CEDEX Hidrológico. ${ }^{(3)}$ Dato obtenido del SAIH del Duero.

\begin{tabular}{|c|c|c|c|}
\hline Paso para peces de estanques su & os conectados po & diduras verticales alineadas y sin orificios & \\
\hline $\begin{array}{l}\text { Estado de mantenimiento y limpieza durante la evaluación } \\
\text { Solera naturalizada (con piedras) } \\
\text { Vertedero de umbral móvil en la entrada de peces }\end{array}$ & $\begin{array}{l}\text { Muy adecuado } \\
\text { Sí } \\
\text { No }\end{array}$ & $\begin{array}{l}\text { Compuerta en la salida de peces } \\
\text { Dispositivo para evitar la entrada de arrastres } \\
\text { Salida de peces segura (alejada del azud, turbinas, ...) }\end{array}$ & $\begin{array}{l}\text { Sí } \\
\text { Sí } \\
\text { Sí }\end{array}$ \\
\hline
\end{tabular}

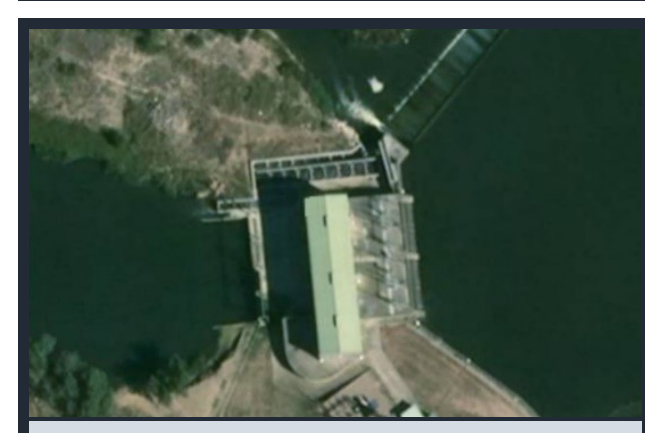

Figura 2. Ortofoto de la zona (fuente: SigPac).

\begin{tabular}{|c|c|c|c|}
\hline \multicolumn{4}{|c|}{$\begin{array}{l}\text { RESUMEN DE LA EVALUACIÓN DEL PASO PARA PECES } \\
\text { (CON LA METODOLOGÍA AEPS) }\end{array}$} \\
\hline Etapa o categoría & Puntuación & Evaluación & ¿Mejoras? \\
\hline Atracción & 10,0 & Muy favorable & Opcionales \\
\hline Entrada & 9,1 & Muy favorable & Opcionales \\
\hline Pasaje & 10,0 & Muy favorable & Opcionales \\
\hline Salida & 8,9 & Muy favorable & Opcionales \\
\hline
\end{tabular}

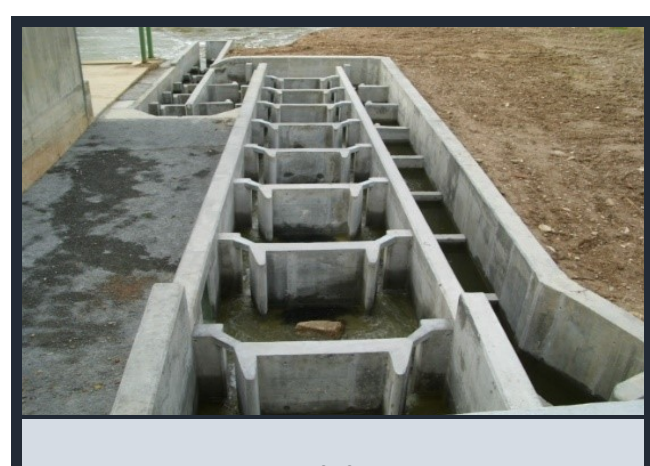

Figura 3. Imagen del paso para peces. 


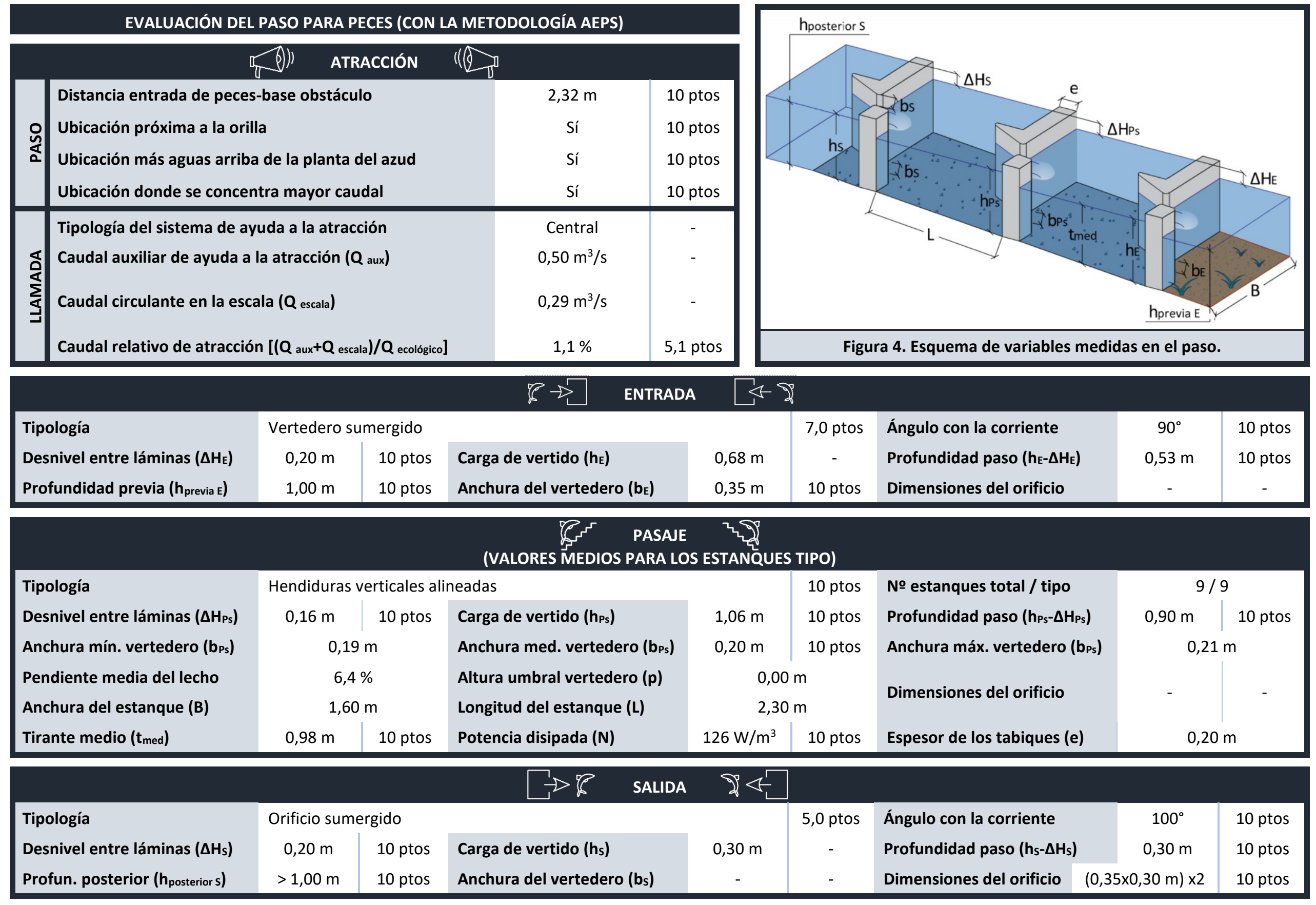




\section{PASO PARA PECES ASOCIADO AL AZUD DE LA CENTRAL DE NUESTRA SEÑORA DE LAS MERCEDES (TRAMO COMÚN)}

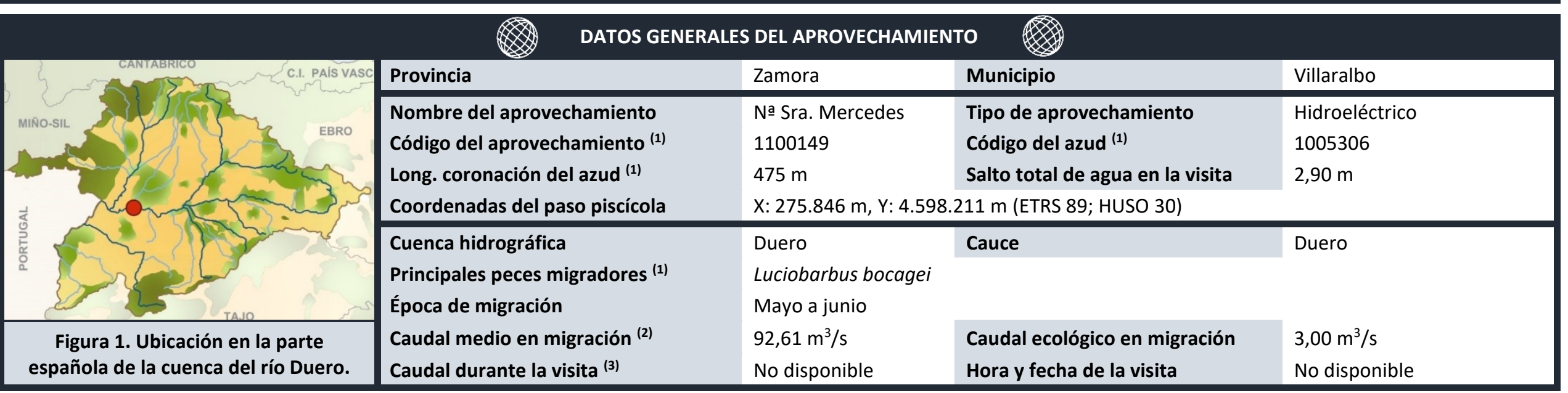

(1) Dato obtenido de MíRAME-IDE Duero. ${ }^{(2)}$ Dato obtenido del CEDEX Hidrológico. ${ }^{(3)}$ Dato obtenido del SAIH del Duero.

\begin{tabular}{|c|c|c|c|}
\hline Paso para peces de estanques su & os conectados pc & les hendiduras verticales alineadas y sin orificios & \\
\hline $\begin{array}{l}\text { Estado de mantenimiento y limpieza durante la evaluación } \\
\text { Solera naturalizada (con piedras) } \\
\text { Vertedero de umbral móvil en la entrada de peces }\end{array}$ & $\begin{array}{l}\text { Muy adecuado } \\
\text { Sí } \\
\text { No }\end{array}$ & $\begin{array}{l}\text { Compuerta en la salida de peces } \\
\text { Dispositivo para evitar la entrada de arrastres } \\
\text { Salida de peces segura (alejada del azud, turbinas, ...) }\end{array}$ & $\begin{array}{l}\text { Sí } \\
\text { Sí } \\
\text { Sí }\end{array}$ \\
\hline
\end{tabular}

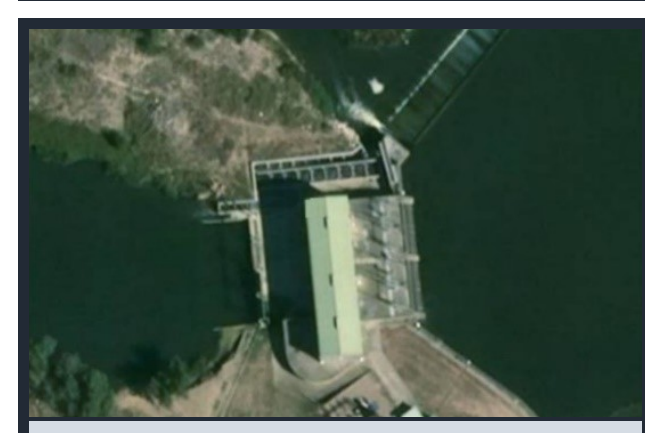

Figura 2. Ortofoto de la zona (fuente: SigPac).

\begin{tabular}{lccl}
\multicolumn{5}{c}{$\begin{array}{c}\text { RESUMEN DE LA EVALUACIÓN DEL PASO PARA PECES } \\
\text { (CON LA METODOLOGíA AEPS) }\end{array}$} \\
\hline $\begin{array}{l}\text { Etapa o categoría } \\
\text { Atracción }\end{array}$ & $\begin{array}{c}\text { Puntuación } \\
\text { Entrada }\end{array}$ & Evaluación & ¿Mejoras? \\
Pasaje & 8,8 & Muy favorable & Opcionales \\
Salida & 9,1 & Muy favorable & Opcionales \\
& 10,0 & Muy favorable & Opcionales \\
\hline
\end{tabular}

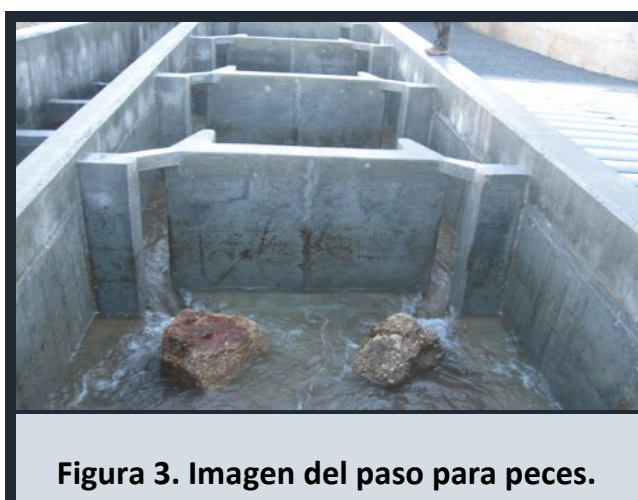




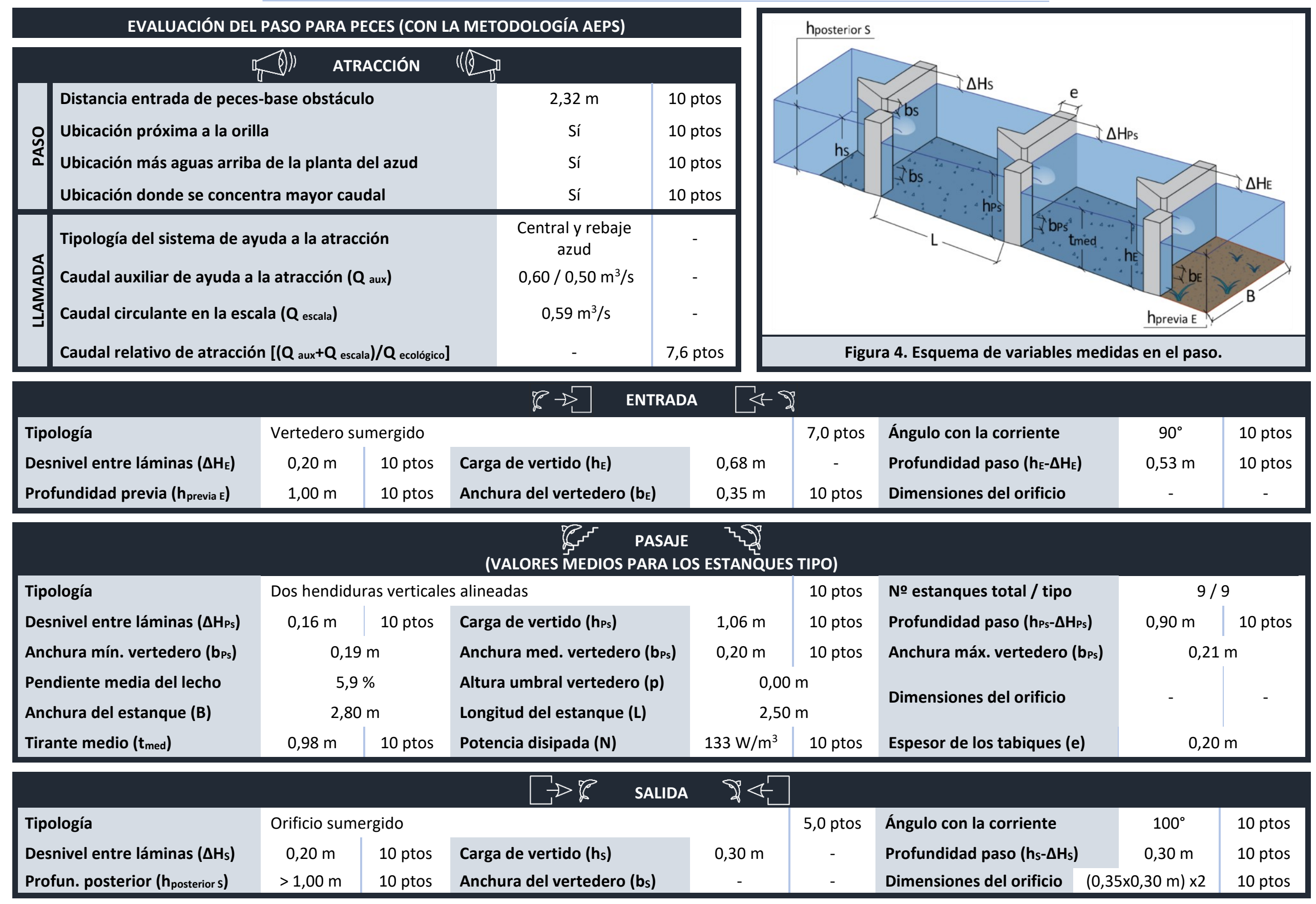




\section{PASO PARA PECES ASOCIADO AL AZUD DEL EMBALSE DE SAN ROMÁN (AZUD)}

\begin{tabular}{|c|c|c|c|c|}
\hline & Provincia & Zamora & Municipio & Pereruela \\
\hline & $\begin{array}{l}\text { Nombre del aprovechamiento } \\
\text { Código del aprovechamiento } \\
\text { Long. coronación del azud } \\
\text { (1) } \\
\text { Coordenadas del paso piscícola }\end{array}$ & $\begin{array}{l}\text { Pereruela } \\
1100203 \\
341 \mathrm{~m} \\
X: 260.866 \mathrm{~m}, \mathrm{Y:}: 4.595 .\end{array}$ & $\begin{array}{l}\text { Tipo de aprovechamiento } \\
\text { Código del azud (1) } \\
\text { Salto total de agua en la visita } \\
539 \text { m (ETRS 89; HUSO 30) }\end{array}$ & $\begin{array}{l}\text { Hidroeléctrico y navegac. } \\
1004025 \\
5,11 \mathrm{~m}\end{array}$ \\
\hline & $\begin{array}{l}\text { Cuenca hidrográfica } \\
\text { Principales peces migradores }{ }^{(1)} \\
\text { Época de migración }\end{array}$ & $\begin{array}{l}\text { Duero } \\
\text { Luciobarbus bocagei } \\
\text { Mayo a junio }\end{array}$ & Cauce & Duero \\
\hline $\begin{array}{c}\text { Figura 1. Ubicación en la parte } \\
\text { española de la cuenca del río Duero. }\end{array}$ & $\begin{array}{l}\text { Caudal medio en migración }{ }^{(2)} \\
\text { Caudal durante la visita }{ }^{(3)}\end{array}$ & $\begin{array}{l}92,61 \mathrm{~m}^{3} / \mathrm{s} \\
\text { No disponible }\end{array}$ & $\begin{array}{l}\text { Caudal ecológico en migración } \\
\text { Hora y fecha de la visita }\end{array}$ & $\begin{array}{l}6,00 \mathrm{~m}^{3} / \mathrm{s} \\
\text { No disponible }\end{array}$ \\
\hline
\end{tabular}

(1) Dato obtenido de MíRAME-IDE Duero. ${ }^{(2)}$ Dato obtenido del CEDEX Hidrológico. ${ }^{(3)}$ Dato obtenido del SAIH del Duero.

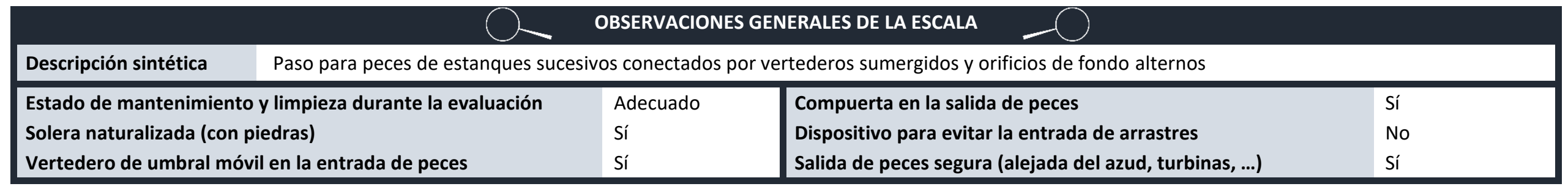

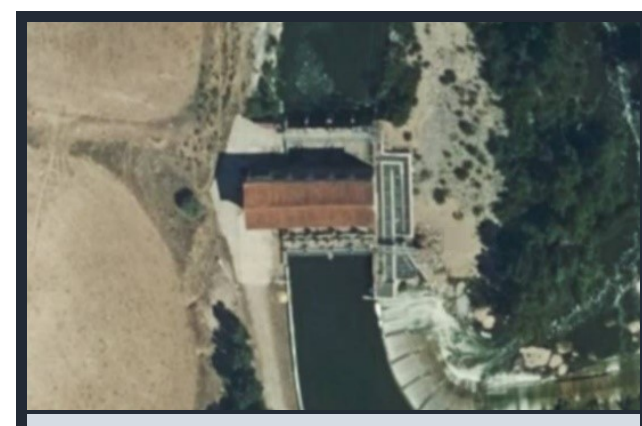

Figura 2. Ortofoto de la zona (fuente: SigPac).

\begin{tabular}{lccl}
\multicolumn{5}{c}{ RESUMEN DE LA EVALUACIÓN DEL PASO PARA PECES } \\
(CON LA METODOLOGÍA AEPS)
\end{tabular}

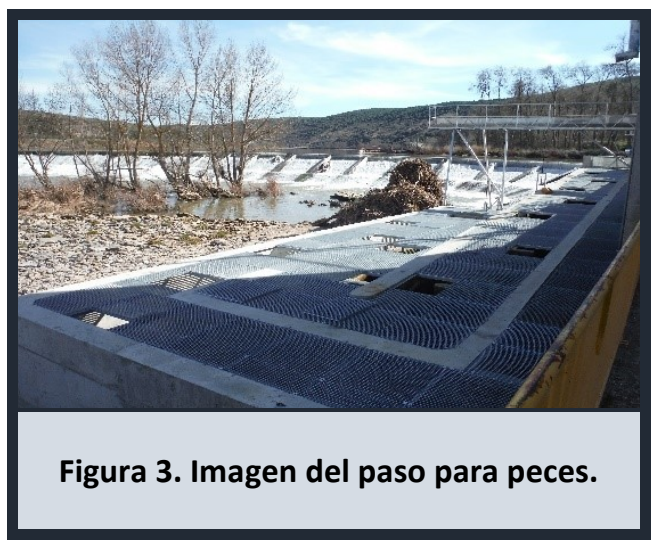




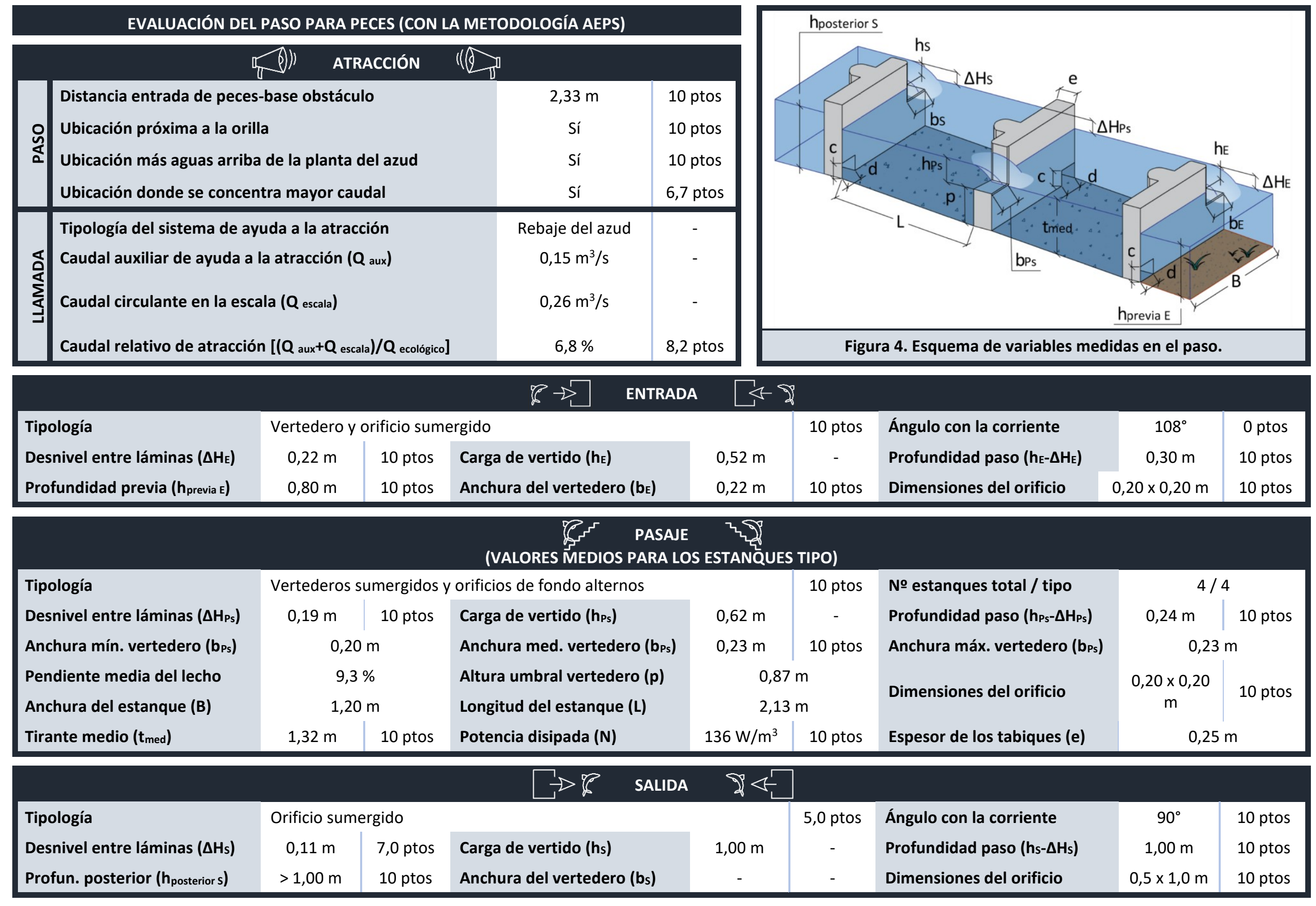




\section{PASO PARA PECES ASOCIADO AL AZUD DEL EMBALSE DE SAN ROMÁN (CENTRAL)}

\begin{tabular}{|c|c|c|c|c|}
\hline & Provincia & Zamora & Municipio & Pereruela \\
\hline & $\begin{array}{l}\text { Nombre del aprovechamiento } \\
\text { Código del aprovechamiento } \\
\text { Long. coronación del azud } \\
\text { (1) } \\
\text { Coordenadas del paso piscícola }\end{array}$ & $\begin{array}{l}\text { Pereruela } \\
1100203 \\
341 \mathrm{~m} \\
X: 260.866 \mathrm{~m}, \mathrm{Y:}: 4.595 .\end{array}$ & $\begin{array}{l}\text { Tipo de aprovechamiento } \\
\text { Código del azud (1) } \\
\text { Salto total de agua en la visita } \\
539 \text { m (ETRS 89; HUSO 30) }\end{array}$ & $\begin{array}{l}\text { Hidroeléctrico y navegac. } \\
1004025 \\
5,73 \mathrm{~m}\end{array}$ \\
\hline & $\begin{array}{l}\text { Cuenca hidrográfica } \\
\text { Principales peces migradores }{ }^{(1)} \\
\text { Época de migración }\end{array}$ & $\begin{array}{l}\text { Duero } \\
\text { Luciobarbus bocagei } \\
\text { Mayo a junio }\end{array}$ & Cauce & Duero \\
\hline $\begin{array}{l}\text { Figura 1. Ubicación en la parte } \\
\text { española de la cuenca del río Duero. }\end{array}$ & $\begin{array}{l}\text { Caudal medio en migración }{ }^{(2)} \\
\text { Caudal durante la visita }{ }^{(3)}\end{array}$ & $\begin{array}{l}92,61 \mathrm{~m}^{3} / \mathrm{s} \\
\text { No disponible }\end{array}$ & $\begin{array}{l}\text { Caudal ecológico en migración } \\
\text { Hora y fecha de la visita }\end{array}$ & $\begin{array}{l}6,00 \mathrm{~m}^{3} / \mathrm{s} \\
\text { No disponible }\end{array}$ \\
\hline
\end{tabular}

(1) Dato obtenido de MíRAME-IDE Duero. ${ }^{(2)}$ Dato obtenido del CEDEX Hidrológico. ${ }^{(3)}$ Dato obtenido del SAIH del Duero.

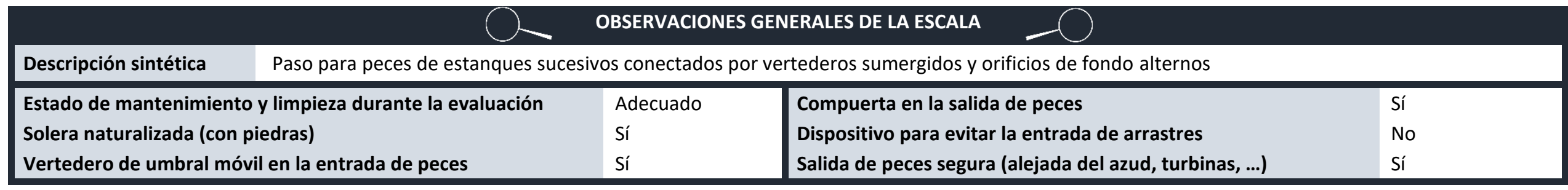

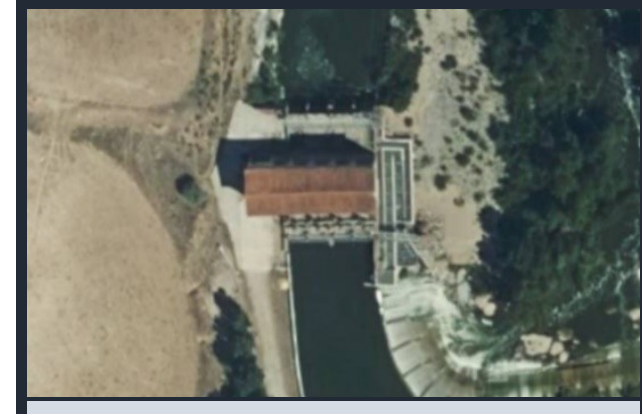

Figura 2. Ortofoto de la zona (fuente: SigPac).

\begin{tabular}{lccc}
\multicolumn{4}{c}{ RESUMEN DE LA EVALUACIÓN DEL PASO PARA PECES } \\
& \multicolumn{4}{c|}{ (CON LA METODOLOGíA AEPS) } & \\
\hline Etapa o categoría & Puntuación & Evaluación & ¿Mejoras? \\
Atracción & 7,6 & Favorable & Recomendables \\
Entrada & 8,9 & Muy favorable & Opcionales \\
Pasaje & 10,0 & Muy favorable & Opcionales \\
Salida & 8,2 & Muy favorable & Opcionales \\
\hline
\end{tabular}

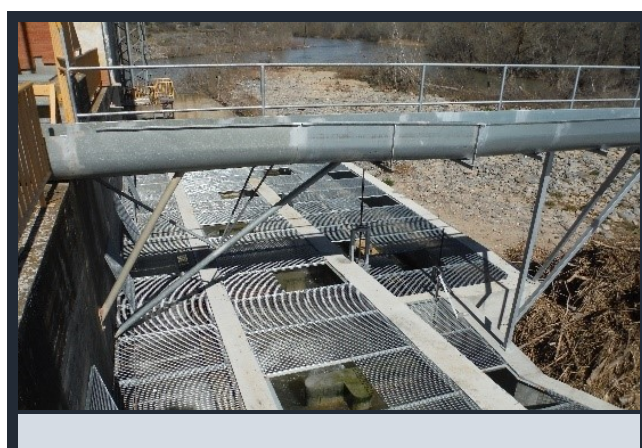

Figura 3. Imagen del paso para peces. 


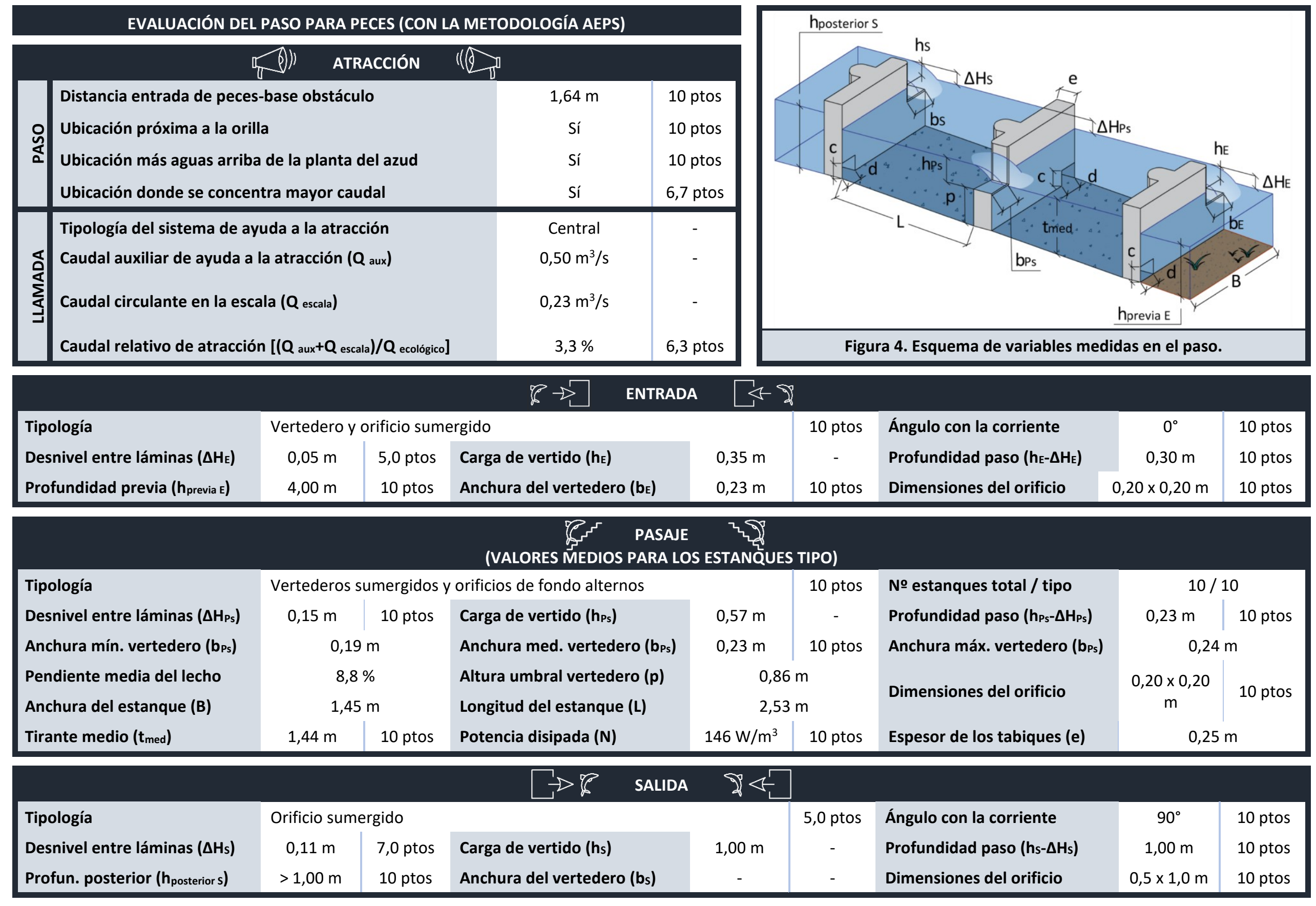




\section{PASO PARA PECES ASOCIADO AL AZUD DEL EMBALSE DE SAN ROMÁN (TRAMO COMÚN)}

\begin{tabular}{|c|c|c|c|c|}
\hline & Provincia & Zamora & Municipio & Pereruela \\
\hline & $\begin{array}{l}\text { Nombre del aprovechamiento } \\
\text { Código del aprovechamiento } \\
\text { Long. coronación del azud } \\
\text { (1) } \\
\text { Coordenadas del paso piscícola }\end{array}$ & $\begin{array}{l}\text { Pereruela } \\
1100203 \\
341 \mathrm{~m} \\
\mathrm{X}: 260.866 \mathrm{~m}, \mathrm{Y:}: 4.595\end{array}$ & $\begin{array}{l}\text { Tipo de aprovechamiento } \\
\text { Código del azud (1) } \\
\text { Salto total de agua en la visita } \\
539 \text { m (ETRS 89; HUSO 30) }\end{array}$ & $\begin{array}{l}\text { Hidroeléctrico y navegac. } \\
1004025 \\
5,73 \mathrm{~m}\end{array}$ \\
\hline & $\begin{array}{l}\text { Cuenca hidrográfica } \\
\text { Principales peces migradores }{ }^{(1)} \\
\text { Época de migración }\end{array}$ & $\begin{array}{l}\text { Duero } \\
\text { Luciobarbus bocagei } \\
\text { Mayo a junio }\end{array}$ & Cauce & Duero \\
\hline $\begin{array}{l}\text { Figura 1. Ubicación en la parte } \\
\text { española de la cuenca del río Duero. }\end{array}$ & $\begin{array}{l}\text { Caudal medio en migración (2) } \\
\text { Caudal durante la visita }{ }^{(3)}\end{array}$ & $\begin{array}{l}92,61 \mathrm{~m}^{3} / \mathrm{s} \\
\text { No disponible }\end{array}$ & $\begin{array}{l}\text { Caudal ecológico en migración } \\
\text { Hora y fecha de la visita }\end{array}$ & $\begin{array}{l}6,00 \mathrm{~m}^{3} / \mathrm{s} \\
\text { No disponible }\end{array}$ \\
\hline
\end{tabular}

(1) Dato obtenido de MíRAME-IDE Duero. ${ }^{(2)}$ Dato obtenido del CEDEX Hidrológico. ${ }^{(3)}$ Dato obtenido del SAIH del Duero.

\begin{tabular}{|c|c|c|c|}
\hline Paso para peces de estanques su & s conectadc & tederos sumergidos y orificios de fondo alternos & \\
\hline $\begin{array}{l}\text { Estado de mantenimiento y limpieza durante la evaluación } \\
\text { Solera naturalizada (con piedras) } \\
\text { Vertedero de umbral móvil en la entrada de peces }\end{array}$ & $\begin{array}{l}\text { Adecuado } \\
\text { Sí } \\
\text { Sí }\end{array}$ & $\begin{array}{l}\text { Compuerta en la salida de peces } \\
\text { Dispositivo para evitar la entrada de arrastres } \\
\text { Salida de peces segura (alejada del azud, turbinas, ...) }\end{array}$ & $\begin{array}{l}\text { Sí } \\
\text { No } \\
\text { Sí }\end{array}$ \\
\hline
\end{tabular}

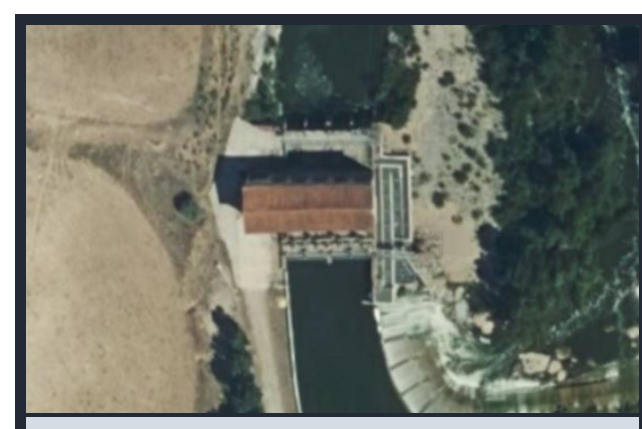

Figura 2. Ortofoto de la zona (fuente: SigPac).

\begin{tabular}{lccl}
\multicolumn{5}{c}{$\begin{array}{c}\text { RESUMEN DE LA EVALUACIÓN DEL PASO PARA PECES } \\
\text { (CON LA METODOLOGíA AEPS) }\end{array}$} \\
\hline $\begin{array}{l}\text { Etapa o categoría } \\
\text { Atracción }\end{array}$ & $\begin{array}{c}\text { Puntuación } \\
\text { Entrada }\end{array}$ & Evaluación & ¿Mejoras? \\
Pasaje & 8,2 & Muy favorable & Opcionales \\
Salida & 8,8 & Muy favorable & Opcionales \\
\end{tabular}

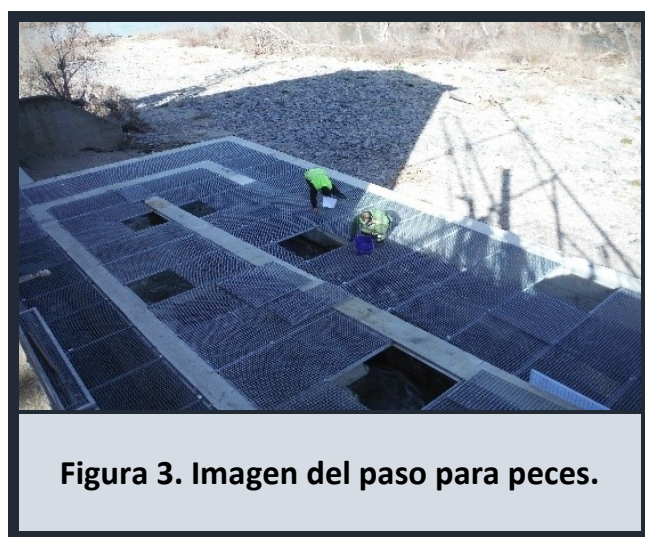




\section{EVALUACIÓN DEL PASO PARA PECES (CON LA METODOLOGíA AEPS)}

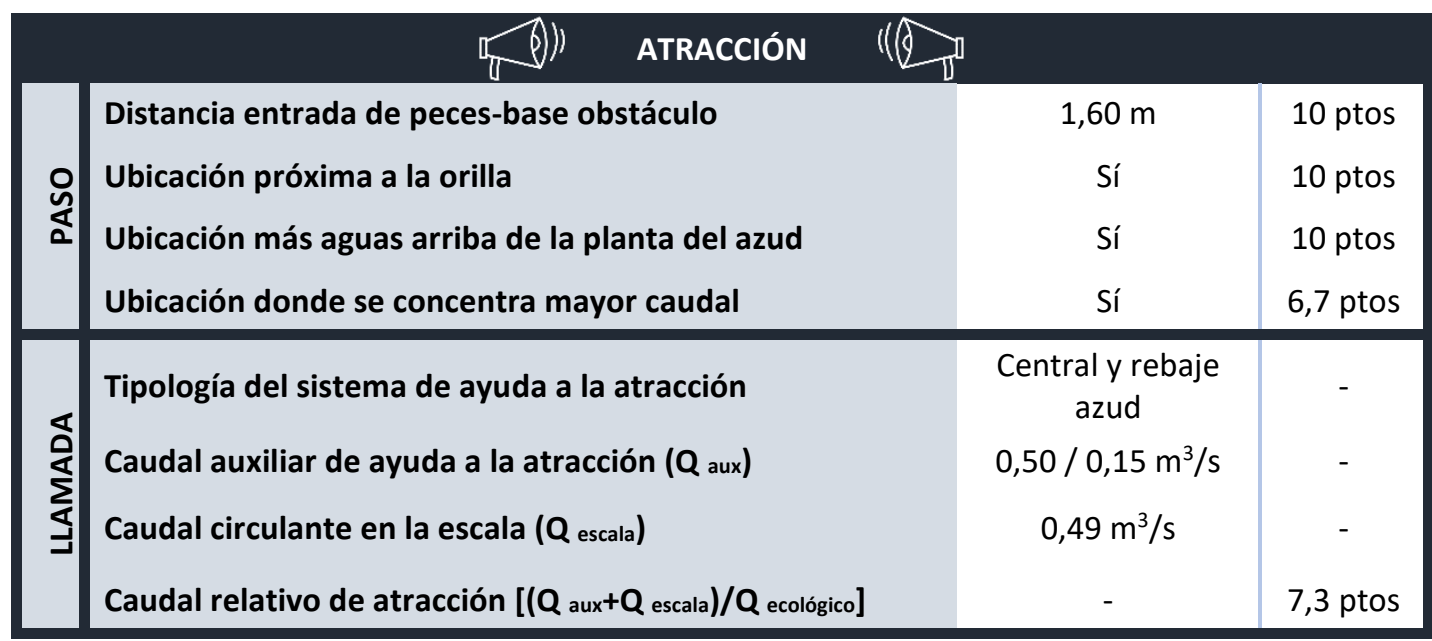

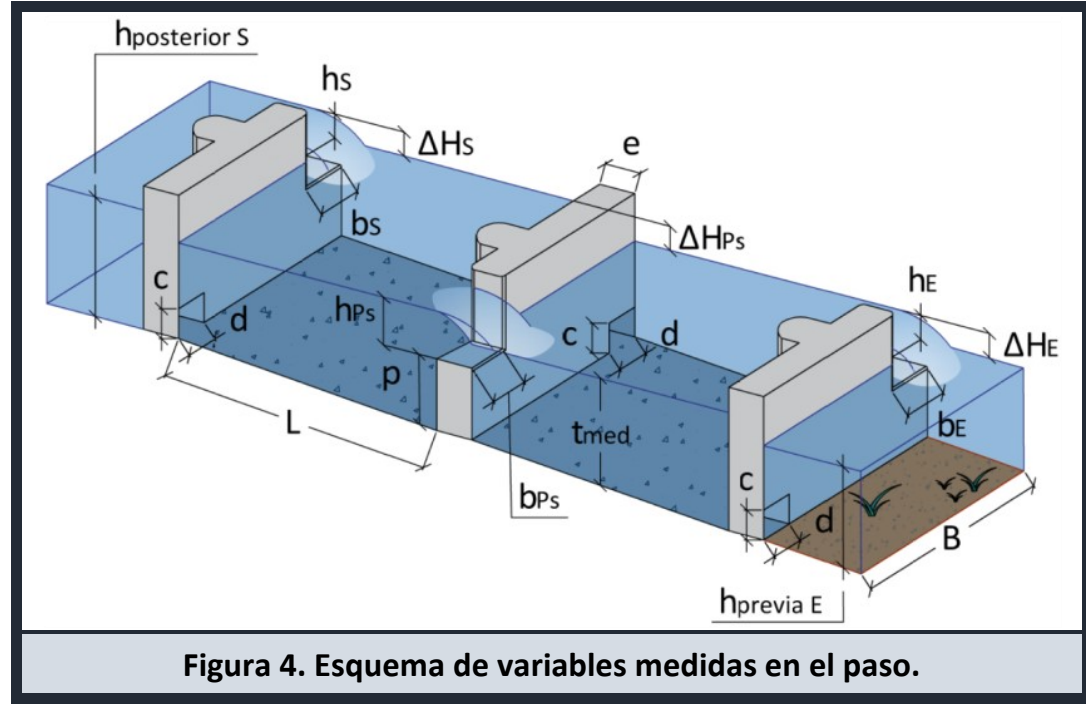

\begin{tabular}{|c|c|c|c|c|c|c|c|c|}
\hline & & & $b \rightarrow$ & 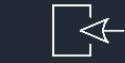 & & & & \\
\hline Tipología & Vertedero & rificio sum & rgido & & 10 ptos & Ángulo con la corriente & $108^{\circ}$ & 0 ptos \\
\hline Desnivel entre láminas $\left(\Delta \mathrm{H}_{\mathrm{E}}\right)$ & $0,32 \mathrm{~m}$ & 7,5 ptos & Carga de vertido $\left(h_{E}\right)$ & $0,44 \mathrm{~m}$ & - & Profundidad paso $\left(\mathrm{h}_{\mathrm{E}}-\Delta \mathrm{H}_{\mathrm{E}}\right)$ & $0,32 \mathrm{~m}$ & 10 ptos \\
\hline Profundidad previa ( $h_{\text {previa }}$ ) & $0,80 \mathrm{~m}$ & 10 ptos & Anchura del vertedero $\left(b_{E}\right)$ & $0,42 \mathrm{~m}$ & 10 ptos & Dimensiones del orificio & $0,30 \times 0,30 \mathrm{~m}$ & 10 ptos \\
\hline
\end{tabular}

\begin{tabular}{|c|c|c|c|c|c|c|c|c|}
\hline Tipología & \multicolumn{3}{|c|}{ Vertederos sumergidos y orificios de fondo alternos } & & 10 ptos & № estanques total / tipo & \multicolumn{2}{|c|}{$13 / 12$} \\
\hline Desnivel entre láminas $\left(\Delta H_{P s}\right)$ & $0,24 \mathrm{~m}$ & 10 ptos & Carga de vertido ( $\left.h_{\mathrm{Ps}}\right)$ & $0,57 \mathrm{~m}$ & - & Profundidad paso ( $\left.\mathrm{h}_{\mathrm{Ps}}-\Delta \mathrm{H}_{\mathrm{Ps}}\right)$ & $0,33 \mathrm{~m}$ & 10 ptos \\
\hline Anchura mín. vertedero ( $\left.b_{P_{s}}\right)$ & \multicolumn{2}{|c|}{$0,40 \mathrm{~m}$} & Anchura med. vertedero ( $\left.b_{P s}\right)$ & $0,42 \mathrm{~m}$ & 10 ptos & Anchura máx. vertedero ( $\left.b_{\mathrm{Ps}}\right)$ & \multicolumn{2}{|c|}{$0,44 \mathrm{~m}$} \\
\hline Pendiente media del lecho & \multicolumn{2}{|c|}{$8,1 \%$} & Altura umbral vertedero (p) & \multirow{2}{*}{\multicolumn{2}{|c|}{$0,85 \mathrm{~m}$}} & Dimensiones del orificio & $0,30 \times 0,30$ & 10 ptos \\
\hline Anchura del estanque (B) & \multicolumn{2}{|c|}{$1,80 \mathrm{~m}$} & Longitud del estanque (L) & $2,72 \mathrm{~m}$ & & & & \\
\hline Tirante medio ( $\left.t_{\text {med }}\right)$ & $1,30 \mathrm{~m}$ & 10 ptos & Potencia disipada (N) & $175 \mathrm{~W} / \mathrm{m}^{3}$ & 8,5 ptos & Espesor de los tabiques (e) & \multicolumn{2}{|c|}{$0,25 \mathrm{~m}$} \\
\hline
\end{tabular}

\begin{tabular}{|c|c|c|c|c|c|c|c|c|}
\hline Tipología & Orificio sur & gido & & & 5,0 ptos & Ángulo con la corriente & $90^{\circ}$ & 10 ptos \\
\hline Desnivel entre láminas $\left(\Delta H_{s}\right)$ & $0,11 \mathrm{~m}$ & 7,0 ptos & Carga de vertido (hs) & $1,00 \mathrm{~m}$ & - & Profundidad paso $\left(h_{s}-\Delta H_{s}\right)$ & $1,00 \mathrm{~m}$ & 10 ptos \\
\hline Profun. posterior ( $\mathrm{h}_{\text {posterior } \mathrm{s} \text { ) }}$ & $>1,00 \mathrm{~m}$ & 10 ptos & Anchura del vertedero (bs) & - & - & Dimensiones del orificio & $0,5 \times 1,0 \mathrm{~m}$ & 10 ptos \\
\hline
\end{tabular}




\section{PASO PARA PECES ASOCIADO AL AZUD DE LA CENTRAL HIDROELÉCTRICA DE TORO I}

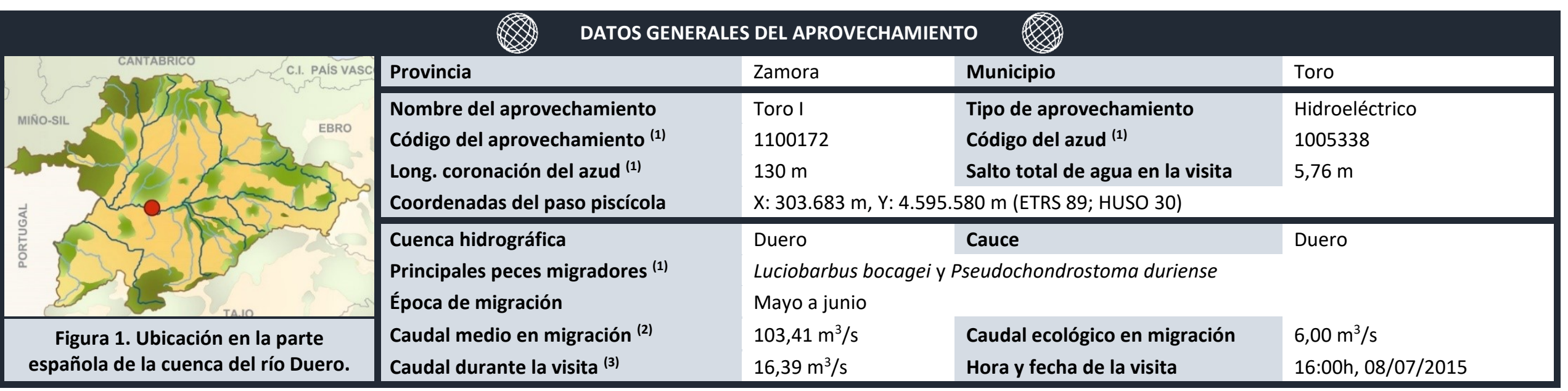

(1) Dato obtenido de MíRAME-IDE Duero. ${ }^{(2)}$ Dato obtenido del CEDEX Hidrológico. ${ }^{(3)}$ Dato obtenido del SAIH del Duero.

\begin{tabular}{|c|c|c|c|}
\hline Paso para peces de estanques si & os conectados $p$ & rtederos no sumergidos y orificios de fondo alternos & \\
\hline $\begin{array}{l}\text { Estado de mantenimiento y limpieza durante la evaluación } \\
\text { Solera naturalizada (con piedras) } \\
\text { Vertedero de umbral móvil en la entrada de peces }\end{array}$ & $\begin{array}{l}\text { No adecuado } \\
- \\
\text { No }\end{array}$ & $\begin{array}{l}\text { Compuerta en la salida de peces } \\
\text { Dispositivo para evitar la entrada de arrastres } \\
\text { Salida de peces segura (alejada del azud, turbinas, ...) }\end{array}$ & $\begin{array}{l}\text { No } \\
\text { No } \\
\text { No }\end{array}$ \\
\hline
\end{tabular}

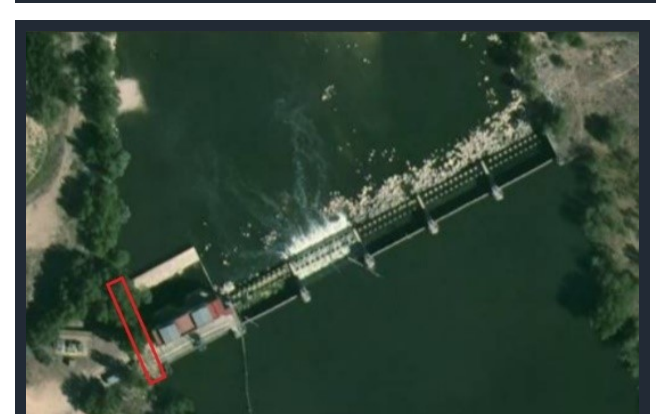

Figura 2. Ortofoto de la zona (fuente: SigPac).

\begin{tabular}{lccc}
\multicolumn{4}{c}{ RESUMEN DE LA EVALUACIÓN DEL PASO PARA PECES } \\
& \multicolumn{4}{c|}{ (CON LA METODOLOGÍA AEPS) } \\
\hline Etapa o categoría & Puntuación & Evaluación & ¿Mejoras? \\
Atracción & 8,6 & Muy favorable & Opcionales \\
Entrada & 0,0 & Muy desfavorable & Imprescindibles \\
Pasaje & 0,0 & Muy desfavorable & Imprescindibles \\
Salida & 7,9 & Favorable & Recomendables \\
\hline
\end{tabular}

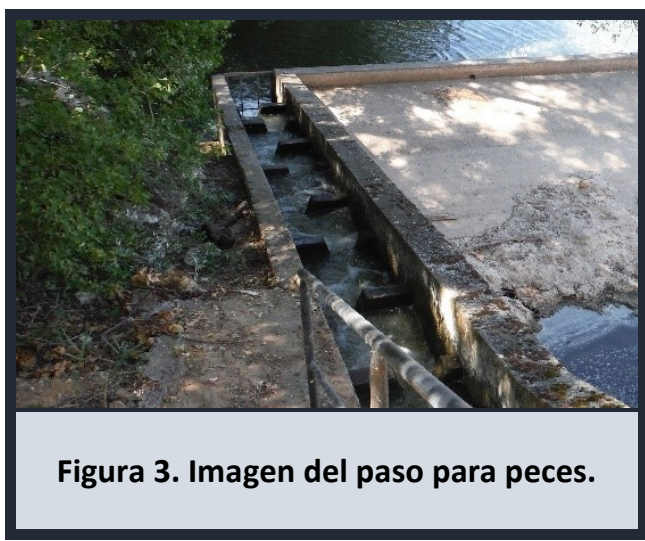




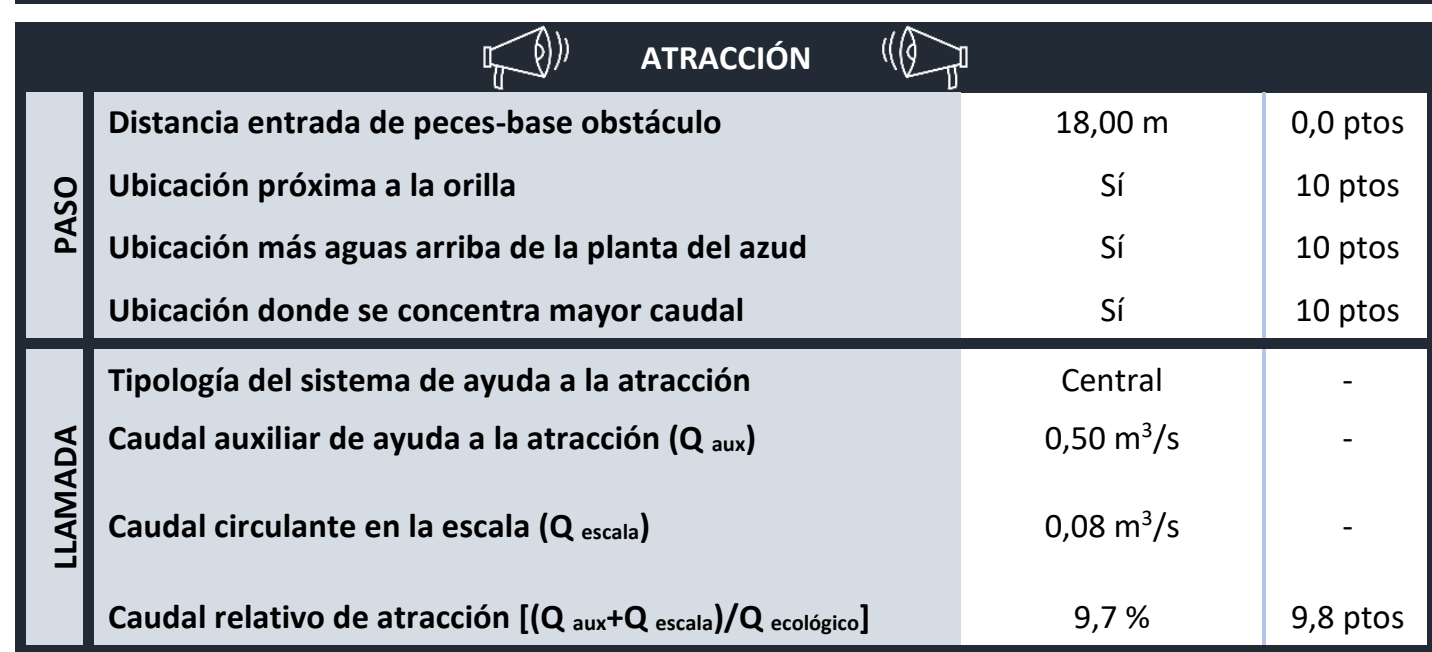

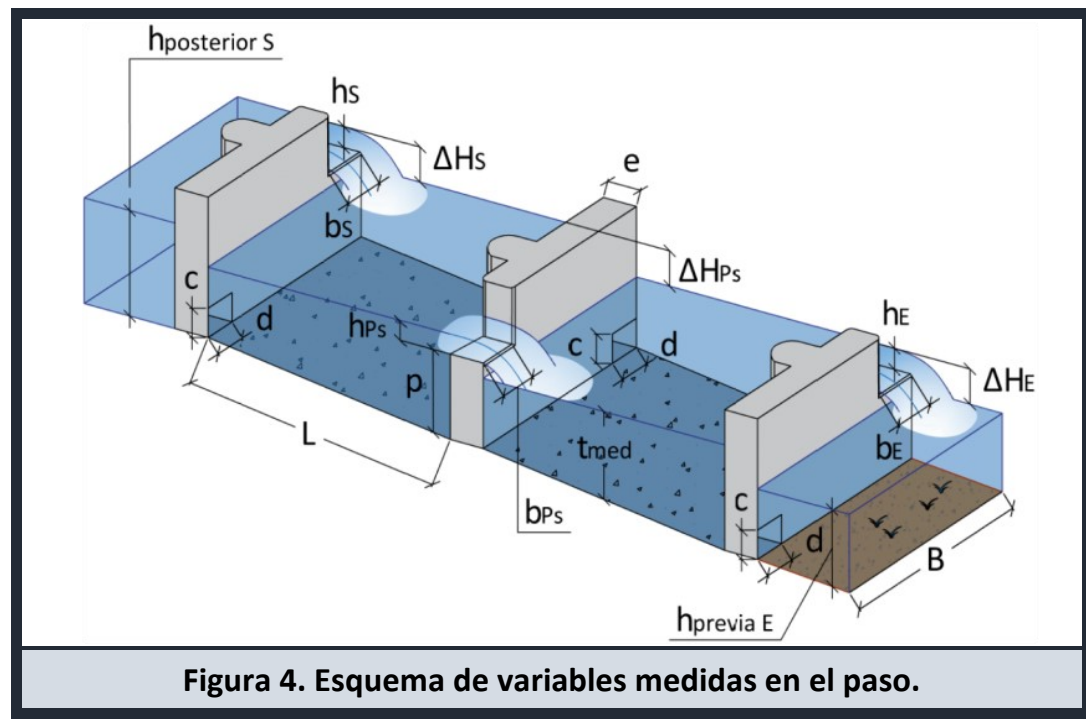

\begin{tabular}{|c|c|c|c|c|c|c|c|c|}
\hline & & & $b \rightarrow$ & & & & & \\
\hline Tipología & Vertedero & sumergido & porque la base de la escala es & calzada & 0,0 ptos & Ángulo con la corriente & $0^{\circ}$ & 10 ptos \\
\hline Desnivel entre láminas $\left(\Delta \mathrm{H}_{\mathrm{E}}\right)$ & $0,39 \mathrm{~m}$ & 5,4 ptos & Carga de vertido $\left(h_{E}\right)$ & $0,02 \mathrm{~m}$ & 0,0 ptos & Profundidad paso $\left(h_{E}-\Delta H_{E}\right)$ & - & - \\
\hline Profundidad previa ( $h_{\text {previa }}$ ) & $0,40 \mathrm{~m}$ & 7,5 ptos & Anchura del vertedero $\left(b_{E}\right)$ & $0,80 \mathrm{~m}$ & 10 ptos & Dimensiones del orificio & - & - \\
\hline
\end{tabular}

\begin{tabular}{|c|c|c|c|c|c|c|c|c|}
\hline Tipología & \multicolumn{3}{|c|}{ Vertederos no sumergidos y orificios de fondo alternos } & & 8,0 ptos & № estanques total / tipo & \multicolumn{2}{|c|}{14 / 14} \\
\hline Desnivel entre láminas $\left(\Delta H_{P S}\right)$ & $0,32 \mathrm{~m}$ & 7,5 ptos & Carga de vertido (hPs) & $0,24 \mathrm{~m}$ & 10 ptos & Profundidad paso (hPs- $\left.\Delta \mathrm{HPs}_{\mathrm{Ps}}\right)$ & - & - \\
\hline Anchura mín. vertedero (bPs) & \multicolumn{2}{|c|}{$0,14 \mathrm{~m}$} & Anchura med. vertedero ( $\left.b_{P s}\right)$ & $0,18 \mathrm{~m}$ & 0,0 ptos & Anchura máx. vertedero ( $\left.b_{P_{S}}\right)$ & \multicolumn{2}{|c|}{$0,33 \mathrm{~m}$} \\
\hline Pendiente media del lecho & \multicolumn{2}{|c|}{$28,3 \%$} & Altura umbral vertedero (p) & \multicolumn{2}{|c|}{$0,50 \mathrm{~m}$} & & \multirow{2}{*}{$\begin{array}{c}0,10 \times 0,11 \\
m\end{array}$} & \multirow{2}{*}{5,0 ptos } \\
\hline Anchura del estanque (B) & \multicolumn{2}{|c|}{$0,80 \mathrm{~m}$} & Longitud del estanque (L) & \multicolumn{2}{|c|}{$1,05 \mathrm{~m}$} & & & \\
\hline Tirante medio $\left(t_{\text {med }}\right)$ & $0,58 \mathrm{~m}$ & 9,8 ptos & Potencia disipada (N) & $505 \mathrm{~W} / \mathrm{m}^{3}$ & 0,0 ptos & Espesor de los tabiques (e) & \multicolumn{2}{|c|}{$0,16 \mathrm{~m}$} \\
\hline
\end{tabular}

\begin{tabular}{|c|c|c|c|c|c|c|c|c|}
\hline Tipología & Orificio sur & gido & & & 5,0 ptos & Ángulo con la corriente & $180^{\circ}$ & 10 ptos \\
\hline Desnivel entre láminas $\left(\Delta \mathrm{H}_{s}\right)$ & $0,05 \mathrm{~m}$ & 5,0 ptos & Carga de vertido (hs) & $0,37 \mathrm{~m}$ & - & Profundidad paso (hs- $\left.\Delta H_{s}\right)$ & $0,37 \mathrm{~m}$ & 10 ptos \\
\hline Profun. posterior ( $h_{\text {posterior } s)}$ & $>1,00 \mathrm{~m}$ & 10 ptos & Anchura del vertedero ( $b_{s}$ ) & _ & - & Dimensiones del orificio & $0,37 \times 0,40 \mathrm{~m}$ & 10 ptos \\
\hline
\end{tabular}




\section{PASO PARA PECES ASOCIADO AL AZUD DEL ARRAL}

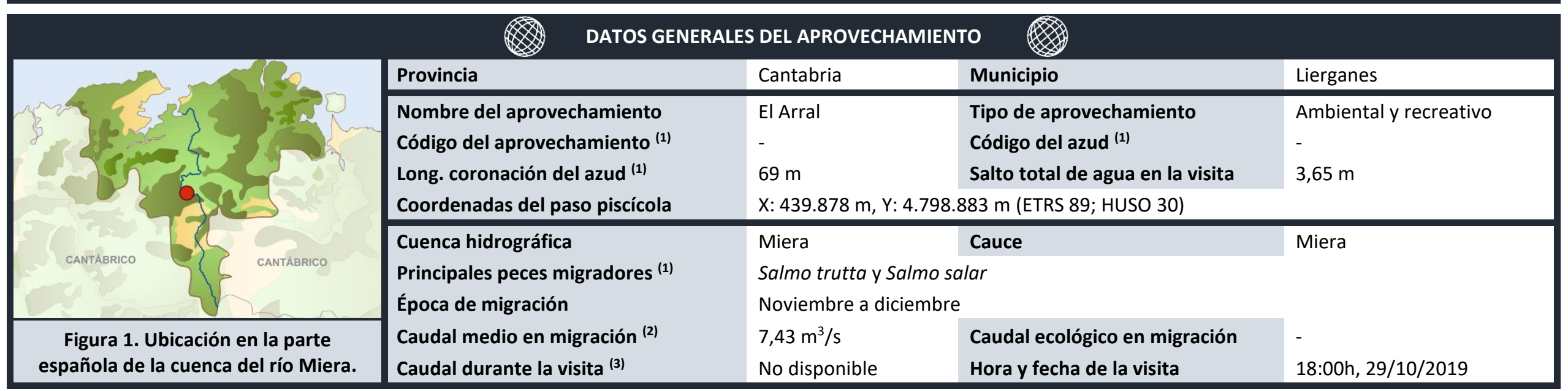

(1) Dato obtenido de MíRAME-IDE Duero. ${ }^{(2)}$ Dato obtenido del CEDEX Hidrológico. ${ }^{(3)}$ Dato obtenido del SAIH del Duero.

\begin{tabular}{|c|c|c|c|}
\hline Paso para peces de estanques su & os conectad & diduras verticales con talón y alineadas pero sin orificio & \\
\hline $\begin{array}{l}\text { Estado de mantenimiento y limpieza durante la evaluación } \\
\text { Solera naturalizada (con piedras) } \\
\text { Vertedero de umbral móvil en la entrada de peces }\end{array}$ & $\begin{array}{l}\text { Adecuado } \\
\text { Sí } \\
\text { Sí }\end{array}$ & $\begin{array}{l}\text { Compuerta en la salida de peces } \\
\text { Dispositivo para evitar la entrada de arrastres } \\
\text { Salida de peces segura (alejada del azud, turbinas, ...) }\end{array}$ & $\begin{array}{l}\text { Sí } \\
\text { Sí (No funcional) } \\
\text { Sí }\end{array}$ \\
\hline
\end{tabular}

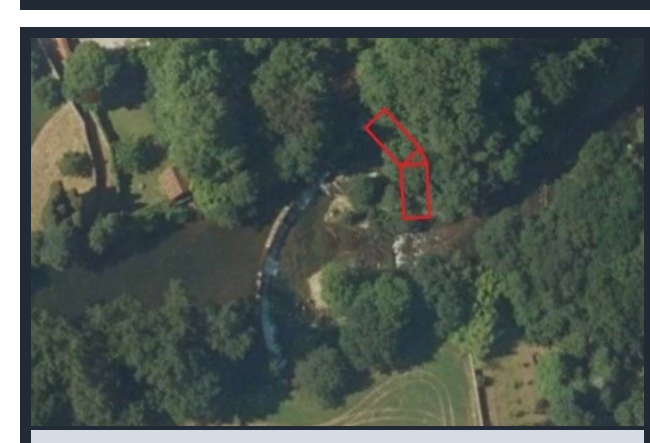

Figura 2. Ortofoto de la zona (fuente: SigPac).

\begin{tabular}{lccc}
\multicolumn{4}{c}{ RESUMEN DE LA EVALUACIÓN DEL PASO PARA PECES } \\
& \multicolumn{2}{c|}{ (CON LA METODOLOGÍA AEPS) } & \\
\hline Etapa o categoría & Puntuación & Evaluación & ¿Mejoras? \\
Atracción & 5,2 & Desfavorable & Muy necesarias \\
Entrada & 9,8 & Muy favorable & Opcionales \\
Pasaje & 9,2 & Muy favorable & Opcionales \\
Salida & 8,5 & Muy favorable & Opcionales
\end{tabular}

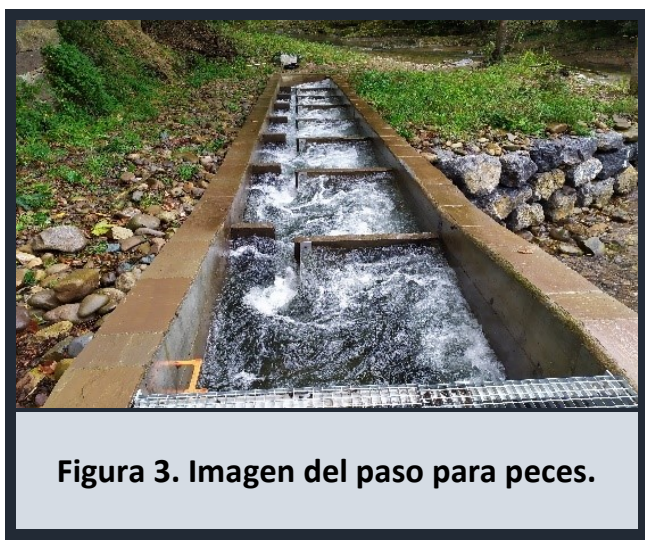




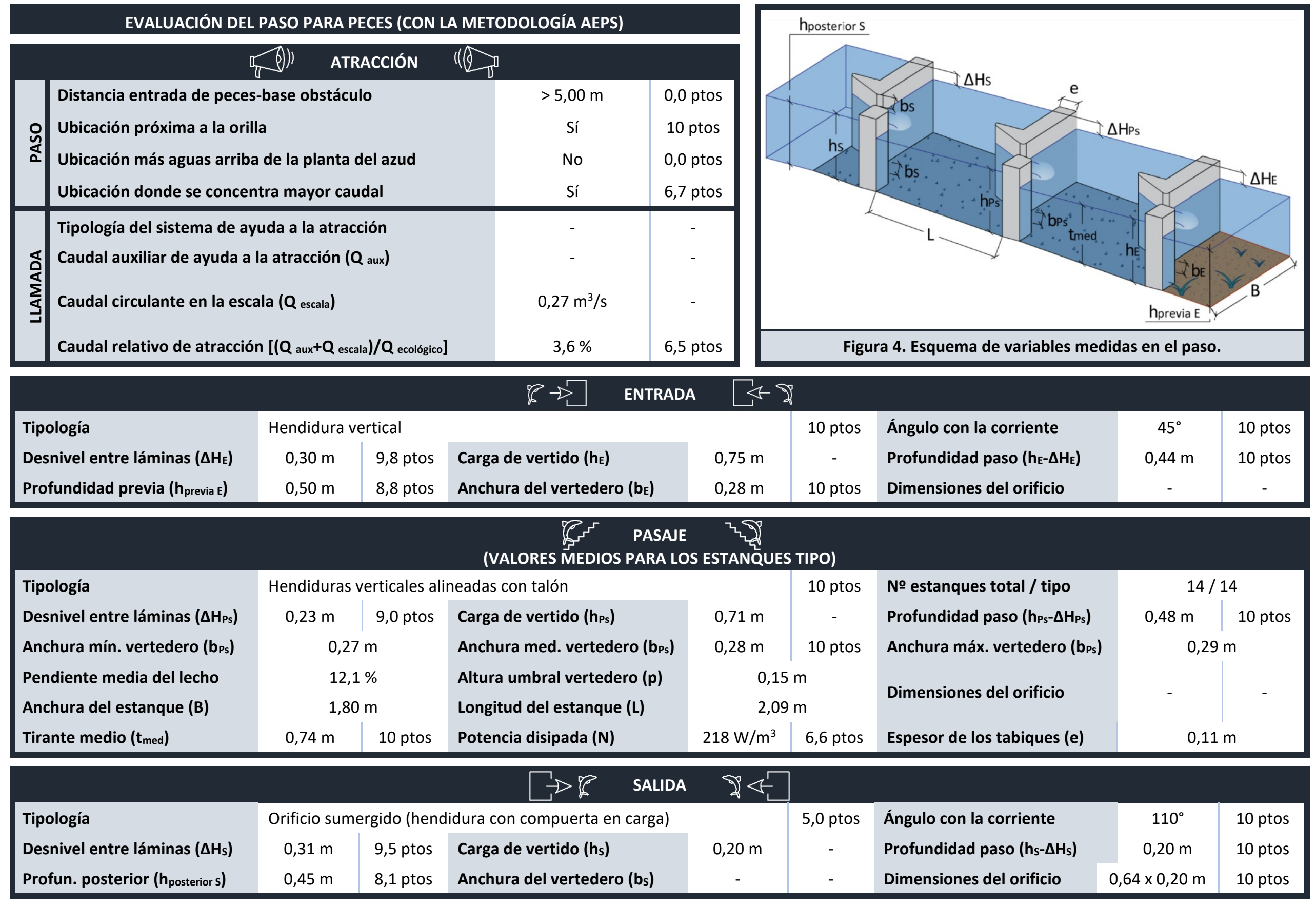




\section{PASO PARA PECES ASOCIADO AL AZUD DE REVOLVO}

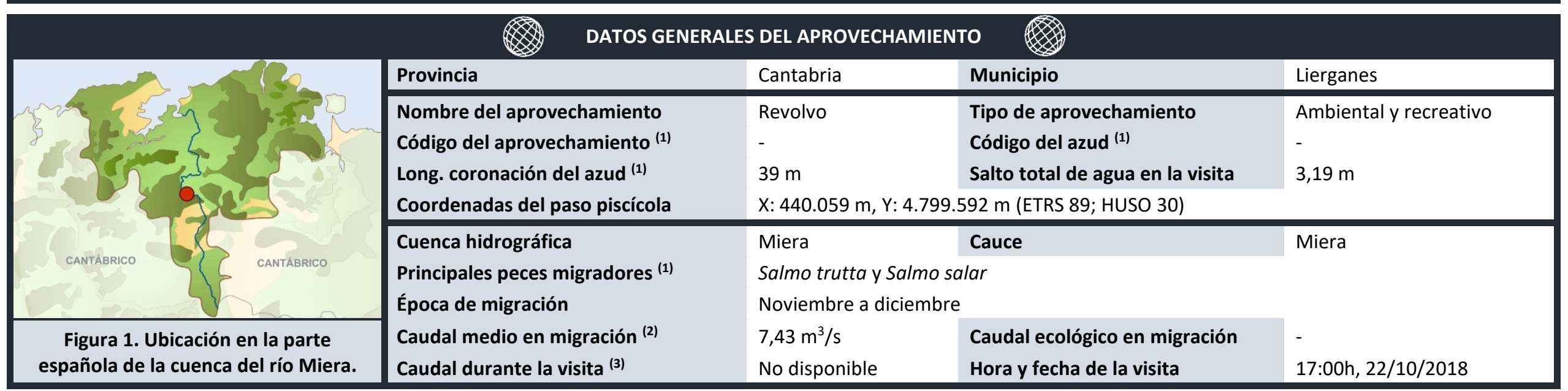

(1) Dato obtenido de MíRAME-IDE Duero. ${ }^{(2)}$ Dato obtenido del CEDEX Hidrológico. ${ }^{(3)}$ Dato obtenido del SAIH del Duero.

\begin{tabular}{|c|c|c|c|}
\hline Paso para peces de estanques & os conectad & diduras verticales alineadas y sin orificios & \\
\hline $\begin{array}{l}\text { Estado de mantenimiento y limpieza durante la evaluación } \\
\text { Solera naturalizada (con piedras) } \\
\text { Vertedero de umbral móvil en la entrada de peces }\end{array}$ & $\begin{array}{l}\text { Adecuado } \\
\text { No } \\
\text { No }\end{array}$ & $\begin{array}{l}\text { Compuerta en la salida de peces } \\
\text { Dispositivo para evitar la entrada de arrastres } \\
\text { Salida de peces segura (alejada del azud, turbinas, ...) }\end{array}$ & $\begin{array}{l}\text { Sí } \\
\text { No } \\
\text { Sí }\end{array}$ \\
\hline
\end{tabular}

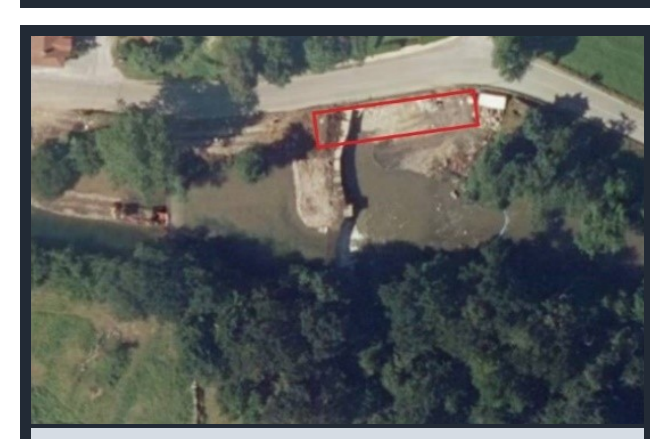

Figura 2. Ortofoto de la zona (fuente: SigPac).

\begin{tabular}{lccc}
\multicolumn{4}{c}{ RESUMEN DE LA EVALUACIÓN DEL PASO PARA PECES } \\
& \multicolumn{4}{c|}{ (CON LA METODOLOGÍA AEPS) } & \\
\hline Etapa o categoría & Puntuación & Evaluación & ¿Mejoras? \\
Atracción & 9,1 & Muy favorable & Opcionales \\
Entrada & 0,0 & Muy desfavorable & Imprescindibles \\
Pasaje & 9,5 & Muy favorable & Opcionales \\
Salida & 5,4 & Desfavorable & Recomendables \\
\hline
\end{tabular}

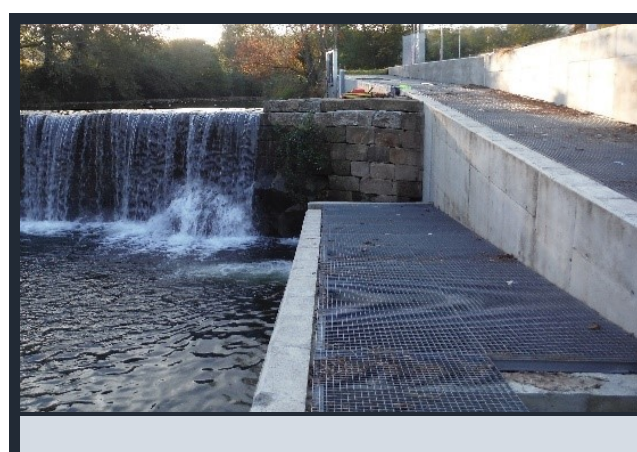

Figura 3. Imagen del paso para peces. 


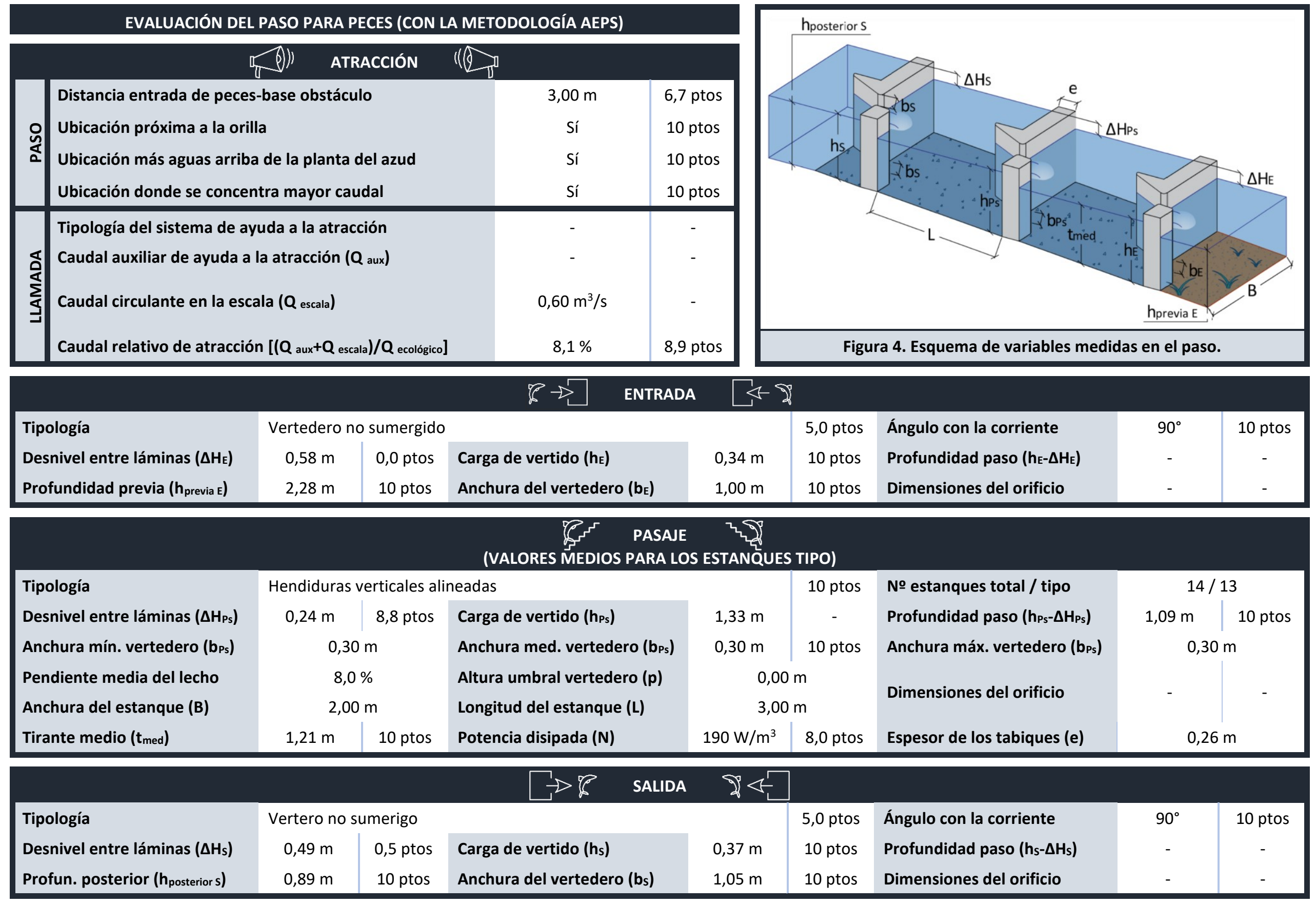




\section{PASO PARA PECES ASOCIADO AL AZUD DE LA CENTRAL HIDROELÉCTRICA DE CAÑAVEROSA}

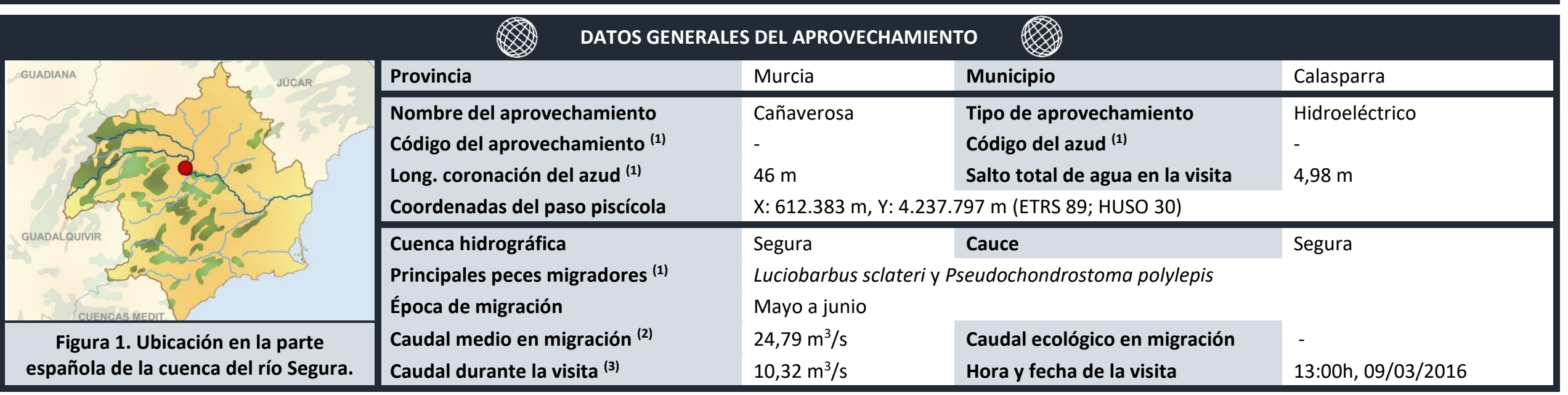

(1) Dato obtenido de MíRAME-IDE Duero. ${ }^{(2)}$ Dato obtenido del CEDEX Hidrológico. ${ }^{(3)}$ Dato obtenido del SAIH del Duero.

\begin{tabular}{|c|c|c|c|}
\hline \multicolumn{4}{|c|}{ OBSERVACIONES GENERALES DE LA ESCALA } \\
\hline $\begin{array}{l}\text { Estado de mantenimiento y limpieza durante la evaluación } \\
\text { Solera naturalizada (con piedras) } \\
\text { Vertedero de umbral móvil en la entrada de peces }\end{array}$ & $\begin{array}{l}\text { Muy adecuado } \\
\text { No } \\
\text { Sí }\end{array}$ & $\begin{array}{l}\text { Compuerta en la salida de peces } \\
\text { Dispositivo para evitar la entrada de arrastres } \\
\text { Salida de peces segura (alejada del azud, turbinas, ...) }\end{array}$ & $\begin{array}{l}\text { Sí } \\
\text { Sí } \\
\text { Sí }\end{array}$ \\
\hline
\end{tabular}

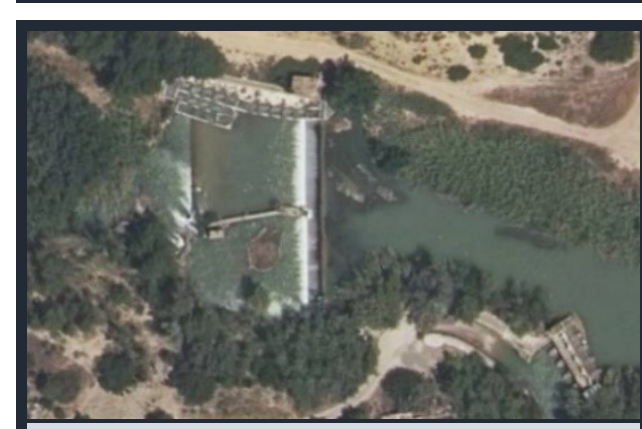

Figura 2. Ortofoto de la zona (fuente: SigPac).

\begin{tabular}{lccc}
\multicolumn{5}{c}{ RESUMEN DE LA EVALUACIÓN DEL PASO PARA PECES } \\
& \multicolumn{4}{c|}{ (CON LA METODOLOGÍA AEPS) } \\
\hline Etapa o categoría & Puntuación & Evaluación & ¿Mejoras? \\
Atracción & 8,7 & Muy favorable & Opcionales \\
Entrada & 9,7 & Muy favorable & Opcionales \\
Pasaje & 8,1 & Muy favorable & Opcionales \\
Salida & 0,0 & Muy desfavorable & Imprescindibles \\
\hline
\end{tabular}

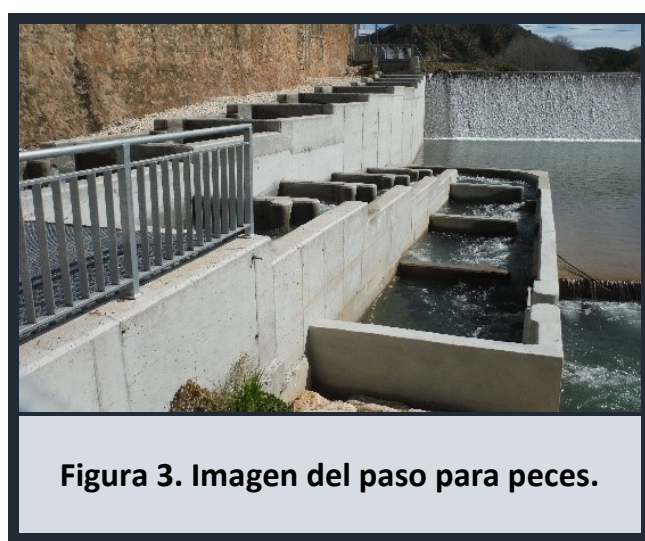




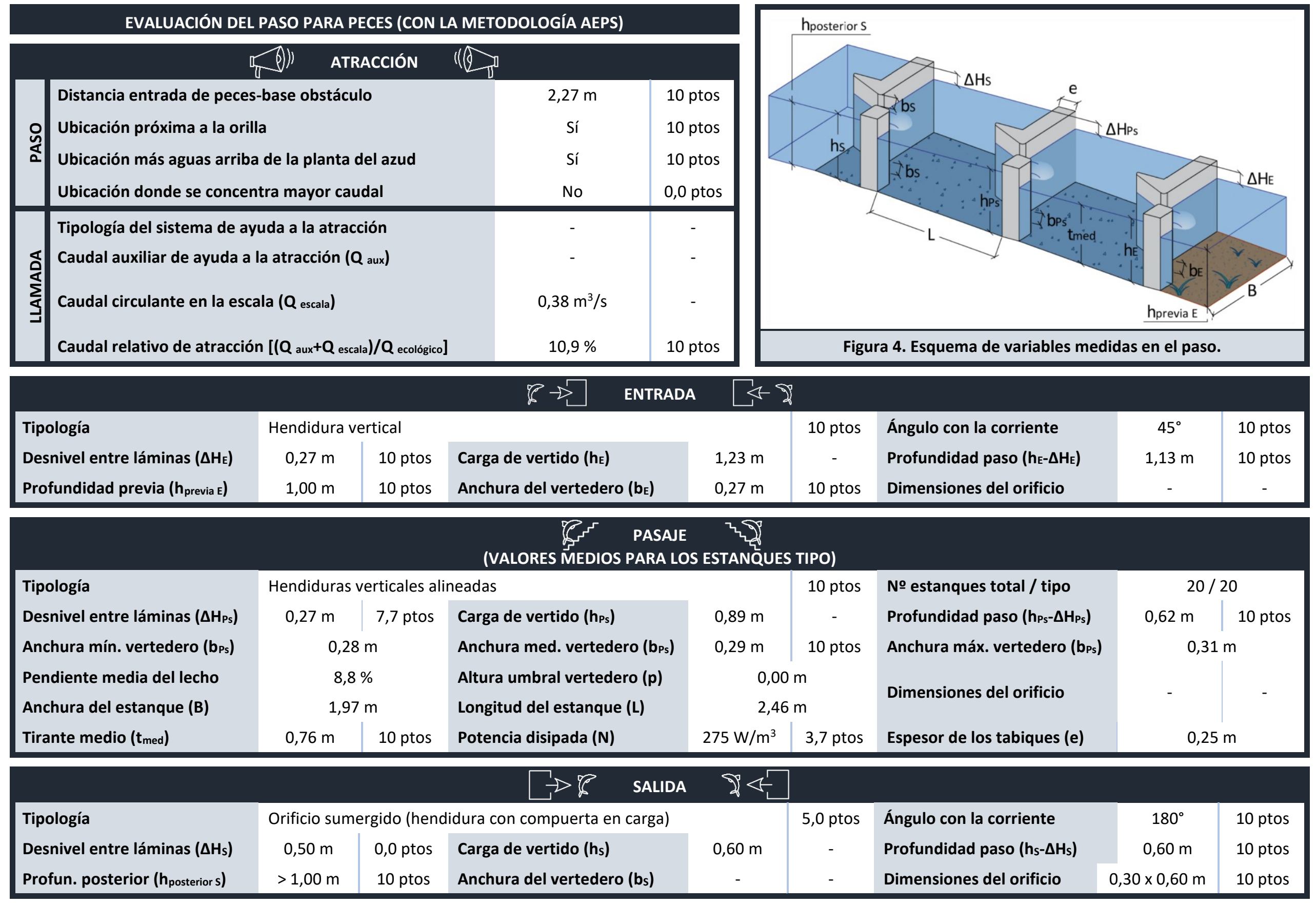




\section{PASO PARA PECES ASOCIADO AL AZUD DEL ESPARRAGAL}

\begin{tabular}{|c|c|c|c|c|}
\hline \multirow{3}{*}{ GUADIANA } & Provincia & Murcia & Municipio & Calasparra \\
\hline & $\begin{array}{l}\text { Nombre del aprovechamiento } \\
\text { Código del aprovechamiento }{ }^{(1)} \\
\text { Long. coronación del azud }{ }^{(1)} \\
\text { Coordenadas del paso piscícola }\end{array}$ & $\begin{array}{l}\text { El Esparragal } \\
- \\
130 \mathrm{~m} \\
X: 617.371 \mathrm{~m} \text {, }\end{array}$ & $\begin{array}{l}\text { Tipo de aprovechamiento } \\
\text { Código del azud (1) } \\
\text { Salto total de agua en la visita } \\
309 \text { m (ETRS 89; HUSO 30) }\end{array}$ & $\begin{array}{l}\text { Riego e hidroeléctrico } \\
- \\
2,61 \mathrm{~m}\end{array}$ \\
\hline & $\begin{array}{l}\text { Cuenca hidrográfica } \\
\text { Principales peces migradores } \\
\text { Época de migración }\end{array}$ & $\begin{array}{l}\text { Segura } \\
\text { Luciobarbus s } \\
\text { Mayo a junio }\end{array}$ & $\begin{array}{l}\text { Cauce } \\
\text { seudochondrostoma polylepis }\end{array}$ & Segura \\
\hline $\begin{array}{l}\text { Figura 1. Ubicación en la parte } \\
\text { española de la cuenca del río Segura. }\end{array}$ & $\begin{array}{l}\text { Caudal medio en migración } \\
\text { Caudal durante la visita } \\
{ }^{(3)}\end{array}$ & $\begin{array}{l}22,15 \mathrm{~m}^{3} / \mathrm{s} \\
\text { No disponible }\end{array}$ & $\begin{array}{l}\text { Caudal ecológico en migración } \\
\text { Hora y fecha de la visita }\end{array}$ & $\begin{array}{l}2,00 \mathrm{~m}^{3} / \mathrm{s} \\
18: 00 \mathrm{~h}, 17 / 03 / 2016\end{array}$ \\
\hline
\end{tabular}

(1) Dato obtenido de MíRAME-IDE Duero. ${ }^{(2)}$ Dato obtenido del CEDEX Hidrológico. ${ }^{(3)}$ Dato obtenido del SAIH del Duero.

\begin{tabular}{|c|c|c|c|}
\hline Paso para peces de estanques su & os conectados po & tederos ligeramente sumergidos y orificios de fondo alt & \\
\hline $\begin{array}{l}\text { Estado de mantenimiento y limpieza durante la evaluación } \\
\text { Solera naturalizada (con piedras) } \\
\text { Vertedero de umbral móvil en la entrada de peces }\end{array}$ & $\begin{array}{l}\text { Muy adecuado } \\
\text { Si } \\
\text { Sí }\end{array}$ & $\begin{array}{l}\text { Compuerta en la salida de peces } \\
\text { Dispositivo para evitar la entrada de arrastres } \\
\text { Salida de peces segura (alejada del azud, turbinas, ...) }\end{array}$ & $\begin{array}{l}\text { Sí } \\
\text { No } \\
\text { Sí }\end{array}$ \\
\hline
\end{tabular}

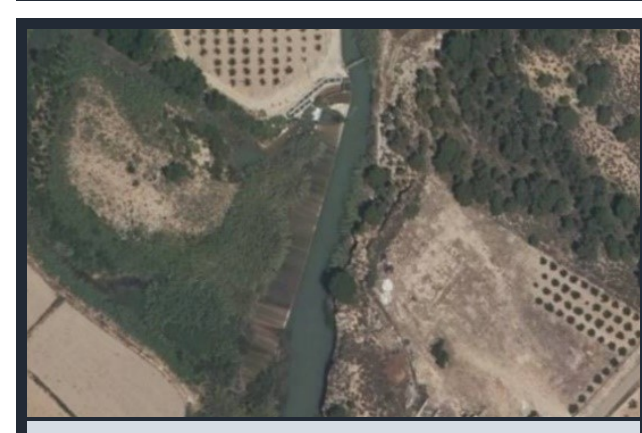

Figura 2. Ortofoto de la zona (fuente: SigPac).

\begin{tabular}{lccc}
\multicolumn{4}{c}{ RESUMEN DE LA EVALUACIÓN DEL PASO PARA PECES } \\
& \multicolumn{4}{c|}{ (CON LA METODOLOGÍA AEPS) } \\
\hline Etapa o categoría & Puntuación & Evaluación & ¿Mejoras? \\
Atracción & 9,6 & Muy favorable & Opcionales \\
Entrada & 7,1 & Favorable & Recomendables \\
Pasaje & 9,5 & Muy favorable & Opcionales \\
Salida & 8,9 & Muy favorable & Opcionales \\
\hline
\end{tabular}

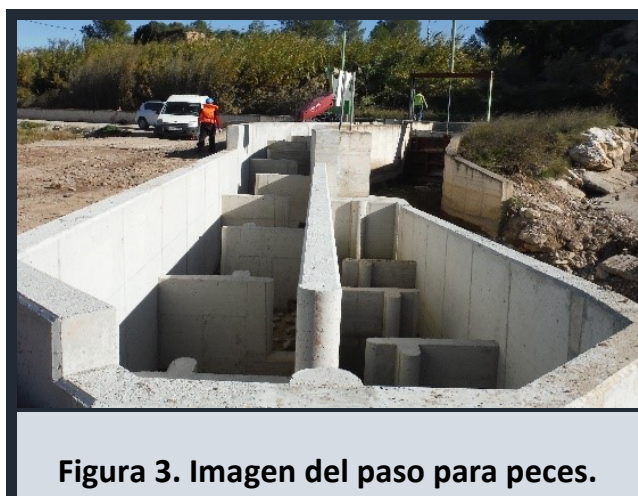




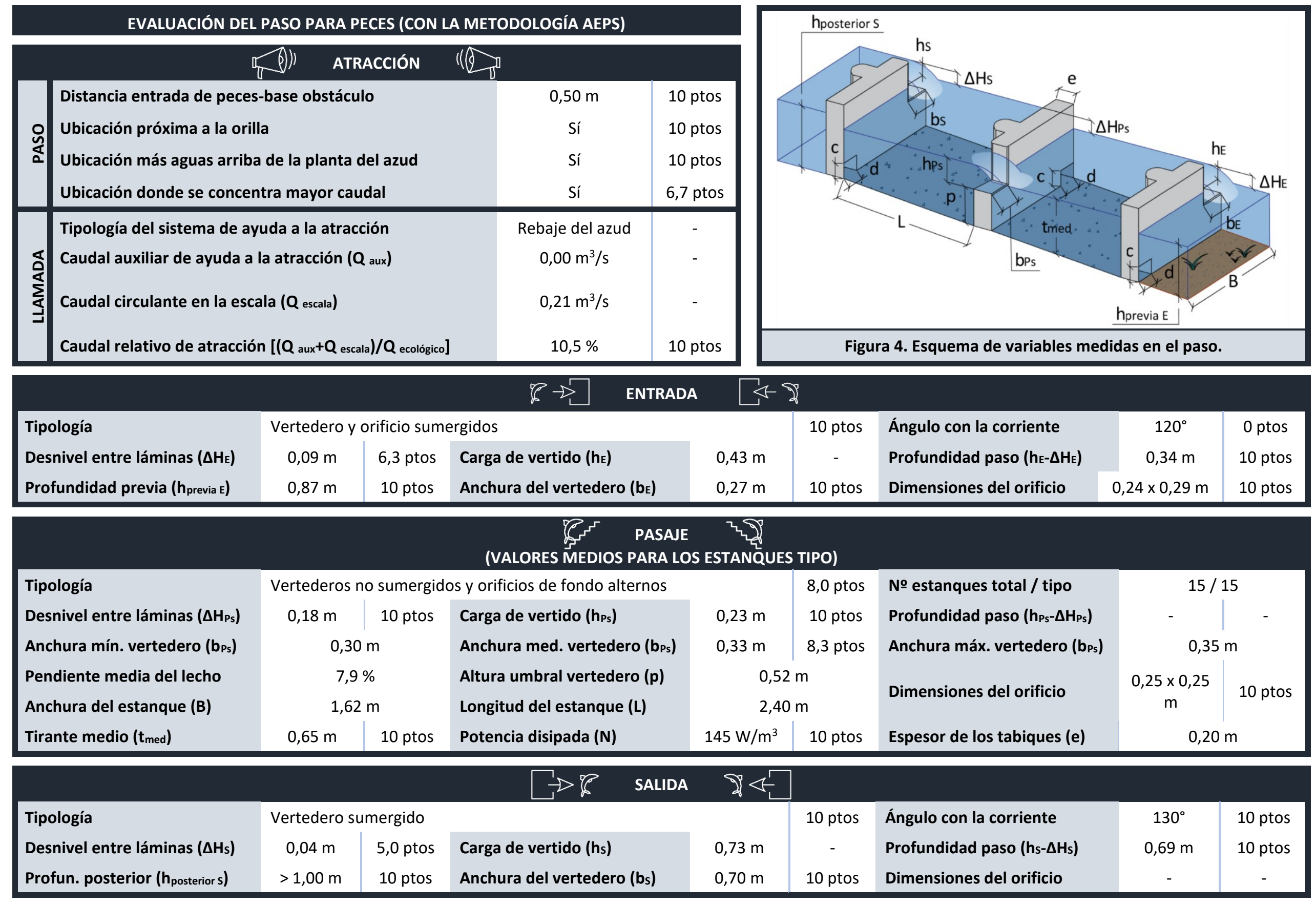




\section{PASO PARA PECES ASOCIADO AL AZUD DE LA ELEVACIÓN ZONA 1 POST-TRASVASE}

\begin{tabular}{|c|c|c|c|c|}
\hline \multirow{3}{*}{ GUADIANA } & Provincia & Murcia & Municipio & Calasparra \\
\hline & $\begin{array}{l}\text { Nombre del aprovechamiento } \\
\text { Código del aprovechamiento }{ }^{(1)} \\
\text { Long. coronación del azud }{ }^{(1)} \\
\text { Coordenadas del paso piscícola }\end{array}$ & $\begin{array}{l}\text { Post-trasvase } \\
- \\
74 \mathrm{~m} \\
\mathrm{X}: 613.788 \mathrm{~m} \text {, }\end{array}$ & $\begin{array}{l}\text { Tipo de aprovechamiento } \\
\text { Código del azud (1) } \\
\text { Salto total de agua en la visita } \\
561 \text { m (ETRS 89; HUSO 30) }\end{array}$ & $\begin{array}{l}\text { Riego e hidroeléctrico } \\
- \\
1,78 \mathrm{~m}\end{array}$ \\
\hline & $\begin{array}{l}\text { Cuenca hidrográfica } \\
\text { Principales peces migradores } \\
\text { Época de migración }\end{array}$ & $\begin{array}{l}\text { Segura } \\
\text { Luciobarbus sc } \\
\text { Mayo a junio }\end{array}$ & $\begin{array}{l}\text { Cauce } \\
\text { seudochondrostoma polylepis }\end{array}$ & Segura \\
\hline $\begin{array}{l}\text { Figura 1. Ubicación en la parte } \\
\text { española de la cuenca del río Segura. }\end{array}$ & $\begin{array}{l}\text { Caudal medio en migración } \\
\text { Caudal durante la visita } \\
{ }^{(3)}\end{array}$ & $\begin{array}{l}23,52 \mathrm{~m}^{3} / \mathrm{s} \\
\text { No disponible }\end{array}$ & $\begin{array}{l}\text { Caudal ecológico en migración } \\
\text { Hora y fecha de la visita }\end{array}$ & $\begin{array}{l}2,76 \mathrm{~m}^{3} / \mathrm{s} \\
17: 00 \mathrm{~h}, 17 / 03 / 2016\end{array}$ \\
\hline
\end{tabular}

(1) Dato obtenido de MíRAME-IDE Duero. ${ }^{(2)}$ Dato obtenido del CEDEX Hidrológico. ${ }^{(3)}$ Dato obtenido del SAIH del Duero.

\begin{tabular}{|c|c|c|c|}
\hline Paso para peces de estanques st & os conectados po & tederos sumergidos y orificios de fondo alternos & \\
\hline $\begin{array}{l}\text { Estado de mantenimiento y limpieza durante la evaluación } \\
\text { Solera naturalizada (con piedras) } \\
\text { Vertedero de umbral móvil en la entrada de peces }\end{array}$ & $\begin{array}{l}\text { Muy adecuado } \\
\text { Sí } \\
\text { Sí }\end{array}$ & $\begin{array}{l}\text { Compuerta en la salida de peces } \\
\text { Dispositivo para evitar la entrada de arrastres } \\
\text { Salida de peces segura (alejada del azud, turbinas, ...) }\end{array}$ & $\begin{array}{l}\text { Sí } \\
\text { Sí } \\
\text { Sí }\end{array}$ \\
\hline
\end{tabular}

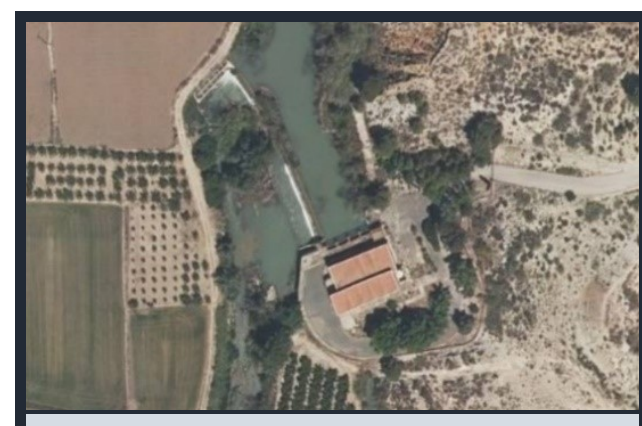

Figura 2. Ortofoto de la zona (fuente: SigPac).

\begin{tabular}{lccl}
\multicolumn{4}{c}{ RESUMEN DE LA EVALUACIÓN DEL PASO PARA PECES } \\
(CON LA METODOLOGÍA AEPS) & \\
\hline $\begin{array}{l}\text { Etapa o categoría } \\
\text { Atracción }\end{array}$ & $\begin{array}{l}\text { Puntuación } \\
\text { Entrada }\end{array}$ & Evaluación & ¿Mejoras? \\
Pasaje & 10,0 & Muy favorable & Opcionales \\
Salida & 8,9 & Muy favorable & Opcionales \\
\end{tabular}

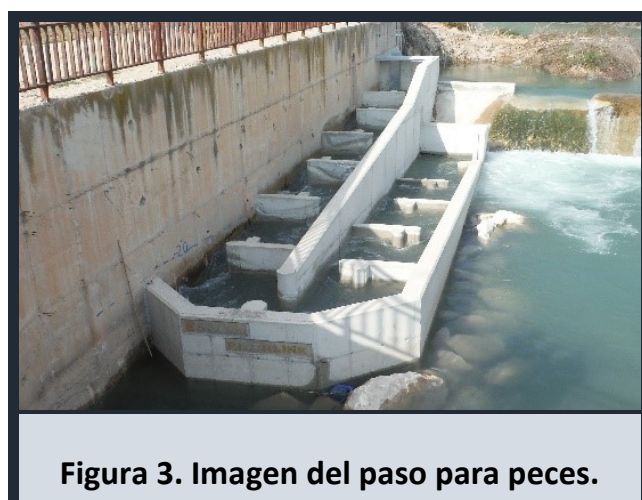




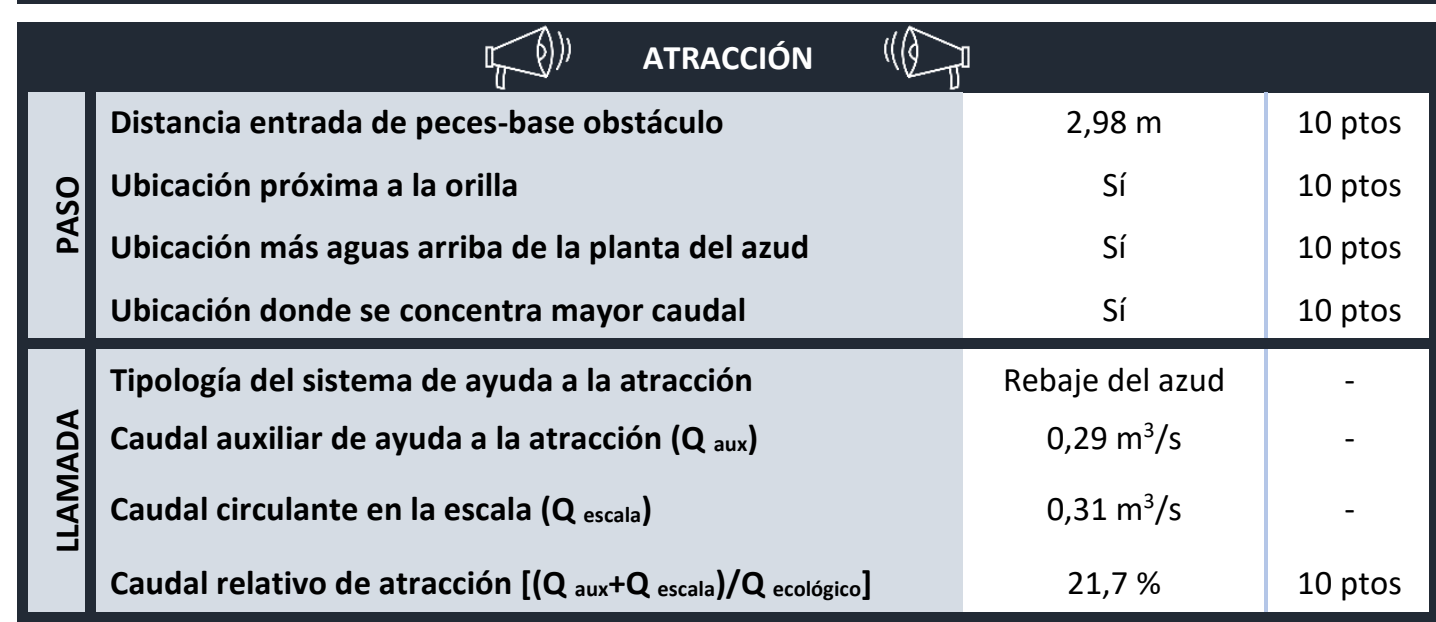

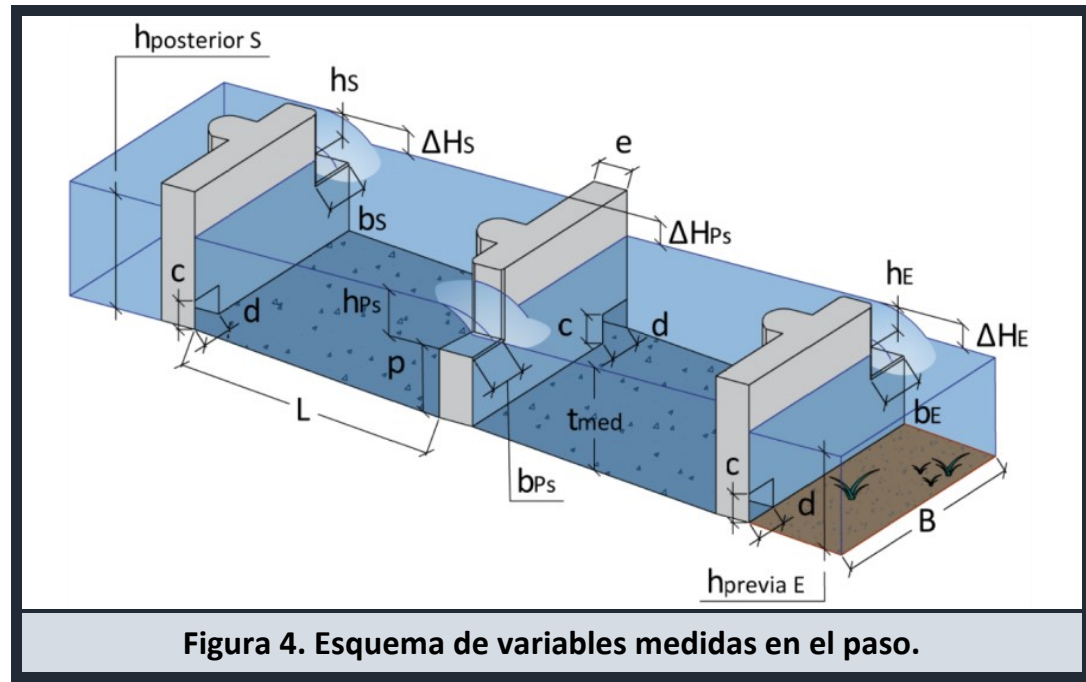

\begin{tabular}{|c|c|c|c|c|c|c|c|c|}
\hline & & & $6 \rightarrow$ & \multicolumn{2}{|c|}{ 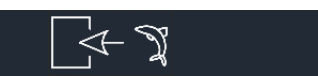 } & & & \\
\hline Tipología & \multicolumn{3}{|c|}{ Vertedero y orificio sumergidos } & & 10 ptos & Ángulo con la corriente & $45^{\circ}$ & 10 ptos \\
\hline Desnivel entre láminas $\left(\Delta \mathrm{H}_{\mathrm{E}}\right)$ & $0,05 \mathrm{~m}$ & 5,0 ptos & Carga de vertido $\left(h_{E}\right)$ & $0,89 \mathrm{~m}$ & - & Profundidad paso $\left(h_{E}-\Delta H_{E}\right)$ & $0,84 \mathrm{~m}$ & 10 ptos \\
\hline Profundidad previa (hrevia E) & $1,00 \mathrm{~m}$ & 10 ptos & Anchura del vertedero $\left(b_{E}\right)$ & $0,30 \mathrm{~m}$ & 10 ptos & Dimensiones del orificio & $0,25 \times 0,25 \mathrm{~m}$ & 10 ptos \\
\hline
\end{tabular}

\begin{tabular}{|c|c|c|c|c|c|c|c|c|}
\hline Tipología & \multicolumn{3}{|c|}{ Vertederos sumergidos y orificios de fondo alternos } & & 10 ptos & № estanques total / tipo & \multicolumn{2}{|c|}{$11 / 11$} \\
\hline Desnivel entre láminas $\left(\Delta H_{P_{S}}\right)$ & $0,19 \mathrm{~m}$ & 10 ptos & Carga de vertido (hPs) & $0,60 \mathrm{~m}$ & - & Profundidad paso ( $\left.h_{\mathrm{Ps}}-\Delta \mathrm{H}_{\mathrm{Ps}}\right)$ & $0,41 \mathrm{~m}$ & 10 ptos \\
\hline Anchura mín. vertedero ( $\left.\mathrm{b}_{\mathrm{Ps}}\right)$ & \multicolumn{2}{|c|}{$0,30 \mathrm{~m}$} & Anchura med. vertedero ( $\left.b_{\mathrm{Ps}_{\mathrm{s}}}\right)$ & $0,32 \mathrm{~m}$ & 10 ptos & Anchura máx. vertedero ( $\left.b_{P_{s}}\right)$ & \multicolumn{2}{|c|}{$0,33 \mathrm{~m}$} \\
\hline Pendiente media del lecho & \multicolumn{2}{|c|}{$7,6 \%$} & Altura umbral vertedero ( $p)$ & \multicolumn{2}{|c|}{$0,49 \mathrm{~m}$} & Dimensiones del orificio & $0,20 \times 0,25$ & 10 ntos \\
\hline Anchura del estanque (B) & \multicolumn{2}{|c|}{$1,60 \mathrm{~m}$} & Longitud del estanque (L) & \multicolumn{2}{|c|}{$2,40 \mathrm{~m}$} & & $m$ & \\
\hline Tirante medio ( $\left.t_{\text {med }}\right)$ & $0,99 \mathrm{~m}$ & 10 ptos & Potencia disipada (N) & $154 \mathrm{~W} / \mathrm{m}^{3}$ & 9,8 ptos & Espesor de los tabiques (e) & \multicolumn{2}{|c|}{$0,20 \mathrm{~m}$} \\
\hline
\end{tabular}

\begin{tabular}{|c|c|c|c|c|c|c|c|c|}
\hline Tipología & \multicolumn{3}{|c|}{ Orificio sumergido (hendidura con compuerta en carga) } & \multirow{3}{*}{$\begin{array}{c}1,09 \mathrm{~m} \\
-\end{array}$} & \multirow{3}{*}{$\begin{array}{c}5,0 \text { ptos } \\
- \\
-\end{array}$} & \multirow{3}{*}{$\begin{array}{l}\text { Ángulo con la corriente } \\
\left.\text { Profundidad paso ( } h_{s}-\Delta H_{s}\right) \\
\text { Dimensiones del orificio }\end{array}$} & \multirow{3}{*}{$\begin{array}{c}140^{\circ} \\
0,90 \mathrm{~m} \\
0,25 \times 0,75 \mathrm{~m}\end{array}$} & \multirow{3}{*}{$\begin{array}{l}10 \text { ptos } \\
10 \text { ptos } \\
10 \text { ptos }\end{array}$} \\
\hline Desnivel entre láminas $\left(\Delta H_{s}\right)$ & $0,19 \mathrm{~m}$ & 10 ptos & Carga de vertido (hs) & & & & & \\
\hline Profun. posterior ( $\mathrm{h}_{\text {posterior } \mathrm{s} \text { ) }}$ & $>1,00 \mathrm{~m}$ & 10 ptos & Anchura del vertedero (bs) & & & & & \\
\hline
\end{tabular}




\section{PASO PARA PECES ASOCIADO AL AZUD DE SOTO DAMIÁN O EL JARRAL}

\begin{tabular}{|c|c|c|c|c|}
\hline \multirow[t]{3}{*}{ GUADIAN } & Provincia & Murcia & Municipio & Abarán \\
\hline & $\begin{array}{l}\text { Nombre del aprovechamiento } \\
\text { Código del aprovechamiento }{ }^{(1)} \\
\text { Long. coronación del azud }{ }^{(1)} \\
\text { Coordenadas del paso piscícola }\end{array}$ & $\begin{array}{l}\text { El Jarral } \\
- \\
105 \mathrm{~m} \\
X: 640.577 \mathrm{~m} \text {, }\end{array}$ & $\begin{array}{l}\text { Tipo de aprovechamiento } \\
\text { Código del azud (1) } \\
\text { Salto total de agua en la visita } \\
308 \text { m (ETRS 89; HUSO 30) }\end{array}$ & $\begin{array}{l}\text { Riego e hidroeléctrico } \\
- \\
2,77 \mathrm{~m}\end{array}$ \\
\hline & $\begin{array}{l}\text { Cuenca hidrográfica } \\
\text { Principales peces migradores } \\
\text { Época de migración }\end{array}$ & \multicolumn{2}{|c|}{$\begin{array}{l}\text { Luciobarbus sclateri y Pseudochondrostoma polylepis } \\
\text { Mayo a junio }\end{array}$} & Segura \\
\hline $\begin{array}{l}\text { Figura 1. Ubicación en la parte } \\
\text { española de la cuenca del río Segura. }\end{array}$ & $\begin{array}{l}\text { Caudal medio en migración } \\
\text { Caudal durante la visita } \\
{ }^{(3)}\end{array}$ & $\begin{array}{l}23,52 \mathrm{~m}^{3} / \mathrm{s} \\
\text { No disponible }\end{array}$ & $\begin{array}{l}\text { Caudal ecológico en migración } \\
\text { Hora y fecha de la visita }\end{array}$ & $\begin{array}{l}2,90 \mathrm{~m}^{3} / \mathrm{s} \\
10: 00 \mathrm{~h}, 17 / 03 / 2016\end{array}$ \\
\hline
\end{tabular}

(1) Dato obtenido de MíRAME-IDE Duero. ${ }^{(2)}$ Dato obtenido del CEDEX Hidrológico. ${ }^{(3)}$ Dato obtenido del SAIH del Duero.

\begin{tabular}{|c|c|c|c|}
\hline Paso para peces de estanques st & os conectados po & diduras verticales alineadas y sin orificios & \\
\hline $\begin{array}{l}\text { Estado de mantenimiento y limpieza durante la evaluación } \\
\text { Solera naturalizada (con piedras) } \\
\text { Vertedero de umbral móvil en la entrada de peces }\end{array}$ & $\begin{array}{l}\text { Muy adecuado } \\
\text { Sí } \\
\text { No }\end{array}$ & $\begin{array}{l}\text { Compuerta en la salida de peces } \\
\text { Dispositivo para evitar la entrada de arrastres } \\
\text { Salida de peces segura (alejada del azud, turbinas, ...) }\end{array}$ & $\begin{array}{l}\text { Sí } \\
\text { Sí } \\
\text { Sí }\end{array}$ \\
\hline
\end{tabular}

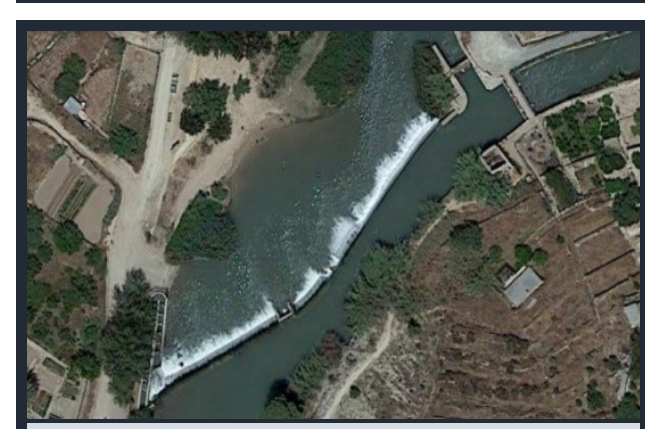

Figura 2. Ortofoto de la zona (fuente: Google Maps).

\begin{tabular}{lccl}
\multicolumn{5}{c}{ RESUMEN DE LA EVALUACIÓN DEL PASO PARA PECES } \\
(CON LA METODOLOGÍA AEPS) \\
Etapa o categoría & Puntuación & Evaluación & ¿Mejoras? \\
Atracción & 8,7 & Muy favorable & Opcionales \\
Entrada & 8,9 & Muy favorable & Opcionales \\
Pasaje & 10,0 & Muy favorable & Opcionales \\
Salida & 8,8 & Muy favorable & Opcionales \\
\hline
\end{tabular}

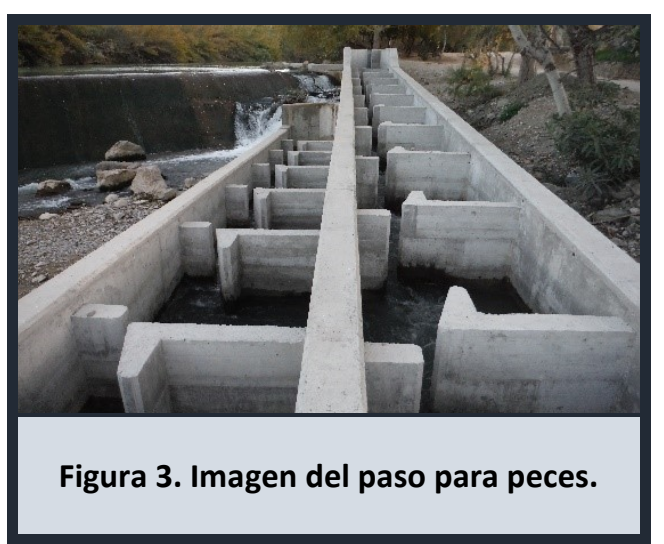




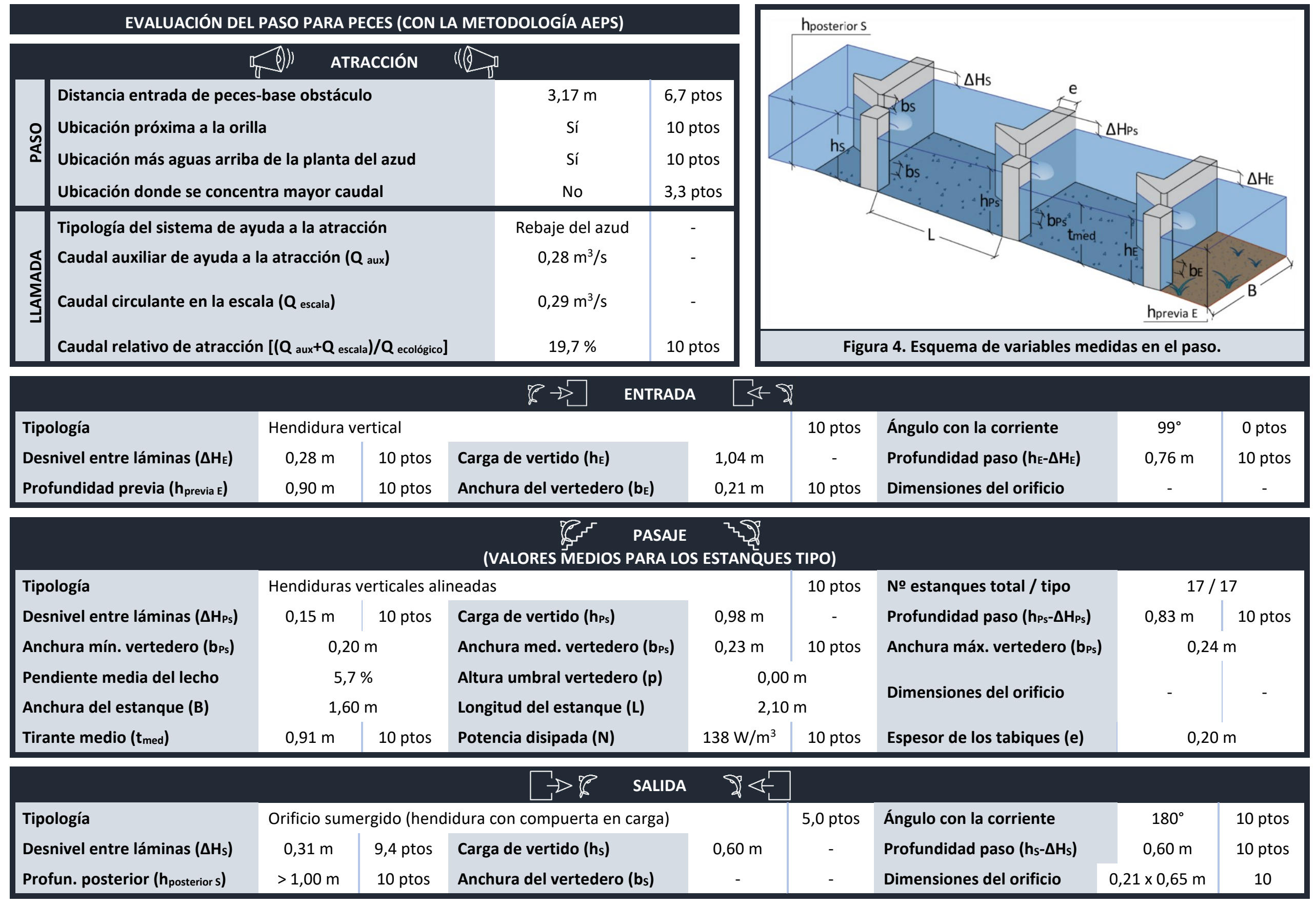




\section{A.5. ANÁLISIS DE DATOS: COMANDOS PARA APLICAR EN R}




\section{A.5. ANÁLISIS DE DATOS: COMANDOS PARA APLICAR EN R}

En este apartado, se detallan los comandos utilizados en el programa informático $R$ ( $R$ Core Team 2020), versión 3.5.2, con el objetivo de orientar y facilitar el tratamiento de datos según lo indicado en el apartado "3.5. Análisis de datos".

\section{A.5.1. MODELO MIXTO:}

Se plantea el desarrollo del modelo mixto más adecuado para predecir la puntuación de una variable a evaluar, determinando cuáles son los factores que influyen en él de manera significativa.

Primero, instalamos y cargamos los paquetes que se necesitan:

install.packages("Ime4")

library(Ime4)

install.packages("nlme")

library(nlme)

Seguidamente cargamos y comprobamos los datos a utilizar:

datos_mixedmodel $<-$ read.table(file = "D:/.../Modelo_mixto.csv", header $=$ TRUE, sep = ";")

head(datos_mixedmodel)

Los modelos mixtos permiten explicar la relación entre una variable respuesta a partir de otras explicativas, conocidas como efectos fijos, y de observaciones correlacionadas o con variabilidad heterogénea, denominadas efectos aleatorios. La expresión general de este tipo de modelos es:

$$
y=X \cdot \mu+Z \cdot u+\epsilon
$$

donde $y$ es el vector de medidas repetidas de un individuo i, $X$ es la matriz de diseño para los efectos fijos, $\mu$ es un vector de efectos fijos, $Z$ es la matriz de diseño para los efectos aleatorios, $u$ es un vector de efectos aleatorios, y $\epsilon$ es el vector de errores aleatorios. 
Donde $u$ y $\epsilon$ se distribuyen normalmente con una media de 0 y una determinada desviación típica.

Empezamos a construir el modelo lineal mixto. Para ello, tenemos que definir las variables que vamos a considerar como respuesta $(y)$, los factores fijos $(X \cdot \mu)$ y aleatorios $(Z \cdot u)$.

En nuestro caso, fijamos la variable "Puntuación de las variables" como la variable respuesta $(y)$ a predecir por el modelo. Los factores fijos $(X \cdot \mu)$ son aquellos que consideran todos sus niveles y tienen una influencia sistemática y predecible sobre los datos. Se consideran como tal la "Etapa" y el "Tipo de escala". El factor aleatorio $(z \cdot u)$ tiene una influencia no sistemática, impredecible o aleatoria sobre los datos. Se considera como factor aleatorio la propia "Variable" evaluada. Así, se plantea un modelo mixto de base:

modelo_mixto1 = Imer(Punt_Variable Tipo+Etapa+(1|Variable),

data=datos_mixedmodel)

A partir del modelo de base, creamos otros modelos que varían sus factores fijos y aleatorios, llegando incluso a eliminar algunos de ellos:

modelo_mixto1 = Imer(Punt_Variable Tipo+Etapa+(1| Variable),

data=datos_mixedmodel, REML=FALSE)

modelo_mixto2 $=$ Imer(Punt_Variable Etapa+(1 $\mid$ Tipo $)+(1 \mid$ Variable $)$,

data=datos_mixedmodel, REML=FALSE)

modelo_mixto3 $=$ Imer(Punt_Variable Etapa+(1|Tipo), data=datos_mixedmodel, REML=FALSE)

modelo_mixto4 =Imer(Punt_Variable ${ }^{\text {Etapa }}+(1 \mid$ Variable $)$, data=datos_mixedmodel, REML=FALSE)

modelo_mixto5 = Imer(Punt_Variable Tipo+(1 $\mid$ Etapa $)+(1 \mid$ Variable $)$,

data=datos_mixedmodel, REML=FALSE)

modelo_mixto6 $=$ Imer(Punt_Variable Tipo+(1 $\mid$ Etapa), data=datos_mixedmodel, REML=FALSE)

modelo_mixto7 $=$ Imer(Punt_Variable Tipo+(1 $\mid$ Variable), data=datos_mixedmodel, REML=FALSE)

modelo_mixto8 =Imer(Punt_Variable 1+(1| Tipo), data=datos_mixedmodel, REML=FALSE)

modelo_mixto9 =Imer(Punt_Variable 1+(1|Etapa), data=datos_mixedmodel, REML=FALSE) 
Comparamos los modelos mediante un análisis de la varianza (ANOVA) con el fin de determinar cuáles presentan un mejor ajuste:

anova(modelo_mixto1,modelo_mixto2, modelo_mixto3, modelo_mixto4, modelo_mixto5, modelo_mixto6, modelo_mixto7, modelo_mixto8, modelo_mixto9)

Atendiendo al test de máxima verosimilitud (logLik), el criterio de información de Akaike (AIC) y al de información bayesiana (BIC) vemos que los modelos más adecuados son el 5 y el 7. Estos modelos no presentan diferencias significativas entre sí. Por ello, se considera el modelo 7 como la mejor opción, ya que entre las opciones que muestran mejor ajuste, resulta el más simplificado.

Los modelos más adecuados, 5 y 7, consideran como factor fijo el "Tipo de escala" y como aleatorio la "Variable". El factor de "Etapa" se elimina en uno de ellos (modelo 7), mientras que en el otro se considera como un factor aleatorio (modelo 5).

Finalmente, se analiza la significación de cada uno de los factores fijos, "Tipo de escala" y "Etapa", considerados en el modelo de base:

Significacion $=$ Ime(Punt_Variable Tipo+Etapa,random= 1|Variable,data=datos_mixedmodel) anova(Significacion)

\section{A.5.2. COMPARACIÓN DE ETAPAS Y TIPOS DE ESCALAS:}

Determinamos la existencia de diferencias significativas entre las puntuaciones obtenidas mediante la metodología AEPS para las distintas etapas y tipos de escalas evaluados.

\section{A.5.2.1. COMPARACIÓN DE ETAPAS:}

Comenzamos instalando los paquetes a utilizar:

install.packages("dplyr")

library(dplyr)

install.packages("nortest")

library(nortest)

install.packages("FSA")

library(FSA) 
install.packages("PMCMR")

library(PMCMR)

install.packages("multcompView")

library(multcompView)

Cargamos y comprobamos los datos:

datos_escalas $<-$ read.table(file $=$ "D:/.../Comparacion_Etapas.csv", header $=$ TRUE, sep $=$ ";")

head(datos_escalas)

Para tener una visión general de los datos, calculamos las medias y errores estándar de las puntuaciones obtenidas por cada tipo de escala para cada una de las etapas:

group_by(datos_escalas, Tipo) \% $>\%$ summarise(mean $=$ mean $($ Punt_Atraccion, na.rm $=$ TRUE), sd=sd(Punt_Atraccion, na.rm=TRUE))

group_by(datos_escalas, Tipo) \% $\%$ summarise $($ mean $=$ mean(Punt_Entrada, na.rm $=$ TRUE), sd=sd(Punt_Entrada, na.rm=TRUE))

group_by(datos_escalas, Tipo) \% $\%$ summarise(mean $=$ mean $($ Punt_Pasaje, na.rm $=$ TRUE), sd=sd(Punt_Pasaje, na.rm=TRUE))

group_by(datos_escalas, Tipo) \% $\%$ summarise(mean = mean $($ Punt_Salida, na.rm = TRUE), sd=sd(Punt_Salida, na.rm=TRUE))

Analizamos la normalidad de los datos con el objetivo de saber si podemos estudiarlos mediante pruebas paramétricas (si son normales) o no paramétricas (si no son normales). Para ello, aplicamos las pruebas de normalidad de Shapiro-Wilk (recomendado para muestras de menos de 30 observaciones) y la de Lilliefors, basada en la de KolmogorovSmirnov (para muestras mayores):

shapiro.test(datos_escalas\$Punt_Atraccion)

shapiro.test(datos_escalas\$Punt_Entrada)

shapiro.test(datos_escalas\$Punt_Pasaje)

shapiro.test(datos_escalas\$Punt_Salida)

shapiro.test(datos_escalas\$Punt_Etapas)

lillie.test(datos_escalas\$Punt_Atraccion) 
lillie.test(datos_escalas\$Punt_Entrada)

lillie.test(datos_escalas\$Punt_Pasaje)

lillie.test(datos_escalas\$Punt_Salida)

lillie.test(datos_escalas\$Punt_Etapas)

Asimismo, aplicamos el test de Fligner-Killeen para comprobar la homocedasticidad de los datos, es decir, si existe homogeneidad de varianzas:

fligner.test(datos_escalas\$Punt_Atraccion datos_escalas\$Punt_Entrada, data=datos_escalas)

fligner.test(datos_escalas\$Punt_Atraccion $\sim$ datos_escalas\$Punt_Pasaje, data=datos_escalas)

fligner.test(datos_escalas\$Punt_Atraccion $\sim$ datos_escalas\$Punt_Salida, data=datos_escalas)

fligner.test(datos_escalas\$Punt_Atraccion datos_escalas\$Punt_Etapas, data=datos_escalas)

fligner.test(datos_escalas\$Punt_Entrada datos_escalas\$Punt_Pasaje, data=datos_escalas)

fligner.test(datos_escalas\$Punt_Entrada datos_escalas\$Punt_Salida, data=datos_escalas)

fligner.test(datos_escalas\$Punt_Entrada datos_escalas\$Punt_Etapas, data=datos_escalas)

fligner.test(datos_escalas\$Punt_Pasaje $\sim$ datos_escalas\$Punt_Salida, data=datos_escalas)

fligner.test(datos_escalas\$Punt_Pasaje $\sim$ datos_escalas\$Punt_Etapas, data=datos_escalas)

Según todo lo anterior, concluimos que nuestros datos no proceden de una población que siga una distribución normal, y son homocedásticos. Por ello, se emplea el test no paramétrico de Kruskal-Wallis, para conocer si existen diferencias entre las puntuaciones de los distintos tipos de escalas en cada una de las etapas:

kruskal.test(Punt_Atraccion Tipo, data $=$ datos_escalas)

kruskal.test (Punt_Entrada Tipo, data $=$ datos_escalas $)$

kruskal.test(Punt_Pasaje $\sim$ Tipo, data $=$ datos_escalas)

kruskal.test(Punt_Salida $\sim$ Tipo, data $=$ datos_escalas $)$

kruskal.test(Punt_Etapas $\sim$ Tipo, data $=$ datos_escalas) 
Los resultados muestran diferencias significativas entre las puntuaciones de los distintos tipos de escala para una misma etapa. Se utiliza el test de Dunn para hacer comparaciones múltiples por pares, y conocer exactamente entre qué tipos existen las diferencias, indicándolas mediante letras:

p.valores.matrizA <- posthoc.kruskal.dunn.test(datos_escalas\$Punt_Atraccion datos_escalas\$TTipo, p.adjust="bonf")

p.valores.matrizA

p.valoresA <- get.pvalues(p.valores.matrizA)

p.valoresA

letras $\mathrm{A}<-$ multcompLetters(p.valoresA, threshold=0.05)

letras A

p.valores.matrizE <- posthoc.kruskal.dunn.test(datos_escalas\$Punt_Entrada datos_escalas\$́Tipo, p.adjust="bonf")

p.valores.matrizE

p.valoresE <- get.pvalues(p.valores.matrizE)

p.valoresE

letrasE $<-$ multcompLetters(p.valoresE, threshold=0.05)

letrasE

p.valores.matrizPs <- posthoc.kruskal.dunn.test(datos_escalas\$Punt_Pasaje datos_escalas\$́Tipo, p.adjust="bonf")

p.valores.matrizPs

p.valoresPs <- get.pvalues(p.valores.matrizPs)

p.valoresPs

letrasPs <- multcompLetters(p.valoresPs, threshold=0.05)

letrasPs

p.valores.matrizS <- posthoc.kruskal.dunn.test(datos_escalas\$Punt_Salida datos_escalas\$́Tipo, p.adjust="bonf")

p.valores.matrizS

p.valoresS <- get.pvalues(p.valores.matrizS)

p.valoresS

letrasS $<-$ multcompLetters(p.valoresS, threshold=0.05) 
letrasS

p.valores.matrizEtapas <- posthoc.kruskal.dunn.test(datos_escalas\$Punt_Etapas datos_escalas\$Tipo, p.adjust="bonf")

p.valores.matrizEtapas

p.valoresEtapas <- get.pvalues(p.valores.matrizEtapas)

p.valoresEtapas

letrasEtapas <- multcompLetters(p.valoresEtapas, threshold=0.05)

letrasEtapas

\section{A.5.2.2. COMPARACIÓN DE TIPOS:}

Instalamos y cargamos los paquetes necesarios:

install.packages("dplyr")

library(dplyr)

install.packages("nortest")

library(nortest)

install.packages("FSA")

library(FSA)

install.packages("PMCMR")

library(PMCMR)

install.packages("multcompView")

library(multcompView)

Cargamos y comprobamos los datos:

datos_HV <-read.table(file = "D:/.../Comparacion_HV.csv", header = TRUE, sep = ";")

head(datos_HV)

datos_VS <- read.table(file = "D:/.../Comparacion_VS.csv", header = TRUE, sep = ";")

head(datos_VS)

datos_VSO <- read.table(file = "D:/.../Comparacion_VSO.csV", header = TRUE, sep = ";")

head(datos_VSO) 


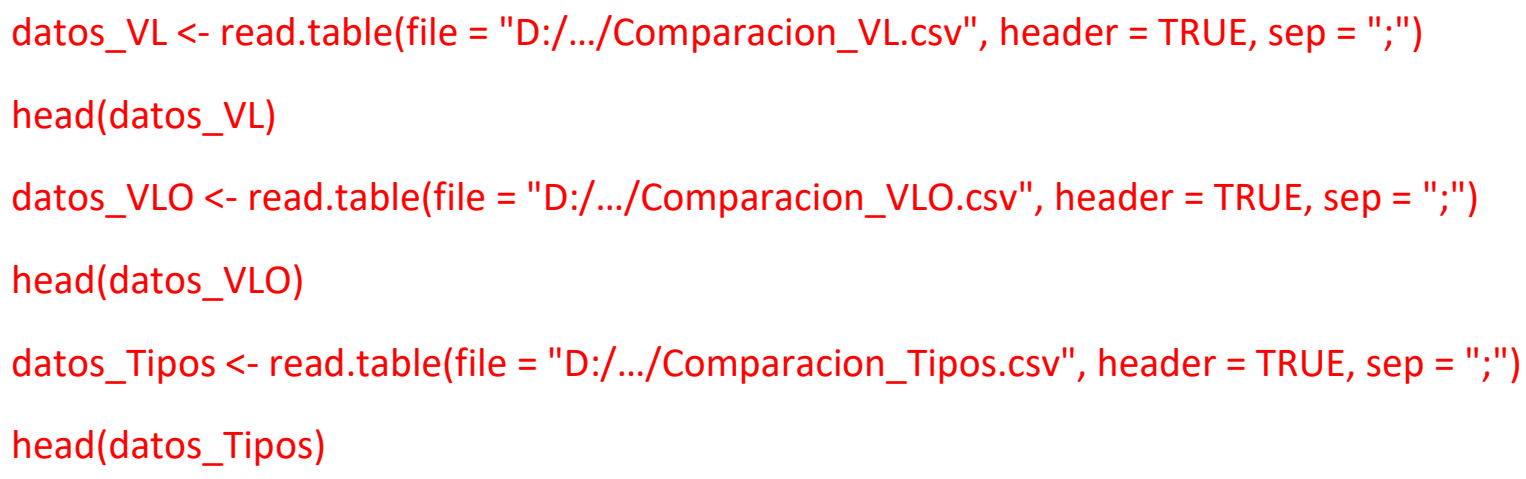

Con el fin de saber si los datos proceden de poblaciones con distribución normal y pueden analizarse mediante pruebas paramétricas (si son normales) o no paramétricas (si no son normales), aplicamos las pruebas de normalidad de Shapiro-Wilk (recomendada para menos de 30 observaciones) y de Lilliefors, basada en la de Kolmogorov-Smirnov (para muestras más grandes):

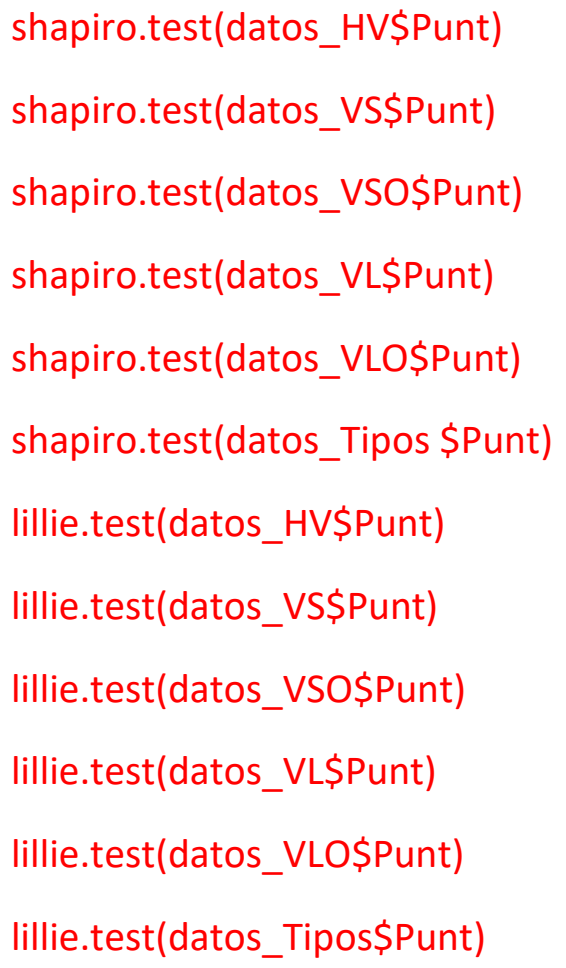

En base a lo anterior, se comprueba que los datos no provienen de poblaciones que se distribuyen normalmente y que sí existe homocedasticidad. Por tanto, se utiliza el test no paramétrico de Kruskal-Wallis para conocer si hay diferencias entre las puntuaciones de las distintas etapas en cada tipo de escala:

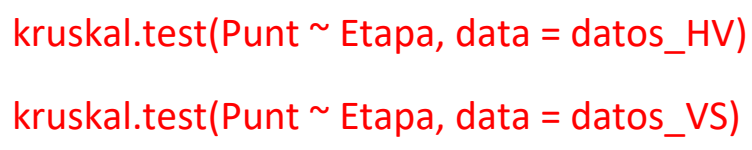


kruskal.test(Punt $\sim$ Etapa, data $=$ datos_VSO)

kruskal.test $($ Punt $\sim$ Etapa, data $=$ datos_VL)

kruskal.test(Punt $\sim$ Etapa, data $=$ datos_VLO)

Los resultados anteriores indican la existencia de diferencias significativas entre las puntuaciones de las etapas para cada tipo de escala. Se usa el test de Dunn para hacer múltiples comparaciones por pares y saber entre qué etapas hay esas diferencias, pudiendo indicarlas con letras:

p.valores.matrizHV <- posthoc.kruskal.dunn.test(datos_HV\$Punt datos_HV\$Etapa, p.adjust="bonf")

p.valores.matrizHV

p.valoresHV <- get.pvalues(p.valores.matrizHV)

p.valoresHV

letrasHV <- multcompLetters(p.valoresHV, threshold=0.05)

letrasHV

p.valores.matrizVS <- posthoc.kruskal.dunn.test(datos_VS\$Punt datos_VS\$Etapa, p.adjust="bonf")

p.valores.matrizVS

p.valoresVS <- get.pvalues(p.valores.matrizVS)

p.valoresVS

letrasVS <- multcompLetters(p.valoresVS, threshold=0.05)

letrasVS

p.valores.matrizVSO <- posthoc.kruskal.dunn.test(datos_VSO\$Punt datos_VSO\$Etapa, p.adjust="bonf")

p.valores.matrizVSO

p.valoresVSO <- get.pvalues(p.valores.matrizVSO)

p.valoresVSO

letrasVSO <- multcompLetters(p.valoresVSO, threshold=0.05)

letrasVSO

p.valores.matrizVL <- posthoc.kruskal.dunn.test(datos_VL\$Punt datos_VL\$Etapa, p.adjust="bonf")

p.valores.matrizVL 
p.valores $\mathrm{VL}<-$ get.pvalues(p.valores.matrizVL)

p.valoresVL

letrasVL <- multcompLetters(p.valoresVL, threshold=0.05)

letrasVL

p.valores.matrizVLO <- posthoc.kruskal.dunn.test(datos_VLO\$Punt $~$ datos_VLO\$Etapa, p.adjust="bonf")

p.valores.matrizVLO

p.valoresVLO <- get.pvalues(p.valores.matrizVLO)

p.valoresVLO

letrasVLO <- multcompLetters(p.valoresVLO, threshold=0.05)

letrasVLO

p.valores.matrizTipos <- posthoc.kruskal.dunn.test(datos_Tipos\$Punt datos_Tipos\$Etapa, p.adjust="bonf")

p.valores.matrizTipos

p.valoresTipos <- get.pvalues(p.valores.matrizTipos)

p.valoresTipos

letrasTipos <- multcompLetters(p.valoresTipos, threshold=0.05)

letrasTipos

\section{A.5.3. EVOLUCIÓN TEMPORAL:}

Se emplea el test Chi cuadrado $\left(\chi^{2}\right)$ para determinar si existe relación entre la efectividad de las escalas y la época en que han sido construidas o modificadas para mejorar su funcionamiento. El test se utiliza para comparar la época y la efectividad de las etapas, por separado y en conjunto, pero no se puede usar con la efectividad de los tipos de escala debido a que algunos han presentado datos insuficientes.

Cargamos la tabla de frecuencias con los datos que necesitamos y convertimos sus filas en vectores atómicos:

datos_tiempo <-read.table(file= "D:/.../Evolucion_tiempo.csv", header = TRUE, sep = ";")

head(datos_tiempo)

datos_ev_tiempo<-matrix(unlist(datos_tiempo), 2)

head(datos_ev_tiempo) 
Aplicamos el test Chi cuadrado:

chisq.test ( $x=$ datos_ev_tiempo) 


\section{A.6. DECLARACIÓN DE LOS COAUTORES}




\section{Universidad deValladolid}

\section{Anexo II \\ ACEPTACIÓN Y RENUNCIA DE LOS COAUTORES DE LA PUBLICACIÓN}

(Art. 8.1. de la Normativa para la presentación y defensa de la Tesis Doctoral en la Universidad de Valladolid, apartados e y f)

D. Juan Francisco Fuentes Pérez, con DNI n 78880235X como coautor de la publicación "Coarse fishway assessment to prioritize retrofitting efforts: A case study in the Duero River basin" doy mi consentimiento para que esta forme parte de la documentación para el depósito y defensa de la Tesis Doctoral, presentada en la Universidad de Valladolid por D. Jorge Valbuena Castro y titulada "Desarrollo y aplicación de una nueva metodología para la evaluación de pasos para peces de estanques sucesivos".

Asimismo, informo de que la contribución del doctorando ha sido la siguiente: investigación, análisis de información, escritura del borrador inicial, revisión y edición.

Finalmente, informo de que no he utilizado dicha publicación/artículo como parte de la documentación de depósito y defensa de otra tesis doctoral y que renuncio a utilizarlo en una futura tesis doctoral.

Palencia (España), 3 de mayo de 2021

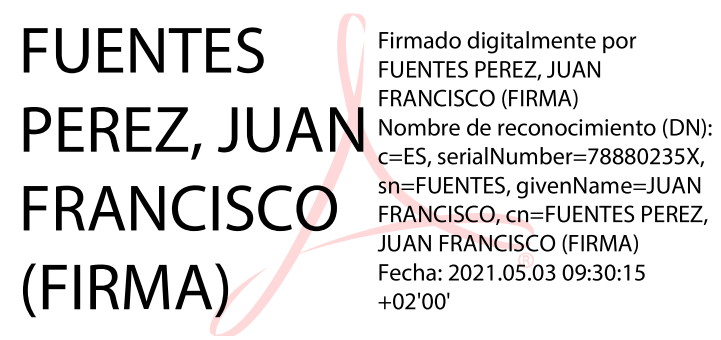

Fdo. Juan Francisco Fuentes Pérez 


\section{Universidad deValladolid}

\section{Anexo II \\ ACEPTACIÓN Y RENUNCIA DE LOS COAUTORES DE LA PUBLICACIÓN}

(Art. 8.1. de la Normativa para la presentación y defensa de la Tesis Doctoral en la Universidad de Valladolid, apartados e y f)

Doña Ana García Vega, con DNI n $71020943 W$ como coautora de la publicación "Coarse fishway assessment to prioritize retrofitting efforts: A case study in the Duero River basin" doy mi consentimiento para que esta forme parte de la documentación para el depósito y defensa de la Tesis Doctoral, presentada en la Universidad de Valladolid por D. Jorge Valbuena Castro y titulada "Desarrollo y aplicación de una nueva metodología para la evaluación de pasos para peces de estanques sucesivos".

Asimismo, informo de que la contribución del doctorando ha sido la siguiente: investigación, análisis de información, escritura del borrador inicial, revisión y edición.

Finalmente, informo de que no he utilizado dicha publicación/artículo como parte de la documentación de depósito y defensa de otra tesis doctoral y que renuncio a utilizarlo en una futura tesis doctoral.

Palencia (España), 3 de mayo de 2021

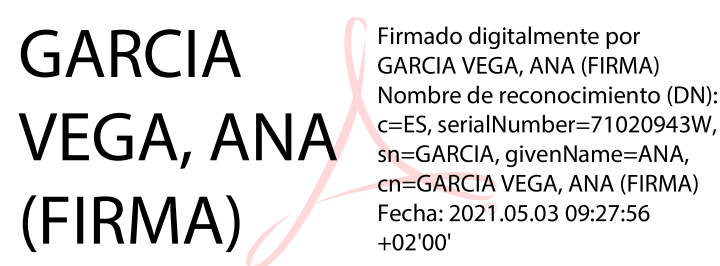

Fdo. Ana García Vega 


\section{Universidad deValladolid}

\section{Anexo II \\ ACEPTACIÓN Y RENUNCIA DE LOS COAUTORES DE LA PUBLICACIÓN}

(Art. 8.1. de la Normativa para la presentación y defensa de la Tesis Doctoral en la Universidad de Valladolid, apartados e y f)

D. Francisco Javier Bravo Córdoba, con DNI n 12781544F como coautor de la publicación "Coarse fishway assessment to prioritize retrofitting efforts: A case study in the Duero River basin" doy mi consentimiento para que esta forme parte de la documentación para el depósito y defensa de la Tesis Doctoral, presentada en la Universidad de Valladolid por D. Jorge Valbuena Castro y titulada "Desarrollo y aplicación de una nueva metodología para la evaluación de pasos para peces de estanques sucesivos".

Asimismo, informo de que la contribución del doctorando ha sido la siguiente: investigación, análisis de información, escritura del borrador inicial, revisión y edición.

Finalmente, informo de que no he utilizado dicha publicación/artículo como parte de la documentación de depósito y defensa de otra tesis doctoral y que renuncio a utilizarlo en una futura tesis doctoral.

Palencia (España), 3 de mayo de 2021

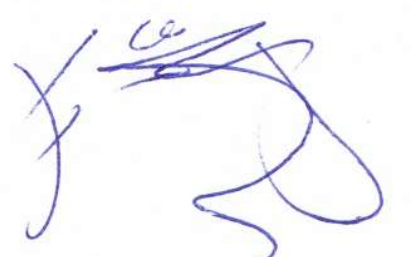

Fdo. Francisco Javier Bravo Córdoba 


\section{Universidad deValladolid}

\section{Anexo II \\ ACEPTACIÓN Y RENUNCIA DE LOS COAUTORES DE LA PUBLICACIÓN}

(Art. 8.1. de la Normativa para la presentación y defensa de la Tesis Doctoral en la Universidad de Valladolid, apartados e y f)

D. Jorge Ruiz Legazpi, con DNI $n^{\circ} 71930325 X$ como coautor de la publicación "Coarse fishway assessment to prioritize retrofitting efforts: A case study in the Duero River basin" doy mi consentimiento para que esta forme parte de la documentación para el depósito y defensa de la Tesis Doctoral, presentada en la Universidad de Valladolid por D. Jorge Valbuena Castro y titulada "Desarrollo y aplicación de una nueva metodología para la evaluación de pasos para peces de estanques sucesivos".

Asimismo, informo de que la contribución del doctorando ha sido la siguiente: investigación, análisis de información, escritura del borrador inicial, revisión y edición.

Finalmente, informo de que no he utilizado dicha publicación/artículo como parte de la documentación de depósito y defensa de otra tesis doctoral y que renuncio a utilizarlo en una futura tesis doctoral.

Palencia (España), 3 de mayo de 2021

\begin{tabular}{l|l} 
RUIZ & $\begin{array}{l}\text { Firmado } \\
\text { digitalmente por }\end{array}$ \\
LEGAZPI & RUIZ LEGAZPI \\
JORGE - \\
JORGE - & 71930325X \\
\cline { 2 - 2 } 71930325X & Fecha: 2021.05.21 \\
15:46:53 +02'00'
\end{tabular}

Fdo. Jorge Ruiz Legazpi 


\section{Universidad deValladolid}

\section{Anexo II \\ ACEPTACIÓN Y RENUNCIA DE LOS COAUTORES DE LA PUBLICACIÓN}

(Art. 8.1. de la Normativa para la presentación y defensa de la Tesis Doctoral en la Universidad de Valladolid, apartados e y f)

D. Andrés Martínez de Azagra Paredes, con DNI n 16792147P como coautor de la publicación "Coarse fishway assessment to prioritize retrofitting efforts: A case study in the Duero River basin" doy mi consentimiento para que esta forme parte de la documentación para el depósito y defensa de la Tesis Doctoral, presentada en la Universidad de Valladolid por D. Jorge Valbuena Castro y titulada "Desarrollo y aplicación de una nueva metodología para la evaluación de pasos para peces de estanques sucesivos".

Asimismo, informo de que la contribución del doctorando ha sido la siguiente: investigación, análisis de información, escritura del borrador inicial, revisión y edición.

Finalmente, informo de que no he utilizado dicha publicación/artículo como parte de la documentación de depósito y defensa de otra tesis doctoral y que renuncio a utilizarlo en una futura tesis doctoral.

Palencia (España), 3 de mayo de 2021

$\begin{array}{ll}\text { MARTINEZ DE } & \begin{array}{l}\text { Firmado digitalmente por } \\ \text { MARTINEZ DE AZAGRA } \\ \text { PAREDES ANDRES MANUEL - } \\ \text { DNI 16792147P }\end{array} \\ \text { AZAGRA PAREDES } \\ \text { ANDRES MANUEL - } & \begin{array}{l}\text { Fecha: 2021.05.20 20:02:23 } \\ +02 ' 00^{\prime}\end{array} \\ \text { DNI 16792147P } & \end{array}$

Fdo. Andrés Martínez de Azagra Paredes 


\section{Universidad deValladolid}

\section{Anexo II \\ ACEPTACIÓN Y RENUNCIA DE LOS COAUTORES DE LA PUBLICACIÓN}

(Art. 8.1. de la Normativa para la presentación y defensa de la Tesis Doctoral en la Universidad de Valladolid, apartados e y $\mathrm{f}$ )

D. Francisco Javier Sanz Ronda, con DNI n 15398294R como coautor de la publicación "Coarse fishway assessment to prioritize retrofitting efforts: A case study in the Duero River basin" doy mi consentimiento para que esta forme parte de la documentación para el depósito y defensa de la Tesis Doctoral, presentada en la Universidad de Valladolid por D. Jorge Valbuena Castro y titulada "Desarrollo y aplicación de una nueva metodología para la evaluación de pasos para peces de estanques sucesivos".

Asimismo, informo de que la contribución del doctorando ha sido la siguiente: investigación, análisis de información, escritura del borrador inicial, revisión y edición.

Finalmente, informo de que no he utilizado dicha publicación/artículo como parte de la documentación de depósito y defensa de otra tesis doctoral y que renuncio a utilizarlo en una futura tesis doctoral.

Palencia (España), 3 de mayo de 2021

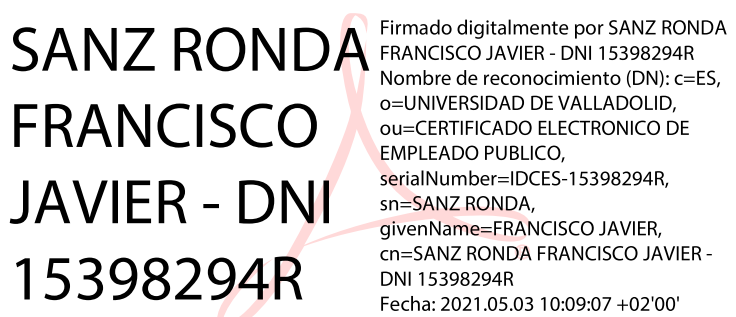

Fdo. Francisco Javier Sanz Ronda 


\section{A.7. PUBLICACIÓN ASOCIADA A LA TESIS}




\title{
Coarse fishway assessment to prioritize retrofitting efforts: A case study in the Duero River basin
}

\author{
Jorge Valbuena-Castro, Juan Francisco Fuentes-Pérez, Ana García-Vega, \\ Francisco Javier Bravo-Córdoba, Jorge Ruiz-Legazpi, Andrés Martínez de Azagra Paredes, \\ Francisco Javier Sanz-Ronda*
}

Applied Ecohydraulics Group (GEA-ecohidraulica.org), E.T.S.II.AA., University of Valladolid, 34004 Palencia, Spain

\section{A R T I C L E I N F O}

\section{Keywords:}

Fishway evaluation

AEPS methodology

Fish migration

River connectivity

\begin{abstract}
A B S T R A C T
Restoring the longitudinal connectivity of rivers is one of the main objectives of environmental European directives and policies. Fish passes or fishways are one of the most common actions for its restoration. Despite the great number of fish passes constructed during the last two decades to comply with these policies, few of them have been assessed and their suitability for fish movements is unknown. There are different options to assess fish passes, but time and economic costs frequently limit their application. Coarse fishway assessment methods (CFAMs) are an easy, fast and economic alternative for this purpose. This study aims to display the potential of CFAMs to evaluate a large number of fishways, to show the actual status of fishways in an Iberian representative river basin, and to diagnose their suitability and problems. For this, the Spanish Duero River Authority promoted the assessment of 64 stepped fishways in the Duero River basin (Spain) using the AEPS methodology. The results were analyzed considering the four stages that a fish must overcome in a fishway (attraction, entry, passage and exit), the fishway type and the construction period. Among others, results show that $50 \%$ of the assessed fishways allow the free movement of fish. However, this percentage could have been greater applying an adequate monitoring program for the fishway design and construction. Furthermore, the diagnosis by stages of the AEPS methodology allowed to identify the attraction and passage as the most problematic stages and also helped to define specific retrofitting solutions for each fishway. The study concludes that the application of CFAM during fishway design, construction and first operation stages can increase their effectiveness and, thus, the number of fish passes that contribute to the restoration of the longitudinal connectivity of rivers.
\end{abstract}

\section{Introduction}

Since the earliest human settlements, rivers have been sources of food, energy, transport and protection. This has generated many alterations in freshwater ecosystems together with many positive and negative environmental impacts all over the world (Dudgeon et al., 2006). One of the most harmful impacts is the rupture of river longitudinal connectivity by cross-sectional barriers (Nilsson et al., 2005). Among other consequences, these obstacles (e.g. dams, weirs, etc.) directly affect to fish fauna by hindering or preventing their natural movements to find suitable habitats for their reproduction, feeding and/or refuge (Lucas et al., 2001; Wofford et al., 2005). This has caused the reduction and the disappearance of many fish populations worldwide (Hall et al., 2011; Porcher and Travade, 2002; Doadrio et al., 2011).

One of the main objectives of environmental European directives and policies is to enhance the longitudinal connectivity of rivers to

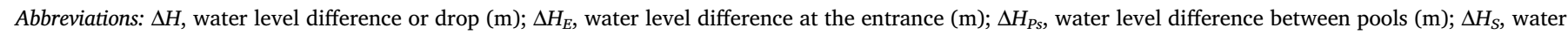

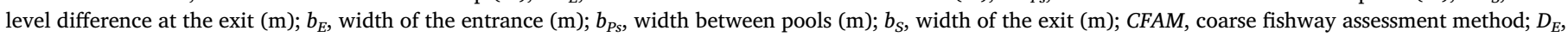

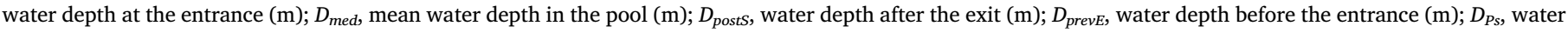

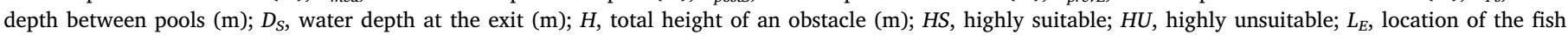

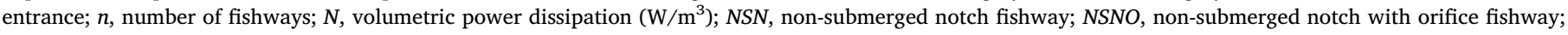

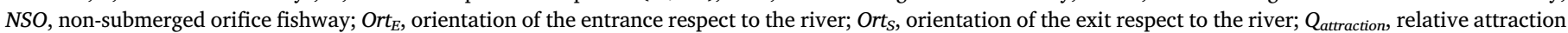

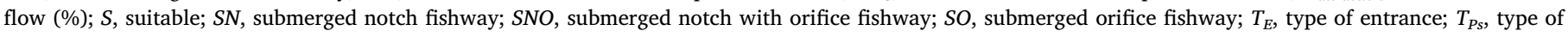
connection between pools; $T_{S}$, type of exit; $U$, unsuitable; VS, vertical slot fishway; WFD, water Framework Directive (2000/60/EC)

* Corresponding author.

E-mail address: jsanz@iaf.uva.es (F.J. Sanz-Ronda). 
improve and recover their biodiversity [e.g. Habitats Directive, 1992; and Water Framework Directive, 2000 (WFD)]. This has led to the accelerated adoption of actions to restore the fluvial connectivity. These actions range from the removal of the in-stream barriers to the capture and transport of fish. Nevertheless, the most common alternative is the construction of fish passes (also named as fishways) (Clay, 1995; FAO/ DVWK, 2002; Larinier, 2002a), being stepped fishways the most widespread solution around the world (Noonan et al., 2012). A stepped fishway consists on a succession of cross-walls in a sloped channel, connected by slots, notches and/or orifices, that divide the total height of the obstacle $(H)$ in smaller drops $(\Delta H)$ to ensure that the hydraulic conditions inside are in the range of the physical capacities of fish fauna and, thus, enable their passage (Fuentes-Pérez et al., 2017).

However, inadequate designs or negligent constructions can lead to the inefficiency of fish passes. Thus, building a fishway does not guarantee that fish fauna can overcome an obstacle (Castro-Santos et al., 2009; Roscoe and Hinch, 2010) and their assessment becomes vital to ensure that they really help to the restoration of river connectivity as well as to identify possible operating problems. Nowadays, a small number of fishways has been assessed worldwide, obtaining despair and in many cases negative results (Bunt et al., 2016, 2012).

The methods for fishway assessment can be classified in two major groups: biological and hydraulic (Sanz-Ronda et al., 2013). Biological methods study the fish that are using a fishway in order to assess its performance. They can be (1) qualitative studies, which assess the effectiveness, determining if a fishway is able or not to allow the fish passage, generally by visual inspection, video recording, samplings, traps, etc.; and (2) quantitative studies, which assess the efficiency, calculating the proportion of fish that locate, entry and overcome a fishway (Bunt et al., 2012; Castro-Santos and Haro, 2010; Larinier, 2001), generally by means of passive integrated transponders (PIT), acoustic or radio telemetry (King et al., 2016; Roscoe and Hinch, 2010).

On the other hand, hydraulic methods compare geometrical and hydraulic characteristics of the fishways with the physical capacities of fish (e.g. swimming or jumping capabilities, turbulence tolerance, etc.), in order to assess the effectiveness of the fish pass via qualitative indicators (Barry et al., 2018; Baudoin et al., 2015). These procedures are usually named as coarse fishways assessment methods (CFAM) and they are very practical because of their fast, simple and inexpensive application (i.e. Armstrong et al., 2004; Solà et al., 2011; Towler et al., 2013). There are some general experiences (Boné-Puyo and Langa-Sánchez, 2011; Santos et al., 2012) and several standardized protocols of this type of hydraulic assessments: SNIFFER (2010), ICF (Solà et al., 2011), ICE (Baudoin et al., 2015) or AEPS (CHD, 2016). SNIFFER and ICF compare values of water level differences, depths and/or velocities inside the fishway with the fish ability to overcome certain thresholds, complemented by expert opinions. ICE and AEPS, besides the above, also include physical characteristics of the fish passes (e.g. pool dimensions, power dissipation, etc.), and they are conceptually objective. In the specific case of AEPS, besides the fish passage, it also considers the attraction, entry and exit from the fishway. Furthermore, it takes into account some outcomes and conclusions of several previous biological assessments (Bravo-Córdoba et al., 2018b; Sanz-Ronda et al., 2019; CHD, 2016) to increase confidence in the estimation of effectiveness.

Despite biological assessment methods provide richer information, their application is more expensive than hydraulic methods as they require more time together with specialized equipment and users (Barry et al., 2018). Therefore, hydraulic based methods as CFAM are more useful to carry out large scale fishway assessments. In addition, CFAM can also be used to detect fishway potential problems and to provide specific solutions for its retrofitting.

In this paper, the use of CFAMs for assessing fish passes and identifying their problematic aspects is analyzed. For this, the AEPS methodology is applied to 64 stepped fishways constructed from the mid-1990s to 2019 in the Duero River basin (Spain). This work aims to (1) highlight the usefulness of CFAM methods for assessing the effectiveness of fishways, and as tool for detecting errors and possible retrofitting actions, (2) show the actual status of the fishways in the Duero River basin, and (3) identify their main potential problems. In addition, the analysis revealed interesting information about evolution of fishways over the last years, their main problems, and the possible influence of recent regulations in their construction. This paper provides a clear example to managers, engineers and biologists on the usage of CFAMs to assess and improve the existent and future fishways and to decide how to prioritize efforts during river restoration.

\section{Material and methods}

To achieve the proposed objectives, the AEPS methodology has been applied to assess 64 stepped fishways. Herein this section, we start by presenting briefly the AEPS methodology (section 2.1) followed by a description of the study cases (section 2.2), and data collection procedure (section 2.3). Finally, we present the data treatment and statistical analyses (section 2.4) in order to obtain comprehensive and statistically relevant results about the ascent stages through fishways (attraction, entry, passage and exit), the type of fishway, its physical and hydraulic parameters, and its construction period.

\subsection{Description of the AEPS methodology}

The AEPS methodology (CHD, 2016) is a CFAM for stepped fishways evaluation developed by the Spanish Duero River Authority (Confederación Hidrográfica del Duero-CHD) in 2016 (www.geaecohidraulica.org/AEPSv1.pdf). The acronym AEPS derives from the Spanish names of the four stages that fish must overcome in their ascent through a fish pass (Castro-Santos et al., 2009): attraction, entry, passage and exit. These stages are assessed studying twenty variables of easy measurement (Table 1 and Fig. 1).

Each variable is graphically or categorically scored from 0 (very unsuitable for the ascent of the target fish fauna) to 10 (very suitable) (Fig. 2). The graphical and categorical scoring systems of AEPS are based on the recommendations of specialized literature, laboratory studies and field experiences. The AEPS methodology is focused on the main potamodromous fish species of the Duero River basin: the brown trout (Salmo trutta, Linnaeus 1758) and two rheophilic cyprinids: the Iberian barbel (Luciobarbus bocagei, Steindachner 1864) and the northern straight-mouth nase (Pseudochondrostoma duriense, Coelho 1985), because they are the most relevant species in terms of biomass and distribution in the basin. However, using the same scores, it can be applied to other species with

Table 1

Variables included in the assessment of the four stages that the AEPS methodology considers (see Fig. 1).

\begin{tabular}{|c|c|}
\hline Stage & Variables (abbreviation) \\
\hline Attraction & $\begin{array}{l}\text { Relative flow of attraction }\left(Q_{\text {attraction }}\right) \\
\text { Location of the fish entrance }\left(L_{E}\right)\end{array}$ \\
\hline Entry & $\begin{array}{l}\text { Water level difference at the entrance }\left(\Delta H_{E}\right) \\
\text { Water depth at the entrance }\left(D_{E}\right) \\
\text { Width of the entrance }\left(b_{E}\right) \\
\text { Water depth before the entrance }\left(D_{p r e v E}\right) \\
\text { Orientation of the entrance respect to the river }\left(\operatorname{Ort}_{E}\right) \\
\text { Type of entrance }\left(T_{E}\right)\end{array}$ \\
\hline Passage & $\begin{array}{l}\text { Water level difference between pools }\left(\Delta H_{P s}\right) \\
\text { Volumetric power dissipation }(N) \\
\text { Mean water depth in the pool }\left(D_{\text {med }}\right) \\
\text { Water depth between pools }\left(D_{P s}\right) \\
\text { Width between pools }\left(b_{P s}\right) \\
\text { Type of connection between pools }\left(T_{P s}\right)\end{array}$ \\
\hline Exit & $\begin{array}{l}\text { Water level difference at the exit }\left(\Delta H_{S}\right) \\
\text { Water depth at the exit }\left(D_{S}\right) \\
\text { Width of the exit }\left(b_{S}\right) \\
\text { Water depth after the exit }\left(D_{\text {posts }}\right) \\
\text { Orientation of the exit respect to the river }\left(\operatorname{Ort}_{S}\right) \\
\text { Type of exit }\left(T_{S}\right)\end{array}$ \\
\hline
\end{tabular}




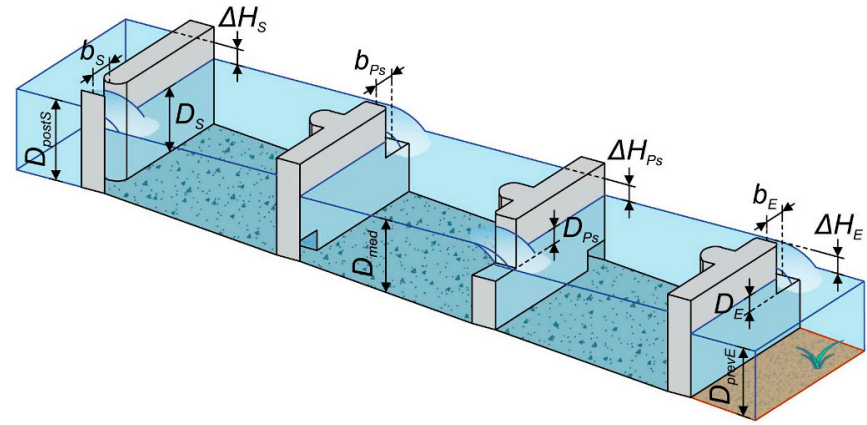

Fig. 1. Variables to be measured in a fishway according to AEPS methodology ( $\Delta H$ - water level difference; $D$ - water depth; $b$ - width for fish passage; $D_{\text {prevE }}-$ water depth before the entrance; $D_{\text {med }}$ - mean water depth in the pool; $D_{\text {post }}-$ water depth after the exit; ${ }_{E}$ - entry; $P_{S}$ - passage; ${ }_{S}$ - exit) (see Table 1 ).

similar capacities and requirements, or it can be adapted to other species modifying the scoring values.

The score of each stage (attraction, entry, passage and exit) is obtained by geometric means of the scored variables (eq. 1 to eq. 4 , see notation section for further clarification). The geometric means allow to classify a whole stage as unsuitable if at least one of its variables is also unsuitable.

$$
\begin{aligned}
& \text { Attraction }=\left(Q_{\text {attraction }} \cdot L_{E}\right)^{1 / 2} \\
& \text { Entry }=\left(H_{E} \cdot D_{E} \cdot b_{E} \cdot D_{\text {prevE }} \cdot \text { Ort }_{E} \cdot T_{E}\right)^{1 / 6} \\
& \text { Passage }=\left(H_{P S} \cdot N_{P S} \cdot D_{\text {med }} \cdot D_{P S} \cdot b_{P S} \cdot T_{P S}\right)^{1 / 6} \\
& \text { Exit }=\left(H_{S} \cdot D_{S} \cdot b_{S} \cdot D_{\text {posts }} \cdot \text { Ort }_{S} \cdot T_{S}\right)^{1 / 6}
\end{aligned}
$$

The methodology classifies the suitability of each stage, as well as the suitability of each variable, as: Highly Suitable or $H S$ $(8<$ Score $\leq 10)$, Suitable or $S(6<$ Score $\leq 8)$, Unsuitable or $U$ $(4<$ Score $\leq 6)$, and Highly Unsuitable or $H U(0 \leq$ Score $\leq 4)$. This discretization of the scores allows to define potential problems of the fishway and their specific solutions. Finally, the lowest value of the four stages is considered as the overall score for the whole fishway.

\subsection{Study cases}

All the studied fishways are located in the Duero River basin, the largest basin of the Iberian Peninsula. It is a transboundary system of $97,290 \mathrm{~km}^{2}$ shared by Portugal (19\%) and Spain (81\%) (CHD, 2020) (Fig. 3). Most of the Spanish side is under Mediterranean-continental climate, with a mean annual precipitation of $612 \mathrm{~mm}$, and a contribution to rivers and underground systems of $15,000 \mathrm{hm}^{3}$ per year (CHD, 2020).

The AEPS methodology was applied to 64 stepped fishways associated

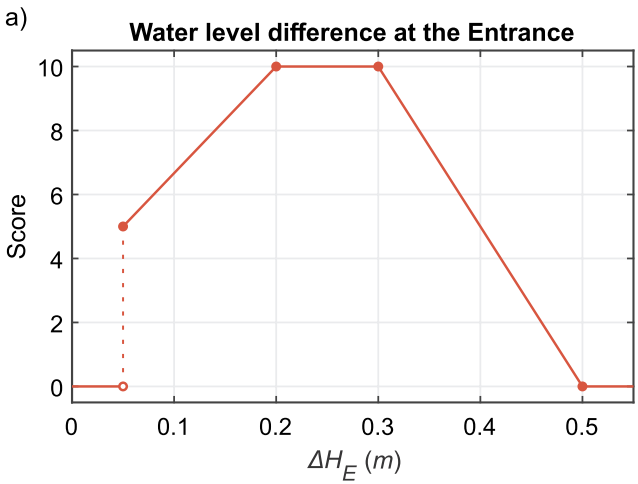

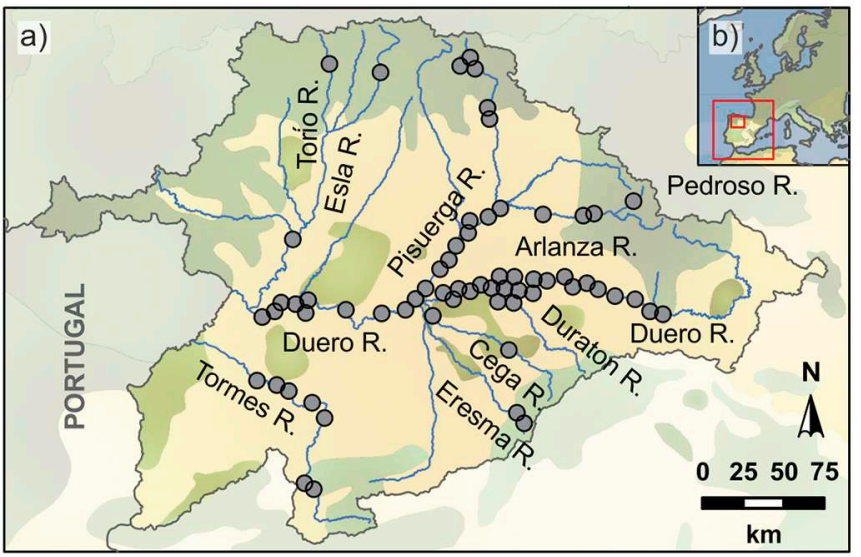

Fig. 3. Study area. (a) Location of the assessed fishways in the Spanish side of the Duero River basin (R. - river), (b) northwest of the Iberian Peninsula, southern Europe.

to hydropower plants located in the Spanish side of the Duero River basin (Fig. 3). Priority for the evaluation was given to those fishways located in sensitive zones, in the mainstem of the Spanish side of the Duero River and the lower parts of its tributaries. However, these fishways are about the $50 \%$ of the existing stepped fish passes in the whole basin and more than $75 \%$ of those built since the implementation of the WFD in 2000 (CHD, 2019a).

\subsection{Data collection}

Data collection was carried out when the river flow of each study site (obtained from SAIH real time gauging stations (CHD, 2019b)) was similar to the one during the reproductive migration of the target species (public database of CEDEX (CEDEX, 2019)). The northern straight-mouth nase and the Iberian barbel usually perform reproductive migrations from April to June, while the brown trout from November to January in the Iberian Peninsula (Doadrio et al., 2011; García-Vega et al., 2017; Kottelat and Freyhof, 2007).

Water levels and height differences in the fishways were measured with a topographic total station Leica TC307 $( \pm 1 \mathrm{~cm})$. Geometrical characteristics of the fishways were measured with metal rulers to the same precision level. Based on the previous information, the discharges through the fishways were estimated using the formulation for stepped fishways proposed by Fuentes-Pérez et al. (2017).

\subsection{Data treatment}

The collected information in each fishway was processed following the AEPS methodology, obtaining the scores for the twenty variables

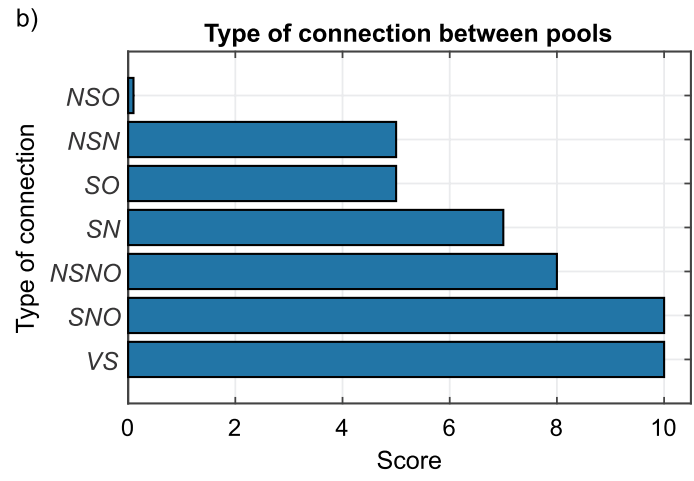

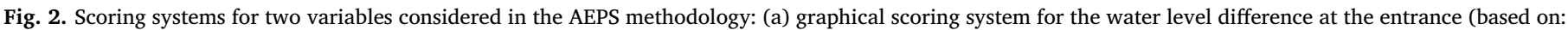

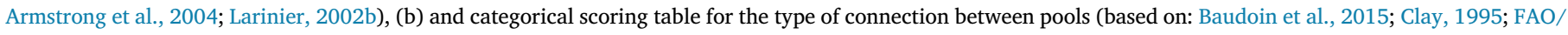

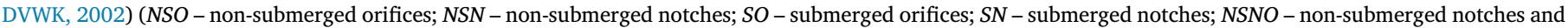
orifices; SNO - submerged notches with orifices; VS - vertical slots) (see the original reference (CHD, 2016) for more information). 
(Table 1), the four stages (eq. 1-4) and the overall score and suitability category ( $H S, S, U$ or $H U$ ) for each assessed fishway. Furthermore, the suitability categories of AEPS methodology were gathered in two final groups of effectiveness: favorable (HS and $S$ ) and unfavorable to fish movements ( $H U$ and $U$ ).

The evaluated stepped fishways were classified in five groups according to their connections between pools: vertical slots (VS), submerged notches $(S N)$, submerged notches with orifices (SNO), nonsubmerged notches (NSN) and non-submerged notches with orifices (NSNO) fishways. To study the relation among variables, stages and the type of stepped fishways, linear mixed models of analysis of variance were used. Mixed models relate a response or dependent variable (type of stepped fishways) with one or more explanatory or independent variables (stages and variables), considering the possible existence of correlated observations or with heterogeneous variability linked to the presence of random factors.

To identify which were the most problematic variables and/or stages, a frequency analysis of the suitability categories by variable, stage and the overall performance of the evaluated fishways was conducted, by type of stepped fishway and construction period. For this purpose, two periods were considered, from the mid-1990s to 2009 and from 2010 to 2019. The division by construction period was considered to assess the possible impact of the implementation of the WFD is the Duero basin. The Chisquared test was used to evaluate if there were significant differences in effectiveness between both construction periods.

All the statistical analyses were performed using SAS $^{\circledR}$ and Statgraphics Centurion.

\section{Results}

Half of the assessed fishways showed a favorable effectiveness (29.7\% $S$ and $20.3 \% H S$ ), meanwhile the other half showed problems related to the design, construction or operation $(10.9 \% U$ and $39.1 \%$ $H U$ ) (Fig. 4a and b) (see appendix A). Most of the problems were identified at the Attraction and Passage stages, where almost the third part of the fishways were classified as unfavorable (Fig. 4b). The mean score of the Attraction was significantly lower than the scores of the rest of the stages (7.05 $\pm 0.37 ; p<0.05$; Table 2).

Attraction problems were mainly caused by an inadequate location of the fish entrance $\left(L_{E}\right)(45.3 \%)$, rather than by an inefficient attraction flow ( $Q_{\text {attraction }}$ ) (28.1\%) (Fig. 4b). These inefficient flows were caused by fishway discharges that, although they ranged from $150 \mathrm{~L} / \mathrm{s}$ to $500 \mathrm{~L} / \mathrm{s}$ and in general were about $300 \mathrm{~L} / \mathrm{s}$, they were lower than $3.0 \%$ of the usual river flow during the migration season.

For the Passage stage, an excesive volumetric power dissipation $(N)$ was the main source of low suitability. This variable is calculated from others such as $\Delta H_{P s}$ and $D_{\text {med }}$ (Towler et al., 2015), which were favorable in a greater proportion of cases ( $89.1 \%$ and $98.4 \%$, respectively), than $N$ (70.3\%) (Fig. 4b).

In the Entry and Exit stages, the variables lower scored were those related to a poor adjustment between the water level in the river and the water level in the fish entrance or exit pools $\left(\Delta H_{E}\right.$ and $\left.\Delta H_{S}\right)$. The Exit stage was also very conditioned by the type of connection between the upper pool and the river $\left(T_{S}\right.$ ), where in many cases were free overfalls (Fig. $4 \mathrm{~b}$ ).

According to the type of stepped fishway, VS were the most effective, with $81.8 \%$ classified as favorable and displaying the greatest score $(9.39 \pm 0.17 ; p<0.05)$. Secondly, SNO showed a score of $8.89 \pm 0.18$ and $63.6 \%$ of favorable cases, meanwhile NSNO and NSN types obtained the lowest scores (Fig. 5 and Table 2).

Most of the evaluated fishways (62.5\%) were constructed or modified during 2010-2019. In addition, there was a variation in the election of type of stepped fishway over time (Table 3a). During the period from the mid-1990s to 2009, the most constructed type was NSN (37.5\%) whereas during 2010-2019 it was SNO (67.5\%) (Table 3a). $N S N$ and $S N$ fishways were exclusively constructed during the first period, whereas VS in the second one. The effectiveness of all assessed stages increased significantly in the last period ( $p<0.05$; Table 3b). In general terms, fishways constructed from 2010 had a significantly greater effectiveness than those built before 2010 (16.7\% vs. $70 \%$ of favorable cases; $\mathrm{p}<0.05$ ) (Fig. 3b).

\section{Discussion}

Since the application of the European policies in the last two decades, a large number of fish passes have been constructed in European rivers (Barry et al., 2018). Therefore, it is essential to find methods to assess the efficiency of these devices in a reliable, fast and economical way. The application of the AEPS methodology, a hydraulic based CFAM, has allowed to describe the individual and global status of a large number of fish passes in a wide geographic area, and to detect fish passes with operational problems, with a lower investment and a faster and easier application than biological assessment methods. In general, for biological efficiency studies, a minimum of 3 months (usual period of active migration) is required to obtain reliable data, whereas CFAM, as AEPS, can be applied in less than one day per fishway.

In this study, the usefulness of hydraulic based methods (AEPS methodology) is demonstrated by assessing 64 stepped fishways in the Duero River basin. The evaluation of fishway effectiveness by means of suitability scores and categories provides a tool to prioritize actions and to distribute the resources for river restoration and management. Likewise, the discretization of the scores by ascent stages (attraction, entry, passage and exit) allows to diagnose possible problems in each fish pass and to propose specific solutions for their retrofitting.

\subsection{Global status}

Regarding the global status of the studied fishways, results show that $50 \%$ of assessed fishways are potentially suitable to allow the movements of main fish species of the Duero River basin. This percentage rises to $70.3 \%$ if only Passage stage is considered. Close results were obtained in other Iberian regions, as Catalonia 55\% (Ordeix et al., 2011; Solà et al., 2011) and Portugal 49\% (Santos et al., 2012). In contrast, in a study developed in the Ebro River basin (one of the largest rivers in Iberia), where 131 fish passes were evaluated, only $17.8 \%$ showed favorable results (Boné-Puyo and Langa-Sánchez, 2011). The construction year (before 2011) of the fishways included in that study may explain the observed differences. Our results show that fishways constructed before 2010 displayed lower scores (higher unsuitability) than fishways constructed after this year. This could be explained by several reasons: (1) an increase in the knowledge of fishway design (e.g. Fuentes-Pérez et al., 2017; Quaresma et al., 2018), (2) a better fit between physical capabilities of fish and designs (e.g. Romão et al., 2012; Sanz-Ronda et al., 2015b), (3) a consolidation of the European guidelines (e.g. FAO/DVWK, 2002; Larinier, 2002b) and (4) a greater concern of Water River Authorities which control and regulate more severely the construction process (Sanz-Ronda et al., 2013).

The study also shows an evolution over time toward streaming connections such as VS and SNO, together with an increase of the scores, which seems to indicate a better performance of these type of fishways. During last years, specialized literature has pointed out that streaming connections are preferable than plunging ones as they usually demand less effort for fish and do not require jumping between pools; consequently they seem to be more suitable for rivers with fish with wide morpho-ecological traits (Branco et al., 2013; Sanz-Ronda et al., 2016; Silva et al., 2009). Furthermore, VS and SNO fishways have demonstrated good performance for the passage of Iberian cyprinids as well as brown trout (Bravo-Córdoba et al., 2018a; Sanz-Ronda et al., 2016; Sanz-Ronda et al., 2019). In addition, VS and SNO present better self-regulation of the hydraulic variables than other fishway types, which compensate possible construction errors and water level oscillations (Fuentes-Pérez et al., 2016; Fuentes-Pérez et al., 2014). Therefore, it seems that $V S$ and $S N O$ are the preferable options for new constructions or retrofitting old ones. 

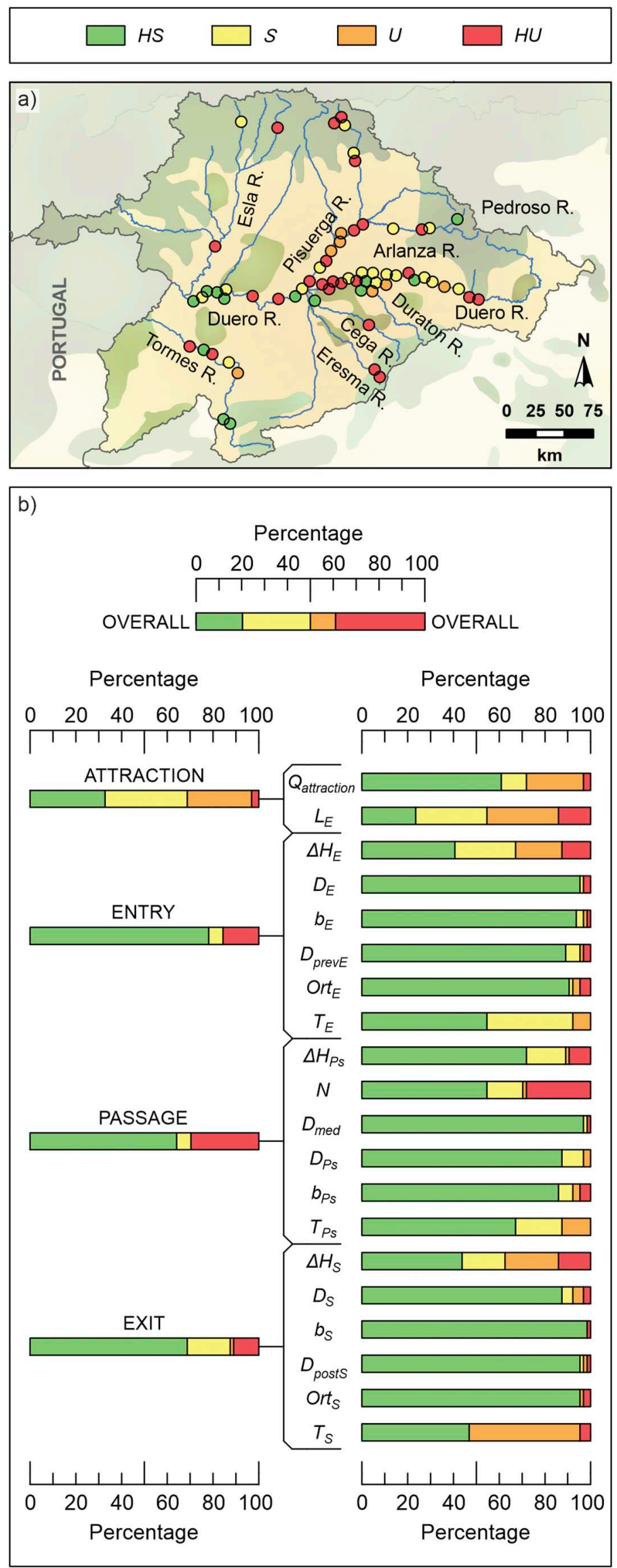

Fig. 4. Effectiveness of the studied fishways according to the AEPS methodology: (a) location of the studied fishways in the Duero River basin and their overall classification (R. - river), (b) percentage of fishways in each suitability category (HS - Highly Suitable; $S$ - Suitable; $U$ - Unsuitable; $H U$ - Highly Unsuitable), in total (overall) and by stages and variables (see Table 1 for abbreviation description). 
Table 2

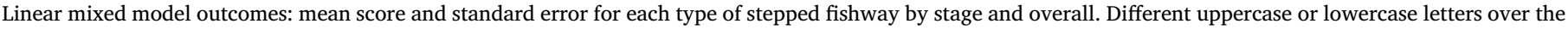

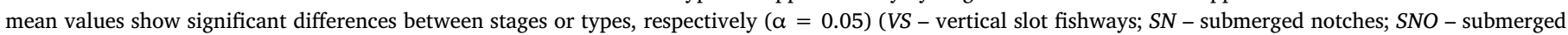
notches with orifices; $N S N$ - non-submerged notches; NSNO - non-submerged notches and orifices; $n$ - number of fishways).

\begin{tabular}{|c|c|c|c|c|c|c|}
\hline \multirow[t]{2}{*}{ Type } & \multirow[t]{2}{*}{$n$} & \multicolumn{4}{|l|}{ Stage } & \multirow[t]{2}{*}{ All stages } \\
\hline & & ATTRACTION & ENTRY & PASSAGE & EXIT & \\
\hline$V S$ & 11 & $\begin{array}{l}\mathrm{C} \mathrm{a} \\
(8.21 \pm 0.65)\end{array}$ & $\begin{array}{l}\text { B a } \\
(9.46 \pm 0.30)\end{array}$ & $\begin{array}{l}\text { A a } \\
(9.91 \pm 0.12)\end{array}$ & $\begin{array}{l}\mathrm{B} \mathrm{a} \\
(9.17 \pm 0.39)\end{array}$ & $\begin{array}{l}\mathrm{a} \\
(9.39 \pm 0.17)\end{array}$ \\
\hline$S N$ & 5 & $\begin{array}{l}\text { C c } \\
(5.08 \pm 1.47)\end{array}$ & $\begin{array}{l}\text { A bc } \\
(8.93 \pm 0.26)\end{array}$ & $\begin{array}{l}\text { B c } \\
(7.28 \pm 0.65)\end{array}$ & $\begin{array}{l}\text { B bc } \\
(8.49 \pm 0.53)\end{array}$ & $\begin{array}{l}c \\
(7.92 \pm 0.31)\end{array}$ \\
\hline SNO & 33 & $\begin{array}{l}\text { B b } \\
(7.38 \pm 0.46)\end{array}$ & $\begin{array}{l}\text { A ab } \\
(9.05 \pm 0.35)\end{array}$ & $\begin{array}{l}\text { A b } \\
(9.15 \pm 0.37)\end{array}$ & $\begin{array}{l}\text { A ab } \\
(8.98 \pm 0.27)\end{array}$ & $\begin{array}{l}\mathrm{b} \\
(8.89 \pm 0.18)\end{array}$ \\
\hline$N S N$ & 9 & $\begin{array}{l}C \text { c } \\
(5.83 \pm 0.44)\end{array}$ & $\begin{array}{l}\text { A d } \\
(7.84 \pm 0.97)\end{array}$ & $\begin{array}{l}\text { В C } \\
(6.59 \pm 0.52)\end{array}$ & $\begin{array}{l}\text { A bc } \\
(8.24 \pm 0.63)\end{array}$ & $\begin{array}{l}\mathrm{d} \\
(7.38 \pm 0.39)\end{array}$ \\
\hline NSNO & 6 & $\begin{array}{l}\text { A abc } \\
(6.54 \pm 2.44)\end{array}$ & $\begin{array}{l}\text { A cd } \\
(7.89 \pm 1.04)\end{array}$ & $\begin{array}{l}\text { A c } \\
(7.37 \pm 1.12)\end{array}$ & $\begin{array}{l}\text { A abc } \\
(7.53 \pm 2.43)\end{array}$ & $\begin{array}{l}c d \\
(7.49 \pm 0.91)\end{array}$ \\
\hline All types & 64 & $\begin{array}{l}\text { B } \\
(7.05 \pm 0.37)\end{array}$ & $\begin{array}{l}\mathrm{A} \\
(8.83 \pm 0.25)\end{array}$ & $\begin{array}{l}\mathrm{A} \\
(8.61 \pm 0.24)\end{array}$ & $\begin{array}{l}\mathrm{A} \\
(8.73 \pm 0.29)\end{array}$ & \\
\hline
\end{tabular}

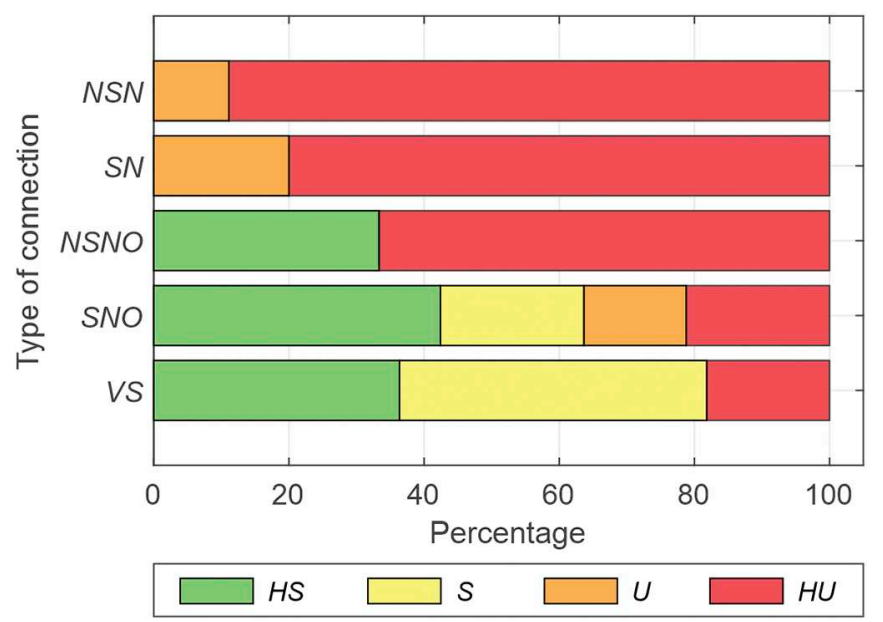

Fig. 5. Studied fishways in each suitability category by type of stepped fishway according to AEPS methodology (HS - Highly Suitable; $S$ - Suitable; $U$ Unsuitable; $H U$ - Highly Unsuitable; NSN - non-submerged notches; $S N$ submerged notches; NSNO - non-submerged notches and orifices; SNO - submerged notches with orifices; VS - vertical slots).

Some of the studied $S N$ fishways were working close to plunging regimens, that is to say, with a low submergence in the notch $(<10 \mathrm{~cm})$. One of the reason could be that despite they were designed to operate in streaming regimens, i.e. as $S N$, the river dynamics or the lack of discharge management through the structures favoured an operation in plugging regimen, i.e. as NSN. Due to the multiple benefits of streaming regimens (Branco et al., 2013; Sanz-Ronda et al., 2015a; Silva et al., 2009) the operation under plugging regimens is penalized by AEPS.

\subsection{Diagnosis of the studied fishways}

The most frequent causes of fish pass failure include the lack of attraction flow, inadequate location of the entrance, absence of maintenance and inadequate hydraulic conditions (e.g. flow patterns, velocities or turbulence) inside the fishway for the target species (FAO/ DVWK, 2002; Larinier, 2001; Silva et al., 2018; Williams et al., 2012). In this study, Attraction and Passage were the two stages with the lowest scores. For Attraction stage, the location of the fish entrance is essential. The optimal location is as close as possible to the most upstream part of the barrier, adjacent to its base and/or to the exit of the turbines in case of a powerhouse (Larinier, 2002b; Williams et al., 2012). Furthermore, an attraction flow near the fish entrance is desirable to create a detectable flow pattern not masked by other flows (Burnett et al., 2017; FAO/DVWK, 2002; Larinier, 2002a). 45.3\% of the studied fishways had an incorrect fish entrance location and $28.1 \%$ lacked an appropriate attraction flow in their surroundings. A large number of works (e.g. Bunt et al., 2012; Larinier et al., 2005; Williams et al., 2012) identify these two variables as the main cause of inadequate operation of the fishways. Once these problems have been identified, it is possible to implement specific solutions for each case.

Table 3

Changes over time of effectiveness (favorable - fishways classified as HS and $S$; unfavorable - fishways classified as $H U$ and $U$ ) by (a) type of stepped fishways (VS vertical slots; $S N$ - submerged notches; $S N O$ - submerged notches with orifices; $N S N$ - non-submerged notches; NSNO - non-submerged notches and orifices) and (b) stages according to AEPS methodology ( $n$ - number of fishways).

\begin{tabular}{|c|c|c|c|c|c|c|c|c|c|c|}
\hline \multicolumn{11}{|c|}{ a) Effectiveness by type of stepped fishway } \\
\hline & \multicolumn{2}{|c|}{ VS } & \multicolumn{2}{|l|}{$S N$} & \multicolumn{2}{|l|}{ SNO } & \multicolumn{2}{|l|}{ NSN } & \multicolumn{2}{|l|}{ NSNO } \\
\hline & 1990-2009 & 2010-2019 & 1990-2009 & 2010-2019 & 1990-2009 & 2010-2019 & 1990-2009 & 2010-2019 & 1990-2009 & 2010-2019 \\
\hline Favorable & - & $81.8 \%$ & $0.0 \%$ & - & $50.0 \%$ & $66.7 \%$ & $0.0 \%$ & - & $25.0 \%$ & $50.0 \%$ \\
\hline Unfavorable & - & $18.2 \%$ & $100 \%$ & - & $50.0 \%$ & $33.3 \%$ & $100 \%$ & - & $75.0 \%$ & $50.0 \%$ \\
\hline$n$ & - & 11 & 5 & - & 6 & 27 & 9 & - & 4 & 2 \\
\hline
\end{tabular}

b) Effectiveness by stage

\begin{tabular}{llllll} 
& \multicolumn{3}{l}{ ATTRACTION } & & \multicolumn{2}{l}{ ENTRY } \\
\cline { 2 - 3 } \cline { 5 - 6 } \cline { 5 - 6 } & $1990-2009$ & $2010-2019$ & & $1990-2009$ & $2010-2019$ \\
\hline Favorable & $41.7 \%$ & $85.0 \%$ & & $70.8 \%$ & $92.5 \%$ \\
Unfavorable & $58.3 \%$ & $15.0 \%$ & & $29.2 \%$ & $7.5 \%$ \\
$n$ & 24 & 40 & 24 & 40 \\
\hline
\end{tabular}

PASSAGE

\begin{tabular}{|c|c|c|c|c|c|}
\hline \multicolumn{2}{|l|}{ PASSAGE } & \multicolumn{2}{|l|}{ EXIT } & \multicolumn{2}{|l|}{ OVERALL } \\
\hline 1990-2009 & 2010-2019 & 1990-2009 & 2010-2019 & 1990-2009 & 2010-2019 \\
\hline $37.5 \%$ & $90.0 \%$ & $79.2 \%$ & $92.5 \%$ & $16.7 \%$ & $70.0 \%$ \\
\hline $62.5 \%$ & $10 \%$ & $20.8 \%$ & $7.5 \%$ & $83.3 \%$ & $30.0 \%$ \\
\hline 24 & 40 & 24 & 40 & 24 & 40 \\
\hline
\end{tabular}


For example, Bunt (2001) showed a positive effect of approaching the fish entrance to the spillways.

Regarding the Passage, results show that it was negatively influenced by both high water drops between pools $\left(\Delta H_{P s}\right.$, in $10.9 \%$ of the fishways) and small size of the pools. This caused an excessive volumetric power dissipation within pools ( $N$, in the $29.7 \%$ of the fishways). $N$ is directly related to turbulence levels inside the pools, which can disorient the fish (Clay, 1995; Larinier, 2002a) and increase the cost of swimming performance (Enders et al., 2005). Likewise, $\Delta H$ is related to the water velocity and, when it exceeds fish swimming or jumping capacities, the fish cannot pass the notches or slots (Larinier, 2002a; Sanz-Ronda et al., 2016). The correction of these deficiencies is usually challenging, and some alternatives can be, for instance, the increase of the water volume in the pool (by increasing the sill elevation in the notches, and thus, the water depth in the pool) or the addition of extra pools and cross-walls in order to share the excessive drops among them. If the failure is localized in a specific pool, this can be retrofitted by modifying the successive cross-walls (Fuentes-Pérez et al., 2016).

The water drop is usually a conflictive variable also in the Entry and Exit stages. Despite the overall better results of these two stages (favorable $>80 \%$ ), in both cases $\Delta H$ was the variable with the lowest score. Failures in this variable are usually linked to (1) not considering the water level oscillations related to changes in river discharge during the migration season in the design and operation of the fishway, (2) a wrong on-site layout during the construction process or (3) the modification of the river control sections during the construction. Although high water level differences or plunging flows at the entrance can be related to a better attraction (Williams et al., 2012), they can also exceed the swimming and/or jumping capacities of fish (Ruiz-Legazpi et al., 2018; Sanz-Ronda et al., 2015b). Likewise, small differences in water levels or excessive submergence can reduce the velocity and turbulence at the entrance, affecting negatively to Attraction. Larinier (2002b) recommends a minimum velocity of $1 \mathrm{~m} / \mathrm{s}$ and a maximum of $2.4 \mathrm{~m} / \mathrm{s}$ at the entrance. Excessive water level differences at the fish entrance can be solved, for example, by installing a set of pre-barrages; meanwhile, the small water drops can be corrected by increasing the sill elevation of the most downstream notch or slot (Fuentes-Pérez et al., 2016).

\subsection{Other considerations}

In general, the overall passage problems identified in this study can have two main origins: (1) not considering the recommended criteria for fishway design or (2) unsupervised modifications during the construction with respect to the original project. Although the former is difficult to solve if there is not a project control agent with advanced knowledge in the fishway design field, the latter could be avoided with an adequate in-site inspection during the construction process (MallenCooper and Brand, 2007; Sanz-Ronda et al., 2013). An inspection based on hydraulic evaluation methods (e.g. AEPS), after construction and prior to the machinery retreat, could have solved the possible deficiencies, increasing the percentage of favorably scored fishways.

In addition, the inspection process also allowed the identification of maintenance problems (also considered in the AEPS methodology (CHD, 2016)). The $32.8 \%$ of the studied fishways presented problems due to obstructions (debris, branches, leaves and other drifts). The fishways were cleaned before measuring the variables needed for the application of the methodology. In absence of this previous cleaning phase, the final scores could had been lower as these obstructions may modify the hydraulics inside the fishway. Therefore, although the first action to restore the longitudinal connectivity of a river stretch is the fishway construction and its evaluation, the second one is the implementation of a maintenance schedule adapted to the river dynamics in order to ensure its adequate operation. Lastly, the final action is the application of a periodical and effective control plan by the water authorities.

\section{Summary and conclusions}

This paper analyses the functionality of AEPS as a coarse fishway assessment method. The application of CFAM or hydraulic methods is in general a faster, less expensive and simpler option than biological assessment methods, mainly due to the nature of the variables to measure and the necessary tools for their application. However, the uncertainties in these methods are greater than in biological assessments due to the absence of fish monitoring. The easy and simple application of the AEPS methodology has made possible to assess a large number of fishways in a wide geographic area. Its application has also demonstrated the need of an assessment after construction of any fishway, as most of the assessed structures require retrofitting actions to ensure their adequate operation.

The application of AEPS showed that $50 \%$ of assessed fishways are potentially suitable for fish movements and that VS and SNO fishway types were the most effective ones. The research also revealed that fishway design improved their effectiveness over time, probably due to an increase of knowledge of native fish species and the consolidation of European regulations.

Attraction and Passage were the two stages with lower suitability scores. Most relevant failures for the attraction were a poor location of the device and low attraction flows, whereas for the passage, they were high water drops between pools and small size of the pools. Fishways design and construction processes were identified as the key causes of those defects, thus the control during these phases have to be guaranteed, together with periodical inspections to ensure a correct maintenance.

CFAMs seems a valid tool to handle the assessment of all the constructed fishways. However, further research is necessary. Specifically, it is necessary the improvement of CFAMs through their direct comparison with results from biological methods, to relate them to biological efficiencies, and to incorporate other fish species as well as other types of fish passes. Until then, we can conclude that AEPS methodology and CFAMs in general, provide a systematic tool to managers, engineers and biologist to identify and solve problems and correct deviations by its application during design, construction and operation phases of the existent and future fish passes.

\section{Declaration of Competing Interest}

The authors declare that they have no known competing financial interests or personal relationships that could have appeared to influence the work reported in this paper.

\section{Acknowledgements}

This research was promoted and financed by the Spanish Duero River Authority (Confederación Hidrográfica del Duero). Authors specially thank the collaboration of the following members of the Agency: Arturo Prieto-Blanco, Urbano Sanz-Cantalejo, José María Rubio-Polo, Juan Carlos Bernabé-de la Iglesia and Ignacio RodríguezMuñoz. Jorge Valbuena-Castro's contribution was initially financed by Confederación Hidrográfica del Duero and afterwards by a public Ph.D. grant from Junta de Castilla y León and European Social Fund PIF2017. Juan Francisco Fuentes-Pérez's and Francisco Javier BravoCórdoba's contributions were partly financed by Torres Quevedo grants PTQ2018-010162 and PTQ-16-08494, respectively. Ana García-Vega's contribution was financed by a Ph.D. grant from the University of Valladolid PIF-UVa 2017. Authors would like to thank Valentín Pando-Fernández for his statistical assistance, and Beatriz BaselgaCervera and Irene Calderón-Pastor for the revision of this paper. 


\section{References}

Armstrong, G., Apahamian, M., Fewings, G., Gough, P., Reader, N., Varallo, P., 2004 Environment Agency Fish Pass Manual: guidance notes on the legislation, selection and approval of fish passes in England and Wales. Environment Agency, Bristol, United Kingdom.

Barry, J., Coghlan, B., Cullagh, A., Kerr, J.R., King, J.J., 2018. Comparison of coarseresolution rapid methods for assessing fish passage at riverine barriers: ICE and SNIFFER protocols. River Res. Appl. 34, 1168-1178.

Baudoin, J.-M., Burgun, V., Chanseau, M., Larinier, M., Ovidio, M., Sremski, W., Steinbach, P., Voegtle, B., 2015. Assessing the passage of obstacles by fish. Concepts, Design and Application. In: Onema, Paris, France.

Boné-Puyo, P., Langa-Sánchez, A., 2011. Evaluación de los pasos de peces en la demarcación del Ebro. In: Confederación Hidrográfica del Ebro y Tecnoma, Zaragoza, Spain.

Branco, P., Santos, J.M., Katopodis, C., Pinheiro, A., Ferreira, M.T., 2013. Pool-type fishways: two different morpho-ecological cyprinid species facing plunging and streaming flows. PLoS One 8, e65089. https://doi.org/10.1371/journal.pone. 0065089.

Bravo-Córdoba, F.J., Sanz-Ronda, F.J., Ruiz-Legazpi, J, Valbuena-Castro, J., Makrakis, S. 2018a. Vertical slot versus submerged notch with bottom orifice: looking for the best technical fishway type for Mediterranean barbels. Ecol. Eng. 122, 120-125.

Bravo-Córdoba, F.J., Sanz-Ronda, F.J., Ruiz-Legazpi, J., Fernandes Celestino, L., Makrakis, S., 2018b. Fishway with two entrance branches: Understanding its performance for potamodromous Mediterranean barbels. Fish. Manag. Ecol. 25, 12-21. https://doi.org/10.1111/fme.12260.

Bunt, C.M., 2001. Fishway entrance modifications enhance fish attraction. Fish. Manag. Ecol. 8, 95-105. https://doi.org/10.1046/j.1365-2400.2001.00238.x.

Bunt, C.M., Castro-Santos, T., Haro, A., 2012. Performance of fish passage structures at upstream barriers to migration. River Res. Appl. 28, 457-478. https://doi.org/10. 1002/rra.1565.

Bunt, C.M., Castro-Santos, T., Haro, A., 2016. Reinforcement and validation of the analyses and conclusions related to fishway evaluation data from Bunt et al.: 'performance of fish passage structures at upstream barriers to migration'. River Res. Appl. 32, 2125-2137. https://doi.org/10.1002/rra.3095.

Burnett, N.J., Hinch, S.G., Bett, N.N., Braun, D.C., Casselman, M.T., Cooke, S.J., Gelchu, A., Lingard, S., Middleton, C.T., Minke-Martin, V., 2017. Reducing carryover effects on the migration and spawning success of sockeye salmon through a management experiment of dam flows. River Res. Appl. 33, 3-15.

Castro-Santos, T., Haro, A., 2010. Fish guidance and passage at barriers. In: Domeneci, P., Kapoor, B.G. (Eds.), An Eco-Ethological Perspective. Science Publishers, Enfield, pp. 62-89.

Castro-Santos, T., Cotel, A., Webb, P., 2009. Fishway evaluations for better bioengineering: an integrative approach a framework for fishway. Am. Fish. Soc. Symp. 69, $557-575$.

CEDEX, 2019. Annual Gauging Databases [WWW Document]. Cent. Stud. Exp. Public Work.

CHD, 2016. Manual para la evaluación de la funcionalidad de pasos para peces de estanques sucesivos. Metodología AEPS (1.0). In: Coordination: Sanz-Ronda et al.; Authors: Valbuena-Castro et al. Confederación Hidrográfica del Duero, Valladolid, Spain available at. http://www.gea-ecohidraulica.org/AEPSv1.pdf.

CHD, 2019a. Information System "Mírame IDEDUERO" [WWW Document]. Confed. Hidrográfica del Duero.

CHD, 2019b. Hydrological Information System of the Spanish River Duero Authority (SAIH) [WWW Document]. Confed. Hidrográfica del Duero.

Clay, C.H., 1995. Design of Fishways and Other Fish Facilities, 2nd ed. CRC Press, Ottawa, Canada.

Doadrio, I., Perea, S., Garzón-Heydt, P., González, J.L., 2011. Ictiofauna continental española: bases para su seguimiento. Ministerio de Medio Ambiente y Medio Rural y Marino, Centro de Publicaciones, Madrid, Spain.

Dudgeon, D., Arthington, A.H., Gessner, M., Kawabata, Z.-I., Knowler, D., Lévêque, C., Naiman, R.J., Prieur-Richard, A.-H., Soto, D., Stiassny, M., 2006. Freshwater biodiversity: importance, threats, status and conservation challenges. Biol. Rev. 81, 163-182. https://doi.org/10.1017/S1464793105006950.

Enders, E.C., Boisclair, D., Roy, A.G., 2005. A model of total swimming costs in turbulent flow for juvenile Atlantic salmon (Salmo salar). Can. J. Fish. Aquat. Sci. 62 1079-1089. https://doi.org/10.1139/f05-007.

FAO/DVWK, 2002. Fish Passes: Design, Dimensions, and Monitoring. FAO, Rome, Italy.

Fuentes-Pérez, J.F., Sanz-Ronda, F.J., Martínez de Azagra, A., García-Vega, A., Martínez de Azagra Paredes, A., García-Vega, A., 2014. Modeling water-depth distribution in vertical-slot fishways under uniform and nonuniform scenarios. J. Hydraul. Eng. 140, 06014016. https://doi.org/10.1061/(ASCE)HY.1943-7900.0000923.

Fuentes-Pérez, J.F., Sanz-Ronda, F.J., de Azagra, A.M., García-Vega, A., 2016. Non-uniform hydraulic behavior of pool-weir fishways: a tool to optimize its design and performance. Ecol. Eng. 86, 5-12. https://doi.org/10.1016/j.ecoleng.2015.10.021.

Fuentes-Pérez, J.F., García-Vega, A., Sanz-Ronda, F.J., Martínez de Azagra-Paredes, A., 2017. Villemonte's approach: validation of a general method for modeling uniform and non-uniform performance in stepped fishways. Knowl. Manag. Aquat. Ecosyst. 418, 11. https://doi.org/10.1051/kmae/2017013.

García-Vega, A., Sanz-Ronda, F.J., Fuentes-Pérez, J.F., 2017. Seasonal and daily upstream movements of brown trout Salmo trutta in an Iberian regulated river. Knowl. Manag. Aquat. Ecosyst. (418), 9. https://doi.org/10.1051/kmae/2016041.

Habitats Directive, 1992. Council Directive 92/43/EEC of 21 May 1992 on the conservation of natural habitats and wild fauna and flora. Off. J. Eur. Communities 206, 7-50. https://doi.org/10.1017/cbo9780511610851.039. 
Hall, C.J., Jordaan, A., Frisk, M.G., 2011. The historic influence of dams on diadromous fish habitat with a focus on river herring and hydrologic longitudinal connectivity. Landsc. Ecol. 26, 95-107. https://doi.org/10.1007/s10980-010-9539-1.

King, S., O’Hanley, J.R., Newbold, L.R., Kemp, P.S., Diebeld, M.W., 2016. A toolkit for optimizing fish passage barrier mitigation actions. J. Appl. Ecol. https://doi.org/10. $1111 / 1365-2664.12706$

Kottelat, M., Freyhof, J., 2007. Handbook of European Freshwater Fishes. Publications Kottelat,, Cornol, Switzerland.

Larinier, M., 2001. Environmental issues, dams and fish migration. In: Marmulla, G. (Ed.), Dams, Fish and Fisheries: Opportunities, Challenges and Conflict Resolution. FAO Fisheries Technical Paper $\mathrm{N}^{\mathrm{O}}$ 419. FAO, Rome, pp. 45-89.

Larinier, M., 2002a. Pool fishways, pre-barrages and natural bypass channels. Bull. Fr. Pêche Piscic. 364, 54-82. https://doi.org/10.1051/kmae/2002108.

Larinier, M., 2002b. Location of fishways. Bull. Fr. Pêche Piscic. 364. https://doi.org/10 $1051 / \mathrm{kmae} / 2002106$.

Larinier, M., Chanseau, M., Bau, F., Croze, O., 2005. The use of radio telemetry for optimizing fish pass design. In: Spedicato, M.T., Lembo, G., Marmulla, G. (Eds.), The use of radio telemetry for optimizing fish pass design. Aquatic telemetry: advances and applications. 33. FAO/COISPA, Rome, Italy, pp. 53-60.

Lucas, M.C., Baras, E., Thom, T.J., Duncan, A., Slavík, O., 2001. Migration of Freshwater Fishes. Wiley Online Library, Oxford, United Kingdom.

Mallen-Cooper, M., Brand, D.A., 2007. Non-salmonids in a salmonid fishway: what do 50 years of data tell us about past and future fish passage? Fish. Manag. Ecol. 14, 319-332. https://doi.org/10.1111/j.1365-2400.2007.00557.x.

Nilsson, C., Reidy, C.A., Dynesius, M., Revenga, C., 2005. Fragmentation and flow regulation of the world's large river systems. Science (80-. ). 308, 405-408. https://doi. org/10.1126/science.1107887.

Noonan, M.J., Grant, J.W.A., Jackson, C.D., 2012. A quantitative assessment of fish passage efficiency. Fish Fish. 13, 450-464. https://doi.org/10.1111/j.1467-2979. 2011.00445.x.

Ordeix, M., Pou-Rovira, Q., Bardina, M., Munné, A., Solà, C., Casamitjana, A., Sellarès, N., 2011. Fish pass assessment in the rivers of Catalonia (NE Iberian Peninsula). A case study of weirs associated with hydropower plants and gauging stations. Limnetica 30, 405-426.

Porcher, J.P., Travade, F., 2002. Chapter 1 Fishways : Biological Basis. In: Bulletin Français de La Pêche et de La Pisciculture, pp. 9-20.

Quaresma, A.L. Romão, F., Branco, P., Ferreira, M.T., Pinheiro, A.N., 2018. Multi slo versus single slot pool-type fishways: a modelling approach to compare hydrodynamics. Ecol. Eng. 122, 197-206.

Romão, F., Quintella, B.R., Pereira, T.J., Almeida, P.R., 2012. Swimming performance of two Iberian cyprinids: the Tagus nase Pseudochondrostoma polylepis (Steindachner, 1864) and the bordallo Squalius carolitertii (Doadrio, 1988). J. Appl. Ichthyol. 28, 26-30. https://doi.org/10.1111/j.1439-0426.2011.01882.x.

Roscoe, D.W., Hinch, S.G., 2010. Effectiveness monitoring of fish passage facilities: historical trends, geographic patterns and future directions. Fish Fish. 11, 12-33. https://doi.org/10.1111/j.1467-2979.2009.00333.x.

Ruiz-Legazpi, J., Sanz-Ronda, F.J., Fuentes-Pérez, J.F., 2018. Influence of environmental and biometric factors on the swimming capacity of the Iberian barbel (Luciobarbus bocagei Steindachner, 1864), an endemic potamodromous cyprinid of the Iberian Peninsula. Limnetica 37, 251-265.

Santos, J.M., Silva, A., Katopodis, C., Pinheiro, P., Pinheiro, A., Bochechas, J., Ferreira, M.T., 2012. Ecohydraulics of pool-type fishways: getting past the barriers. Ecol. Eng.
48, 38-50. https://doi.org/10.1016/j.ecoleng.2011.03.006.

Sanz-Ronda, F.J., Bravo-Córdoba, F.J., Fuentes-Pérez, J.F., Ruiz-Legazpi, J., García-Vega, A., Ramos-González, N., Salgado-González, V.M., Martínez de Azagra Paredes, A.,

2013. PASOS PARA PECES : escalas y otros dispositivos de paso. Notas técnicas del CIREF. 7. pp. 17.

Sanz-Ronda, F.J., Bravo-Córdoba, F.J., Ruiz-Legazpi, J., Fuentes-Pérez, J.F., 2015a. The most evaluated fishway in Spain: a new lesson every year. In: Fish Passage 2015. Internationl Conference on River Connectivity Best Practices and Innovations, Groningen, The Netherlands, pp. 146-147.

Sanz-Ronda, F.J., Ruiz-legazpi, J., Bravo-córdoba, F.J., Makrakis, S., Castro-Santos, T. 2015b. Sprinting performance of two Iberian fish: Luciobarbus bocagei and Pseudochondrostoma duriense in an open channel flume. Ecol. Eng. 83, 61-70. https:// doi.org/10.1016/j.ecoleng.2015.05.033.

Sanz-Ronda, F.J., Bravo-Cordoba, F.J., Fuentes-Pérez, J.F., Castro-Santos, T., 2016. Ascent ability of brown trout, Salmo trutta, and two Iberian cyprinids - Iberian barbel, Luciobarbus bocagei, and northern straight-mouth nase, Pseudochondrostoma duriense in a vertical slot fishway. Knowl. Manag. Aquat. Ecosyst. (417), 10. https://doi.org/ $10.1051 / \mathrm{kmae} / 2015043$.

Sanz-Ronda, F.J., Bravo-Córdoba, F.J., Sánchez-Pérez, A., García-Vega, A., ValbuenaCastro, J., Fernandes-Celestino, L., Torralva, M., Oliva-Paterna, F.J., 2019. Passage performance of technical pool-type fishways for potamodromous cyprinids: novel experiences in semiarid environments. Water 11, 2362.

Silva, A.T., Santos, J.M., Franco, A.C., Ferreira, M.T., Pinheiro, A.N., 2009. Selection of Iberian barbel Barbus bocagei (Steindachner, 1864) for orifices and notches upon different hydraulic configurations in an experimental pool-type fishway. J. Appl. Ichthyol. 25, 173-177. https://doi.org/10.1111/j.1439-0426.2009.01237.x.

Silva, A.T., Lucas, M.C., Castro-Santos, T., Katopodis, C., Baumgartner, L.J., Thiem, J.D., Aarestrup, K., Pompeu, P.S., O'Brien, G.C., Braun, D.C., 2018. The future of fish passage science, engineering, and practice. Fish Fish. 19, 340-362.

SNIFFER, 2010. Trialling of the Methodology for Quantifying the Impacts of Obstacles to Fish Passage. SNIFFER, Edinburgh, United Kingdom.

Solà, C., Ordeix, M., Pou-Rovira, Q., Sellarès, N., Queralt, A., Bardina, M., Casamitjana, A., Munné, A., 2011. Longitudinal connectivity in hydromorphological quality assessments of rivers. The ICF index: a river connectivity index and its application to Catalan rivers. Limnetica 30, 273-292.

Towler, B., Orvis, C., Dow, D., Haro, A., 2013. Fishway Inspection Guidelines. University of Massachusetts, Amherst, United States of America.

Towler, B., Mulligan, K., Haro, A., 2015. Derivation and application of the energy dissipation factor in the design of fishways. Ecol. Eng. 83, 208-217. https://doi.org/10. 1016/j.ecoleng.2015.06.014.

Water Framework Directive, 2000. Directive 2000/60/EC of the European Parliament and Council of 23 October 2000 establishing a framework for Community action in the field of water policy. Off. J. Eur. Communities. https://doi.org/10.1039/ ap9842100196.

Williams, J.G., Armstrong, G., Katopodis, C., Larinier, M., Travade, F., 2012. Thinking like a fish: a key ingredient for development of effective fish passage facilities at river obstructions. River Res. Appl. 28, 407-417. https://doi.org/10.1002/rra.1551.

Wofford, J.E.B., Gresswell, R.E., Banks, M.A., 2005. Influence of barriers to movement on within-watershed genetic variation of coastal cutthroat trout. Ecol. Appl. 15, 628-637. https://doi.org/10.1890/04-0095.

CHD, 2020. Website of the Spanish Duero River Authority [WWW Document]. Confed. Hidrográfica del Duero. 